US Army Corps of Engineers ${ }_{\circledast}$

Engineer Research and

Development Center

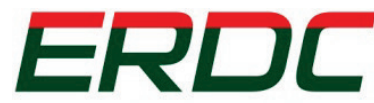

INNOVATIVE SOLUTIONS for a safer, better world

Strategic Environmental Research and Development Program (SERDP)

\title{
Review and Synthesis of Evidence Regarding Environmental Risks Posed by Munitions Constituents (MC) in Aquatic Systems
}

Guilherme R. Lotufo, Mark A. Chappell, Cynthia L. Price,

Mark L. Ballentine, Ashley A. Fuentes, Todd S. Bridges,

Robert D. George, Eric J. Glisch, and Geoffrey Carton

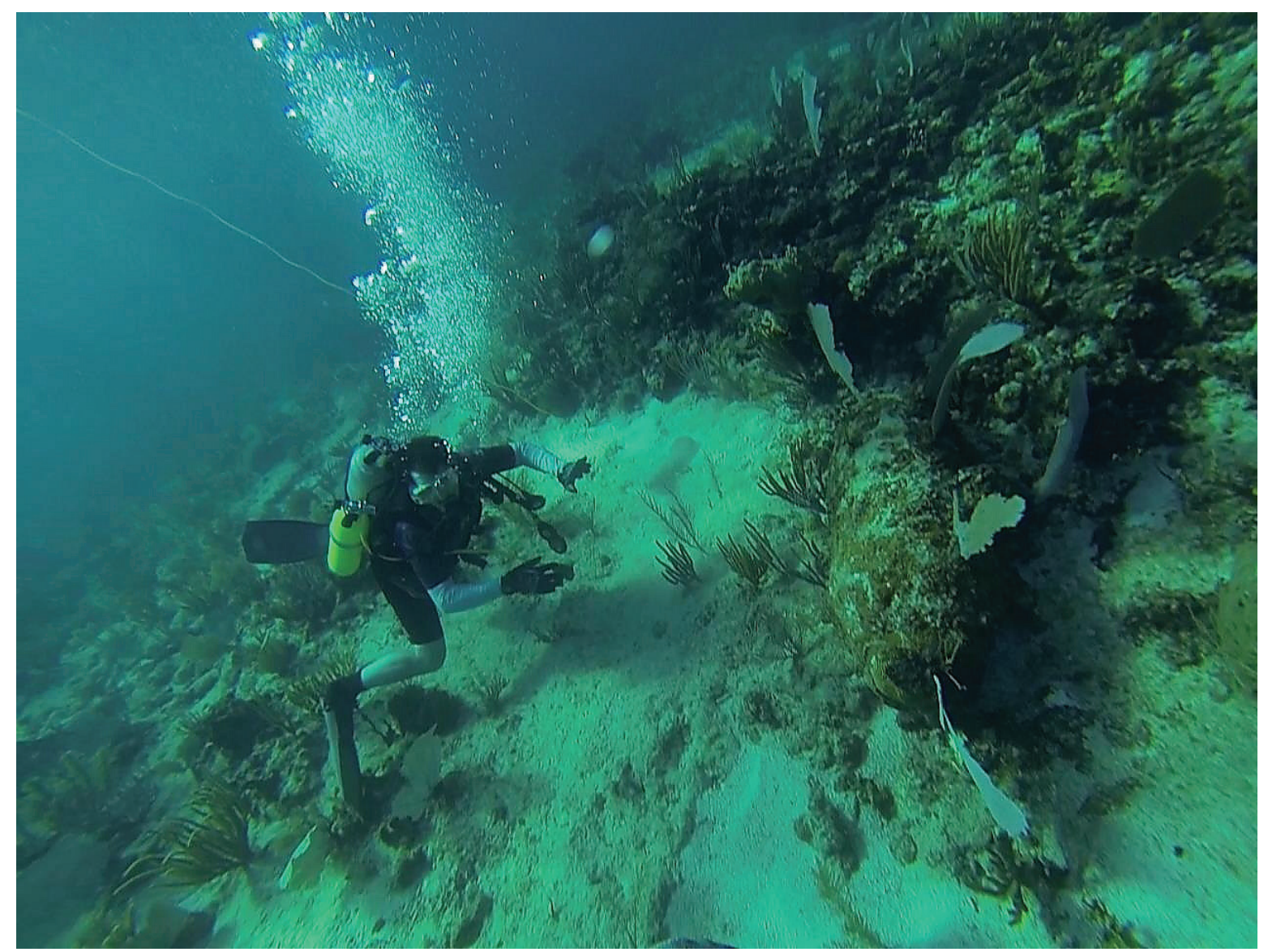


The U.S. Army Engineer Research and Development Center (ERDC) solves the nation's toughest engineering and environmental challenges. ERDC develops innovative solutions in civil and military engineering, geospatial sciences, water resources, and environmental sciences for the Army, the Department of Defense, civilian agencies, and our nation's public good. Find out more at www.erdc.usace.army.mil.

To search for other technical reports published by ERDC, visit the ERDC online library at http://acwc.sdp.sirsi.net/client/default.

Cover Image: Munitions response diver approaching an unexploded 1,00o pound General Purpose Bomb at Bahia Salina del Sur (Island of Vieques, PR). Photo provided courtesy of CH2M Hill Munitions Response and Scientific Dive Teams. 


\section{Review and Synthesis of Evidence Regarding Environmental Risks Posed by Munitions Constituents (MC) in Aquatic Systems}

Guilherme R. Lotufo, Mark A. Chappell, Cynthia L. Price, Mark L. Ballentine, Ashley A. Fuentes, and Todd S. Bridges

Environmental Laboratory

U.S. Army Engineer Research and Development Center 3909 Halls Ferry Rd, Building 3270

Vicksburg, MS 39180-6199

Eric J. Glisch

U.S. Army Corps of Engineers, New Orleans District

7400 Leake Avenue

New Orleans, LA 70118

Robert D. George

U.S. Navy, SPAWAR Systems Center Pacific

5622 Hull Street

San Diego, CA 92152

Geoffrey Carton

CALIBRE Systems

6354 Walker Ln Suite 300, Alexandria, VA 22310.

Alexandria, VA 22310

Final report

Approved for public release; distribution is unlimited.

Prepared for Strategic Environmental Research and Development Program (SERDP)

Under Project ER-2341, "Review and Synthesis of Evidence Regarding Environmental Risks Posed by Munitions Constituents (MC) in Aquatic Systems" 


\section{Abstract}

Underwater military munitions (UWMM) may pose a risk to aquatic environments because they typically contain munitions constituents (MC) such as 2,4,6-trinitrotoluene (TNT) and hexahydro-1,3,5-trinitro-1,3,5triazine (RDX). If UWMM become corroded or breaches, the fill material may leak or dissolve into the surrounding environment, which could potentially adversely affecting affect the exposed biota. In large part, because of the high cost and complexity associated with sampling $\mathrm{MC}$ at UWMM sites, detailed and reliable information about MC in water, sediment, and biota is available for only a few sites, and therefore temporal and spatial uncertainties persist. Examination of available data indicates that concentrations of $\mathrm{MC}$ in water and sediment were largely below detection or were relatively low (e.g., parts per billion), with higher concentrations being highly localized and typically near a point source. These findings were in accordance with predictive modeling and with fate studies. Available toxicity data derived for a variety of freshwater and marine species were compiled and used to derive interim water quality criteria and protective values derived from species sensitivity distributions. Toxicity varied widely across a diversity of $\mathrm{MC}$ and species. For most aquatic sites, MC contamination in sediment and in the watercolumn presents low risk to the resident biota.

DISCLAIMER: The contents of this report are not to be used for advertising, publication, or promotional purposes. Citation of trade names does not constitute an official endorsement or approval of the use of such commercial products. All product names and trademarks cited are the property of their respective owners. The findings of this report are not to be construed as an official Department of the Army position unless so designated by other authorized documents. 


\section{Contents}

Abstract....................................................................................................................... if

Figures and Tables............................................................................................................tif

Preface

Acronyms and Abbreviations.................................................................................xvii

Unit Conversion Factors................................................................................................ xxi

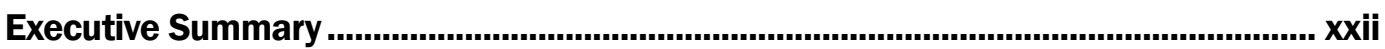

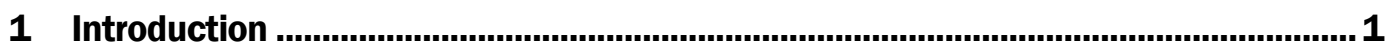

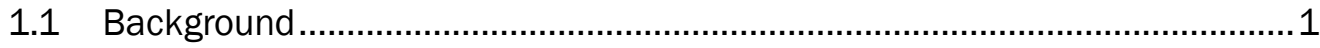

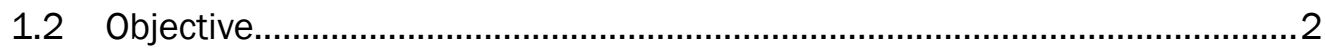

2 Generic Problem Formulation and Conceptual Model for Underwater

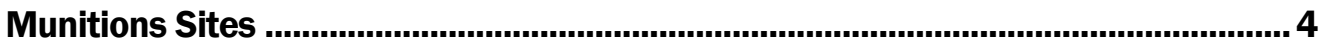

2.1 Underwater munitions in aquatic environments ......................................... 4

2.2 Conceptual site model............................................................................. 5

2.3 Munitions constituents of potential ecological concern ............................... 7

2.4 Assessment and measurement endpoints ................................................

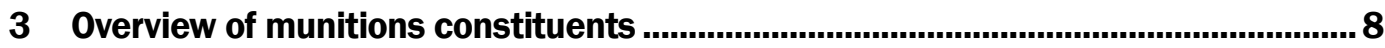

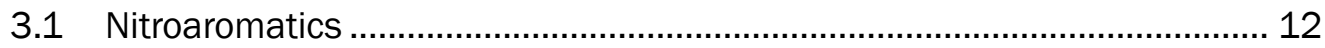

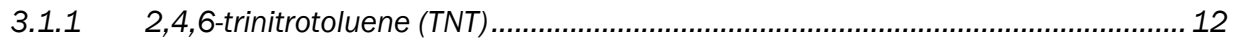

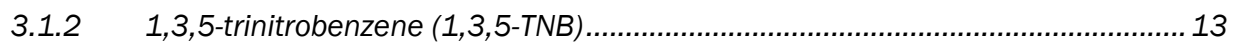

3.1.3 2,4-and 2,6- Dinitrotoluene (2,4-DNT and 2,6-DNT) ......................................... 13

3.1.4 Tetryl, ammonium picrate (Explosive D), and picric acid...................................... 14

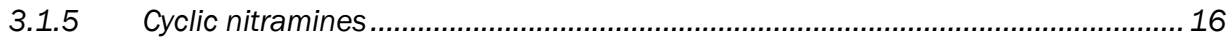

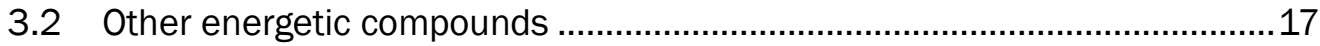

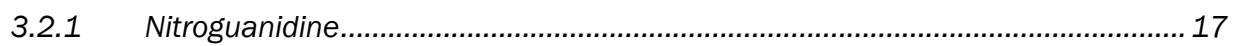

3.2.2 Nitrate esters: nitroglycerin, nitrocellulose, PETN, and DEGDN

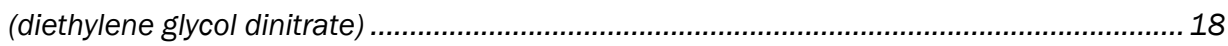

4 Underwater Munitions Sites Investigated for MC Contamination .........................20

4.1 Jackson Park housing complex (WA, USA) .................................................. 20

4.1.1 Site overview ................................................................................................... 20

4.1.2 Sampling efforts......................................................................................... 21

4.1.3 Analytical chemistry ................................................................................2 22

4.2 Sea disposal site Hawaii (HI-06) “Ordnance Reef” (HI, USA) ....................... 23

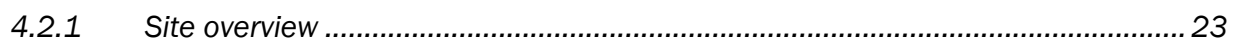

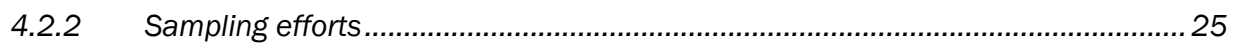

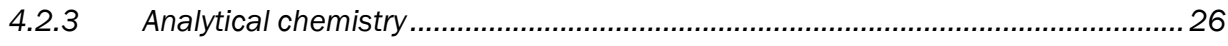

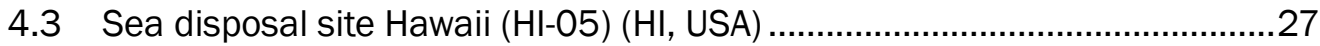




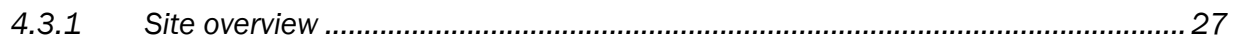

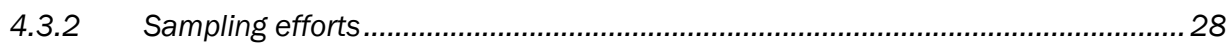

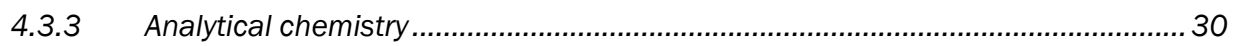

4.4 Isla de Vieques bombing range (PR, USA) .............................................. 30

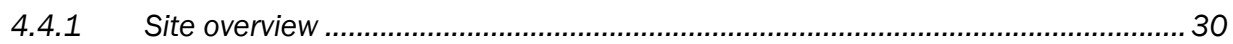

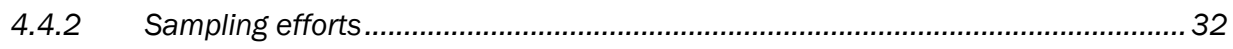

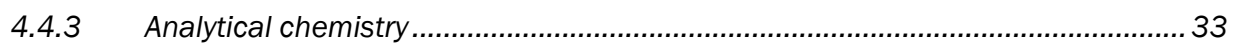

4.5 Former Seattle Naval Supply Depot piers 90 and 91, Port of Seattle

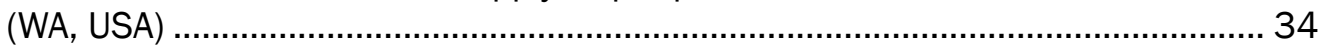

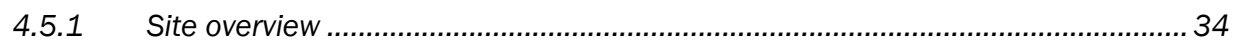

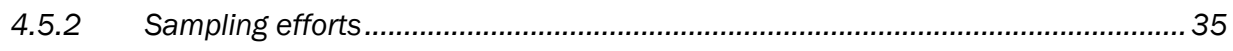

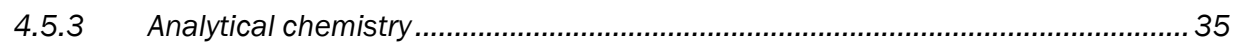

4.6 Halifax Harbor (Nova Scotia, Canada)....................................................... 36

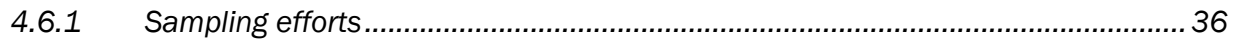

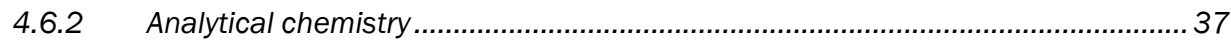

4.7 Halifax Harbor area (Nova Scotia, Canada) ...............................................37

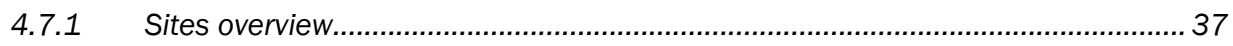

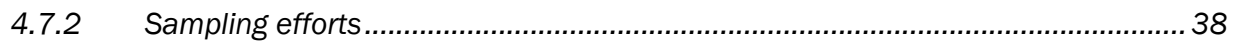

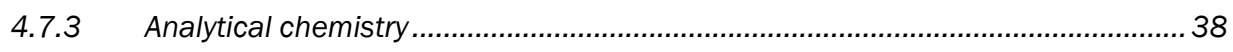

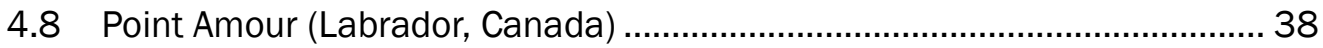

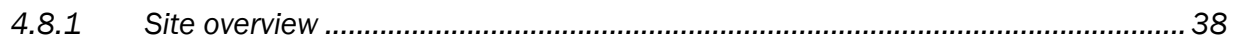

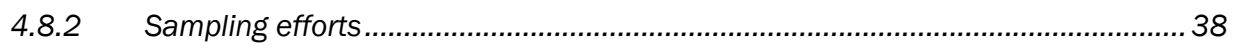

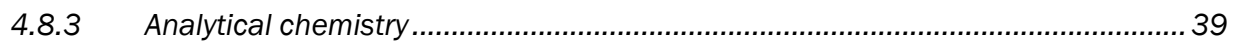

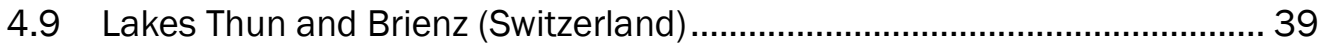

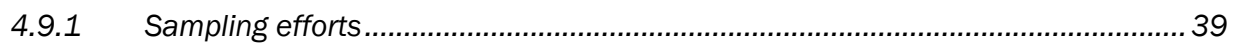

4.9.2 Analytical chemistry .......................................................................................... 40

4.10 Lakes Limmaren, Stensele, Pengsjön, and Lomtjärn and Fårö and Möja, Baltic Sea and Stora Pölsan, North Sea (Sweden) .............................. 40

4.10.1 Sites overview.......................................................................................................... 40

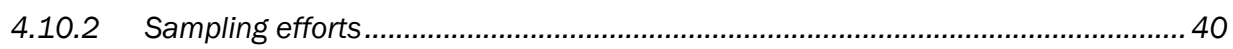

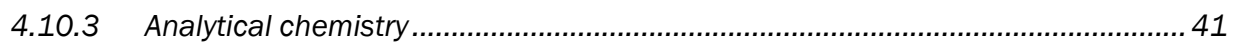

4.11 Lake of Mjøsa and Lake Randsfjorden (Norway) ................................41

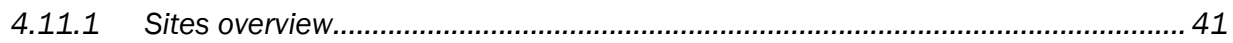

4.11.2 Sampling efforts and analytical chemistry ....................................................... 41

4.12 Coastal fortifications in Norway.................................................... 42

4.12.1 Sites overview and sampling efforts ................................................................... 42

4.12.2 Analytical chemistry ..............................................................................................43

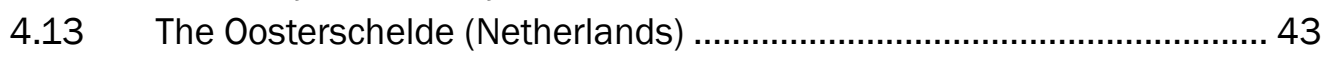

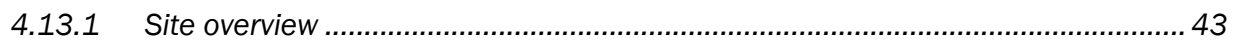

4.13.2 Sampling efforts and analytical chemistry ......................................................4 44

4.14 Beaufort's Dyke (North-East Atlantic) ........................................... 44

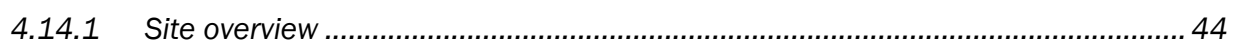

4.14.2 Sampling efforts and analytical chemistry ...................................................... 44

5 MC Contamination at Underwater Munitions Sites - Water Column .....................45

5.1 Sites with MC concentrations below DL in all samples.............................. 45 
5.1.1 Sea disposal site Hawaii (HI-06) "Ordnance Reef" (HI, USA) ................................ 45

5.1.2 Sea disposal site Hawaii (HI-05) "HUMMA study"................................................. 45

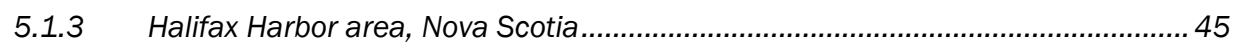

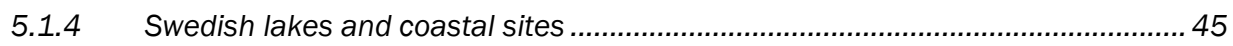

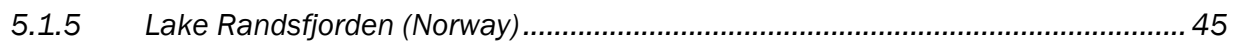

5.1.6 The Oosterschelde (Netherlands) ....................................................................... 45

5.2 Sites reporting MC contamination in water samples ................................. 46

5.2.1 Isla de Vieques Bombing Range site (PR)..........................................................46

5.2.2 Halifax Harbor (Halifax, Canada)......................................................................... 49

5.3 Point Amour (Labrador, Canada) ..........................................................51

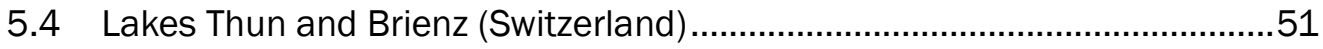

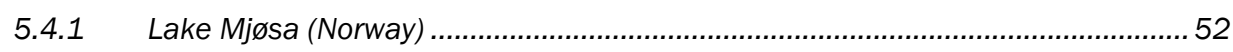

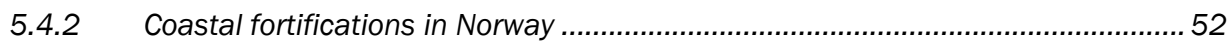

6 MC Contamination at Underwater Munitions Sites - Sediment ............................53

6.1 Sites with MC concentrations below DL in all samples or with

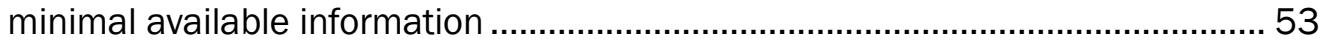

6.1.1 Halifax Harbor area, Nova Scotia ...................................................................... 53

6.1.2 Swedish lakes and coastal sites ..................................................................... 53

6.1.3 Beaufort's Dyke (North-East Atlantic) ........................................................... 53

6.1.4 Lake of Mjøsa and Lake Randsfjorden (Norway) ...............................................53

6.2 Sites reporting MC contamination in sediment samples............................ 53

6.2.1 Jackson Park housing complex (WA) .................................................................. 53

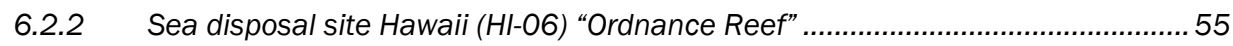

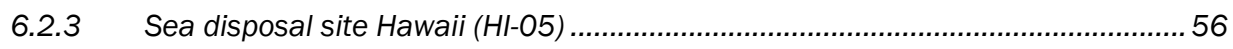

6.2.4 Former Seattle Naval Supply Piers 90 and 91 - Port of Seattle (WA)...................57

6.2.5 Isla de Vieques Bombing Range (PR)..............................................................58

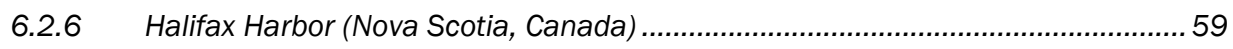

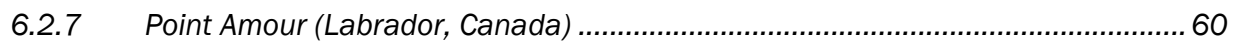

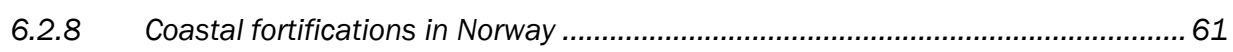

7 MC Contamination at Underwater Munitions Sites - Biota.....................................63

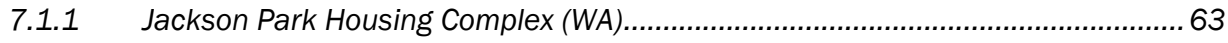

7.1.2 Sea disposal site Hawaii (HI-06) “Ordnance Reef” .............................................. 65

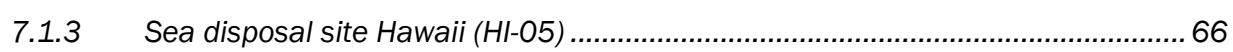

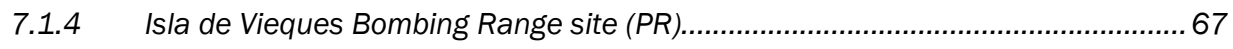

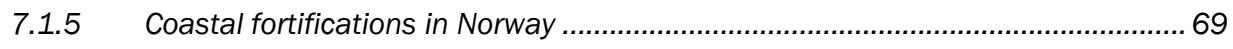

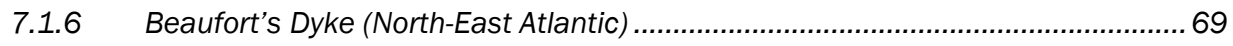

\section{An Analysis of the Environmental Fate Data for Munition Constituents as}

Collected from the Scientific Literature............................................................ 70

8.1 Fate modeling via evaluative environments ........................................... 70

8.2 Experimental $\mathrm{F}$ and $\mathrm{T}$ parameters included in the Mackay models ..............76

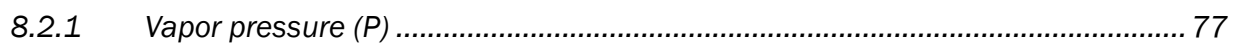

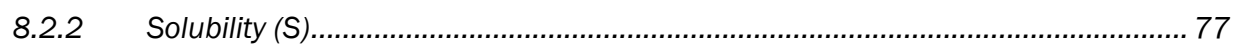

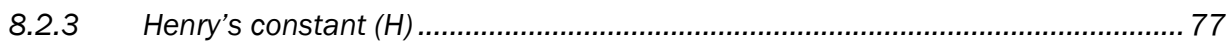


8.2.4 Octanol-water partitioning coefficient (Kow) ................................................... 77

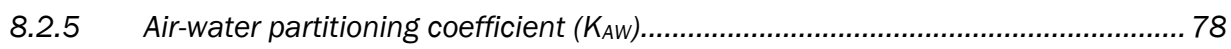

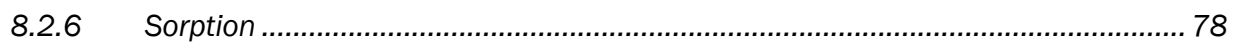

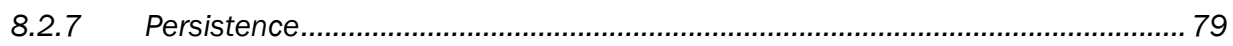

8.3 MC F and T data from the scientific literature .................................... 79

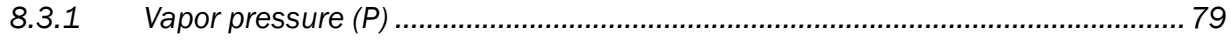

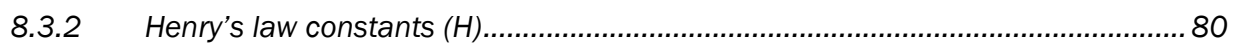

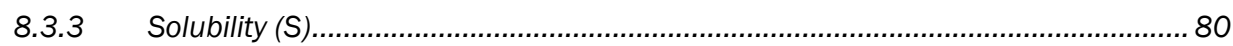

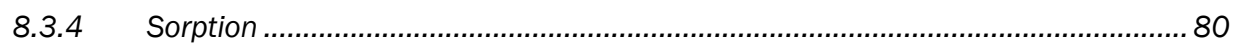

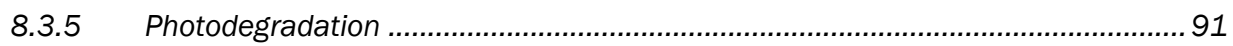

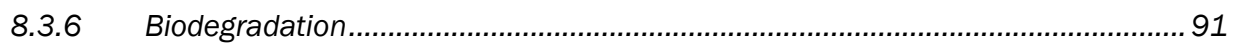

8.3.7 Degradation in soil ......................................................................................... 91

8.4 Covariant structure in sediments: preliminary assessment as basis for developing improved MC persistence predictions ....................................... 102

8.5 TNT and RDX Environmental fate modeling ........................................... 106

8.5.1 Simulations of TNT and RDX environmental fate................................................107

8.5.2 Inputted TNT fate parameters.............................................................................. 108

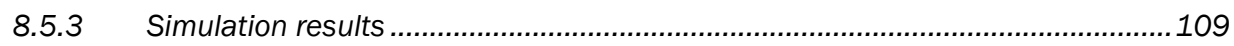

8.5.4 Inputted RDX fate parameters .................................................................. 112

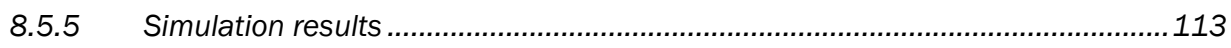

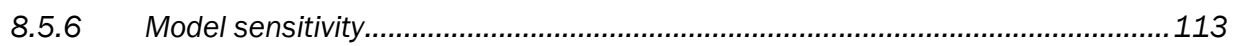

9 Release of MC from Breached Shells in Aquatic Environments .......................... 116

9.1 Source characterization ..................................................................... 116

9.2 Release modeling for fate and transport purposes................................ 117

9.3 Modeling release of MCs such as TNT, RDX and HMX ........................... 118

9.4 Probabilistic modeling ........................................................................ 119

9.4.1 Underwater munitions site modeling approach and methodology .....................120

9.5 Characterization of munitions distributions at UWMM sites .................... 124

9.6 Probabilistic MC release using munitions distributions at UWMM sites ..... 127

9.7 Discussion of scenario $A$ and $B$ results............................................... 139

\section{Fate of TNT and RDX in Marine Environments Determined Using a Stable}

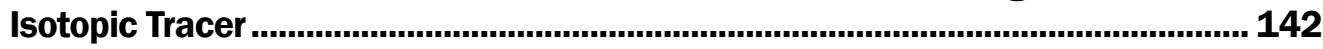

10.1 Tracing the fate of TNT using a stable isotopic tracer.......................... 145

10.2 RDX in Marine Systems....................................................................147

11 Overview of the Toxicity of Munitions Constituents to Aquatic Organisms......... 149

11.1 Toxicity of MC to aquatic larval stages of amphibians......................... 149

$11.2 \quad$ Toxicity of MC to fish...................................................................... 150

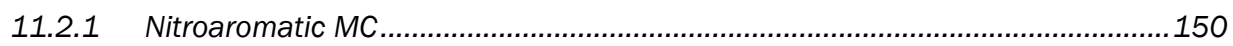

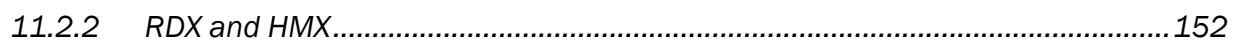

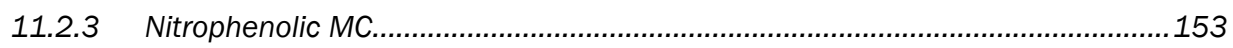

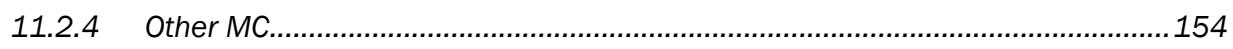

11.3 Toxicity of MC to invertebrates.................................................... 154

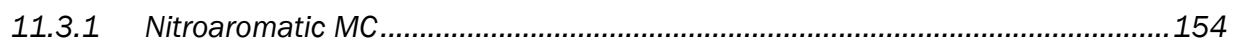




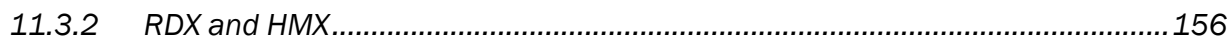

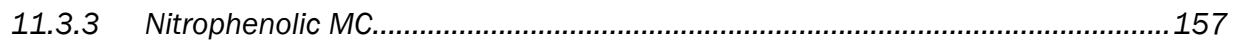

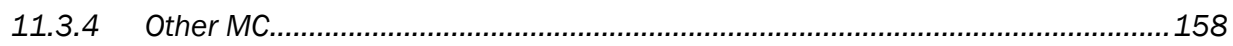

11.3.5 Relative responsiveness of effects on reproduction............................................158

11.4 Toxicity of MC to autotrophs.......................................................... 160

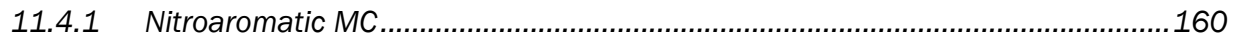

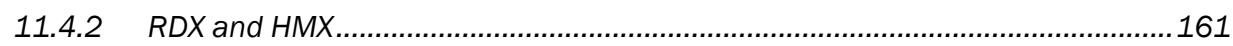

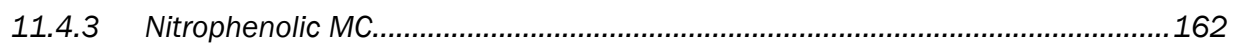

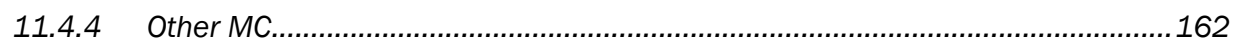

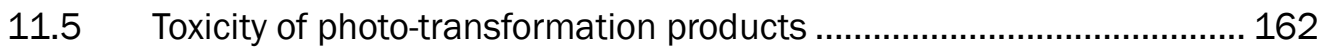

11.6 Biochemical and histopathological effects....................................... 163

11.7 Toxicity of MC to aquatic invertebrates and fish in sediment

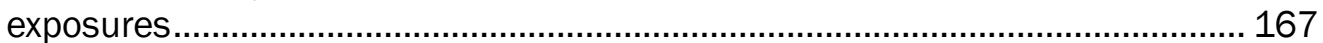

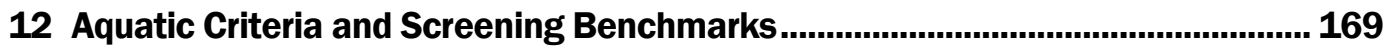

12.1 Aquatic acute and chronic ambient water quality criteria .................... 169

12.2 Biological Technical Assistant Group (BTAG) screening benchmark.

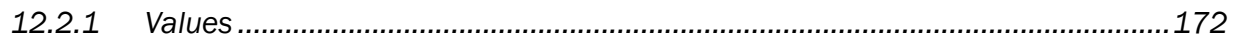

12.2.2 Species sensitivity distributions using aqueous exposure data..........................173

12.3 Preliminary sediment screening criteria for the protection of benthic invertebrates ......................................................................................... 186

13 Screening-level Generic Risk Assessment of MC at UWMM sites ....................... 189

13.1 Evaluation of risk posed by MC in the water column ........................... 190

13.2 Evaluation of risk posed by MC in sediment ....................................... 192

13.2.1 Sea disposal site Hawaii (HI-06) "Ordnance Reef" ..............................................192

13.2.2 Seattle Harbor piers 90 and 91 (USACE 2013) .................................................194

13.2.3 Isla de Vieques bombing range ....................................................................... 195

13.2.4 Halifax Harbor ............................................................................................... 195

13.2.5 Coastal fortifications in Norway ........................................................................ 196

13.2.6 Conclusions regarding risk posed by MC in sediment ........................................196

13.3 Evaluation of risk using MC concentration in biota ............................ 198

14 Ecological risk assessment of MC at UWMM sites - summary and

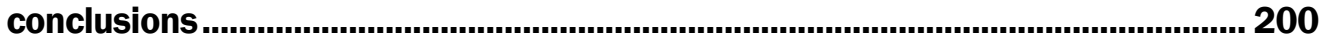

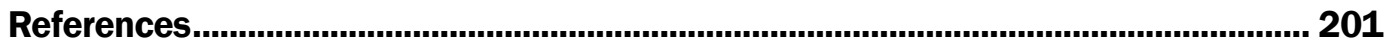

Appendix A: Munitions Constituents in Aquatic Systems Database........................... 219

Appendix B: Munitions Constituents General Environmental Properties

Database ........................................................................................................................ 225

Appendix C: Munitions Constituents Aquatic Toxicity Database ............................. 226

Report Documentation Page 


\section{Figures and Tables}

\section{Figures}

Figure 1. Chemical structure of 2,4,6 trinitrotoluene (TNT).............................................12

Figure 2. Chemical structure of trinitrobenzene $(1,3,5-\mathrm{TNB})$...........................................13

Figure 3. Chemical structure of 2,4-and 2,6- Dinitrotoluene (2,4-DNT),............................14

Figure 4. Chemical structure of tetryl, ammonium picrate (Explosive D), and picric

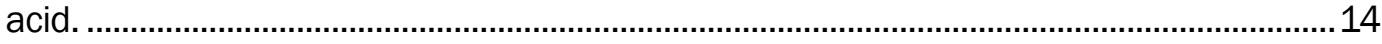

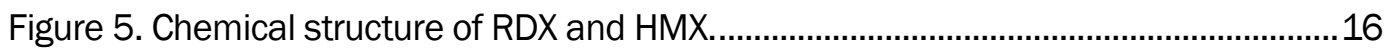

Figure 6. Chemical structure of Nitroguanidine. ........................................................... 17

Figure 7. Chemical structure of Nitrate esters: nitroglycerin, nitrocellulose, PETN, and DEGDN (diethylene glycol dinitrate).

Figure 8. Fraction (as percent) of water samples collected at Bahia Salina del Sur (Vieques, PR) at approximately 10-15 cm away from UWMM target items for which MC concentrations were reported as quantified values. Based on Rosen et al. 2017.

Figure 9. MC concentrations for water samples collected at Bahia Salina del Sur (Vieques, PR) in proximity to UWMM target items. Based on Porter et al. (2011) and Rosen et al. (2017).

Figure 10. MC concentrations for water samples collected at Bahia Salina del Sur (Vieques, PR) in a grid-pattern representing the majority of the site. Based on Rosen et al. (2017).

Figure 11. Fraction (as percent) of water samples collected at Halifax Harbor (Halifax, Canada) for which MC concentrations were reported as quantified values. Based on Rodacy et al. (2001).

Figure 12. MC concentrations for water samples collected at Halifax Harbor (Halifax, Canada). Based on Rodacy et al. (2001).

Figure 13. Fraction (as percent) of sediment samples collected at Jackson Park Housing Complex (WA, USA) for which MC concentrations were reported as quantified values. Based on Blakley (2005) and NAVFAC NW (2010a, 2010b).

Figure 14. MC concentrations for sediment samples collected at Jackson Park Housing Complex (WA, USA). Based on Blakley (2005) and NAVFAC NW (2010a, 2010b).

Figure 15. Fraction (as percent) of sediment samples collected at Sea Disposal Site Hawaii (HI-06) "Ordnance Reef" (HI, USA) for which MC concentrations were reported as quantified values. Based on UH (2014a, 2014b).

Figure 16. MC concentrations for sediment samples collected at Sea Disposal Site Hawaii (HI-06) "Ordnance Reef” (HI, USA). Based on UH (2014a, 2014b).

Figure 17. Fraction (as percent) of sediment samples collected at Sea Disposal Site Hawaii (HI-05) for which MC concentrations were reported as quantified values. Based on UH (2010).

Figure 18. Fraction (as percent) of sediment samples collected at Seattle Harbor Piers 90 and 91 (WA) for which MC concentrations were reported as quantified values. Based on USACE (2013). 
Figure 19. Fraction (as percent) of sediment samples collected at Halifax Harbor (Halifax, Canada) for which MC concentrations were reported as quantified values. Based on Rodacy et al. (2001).

Figure 20. MC concentrations for sediment samples collected at Halifax Harbor (Halifax, Canada). Based on Rodacy et al. (2001).

Figure 21. Fraction (as percent) of sediment samples collected at Point Amour (Labrador, Canada) for which MC concentrations were reported as quantified values. Based on Ampleman et al. (2004).

Figure 22. Fraction (as percent) of sediment samples collected at coastal fortifications in Norway for which MC concentrations were reported as quantified values. Based on Rossland et al. (2010).

Figure 23. MC concentrations for sediment samples collected at coastal fortifications in Norway. Based on Rossland et al. (2010).

Figure 24. Fraction (as percent) of biota samples collected at Jackson Park Housing Complex (WA, USA) for which MC concentrations were reported as quantified values. Based on NAVFAC NW (2010b and 2011).

Figure 25. MC concentrations for biota samples collected at Jackson Park Housing Complex (WA, USA). Based on NAVFAC NW (2010c and 2011).

Figure 26. Fraction (as percent) of biota samples collected at sea disposal site Hawaii (HI-06) "Ordnance Reef" (HI, USA) for which MC concentrations were reported as quantified values. Based on University of Hawaii (2014a and 2014b).

Figure 27. MC concentrations for biota samples collected at sea disposal site Hawaii (HI-06) "Ordnance Reef” (HI, USA). Based on University of Hawaii (2014a and 2014b).

Figure 28. Fraction (as percent) of biota samples collected at sea disposal site Hawaii (HI-05) (HI, USA) for which MC concentrations were reported as quantified values. Based on University of Hawaii (2010) and Koide et al. (2016).

Figure 29. MC concentrations for biota samples collected at sea disposal site Hawaii (HI-05) (HI, USA). Based on University of Hawaii (2010) and Koide et al. (2016)

Figure 30. Schematic representing a generalized environmental $\mathrm{F}$ and T model. At the lowest resolution, the model is broken up into four main environmental compartments: soil, sediment, water, and air. The arrows indicate intercompartment transfer of contaminants (red arrows) as well as contaminant inputs (via external inputs - yellow arrows) and process outputs (advective transport - blue arrows; abiotic/biotic disappearance - green arrows). The bulk of experimental work in environmental $\mathrm{F}$ and $\mathrm{T}$ involves generating parameters, which the red and green arrows describe.

Figure 31. Box and whisker plot summarizing the reported Henry Constants for TNT and RDX in the scientific literature. The middle line in the box represents the median of reported data; the dashed line represents the mean, and the borders on the box represent the first and third quartiles of the analytical data, respectively. The error bars represent the minimum and maximum values of the reported analytical data, while the cross-hair on the error bars represents the values located outside the inner quartile range (i.e., outliers).

Figure 32. Plots showing the range of experimental values within the Henry's constant for (A) TNT and (B) RDX as reported in the scientific literature. 
Figure 33. Box and whisker plot summarizing the reported solubility for TNT and RDX in the scientific literature. The middle line in the box represents the median of reported data; the dashed line represents the mean, and the borders on the box represent the first and third quartiles of the analytical data, respectively. The error bars represent the minimum and maximum values of the reported analytical data, while the cross-hair on the error bars represents the values located outside the inner quartile range (i.e., outliers).

Figure 34. Box and whisker plot summarizing the reported dissolution rates for TNT and RDX in the scientific literature. The middle line in the box represents the median of reported data; the dashed line represents the mean, and the borders on the box represent the first and third quartiles of the analytical data, respectively. The error bars represent the minimum and maximum values of the reported analytical data, while the cross-hair on the error bars represents the values located outside the inner quartile range (i.e., outliers).

Figure 35. Plots showing the solubility of (A) TNT and (B) RDX with temperature as reported in the scientific literature.

Figure 36. Plots showing the dissolution rates of (A) TNT and (B) RDX with temperature as reported in the scientific literature. The $\mathrm{X}$-axis represents each individual data point obtained from the literature.

Figure 37. Calculated sorption coefficients $\left(K_{D}\right)$ for $(A)$ TNT and (B) RDX in a variety of soils, sediments, and geological materials as Brannon and Pennington (2002) summarized.

Figure 38. Box and whisker plot summarizing the reported sorption coefficients $\left(K_{D}\right)$ for TNT and RDX in the scientific literature. The middle line in the box represents the median of reported data; the dashed line represents the mean; and the borders on the box represent the first and third quartiles of the analytical data, respectively. The error bars represent the minimum and maximum values of the reported analytical data while the cross-hair on the error bars represents the values located outside the inner quartile range (i.e., outliers).

Figure 39. Partial least squares (PLS) analysis (preliminary) of TNT soil sorption data compared to a small set of soil properties. (A) Percent explained variance using a three-factor model; (B) plot showing correlation between the calculated and predicted $K_{D}$ values. (C) Score plot; (D) loading plot.

Figure 40. Partial least squares (PLS) analysis (preliminary) of RDX soil sorption data compared to a small set of soil properties. (A) Percent explained variance using a 2-Factor model; (B) plot showing correlation between the calculated and predicted $\mathrm{K}_{\mathrm{D}}$ values. (C) Score plot; (D) loading plot.

Figure 41. Box and whisker plot summarizing the reported Koc values as well as those calculated from $K_{D}$ values for TNT and RDX in the scientific literature. The middle line in the box represents the median of reported data; the dashed line represents the mean, and the borders on the box represent the first and third quartiles of the analytical data, respectively. The error bars represent the minimum and maximum values of the reported analytical data while the crosshair on the error bars represents the values located outside the inner quartile range (i.e., outliers).

Figure 42. Data from the scientific literature showing the photodegradation halflife of (A) TNT and (B) RDX. 
Figure 43. Box and whisker plot summarizing the reported photodegradation half-lives ( $\left.\mathrm{t}_{1 / 2}\right)$ for TNT and RDX in the scientific literature. The middle line in the box represents the median of reported data; the dashed line represents the mean, and the borders on the box represent the first and third quartiles of the analytical data, respectively. The error bars represent the minimum and maximum values of the reported analytical data while the cross-hair on the error bars represents the values located outside the inner quartile range (i.e., outliers).

Figure 44. Data for the biodegradation half-life of (A) TNT and (B) RDX collected from the scientific literature. (C) Plot comparing the TNT biodegradation half-life to experimental system temperature. For A-B, labels on the $\mathrm{x}$-axis contain additional notes (when available) regarding the experimental test conditions.

Figure 45. Box and whisker plot summarizing the reported biodegradation halflives ( $\left.\mathrm{t}_{1 / 2}\right)$ for TNT and RDX in the scientific literature. The middle line in the box represents the median of reported data; the dashed line represents the mean, and the borders on the box represent the first and third quartiles of the analytical data, respectively. The error bars represent the minimum and maximum values of the reported analytical data while the cross-hair on the error bars represents the values located outside the inner quartile range (i.e., outliers).

Figure 46. Box and whisker plot summarizing the reported biodegradation constants $(k)$ for TNT and RDX in the scientific literature. The middle line in the box represents the median of reported data; the dashed line represents the mean, and the borders on the box represent the first and third quartiles of the analytical data, respectively. The error bars represent the minimum and maximum values of the reported analytical data while the cross-hair on the error bars represents the values located outside the inner quartile range (i.e., outliers). 100

Figure 47. Data from the scientific literature showing the degradation rate of (A) TNT and (B) RDX in different soil types. 101

Figure 48. Preliminary principal component analysis (PCA) of the sediment samples based on the selected geochemical characterization data. Samples were preliminarily grouped based on their sampling designations.

Figure 49. Two-dimensional representation of the PCs 1-3, where a 90 degree rotation of the $x$-axis changes this axis from PC-1 to PC-2. The legend in Figure 8-19 explains the symbols used in this figure. 105

Figure 50. Three-dimensional representation of PC 1-3 from a multivariate decomposition of the SedDB characterization data. The legend in Figure 8-19 explains the symbols. 106

Figure 51. Graphical representation of the different environmental processes captured in the QWASI model (Mackay et al. 1983a).

Figure 52. Output diagram representing the distribution and movement of TNT among the different compartments as calculated from the QWASI model.

Figure 53. Output diagram representing the distribution and movement of RDX among the different compartments as calculated from the QWASI model.

Figure 54. Process flow for implementing the shell model release function at a site with discrete parameters or probabilistic parameter distributions. 124

Figure 55. Release rate function $(F)$ dependencies on (a) Breach hole radius at $R$ $=1 \mathrm{e}-2 \mathrm{~m}$ and $\mathrm{U}=0.5 \mathrm{~m} / \mathrm{s}$, (b) Internal cavity radius $(\mathrm{R})$ at $\mathrm{b}=1 \mathrm{e}-4 \mathrm{~m}$ and $\mathrm{U}=$ $0.5 \mathrm{~m} / \mathrm{s}$, and (c) Current velocity $(\mathrm{U})$ at $\mathrm{b}=1 \mathrm{e}-3 \mathrm{~m}$ and $\mathrm{R}=2 \mathrm{e}-2 \mathrm{~m}$. 
Figure 56. Distribution of munitions at Site 1, characterized as an underwater munitions site that was part of a former military training range

Figure 57. Distribution of munitions at Site 2, characterized as an underwater munitions site that was a former discarded military munitions area. (Based on Table 1 in Garcia et al. 2009) * Note: Totals do not include 20-mm cartridges (49\% of total).

Figure 58. Graphical distribution functions for parameters treated probabilistically are (a) ambient current velocity, (b) breach hole radius, (c) breach cavity radius, (d) number of breached munitions of a given type, and (e) mass remaining in each breached munition. Minimum, maximum, and central tendency (most likely) are tabulated in Tables 9-2 and 9-3.

Figure 59. TNT release function distribution $\mathrm{F}$ (single munition).

Figure 60.TNT total site release function distribution F' ( $F$ applied to the distribution of munitions at the site)

Figure 61. Explosive $D$ release function distribution $F$ (single munition).

Figure 62. Explosive $D$ total site release function distribution $F$ ' (F applied to the distribution of munitions at the site).

Figure 63. Graphical distribution functions for parameters treated probabilistically at fVNTR-BSS are (a) ambient current velocity, (b) breach hole radius, (c) breach cavity radius, (d) number of breached munitions of a given type, and (e) mass remaining in each breached munition. Minimum, maximum, and central tendency (most likely) are tabulated in Table 26.

Figure 64. TNT release function distribution $\mathrm{F}$ (single munition). 138

Figure 65. TNT total site release function distribution F' (F applied to the distribution of munitions at the site). 139

Figure 66. Lethal concentrations of $\mathrm{MC}$ to aquatic larval stages of amphibians. 150

Figure 67. Lethal concentrations, as $\mathrm{LC}_{50}$ values derived from exposure of varying durations, of MC to fish.

Figure 68. Lethal concentrations, as $\mathrm{LC}_{50}$ values derived from exposure of varying durations, of MC to invertebrates.

Figure 69. $\mathrm{LC}_{50}$ and $\mathrm{EC}_{50}$ values for survival and offspring production, respectively, of the polychaete Dinophilus gyrociliatus (from Nipper et al. 2001).

Figure 70. Toxic concentrations of MC to autotrophs. 161

Figure 71 . Species sensitivity distribution for 2,4,6-TNT using effects data. The outer lines represent $95 \%$ confidence intervals.

Figure 72. Species sensitivity distribution for 2-A-2,4-DNT using effects data. The outer lines represent 95\% confidence intervals.

Figure 73. Species sensitivity distribution for 4-A-2,5-DNT using effects data. The outer lines represent 95\% confidence intervals.

Figure 74. Species sensitivity distribution for 1,3,5 TNB using effects data. The outer lines represent 95\% confidence intervals.

Figure 75. Species sensitivity distribution for 1,3 DNB using effects data. The outer lines represent 95\% confidence intervals.

Figure 76. Species sensitivity distribution for 2,4 DNT using effects data. The outer lines represent 95\% confidence intervals. 
Figure 77. Species sensitivity distribution for 2,6 DNT using effects data. The outer lines represent 95\% confidence intervals.

Figure 78. Species sensitivity distribution for RDX using effects data. The outer lines represent $95 \%$ confidence intervals.

Figure 79. Species sensitivity distribution for Picric Acid using effects data. The outer lines represent 95\% confidence intervals.

Figure 80. Species sensitivity distribution for NG using effects data. The outer lines represent 95\% confidence intervals.

Figure 81. Species sensitivity distribution for 2,4,6-TNT using no-effects data. The outer lines represent 95\% confidence intervals.

Figure 82. Species sensitivity distribution for 1,3,5-TNB using no-effects data. The outer lines represent 95\% confidence intervals.

Figure 83. Species sensitivity distribution for 1,3-DNB using no-effects data. The outer lines represent 95\% confidence intervals.

Figure 84. Species sensitivity distribution for 2,4-DNT using no-effects data. The outer lines represent 95\% confidence intervals.

Figure 85. Species sensitivity distribution for 2,6-DNT using no-effects data. The outer lines represent 95\% confidence intervals.

Figure 86. Species sensitivity distribution for RDX using no-effects data. The outer lines represent 95\% confidence intervals.

Figure 87. Species sensitivity distribution for HMX using no-effects data. The outer lines represent 95\% confidence intervals.

Figure 88. Species sensitivity distribution for Picric Acid using no-effects data.

The outer lines represent $95 \%$ confidence intervals.

Figure 89. Species sensitivity distribution for NG using no-effects data. The outer lines represent $95 \%$ confidence intervals.

Figure 90. Species sensitivity distribution for NQ using no-effects data. The outer lines represent $95 \%$ confidence intervals.

\section{Tables}

Table 1. Energetic chemicals present in military explosive and propellant formulations (USEPA 2012)

Table 2. Physicochemical properties of munitions constituents and their common transformation products (USEPA 2012, unless specified).

Table 3. Concentrations of MC in water samples collected near a 2000-lb bomb in Isla de Vieques Bombing Range site (PR).

Table 4. Detection frequency and concentrations of MC in the water column near UWMM as measured by passive samplers and grab samples at grid locations as measured by grab samplers at the Isla de Vieques Bombing Range site (PR).

Based on Rosen et al. (2017).

Table 5. Detection frequency and range of measured concentrations of $\mathrm{MC}$ in the water collected at Halifax Harbor (Halifax, Canada). Based on Rodacy et al. (2001).

Table 6. Concentrations of MC in sediment samples collected near a $2000 \mathrm{lb}$. GP bomb in Isla de Vieques Bombing Range site (PR). 
Table 7. Detection frequency and range of measured concentrations of MC detected in biota collected at Jackson Park Housing Complex. Based on NAVFAC NW (2010c, 2011)

Table 8. Concentrations of MC in biota collected near a 2000-lb bomb in Isla de Vieques Bombing Range site, PR.

Table 9. Summary of the fugacity capacity (Zi) equations defining different

environmental compartments in the Level I fate model (after Mackay, 2001).

Table 10. Equations for the $\mathrm{D}$ parameter (called the fugacity rate constant) in the Level II fate calculations (from Mackay, 2001).

Table 11. Parameters for environmental properties, including suggested values (from Mackay, 2001).

Table 12. Level III intermedia transfer equations for D values (from Mackay, 2001).

Table 13. Tests for normality and descriptive statistics and information regarding the environmental fate parameters for TNT reported in the scientific literature. 102

Table 14. Tests for normality and descriptive statistics and information regarding the environmental fate parameters for RDX reported in the scientific literature. 102

Table 15. Pairwise Pearson correlation coefficients for the sediment data from the SedDB database. Values in bold indicate the correlation constants were statistically significant $(p=0.05)$. The diagonal (containing value $=1$ ) represent self-correlation.

Table 16. Environmental properties of the hypothetical water-body. 110

Table 17. TNT partitioning among the different environmental compartments as calculated by the QWASI model.

Table 18. Fugacity capacities (Z) describing the partitioning of TNT to different environmental compartments and selected sub-compartments as calculated by the QWASI model.

Table 19. Estimated TNT losses, calculated from the QWASI model.

Table 20. RDX partitioning coefficients among the different environmental compartments as calculated by the QWASI model.

Table 21. Fugacity capacities (Z) describing the partitioning of RDX to different environmental compartments and selected sub-compartments as calculated by the QWASI model.

Table 22. Estimated RDX losses calculated from the QWASI model.

Table 23. Discreet examples of functional values for shell model release defined by Equation 1.

Table 24. Model parameters for TNT-filled munitions at a generic site.

Distribution-based parameters are in gray and shown graphically in Figure 58.

Table 25. Model parameters for Explosive D-filled munitions at a generic site.

Distribution-based parameters in gray are the same as for TNT-filled munitions

for purposes of comparison, as shown graphically in Figure 58

Table 26. Model parameters for Mk 82 TNT-filled munitions at fVNTR-BSS.

Distribution-based parameters are in gray and shown graphically in Figure 63.

Table $27 .{ }^{15} \mathrm{~N}$ mass balance for $\mathrm{MC}$ addition into an intertidal marsh system. 
Table 28. $\mathrm{LC}_{50}$ and $\mathrm{EC}_{50}$ values for survival and offspring production, respectively, of the polychaete Dinophilus gyrociliatus (from Nipper et al. 2001).

Table 29. Hypothesis-testing-based NOEC and LOEC values for survival and offspring production of the cladoceran Ceriodaphia dubia (from Burton et al. 1983).

Table 30. MC toxic effects on marine corals fragments. Based on Woodley and Downs (2014).

Table 31. Lethal toxicity data for MC determined for aquatic invertebrates using spiked sediment exposures.

Table 32. Provisional Acute and Chronic Values Derived as Water Quality Criteria

Table 33. Biological Technical Assistance Group screening benchmark values (BTAG 2006).

Table 34. Hazardous concentrations of munitions constituents. 175

Table 35. Sediment quality benchmarks (SQB) for MC

Table 36. Maximum concentrations of MC in water samples collected at UWMM sites and ecological screening levels from Chapter 12. Values in bold indicate exceedance of one or more screening levels.

Table 37. Maximum concentrations (noted as 95\% upper confidence limit, where indicated) of MC in sediment samples collected at UWMM sites, number of samples, detection frequency, and hazard quotients calculated using sediment benchmark values reported in Chapter 12 . Values in bold indicate $\mathrm{HQ}>1$ (rounded to the unit).

Table 38. Comparison of limit of detection for Seattle Harbor piers 90 and 91 study (USACE 2013) with revised sediment quality benchmark (SQB) values (Chapter 12).

Table 39. Number of samples, and hazard quotients for MC exceeding sediment quality benchmarks (SQB) at UWMM sites. 


\section{Preface}

This study was conducted for the Strategic Environmental Research and Development Program (SERDP) under "Review and Synthesis of Evidence Regarding Environmental Risks Posed by Munitions Constituents (MC) in Aquatic Systems," Project ER-12341. The technical monitor was Dr. Andrea Leeson, Deputy Director and Environmental Restoration Program Manager (SERDP and ESTCP).

The work was performed by the Environmental Processes and Risk Branch of the Environmental Processes Division (CEERD-EPR), U.S. Army Engineer Research and Development Center, Environmental Laboratory (ERDC-EL). At the time of publication, Dr. William Nelson was Chief, CEERD-EPR; Mr. Warren Lorentz was Chief, CEERD-EP; and Dr. Elizabeth Ferguson, CEERD-EMJ was the Technical Director for Military Environmental Quality and Installations. The Deputy Director of ERDC-EL was Dr. Jack Davis and the Director was Dr. Beth Fleming.

COL Bryan S. Green was the Commander of ERDC, and Dr. David W. Pittman was the Director. 


\section{Acronyms and Abbreviations}

\begin{tabular}{|c|c|}
\hline $1,3,5-\mathrm{TNB}$ & 1,3,5-trinitrobenzene \\
\hline $1,3-\mathrm{DNB}$ & 1,3-dinitrobenzene \\
\hline 2,4-DA-6-NT & 2,4-diamino-6-nitrotoluene \\
\hline 2,4-DNP & 2,4-dinitrophenol \\
\hline 2,6-DA-4-NT & 2,6-diamino-4-nitrotoluene \\
\hline 2,6-DNT & 2,6-dinitrotoluene \\
\hline 2-A-4,6-DNT & 2-amino-4,6-dinitrotoluene \\
\hline 2-A-6-NT & 2-amino-6-nitrotoluene \\
\hline 2-NT & 2-nitrotoluene \\
\hline 3,5 -DNA & 3,5-dinitroaniline \\
\hline $3-\mathrm{NT}$ & 3-nitrotoluene \\
\hline 4-A-2,6-DNT & 4-amino-2,6-dinitrotoluene \\
\hline $4-\mathrm{NT}$ & 4-nitrotoluene \\
\hline$\mu$ & Dissolution speed \\
\hline ACR & Acute-chronic ratio \\
\hline AFWTF & Atlantic Fleet Weapons Training Facility \\
\hline $\mathrm{Al}$ & Aluminum \\
\hline ARARs & Applicable or relevant and appropriate requirements \\
\hline ATSDR & The Agency for Toxic Substances and Disease Registry \\
\hline $\mathrm{b}$ & Hole size \\
\hline BIP & Blow-in-place \\
\hline BRAC & Base Realignment and Closure \\
\hline BTAG & Biological Technical Assistant Group \\
\hline $\mathrm{Ca}$ & Calcium \\
\hline $\mathrm{CCP}$ & Comprehensive conservation plan \\
\hline $\mathrm{CDF}$ & Cumulative distribution function \\
\hline cDNA & Complementary DNA \\
\hline CEC & Cation exchange capacity \\
\hline CERCLA & Comprehensive Environmental Response, Compensation, and Liability Act \\
\hline COPCs & Chemicals of potential concern \\
\hline CSM & Conceptual site model \\
\hline CWA & Chemical warfare agent \\
\hline $\mathrm{D}$ & Diffusivity coefficient \\
\hline DEGDN & Diethylene glycol dinitrate \\
\hline DIN & Dissolved inorganic nitrogen \\
\hline
\end{tabular}




\begin{tabular}{|c|c|}
\hline DL & Detection limit \\
\hline DMM & Discarded military munitions \\
\hline DOD & Department of Defense \\
\hline DSIS & Deep Seabed Intervention System \\
\hline EC & Effects concentration \\
\hline EC50 & $\begin{array}{l}\text { A statistically or graphically estimated concentration that is expected to cause } \\
\text { one or more specified effects in } 50 \% \text { of a group of organisms under specified } \\
\text { conditions }\end{array}$ \\
\hline EMA & Eastern maneuver area \\
\hline $\mathrm{EqP}$ & Equilibrium partitioning \\
\hline ERA & Environmental risk assessment \\
\hline EROD & Ethoxyresorufin- O -deethylase \\
\hline ESL & Ecological screening level \\
\hline ESTCP & $\begin{array}{l}\text { U.S. Department of Defense's Environmental Security Technology Certification } \\
\text { Program }\end{array}$ \\
\hline $\mathrm{F}$ & Probabilistic estimate of the release function distribution for a single munition \\
\hline $\mathrm{F}^{\prime}$ & $\mathrm{F}$ applied to the distribution of munitions at the site \\
\hline $\mathrm{F}$ and $\mathrm{T}$ & Fate and transport \\
\hline FAV & Final acute value \\
\hline $\mathrm{Fe}$ & iron \\
\hline FUDS & Formerly Used Defense Sites \\
\hline FUI & Follow-up Investigation \\
\hline fVNTR & Former Vieques Naval Training Range \\
\hline FWS & Fish and Wildlife Service \\
\hline GC/ECD & Gas chromatograph-electron capture detector \\
\hline GP & General purpose \\
\hline $\mathrm{H}$ & Henry's constant \\
\hline $\mathrm{HC}$ & Hazardous concentration \\
\hline HLB & Hydrophilic lipophilic balance \\
\hline HMX & Octahydro-1,3,5,7-tetranitro-1,3,5,7-tetrazocine \\
\hline HOV & Human occupied vehicles \\
\hline HQ & Hazard quotient \\
\hline HUMMA & Hawaii Undersea Military Munitions Assessment \\
\hline IEDA & Integrated Earth Data Applications \\
\hline JPHC & Jackson Park Housing Complex \\
\hline$K_{d}$ & Distribution coefficient describing linear sorption to soil or sediment \\
\hline$K_{\mathrm{oc}}$ & Organic carbon-water partitioning coefficient \\
\hline$K_{\mathrm{ow}}$ & Octanol-water partitioning coefficient \\
\hline LC & Liquid chromatography \\
\hline
\end{tabular}


LC/MS/MS Liquid chromatography/mass spectrometry/mass spectrometry

LC50 A statistically or graphically estimated concentration that is expected to be lethal to $50 \%$ of a group of organisms under specified conditions.

LCA Life cycle assessment

LIA Live Impact Area

LIS Long Island Sound

LOEC Lowest-observable-effect concentration. In a toxicity test, the lowest tested concentration of a material at which organisms were adversely affected compared to control organisms as determined by statistical hypothesis tests

LRL Laboratory reporting limit

MC Munitions constituents

MDL Method detection limit

$\mathrm{Mg} \quad$ Magnesium

MIDAS Munitions items disposition system

MLLW Mean lower low water

MM Mass molar

Mn Manganese

MRP Munitions Response Program

MS Mass spectrometry

MTC Mass transfer coefficient

NAD Naval Ammunitions Depot

NADPH Nicotinamide adenine dinucleotide phosphate

NAVFAC Naval Facilities Engineering Command

NC Nitrocellulose

ND Not detected

NG Nitroglycerin

NHB Naval Hospital Bremerton

NOAA National Oceanic and Atmospheric Association

NOEC No-observable-effect concentration. In a toxicity test, the highest tested concentration of a material at which organisms did as well as control organisms as determined by statistical hypothesis tests

NQ Nitroguanidine

OC Organic carbon

OU Operable unit

$\mathrm{P} \quad$ Vapor pressure

PCA Principle component analysis

PERT Program Evaluation Review Technique

PLS Partial least squares

POCIS Polar Organic Chemical Integrative Samplers 


$\begin{array}{ll}\text { PETN } & \text { Pentaerythritol tetranitrate } \\ \text { QWASI } & \text { Quantitative Water-Air-Sediment Interactions } \\ \text { R } & \text { Cavity radius } \\ \text { RDX } & \text { Hexahydro-1,3,5-trinitro-1,3,5-triazine } \\ \text { ROV } & \text { Remotely Operated Vehicle } \\ \text { S } & \text { Solubility } \\ \text { SAF } & \text { Secondary acute factor } \\ \text { Si } & \text { Silicon } \\ \text { SLRA } & \text { Screening-level risk assessment } \\ \text { SONAR } & \text { Sound Navigation and Ranging } \\ \text { SPE } & \text { Solid-phase extraction } \\ \text { SPME } & \text { Solid phase microextraction } \\ \text { SPAWAR } & \text { Space and Naval Warfare } \\ \text { SQB } & \text { Sediment quality benchmark } \\ \text { SSC-PAC } & \text { SPAWAR Systems Center Pacific } \\ \text { SSD } & \text { Species sensitivity distribution } \\ \text { 2,4,6-TNT } & \text { 2,4,6-Trinitrotoluene } \\ \text { T } & \text { Temperature } \\ \mathrm{t}_{1 / 2} & \text { Half-life } \\ \text { Ti } & \text { Titanium } \\ \text { TOC } & \text { Total organic carbon } \\ \text { TRIM2D } & \text { Two Dimensional Tidal Residual Intertidal Mudflat (TRIM2D) } \\ \text { TSERAWG } & \text { Tri-Service Ecological Risk Assessment Working Group } \\ \text { TWA } & \text { Time-weighted average } \\ \text { U } & \text { Ambient current } \\ \text { USACE } & \text { U.S. Army Corps of Engineers } \\ \text { UWMM } & \text { Underwater military munitions } \\ \text { UXO } & \text { Unexploded ordnance } \\ \text { WASP } & \text { Water Quality Analysis Simulation Program } \\ \text { WQC } & \text { Water quality criteria } \\ \text { WWTP } & \text { Wastewater treatment plant } \\ & \end{array}$




\section{Unit Conversion Factors}

\begin{tabular}{|c|c|c|}
\hline Multiply & By & To Obtain \\
\hline acres & $4,046.873$ & square meters \\
\hline feet & 0.3048 & meters \\
\hline gallons (U.S. liquid) & $3.785412 \mathrm{E}-03$ & cubic meters \\
\hline hectares & $1.0 \mathrm{E}+04$ & square meters \\
\hline inches & 0.0254 & meters \\
\hline miles (U.S. statute) & $1,609.347$ & meters \\
\hline pounds (mass) & 0.45359237 & kilograms \\
\hline square miles & $2.589998 \mathrm{E}+06$ & square meters \\
\hline tons ( 2,000 pounds, mass) & 907.1847 & kilograms \\
\hline
\end{tabular}




\section{Executive Summary}

\section{Objectives}

As a result of military training and weapons testing activities, munitions are present at numerous current and former Department of Defense (DoD) sites. Many active and former military installations have ranges and training areas that include aquatic environments, such as ponds, lakes, rivers, estuaries and coastal zones. In addition, until 1970, it was accepted practice to dispose of wastes - including excess, obsolete, and unserviceable munitions - in deep water areas. Munitions are also present in water bodies around the world due to combat and training operations.

The overarching objective of Project ER-2341 was towards an improved and concise understanding of the fate and environmental risks of munitions constituents (MC) released from munitions present at underwater military munitions (UWMM) sites. Specific objectives were (1) to compile and review existing evidence regarding environmental exposure and risks posed by MC in aquatic systems impacted by the presence of unexploded or munitions discarded underwater; (2) to decrease uncertainty concerning environmental exposure by summarizing and analyzing environmental fate data collected from the scientific literature; (3) to estimate the release of munitions compounds into the underwater environment under realistic scenarios; (4) to decrease uncertainly concerning hazard by compiling and summarizing ecotoxicity data; (5) to provide revised aquatic criteria and screening benchmarks for $\mathrm{MC}$ for use in site-specific ecological risk assessment; and (6) to conduct a screening-level generic risk assessment of MC at UWMM sites.

\section{Technical Approach}

Available data on $\mathrm{MC}$ concentrations in exposure media (water and sediment) and biota for marine and freshwater UWMM sites were compiled into a database. In addition, concise summaries of MC contamination were prepared for UWMM sites throughout the world. Available data on environmental properties of MC, including dissolution rate constants, sorption constants on soils and sediments, biotic and abiotic degradation rate constants, and mobility parameters were compiled and analyzed. To provide further understanding on the fate of $\mathrm{MC}$ in aquatic systems, experimental research on the tracking, uptake, 
translocation, and transformation of $\mathrm{MC}$ in the marine environment using stable nitrogen isotopes (SERDP project ER-2122) was summarized.

Fugacity model calculations were developed for predictions of MC environmental fate. Exposure estimates were enhanced by utilizing multivariate analysis to create a mathematical function, which correlates published literature data for sediment properties to $\mathrm{MC}$ residence time in biphasic sediment systems to provide a more accurate estimate of MC residence time in systems containing solid-phase sediment materials. Existing fate and transport ( $\mathrm{F}$ and $\mathrm{T}$ ) models were integrated into a comprehensive modeling approach to predict MC concentration in sediment and water to estimate the distribution of $\mathrm{MC}$ and exposures to organisms. Worst-case scenarios, where a large mass of $\mathrm{MC}$ are released to open water, were assumed. Model calculations allowed estimates of potential exposure based on initial loading and system residence times based on the inter-media transport of the MC solutes.

A release rate function developed under a previous SERDP effort was used to provide representative $\mathrm{MC}$ source terms via release from munitions under various states of integrity at known UWMM sites. Because of the paucity of data describing the numbers of such potentially breached munitions at such sites, a probabilistic approach was employed using known and statistical distributions for the environmental process parameters that dictate $\mathrm{MC}$ release. Such an approach allowed for a cumulative distribution function to be derived for the total release at the former Vieques Navy Training Range (fVNTR), a site for which sufficiently robust numbers of total munitions are known. The total release at this site was then used to provide a conservative concentration estimate for comparison and validation of empirical data collected at the site. Data validated in this manner is suitable for MC source term characterization and subsequent $\mathrm{F}$ and Tof aqueous MC chemical species at an UWMM site in the overall risk assessment process.

Available data on the biological effects of MC, including lethal and sublethal toxicity to aquatic vertebrates and invertebrates in exposures to spiked water or sediment, were compiled into a database and summarized. Compiled toxicity data was used for the development of species sensitivity distributions (SSD). The SSD is a statistical distribution constructed by fitting a cumulative distribution function to a series of species toxicity data, against the rank-assigned centile, which allows the calculation of 
hazardous concentration ( $\mathrm{HC}) . \mathrm{HC}_{5}$ values representing the probability of $5 \%$ of species being affected were derived for use in risk assessment. In addition, aquatic acute, and chronic ambient water quality criteria (WQC) and preliminary sediment screening criteria (SSC) were compiled, and when appropriate, revised using recent toxicity data.

A screening-level risk assessment (SLRA) approach was used to evaluate whether MC released to the biologically accessible environment at UWMM sites at certain levels could adversely affect fish and invertebrates inhabiting the impacted area. SLRA was performed to identify MC that may have posed unacceptable risks and those that could have been conservatively ruled out as posing a concern at UWMM sites. Exposure estimates were based on site-specific data, while effects characterizations were based on effects benchmarks (e.g., $\mathrm{HC}_{5}$, WQC, and preliminary SSC).

\section{Results}

Data for eight waterbodies from four countries, i.e., Bahia Salina del Sur, (Puerto Rico (PR), USA), Ostrich Bay and Former Seattle Naval Supply Depot Terminal 91 (Washington, USA), Sea Disposal Sites HI-05 and HIo6 (Hawaii, USA), Canada Coastal Waterbodies (Newfoundland and Labrador and Nova Scotia, Canada), Lakes Thun and Brienz and tributaries (Bern, Switzerland), were incorporated into a detailed database and summarized. In addition, site summaries were provided for the Oosterschelde (Netherlands) and various Swedish and Norwegian lakes and coastal sites. The authors' compilation and examination of available data revealed that $\mathrm{MC}$ concentrations in water, sediment, and biota at UWMM sites were largely below detection, with a few samples indicating contamination as highly localized and typically near the UWM. To complement available site data, $\mathrm{F}$ and $\mathrm{T}$ models predicted concentrations of MC in the water columns at UWMM sites of the same magnitude or lower than reported data. Available toxicity data derived for freshwater and marine fish as well as invertebrates and autotrophs was compiled, and species sensitivity distributions were derived. Risks to biota were determined to be low at UWMM sites when measured or modeled site concentrations were compared to toxicity data.

\section{Benefits}

Information presented is critical for the DoD Munitions Response Program to make scientifically defensible risk management decisions with 
regard to underwater munitions, leave in place mitigation, and low order detonation (LOD) vs. removal or blow-in-place (BIP) options. Information compilation, summary, and the analysis presented in this document are expected to be extremely useful for developing data quality objectives for investigations of UWMM sites. The ability to leave munitions in place due to lack of ecological impact could result in significant savings to the DoD. In addition, the assessment has direct applicability to developing best management practices for a variety of watered ranges. This will be used in maintaining the sustainability of DoD operational ranges. 


\section{Introduction}

\subsection{Background}

As a result of military training and weapons testing activities, munitions are present at numerous current and former Department of Defense (DoD) sites. Many active and former military installations have ranges and training areas that include aquatic environments, such as ponds, lakes, rivers, estuaries and coastal zones. In addition, until 1970, it was accepted practice to dispose of wastes - including excess, obsolete and unserviceable munitions - in deep water areas. Munitions are also present in water bodies around the world due to combat and training operations. Munitions constituents (MC) are defined in 10 U.S.C. 2710 (e) (4) as "Any materials originating from unexploded ordnance, discarded military munitions, or other military munitions, including explosive and non-explosive materials, and emission, degradation, or breakdown elements of such ordnance or munitions."

It is critical to accurately characterize the effects of MC on biological receptors, such that risk assessments can be conducted and reasonable and effective response actions can be taken. Many MC undergo extensive transformation in aquatic systems by microbial action or by abiotic mechanisms such as hydrolysis, oxidation, and photo-transformation. Therefore, aquatic receptors may be exposed not only to $\mathrm{MC}$ released to the environment but also to their transformation products. Most research conducted on the aqueous toxicity of $\mathrm{MC}$ focused on 2,4,6-trinitrotoluene (TNT) and hexahydro-1,3,5-trinitro-1,3,5-triazine (RDX) and their impacts on freshwater organisms via short-term assays. To assess the potential biological effects of $\mathrm{MC}$, the range of susceptibility of species to compounds that are potentially released to the aquatic environment must be understood. Traditionally, risk assessments have used toxicity data that corresponds to the most sensitive organism or group of organisms. Expressing the results of a refined risk characterization analysis as a distribution of toxicity values rather than single-point estimates provides a more robust approach for risk characterization, which prevents the use of overly conservative exposure estimates. 


\subsection{Objective}

The objectives of Project ER-2341 "Review and Synthesis of Evidence Regarding Environmental Risks Posed by Munitions Constituents (MC) in Aquatic Systems" are to (i) compile and review existing evidence regarding environmental exposure and risks posed by $\mathrm{MC}$ in aquatic systems impacted by the presence of unexploded or munitions discarded underwater and (ii) to decrease uncertainty concerning environmental exposure by developing an improved model to predict $\mathrm{MC}$ concentration distributions in aquatic environments. The DoD has custody and responsibility for human safety and environmental stewardship for operational and non-operational ranges, including underwater ranges that are known to have certain residue military munitions (e.g., unexploded ordnance [UXO]) present as a result of historic military activities. Although the risk of detonation is considered very low in aquatic environments, given that "wet" munitions exhibit lower sensitivity and strength of detonation, it is often raised as a concern in the environmental community. In addition to explosive safety considerations, regulators are increasingly concerned about potential biological impacts of released MC on the aquatic environment, including health impacts from direct physical contact, impacts to aquatic organisms inhabiting the contaminated site, and consumption of potentially contaminated biota. Such concerns have resulted in costly site investigations and could lead to potentially unnecessary response efforts.

This final report contains the following: (1) a generic problem formulation and conceptual model for underwater munitions in aquatic environments (Chapter 2); (2) an overview of MC known to be contaminants of concern at underwater munitions sites (Chapter 3); (3) an overview of underwater munitions sites used in this investigation (Chapter 4); (4) an overview of water column MC concentrations at underwater munitions sites (Chapter

5); (5) an overview of sediment MC concentrations at underwater munitions sites (Chapter 6); (6) an overview of biota $\mathrm{MC}$ concentrations at underwater munitions sites (Chapter 7); (7) an overview of the environmental fate parameters of $\mathrm{MC}$ as published in the scientific literature and from model calculations (Chapter 8); (8) a modeling approach for characterizing the release and transport of $\mathrm{MC}$ from breached shells in aquatic environments (Chapter 9); (9) an overview of the fate of TNT and RDX in marine environments determined by using a stable isotopic tracer (Chapter 10); (10) an overview of the toxicity of MC to aquatic stages of amphibians, fish, aquatic invertebrates and autotrophs (Chapter 11); (11) aquatic screening 
benchmarks (Chapter 12); (12) screening-level generic risk assessment of MC at underwater munitions sites (Chapter 13); (13) a database containing measured $\mathrm{MC}$ concentrations in water, sediment, and biota collected from underwater munitions sites (Appendix A); (14) a database containing general environmental properties of MC (Appendix B); a database with available data for the toxicity of MC to aquatic stages of amphibians, fish, aquatic invertebrates, and autotrophs (Appendix C). 


\section{Generic Problem Formulation and Conceptual Model for Underwater Munitions Sites}

\subsection{Underwater munitions in aquatic environments}

Manufacturing of explosives and their loading, assembling, and packing into munitions for use in testing, training, and combat has resulted in contamination of terrestrial and aquatic systems. Thousands of sites throughout the world are potentially contaminated with MC in soil, sediment, and inland habitats ground or surface water at concentrations that span several orders of magnitude (Talmage et al. 1999; Jenkins et al. 2001). Explosives loaded into munitions and fragments of explosives and munitions remaining following incomplete detonations may be present in surface soils, sediments, and in aquatic habitats.

In the United States, UXO and discarded military munitions (DMM) are present at sites designated for base realignment and closure (BRAC), at formerly used defense sites (FUDS) and at operational military ranges. Within the FUDS program, the U.S. Army Corps of Engineers (USACE) has identified more than 400 sites, totaling more than 10 million acres that potentially contain munitions in underwater environments. Many active and former military installations have ranges and training areas adjacent to water environments such as ponds, lakes, rivers, estuaries, and coastal zones. The U.S. Navy and U.S. Marine Corps' munitions response program (MRP) has identified an additional 33 sites containing munitions. The inventory includes sites that date back to the 18th century and some that were used during the early 1900s (SERDP 2010).

After the end of World War I and II, options for the disposal of munitions were limited to combustion, burial, or disposal at sea. Disposal at sea was considered the best option following the World Wars and large quantities of munitions were dumped into the ocean, which allowed for quick disposal of large quantities of munitions while minimizing risks to workers. The United States military conducted open water disposal of a portion of both U.S. and foreign (captured) excess, obsolete or unserviceable, conventional, and chemical munitions dating back to the 180o's; however, in 1970 the DoD discontinued this practice. In 1972, Congress enacted the Marine Protection, Research, and Sanctuaries Act 
(Public Law 92-532) that prohibited ocean disposal of this type of material (Davis 2009).

\subsection{Conceptual site model}

Underwater munition sites encompass a variety of dynamic environmental conditions with complex characteristics and chemistry, such as depth, temperature, salinity, bathymetry, hydrodynamic conditions, and sediment types. These sites represent a wide variety of environments, including near-shore and off-shore ocean sites, swamps, rivers, and lakes, including a vast array of characteristics that influence the fate of $\mathrm{MC}$ away from their point source (SERDP 2010). Chapter 4 provides an overview of underwater military munitions (UWMM) sites found in the United States and in other countries that were investigated for MC contamination as well as potential for adverse effects to biological receptors.

Munitions in the environment may release $\mathrm{MC}$ to the surrounding environment due to corrosion and breaching in terrestrial and aquatic sites or blow-in-place (BIP) detonation (Pennington et al. 2008; Lewis et al. 2009; Pascoe et al. 2010). Munitions also pose risks associated with the physical impacts of accidental detonation (MacDonald et al. 2009). Areas where explosives impact soil or sediment quality are sometimes extensive; some artillery ranges are several square miles in area. The MC residues found in these areas are typically heterogeneous in terms of spatial distribution (Jenkins et al. 2001).

Military testing and training ranges may have both terrestrial and aquatic components. Although many aquatic environments encumbered with munitions have resulted from overshoots of land ranges, offshore areas also have been used as ranges. This is evident in many areas by simple inspection of the shoreline adjacent to target and practice ranges (MacDonald 2009). Munitions present at these sites include inert and training rounds, munitions that failed to function as designed, remained unexploded (e.g., UXO), or did not fully consume their explosive fill (e.g., low order rounds). Munitions and explosives of concern may also be present in the underwater environment due to disposal, accidents, and combat.

Underwater sites may contain a variety of munition types, including bombs, projectiles, mortars, grenades, and rockets. Information can be gathered on the munition types, quantity, age, and distribution by investigating historical service records concerning range use or disposal method. 
However, records on specific munitions, whether used or disposed, and quantities are generally incomplete. There is also a high degree of uncertainty concerning the quantities of munitions present at most, if not all, sites (Carton and Jagusiewicz 2009). Some of this information can be gathered through site characterization via field surveys.

A conceptual site model (CSM) identifies the primary source(s) of the constituents of concern at a site and evaluates release mechanisms and $\mathrm{F}$ and $\mathrm{T}$ processes that control exposures of ecological receptors to these constituents or their breakdown products. Evaluating the mobility of munitions in the underwater environment is important for assessing exposures of ecological receptors. Physical characteristics of the munitions combined with the dynamic environmental conditions at a site may be used as inputs to models for determining whether munitions can be expected to be stationary or mobile (SERDP 2010).

When undissolved MCs (i.e., still contained within a munition) are introduced into the aquatic environment, they are not immediately released; environmental releases only occur after the munition is breached by corrosion or other mechanical breakages. Therefore, as long as the munitions remain intact, no chemicals are released to the environment. Since the munitions will typically corrode or breach gradually, it is likely that their contents will be released gradually until totally depleted. Breach size (i.e., shell casing hole size) is assumed to be a function of time in the instance of corrosion. Understanding the condition of munitions and their potential to breach via corrosion will help characterize the potential for energetic fill material that will transfer to the environment (Wang et al. 2013). After a breach, the MC release rate can be explicitly expressed as a function of the following five parameters: ambient current speed, hydrodynamic mixing coefficient, size of the breach hole, cavity radius inside the shell, and dissolution rate of $\mathrm{MC}$ from the solid to aqueous phase inside the shell (Wang et al. 2013).

Once released into the environment, the MCs are subject to fate processes, such as phase partitioning, microbially driven biodegradation, and transport (e.g., advection, diffusion) processes that exchange the materials between the water column and the resuspended sediment bed. In open water environments, MCs dissolve and are released to the overlying water, carried away from the source by currents, readily diluted, and subjected to similar transformative processes in the water column. Overall, MC persistence in the environment is a key determinant of exposure. Chapters 
8 and 10 summarize the fate of MC that slowly leaks out of UWMM into the surrounding aquatic environment.

Uptake by aquatic biota may occur from direct exposure to water and sediment (e.g., dermal contact and through gills) or through ingestion. The ingestion pathway can include the ingestion of contaminated sediment and food items that have accumulated MC in their tissues. Because MCs are poorly accumulated in fish and invertebrates and most undergo extensive transformation in the tissues, food chain transfers and bioaccumulation of these compounds are not expected to be significant (reviewed in Lotufo et al. 2009a and 2013; see also Lotufo et al. 2016 and Ballentine et al. 2015, 2016).

\subsection{Munitions constituents of potential ecological concern}

Commonly used explosive fillers may leak from breached and corroded UWMM as well as fragments of explosives formulations that remain following low-order (incomplete) detonations (Wang et al. 2011). Typical munitions fillers from the World War II era include TNT, Composition B (a mixture of RDX and TNT), torpex (a mixture of RDX, TNT, and aluminum, used in torpedoes), amatol (a mixture of TNT and ammonium nitrate), and Explosive D (ammonium picrate).

The presence of munitions in aquatic environments has been documented in several studies, with low concentrations of some MC measured in water and sediments. Detections of MC in surface water, sediment, and biota at UWMM sites are summarized in Chapters 5,6 , and 7, respectively.

\subsection{Assessment and measurement endpoints}

Assessment endpoints in the Environmental Risk Assessment (ERA) process identify the ecological resources, functions, or values that will be evaluated by the ERA. Measurement endpoints identify the specific method by which the ERA will address each of the assessment endpoints. The overarching assessment endpoint that will be used for the generic risk assessment for MC at UWMM sites is "maintenance of the diversity, viability, and sustainability of the benthic and pelagic communities."

The overarching measurement endpoint that will be used to address these assessment endpoints is "compare measured and model-derived MC concentrations in the water column, sediment, and biota to available toxicity-based values." 


\section{Overview of munitions constituents}

Over the past 100 years, high explosives have been extensively used by the DoD. Contamination of terrestrial sites by $\mathrm{MC}$ has occurred largely due to (1) explosive manufacturing operations, (2) DMM, or (3) remaining sources of UXO. In addition to the munitions themselves, the U.S. Environmental Protection Agency (USEPA 1993) classifies all "explosive waste" as energetic material.

Explosive compounds are further distinguished as primary or secondary explosives based on their susceptibility to initiation. Primary explosives, which include lead azide and lead styphnate, are highly susceptible to initiation. Furthermore, primary explosives are often referred to as "initiating explosives" because they can be used to ignite secondary explosives (USEPA 1993), and thus are designed to detonate only under specific circumstances. Secondary explosives are classified based on their chemical structure. Common secondary explosives are composed of either nitroaromatic or nitro-cyclotriazine functional groups. The most common nitroaromatic explosive used by the DoD is TNT. Dinitrotoluenes (DNT) are components of many single-base propellants. The most common nitroamine explosives are RDX, and octahydro-1,3,5,7-tetranitro-1,3,5,7tetrazocine (HMX). Other nitrated organic compounds, such as nitroglycerin (NG) and nitrocellulose (NC), represent nitrate esters that are used in guns and selected rocket propellants. Energetic formulations may contain other MCs such as tetryl or ammonium picrate.

Table 1 summarizes the energetic chemicals present in selected military explosive formulations. These formulations are often mixtures consisting of two or more explosive compounds mixed at specific proportions, tailoring the characteristics of the formulation for particular applications.

This report focuses almost exclusively on the environmental risks of secondary explosives, which are used in significantly greater quantities in the manufacturing of munitions than primary explosives, also known as initiators. Specifically, the current state of knowledge with respect to the environmental fate and aquatic toxicity potential of explosives in the environment is discussed. This review is particularly focused on MC fate in underwater environments. 
Table 1. Energetic chemicals present in military explosive and propellant formulations (USEPA 2012).

\begin{tabular}{|l|l|l|}
\hline $\begin{array}{l}\text { Compound or Explosive } \\
\text { Formulations }\end{array}$ & Uses & Chemical Ingredients \\
\hline Composition B & Artillery; mortar & $\begin{array}{l}\text { 60\% Military-grade RDX (Contains . 10\% } \\
\text { HMX) 39\% Military-grade TNT (Contains 1\% } \\
\text { other TNT isomers and DNTs); 1 \% wax }\end{array}$ \\
\hline Composition C4 & Demolition explosive & 91\% Military-grade RDX \\
\hline Tritonal & Air Force bombs & Military-grade TNT, aluminum \\
\hline Composition A4 & 40-mm grenades & Military-grade RDX \\
\hline TNT & Artillery & Military-grade TNT \\
\hline Composition H-6 & $\begin{array}{l}\text { Navy and Marine } \\
\text { bombs }\end{array}$ & Military-grade RDX and TNT, aluminum \\
\hline Octol & Antitank rockets & Military-grade HMX and TNT \\
\hline Explosive D & Naval projectiles & Ammonium Picrate \\
\hline
\end{tabular}

Information on the content of specific munitions may be found in Army and Navy manuals (e.g., U.S. Department of the Army 1990, 1993; U.S. Department of the Navy 1987, 1999) and from online sources such as ORDATA (http://ordatamines.maic.jmu.edu/default.aspx). DoD employees can obtain detailed information about munitions through the Defense Ammunition Center's Munitions Items Disposition System (MIDAS) database. Access to MIDAS requires a Common Access Card.

With the exception of NG, the major energetic compounds used by the DoD are solids at ambient temperatures. As a group, military-grade explosives have relatively low vapor pressure, low water solubility, and are weakly polar (Table 2).

The environmental fate of an MC is determined, in part, by the physiochemical properties of the compounds and how these properties affect the compounds' interactions in particular types of environments. Typical physical and chemical descriptors for MC include solubility, density, melting point, vapor pressure, Henry's Law constant, and octanol-water partitioning coefficients (discussed in detail in Chapter 4). On the other hand, MC environmental fate is typically described in terms of the characteristics of the aquatic environment, which include temperature, $\mathrm{pH}$, salinity, dissolved oxygen, sunlight exposure levels, and the ionic strength of seawater. Chapter 4 of this report gives a thorough review of 
the most common environmental fate descriptors. Likewise, Noblis, Inc. (2011) gave a review of MC environmental fate, particularly with respect to marine environments. In addition, Singh et al. (2012) reviewed major biodegradation and biotransformation pathways (not discussed in this report) for explosives. 
Table 2. Physicochemical properties of munitions constituents and their common transformation products (USEPA 2012, unless specified).

\begin{tabular}{|c|c|c|c|c|}
\hline Chemical name & $\begin{array}{l}\text { Abbreviation or } \\
\text { common name }\end{array}$ & $\begin{array}{l}\text { Chemical } \\
\text { Abstract Service } \\
\text { Number }\end{array}$ & $\begin{array}{l}\text { Molecular } \\
\text { Weight (g/mol) }\end{array}$ & $\begin{array}{l}\text { Octanol/Water } \\
\text { Partition Coeff. } \\
\text { (log Kow) }\end{array}$ \\
\hline 1,3,5-trinitrobenzene & 1,3,5-TNB & $99-35-4$ & 213.1 & $1.18^{a}$ \\
\hline 1,3-dinitrobenzene & 1,3-DNB & $99-65-0$ & 168.12 & $1.55^{a}$ \\
\hline 2,4,6-trinitrotoluene & 2,4,6-TNT & $118-96-7$ & 227.13 & 1.6 \\
\hline 2,4,6-trinitrophenol & Picric acid & $88-89-1$ & 229.10 & 1.33 \\
\hline $\begin{array}{l}\text { 2,4,6- } \\
\text { trinitrophenylmethylnitramine }\end{array}$ & Tetryl & $479-45-8$ & 287.17 & 2.04 \\
\hline 2,4-diamino-6-nitrotoluene & 2,4-DA-6-NT & 6629-29-4 & 167.167 & $0.7^{b}$ \\
\hline 2,4-dinitrophenol & 2,4-DNP & $51-28-7$ & 184.11 & $1.54^{c}$ \\
\hline 2,6-diamino-4-nitrotoluene & 2,6-DA-4-NT & $59229-75-2$ & 167.167 & $0.67^{b}$ \\
\hline 2,4-dinitrotoluene & 2,4-DNT & $121-14-2$ & 182.15 & 1.98 \\
\hline 2,6-dinitrotoluene & 2,6-DNT & $606-20-2$ & 182.15 & 2.02 \\
\hline 2-Amino-4,6-dinitrotoluene & 2-A-4,6-DNT & $35572-78-2$ & 197.17 & 1.94 \\
\hline 2-amino-6-nitrotoluene & 2-A-6-NT & $603-83-8$ & 152.15 & no data \\
\hline 2-nitrotoluene & 2-NT & $88-72-2$ & 137.14 & $2.3^{a}$ \\
\hline 3,5-dinitroaniline & 3,5-DNA & $618-87-1$ & 183.123 & no data \\
\hline 3-nitrotoluene & 3-NT & $99-08-1$ & 137.14 & $2.4^{a}$ \\
\hline 4-amino-2,6-dinitrotoluene & 4-A-2,6-DNT & $19406-51-0$ & 197.17 & 1.91 \\
\hline 4-nitrotoluene & 4-NT & $99-99-0$ & 137.14 & $2.3^{a}$ \\
\hline Diethylene glycol dinitrate & DEGDN & $693-21-0$ & 196.12 & $0.98^{d}$ \\
\hline $\begin{array}{l}\text { Hexahydro-1,3,5-trinitro-1,3,5- } \\
\text { triazine }\end{array}$ & RDX & $121-82-4$ & 222.26 & 0.90 \\
\hline Nitrocellulose & NC & $9004-70-0$ & $10^{5}-10^{6}$ & no data \\
\hline Nitroglycerin & $N G$ & $55-63-0$ & 227.11 & 1.62 \\
\hline Nitroguanidine & NQ & $556-88-7$ & 104.07 & -0.89 \\
\hline $\begin{array}{l}\text { Octahydro-1,3,5,7-tetranitro- } \\
\text { 1,3,5,7-tetrazocine }\end{array}$ & HMX & 2691-41-0 & 296.16 & 0.17 \\
\hline Pentaerythritol tetranitrate & PETN & $78-11-5$ & 316.17 & 3.71 \\
\hline
\end{tabular}

a from Freidig and Hermens (2000), b from Elovitz and Weber (1999), c from Altenburger et al. (2000), d from Rosenblatt et al. (1991).

The following sub-sections provide basic background information on different explosive and propellant compounds for which data on toxicity and bioaccumulation in aquatic organisms are available. 


\subsection{Nitroaromatics}

\subsubsection{2,4,6-trinitrotoluene (TNT)}

The U.S. military's use of TNT began around 1912. TNT was frequently used as a sole explosive compound, but was also mixed with powdered aluminum or other explosives for enhanced blast effect (Figure 1). TNT is a stable explosive, being relatively insensitive to shock. Due to production limitations preceding both World War I and early World War II, TNT was blended with other energetics (e.g., Amatol is $50-80 \%$ ammonium nitrate and $50-20 \%$ TNT) to stretch existing inventories and satisfy demands for large quantities of wartime explosives. TNT continues to serve as an important explosive component of modern military munitions, although these formulations commonly mix TNT with other compounds (e.g., RDX). TNT-containing formulations include pentolite, tetrytol, torpex, tritonal, picratol, and Composition B.

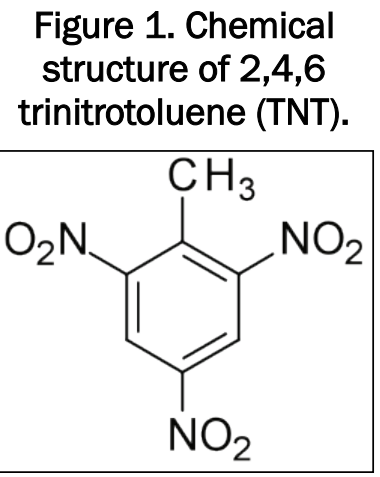

At room temperature, TNT is a yellow solid. As a weakly polar compound, it exhibits low solubility in water. TNT typically readily degrades in the environment. For example, TNT is highly susceptible to photochemical transformation (i.e., photolysis or photooxidation) in seawater (O'Sullivan et al. 2011). When associated with suspended organic matter in the water column, or on soil and/or sediment, TNT's nitrate groups are readily bioreduced to form amino-substituents. Primary decomposition products include differently substituted mono-amino-nitrotoluene derivatives, such as 4-amino-2,6-DNT. Further reduction of TNT's nitrated groups produces diamino-nitrotoluene compounds, such as 2,4-DA-6-NT (Monteil-Rivera et al. 2009). Where sediments typically exhibit a low preference for TNT sorption, the positively charged, reduced amino-NT products are readily adsorbed to the sediment cation exchange complex. Thus, hydrophobic partitioning by the sediment organic matter, a behavior typically used to explain the mechanistic basis for TNT sorption, does not satisfactorily explain the 
sorption behavior of TNT-degradation products in freshwater (Elovitz and Weber 1999) and marine sediment (Pennington et al. 2011) systems.

\subsubsection{1,3,5-trinitrobenzene (1,3,5-TNB)}

The compound 1,3,5-TNB has been produced for use as an explosive (Figure 2). It can also be used to vulcanize natural rubber and as an acidbase indicator in the $\mathrm{pH}$ range of 12 . The compound $1,3,5$-TNB is also formed as a by-product of TNT manufacturing and as a product of TNT environmental transformation, including its photolysis (Talmage et al. 1999).

Figure 2. Chemical structure of trinitrobenzene $(1,3,5-\mathrm{TNB})$

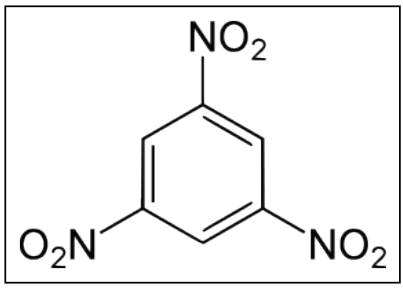

At room temperature, $1,3,5$-TNB is a clear to light yellow solid. It is slightly soluble in water. The compound 1,3,5-TNB appears to be resistant to photolysis; biotransformation of 1,3,5-TNB involves reduction of the nitro groups to form amino groups (Talmage et al. 1999). Extensive transformation of 1,3,5-TNB has been shown to occur in freshwater (Steevens et al. 2002; Lotufo and Farrar 2005) and marine sediment (Lotufo et al. 2001).

\subsubsection{2,4-and 2,6- Dinitrotoluene (2,4-DNT and 2,6-DNT)}

DNTs are primary products used in propellants and are also formed as a byproduct during the TNT manufacturing process (Figure 3). Like TNT, DNTs can be reduced to the corresponding mono- or diamine derivatives (Monteil-Rivera et al. 2009). DNTs have also been associated, as either precursors or by-products, with the synthesis of polyurethane foams, coatings, and elastomers (USAPHC 2012). There are six isomers of DNT; the most common one is 2,4-DNT. Technical grade DNT is composed of approximately $75 \% 2,4$-DNT, $20 \% 2,6$-DNT, and $5 \%$ other isomers (USAPHC 2012). 
Figure 3. Chemical structure of 2,4-and 2,6-

Dinitrotoluene $(2,4-$ DNT).<smiles>Cc1ccc([N+](=O)[O-])cc1[N+](=O)[O-]</smiles>

The 2,4-DNT and 2,6-DNT isomers are yellow to reddish crystalline solids at room temperature and are moderately soluble in water. Reported low log organic carbon (OC)-water partitioning coefficient $\left(K_{\mathrm{oc}}\right)$ (1.65 and 1.96 for 4-DNT and 2,6-DNT respectively) values for DNT compounds suggest a low affinity for organic particulate matter (USEPA 2012). However, strong sorption of 2,4-DNT to soil organic matter has been reported (Singh et al. 2010).

\subsubsection{Tetryl, ammonium picrate (Explosive D), and picric acid}

Tetryl (methyl-N-2,4,6-trinitrophenylnitramine-) was created in 1877 (Figure 4). It was initially used in 1906 as an explosive in booster and detonator charges, then during World War II as a component of explosives mixtures (Tetrytols) (U.S. Department of the Army 1960). Since 1973, the U.S. military's use of tetryl has been gradually phased out in favor of plastic bonded RDX and HMX formulas (Talmage et al. 1999).

Figure 4. Chemical structure of tetryl, ammonium picrate (Explosive D), and picric acid.

\begin{tabular}{|c|c|c|}
\hline $\mathrm{O}_{2} \mathrm{~N}-\mathrm{CH}_{3}$ & Ammonium Picrate \\
\hline
\end{tabular}


Tetryl is a yellow crystalline solid powder material with low solubility in water. Photolysis and hydrolysis are major environmental transformation processes for tetryl in aqueous media, as detailed in Talmage et al. (1999). In natural, sunlit waters, tetryl is transformed via photolysis and hydrolysis to several degradation products, including picric acid, which is the primary hydrolysis product of tetryl (Talmage et al. 1999). Information on the fate of tetryl in sediments is limited to a single paper (Nipper et al. 2002) that reported the formation of unknown breakdown products in sandy and finegrained marine sediments spiked with tetryl.

Beginning in the 1880 s, picric acid (2,4,6-trinitrophenol), a colorless, yellow, or yellow-red crystalline powder and a strongly acidic phenol $\left(\mathrm{pK}_{\mathrm{a}}=\right.$ 0.38), was used as a military explosive. However, due to its tendency to form shock-sensitive picrates in the presence of metals and its corrosive effects on shell casings, picric acid, was largely discontinued as an explosive composition in favor of other formulations during the first part of the $2 \mathrm{O}^{\text {th }}$ century (USEPA 1993).

Ammonium picrate (2,4,6-trinitrophenol ammonium salt or picric acid ammonium salt) is a salt formed by reacting picric acid and ammonia. It was created in 1841 and adopted for use as a bursting-charge explosive by the U.S. Navy in 1907. From 1917 to World War II, ammonium picrate, also known by the military formula designation "Explosive D," was a common explosive in virtually all calibers of armor-piercing ammunition due to its relative insensitivity to shock and friction (U.S. Department of the Army 1960). Picratol, a mixture consisting of $48 \%$ TNT and 52\% ammonium picrate, was developed during World War II to allow faster production of cast bomb and projectiles. Toward the end of World War II, RDX blends such as Composition A gradually replaced Explosive D, which has been of limited use in the post-war era.

Ammonium picrate and picric acid are very soluble in water. When dissolved in water, ammonium picrate and picric acid dissociate to unstable picrate salts such as potassium picrate or picramic acid (2-amino-4,6dintrophenol) (Thorne and Jenkins 1997). Similar to TNT, picric acid is also degraded through electronic reduction. Microbial biodegradation of picric acid results in the formation of 2-amino-dinitrophenol (MonteilRivera 2009). Under aerobic conditions, the mono- or dinitrophenol can then be oxygenated via subsequent ring cleavage (Monteil-Rivera 2009). Nipper et al. (2005) investigated the fate of picric acid in marine 
sediments. Transformation rates were highest in incubated, fine-grained sediment with major transformation products including 4-dinitrophenol, aminodinitrophenols (including picramic acid), 3,4-diaminophenol, amino nitrophenol, and nitrodiaminophenol. In research conducted by Dave et al. (2000), picric acid bound to sediment resisted hydrolysis, biodegradation, and photolysis.

\subsubsection{Cyclic nitramines}

RDX (cyclo-1,3,5-trimethylene-2,4,6-trinitramine, hexahydro-1,3,5trinitro-1,3,5-triazine or cyclonite), commonly referred to as Royal Demolition Explosive, was first synthesized for medicinal use in 1899 (Figure 5). Although its value as an explosive was soon recognized, it was not until the early to mid-1940s that mass production techniques improved sufficiently enough to supply the necessary quantities for use in military formulations. HMX (octahydro-1,3,5,7-tetranitro-1,3,5,7tetrazocine) is a component of plastic explosives, solid fuel rocket propellants, and military munitions (Figure 5). HMX is the chief impurity of military-grade RDX.

Figure 5. Chemical structure of RDX and HMX.

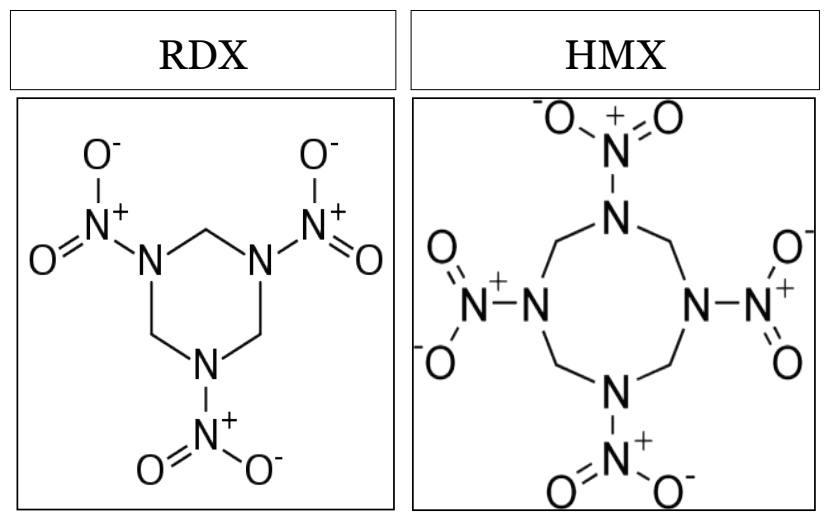

At room temperature, both RDX and HMX are crystalline solids. Militarygrade RDX generally contains up to 10\% HMX as an impurity of the manufacturing process (Talmage et al. 1999). RDX has low solubility in water, and HMX is even less soluble. Their low Kow values indicate these compounds are weakly polar and will preferentially partition to hydrophobic phases.

The biodegradation of RDX occurs under both aerobic and anaerobic conditions (Monteil-Rivera et al. 2009) via ring cleavage, with the anaerobic process being significantly faster. Enzymatically driven cleavage 
of one of the $\mathrm{N}-\mathrm{NO}_{2}$ bonds produces unstable intermediates under aerobic conditions (Monteil-Rivera et al. 2009). Interactions of the newly formed intermediates with water largely govern subsequent degradation reactions and eventually produce $\mathrm{NO}_{2}^{-}, \mathrm{N}_{2} \mathrm{O}, \mathrm{NH}_{3}, \mathrm{HCHO}$, and $\mathrm{HCOOH}$ (MonteilRivera et al. 2009). Sequential reduction of the nitro groups produces mono-, di- and trinitroso derivatives anaerobically (MNX, DNX and TNX, respectively). The nitroso derivatives may be further transformed to produce the unstable hydroxylamine derivatives, which lead to ring cleavage (Crocker et al. 2006). Degradation of HMX does not appear to occur in the field under aerobic conditions, such that its half-life in the environment can span decades (Clausen and Korte 2011). Monteil-Rivera et al. (2009) reviewed anaerobic degradation of HMX.

RDX and HMX have lower water solubility and significantly less binding affinity with soil organic matter than TNT; RDX and HMX are only poorly immobilized by soils (Monteil-Rivera et al. 2009). Extensive transformation of RDX occurred after spiking to fine-grained sediment (Lotufo et al. 2001; Pennington et al. 2011), but the transformation products were not identified. Different from the fate of RDX in organically rich sediment, transformation was minimal in sandy sediment (Rosen and Lotufo 2005).

\subsection{Other energetic compounds}

\subsubsection{Nitroguanidine}

Nitroguanidine is also known by its military designation - NQ. It is a nitroamino compound that exists in two tautomeric forms; the tautomer form depicted above is predominant (Figure 6). It is a stable explosive compound that is combined with $\mathrm{NC}$ and $\mathrm{NG}$ for triple-based propellant.

Figure 6. Chemical structure of Nitroguanidine.

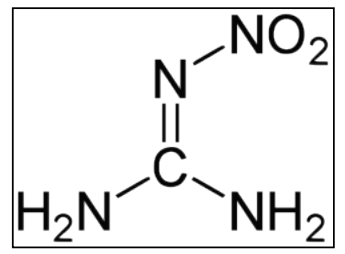

Nitroguanidine is water soluble and may enter the environment via discharge streams from handling facilities (Kaplan et al. 1982). NQ residue has been identified on soils at Army ranges as a result of live-fire training 
(Clausen 2011). NQ is relatively stable in the environment. Degradation of NQ was shown to be negligible in activated sludge under aerobic conditions and in sterile sludge under reducing conditions (Kaplan et al. 1982).

\subsubsection{Nitrate esters: nitroglycerin, nitrocellulose, PETN, and DEGDN (diethylene glycol dinitrate)}

Nitroglycerin or glycerol trinitrate (propane-1,2,3-triyl trinitrate) is used in the manufacture of dynamite, gunpowder, and rocket propellants (Figure 7). It is also used as a therapeutic agent (Rocheleau et al. 2011). Double-base propellants used with newer small-arms ammunition typically contain up to $84 \% \mathrm{NC}$, with $10 \% \mathrm{NG}$ (a stabilizer) and up to $6 \%$ filler compounds. The combination of NG, NC, and NQ forms a triple-base propellant mixture. Nitroglycerin can be released into the environment at firing positions, and in the target areas from low-order detonation of propellant (Rocheleau et al. 2011). Nitroglycerin is poorly soluble in water and may enter and persist in freshwater environments (USACHPPM 2007). In recent literature, microbial degradation of NG has been reported (Podlipná et al. 2008).

Figure 7. Chemical structure of Nitrate esters: nitroglycerin, nitrocellulose, PETN, and DEGDN (diethylene glycol dinitrate).

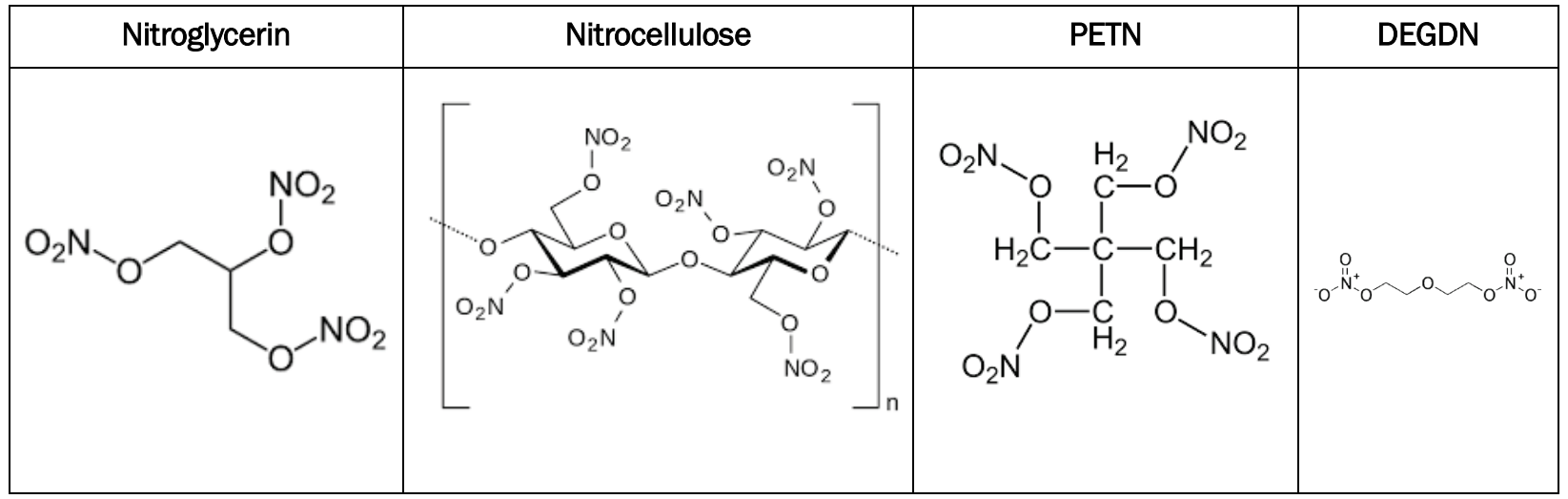

Nitrocellulose is a highly flammable compound formed by nitrating cellulose through exposure to nitric acid or another powerful nitrating agent. When used as a propellant or low-order explosive, it is known as guncotton. Nitrocellulose occurs as a particulate that is essentially insoluble in water (Bentley et al. 1977c) and very recalcitrant to microbial degradation (Podlipná et al. 2008).

PETN or pentyl (1,3-dinitrato-2,2-bis(nitratomethyl) propane, or pentaerythritol tetranitrate) is used in some booster charges, demolition 
explosives, and initiating explosives such as primer cord. PETN is considered practically insoluble in water, not prone to hydrolyze at ambient temperature, and recalcitrant to microbial degradation (Podlipná et al. 2008).

Diethylene glycol dinitrate (DEGDN) is an explosive ingredient (60-80\%) in dynamite that has also been used in propellant mixtures as a plasticizer (Fisher et al. 1989). DEGDN is a colorless, odorless, viscous, oily liquid. Environmental fate studies indicate that DEGDN is a stable compound once dissolved in water (Spanggord et al. 1985). 


\section{Underwater Munitions Sites Investigated for MC Contamination}

This chapter provides an overview as well as a description of sampling and chemical analyses for each site. The following sections detail the results of the investigations for aqueous (Chapter 5), sediment (Chapter 6), and biota (Chapter 7) samples.

\subsection{Jackson Park housing complex (WA, USA)}

\subsubsection{Site overview}

The Jackson Park Housing Complex (JPHC) lies on the shore of Ostrich Bay, which is a part of the complex system of Puget Sound embayments and channels near the city of Bremerton, WA. The bay is about $1.9 \mathrm{~km}$ long and $0.8 \mathrm{~km}$ wide, and connects with Dyes Inlet to the north and Oyster Bay to the south. Depths in Ostrich Bay are generally -6 to -9 m mean lower low water (MLLW), with a maximum depth of about $-14 \mathrm{~m}$ (NAVFAC NW 2010a).

JPHC consists of an off-site family housing area for military personnel stationed in the Bremerton area and Naval Hospital Bremerton (NHB), located immediately north of the military housing area (NAVFAC NW 2010a).

The JPHC is the site of a former Naval Ammunitions Depot (NAD). Navy operations associated with the former depot began in 1904, while munitions-related operations officially began at the depot in 1909. After closure in 1959, portions of land belonging to the depot were transferred to the city of Bremerton for the eventual construction of a 41-hectare park and part of State Highway 3 (13 hectares). The Navy turned over the remaining land to the Puget Sound Naval Shipyard and began construction of the JPHC in 1966. In May 1994, JPHC was listed on the United States Environmental Protection Agency's (USEPA) National Priorities List, which resulted in the Navy and USEPA signing an interagency agreement in December 2004. During the Comprehensive Environmental Response, Compensation, and Liability Act (CERCLA) investigation and remediation process, the JPHC was divided into five operable units (OU). The OU defined a specific portion of the site (e.g., marine versus terrestrial), as well as specific types of hazards (e.g., 
chemical contamination versus physical munitions hazards) (NAVFAC NW 2010a).

Munitions-related operations officially began in 1909 when the NAD received its first shipment of ammunition and smokeless powder; Munitions-related operations ended in 1959. The NAD's mission included assembly and maintenance of munitions and explosives, disposal of obsolete and unserviceable munitions and explosive components, storage of munitions and explosives, and storage of munitions and explosives on marine vessels. Specific munitions-related activities included case and projectile cleaning, tank and powder can repair, bag dyeing, and fuze operations. Items commonly produced at the depot included 5 -inch projectiles, 14-inch bag charges, and 14-inch projectiles. In addition, 20 $\mathrm{mm}$ and $40 \mathrm{~mm}$ projectiles were also assembled in large quantities at the depot. These projectiles were filled with various energetic compounds (NAVFAC NW 2010a). Facility-related chemicals contaminated Ostrich Bay via direct discharge of wash-down wastewater through outfall drainage pipes, seeps from contaminated groundwater, storm drains, spills, and surface soil runoff (Pascoe et al. 2010).

Navy records indicate that in 1981, explosive ordnance disposal divers removed 245 primers and 142 fuzes from Ostrich Bay, which contained a total of $71 \mathrm{~kg}$ of primary explosives. Since the main function of the NAD was the assembly and refurbishment of naval ammunition, several types of secondary explosives and other munitions fillers were used extensively onsite during the active production period for the facility. The most common munitions fillers present on-site would have included tetryl, TNT, Explosive D, RDX, smokeless powder, black powder, and magnesium (NAVFAC NW 2010a).

Although munitions items may remain buried underneath sediments within intertidal areas and along the immediate shoreline, the Navy continues to collect, identify, and remove existing munitions items at JPHC.

\subsubsection{Sampling efforts}

Twelve sediment samples within Ostrich Bay and one reference sediment sample near Carr Inlet, approximately $24 \mathrm{~km}$ south of Ostrich Bay, were collected in October 2004 and evaluated for compliance with the Washington State Sediment Management Standards (Blakley 2005). 
Samples were collected from a research vessel using a $0.1 \mathrm{~m} 2$ stainless steel Van Veen grab.

During September-December 2009, surface and subsurface sediment were collected from OU2 of the JPHC and NHB in Ostrich Bay, and from a nearby reference site (NAVFAC NW 2010b; Pascoe et al. 2010). A total of 52 surface and 74 subsurface sediment samples were collected from OU 2 , and 5 surface sediment samples were collected from a nearby reference site. Nine of the surface samples collected from Ostrich Bay were collected during phase 2 of sampling, following dredging of a portion of the bay to remove contaminated sediments. Surface samples were collected from a research vessel using a $0.1 \mathrm{~m} 2$ stainless steel Van Veen grab. Subsurface samples were obtained by coring.

During December 2009, fish (e.g., starry flounder) and invertebrates (e.g., graceful crab, bent-nose clam, and sea cucumbers) were collected from OU2 of the JPHC and NHB in Ostrich Bay and from a nearby reference site (NAVFAC NW 2010c). Six individual Starry flounder samples were collected by hook and line method from a sampling vessel. Graceful crabs (six samples, each a composite of three specimens) were collected using crab pots deployed and retrieved from a sampling vessel. Clams (6 samples, each a composite of 8-10 specimens) were collected during low tide periods. Six individual sea cucumbers samples were collected in shallow water by divers.

During 2002, 2004, and 2009, bent-nose clam and an unidentified crab species were collected for tissue analysis from within OU1 and other reference areas (NAVFAC NW 2011). Clam tissue samples were collected from intertidal areas ( 15 samples from OU1, and 3 samples from the reference area), and crab tissue samples were collected from subtidal areas (10 samples from OU1, and 3 samples from the reference area).

\subsubsection{Analytical chemistry}

For the Blakley (2005) study, sediment samples were analyzed for MC using USEPA Method 8330. Laboratory reporting limits (LRL) are provided in Appendix A of this report. For surface and subsurface sediment collected from OU2 of the JPHC and NHB in Ostrich Bay, and from a nearby reference site (NAVFAC NW 2010a, 200ob; Pascoe et al. 2010); USEPA regional guidelines for Puget Sound was used for sediment sample storage. The analytical laboratory (Columbia Analytical Services Inc., Kelso, WA) 
modified USEPA Method 8330B, which was used to analyze all MC except $\mathrm{NC}$ to achieve MDLs below or as close as possible to their preliminary sediment quality benchmarks (SQBs) Pasco et al. (2010) proposed. The MC NQ, NG, nitrobenzene, 2-NT, 3-NT, and 4-NT were analyzed using USEPA Method 8330B with HPLC-UV; N-nitrosodiphenylamine, dibutylphthalate, diethylphthalate, and diphenylamine were analyzed using USEPA Method 8270 with GC/MS; picric acid, picramic acid, and 2,4-dinitrophenol were analyzed using USEPA Method 8330B with HPLC-MS/MS; HMX, RDX, 1,3,5-TNB, 1,3-DNB, tetryl, TNT, 2-A-4,6-DNT, 4-A-2,6-DNT, 2,4-DNT, 2,6-DNT, 3,5-DNA, PETN, 2,4-DA-6-NT, and 2,6-DA-4-NT were analyzed using USEPA Method 8330 B with HPLC-UV and LC-MS/MS. Samples for $\mathrm{NC}$ analysis were prepared following the method of MacMillan et al. (2008) and analyzed using modified USEPA Method 353.2. Methods reporting limits (MDLs) and LRLs are provided in Appendix A of this report.

Whole body tissues for marine organisms (NAVFAC NW 2010c and 2011) were analyzed for all MC using USEPA method $8330 \mathrm{~B}$ with HPLC-UV and LC-MS/MS, with the exception of the following: diphenylamine, Nnitrosodiphenylamine, dibutylphthalate, and diethylphthalate used USEPA 8270 LL with GC/MS; picric acid, picramic acid, and 2,4dinitrophenol used USEPA method 8330 B with HPLC-MS/MS. LRLs are provided in Appendix A of this report.

\subsection{Sea disposal site Hawaii (HI-06) "Ordnance Reef” (HI, USA)}

\subsubsection{Site overview}

Ordnance Reef covers an approximately $1.9 \mathrm{~km}$ by $0.9 \mathrm{~km}$ area with water depths ranging between approximately 10 and $70 \mathrm{~m}, 5 \mathrm{~km}$ to the northeast of Wai'anae, HI. Ordnance Reef studies (University of Hawaii [UH] 2014a, 2014b) focused on an area that the U.S. Army Corps of Engineers (USACE), the National Oceanic and Atmospheric Administration (NOAA), and the University of Hawaii previously studied. Because the studies focused on assessing potential threats to human health, only the area of the reef with water bottoms reachable by recreation activities $(10-37 \mathrm{~m}$, via scuba diving) was studied. This study area includes discarded military munitions from activities during World War II and areas where previous investigations found elevated concentrations of metals, other trace elements, and munitions constituents. 
During a benthic survey of the Wai'anae wastewater treatment plant (WWTP) ocean outfall in 1992, the City and County of Honolulu, Department of Wastewater Management's oceanographic team discovered discarded military munitions approximately $0.5^{-0.9} \mathrm{~km}$ northwest of the existing treatment plant outfall's diffuser. The team also discovered discarded military munitions south of the treatment plant outfall and just west of the State of Hawaii-designated fish haven (UH 2014a).

In July 2002, a diver survey was conducted to determine the various amounts and types of munitions near Ordnance Reef. The discarded military munitions observed from depths of 18-49 m included clipped 0.50 caliber rounds, 2-in Special Operations Forces Combat Assault Rifle munitions, $105 \mathrm{~mm}$ shells, $155 \mathrm{~mm}$ shells, mines, mortars, naval artillery projectiles, and other munitions. Most of the munitions found were described as live and unfired with the majority of the munitions at Ordnance Reef being small arms ammunition (UH 2014a). In 2010, the NOAA conducted a detailed survey that estimated 21,200 individual munitions lie within HI-06 (Carton et al. 2012).

The munitions present at Ordnance Reef appear to be discarded military munitions, not unexploded ordnance. As such, they are considered less hazardous, because they have not been through their arming sequence. Despite extensive research efforts, records detailing the disposal of munitions at this location have not been discovered. It is presumed that the munitions are from activities associated with World War II. Therefore, UWMM present at Ordnance Reef (HI-06) are expected to contain one or more of the following munitions-related compounds: TNT (boosters) and ammonium picrate (Explosive D). The field activities performed during the U.S. Army's technology demonstration recovered munitions containing TNT, ammonium nitrate, tetryl, and ammonium picrate (Carton et al. 2012).

The U.S. Army has invested significant resources to investigate the munitions present at Ordnance Reef. Multiple investigations at HI-06 include a 2006 NOAA screening-level survey (Cox et al. 2007), a $2009 \mathrm{UH}$ environmental study designed to fill data gaps in the 2006 NOAA screening-level survey (UH 2014a), a 2011 technology demonstration (Carton et al. 2012), and a $2013 \mathrm{UH}$ follow-up environmental investigation (UH 2014b). 


\subsubsection{Sampling efforts}

After a review of the NOAA's report (Cox et al. 2007) and the various risk evaluations, the DoD determined that potential shortcomings of the 2006 NOAA study indicated by the U.S. Army Center for Health Promotion and Preventive Medicine (USCHPPM b2007) needed to be addressed. The U.S. Army contracted UH to conduct follow up studies to address the data gaps and answer the community's concerns: (1) Do the UWMM at Ordnance Reef (HI-06) pose a risk to human health and the environment?, and (2) Is seafood from the area safe to eat? During two sampling efforts which occurred in April and September/October of 2009, water, sediment, and biota samples were collected from the wastewater treatment plant, nonpoint source, discarded military munitions (DMM), and control sampling areas (or strata) for chemical analyses (UH2014a).

During two sampling efforts in 2009 (UH 2014a), water samples were collected and analyzed. Divers performed water column sampling using precleaned Niskin bottles, which were modified for trace element work. The 2.5-liter modified Niskin bottles used during the study were equipped with a triggering mechanism, which was constructed with epoxy-coated springs and silicone O-rings. Water sampling was intended to collect seawater samples close to the seafloor and directly above the sediment sampling locations. Water sampling should be performed prior to collection of sediment samples in order to produce a water sample that could be collocated with a sediment sample. To accomplish this task, divers deployed Niskin bottles that the study field team secured in the "open" position. When a sediment sample location was selected, the diver suspended the Niskin bottle less than $0.3 \mathrm{~m}$ above the sediment sampling location and triggered the closing mechanism. At DMM sites, seawater samples were collected from the sediment sampling location closest to the DMM.

Sediment samples were collected during the April 2009 Ordnance Reef environmental study (UH2014b). Divers initially attempted to use the ponar to collect samples; however, when use of the ponar was not successful, divers collected sediment samples by scooping sediment from the top 2 to $4 \mathrm{~cm}$ of the substrate directly into pre-labeled gallon-sized plastic storage bags. Samples within the DMM stratum were collected from three locations associated with specific DMM. When possible, given bottom conditions and the presence of an adequate amount of sediment for analyses, samples were collected directly adjacent to, approximately 1 $\mathrm{m}$ away from, and approximately $2 \mathrm{~m}$ away from specific DMM. 
Target biota species were selected based on discussions with local community members. Biota samples included fish, octopus, crab, and seaweed and were collected during the 2009 environmental study. Octopi were caught using a tactical spearing technique, Kona crab were caught in bottom traps, and seaweed was harvested by hand. Fish (red wake and white wake) were trapped in nets left in place overnight at prime collection spots within each stratum. Based on a suggestion by the local community, only edible portions of the biota collected were analyzed.

A technology demonstration effort at HI-06 was conducted in 2011 to remove and demilitarize the DMM by degrading explosives and propellants using the energetic hazard demilitarization system (Carton et al. 2012). DMM unearthed at the technology demonstration included 74 medium and large munitions and 2,300 small arms munitions that were discovered at depths between approximately 30 and $120 \mathrm{ft}$.

A follow-up investigation (FUI) was conducted to quantify the effects of the UWMM removal effort on MC contamination in sediment and biota at HI-06 (UH2014b). Water samples were not collected during the FUI investigation. Sampling occurred in August 2011 (sediment only), JulyAugust 2012 (sediment and biota), and June 2013 (sediment and biota). Biota samples included fish, octopus, crab, and seaweed, preferably of the same species as those collected in 2009. Samples were prepared in the same manner as those collected for the 2009 study, and only edible portions of the biota collected were analyzed. Given the primary objective of the FUI, considerable emphasis was placed on collecting sediment and biota samples from locations where DMM were recovered during the technology demonstration.

\subsubsection{Analytical chemistry}

Target MC for water, sediment and biota analyses were TNT, 2-A-4,6DNT, 4-A-2,6-DNT, 2,4-DNT, 2,6-DNT, RDX, picric acid, 2,4-dinitrophenol (FUI only), picramic acid (FUI only), and NG.

For UH (2014a), seawater samples were submitted to TestAmerica Laboratories, Inc. located in West Sacramento, CA. The samples were analyzed for energetics using USEPA method 8330. LRLs are provided in Appendix A of this report. 
Sediment samples were also submitted to TestAmerica Laboratories, Inc. and analyzed for energetics using USEPA method 8330. LRLs are provided in Appendix A of this report.

According to UH (2014a), meat collected from each fish specimen was filleted, crabmeat and appendages were extracted, and the ink sac and beak were removed from octopus specimen. Following biota sample preparation, all biota samples were stored frozen and subsequently shipped to the contract laboratory for chemical analysis. All biota tissue samples were analyzed for trace elements and energetics at TestAmerica Laboratories, Inc. using USEPA Method 8330, and modified for marine matrices (UH 2014a). LRLs for tissue samples (UH 2014a, 2014b) are provided in Appendix A of this report.

\subsection{Sea disposal site Hawaii (HI-05) (HI, USA)}

\subsubsection{Site overview}

In 2007, the DoD established the Hawaii Undersea Military Munitions Assessment (HUMMA) to investigate the region south of Pearl Harbor, Oahu (HI). Historical documents indicated that approximately 16,000 M47A2, 100-lb mustard-filled bombs were disposed in the area between October and November of 1944. The DoD designated this sea-disposal site as HI-05. HI-05 contained DMM of both chemical and conventional varieties, which provided the opportunity to investigate the environmental effects of different types of munitions constituents (UH 2010). This region, which stretches from Barber's Point on the western side of Oahu to Diamond Head crater on the eastern side and from Pearl Harbor to $50 \mathrm{~km}$ due south of Oahu, was selected for the HUMMA study. The northern boundary of the study area contains a shallow shelf (water depths ranging from 50 to $75 \mathrm{~m}$ ) that extends south for approximately $3.2 \mathrm{~km}$. South of the 3.2-km mark, there is an abrupt drop-off to $\sim 300 \mathrm{~m}$ depth (UH 2010).

HUMMA's overarching scientific objective was to bound and assess a historic deep-water munitions sea-disposal site to determine the potential impact of the ocean environment on sea-disposed munitions and of seadisposed munitions on the ocean environment and those that use it. Additionally, HUMMA had technological objectives to develop and demonstrate effective, cost-efficient methodologies for surveying and sampling other historic munitions sea-disposal sites (UH 2010). 
The integrity of DMM in the HUMMA study area spans a broad spectrum. The deterioration level of casings ranged from almost pristine to virtually disintegrated. The state of deterioration varied within similar munitions types located in the same general area, as well as between different types of munitions spread over a wide region. In general, munitions with thicker casings were better preserved. Most of the munitions casings were not obviously breached (UH 2010).

HUMMA field programs were designed to collect water, sediment, and biota samples to test for various chemicals of potential concern (COPCs) around DMM, including specific MC and associated MC degradation products related to chemical and conventional bombs and other munitions materials. HUMMA COPCs fall into three general categories: chemical warfare agents (CWA) and agent breakdown products from bomb fill materials; energetic materials from conventional munitions as well as explosive charges designed to rupture bomb casings (known as a bursters); and metals from munitions casings. The burster for M47A2 bombs had one of three possible fills: (1) TNT; (2) a 50/50 mix of black powder (a mixture of sulfur, charcoal, and potassium nitrate) and magnesium; or (3) TNT and tetryl pellets. In addition to the M47A2 bombs, thousands of conventional munitions were detected in the HUMMA study area. Based on knowledge about munitions from the World War II era, high explosive fills may contain TNT, 2,4-DNT, 2,6-DNT, RDX, or tetryl (UH 2010).

\subsubsection{Sampling efforts}

Sediment and biota were sampled at chemical and conventional DMM sites at depths of $400-650 \mathrm{~m}$, where temperatures range from 6 to $8^{\circ} \mathrm{C}$. These sediment and biota samples were taken to comprehensively describe the behavior and potential impacts of CWA at sea disposal site HI-05 to make informed decisions regarding the location, impacts, risks, and actions that could potentially be taken at DMM sites. The distribution of CWA, energetics, and select metals in proximity to sea-disposed munitions was assessed and compared to nearby control sites (Edwards et al. 2016; Briggs et al. 2016; Koide et al. 2016). Two sampling cruises were performed in 2009 (UH2010) and in 2012. The report for the 2012 sampling has not yet been published; however, draft versions were made available by the authors. Information about sediment and biota sampling and contamination for samples collected in 2012 were obtained from Briggs et al. (2016) and Koide et al. (2016). 
During the 2009 cruise, ten conventional DMM sites were sampled. DMM were classified as either minimally breached or significantly breached based on high-definition video imagery acquired simultaneously with the samples. The integrity of DMM in the 2009 HUMMA area spanned a broad spectrum, with even the best-preserved munitions casings showing signs of deterioration. Thirty water samples, 94 sediment samples, 19 deep-water shrimp (tail muscle tissue only) samples, and 16 long tail red snapper (fillet tissue) samples were collected and submitted for analysis.

For the 2012 HUMMA sampling survey (Edwards et al., 2016), six CWA DMM were selected for sampling: three minimally breached and three significantly breached. Samples were also collected at three additional conventional DMM sites and three control sites within the 2012 study area. Although degrading to varying extents, the majority of conventional munitions encountered did not appear to be breached. Chemical munitions casings were highly degraded, and a thin yellow coating was present on the sediment surface adjacent to some of the chemical munitions. This coating did not appear to permeate the adjacent sediments.

For sediment sampling in 2009, six sample locations were randomly selected at each site: three at a radial distance of $3 \mathrm{~m}$ from the munitions object, and three at a radial distance of $6 \mathrm{~m}$ from the munitions object. During the 2012 cruise, sediments were collected at multiple distances (o, 0.5, 1.0, and 2.0 m) from each of the nine DMM sampled in linear transects from the nose, upper half of munitions casing, lower half of casing, and tail. For control sites, samples were collected at distances of $o$ to $0.5 \mathrm{~m}$ from a central point. Samples were collected using custom-made sediment scoops composed of polyvinyl chloride tubes and end caps, with a stainless steel "T"-bolt handle.

A minimum of two seawater samples were targeted for collection near the seafloor at each site, from two randomly selected locations; this was not always possible due to time and equipment limitations. The human occupied vehicle (HOV) collected the seawater samples from the randomly selected locations down-current from the DMM, and at a height above the sediment of approximately 1 to $1.5 \mathrm{~m}$.

In 2009, a commercial fishing vessel was used to collect locally consumed biota, long tail red snapper, and shrimp locally known as ama ebi. Shrimp 
was sampled from multiple discrete sampling sites where sediment and water had been collected using HOVs. Given the collection method used, it is very unlikely that these shrimp samples were acquired close to the target DMM. Due to scarcity in some sampling sites, fish were collected throughout the overall HUMMA study area, as opposed to the discrete sampling sites, which was justified due to its highly transient and farranging habitats.

The deep-sea shrimp Heterocarpus ensifer, which was observed in abundance within close proximity to munitions at most of the study sites during the 2009 HUMMA sampling program, was selected for the 2012 study. HOVs were used to deploy and recover shrimp traps at locations adjacent to the DMM targets of interest as well as control sites. Traps were deployed adjacent to likely CWA-containing DMM with casings that appeared minimally breached, likely CWA-containing DMM that appeared significantly breached, DMM classified as conventional explosive munitions, and at control sites that were located in excess of $50 \mathrm{~m}$ from any munitions-related objects. At each study site, the HOV placed the shrimp trap on the seafloor proximal to the main body of the DMM, within $0.5^{-2} \mathrm{~m}$ of the casing. Typically, the traps were left in place for less than two hours prior to HOV departure for another site or return to the ocean surface.

\subsubsection{Analytical chemistry}

Seawater, sediment extracts, and tissue extracts were analyzed for MC (1,3,5-TNB, 1,3-DNB, nitrobenzene, TNT, 2-A-4,6DNT, 4-A-2,6-DNT, 2,4DNT, 2,6-DNT, 2-NT, 3-NT, 4-NT, HM, RDX, and tetryl) using USEPA method 8330a for the 2009 sampling effort. LRLs are provided in Appendix A of this report. For the 2012 sampling effort, tissue samples were sent to TestAmerica Laboratories, Inc. for analysis of MC using USEPA method 8330 (Koide et al. 2016). LRLs are provided in Koide et al. (2016).

\subsection{Isla de Vieques bombing range (PR, USA)}

\subsubsection{Site overview}

Isla de Vieques, or Vieques Island, is located off the Commonwealth of Puerto Rico's east coast. In 1941, as the United States entered World War II, the U.S. Navy began to acquire Vieques property by condemnation of 
private lands. By 1950, the Navy owned the island's entire eastern and western portions. The Navy's Atlantic Fleet Weapons Training Facility (AFWTF) established its so-called Inner Range on Vieques, including the eastern maneuver area (EMA), and the live impact area (LIA). Aerial explosive-ordnance and naval gunfire practice were limited to the LIA, on the island's easternmost end, including at Bahia Salina del Sur. For decades, particularly after the mid-1970s, ships and aircrafts fired, launched, and dropped live bullets, artillery rounds, rockets, missiles, and bombs into the LIA. In early 2003, all military activities on Vieques Island ceased (Agency for Toxic Substances and Disease Registry [ATSDR] 2013).

The former Vieques Naval Training Range (fVNTR), which consisted of the LIA, is managed as a wilderness area under the U.S. Fish and Wildlife Service (FWS) jurisdiction, where public access is prohibited. The Department of Interior developed a Comprehensive Conservation Plan (CCP) in 2007 for the Vieques National Wildlife Refuge that outlines its concept for managing the refuge. Environmental restoration of the fVNTR is based on potential risks to human health and the environment identified via the CERCLA process, applicable or relevant and appropriate requirements (ARARs), and the prospect of future land use as identified in the CCP (Rosen et al. 2016).

Located within the LIA, Bahia Salina del Sur encompasses an area of $\sim 0.5$ $\mathrm{X}$ 0.75 nautical miles. Water depths vary from breaking surf to slightly over $30 \mathrm{ft}$. The bay bottom consists open sand areas, marine sea grass covered areas, and coral reefs (in about equivalent extents). The coral in the main part of the bay is in fringing clusters, with some additional growths associated with solid bottom structures. Much of the UXO present in the Bahia Salinas del Sur resulted from overshoots of terrestrial ranges; offshore areas have also been used for ranges (McDonald 2009). However, sometime between the mid-1960s and the early 1970s, the Fletcher Class destroyer USS Killen (DD-593) was towed into the Bahia Salinas del Sur and sunk by naval gunfire, which caused the vessel to break into three major pieces (and numerous smaller fragments) that currently lie in the center of the bay (McDonald 2009).

In 2006, Naval Facilities Engineering Command (NAVFAC) Atlantic Division began preliminary activities to evaluate the types and extent of damage and contamination of the offshore areas in bays on both the north and south sides of the LIA. In late 2006, NOAA, working with NAVFAC, 
undertook new bathymetry mapping and environmental investigations of these areas. The DoD Environmental Security Technology Certification Program ([ESTCP] Project MM-0324), working in cooperation with NAVFAC Atlantic, sponsored a magnetometry geophysical demonstration survey of the Bahia Salinas del Sur and adjacent areas to map out the extent of the ferrous/MEC contamination (McDonald 2009).

\subsubsection{Sampling efforts}

In 2001, the Agency for Toxic Substances and Disease Registry (ATSDR) collected fish and shellfish from reefs surrounding Vieques (ATSDR 2003, 2013). Two reefs were located off the eastern portion of the island near the LIA where military exercises formerly occurred; one of these locations included the area where the USS Killen was sunk. Their samples included grouper, snapper, parrotfish, grunt, goatfish, conch, lobster, blue land crab, and fiddler crab.

In June 2003, sediment, water, fish, and benthic invertebrates were collected in close association to wreck sites of the USS Killen and near a 2000-pound bomb resting immediately on the bottom south of Roca Alcatraz at Bahia Salinas der Sur (Barton and Porter 2004; Porter et al. 2011). Sediment and water near the 2000-pound bomb were collected from within the solution cavity of the bomb and from distances that varied between $0.01 \mathrm{~m}$ (adjacent to the bomb) and 1, 2 and $15 \mathrm{~m}$ from the bomb. Sediment samples were collected using a Nalgene pipette and placed in a 1-liter wide mouth, clear plastic sample container. Water samples were collected in 1-liter clear plastic jars. The following biota samples were obtained near the bomb: a dusky damselfish, which had taken up residence in the bomb; a feather duster worm attached to the bomb at the entrance of the corrosion hole; a mountainous star coral physically adjacent to the bomb; a grooved brain coral living $15 \mathrm{~m}$ from the bomb; and a long-spined sea urchin grazing on the nose-cone of the bomb.

In June 2005, NOAA sampled land crabs from mudflats, mangrove wetlands, coastal forested areas, and sandy areas on the east and west ends of Vieques Island, including the LIA (ATSDR 2006).

In May and October 2007, sediment samples were collected from the nearshore waters surrounding Isla de Vieques, including Bahia Salinas del Sur, for chemical analysis (Pait et al. 2010). 
Bahia del Sur was selected as a demonstration site for project ER-201433 "Validation of Passive Sampling Devices for Monitoring of Munitions Constituents in Underwater Environments," funded by ESTCP. Following a successful reconnaissance survey that identified more than 25 UWMM of varying type, condition, position, and substrate, divers deployed a total of 30 canisters containing polar organic chemical integrative samplers (POCIS) (Belden et al. 2015); 15 spatially located on a grid across Bahia Salinas der Sur, hereafter referred to as "grid" samplers, and 15 spatially located near observed UWMM items, hereafter referred to as "target" samplers. When feasible, the target samplers were placed in close proximity (e.g., $15 \mathrm{~cm}$ ) to visible breaches. When breaches were assumed, but not obvious, the divers placed the samplers at locations where they would expect corrosion failure to occur, such as near the base of the munition. Samplers were placed at depths ranging from 2 to $9 \mathrm{~m}$ and were left in place for 19-21 days. Divers collect discrete (grab) water samples at grid and target stations during both the deployment and the recovery of the POCIS. Water samples were collected within $30 \mathrm{~cm}$ of the POCIS sampler and concentrated on-site using solid phase extraction.

\subsubsection{Analytical chemistry}

The water, sediment, and biota samples collected in June 2003 were analyzed for 1,3,5-TNB, 1,3-DNB, TNT, 2,4-DNT + 2,6-DNT, 4- and 2-NT, and RDX (Porter et al. 2011). Samples were analyzed for MC content by methods outlined in the USEPA Solid Waste Analytical Manual SW-846 Version 2 as follows: MCs by immunoassay (USEPA methods 4050 and 4051), MC by HPLC (USEPA method 8330). Samples for analysis of MC were screened by immunoassay for TNT and RDX. Samples that tested positive by immunoassay were then confirmed by HPLC. Detection limits (DLs) (not specified if method detection or laboratory reporting limits) for seawater $(1.3-1.7 \mu \mathrm{g} / \mathrm{L})$, sediment $(0.5-1.3 \mathrm{mg} / \mathrm{kg})$, and tissue $(0.5-1.3$ $\mathrm{mg} / \mathrm{kg}$ ) were inferred from information provided in Porter et al. (2011).

NOAA analyzed land crab tissue samples (ATSDR 2006) for 1,3,5-TNB, 1,3-DNB, nitrobenzene, TNT, 2-A-4,6DNT, 4-A-2,6DNT, 2- 3- and 4-NT, 2,4- and 2,6- DNT, HMX, RDX, and tetryl, using USEPA method 8330. DLs and LRLs were not provided in ATSDR (2006).

Sediment samples collected in 2007 (Pait et al. 2010) were analyzed for the same MC as listed for ATSDR (2006) using USEPA method 8330. Samples with energetics concentrations that appeared to be above the 
method detection level were subsequently reanalyzed using USEPA Method 8330, followed by liquid chromatography/mass spectrometry/mass spectrometry to confirm their presence. None of the analyzed estuarine sediment samples contained energetics above the reporting limit. DLs and LRLs were not provided in Pait et al. (2010).

Analyses of MC in water collected under ETCP project ER-201433 were described in Rosen et al. $(2016,2017)$. Water samples $(1 \mathrm{~L})$ were extracted by solid-phase extraction (SPE) using Oasis hydrophilic lipophilic balance (HLB) SPE columns, eluted with ethyl acetate, and brought to a final volume of $0.5 \mathrm{~mL}$. Extracts were removed via an Agilent $6850 \mathrm{GC}$ coupled with a $5975 \mathrm{C}$ mass selective detector using negative chemical ionization with 3 selected ion monitoring for each analyte.

\subsection{Former Seattle Naval Supply Depot piers 90 and 91, Port of Seattle (WA, USA)}

\subsubsection{Site overview}

The former Seattle naval supply depot piers 90 and 91 (collectively identified as Terminal 91) are located along Elliot Bay in Seattle (WA). The Port of Seattle manages the property under the FUDS Military Munitions Response Program. The facility was a hub for Seattle commerce and was used for loading and offloading lumber, coal, and other materials (USACE 2013). In the early 1940 , the property was condemned and the U.S. Navy acquired the property for use as a bulk fuel and material storage area. During World War II, the U.S. Navy used these piers as marine terminals for naval vessels, including aircraft carriers, battleships, cruisers, and submarines (USACE 2013). It was during this period that DMM from naval vessels were likely introduced into pier waters. The piers were not utilized as an ammunition resupply facility, and there are no records of live fire actions ever occurring at the piers, suggesting that only small quantities of unfired munitions items were dropped overboard during vessel loading, and no UXO were introduced into adjacent waters. Currently, the Port of Seattle uses the property as a marine terminal for cargo ships, factory trawlers, and as the prime terminal for passenger cruise ships (USACE 2013).

Munitions present at the piers were likely discarded during their use by the U.S. Navy during World War II. Historic records suggest that munitions were infrequently dropped overboard from military vessels in 
port without documentation. No evidence was found that would indicate deliberate disposal of military munitions as a normal practice. All DMM discovered were subject to removal and disposition (USACE 2013).

In December of 2010, USACE initiated the Piers 90 and 91 Remedial Investigation. The overall objective of the investigation was to characterize the nature and extent of DMM to allow assessment of explosive hazard and exposure risk for MC associated with the DMM. Sediment samples were collected and submitted for analytical quantification of explosive energetics and related compounds (USACE 2013).

\subsubsection{Sampling efforts}

Sediment samples were collected during the 2012 field season. Thirteen sediment samples were collected, and twelve samples were sent to the laboratory for analysis. Eight of the thirteen samples were collected under munitions items located on the surface of the seafloor. Three samples were collected below excavated munitions items. Sediment samples were collected with the hand-held coring device deployed by divers (USACE 2013).

\subsubsection{Analytical chemistry}

Columbia Analytical Services (Kelso, WA), a National Environmental Laboratory Accreditation Conference, and DoD-Environmental Laboratory Accreditation Program laboratory, analyzed the samples. Target $\mathrm{MC}$ for sediment sample analyses were 1,3,5-TNB, 1,3-DNB, nitrobenzene, 2,4and 2,6-DNT, TNT, 2-A-4,6DNT, 4-A-2,6DNT, 2- 3- and 4-nitrotoluene, 3,5-dinitroaniline, picramic acid, picric acid, tetryl, 2,4-dinitrophenol, RDX, HMX, NG, and PETN as well as munitions related propellant stabilizers (diphenylamine, $N$-nitrosodiphenylamine). Munitions related propellant plasticizers (di-n-butyl phthalate, diethyl phthalate) were analyzed if positive detections for energetics and/or propellant stabilizers were observed in the sample (USACE 2013). Analytical methods that were used include USEPA method $8330 \mathrm{~B}$ for nitroaromatics and nitramines, and liquid chromatography and tandem mass spectrometry for picric acid, picramic acid, and 2,4-dinitrophenol (USACE 2013). Method detection limits (MDL) and LRLs are provided in Appendix A of this report. 


\subsection{Halifax Harbor (Nova Scotia, Canada)}

Halifax harbor is a deep natural harbor. The inner harbor, known as Bedford Basin, was ideal for assembling convoys of warships, which escorted the transport ships to protect them from German U-boats. A considerable number of ships have sunk in the Halifax region throughout the years, and some of them were carrying important ammunition stocks. A primary example is the Halifax explosion in 1917, when the collision of two military ships-the Belgian Imo and the French Mont Blanc-resulted in what is still considered the world's largest accidental explosion. The Mont Blanc was a cargo vessel, and at the time was carrying approximately 32 metric tons of benzol, 300 rounds of ammunition, and many tons of picric acid and TNT. During World War II, Halifax was again the primary port for ships heading to Europe. Munitions were sometimes lost overboard, several ships collided and sunk with their cargo, and there were several explosions that once again scattered munitions. n 1998, divers collected sediment samples near UXO dating from World War II, and some MC were detected (Darrach et al. 1998). Rodacy et al. (2001) completed an expanded study on this collection, which is summarized below.

\subsubsection{Sampling efforts}

Sampling occurred at Bedford Basin off the ammo pier at Rent Point and at Black Rock point because of their accessibility and the variety of UWMM present at these sites. Water samples were collected at distances of $0.3 \mathrm{~m}, 1.0 \mathrm{~m}, 2.0 \mathrm{~m}$, and $3.0 \mathrm{~m}$ down current from the UWMM at a vertical distance of approximately $0.3 \mathrm{~m}$ above the sea bottom. The target UWMM were located 10-30 m deep. Sediment samples were collected at the same distances down current and in-line with the water samples. Only intact shells were sampled.

Divers collected water grab samples. Divers transported empty, amber, high-density polyethylene bottles to the sampling location. At specified locations, the lids were opened to fill the bottles and then recapped.

A diver using a submersible hand-held device collected water to take to the target where a surface sampler that sampled water collected by a diverheld hose and a surface-mounted pump were located. These methods were used to concentrate a large volume of water using solid phase microextraction (SPME) fibers. Most SPME samples were analyzed on-site using an Ion Mobility Spectrometer. Some duplicate SPME samples were 
solvent-extracted and analyzed by gas chromatography using an electron capture detector in the laboratory for 1,3,5-TNB, 1,3-DNB, TNT, 2-A4,6DNT, 4-A-2,6DNT, 2,4-DNT, and 2,6-DNT.

Sediment samples were collected by manually filling amber, high-density polyethylene bottles with seabed material collected o.3, 1.0, 2.0, and $3.0 \mathrm{~m}$ from the target UWMM. The seabed was often rocky, so sediment samples were not always available. All sediment samples were shipped overnight and kept frozen until extraction and analysis.

\subsubsection{Analytical chemistry}

Water samples were extracted, and gas chromatograph-electron capture detector (GC/ECD) was used to analyze the extracts via method SW846 8095. Rodacy et al. (2001) LRLs.

Sediment samples were extracted wet with acetonitrile. GC/ECD was used to analyze the extracts via method SW846 8095 for 1,3,5-TNB, 1,3-DNB, TNT, 2-A-4,6DNT, 4-A-2,6DNT, 2,4-DNT, and 2,6-DNT. Rodacy et al. (2001) did not provide LRLs.

\subsection{Halifax Harbor area (Nova Scotia, Canada)}

\subsubsection{Sites overview}

The Halifax Harbor sites investigated include the wrecks of the HMCS Clayoquot, SS Kaarpen, and Emerald Basin; all of which are located south of Halifax, Nova Scotia, Canada. The HMCS Clayoquot was a Canadian Bangor class minesweeper that was torpedoed by a U-Boat in 1944. The ship was carrying two $20 \mathrm{~mm}$ guns along with a 12-pounder gun. The wreck is approximately $28 \mathrm{~km}$ south of Halifax in $80 \mathrm{~m}$ of water. UXO is believed to be present containing mainly TNT as the explosive charge. Bottom type in this area is thick silt and clay. The SS Kaaparen was a Norwegian warship that was sold to the Swedish navy. The ship sank in 1942 after a collision during a convoy organization. No specific data was available concerning the type of ammunition carried onboard this ship. The wreck is located approximately $19 \mathrm{~km}$ south of Halifax, on rocky bottom. Emerald Basin, a large area in deeper waters (greater than $180 \mathrm{~m}$ ) located $93 \mathrm{~km}$ south of Halifax, was also investigated. During past military activities in this area, numerous cases of munitions dumping have occurred (Ampleman et al. 2004). 


\subsubsection{Sampling efforts}

A Deep Seabed Intervention System (DSIS) was used to conduct sampling for this project. Sampling. The DSIS is comprised of a remotely operated vehicle (ROV) fitted inside an aluminum cage. In addition, 6-ganged PVC bottles, each containing 1.2 l of water, were used in sampling efforts. These bottles contain a cap at each end that is joined together with an elastic rubber tube inside the bottle. Sediment samples were obtained by coring using aluminum tubes. The core samplers were disposed in a rack containing PVC tubes with a rubber stopper at the bottom (Ampleman et al. 2004).

\subsubsection{Analytical chemistry}

Water samples were concentrated using the USEPA Method 3535A. Sediment and water extracts were analyzed using HPLC (USEPA Method 8330) for TNT, 2-A-4,6DNT, 4-A-2,6DNT, 2,4-DNT, and 2,6-DNT, RDX, HMX, and nitroso derivatives of RDX (Ampleman et al. 2004). DLs are provided in Appendix A of this report.

\subsection{Point Amour (Labrador, Canada)}

\subsubsection{Site overview}

The HMS Raleigh ran aground in 1922 at Point Amour, Labrador, Canada. The wreck is located within $9 \mathrm{~m}$ of the Labrador shoreline, in approximately $12 \mathrm{~m}$ of water. Salvage and scuttling operations for the HMS Raleigh did not clear all munitions from the wreck. Shells were discovered $15 \mathrm{~m}$ from the shoreline in water depths varying between 9-12 m. UXO near the wreck of HMS Raleigh included $19 \mathrm{~cm}$ projectiles that contained, mainly, Lyddite (picric acid), TNT, or black powder; $7.5 \mathrm{~cm}$ projectiles; small arms munitions; and Cordite (smokeless powder). UXO was destroyed on-site via open detonation (Ampleman et al. 2004).

\subsubsection{Sampling efforts}

Because the wreck of the HMS Raleigh resulted in the spread of UXO in its vicinity, removal and disposal of UXOs was conducted 6-15 May 2002. In addition to removal, a study was conducted to evaluate whether underwater detonation of the UXO results in the spread of MC contamination into the environment (Ampleman et al. 2004). 
Divers performed water and sediment sampling before and after each detonation, along with a control site. Sample collection was performed directly in the sampling container. Six water and sediment samples were taken near the wreck, one sediment sample from an adjacent reference site, prior to in-situ detonation of UXO (May 21, 2003), three samples near the wreck, and one sediment sample from the reference site following detonation (May 26, 2003) (Ampleman et al. 2004).

\subsubsection{Analytical chemistry}

Water samples underwent paper filtration to remove excess salt and small rocks, and then were passed through the sep-pack for adsorption. Five hundred $\mathrm{mL}$ was the target amount of water to be passed through the seppack, however most samples were limited to $100-250 \mathrm{~mL}$. The amount of water passed through the sep-pack was taken into account for calculation corrections. The MCs were extracted from the sep-pack using $5 \mathrm{~mL}$ of acetonitrile. The water extracts were then analyzed using HPLC (USEPA Method 8330) for TNT, 2-A-4,6DNT, 4-A-2,6DNT, 2,4-DNT, and 2,6DNT, RDX, HMX, and nitroso derivatives of RDX (Ampleman et al. 2004).

DLs for water extracts are summarized in Appendix A of this report. Sediment extracts were also analyzed using USEPA Method 8330 for the same MC as the water extracts. DLs are provided in Appendix A of this report.

\subsection{Lakes Thun and Brienz (Switzerland)}

Lakes Thun and Brienz are nutrient-poor Alpine lakes located in the Canton of Bern, Switzerland. Lake Thun has an average depth of $136 \mathrm{~m}$, while Lake Brienz has an average depth of $173 \mathrm{~m}$. Ammunition disposal in the lakes occurred from 1920-1964; approximately 4,170 metric tons are buried in the sediments of Lake Thun, and 250 metric tons in Lake Brienz. A 2005 study concluded that Lake Thun underwent sedimentation, and ammunition was buried, which limited the dispersal of MC (Laugesen and Bjørnstad 2008).

\subsubsection{Sampling efforts}

Water samples from Lakes Thun and Brienz, as well as three tributaries of Lake Thun, were collected in 2006 and in 2007 (Ochsenbein et al. 2008). Lake Thun samples were collected from depths of 1, 10, 20, 100, and 
212 m, while Lake Brienz samples were collected from 1, 10, 20, 100, 200, and $255 \mathrm{~m}$. River water samples (tributaries) were collected as grab samples during the same time.

\subsubsection{Analytical chemistry}

Unfiltered water was concentrated using SPE. Extracts were concentrated to $30 \mu \mathrm{L}$ and reconstituted in $500 \mu \mathrm{L}$ of Milli-Q water before analysis were conducted using high performance liquid chromatography-tandem mass spectrometry. MC that was analyzed include TNT, 2-A-4,6DNT, 4-A2,6DNT, 2,4-DANT, 2,6-DANT, RDX, HMX, and PETN (Ochsenbein et al. 2008). LRLs for water samples are provided in Appendix A of this report.

\subsection{Lakes Limmaren, Stensele, Pengsjön, and Lomtjärn and Fårö and Möja, Baltic Sea and Stora Pölsan, North Sea (Sweden)}

\subsubsection{Sites overview}

Between the 1940's and 1960's, munitions were discarded into 106 sites in Sweden, including lakes and coastal waters. As a result, four lakes representing a variety of sizes and characteristics were investigated. Lake Limmaren is large with well-buffered water that contains approximately $500 \mathrm{~kg}$ of dumped explosives. Lake Stensele is a small, woodland lake with a probable high organic sedimentation and contains approximately 1,000 $\mathrm{kg}$ of dumped explosives. Lake Lomtjärn is a swampy, woodland lake that contains approximately 2,000 kg of dumped explosives (Sjostrom et al. 2004).

The seafloors at Möja and Stora Pölsan are oxygen-rich, while that at Fårö is oxygen-poor. Carbon and nitrogen content of the different sediments was low. Möja and Fårö are brackish sites (Sjostrom et al. 2004).

\subsubsection{Sampling efforts}

The lakes were investigated with respect to water quality, and the concentration of TNT. Water samples were taken $0.5 \mathrm{~m}$ above the lake floor at the dumping grounds. Sediment samples down to a depth of $1 \mathrm{~m}$ were also taken (Sjostrom et al. 2004). 


\subsubsection{Analytical chemistry}

Sediment and water from the coastal sites were analyzed for TNT. Sjostrom et al. (2004) did not provide additional detail concerning the sampling and analysis methods used.

\subsection{Lake of Mjøsa and Lake Randsfjorden (Norway)}

\subsubsection{Sites overview}

Lake Mjøsa, located in Akershus, Hedmark, and Oppland counties, Norway, is the largest lake in Europe, and the fourth deepest lake in Norway. It has a maximum depth of $468 \mathrm{~m}$. From the early 1940 s to 1971 , munitions dumping occurred in three areas of the lake that range from $160-400 \mathrm{~m}$. The amounts and locations of what was dumped remains unknown. Dumped munitions contained, mainly, TNT, picric acid, NG, and $\mathrm{NC}$ and are known to be at 160-400 m depth. Skreia, Lake Mjøsa's deepest point, was used as a training site for nearly 50 years; however, the use of this site was discontinued in June 2009. Ammunitions, such as a mortar shell of a grenade burst, were found at the site (Laugesen and Bjørnstad 2008; Rossland et al. 2010).

Lake Randsfjorden is Norway's fourth largest lake, and its greatest depth is 120 m. According to Rossland et al. (2010), a 2003 survey using ROVs investigated two dumped munitions sites at Randsfjorden, which estimated that approximately 1,000 objects from 75 to $150 \mathrm{~mm}$ caliber weapons, totaling to 2.5 tons of ammunition, were recovered at the bottom of the lake.

\subsubsection{Sampling efforts and analytical chemistry}

According to Laugesen and Bjørnstad (2008), a 2001 survey of sediment and water quality was conducted for Lake Mjøsa that included the analyses of TNT, 2,4-DNT, 2-A-4,6-DNT, 4 -2,6-DNT, 1,3,5-TNB, and picric acid. According to Rossland et al. (2010), in 2004 and 2007, sediment and porewater analyzed for $\mathrm{MC}$ and water samples were collected and assessed for MC during 2002-2006. No additional detail on the 2002-2006 sampling and analysis methods were provided in Rossland et al. (2010), and reports cited therein (in Norwegian) failed to be obtained. 


\subsection{Coastal fortifications in Norway}

\subsubsection{Sites overview and sampling efforts}

Rossland et al. (2010) obtained the data that is summarized here from the original report in Norwegian. Translation was conducted using free online language conversion tools.

Preliminary studies were conducted to assess terrestrial and aquatic contamination from explosives and heavy metals at coastal fortification sites in Norway. The following sites were investigated:

- Solstrand, city of Tromso. During World War II, German grenades were ejected over the water due to a fire. In 2008, the Defense Department removed a portion of the ammunition from the lake. Samples were taken under a demolished pier at low tide (four lake sediment samples and two seawater samples), snails and mussels were also collected (unspecified number) and analyzed.

- Tælavåg, city of Bergen. In 2009, a German anchored mine was discovered. It was raised and towed about $300 \mathrm{~m}$ into deeper waters to avoid harm to local wildlife when detonated. Due to poor condition of the mine, the shell partially fell apart during transportation. Water samples were taken from around the German anchored mine an hour after it had settled into the new location, just before detonation. Samples of sediment surrounding the mine were taken, as well as samples of kelp on top of the mine. TNT and RDX were used as counter charges and PETN was used to initiate the detonation. Immediately after detonation, samples were taken from the surrounding waters, and seafloor.

- Justoya, city of Lillesand housed Fortress Birchstrasse, one of the major coastal batteries. During the war, mines were placed around the fortress, and once the war ended, they were dug up. Anti-tank mines were dumped into the sea where they have been observed in a $300 \mathrm{X}$ 300 meter area. In 2008, an attempt was made to locate 7-8 mines; however, none were found again, but 14 new mines were discovered. Water samples were taken at Fortress Birchstrasse in October of 2009.

- The German ship DS Selma located in the city of Nesodden unloaded munitions in December of 1943. The ammunition that was left in the ship exploded and caused the ship to sink in January of 1944. The DS Selma now sits $22 \mathrm{~m}$ below the surface. DS Selma had surface 
sediment samples taken surrounding both a $105 \mathrm{~mm}$ shell and an area where gunpowder rods are partially buried beneath the surface.

Water samples were collected in $1 \mathrm{~L}$ plastic containers with a screw cap and transferred to $1 \mathrm{~L}$ glass bottles. Sediment samples were collected in $250 \mathrm{ml}$ glass, screw cap jars using a $40 \mathrm{ml}$ metal bucket or directly by using the glass jar.

\subsubsection{Analytical chemistry}

All samples were analyzed with HPLC and MS quadrupole connected to an ultraviolet light detector for TNT, 2-A-4,6-DNT, 4-A -2,6-DNT, 2,4-DNT, 2,6-DNT, 1,3,5-TNB, 1,3-DNB, RDX, HMX, tetryl, PETN, and NG.

Laboratory reporting limitsLRLs for water and sediment samples are provided in Appendix A of this report. Reporting limitsLRLs for tissue samples were not provided in Rossland et al. (2010).

\subsection{The Oosterschelde (Netherlands)}

\subsubsection{Site overview}

At the end of World War II, the Netherlands harbored approximately 110 metric tons of unused military munitions. Because of the risk of explosion, munitions were dumped at sea including at the Oosterschelde, a 37,000 hectare tidal basin in the province of Zeeland. A storm surge barrier connects it to the North Sea, and it includes estuary surface waters, sand and mud flats, salt marshes, wetlands, and tidal creeks. Dumping in the Oosterschelde continued until 1967, by which time 27 metric tons of munitions were present (van Ham et al. 2007).

In 2001, research on the effects of explosives in the environment and the possible impact on the aquatic system were conducted (van Ham et al. 2007). The Oosterschelde site was investigated using an ROV, which revealed that ammunition was spread over a surface area of approximately $1 \mathrm{~km} 2$. Most of the ammunition was dumped at a depth of $30-50 \mathrm{~m}$ and covered with sediment. After viewing the ROV pictures, it was also concluded that the munitions remain in the locations where they were originally discarded; the munitions were not washed away by the strong sea current that exists in this area. 
In the Oosterschelde dumpsite, the most important ammunition related chemical is TNT. Based on the amount of ammunition present at this site, it is estimated that a total of $3,000,000 \mathrm{~kg}$ of TNT is present (van Ham et al. 2007).

\subsubsection{Sampling efforts and analytical chemistry}

According to van Ham et al (2007), in 1999, water grab samples were collected from the dumping site and analyzed for TNT. Water samples collected again in 2001 were extracted using SPME fibers and analyzed for TNT and its breakdown products. No additional detail on the sampling and analysis methods were provided in van Ham et al. (2007).

\subsection{Beaufort's Dyke (North-East Atlantic)}

\subsubsection{Site overview}

Beaufort's Dyke is a comparatively deep trench located between the Rhins of Galloway and Northern Ireland. The trench is more than $50 \mathrm{~km}$ in length, has a maximum width of approximately $3.5 \mathrm{~km}$, and the deepest areas are in excess of $300 \mathrm{~m}$. At the center of the trench is the Beaufort's Dyke explosives disposal site, which was used for dumping redundant munitions after World Wars I and II. The majority of the explosives disposal site is confined to water depths in excess of $100 \mathrm{~m}$, although it extends into slightly shallower waters on the Scottish side of the trench (Aberdeen Marine Laboratory 1996). According to Carton and Jagusiewicz (2009), an estimated one million metric tons of munitions were discarded in Beaufort's Dyke.

\subsubsection{Sampling efforts and analytical chemistry}

In 1995 and 1996, Aberdeen Marine Laboratory (1996) reported the collection and analysis of sediment, fish (e.g., cod, haddock, hake, flatfish, and whiting), and invertebrate (e.g., prawns and scallops) samples near Beaufort's Dyke disposal site and a reference site in the Moray Firth. MC included in analyses were NG, RDX, tetryl, and TNT. The report did not provide additional details about the sampling and analysis methods used. 


\section{MC Contamination at Underwater Munitions Sites - Water Column}

See appendix A for comprehensive data compilation of MC contamination in the water column at UWMM sites.

\subsection{Sites with MC concentrations below DL in all samples}

\subsubsection{Sea disposal site Hawaii (HI-06) “Ordnance Reef” (HI, USA)}

MC were not detected in any of the seawater samples at concentrations exceeding their corresponding MDL. LRLs ranged from 0.1 to $1.4 \mu \mathrm{g} / \mathrm{L}$ (UH 2014a; provided in Appendix A of this report).

\subsubsection{Sea disposal site Hawaii (HI-05) "HUMMA study"}

Energetics nor their degradation products were detected at concentrations exceeding their corresponding MDL in seawater samples. LRLs ranged from 0.14 to $43 \mu \mathrm{g} / \mathrm{L}$ (UH 2010; provided in Appendix A of this report).

\subsubsection{Halifax Harbor area, Nova Scotia}

No MC were detected in any of the seawater samples at concentrations exceeding the MDL for all MC, $0.001 \mu \mathrm{g} / \mathrm{L}$ (Ampleman et al 2004).

\subsubsection{Swedish lakes and coastal sites}

Neither TNT nor its by- and degradation products were detected. In addition, information concerning DL was not found (Sjostrom et al. 2004).

\subsubsection{Lake Randsfjorden (Norway)}

$\mathrm{MC}$ were not detected in any of the water samples. Information on DL was not found (Rossland et al. 2010).

\subsubsection{The Oosterschelde (Netherlands)}

In 1999, TNT was not detected in sea water samples taken from the dump site. The DL was reported as $1 \mu \mathrm{g} / \mathrm{L}$. When SPME were used to concentrate samples in 2001, TNT was detected at concentrations ranging from 0.005 to $0.5 \mu \mathrm{g} / \mathrm{L}$ (van Ham et al. 2007). 


\subsection{Sites reporting MC contamination in water samples}

\subsubsection{Isla de Vieques Bombing Range site (PR)}

Porter et al. (2011) reported the concentration of MC in water samples were collected at various distances from a 2,00o lb. general purpose (GP) airdropped bomb. For samples taken from within the solution cavity of the bomb, 1,3,5-TNB, 1,3-DNB, TNT, 2,4-DNT + 2,6-DNT, 4-NT, 2-NT, and RDX were detected at concentrations ranging from 4,120 to $85,700 \mu \mathrm{g} / \mathrm{L}$ (Table 3). Concentrations for those MC decrease dramatically when samples were taken adjacent (i.e., $10 \mathrm{~cm}$ ) from the breach, with concentrations ranging from 3.3 to $107 \mu \mathrm{g} / \mathrm{L}$ (Table 3; Figure 9). According to Barton and Porter (2004), samples taken at $1 \mathrm{~m}$ from the bomb contained concentrations of TNT measuring 17.7 and $7.87 \mu \mathrm{g} / \mathrm{L}$. Porter et al. (2011) reported that those same concentrations are associated with samples taken at $1 \mathrm{~cm}$ from the bomb; however, Figure 9 in Porter et al. (2011) shows that they are associated with samples taken $1 \mathrm{~m}$ from the bomb, which corroborates Barton and Porter's (2004) assumption that " $1 \mathrm{~cm}$ " is likely a typo in the text.

Table 3. Concentrations of MC in water samples collected near a 2000-lb bomb in Isla de Vieques Bombing Range site (PR).

\begin{tabular}{|c|c|c|c|c|c|c|c|}
\hline \multirow[b]{2}{*}{$\begin{array}{l}\text { Distance } \\
(\mathrm{m})\end{array}$} & \multicolumn{7}{|c|}{ Concentration ( $\mu \mathrm{g} / \mathrm{L})$} \\
\hline & TNB & DNB & TNT & $\begin{array}{c}2,4+2,6- \\
\text { DNT }\end{array}$ & 4-NT & 2-NT & RDX \\
\hline $\begin{array}{l}0 \\
(n=1)\end{array}$ & 11,255 & 18,500 & 85,700 & 82,500 & ND & 40,500 & 4,120 \\
\hline $\begin{array}{l}0.1 \\
(n=2)\end{array}$ & $\begin{array}{l}8.15 \\
14.9\end{array}$ & $13.6 ; 23.4$ & $66.4 ; 105$ & $58 ; 107$ & ND & $\begin{array}{l}26.4 \\
54.6\end{array}$ & $\begin{array}{l}3.28 \\
4.96\end{array}$ \\
\hline $\begin{array}{l}1 \\
(n=2)\end{array}$ & & & $17.1 ; 7.87$ & & & & \\
\hline
\end{tabular}

ND = not detected. Based on Porter et al. (2011) and Barton and Porter (2004).

A field technology demonstration project reported concentrations of $\mathrm{MC}$ in the water column near UWMM target items (Rosen et al. 2016, 2017). Concentrations were reported for two sampling rounds of grab samples of water collected at approximately $30 \mathrm{~cm}$ away from UWMM and also reported as estimated time-weighted average (TWA) concentrations based on concentrations measured in POCIS placed near (when feasible, approximately $15 \mathrm{~cm}$ away) visible breaches in the UWMM. When breaches were assumed, but not obvious, the samplers were placed at 
locations where corrosion failure was expected to occur, such as near the base of the munition. The MC 3,5-DNB, 2,6-DNT, and 3,5-DNA were below the limit of detection in all samples. Detection frequency for grab samples was $7 \%$ for TNT, 2-A-4,6DNT, 4-A-2,6DNT, 2,4-DNT, 1,3,5-TNB and $10 \%$ for and RDX (Table 4). The MC 2,6-DNT and 1,3,5-TNB were below in the limit of detection for all passive sampler samples. Detection frequency for passive samplers was $7 \%$ for TNT, 4-A-2,6DNT, 2,4-DNT, 3,5 -DNB and 3,5-dinitroaniline, $14 \%$ for $2-\mathrm{A}-4,6 \mathrm{DNT}$, and $79 \%$ for RDX (Table 4, Figure 8). Passive sampler-estimated TWA concentrations were $3.8 \mu \mathrm{g} / \mathrm{L}$ for TNT; 0.01 and 0.26 for $2-\mathrm{A}-4,6 \mathrm{DNT}$; 0.32 for 4-A-2,6DNT; 0.07 for 2,4-DNT, 0.09 for 3,5-DNB, 0.02 for 3,5-DNA, and 0.004 to 0.011 $\mu \mathrm{g} / \mathrm{L}$ for RDX (Table 4, Figure 9). Concentrations measured in grab samples were 4.5 and $7.5 \mu \mathrm{g} / \mathrm{L}$ for TNT, 0.004 and $0.09 \mu \mathrm{g} / \mathrm{L}$ for $2-\mathrm{A}-$ 4,6DNT; 0.02 and 0.07 for $\mu \mathrm{g} / \mathrm{L} 4-\mathrm{A}-2,6 \mathrm{DNT}$; 0.01 and $0.02 \mu \mathrm{g} / \mathrm{L}$ for 2,4DNT; 0.02 and $0.04 \mu \mathrm{g} / \mathrm{L}$ for 1,3,5-TNB; 0.02, 0.03 and $0.05 \mu \mathrm{g} / \mathrm{L}$ for RDX (Table 4, Figure 8).

Table 4. Detection frequency and concentrations of MC in the water column near UWMM as measured by passive samplers and grab samples at grid locations as measured by grab samplers at the Isla de Vieques Bombing Range site (PR). Based on Rosen et al. (2017).

\begin{tabular}{|c|c|c|c|c|c|c|}
\hline \multirow[b]{3}{*}{ MC } & \multicolumn{4}{|c|}{ Samples near UWMM } & \multirow{2}{*}{\multicolumn{2}{|c|}{$\begin{array}{c}\text { Grid samples } \\
\text { Passive sampler }\end{array}$}} \\
\hline & \multicolumn{2}{|c|}{ Passive sampler } & \multicolumn{2}{|c|}{ Grab samples } & & \\
\hline & $\begin{array}{l}\text { Detect. } \\
\text { freq. (\%) }\end{array}$ & Conc. ( $\mu \mathrm{g} / \mathrm{L})$ & $\begin{array}{l}\text { Detect. } \\
\text { freq. (\%) }\end{array}$ & 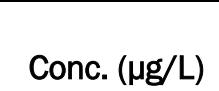 & $\begin{array}{l}\text { Detect. } \\
\text { freq. (\%) }\end{array}$ & Conc. ( $\mu \mathrm{g} / \mathrm{L})$ \\
\hline TNT & 7 & 3.8 & 7 & $4.5 ; 7.5$ & 7 & 0.006 \\
\hline 2-A-4,6-DNT & 14 & $0.01 ; 0.26$ & 7 & $0.004 ; 0.09$ & 0 & NA \\
\hline 4-A-2,6-DNT & 7 & 0.32 & 7 & $0.02 ; 0.07$ & 0 & NA \\
\hline 2,4-DNT & 7 & 0.07 & 7 & $0.01 ; 0.02$ & 0 & NA \\
\hline 2,6-DNT & 0 & NA & 0 & NA & 0 & NA \\
\hline 1,3,5-TNB & 0 & NA & 7 & $0.02 ; 0.04$ & 0 & NA \\
\hline 3,5-DNB & 7 & 0.09 & 0 & NA & 0 & NA \\
\hline 3,5-DNA & 7 & 0.02 & 0 & NA & 0 & NA \\
\hline RDX & 79 & $\begin{array}{l}0.004 \text { to } \\
0.011\end{array}$ & 10 & $\begin{array}{l}0.02 ; 0.03 ; \\
0.05\end{array}$ & 40 & $\begin{array}{l}0.004 \text { to } \\
0.011\end{array}$ \\
\hline
\end{tabular}


Figure 8. Fraction (as percent) of water samples collected at Bahia Salina del Sur (Vieques, PR) at approximately 10-15 cm away from UWMM target items for which MC concentrations were reported as quantified values. Based on Rosen et al. 2017.

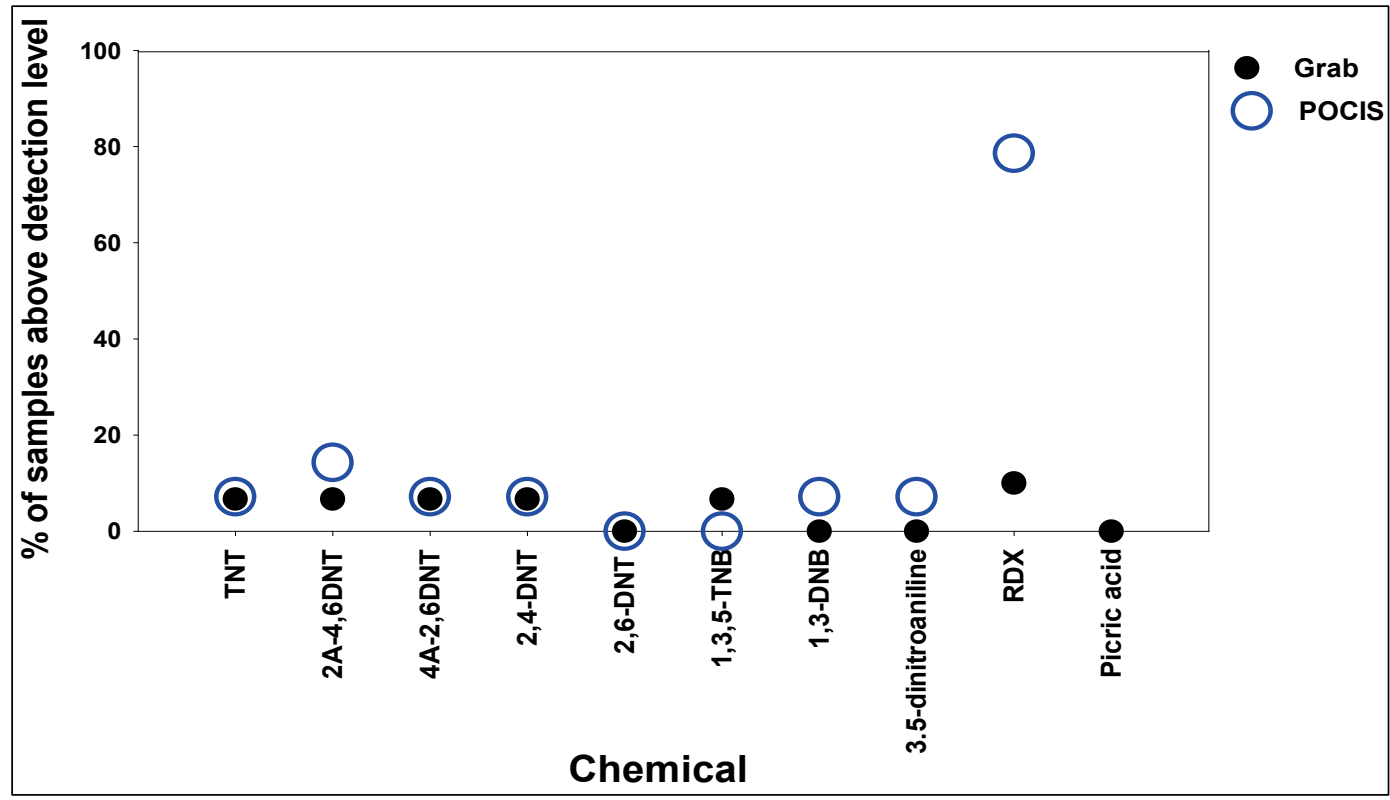

Figure 9. MC concentrations for water samples collected at Bahia Salina del Sur (Vieques, PR) in proximity to UWMM target items. Based on Porter et al. (2011) and Rosen et al. (2017).

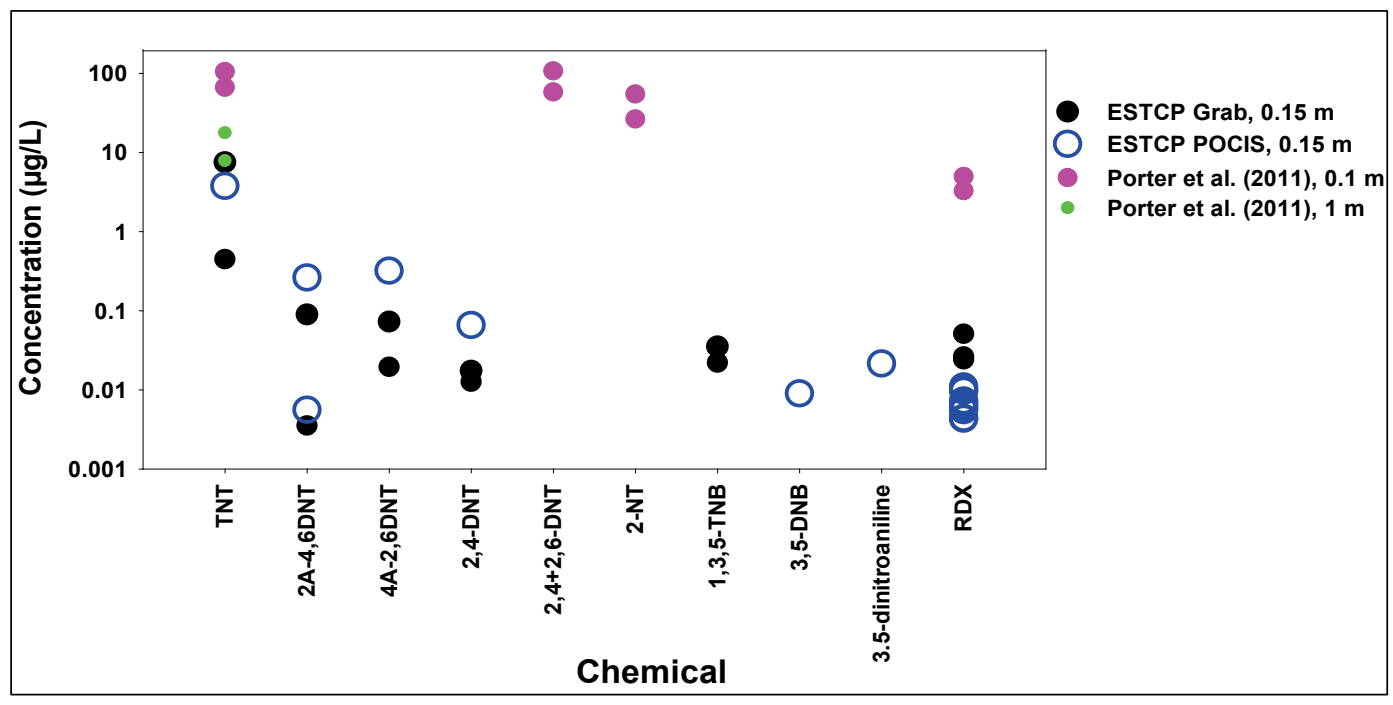

Rosen et al. $(2016,2017)$ reported concentrations of $\mathrm{MC}$ in the water column from 15 passive samplers placed in a grid pattern approximately equidistant from each other, and representing the majority of the sites. Only TNT and RDX were detected, and the frequency of detection was of 7 and 40\%, respectively. TNT was detected in one location at $0.006 \mu \mathrm{g} / \mathrm{L}$, and $\mathrm{RDX}$ in 6 locations at concentrations ranging from 0.004 to 0.011 $\mu \mathrm{g} / \mathrm{L}$ (Table 4, Figure 10). 
Figure 10. MC concentrations for water samples collected at Bahia Salina del Sur (Vieques,

PR) in a grid-pattern representing the majority of the site. Based on Rosen et al. (2017).

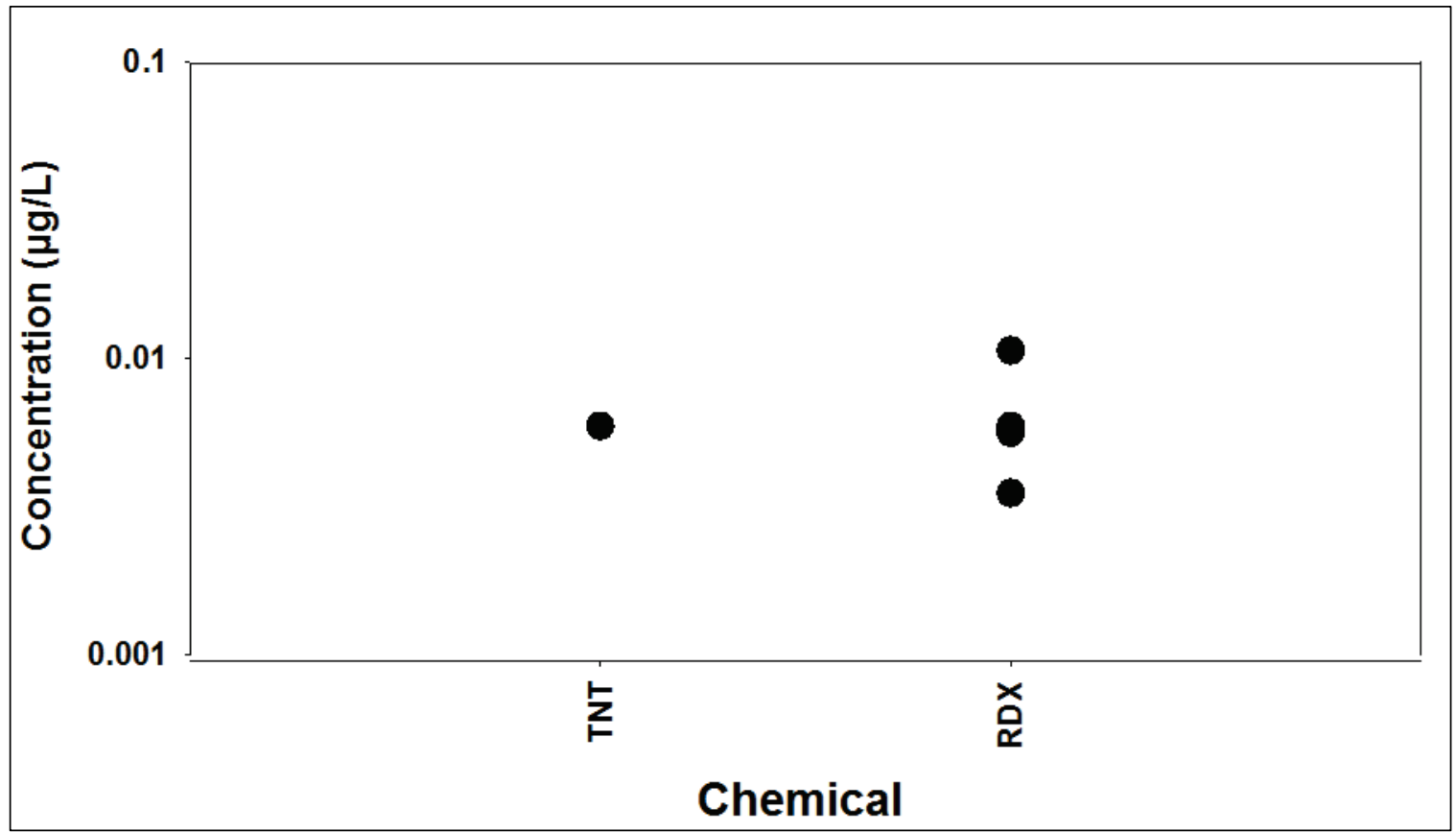

\subsubsection{Halifax Harbor (Halifax, Canada)}

In water samples from 0.3 to $3 \mathrm{~m}$ down-current from UWMM and surface water above the UWMM present at Bedford Basin (Rent Point and Claire Lily sites), TNT, 2-A-4,6DNT, 4-A-2,6DNT, 2,4-DNT, 2,6- DNT, 1,3,5TNB, and 1,3-DNB were detected (Rodacy et al. 2001). The detection frequency ranged from 7 to 50\% (Table 5 and Figure 11). Maximum concentrations were 14.2, 108, 123, 3.1, 2.0, 1.2, and $5.9 \mu \mathrm{g} / \mathrm{L}$ for TNT, 2A-4,6DNT, 4-A-2,6DNT, 2,4- and 2,6- DNT, 1,3,5-TNB, and 1,3-DNB, respectively (Table 5, Figure 12). For 10 of the UWMM investigated, concentrations were $\leq 6 \mu \mathrm{g} / \mathrm{L}$ for all MC. Higher concentrations (14.2, 108, and $123 \mu \mathrm{g} / \mathrm{L}$ for TNT, 2-A-4,6DNT and 4-A-2,6DNT, respectively) were reported for one UWMM. Rodacy et al. (2001) speculated that the variability of detections as a function of distance from the target is likely due to the filamentous nature of the plumes emanating from the target. 
Table 5. Detection frequency and range of measured concentrations of $\mathrm{MC}$ in the water collected at Halifax Harbor (Halifax, Canada). Based on Rodacy et al. (2001).

\begin{tabular}{|c|c|c|}
\hline MC & Detect. freq. (\%) & Range of conc. $(\mu \mathrm{g} / \mathrm{L})$ \\
\hline TNT & 25 & $0.01-14.2$ \\
\hline 2-A-4,6-DNT & 38 & $0.04-108$ \\
\hline 4-A-2,6-DNT & 46 & $0.03-123$ \\
\hline $2,4-D N T$ & 50 & $0.02-3.14$ \\
\hline $2,6-D N T$ & 8 & $1.7-2.0$ \\
\hline 1,3,5-TNB & 9 & $0.10-1.24$ \\
\hline 1,3-DNB & 7 & $1.02-5.9$ \\
\hline
\end{tabular}

Figure 11. Fraction (as percent) of water samples collected at Halifax Harbor (Halifax, Canada) for which MC concentrations were reported as quantified values. Based on Rodacy et al. (2001).

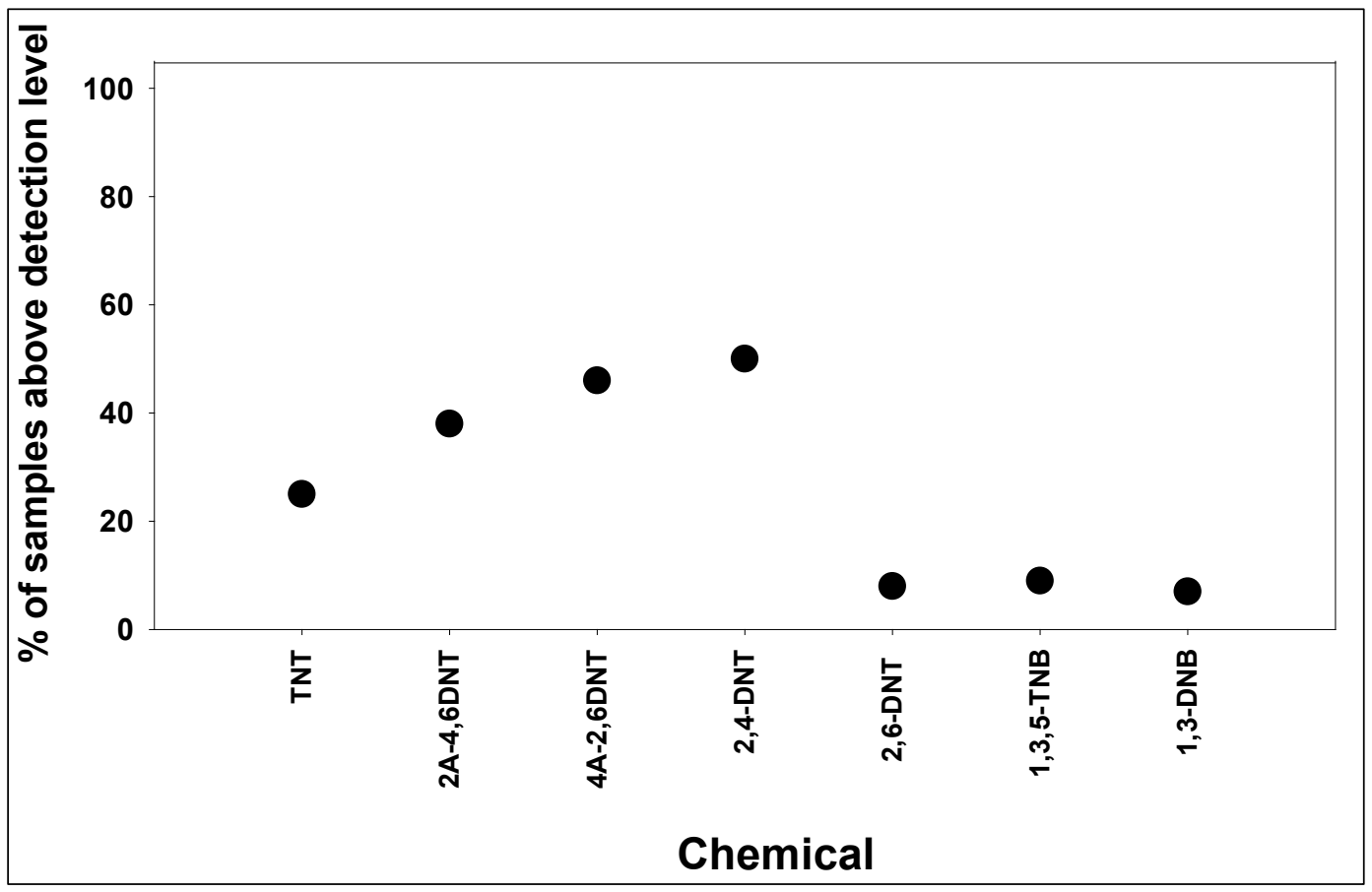


Figure 12. MC concentrations for water samples collected at Halifax Harbor (Halifax, Canada). Based on Rodacy et al. (2001).

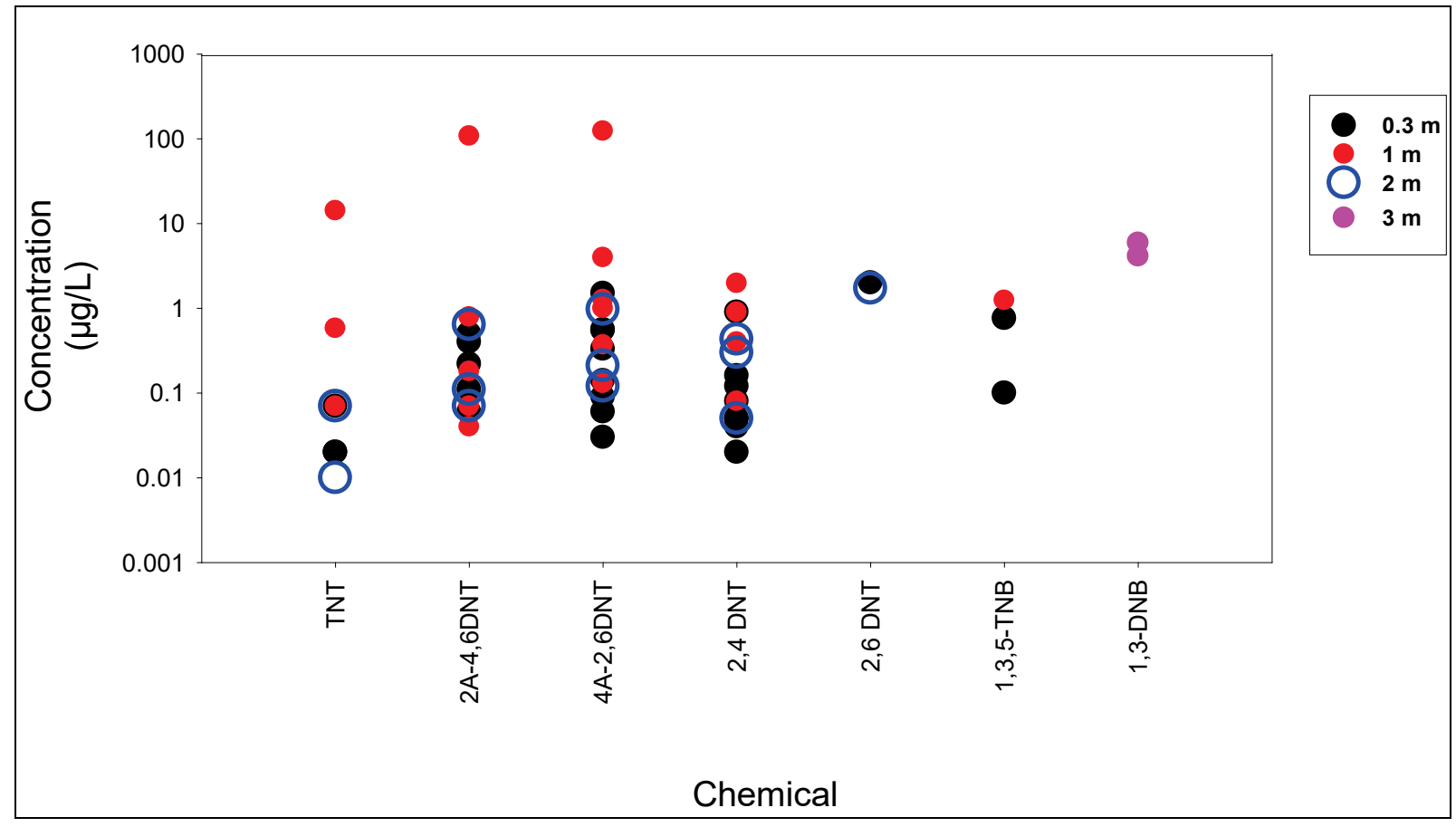

\subsection{Point Amour (Labrador, Canada)}

The concentration of TNT in water samples collected near the wreck of the HMS Raleigh were $0.002 \mu \mathrm{g} / \mathrm{L}$ or lower. All other MC investigated were $<0.001 \mu \mathrm{g} / \mathrm{L}$ (Ampleman et al. 2004).

\subsection{Lakes Thun and Brienz (Switzerland)}

The use of liquid chromatography-electrospray tandem mass spectrometry for this study allowed for the attainment of extremely low reporting limits, between 0.00003 and $0.005 \mu \mathrm{g} / \mathrm{L}$. The MC HMX, RDX, and PETN were detected in all samples from lakes Thun and Brienz at $0.0004 \mu \mathrm{g} / \mathrm{L}$ or lower concentrations. Concentration profiles obtained during a 12-month period showed a homogeneous distribution of the explosives.

Consequently, UMMM at the bottom of the lakes does not seem to be responsible for the contamination of the water column at the lakes. HMX, RDX, and PETN were detected in lake tributaries at concentrations as high as $0.0009 \mu \mathrm{g} / \mathrm{L}$, which showed that tributaries seem to play an important role as external sources for the explosives found in the lakes (Ochsenbein et al. 2008). 


\subsubsection{Lake Mjøsa (Norway)}

A 2001 survey did not find detectable concentrations of MC in the water at Mjøsa (Norway) (Rossland et al. 2010). Sampling of water from Mjøsa's deepest point "station Skreia" in 2003 resulted in the detection of TNT at $0.17 \mu \mathrm{g} / \mathrm{L}$ and 1,3-DNB at $0.18 \mu \mathrm{g} / \mathrm{L}$. Rossland et al. (2010) reported traces of 2,6-DNT (actual concentration not reported) in water taken immediately adjacent to an underwater grenade during their 2009 survey.

\subsubsection{Coastal fortifications in Norway}

MC were not detected in any of the seawater samples collected at the Solstrand site (Rossland et al. 2010). The single water sample collected near the German anchored mine at the Tælavåg site after transport to a safe location and before detonation, contained detectable concentrations of RDX (12.7 $\mu \mathrm{g} / \mathrm{L})$ and HMX (0.62 $\mu \mathrm{g} / \mathrm{L})$. Those explosives were not found in the three samples taken after detonation of the mine, but TNT was detected in all samples at $0.2,0.14$ and $0.1 \mu \mathrm{g} / \mathrm{L}$ while $2-\mathrm{A}-4,6 \mathrm{DNT}$ and 4-A-26DNT were found in one sample at 0.1 and $0.32 \mu \mathrm{g} / \mathrm{L}$. The authors speculate that aminated products of TNT could have been formed during room-temperature storage of the water sample.

TNT was the only MC detected (0.03 $\mu \mathrm{g} / \mathrm{L})$ in the single water sampled at the Justøya site. 


\section{MC Contamination at Underwater Munitions Sites - Sediment}

See appendix A for comprehensive data compilation of MC contamination in sediment at UWMM sites.

\subsection{Sites with MC concentrations below DL in all samples or with minimal available information}

\subsubsection{Halifax Harbor area, Nova Scotia}

MC were not detected in any of the sediment samples at concentrations exceeding their DL (0.1 mg/kg) Ampleman et al. (2004).

\subsubsection{Swedish lakes and coastal sites}

TNT nor its degradation products were detected in any of the sediment samples at concentrations exceeding their corresponding MDL. Information on DL was not found (Sjostrom et al. 2004).

\subsubsection{Beaufort's Dyke (North-East Atlantic)}

TNT, RDX, tetryl nor NG were detected in any of the sediment samples at concentrations exceeding their DL. Information on DL was not found (Aberdeen Marine Laboratory 1996).

\subsubsection{Lake of Mjøsa and Lake Randsfjorden (Norway)}

Picric acid was present above the detection level in the pore water of the sediments in 2004, while in 2007 there was no picric acid was detected in the pore water. This indicates that small amounts of explosives in the sediments resulted in concentrations above the DL in sporadic cases. Information on sampling effort, frequency of detection, and DL was not found (Rossland et al. 2010).

\subsection{Sites reporting MC contamination in sediment samples}

\subsubsection{Jackson Park housing complex (WA)}

For surface sediment collected from Ostrich Bay, RDX, and 2-A-4,6-DNT were the only compounds detected (Figure 13 and Figure 14), although with 
low confidence (Blakley 2005). RDX concentrations (0.27-0.38 mg/kg) were below the MDL ( $1.8-2 \mathrm{mg} / \mathrm{kg}$ ) at every station where the compound was found; and the identifications were flagged "JN" and described as tentative. These stations included the Carr Inlet reference station, which reinforced the low confidence in RDX detections. Although Table 5 of Blakley (2005) shows the concentration of 2-A-4,6-DNT (0.2 mg/kg) flagged as "JN", the text states that only RDX was detected below the MDL.

A variety of $\mathrm{MC}$ were detected in surface and subsurface samples from Ostrich Bay OU 2 and a reference site (NAVFAC NW 2010b) (Figure 14); however, the only MC detected with a frequency higher than $20 \%$ were 2,4-DNP, NC, and NQ (Figure 13). For the subsurface samples, only a small fraction of samples ( $9 \%$ or less) had detectable concentrations of TNT, 2-A-4,6-DNT, 4-A-2,6-DNT, 3,5-dinitroaniline, HMX, RDX, 2,4DNP, NC, NG, and PETN. Concentrations were below $0.005 \mathrm{mg} / \mathrm{kg}$ for all MC detected except NC (1.6-31 mg/kg) and NG $(6.6 \mathrm{mg} / \mathrm{kg})$. Ostrich Bay OU 2 surface sediments had detectable concentrations 2,4-DNP, NC, NG, picric acid, and picramic acid. Concentrations were below $0.005 \mathrm{mg} / \mathrm{kg}$ for all MC detected except NC (1.6-14 mg/kg) and NG (0.14-0.65 mg/kg). For the study reference site, only picramic acid $(0.00045-0.013 \mathrm{mg} / \mathrm{kg}), \mathrm{NC}$ $(3.2,3.7 \mathrm{mg} / \mathrm{kg})$, and NG $(0.15,0.16 \mathrm{mg} / \mathrm{kg})$ were detected in surface sediment (Figure 14), but non-detects were reported for subsurface sediments.

Figure 13. Fraction (as percent) of sediment samples collected at Jackson Park Housing Complex (WA, USA) for which MC concentrations were reported as quantified values. Based on Blakley (2005) and NAVFAC NW (2010a, 2010b).

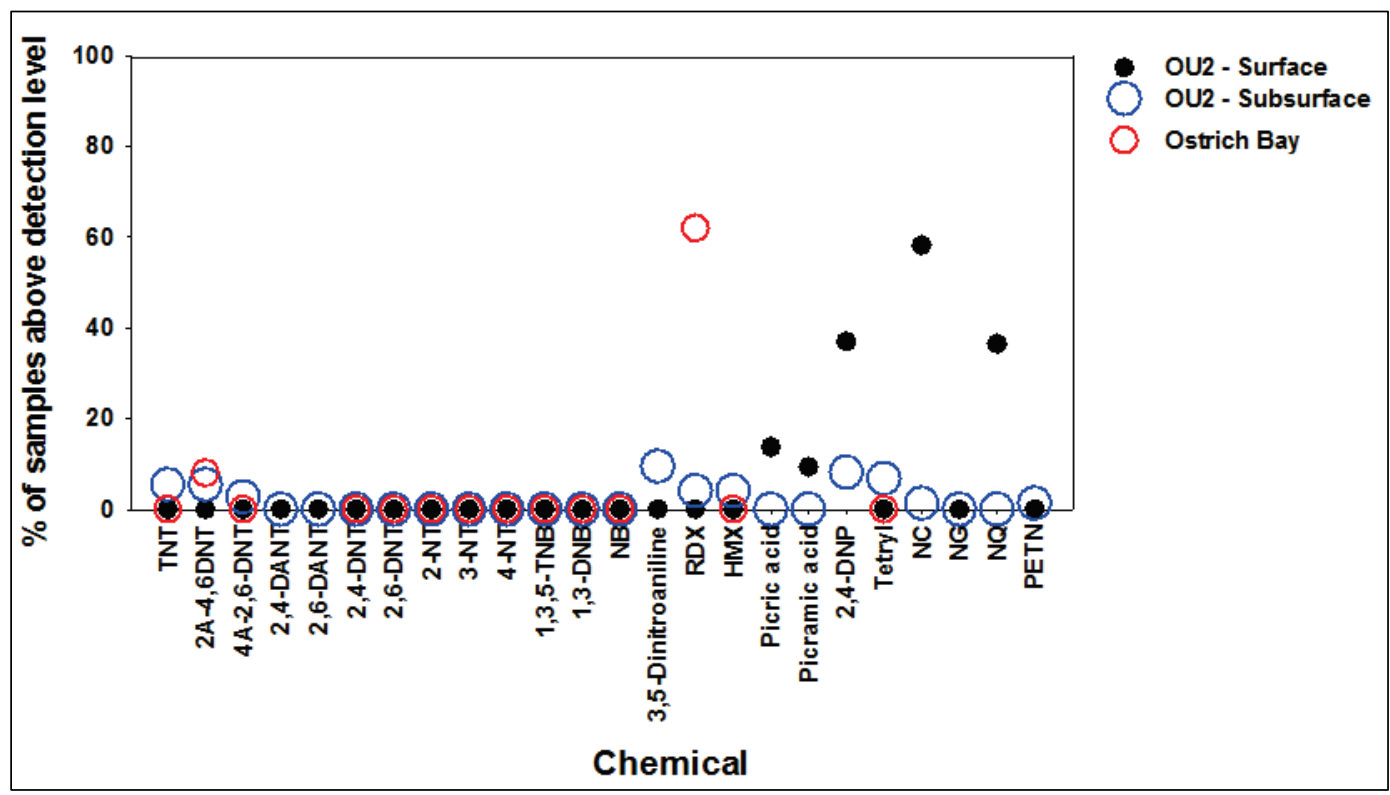


Figure 14. $M C$ concentrations for sediment samples collected at Jackson Park Housing Complex (WA, USA). Based on Blakley (2005) and NAVFAC NW (2010a, 2010b).

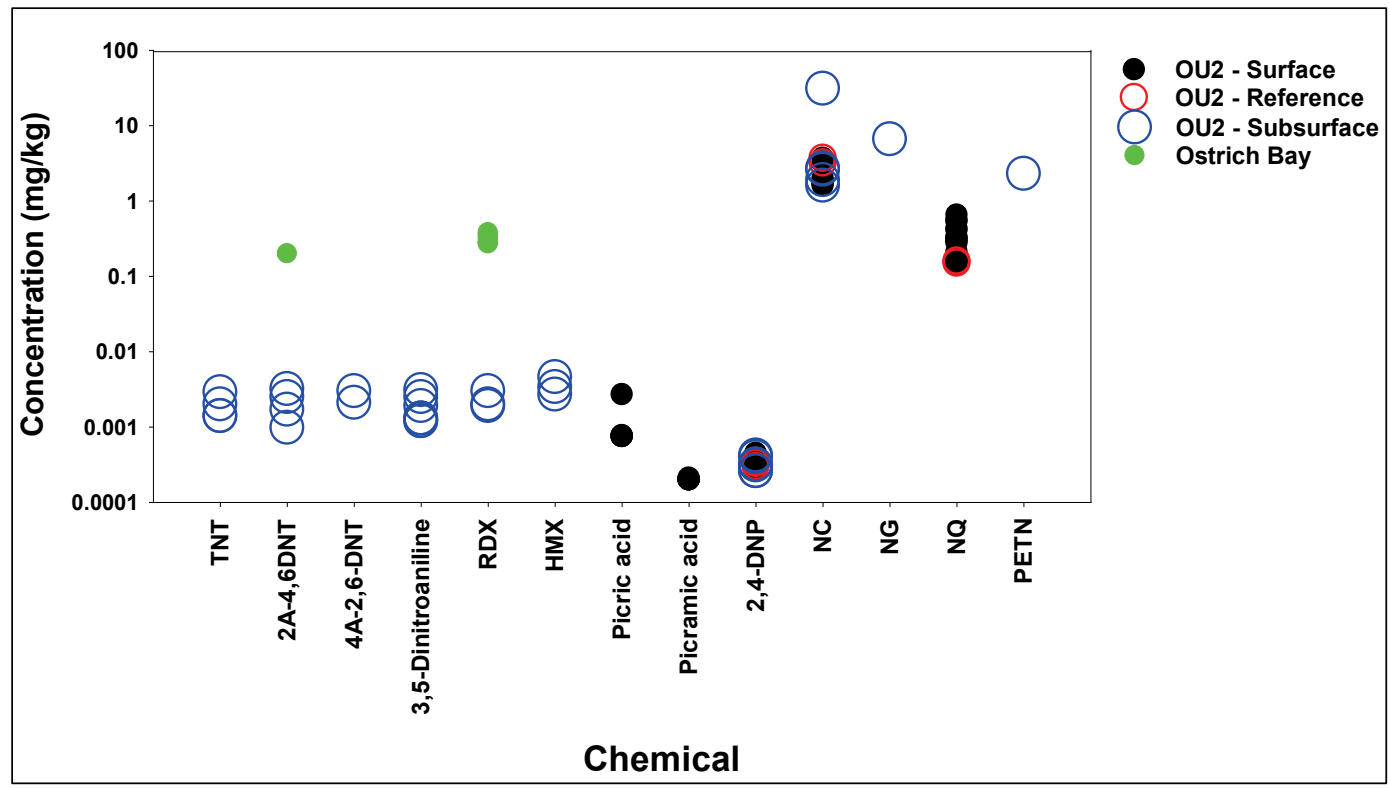

\subsubsection{Sea disposal site Hawaii (HI-06) "Ordnance Reef"}

For surface sediment collected from the DMM stratum at HI-06 during 2009, 2,4-DNT, 2,6-DNT, and 1,3,5-TNB were the only compounds detected (Figure 15 and Figure 16). Detection was reported for samples collected adjacent or at $1.2 \mathrm{~m}$ from DMM. The detection frequency was 61, 11, 5\% for 2,4-DNT, 2,6-DNT, and 1,3,5-TNB, respectively. Concentrations were $0.03-3.3 \mathrm{mg} / \mathrm{kg}$ for 2,4-DNT, 0.098 and $0.380 \mathrm{mg} / \mathrm{kg}$ for 2,6-DNT and 0.022-0.025 mg/kg for 1,3,5-TNB. The MC 2,4-DNT, and 1,3,5-TNB were also detected outside the DMM stratum at 0.030 and $0.048 \mathrm{mg} / \mathrm{kg}$ and 0.021-0.047 mg/kg, respectively. All other MC were below their DL (0.25 mg/kg or lower) (UH 2014a).

For surface sediment collected from the DMM stratum at HI-06 collected for the FUI (UH 2014b), mostly from locations where DMM were removed during DMM removal technology demonstration (Carton et al. 2012), 2,4DNT, 2,6-DNT, 2-NT, 4-NT, RDX and NG were the only compounds detected (Figure 15 and Figure 16). The detection frequency was 55, 21, 4, 2, 2, and $2 \%$ for 2,4-DNT, 2,6-DNT, 2-NT, 4-NT, RDX and NG, respectively. Concentrations were $0.03-110 \mathrm{mg} / \mathrm{kg}$ for 2,4-DNT; 0.07-10 for 2,6-DNT; 0.08, $1.1 \mathrm{mg} / \mathrm{kg}$ for 2-NT; 0.49 for 4-NT; $0.14 \mathrm{mg} / \mathrm{kg}$ for RDX; and 0.56, 1.7 for NG. The MC 2,4-DNT was also detected outside the DMM stratum at 0.03 and $0.06 \mathrm{mg} / \mathrm{kg}$. All other MC were below their DL (2.5 $\mathrm{mg} / \mathrm{kg}$ or lower). 
Figure 15. Fraction (as percent) of sediment samples collected at Sea Disposal Site Hawaii (HI-06) "Ordnance Reef" (HI, USA) for which MC concentrations were reported as quantified values. Based on UH (2014a, 2014b).

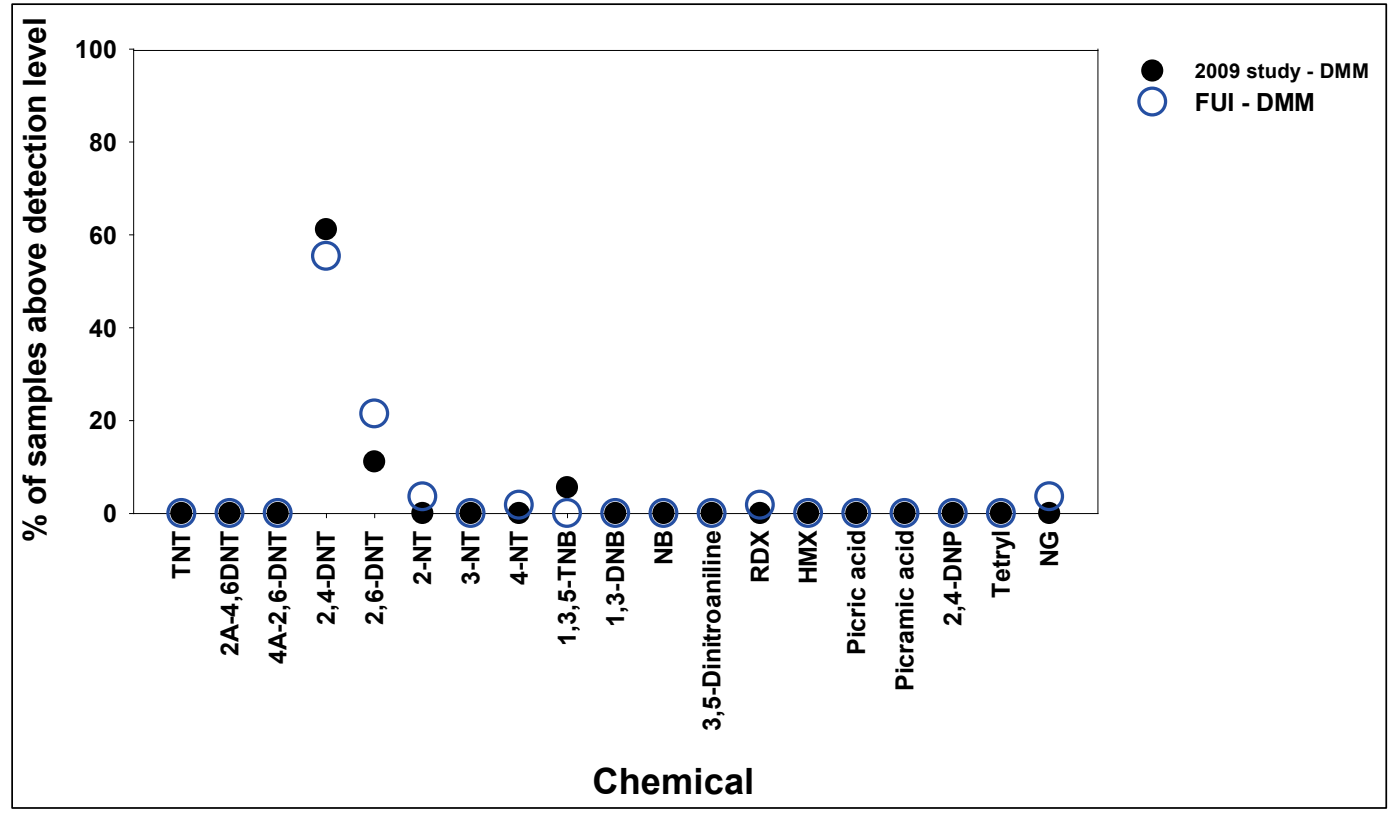

Figure 16. $\mathrm{MC}$ concentrations for sediment samples collected at Sea Disposal Site Hawaii (HI-06) “Ordnance Reef” (HI, USA). Based on UH (2014a, 2014b).

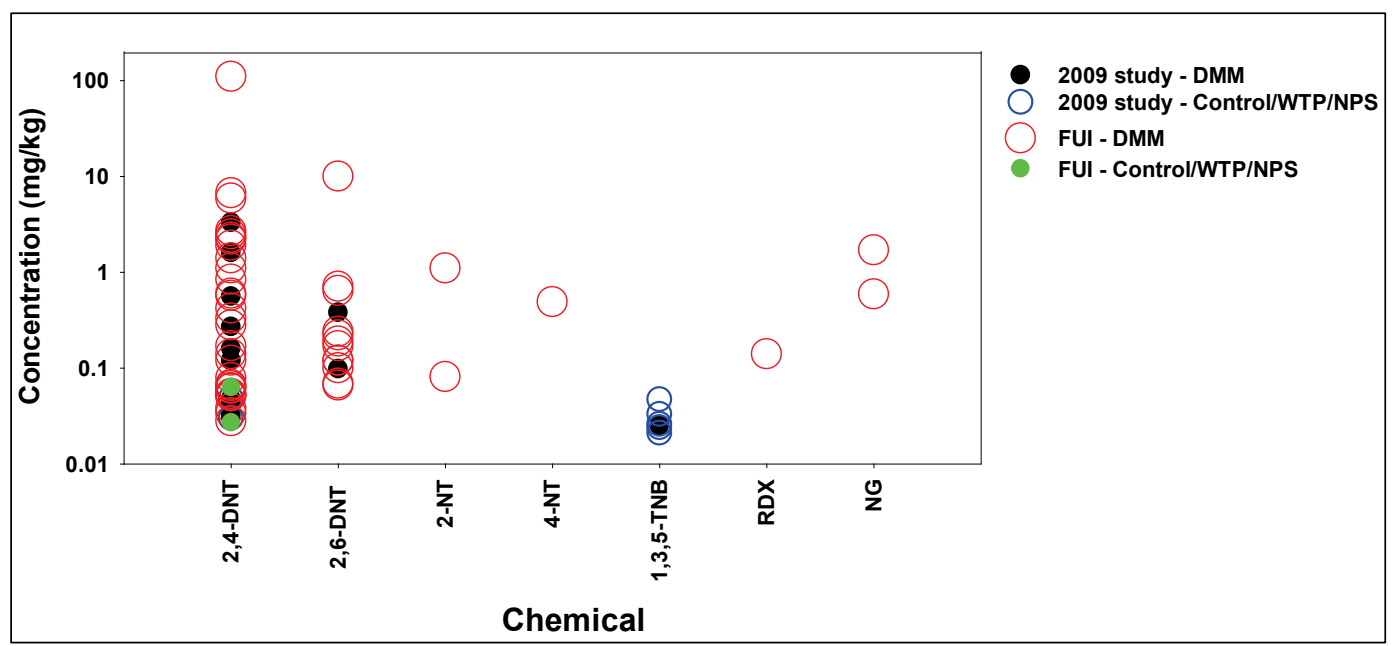

\subsubsection{Sea disposal site Hawaii (HI-05)}

Energetic compounds were not detected in any of the sediment samples collected during the 2009 HUMMA sampling event. The DL was 0.1 $\mathrm{mg} / \mathrm{kg}$ or lower. Samples were collected 1-2 $\mathrm{m}$ away from the munitions casing (UH 2010; Briggs et al. 2016). 
Samples collected during the 2012 HUMMA sampling event resulted in detection of a single energetic MC (4-NT) in only 2 of the 121 samples analyzed (Figure 17), both of which were from a single site (site DMMsb1) and were collected within $0.5 \mathrm{~m}$ of the munitions casing. The measured concentrations of 4-NT were 0.09 and $0.12 \mathrm{mg} / \mathrm{kg}$. The DL for MC ranged from 0.078 to $0.080 \mathrm{mg} / \mathrm{kg}$ (UH 2010; Briggs et al. 2016).

Figure 17. Fraction (as percent) of sediment samples collected at Sea Disposal Site Hawaii (HI-05) for which MC concentrations were reported as quantified values.

\section{Based on UH (2010).}

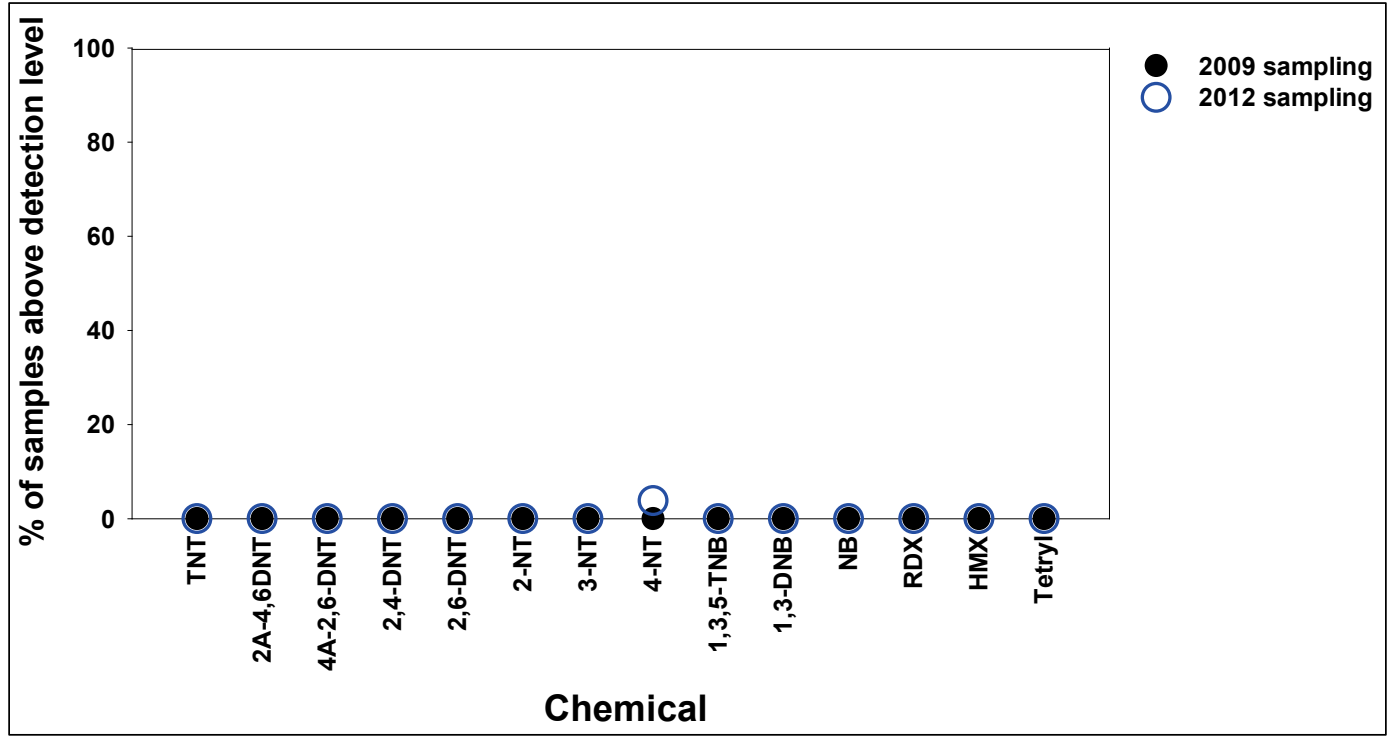

\subsubsection{Former Seattle Naval Supply Piers 90 and 91 - Port of Seattle} (WA)

For surface sediment collected from Seattle Harbor Piers 90 and 91, 2,4DNT, 2,6-DNT, RDX, picric acid, and tetryl were the only compounds detected (Figure 18). The detection frequency was $25,8,17,8$, and $8 \%$ for 2,4-DNT, 2,6-DNT, RDX, picric acid, and tetryl, respectively. Concentrations were $0.2-0.97 \mathrm{mg} / \mathrm{kg}$ for 2,4-DNT; $0.12 \mathrm{mg} / \mathrm{kg}$ for 2,6DNT; $0.58,0.59 \mathrm{mg} / \mathrm{kg}$ for RDX; $0.003 \mathrm{mg} / \mathrm{kg}$ for picric acid; and $0.23 \mathrm{mg} / \mathrm{kg}$ for tetryl. All other MC were below the MDL of $0.4 \mathrm{mg} / \mathrm{kg}$ or lower (USACE 2013). 
Figure 18. Fraction (as percent) of sediment samples collected at Seattle Harbor Piers 90 and 91 (WA) for which MC concentrations were reported as quantified values. Based on USACE (2013).

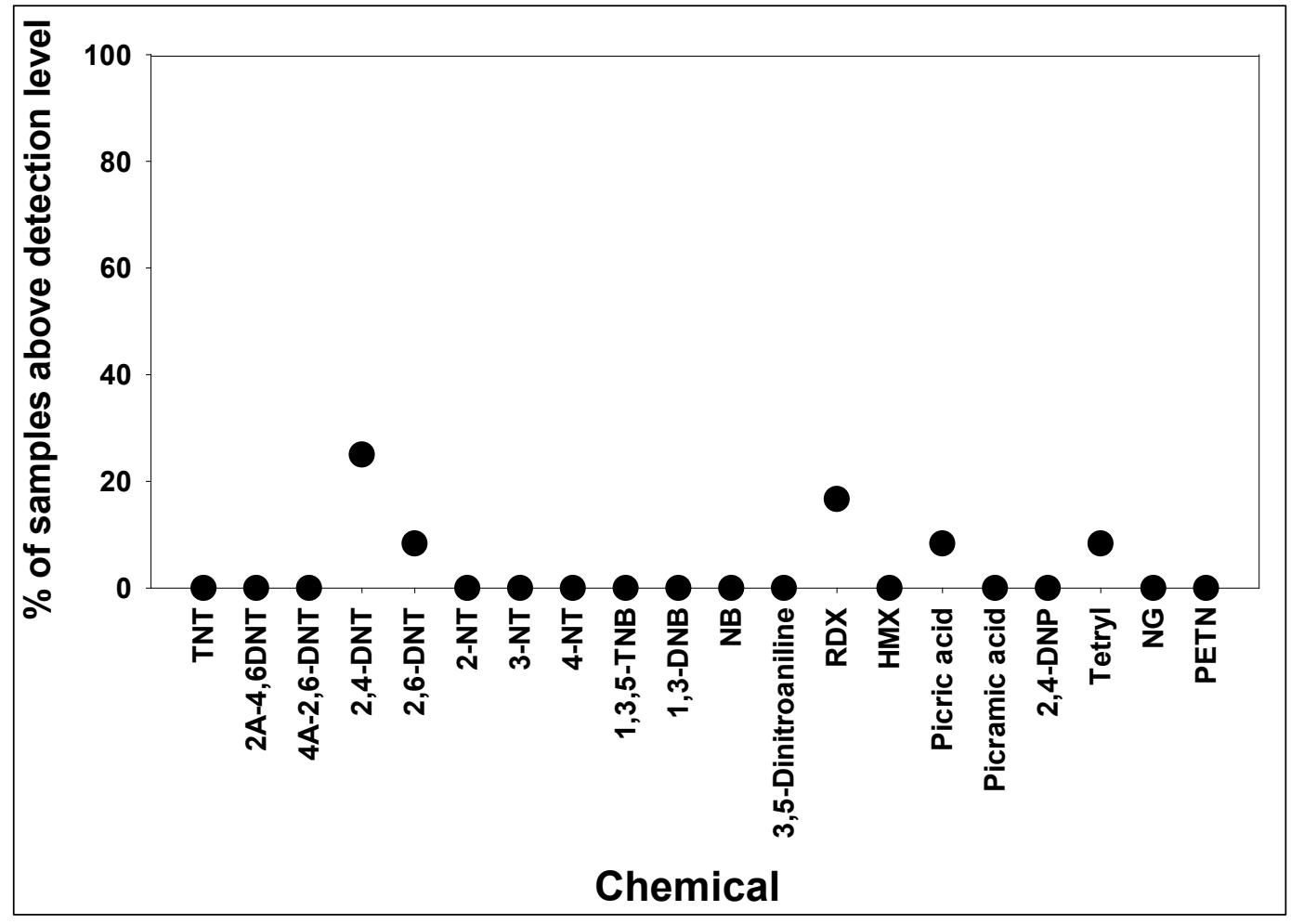

\subsubsection{Isla de Vieques Bombing Range (PR)}

MC contamination was not reported for sediment samples collected in 2007 from the nearshore waters surrounding Isla de Vieques, including Bahia Salinas del Sur (Pait et al. 2010).

Barton and Porter (2004) and Porter et al. (2011) reported the concentration of $\mathrm{MC}$ in sediment samples were collected at various distances from a 2,000 lb. GP air-dropped bomb. For samples taken adjacent to the bomb, TNT, 1,3,5-TNB, 1,3-DNB, 2,4-DNT + 2,6-DNT, 4and 2-NT, and RDX were detected at concentrations ranging from 5.39 to $19,333 \mathrm{mg} / \mathrm{kg}$ (Table 6 ). Concentrations of TNT decreased exponentially when samples were taken at increasing distances from the bomb, down to below the limit of detection (value not provided) at $1 \mathrm{~m}$ (Table 6) (Barton and Porter 2004). 
Table 6. Concentrations of MC in sediment samples collected near a $2000 \mathrm{lb}$. GP bomb in Isla de Vieques Bombing Range site (PR).

\begin{tabular}{|c|c|c|c|c|c|c|c|}
\hline & \multicolumn{7}{|c|}{ Concentration (mg/kg) } \\
\cline { 2 - 9 } Distance $(\mathrm{m})$ & 1,3,5-TNB & 1,3-DNB & TNT & $\begin{array}{c}2,4+ \\
\text { 2,6-DNT }\end{array}$ & 4-NT & 2-NT & RDX \\
\hline $\begin{array}{c}0 \\
(n=1)\end{array}$ & 30.7 & 3.47 & 19,333 & 26 & 5.39 & ND & 5.32 \\
\hline 0.01 & NR & NR & 506 & NR & NR & NR & NR \\
\hline 0.1 & NR & NR & 404 & NR & NR & NR & NR \\
\hline 1.0 & NR & NR & ND & NR & NR & NR & NR \\
\hline 2.0 & NR & NR & ND & NR & NR & NR & NR \\
\hline
\end{tabular}

ND = not detected; NR = not reported. Based on Barton and Porter (2004).

\subsubsection{Halifax Harbor (Nova Scotia, Canada)}

For surface sediment collected from up to $3 \mathrm{~m}$ down-current from UWMM present at Bedford Basin, TNT, 2-A-4,6DNT, 4-A-2,6DNT, 2,4- and 2,6DNT, 1,3,5-TNB, and 1,3-DNB were detected. The detection frequency was $100,30,39,48,35,96$, and $22 \%$ for TNT, 2-A-4,6DNT, 4-A-2,6DNT, 2,4and 2,6- DNT, 1,3,5-TNB, and 1,3-DNB, respectively (Figure 19) (Rodacy et al. 2001). Minimum concentrations were $0.003 \mathrm{mg} / \mathrm{kg}$ or lower and maximum concentrations were $0.17,0.09,0.55,0.56,0.85,0.09$, and $0.09 \mathrm{mg} / \mathrm{kg}$ for TNT, 2-A-4,6DNT, 4-A-2,6DNT, 2,4- and 2,6- DNT, 1,3,5$\mathrm{TNB}$, and 1,3-DNB, respectively (Figure 20). 
Figure 19. Fraction (as percent) of sediment samples collected at Halifax Harbor (Halifax, Canada) for which MC concentrations were reported as quantified values. Based on Rodacy et al. (2001).

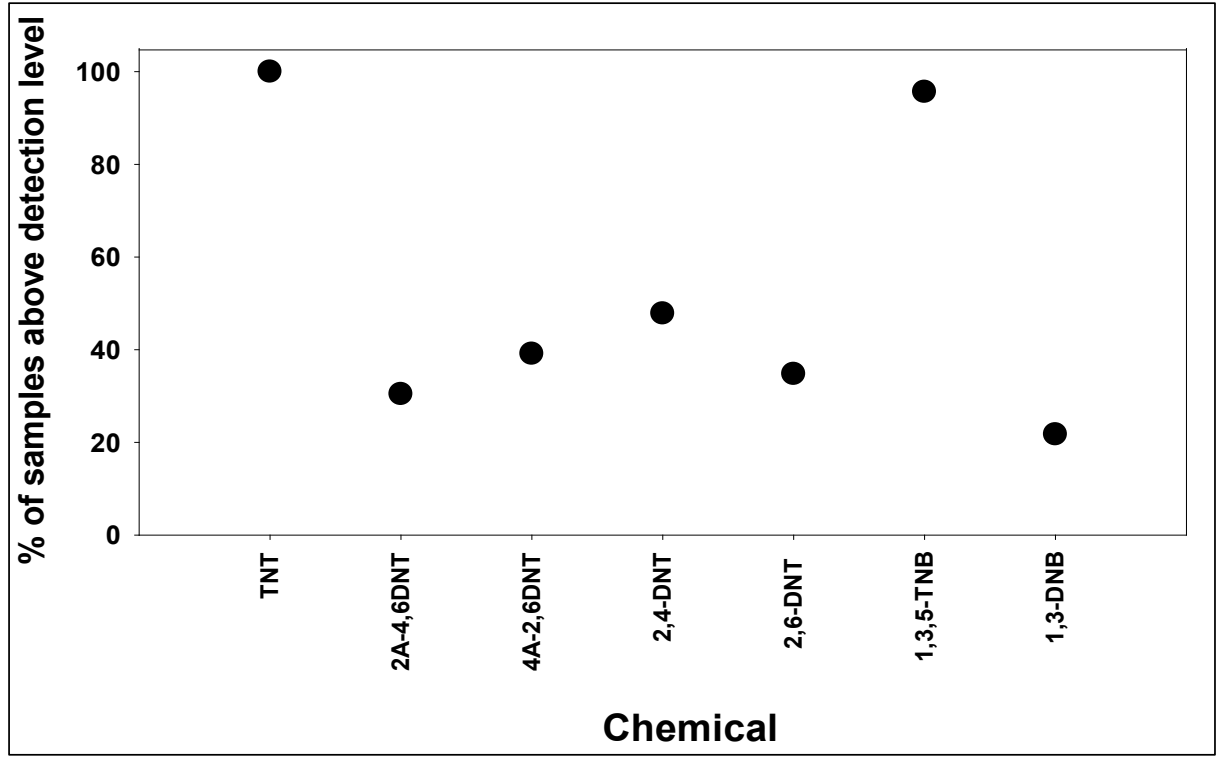

Figure 20. MC concentrations for sediment samples collected at Halifax Harbor (Halifax, Canada). Based on Rodacy et al. (2001).

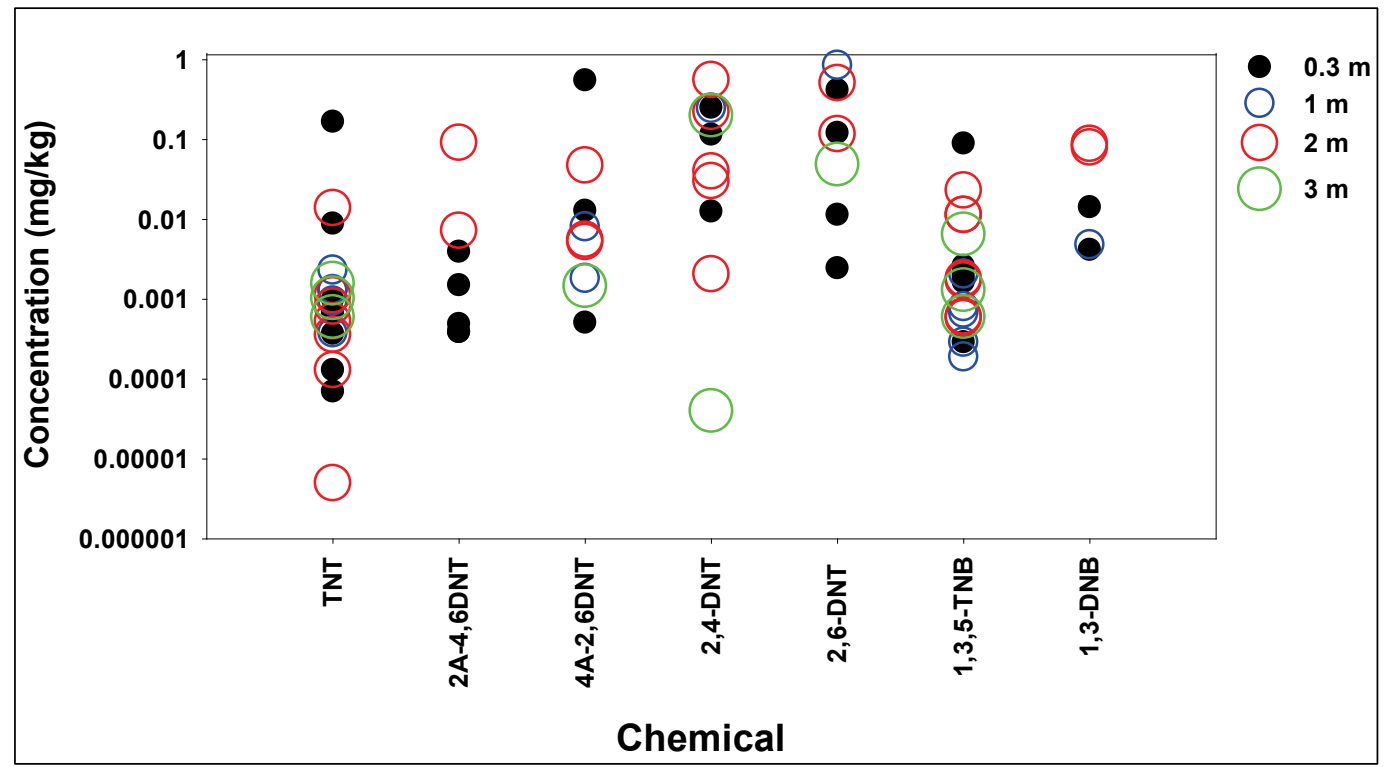

\subsubsection{Point Amour (Labrador, Canada)}

For sediment samples collected near the wreck of the HMS Raleigh, only HMX was detected (Figure 21). HMX was detected at trace levels $(<0.15 \mathrm{mg} / \mathrm{kg})$ at the ship site, and after detonation, at the detonation site, and at the control site (18\% detection frequency). All other MC were below the DL of $0.1 \mathrm{mg} / \mathrm{kg}$ (Ampleman 2004). 
Figure 21. Fraction (as percent) of sediment samples collected at Point Amour (Labrador, Canada) for which MC concentrations were reported as quantified values. Based on Ampleman et al. (2004).

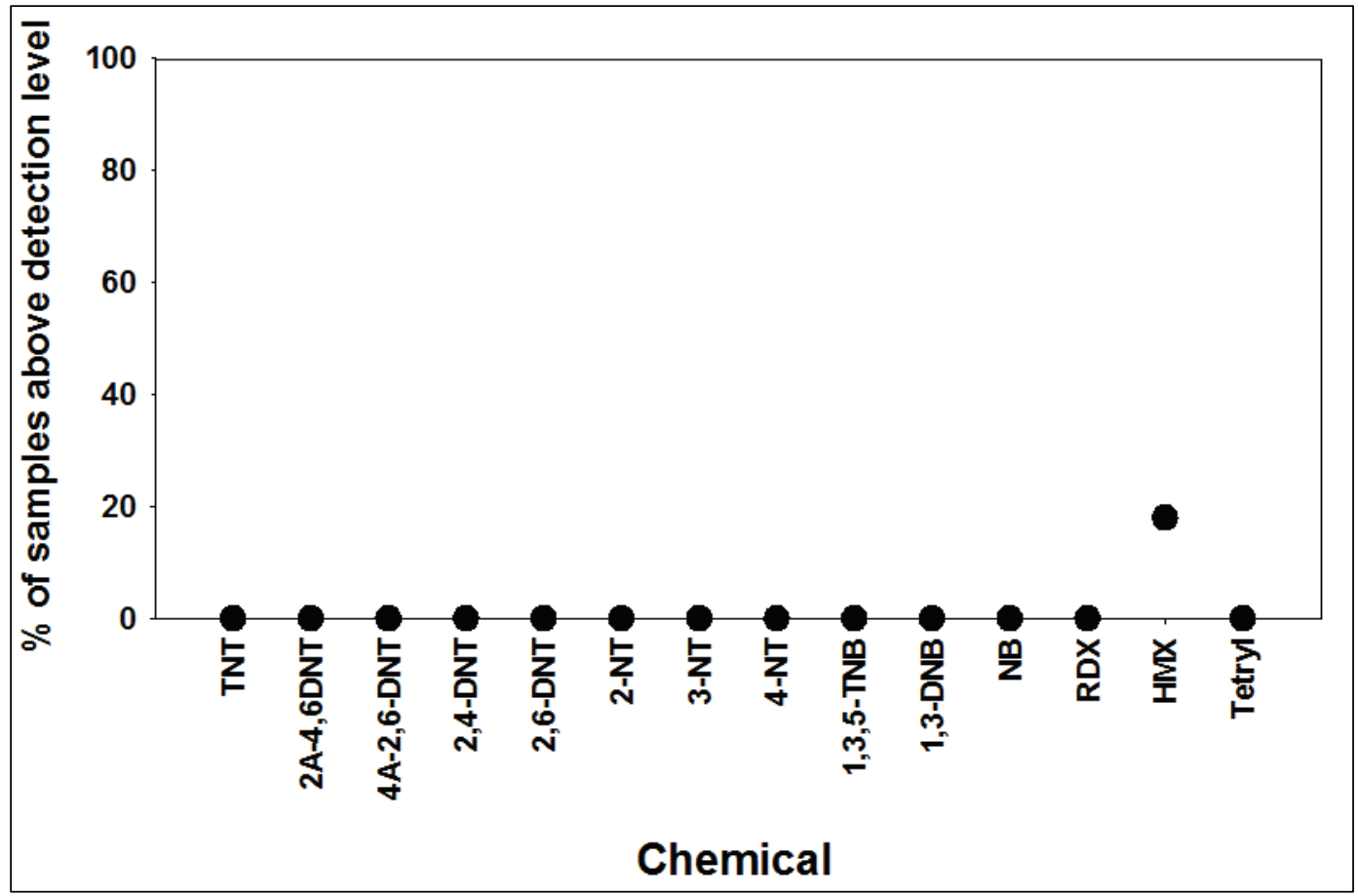

\subsubsection{Coastal fortifications in Norway}

For surface sediment collected from coastal fortifications in Norway, only TNT, RDX, and HMX were detected in quantifiable concentrations (Figure 22 and Figure 23) (Rossland et al. 2010).

For the Solstrand site, one of the four sediment samples collected at sea contained TNT $(0.07 \mathrm{mg} / \mathrm{kg})$. The other three contained no detectable TNT, but contained traces of the 2-A-4,6DNT and 4-A-2,6DNT. For the three sediment samples collected under the pier, three samples contained TNT (0.05, 0.07, and $0.08 \mathrm{mg} / \mathrm{kg}$ ), and one sample contained HMX $(0.06 \mathrm{mg} / \mathrm{kg})$. All other MC were below their DL.

The single sediment sample taken near the German anchored mine at the Tælavåg site after transport to a safe location and before detonation, contained detectable concentrations of TNT $(0.05 \mathrm{mg} / \mathrm{kg})$ and HMX $(0.24$ $\mathrm{mg} / \mathrm{kg})$. After detonation, TNT was detected in one sample, $(0.08 \mathrm{mg} / \mathrm{kg}$ ), which also contained RDX (0.05 mg/kg). The second sample contained RDX (0.05 mg/kg) and HMX (0.29 mg/kg), but not TNT. All other MC were below their DL. 
TNT and RDX HMX were the only MC detected in the two sediment samples collected near the DS Selma (0.31 and $0.41 \mathrm{mg} / \mathrm{kg}$ TNT and HMX in one sample, and 0.14 and $0.12 \mathrm{mg} / \mathrm{kg}$ TNT and HMX in the other sample). All other MC were below their DL (Figure 23).

Figure 22. Fraction (as percent) of sediment samples collected at coastal fortifications in Norway for which MC concentrations were reported as quantified values. Based on Rossland et al. (2010).

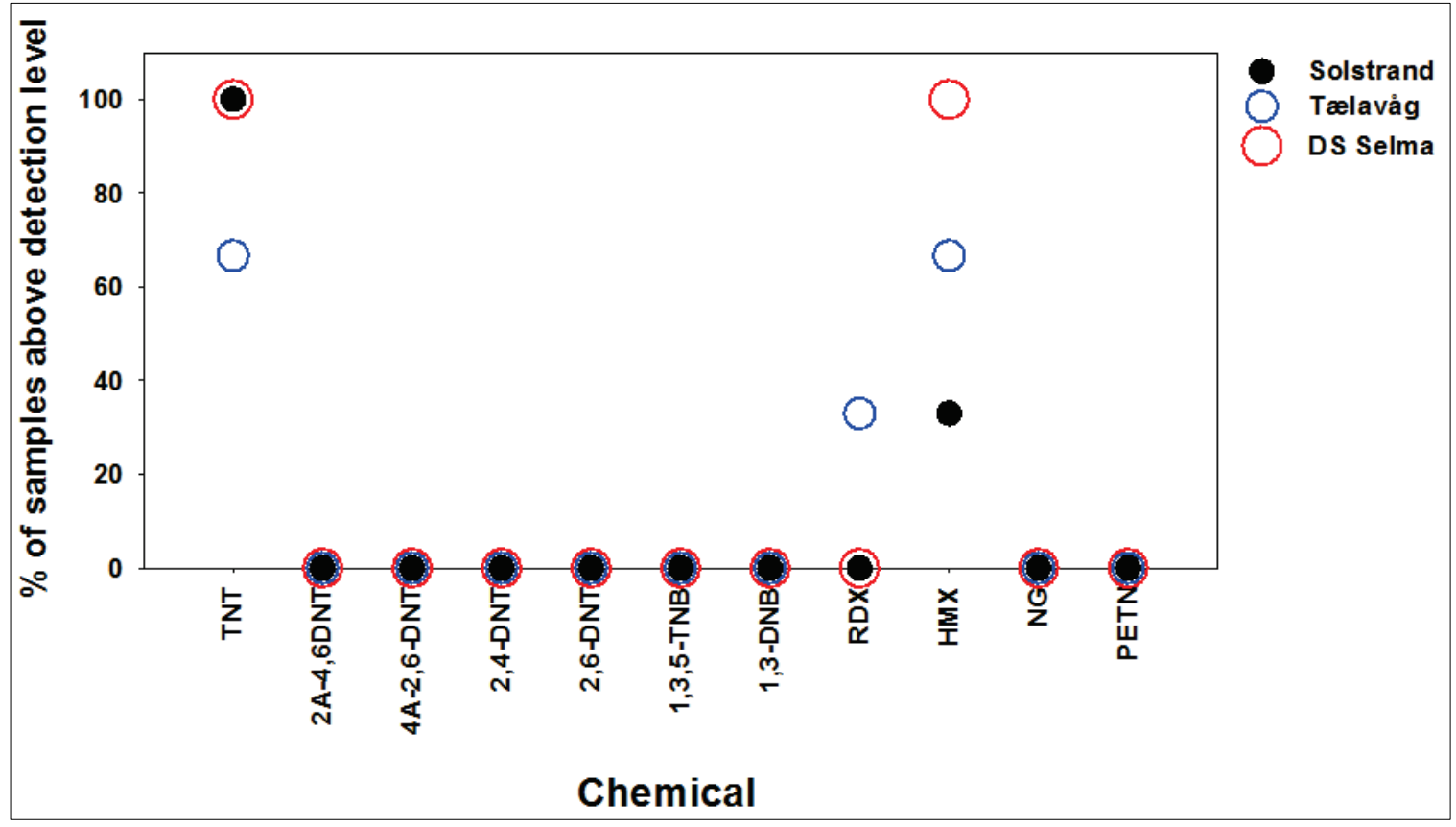

Figure 23. MC concentrations for sediment samples collected at coastal fortifications in Norway. Based on Rossland et al. (2010).

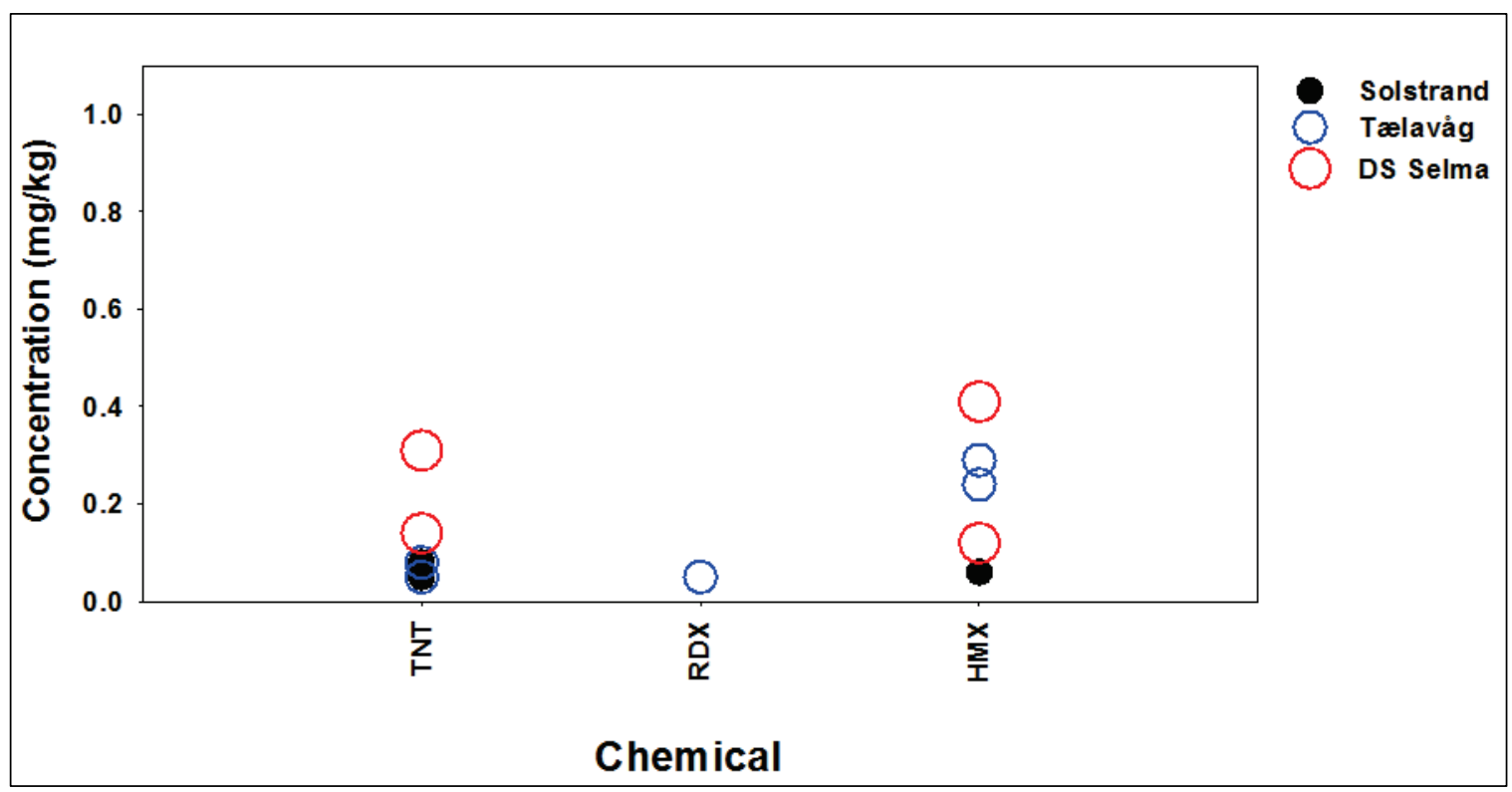




\section{MC Contamination at Underwater Munitions Sites - Biota}

See appendix A for comprehensive data compilation of MC contamination in biota at UWMM sites.

\subsubsection{Jackson Park Housing Complex (WA)}

For OU 2 (NAVFAC NW 2010c), 3-NT, 1,3,5-TNB, nitrobenzene, picric acid, picramic acid, and NG were detected in the resident biota (Table 7;

Figure 24 and Figure 25). For OU 1 (NAVFAC NW 2011), 2,4-DNT, 2,6-

DNT, and 1,3,5-TNB were detected in the resident biota (Table 7; Figure 24 and Figure 25).

Figure 24. Fraction (as percent) of biota samples collected at Jackson Park Housing Complex (WA, USA) for which MC concentrations were reported as quantified values. Based on NAVFAC NW (2010b and 2011).

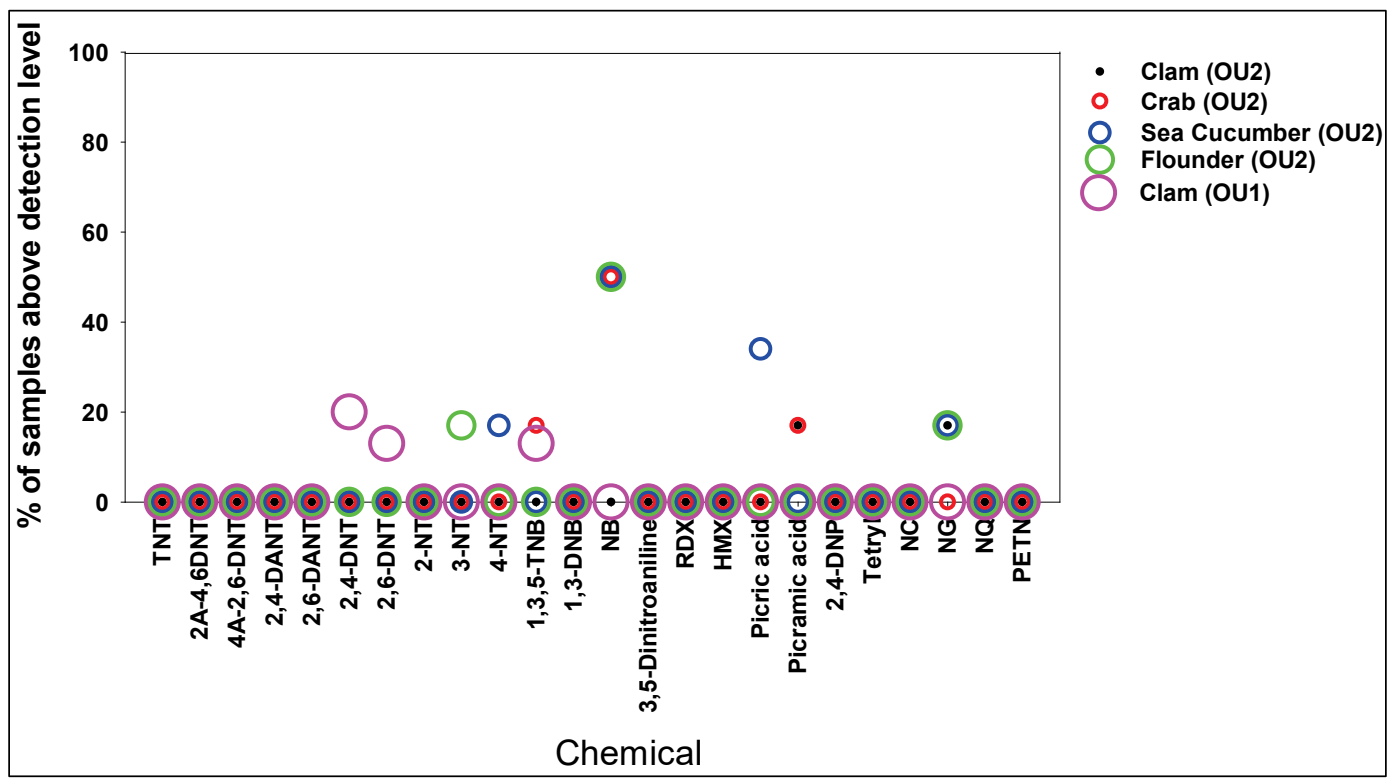


Table 7. Detection frequency and range of measured concentrations of MC detected in biota collected at Jackson Park Housing Complex. Based on NAVFAC NW (2010c, 2011).

\begin{tabular}{|c|c|c|c|c|}
\hline MC & Biota & Number of samples & $\begin{array}{l}\text { Detect. freq. } \\
\text { (\%) }\end{array}$ & $\begin{array}{l}\text { Conc. or range } \\
\text { of conc. } \\
(\mu g / k g)\end{array}$ \\
\hline \multicolumn{5}{|c|}{ Operational Unit 2} \\
\hline 3-NT & Flounder & 6 & 17 & 460 \\
\hline 4-NT & Sea cucumber & 6 & 17 & 330 \\
\hline 1,3,5-TNB & Crab & 6 & 17 & 2.2 \\
\hline \multirow[b]{3}{*}{ Nitrobenzene } & Crab & 6 & 50 & $480-580$ \\
\hline & Sea cucumber & 6 & 50 & $670-950$ \\
\hline & Flounder & 6 & 50 & $220-320$ \\
\hline Picric acid & Sea cucumber & 6 & 33 & $0.35-041$ \\
\hline \multirow[b]{2}{*}{ Picramic acid } & Clam & 6 & 17 & 10.9 \\
\hline & Crab & 6 & 17 & 5.9 \\
\hline \multirow[b]{3}{*}{$N G$} & Clam & 6 & 17 & 290 \\
\hline & Sea cucumber & 6 & 17 & 520 \\
\hline & Flounder & 6 & 17 & 650 \\
\hline \multicolumn{5}{|c|}{ Operational Unit 1} \\
\hline 2,4-DNT & Clam & 15 & 20 & $47-53$ \\
\hline 2,6-DNT & Clam & 15 & 13 & $77-130$ \\
\hline 1,3,5-TNB & Clam & 15 & 13 & $7,300-7,800$ \\
\hline
\end{tabular}

Figure 25. MC concentrations for biota samples collected at Jackson Park Housing Complex (WA, USA). Based on NAVFAC NW (2010c and 2011)

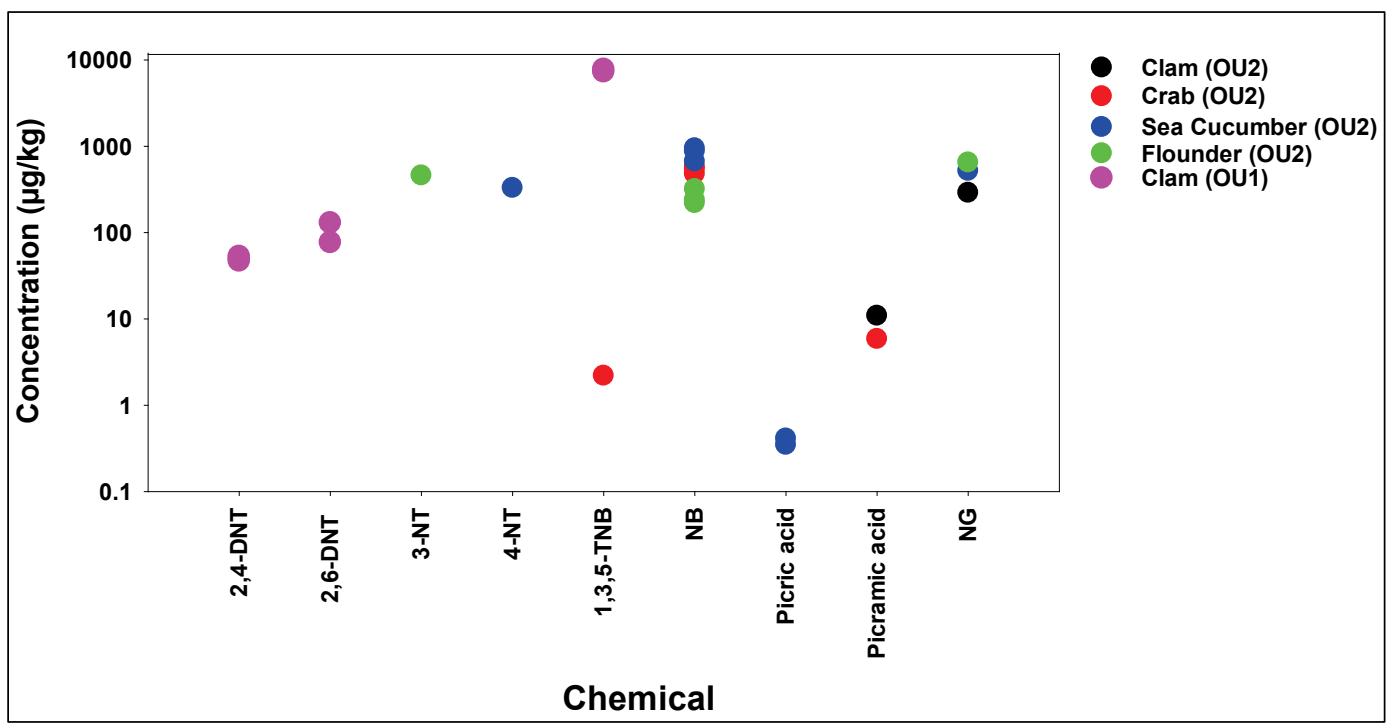




\subsubsection{Sea disposal site Hawaii (HI-06) "Ordnance Reef”}

MC was not detected for biota collected from the DMM stratum at HI-O6 in 2009. Likewise, MC was not detected in any Kona crab, or seaweed sample; However, HMX was detected in one octopus sample at $62 \mu \mathrm{g} / \mathrm{kg}$, and 2,4DNT, 2-NT, 4-NT, 3,5-dinitroaniline, RDX, HMX, and tetryl were detected in fish samples with a frequency of up to $32 \%$ (for HMX) (Figure 26). Concentrations in fish were $4-180 \mu \mathrm{g} / \mathrm{kg}$ for 2,4-DNT; 46 and $55 \mu \mathrm{g} / \mathrm{kg}$ for 2-NT; $92 \mu \mathrm{g} / \mathrm{kg}$ for 4-NT; 45, 53 for 3,5-dinitroaniline; 1,600 $\mu \mathrm{g} / \mathrm{kg}$ RDX; $37-420 \mu \mathrm{g} / \mathrm{kg}$ for HMX; and 390 and $850 \mu \mathrm{g} / \mathrm{kg}$ for tetryl (Figure 27).

Detectable concentrations in biota samples also occurred for fish from the control sampling area for $1,3,5$-TNB $(76 \mu \mathrm{g} / \mathrm{kg})$ and the non-point source sampling area for 2,4-DNT (46 $\mu \mathrm{g} / \mathrm{kg})$, for HMX (37-42 $\mu \mathrm{g} / \mathrm{kg})$, and for crab from the waste water treatment area for 1,3,5-TNB (67 $\mu \mathrm{g} / \mathrm{kg})$ (UH 2014a).

For biota collected from the DMM stratum at HI-06 during the FUI, no $\mathrm{MC}$ was detected in any Kona crab, octopus, or seaweed sample, and 2,4DNT, 2,6-DNT, and 1,3,5-TNB were detected in fish samples with a frequency of up to $11 \%$ (for 1,3,5-TNB) (Figure 26). Concentrations in fish were $39 \mu \mathrm{g} / \mathrm{kg}$ for 2,4-DNT; $140 \mu \mathrm{g} / \mathrm{kg}$ for 2,6-DNT; and $53-62 \mu \mathrm{g} / \mathrm{kg}$ for 1,3,5-TNB (Figure 27). Detectable concentrations in biota samples also occurred for one fish from the control area sample for $1,3,5$-TNB (55 $\mu \mathrm{g} / \mathrm{kg})$ (Figure 27) (UH 2014b).

Figure 26. Fraction (as percent) of biota samples collected at sea disposal site Hawaii (HI-06) "Ordnance Reef" (HI, USA) for which MC concentrations were reported as quantified values. Based on University of Hawaii (2014a and 2014b).

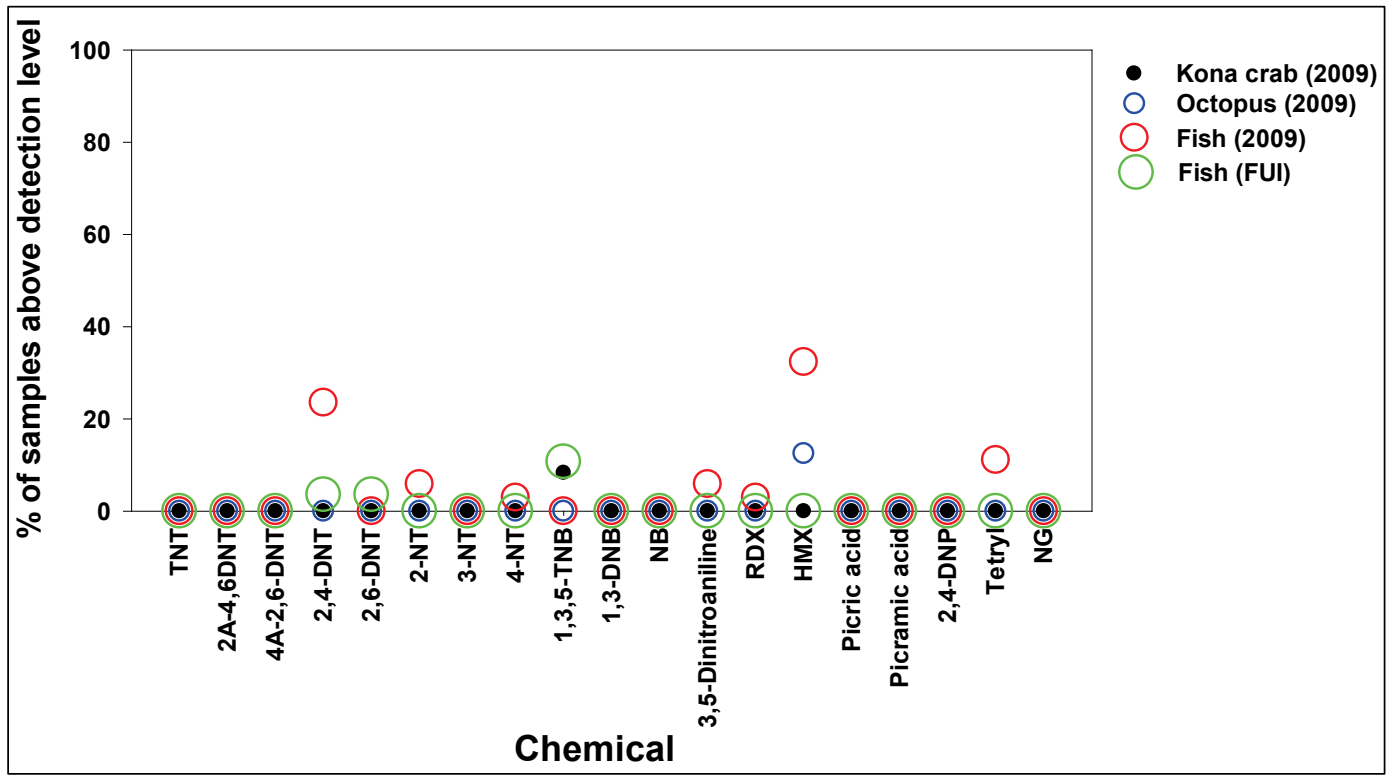


Figure 27. MC concentrations for biota samples collected at sea disposal site Hawaii (HI-06) “Ordnance Reef” (HI, USA). Based on University of Hawaii (2014a and 2014b).

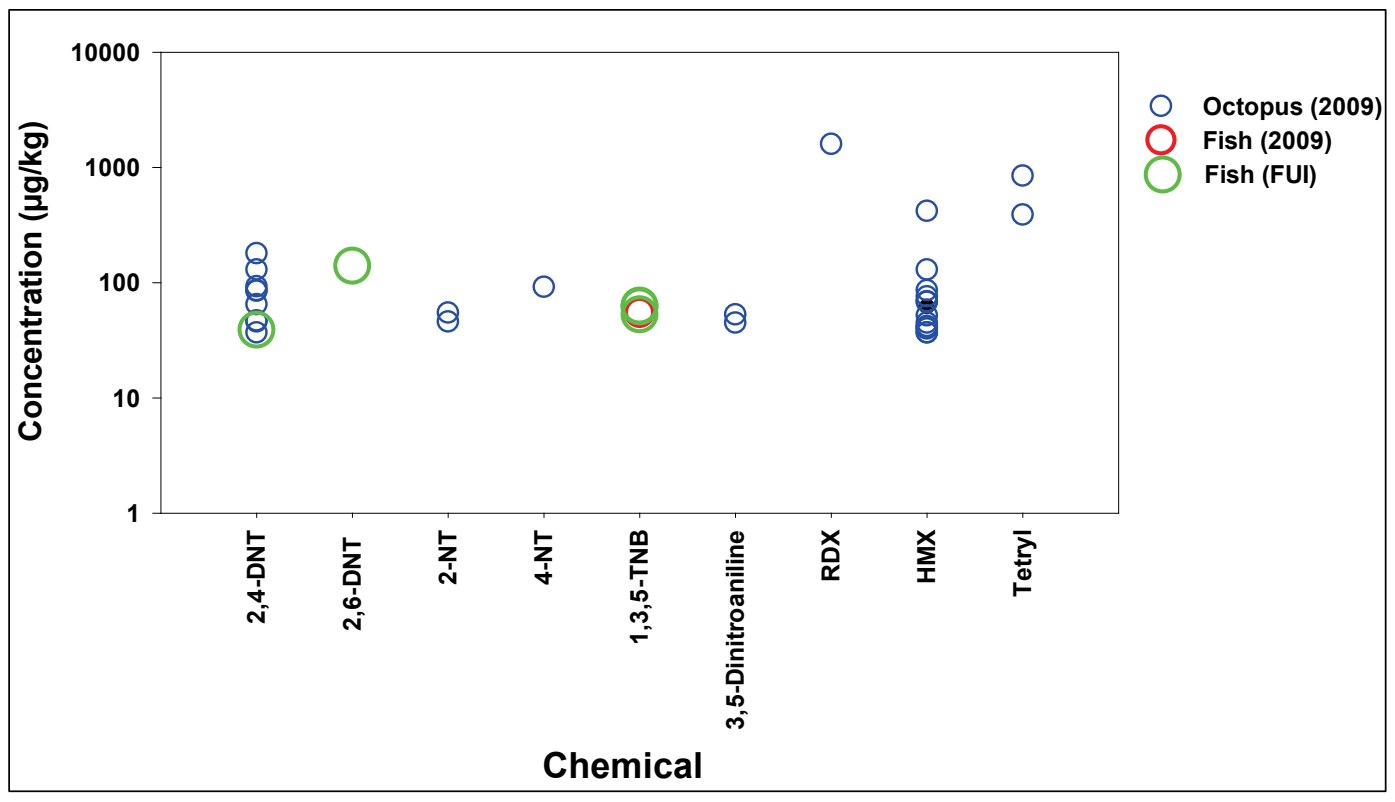

\subsubsection{Sea disposal site Hawaii (HI-05)}

MC were not detected in shrimp or fish sampled at sea disposal site Hawaii (HI-05) in 2009 (UH 2010). For shrimp trapped and sampled in 2012, 4-A-2,6DNT was detected at estimated concentrations (33 $\mu \mathrm{g} / \mathrm{kg}$ and $45 \mu \mathrm{g} / \mathrm{kg}$ ) in two samples collected at a conventional munitions site (7\% of the samples) (Figure 28 and Figure 29) (Koide et al. 2016).

Nitrobenzene $(76-230 \mu \mathrm{g} / \mathrm{kg}, 22 \%$ of the samples), 1,3,5-TNB (38$81 \mu \mathrm{g} / \mathrm{kg}, 26 \%$ of the samples), and TNT (57 $\mu \mathrm{g} / \mathrm{kg}$ and $0.050 \mathrm{mg} / \mathrm{kg}, 7 \%$ of the samples) were found in shrimp trapped in the vicinity of CWAcontaining DMM. It was speculated that because the shrimp traps in the 2012 sampling program were placed adjacent to the UWMM while sediment samples were being collected, the exposed organisms may have experienced an increased exposure that resulted in the low detected concentrations of energetic materials observed in some of the shrimp tissue samples (Koide et al. 2016). In contrast, during the 2009 sampling program, biota samples were collected approximately 1-2 months after HOV sampling operations were completed and samples were taken from the UWMM area, but not adjacent to the target items (UM 2010). 
Figure 28. Fraction (as percent) of biota samples collected at sea disposal site Hawaii (HI-05) (HI, USA) for which MC concentrations were reported as quantified values.

Based on University of Hawaii (2010) and Koide et al. (2016).

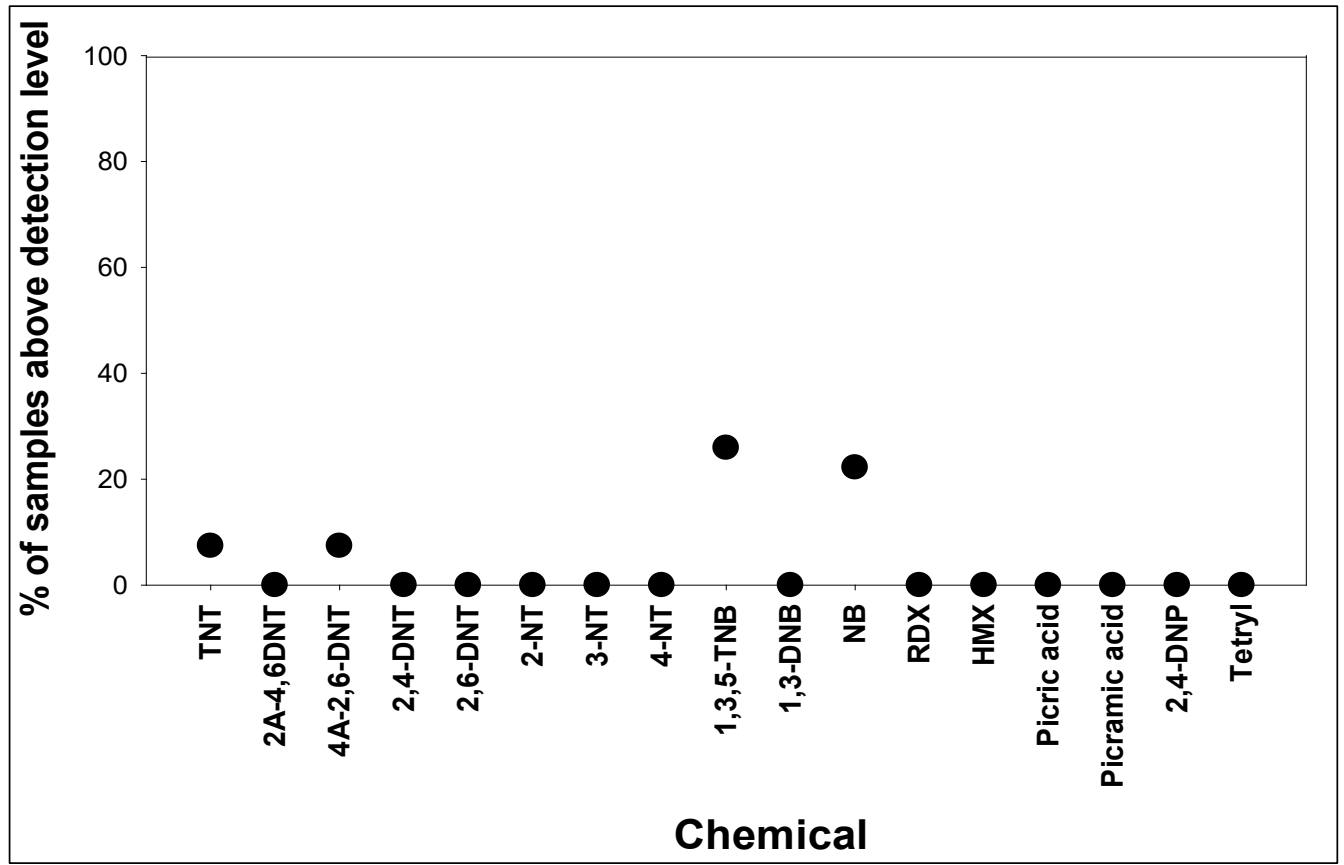

Figure 29. MC concentrations for biota samples collected at sea disposal site Hawaii (HI-05) (HI, USA). Based on University of Hawaii (2010) and Koide et al. (2016).

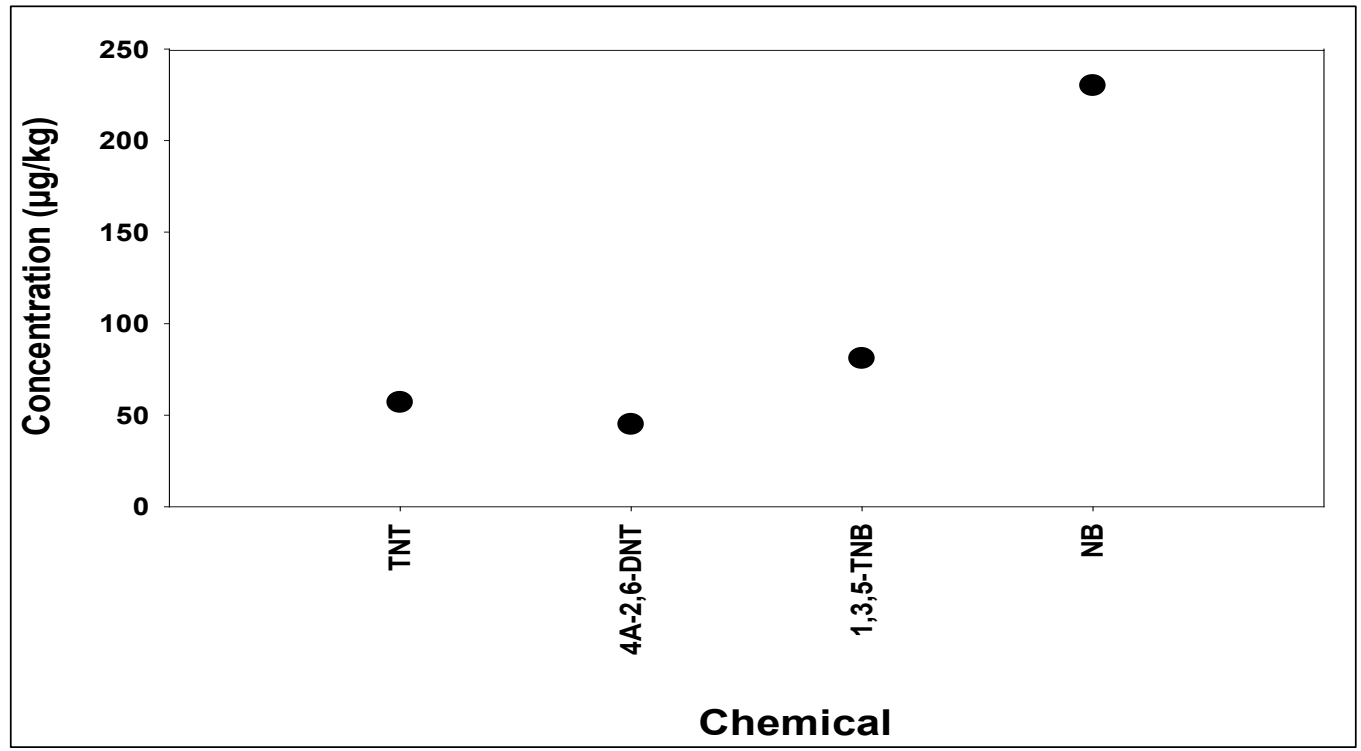

\subsubsection{Isla de Vieques Bombing Range site (PR)}

MC were not detected in fish and shellfish collected from the sampling site near the LIA during studies conducted in 2001 and 2005 (ATSDR 2003, 2006, 2013). 
In 2003, various marine organisms (one damselfish, one feather duster worm, and one sea urchin) collected near a 2000-lb bomb in Bahia Salina del Sur showed explosive residues (Table 8). TNT was found in the feather duster worm $(40,200 \mathrm{mg} / \mathrm{kg})$, the sea urchin $(721 \mathrm{mg} / \mathrm{kg})$, and the mountainous star coral $(600 \mathrm{mg} / \mathrm{kg}) .1,3$, TNB was detected in the damselfish sample $(4.6 \mathrm{mg} / \mathrm{kg})$, the feather duster worm $(23.9 \mathrm{mg} / \mathrm{kg})$, and the mountainous star coral $(250 \mathrm{mg} / \mathrm{kg}) ; 2,4+2,6$-DNT was found in the mountainous star coral $(250 \mathrm{mg} / \mathrm{kg}) .1,3$-DNB was detected in the mountainous star coral $(250 \mathrm{mg} / \mathrm{kg}$ ) and the feather duster worm $(9.5 \mathrm{mg} / \mathrm{kg})$, that also contained 4-NT $(95.5 \mathrm{mg} / \mathrm{kg}$ ) (Barton and Porter 2004; Porter et al. 2011).

Table 8. Concentrations of MC in biota collected near a 2000-lb bomb in Isla de Vieques Bombing Range site, PR.

\begin{tabular}{|c|c|c|c|c|c|c|c|c|c|}
\hline \multirow[b]{2}{*}{ Biota } & \multirow[b]{2}{*}{ Species } & \multirow[b]{2}{*}{ Location } & \multicolumn{7}{|c|}{ Tissue concentration (mg/kg) } \\
\hline & & & TNB & DNB & TNT & $\begin{array}{l}2,4+2,6- \\
\text { DNT }\end{array}$ & 4-NT & 2-NT & RDX \\
\hline $\begin{array}{l}\text { Feather } \\
\text { Duster } \\
\text { Worm }\end{array}$ & $\begin{array}{l}\text { Sabellastarte } \\
\text { magnifica }\end{array}$ & $\begin{array}{l}\text { Attached } \\
\text { to the } \\
\text { bomb }\end{array}$ & 23.9 & 9.52 & 40,200 & ND & 95.5 & ND & \\
\hline $\begin{array}{l}\text { Dusky } \\
\text { Damselfish }\end{array}$ & $\begin{array}{l}\text { Stegastes } \\
\text { adustus }\end{array}$ & $\begin{array}{l}\text { Inside } \\
\text { cavity }\end{array}$ & 4.6 & ND & $<1.2$ & ND & ND & ND & $<1.3$ \\
\hline Star coral & $\begin{array}{l}\text { Montastraea } \\
\text { faveolata }\end{array}$ & $\begin{array}{l}\text { Attached } \\
\text { to bomb }\end{array}$ & 250 & 250 & 600 & 250 & ND & ND & ND \\
\hline Brain coral & $\begin{array}{l}\text { Diploria } \\
\text { labyrinthiformi } \\
\mathrm{s}\end{array}$ & $\begin{array}{l}15 \mathrm{~m} \\
\text { from } \\
\text { bomb }\end{array}$ & ND & ND & ND & ND & ND & ND & ND \\
\hline $\begin{array}{l}\text { Long- } \\
\text { spined Sea } \\
\text { Urchin }\end{array}$ & $\begin{array}{l}\text { Diadema } \\
\text { antellarum }\end{array}$ & $\begin{array}{l}\text { Grazing } \\
\text { on top of } \\
\text { the bomb }\end{array}$ & ND & ND & 721 & ND & ND & ND & ND \\
\hline
\end{tabular}

ND = not detected. Based on Porter et al. (2011).

Explosive residues were not detected in fish and lobster samples collected near the former USS Killen. One out of six coral samples collected from the USS Killen area contained detectable TNT residues $(252 \mathrm{mg} / \mathrm{kg})$. All other coral samples contained no detectable TNT $(<1.2 \mathrm{mg} / \mathrm{kg})$ or RDX $(<1.3$ $\mathrm{mg} / \mathrm{kg}$ ) (Barton and Porter 2004; Porter et al. 2011). 


\subsubsection{Coastal fortifications in Norway}

For the Solstrand site, HMX was found in mussels at $7 \mu \mathrm{g} / \mathrm{kg}$ and in snails at $10 \mu \mathrm{g} / \mathrm{L}$. Both biota also contained unspecified trace concentrations of TNT and 2-A-4,6DNT (Rossland et al. 2010).

The sample of kelp growing on the mine at the Tælavåg site contained detectable concentrations of TNT $(49 \mu \mathrm{g} / \mathrm{kg}), \mathrm{HMX}(85 \mu \mathrm{g} / \mathrm{kg})$, and RDX (18 $\mu \mathrm{g} / \mathrm{kg}$ ) (Rossland et al. 2010).

\subsubsection{Beaufort's Dyke (North-East Atlantic)}

TNT, RDX, tetryl, nor NG were detected in any of the biota samples at concentrations exceeding their DL. Information on DL was not found (Aberdeen Marine Laboratory 1996). 


\section{An Analysis of the Environmental Fate Data for Munition Constituents as Collected from the Scientific Literature}

\subsection{Fate modeling via evaluative environments}

Environmental systems are extremely complex and consist of a wide variety of independent and interrelated processes, reactions, and interfaces that control the persistence of anthropogenic materials. In an effort to strategically reduce this complexity, fate models construct "evaluative environments" where natural processes are represented using mathematical functions populated via a short list of essential, solutespecific parameters, such as sorption or degradation potential. One important example of this approach involves mass-balance, fugacity-based Mackay models (Mackay 2001), where the distribution and fate of materials are defined in thermodynamic fugacity $\left(f_{i}\right)$ units. While the concept of fugacity is traditionally reserved for characterizing the nonideality of gases, Mackay and other authors utilized the fugacity concept to describe the interaction of solutes among different phases (Mackay 1979; Mackay and Paterson 1981; Connolly and Pederson 1988). For a solute in water,

$$
\mathrm{C}_{\mathrm{w}}=\mathrm{f}_{\mathrm{w}} \mathrm{Z}_{\mathrm{w}}
$$

where $\mathrm{f}_{\mathrm{w}}=$ solute fugacity (in units of pressure, $\mathrm{Pa}$ ), $\mathrm{C}_{\mathrm{w}}=$ solute concentration $\left(\mathrm{mol} \mathrm{m}^{-3}\right)$, and $\mathrm{Z}_{\mathrm{w}}$ = fugacity capacity, or quantity representing the capacity of the phase for fugacity $\left(\mathrm{mol} \mathrm{m}^{3} \mathrm{~Pa}^{-1}\right)$. For a given fugacity $\left(f_{w}\right)$, a lower $Z_{w}$ requires a higher $\mathrm{C}_{\mathrm{w}}$ to enable the solute to "escape" from its phase, such as by volatilization or solid-phase partitioning. For dissolved solutes, $f$ is also related to the solute's Henry constant as $f_{w}=\mathrm{HC}_{\mathrm{w}}$, where $\mathrm{Z}_{\mathrm{w}}=1 / \mathrm{H}$ (Mackay 1979). For a solid, fugacity is also defined as $\mathrm{C}_{\mathrm{s}}=f_{\mathrm{s}} Z_{\mathrm{s}}$. Solute distribution between two phases $\left(\mathrm{K}_{\mathrm{sw}}\right)$ are calculated by assuming that the solute fugacities are equal $\left(f_{w}=f_{S}\right)$ at equilibrium. Substituting, $\mathrm{C}_{\mathrm{w}} / \mathrm{Z}_{\mathrm{w}}=\mathrm{C}_{\mathrm{s}} / \mathrm{Z}_{\mathrm{s}}$ and rearranging, we show

$$
\mathrm{Z}_{\mathrm{s}} / \mathrm{Z}_{\mathrm{w}}=\mathrm{C}_{\mathrm{s}} / \mathrm{C}_{\mathrm{w}}=\mathrm{K}_{\mathrm{sw}}
$$

where $\mathrm{K}_{\mathrm{sw}}$ is unitless. This convention is applied to describe the distribution and movement of any contaminant among all natural phases. 
In Mackay models, the evaluative environments consist (at minimum) of four fundamental "compartments" that influence the fate of materials: water (freshwater or marine), soil, sediment, and air (or atmosphere). The basic evaluative environment is represented schematically in Figure 30. Fundamental features and processes that occur within this evaluative environment are represented by colored arrows and are described as follows:

Figure 30. Schematic representing a generalized environmental $\mathrm{F}$ and $\mathrm{T}$ model. At the lowest resolution, the model is broken up into four main environmental compartments: soil, sediment, water, and air. The arrows indicate inter-compartment transfer of contaminants (red arrows) as well as contaminant inputs (via external inputs - yellow arrows) and process outputs (advective transport - blue arrows; abiotic/biotic disappearance green arrows). The bulk of experimental work in environmental $F$ and $T$ involves generating parameters, which the red and green arrows describe.

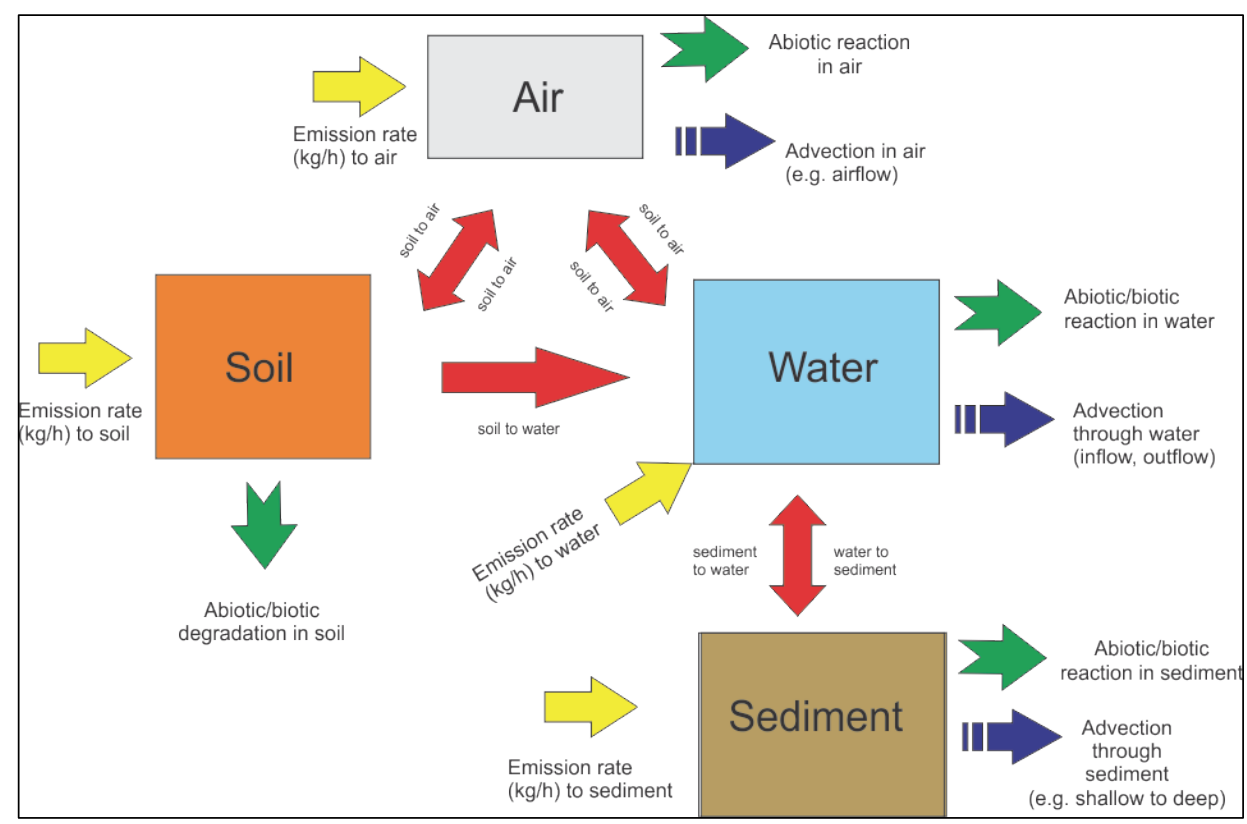

- Yellow arrows: Life cycle stage, such as manufacturing or processassociated inputs and releases, such as wastewater emissions. This is directly associated with constructing the inventory (and its associated emissions) as defined by classical Eco-Life Cycle Assessment (LCA).

- Red arrows: These are experimentally determined. They include chemically and geochemically relevant data such as sorption, mobility, acid-dissociation, partitioning (e.g., $\mathrm{K}_{\mathrm{oc}}$ and $\mathrm{K}_{\mathrm{ow}}$ ), solubility, polymerization, and pairing/complexation constants. 
- Blue arrows: These include physical and climatic variables (e.g., sitespecific). At low resolution, these can be represented on a regional level or manipulated based on the desired scenario.

- Green arrows: These are experimentally determined and include aquatic and soil microbial biodegradation kinetic constants (persistence) and photodegradation kinetic constants.

In practice, the models can be customized to specific sites by manipulating the size of the different compartments.

The influence of these phases, and the processes mediated at their interfaces are represented by different "levels" of model complexity, called Levels I-IV. Level I represents the simplest model (or evaluative environment), which in turn possesses the least expensive data requirements. Moving to models that are more complex provides a more in-depth description of a material's environmental fate, yet this complexity comes at a cost of more expensive data requirements. Also, the uncertainty of the more complex models increases due to the increasing number of assumptions that must be considered. Overall, the strategy of assessing material fate starting at Level I and then progressing to models that are more complex can provide valuable insight into the complete picture of a material's environmental fate.

Below, we provide a brief description of the evaluative environments included in Levels I-IV.

Level I. This is an equilibrium-distribution model where the material's fugacity is assumed to be equal for all environmental compartments. Parameters used in the Level I model are given in Table 9. 
Table 9. Summary of the fugacity capacity (Zi) equations defining different environmental compartments in the Level I fate model (after Mackay, 2001).

\begin{tabular}{|c|c|c|}
\hline Compartment & $Z_{i}$ Equation & Notes \\
\hline Air & $Z_{A}=1 /(R T)$ & $\begin{array}{l}\mathrm{R}=\text { universal gas constant, } 8.314 \mathrm{~Pa} \\
\mathrm{~m}^{3} / \mathrm{mol}, \mathrm{T}=\text { temperature }\end{array}$ \\
\hline Water & $Z_{W}=1 / H=Z_{A} K_{A W}$ & $\begin{array}{l}\mathrm{H}=\text { Henry's Law Constant }\left(\mathrm{Pa} \mathrm{m} \mathrm{m}^{3} / \mathrm{mol}\right) ; \\
\mathrm{K}_{\mathrm{AW}}=\text { air-water partition coefficient } \\
\text { (dimensionless). }\end{array}$ \\
\hline Octanol & $Z_{0}=Z_{w} K_{o w}=Z_{L}$ & $\begin{array}{l}\text { Kow }=\text { octanol-water partition } \\
\text { coefficient (dimensionless); L } \\
\text { represents lipids phase }\end{array}$ \\
\hline Aerosols & $Z_{Q}=K_{Q A} Z_{A}$ & $\begin{array}{l}\mathrm{K}_{\mathrm{QA}}=\text { aerosol-air partition coefficient } \\
\text { (dimensionless) }\end{array}$ \\
\hline Organic carbon & $Z_{o c}=K_{o c} Z_{w}\left(\rho_{o c} / 1000\right)$ & $\begin{array}{l}K_{o c}=\text { organic carbon partitioning } \\
\text { coefficient }(\mathrm{L} / \mathrm{kg})=\mathrm{K}_{\mathrm{D}} / f_{\mathrm{Oc}} \text {, where } \mathrm{K}_{\mathrm{D}} \text { is } \\
\text { the distribution coefficient describing } \\
\text { linear sorption and } f_{\mathrm{O}} \text { is the fraction of } \\
\text { organic carbon; } \rho_{\mathrm{O}}=\text { density of organic } \\
\text { carbon }\left(\mathrm{kg} / \mathrm{m}^{3}\right)\end{array}$ \\
\hline Mineral matter & $\begin{array}{l}Z_{M M}=K_{M M} Z_{W} \\
\left(\rho_{M M} / 1000\right)\end{array}$ & $\begin{array}{l}\mathrm{K}_{M M}=\text { mineral-water partition } \\
\text { coefficient }(\mathrm{L} / \mathrm{kg})=\mathrm{K}_{\mathrm{D}} / f_{M M}, \text { where } f_{M M} \text { is } \\
\text { the fraction of mineral matter, } \rho_{M M}= \\
\text { density of mineral matter }\left(\mathrm{kg} / \mathrm{m}^{3}\right)\end{array}$ \\
\hline Biota & $Z_{B}=L Z_{L}$ & $\mathrm{~L}=$ lipid volume fraction $(\mathrm{v} / \mathrm{v})$ \\
\hline
\end{tabular}

Level II. The more complex Level II model incorporates parameters for advective inflows and outflows towards each environmental compartment, but does not describe interactions among the compartments themselves. The advective flows (indicated with the variable $\mathrm{D}_{\mathrm{i}}$ ) modeled in Level II include solute mass transfer, diffusion, and reactions (i.e., photolytic, hydrolytic, biotic degradation, andredox reactions), represented by the blue, green, and yellow arrows in Figure 30. All reactions are assumed to follow first order kinetics. Parameters generated for Level II calculations are described in Table 10. Note that all D values represent functions of each compartment's calculated $Z_{i}$, which were determined in Level I.

Level III. This level overcomes the limits of Level II by incorporating elements of inter-compartment transport. Kinetic processes are modeled at steady-state. Borrowing from electrical resistance theory, a material's potential for inter-compartment transport represents a function of a tworesistance mass transfer coefficient (MTC) (Liss and Slater 1974; Mackay and Leinonen 1975). Inter-compartment solute transport is modeled either 
in series (where $1 / D=\sum 1 / D_{i}$ ) or in parallel (where $\mathrm{D}=\sum \mathrm{D}_{\mathrm{i}}$ ). In Level III, environmental properties that may indirectly affect the material's fate are included in the parameter list in Table 11, while equations describing intercompartment transport are listed in Table 12. Mackay (2001) gives the overall mass balance equations for each compartment.

Level IV. In Level IV, kinetic processes are represented in non-steady-state conditions. This level requires expensive data and a large number of assumptions, which can adversely impact the uncertainty of the model. Level IV models are commonly used within the environmental fate models in LCA, such as SimpleBox 2.o. Mayo et al. (2014) recently published a sensitivity analysis which showed that Level IV SimpleBox models exhibit uncertainties on the order of $10^{8}$. Use of Level IV models is beyond the scope of this project.

Table 10. Equations for the D parameter (called the fugacity rate constant) in the Level II fate calculations (from Mackay, 2001).

\begin{tabular}{|l|l|l|}
\hline Compartment & $\mathrm{D}(\mathrm{mol} / \mathrm{h})$ value equation & Notes \\
\hline Advection or flow & & $\begin{array}{l}\mathrm{G}=\text { medium flow }\left(\mathrm{m}^{3} \mathrm{~h}^{-1}\right), \mathrm{U}= \\
\text { medium velocity }(\mathrm{m} / \mathrm{h}) ; \mathrm{A}=\text { area } \\
\left(\mathrm{m}^{2}\right) ; \mathrm{Z}=\text { fugacity capacity for any } \\
\text { designated compartment }\end{array}$ \\
\hline Reaction & $\mathrm{D}=\mathrm{G} \mathrm{Z}=(\mathrm{U} \mathrm{A}) \mathrm{Z}$ & $\begin{array}{l}\mathrm{V}=\text { volume }\left(\mathrm{m}^{3}\right) \text { and } \mathrm{k}=\text { rate } \\
\text { constant }\left(\mathrm{h}^{-1}\right)\end{array}$ \\
\hline Diffusion & $\mathrm{D}=\mathrm{V} \mathrm{Z} \mathrm{k}$ & $\begin{array}{l}\mathrm{B}=\text { molecular or effective diffusivity } \\
\left(\mathrm{m}^{2} / \mathrm{h}\right) ; \mathrm{Y}=\text { path length }(\mathrm{m})\end{array}$ \\
\hline Mass transfer & $\mathrm{D}=\mathrm{B} \mathrm{A} \mathrm{Z/Y}$ & $\mathrm{k}=$ mass transfer coefficient \\
\hline Growth dilution & $\mathrm{D}=\mathrm{kAZ}$ & $\begin{array}{l}\mathrm{dV} / \mathrm{dt}=\text { growth rate }\left(\mathrm{m}^{3} / \mathrm{h}\right) ; \mathrm{k}= \\
\mathrm{growth} \text { rate constant }\left(\mathrm{h}^{-1}\right) \text { or } \\
(\mathrm{dV} / \mathrm{dt}) / \mathrm{V}\end{array}$ \\
\hline
\end{tabular}


Table 11. Parameters for environmental properties, including suggested values (from Mackay, 2001).

\begin{tabular}{|c|c|c|}
\hline Parameter & Symbol & Suggested value \\
\hline Air-side MTC over water & kva & $3 \mathrm{~m} / \mathrm{h}$ \\
\hline Water-side MTC & kvw & $0.03 \mathrm{~m} / \mathrm{h}$ \\
\hline Transfer rate to higher altitude & $U_{s}$ & $0.01 \mathrm{~m} / \mathrm{h}$ \\
\hline Rain rate ( $\mathrm{m}^{3}$ rain/m²area) & $U_{R}$ & $9.7 \times 10^{-5} \mathrm{~m} / \mathrm{h}$ \\
\hline Scavenging ratio & Q & $2 \times 10^{5}$ (no units) \\
\hline Volume fraction of aerosols & $\mathrm{V}_{\mathrm{Q}}$ & $30 \times 10^{-12}$ (no units) \\
\hline Dry deposition velocity & $U_{Q}$ & $10.8 \mathrm{~m} / \mathrm{h}$ \\
\hline Air-side MTC over soil & $\mathrm{K}_{\mathrm{EA}}$ & $1 \mathrm{~m} / \mathrm{h}$ \\
\hline Diffusion path length in soil & $Y_{3}$ & $0.05 \mathrm{~m}$ \\
\hline Molecular diffusivity in air & $\mathrm{B}_{\mathrm{MA}}$ & $0.04 \mathrm{~m}^{2} / \mathrm{h}$ \\
\hline Molecular diffusivity in water & $\mathrm{B}_{\mathrm{MW}}$ & $4.0 \times 10^{-6} \mathrm{~m}^{2} / \mathrm{h}$ \\
\hline Water runoff rate from soil & $U_{w w}$ & $3.9 \times 10^{-5} \mathrm{~m} / \mathrm{h}$ \\
\hline Solids runoff rate from soil & $\mathrm{U}_{\mathrm{EW}}$ & $2.3 \times 10^{-8} \mathrm{~m}^{3} / \mathrm{m}^{2} \mathrm{~h}$ \\
\hline Water-side MTC over sediment & ksw & $0.01 \mathrm{~m} / \mathrm{h}$ \\
\hline Diffusion path length in sediment & $Y_{4}$ & $0.005 \mathrm{~m}$ \\
\hline Sediment deposition rate & $U_{D P}$ & $4.6 \times 10^{-8} \mathrm{~m}^{3} / \mathrm{m}^{2} \mathrm{~h}$ \\
\hline Sediment resuspension rate & URS & $1.1 \times 10^{-8} \mathrm{~m}^{3} / \mathrm{m}^{2} \mathrm{~h}$ \\
\hline Sediment burial rate & $U_{B S}$ & $3.4 \times 10^{-8} \mathrm{~m}^{3} / \mathrm{m}^{2} \mathrm{~h}$ \\
\hline Leaching rate of water (soil to groundwater) & $U_{L}$ & $3.9 \times 10^{-5} \mathrm{~m}^{3} / \mathrm{m}^{2} \mathrm{~h}$ \\
\hline
\end{tabular}


Table 12. Level III intermedia transfer equations for D values (from Mackay, 2001).

\begin{tabular}{|c|c|c|}
\hline Compartments & Process & Equations for $D$ values \\
\hline \multirow[t]{5}{*}{ Air(1) - water(2) } & Diffusion & $\begin{array}{l}\mathrm{Dv}_{\mathrm{v}}=1 /\left(1 / \mathrm{kv}_{A} \mathrm{~A}_{12} \mathrm{Z}_{\mathrm{A}}+\right. \\
\left.1 / \mathrm{kvwA}_{12} \mathrm{Zw}_{\mathrm{w}}\right)\end{array}$ \\
\hline & Rain dissolution & $\mathrm{D}_{\mathrm{RW} 2}=\mathrm{A}_{12} \mathrm{U}_{\mathrm{Q}} \mathrm{Z}_{\mathrm{w}}$ \\
\hline & Wet deposition & $D_{Q W 2}=A_{12} U_{R} Q v_{Q} Z_{Q}$ \\
\hline & Dry deposition & $\mathrm{D}_{\mathrm{QD} 2}=\mathrm{A}_{12} \mathrm{U}_{\mathrm{Q}} \mathrm{V}_{\mathrm{O}} \mathrm{Z}_{\mathrm{Q}}$ \\
\hline & Total D values & $\begin{array}{l}D_{12}=D_{v}+D_{R W 2}+D_{Q D 2}+D_{Q W 2} \\
D_{21}=D_{v}\end{array}$ \\
\hline \multirow[t]{5}{*}{ Air(1) - soil(3) } & Diffusion & $\begin{array}{l}D_{E}=1 /\left(1 / k_{E A} A_{13}\right. \\
\left.Z+Y_{3} /\left(A_{13}\left(B_{M A} Z_{A}+B_{M w} Z_{w}\right)\right)\right)\end{array}$ \\
\hline & Rain dissolution & $D_{\mathrm{RW} 3}=\mathrm{A}_{13} \mathrm{U}_{\mathrm{Q}} \mathrm{Z}_{\mathrm{W}}$ \\
\hline & Wet deposition & $D_{Q W 3}=A_{13} U_{R} Q v_{Q} Z_{Q}$ \\
\hline & Dry deposition & $\mathrm{D}_{\mathrm{QD} 2}=\mathrm{A}_{13} \mathrm{U}_{\mathrm{Q}} \mathrm{v}_{\mathrm{O}} \mathrm{Z}_{\mathrm{Q}}$ \\
\hline & Total D values & $\begin{array}{l}D_{13}=D_{v}+D_{R W 3}+D_{Q D 3}+D_{Q W 3} \\
D_{13}=D_{v}\end{array}$ \\
\hline \multirow[t]{4}{*}{ Soil(3) - water(2) } & Soil runoff & $D_{s W}=A_{13} U_{E W} Z_{E}$ \\
\hline & Water runoff & $D_{w w}=A_{13} U_{w w} Z_{w}$ \\
\hline & & $D_{32}=D_{s w}+D_{w w}$ \\
\hline & & $D_{23}=0$ \\
\hline \multirow[t]{5}{*}{ Sediment(4) - water(2) } & diffusion & $\begin{array}{l}D_{Y}=1 /\left(1 / k_{s w A} A_{24} Z_{w}+Y_{4}\right. \\
\left./\left(A_{13}\left(B_{w 4} Z_{A}+B_{M w} Z_{w} A_{24}\right)\right)\right)\end{array}$ \\
\hline & deposition & $D_{D S}=U_{D P} A_{23} Z_{P}$ \\
\hline & resuspension & $D_{R S}=U_{R S} A_{23} Z_{s}$ \\
\hline & & $D_{24}=D_{Y}+D_{D S}$ \\
\hline & & $D_{42}=D_{Y}+D_{R S}$ \\
\hline Reaction (solute $i$ ) & & $\begin{array}{l}D_{R i}=k_{R i} V_{i} Z_{i} \text { (bulk phase) } \\
D_{R i}=\sum\left(k_{R i} V_{i} Z_{i}\right) \text { (all phases) }\end{array}$ \\
\hline Advection (bulk phase) & & $D_{A i}=G_{i} Z_{i}$ or $U_{i} A_{i} Z_{i}$ \\
\hline
\end{tabular}

\subsection{Experimental $F$ and $T$ parameters included in the Mackay models}

In order to conduct calculation for Levels I-III, some basic experimental parameters are needed. The parameters below largely apply to calculations for Levels I-II; however, the parameters and terms generated with these levels are also used to determine calculations for Levels III-IV. These data are included in Appendix B. 


\subsubsection{Vapor pressure (P)}

Vapor pressure $(\mathrm{P})$ represents the pressure of a vapor that when in equilibrium with a liquid, contains the same substance (i.e., contaminant). Thus, the vapor pressure is directly related to the concentration of solute contaminant in solution (Atkins 1998).

\subsubsection{Solubility (S)}

Solubility (S) represents the potential for a solid-phase solute to dissolve in water. Solubility is usually represented in terms of a maximum concentration in solution wherein a solute can solubilize (typically, in units of parts per million). A solute concentration that equals $\mathrm{S}$ is proportional to the saturated $\mathrm{P}$.

\subsubsection{Henry's constant $(\mathrm{H})$}

Henry's Constant $(\mathrm{H})$ is used to describe the relationship between solute concentration (from its mole fraction, $\mathrm{x}_{\mathrm{i}}$ ) to $\mathrm{P}$ (Atkins 1998). In particular, $\mathrm{H}$ is a proportionality constant described by Henry's law in Equation 3:

$$
\mathrm{f}_{\mathrm{i}}=\mathrm{x}_{\mathrm{i}} \mathrm{H}
$$

When the solution concentration $=\mathrm{S}$, then

$$
\mathrm{H}=\frac{\mathrm{P} \times \mathrm{MM}}{\mathrm{S}}
$$

where, $\mathrm{MM}=$ molar mass of the solute $\left(\mathrm{g} \mathrm{mol}^{-1}\right) . \mathrm{H}$ is used to describe the relationship between $\mathrm{P}$ and solute concentration for diluted contaminants, where its concentration represents only a minor proportion of the solvent concentration (such as water). Thus, this constant is appropriate for environmental systems.

\subsubsection{Octanol-water partitioning coefficient (Kow)}

Octanol-water portioning coefficient (Kow) is a unitless parameter, which describes the distribution of a contaminant if dispersed in water that contains an immiscible octanol phase. Thus, this parameter is an indirect representation of a solute's affinity for hydrophobic phases, such as lipids, etc. The logarithm of Kow is typically used in Mackay models. 


\subsubsection{Air-water partitioning coefficient $\left(\mathrm{K}_{\mathrm{AW}}\right)$}

The Air-water partitioning coefficient (KAw) is a unitless parameter that describes the potential for a vaporized solute to partition to the liquid phase, or aqueous phase, in environmental systems. This partitioning coefficient is influenced by the solute's $\mathrm{P}, \mathrm{K}_{\mathrm{AW}}=\mathrm{H} / \mathrm{RT}$, where H is Henry's constant, $\mathrm{R}$ is the universal gas constant, and $\mathrm{T}$ is temperature, as defined in Table 9.

\subsubsection{Sorption}

Sorption describes the potential for dissolved solutes to be removed from solution and distributed to an environmental solid-phase surface. This value is used to describe solute partitioning to both, bulk sediments and suspended particulates in water, such as those that sediment inflows or resuspension processes introduce. Linear models are the simplest and most commonly used models for generating sorption constants for organic compounds. In terms of fugacity, sorption is described in Equation 5

$$
Z_{S}=K_{D}
$$

where, $\mathrm{Z}_{\mathrm{S}}$ = fugacity capacity of $\mathrm{MC}$ sorption to the soil, $\mathrm{Z}_{\mathrm{W}}=$ fugacity capacity for $\mathrm{MC}$ in solution, and $\mathrm{K}_{\mathrm{D}}$ is the sorption distribution coefficient. This parameter is represented empirically in units of $\mathrm{L} / \mathrm{Kg}$ (representing solute distributions in both the solid and liquid phases). Given the difficulty of defining heterogeneous soil and sediment surfaces thermodynamically, empirical sorption coefficients are used.

For organic solutes, the organic carbon content of soils often normalizes $\mathrm{K}_{\mathrm{D}}$, giving the parameter $\mathrm{K}_{\mathrm{OC}}$. This normalization is based on a commonly accepted mechanism of sorption involving the partitioning of organic solutes to the organic carbon fraction of soils. From this mechanism, Karickhoff (1981) proposed an empirical equation using a solute's octanolwater coefficient.

$$
\mathrm{K}_{\mathrm{OC}}=0.41 \mathrm{~K}_{\mathrm{ow}}
$$

In separate work, Seth et al (1999) similarly reported

$$
\mathrm{Koc}=0.35 \mathrm{Kow}
$$


In spite of their similarities, the variability of these functions is on the order of $10^{2.5}$, meaning that there remains substantial uncertainty associated with predicting the sorption of organic solutes. This limitation is largely attributed to the heterogeneous composition of soil and soil organic matter, suggesting that other soil properties are important for predicting sorption that Koc does not consider. Chappell et al. (2011) improved predictions of the $\mathrm{K}_{\mathrm{D}}$ for TNT sorption by including other soil properties, such as cation exchange capacity (CEC), percent clay, and extractable iron $(\mathrm{Fe})$, into a single multivariate function $\left(\mathrm{K}_{\mathrm{D}-\mathrm{TNT}}=1.842+\right.$ $\left.0.028^{*} \mathrm{CEC}+0.004^{*} \mathrm{Fe}-0.027 \mathrm{Ca}\right)$. This work showed that $\mathrm{K}_{\mathrm{D}}$ values should be considered more as a mathematical function of soil properties instead of a single or "absolute" parameter.

\subsubsection{Persistence}

Degradation is modeled as a Level II process. Here, the authors focus on describing the persistence of MC based largely on the MC biodegradation potential in water and sediment systems, although other reactions, such as photolytic degradation, may occur. As shown in Table 10, the fugacity rate constant in sediment (Ds) is represented as in Equation 8:

$$
D_{s}=V_{s} Z_{s} k_{s}
$$

Which contains the sorption fugacity capacity $\left(Z_{s}\right)$ term from the Level I in addition to an experimentally determined degradation rate constant $(k s$, in units of time-1). Since all Level II reactions are modeled as first-order, the persistence or half-life $\left(t_{1 / 2}\right)$ of MC solutes is given in Equation 9:

$$
\mathrm{t}_{1 / 2}=\ln 2 / \mathrm{ks}_{\mathrm{s}}
$$

\subsection{F and T data from the scientific literature}

This section reports the authors' survey results of the environmental fate parameters of TNT and RDX as reported in the scientific literature. Mayo et al. (2014) previously summarized these results.

\subsubsection{Vapor pressure $(P)$}

Vapor Pressure for TNT was calculated from the empirical function expressed in Equation 10 (Hikal et al. 2011) 


$$
\operatorname{Ln} \mathrm{P}_{\mathrm{TNT}}=(39.6-15459) / \mathrm{T}
$$

where, $\mathrm{T}=$ temperature in Kelvin. At $25^{\circ} \mathrm{C}, \mathrm{P}_{-\mathrm{TNT}}=3.9 \times 10^{-3} \mathrm{~Pa}$. Also, Hikal et al. (2011) reported a similar empirical function for RDX as represented in Equation 11

$$
\operatorname{Ln} \mathrm{P}_{-\mathrm{RDX}}=(39.6-15489) / \mathrm{T}
$$

At $25^{\circ} \mathrm{C}, \mathrm{P}-\mathrm{RDX}=4.78 \times 10^{-6} \mathrm{~Pa}$.

\subsubsection{Henry's law constants $(\mathrm{H})$}

As described above, $\mathrm{H}$ values represent the proportionality constant between $\mathrm{P}$ and dissolved concentrations of a dilute solute. Box plots summarizing the reported $\mathrm{H}$ values for TNT and RDX are given in Figure $31 . \mathrm{H}$ values are commonly reported in the scientific literature relative to temperature (Figure 32), making $\mathrm{H}$ largely predictable using an exponential model. At $2 \mathrm{O}^{\circ} \mathrm{C}$, reported $\mathrm{H}$ values for TNT and $\mathrm{RDX}$ varied by approx. $2-3$ orders of magnitude.

\subsubsection{Solubility (S)}

Similar to Henry's constants, $\mathrm{S}$ is commonly reported as a function of temperature. Statistical analysis of TNT and RDX solubility (Figure 33) and dissolution rates (Figure 34) reported in the scientific literature are given below. Figure 35 shows that both TNT and RDX solubility have an exponential relationship with temperature. Data from the scientific literature also shows that the dissolution rate is a function of temperature (Figure 36).

\subsubsection{Sorption}

Calculated $\mathrm{K}_{\mathrm{D}}$ values describing the sorption of TNT and RDX on various soils, sediments, and geological materials are reported in Figure 37, showing four and three orders of magnitude, respectively. Statistical distribution analysis of this data is shown in Figure 38. Using the characterization data for the solids containing only CEC, total clay content (\%) and total organic matter (\%), a multivariate dimension-reduction and correlation calculation, was conducted through partial least squares (PLS). From the analysis, a simple three-factor model was constructed to predict the sorption coefficient for TNT (Figure 39) as in Equation 12:

$$
\mathrm{K}_{\mathrm{D}-\mathrm{TNT}}=1.3849 \mathrm{CEC}-0.3946 \% \text { clay }+1.00854
$$


Figure 31. Box and whisker plot summarizing the reported Henry Constants for TNT and RDX in the scientific literature. The middle line in the box represents the median of reported data; the dashed line represents the mean, and the borders on the box represent the first and third quartiles of the analytical data, respectively. The error bars represent the minimum and maximum values of the reported analytical data, while the cross-hair on the error bars represents the values located outside the inner quartile range (i.e., outliers).

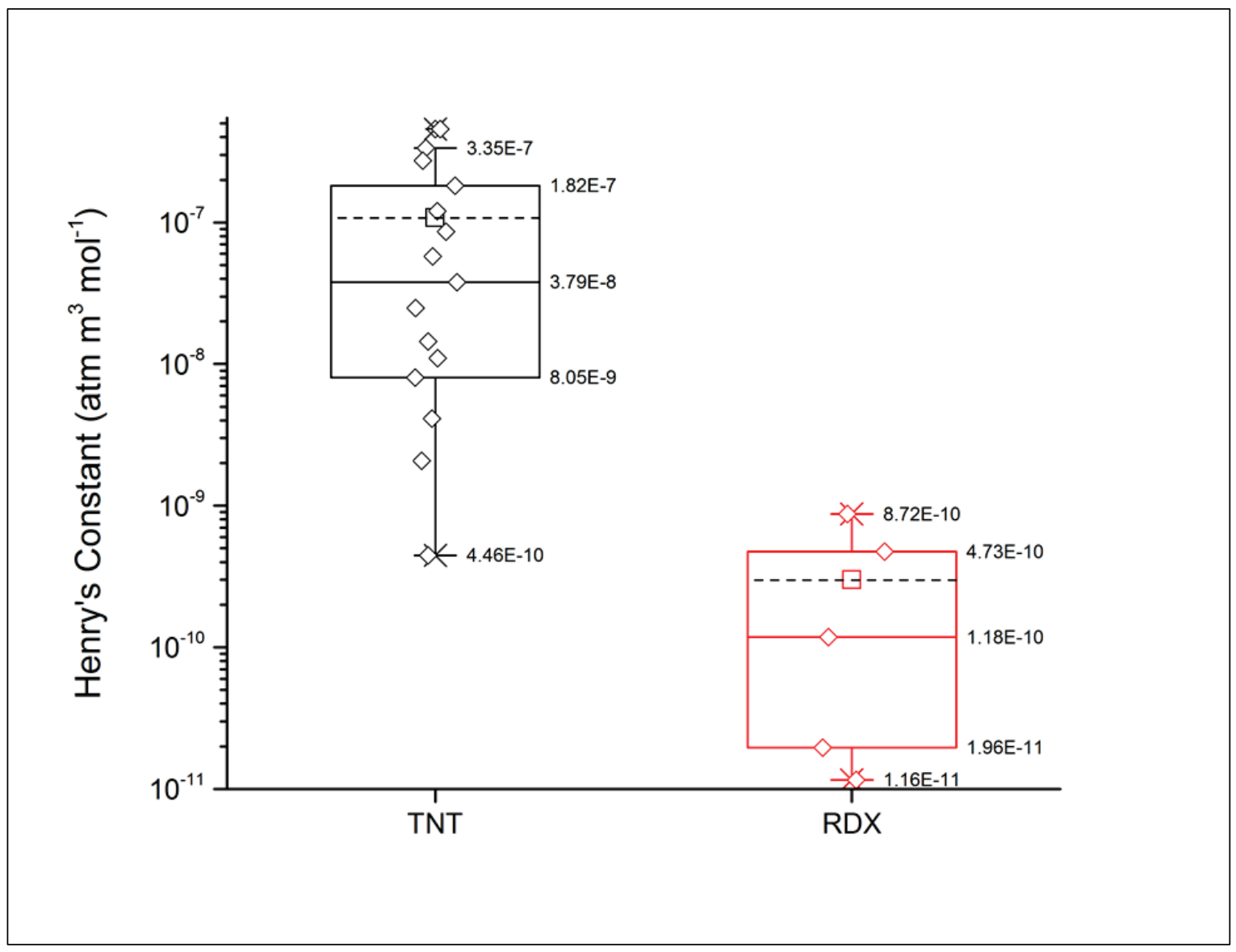


Figure 32. Plots showing the range of experimental values within the Henry's constant for (A) TNT and (B) RDX as reported in the scientific literature.

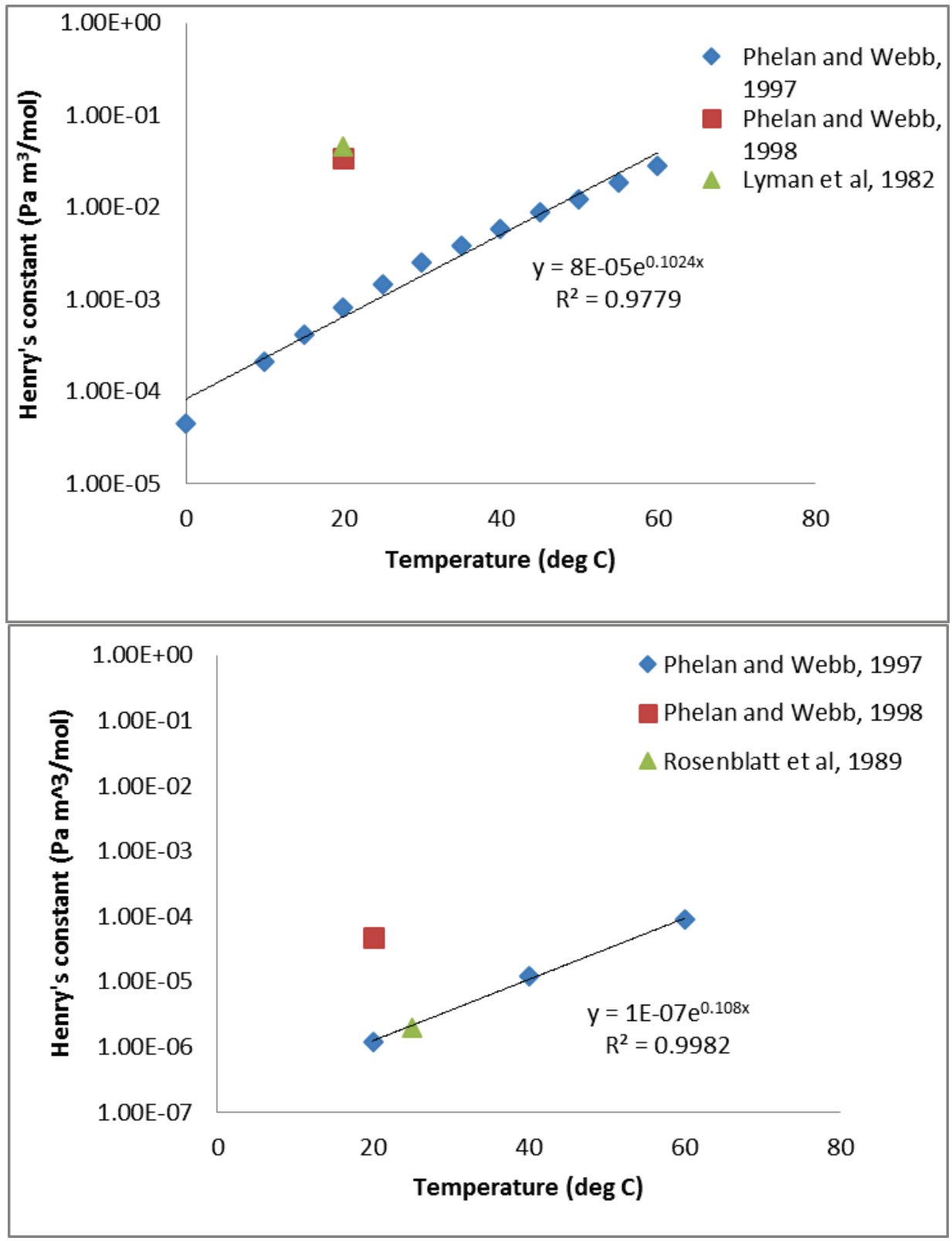


Figure 33. Box and whisker plot summarizing the reported solubility for TNT and RDX in the scientific literature. The middle line in the box represents the median of reported data; the dashed line represents the mean, and the borders on the box represent the first and third quartiles of the analytical data, respectively. The error bars represent the minimum and maximum values of the reported analytical data, while the cross-hair on the error bars represents the values located outside the inner quartile range (i.e., outliers).

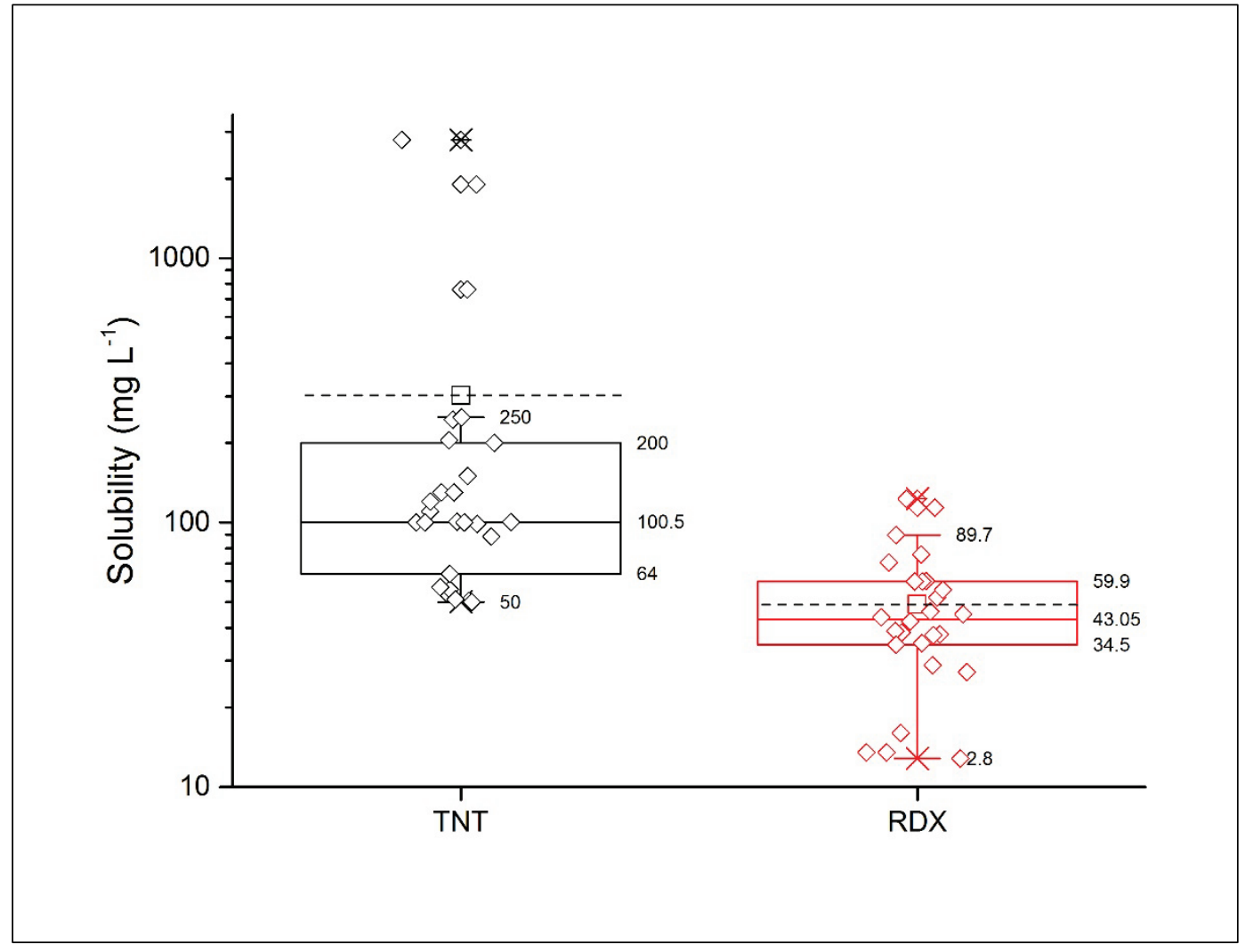


Figure 34. Box and whisker plot summarizing the reported dissolution rates for TNT and RDX in the scientific literature. The middle line in the box represents the median of reported data; the dashed line represents the mean, and the borders on the box represent the first and third quartiles of the analytical data, respectively. The error bars represent the minimum and maximum values of the reported analytical data, while the cross-hair on the error bars represents the values located outside the inner quartile range (i.e., outliers).

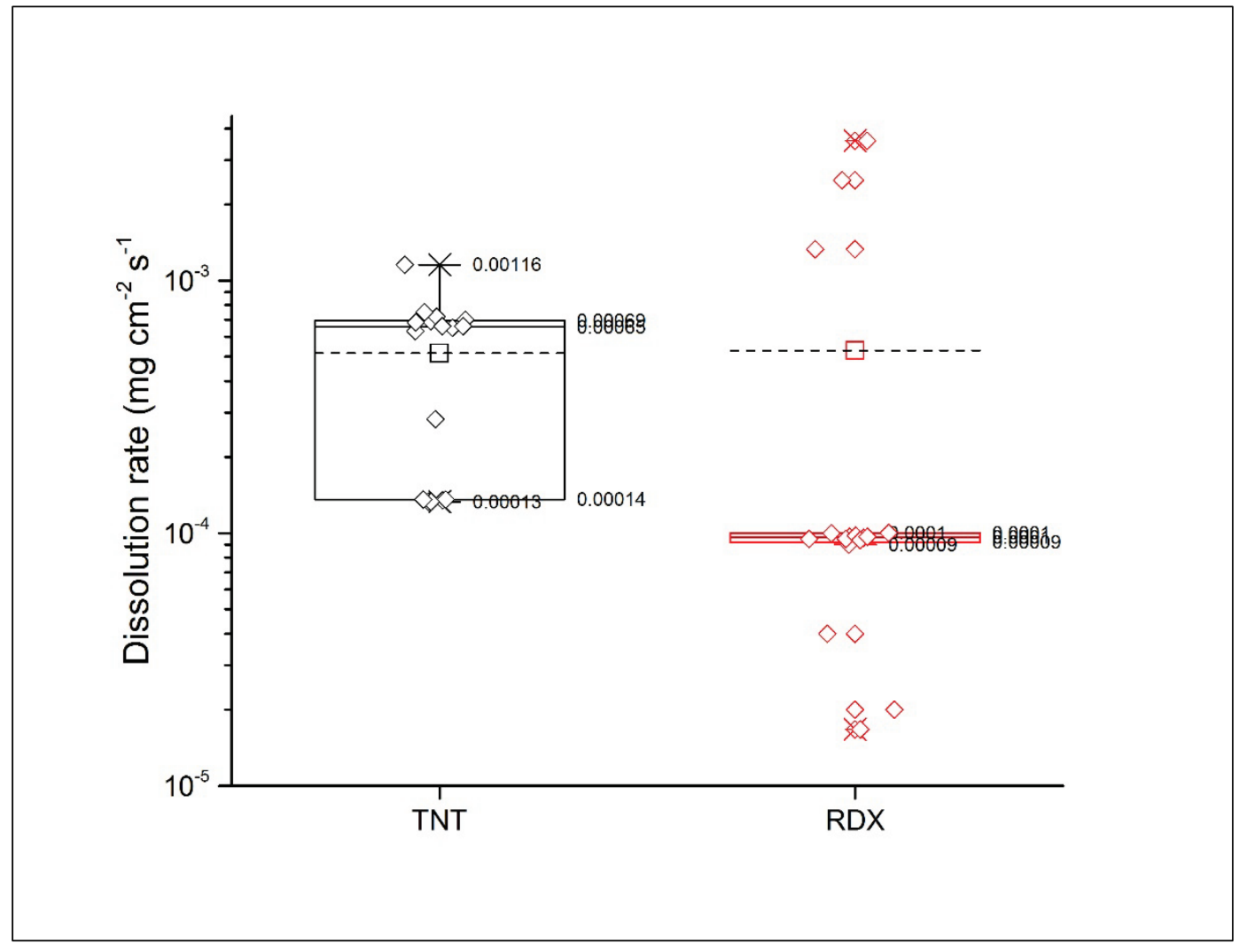


Figure 35. Plots showing the solubility of (A) TNT and (B) RDX with temperature as reported in the scientific literature.

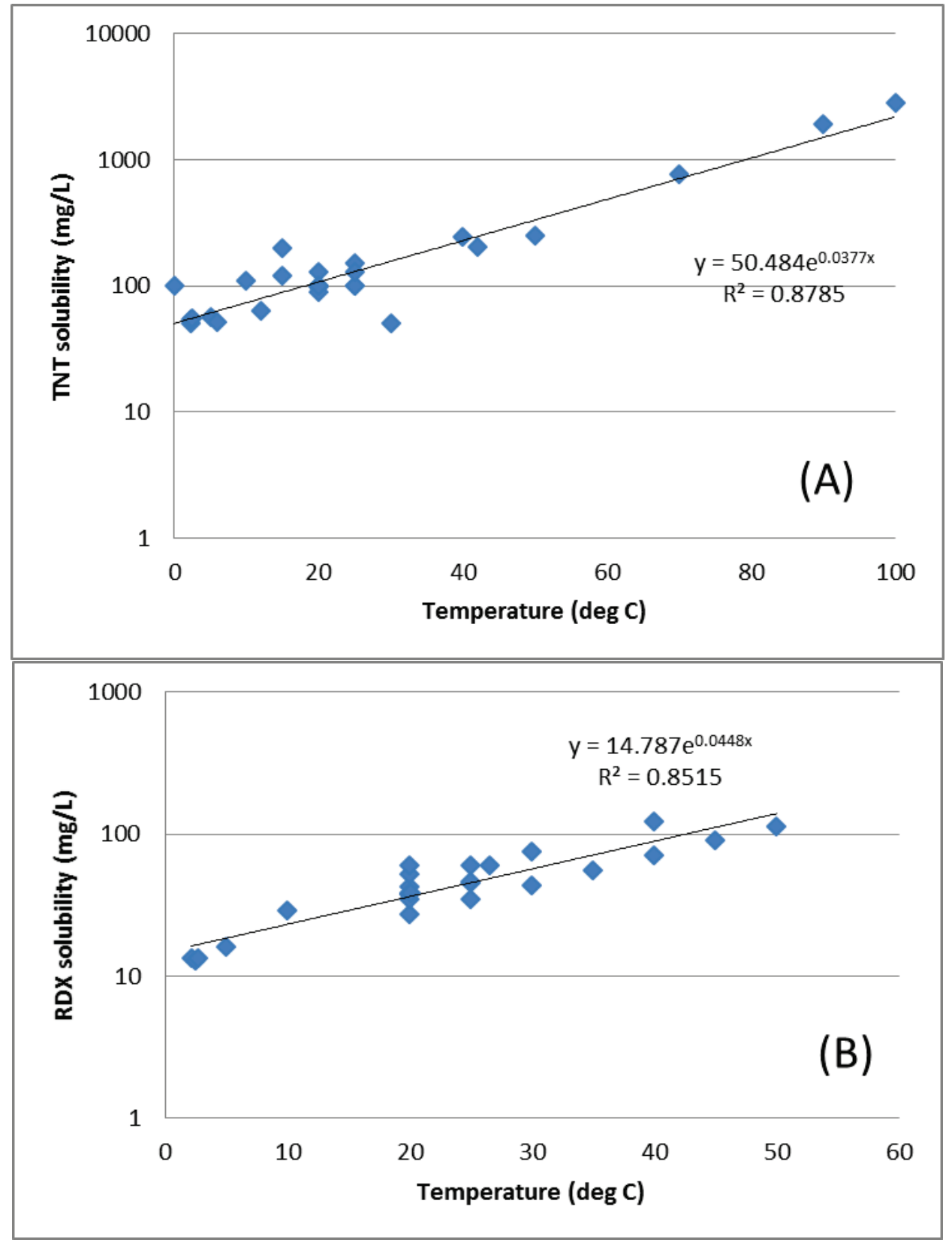


Figure 36. Plots showing the dissolution rates of (A) TNT and (B) RDX with temperature as reported in the scientific literature. The $\mathrm{x}$-axis represents each individual data point obtained from the literature.

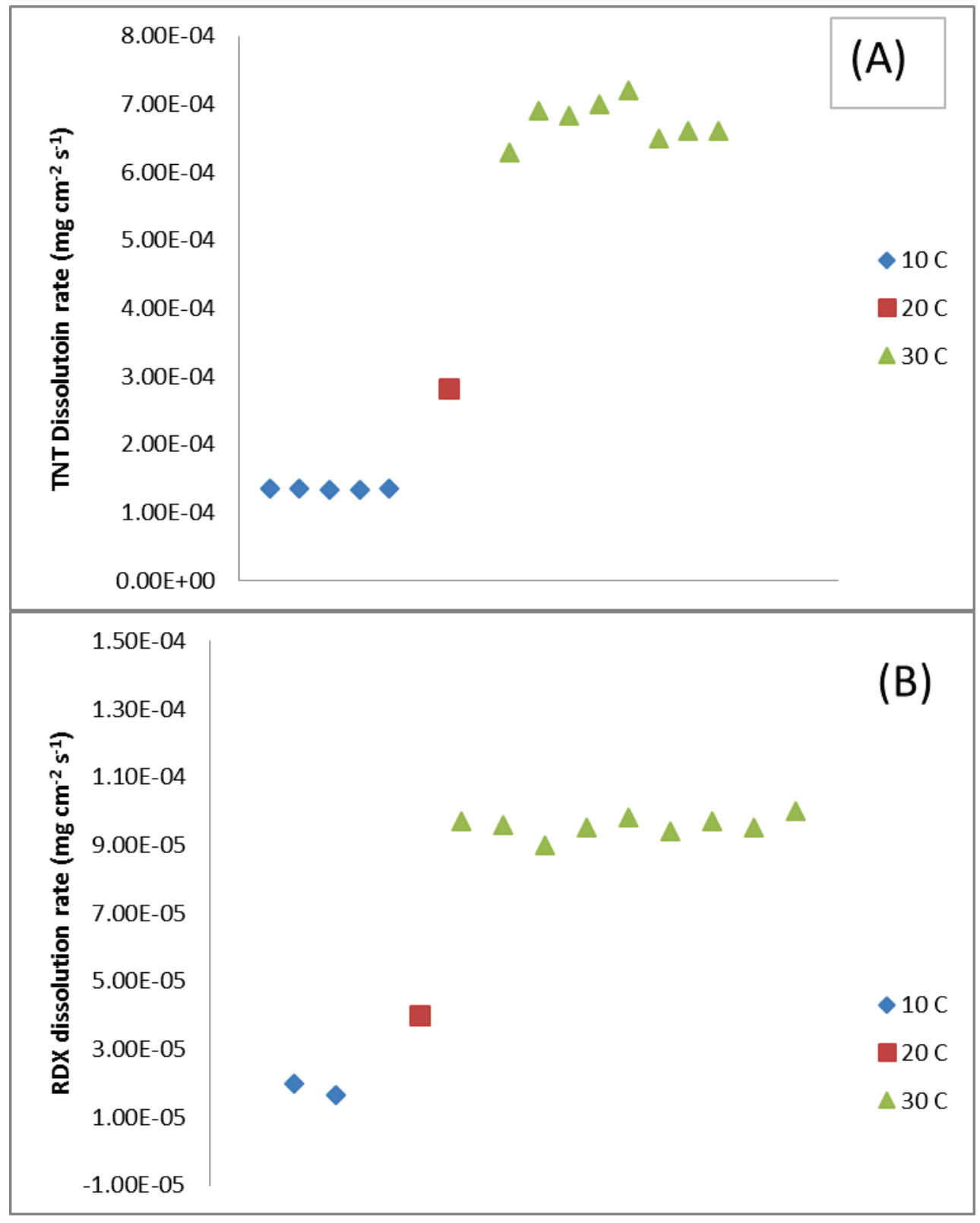


Figure 37. Calculated sorption coefficients $\left(K_{D}\right)$ for $(A)$ TNT and (B) RDX in a variety of soils, sediments, and geological materials as Brannon and Pennington (2002) summarized.
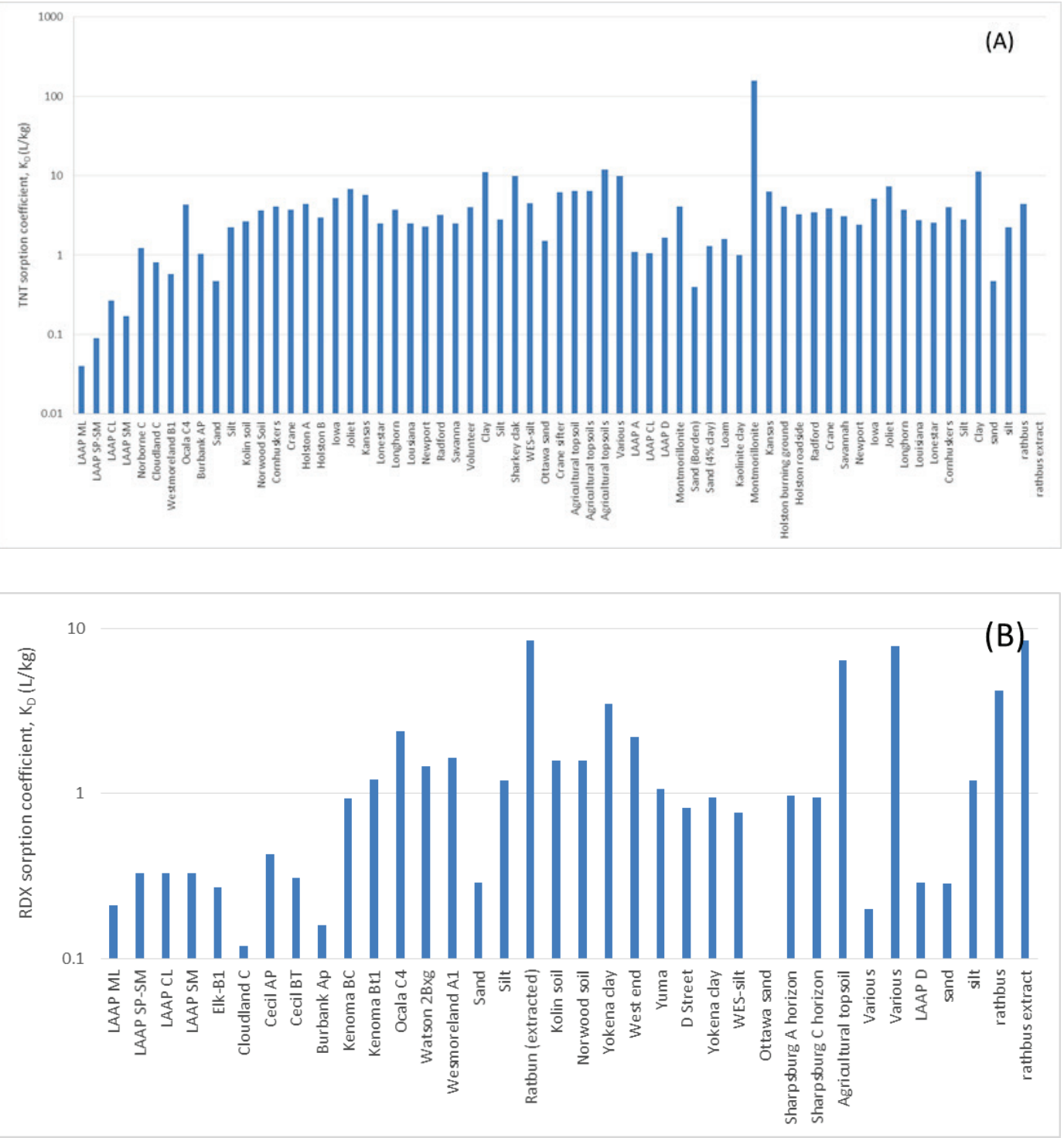
Figure 38. Box and whisker plot summarizing the reported sorption coefficients $\left(K_{D}\right)$ for TNT and RDX in the scientific literature. The middle line in the box represents the median of reported data; the dashed line represents the mean; and the borders on the box represent the first and third quartiles of the analytical data, respectively. The error bars represent the minimum and maximum values of the reported analytical data while the cross-hair on the error bars represents the values located outside the inner quartile range (i.e., outliers).

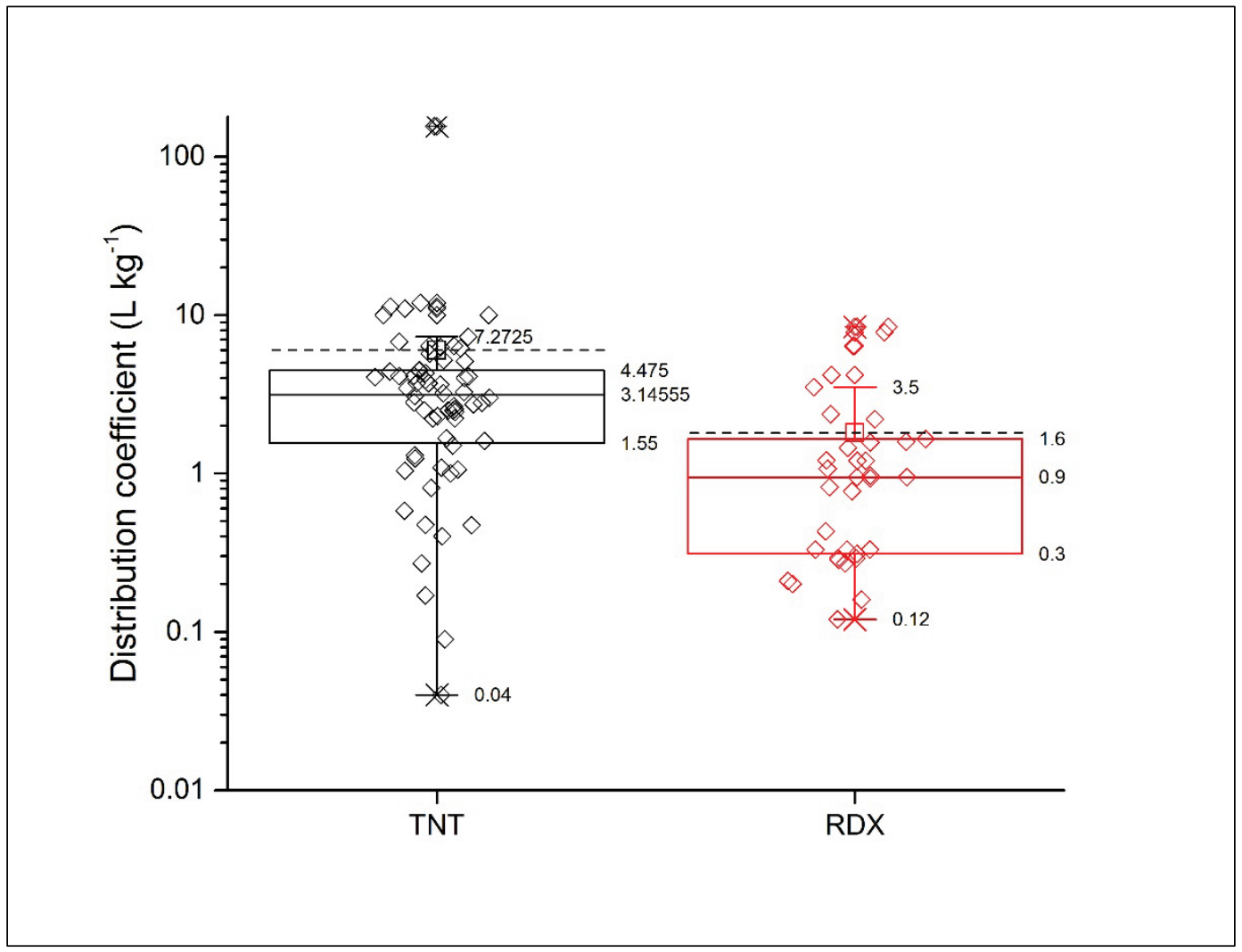


Figure 39. Partial least squares (PLS) analysis (preliminary) of TNT soil sorption data compared to a small set of soil properties. (A) Percent explained variance using a three-factor model; (B) plot showing correlation between the calculated and predicted $K_{D}$ values. (C) Score plot; (D) loading plot.

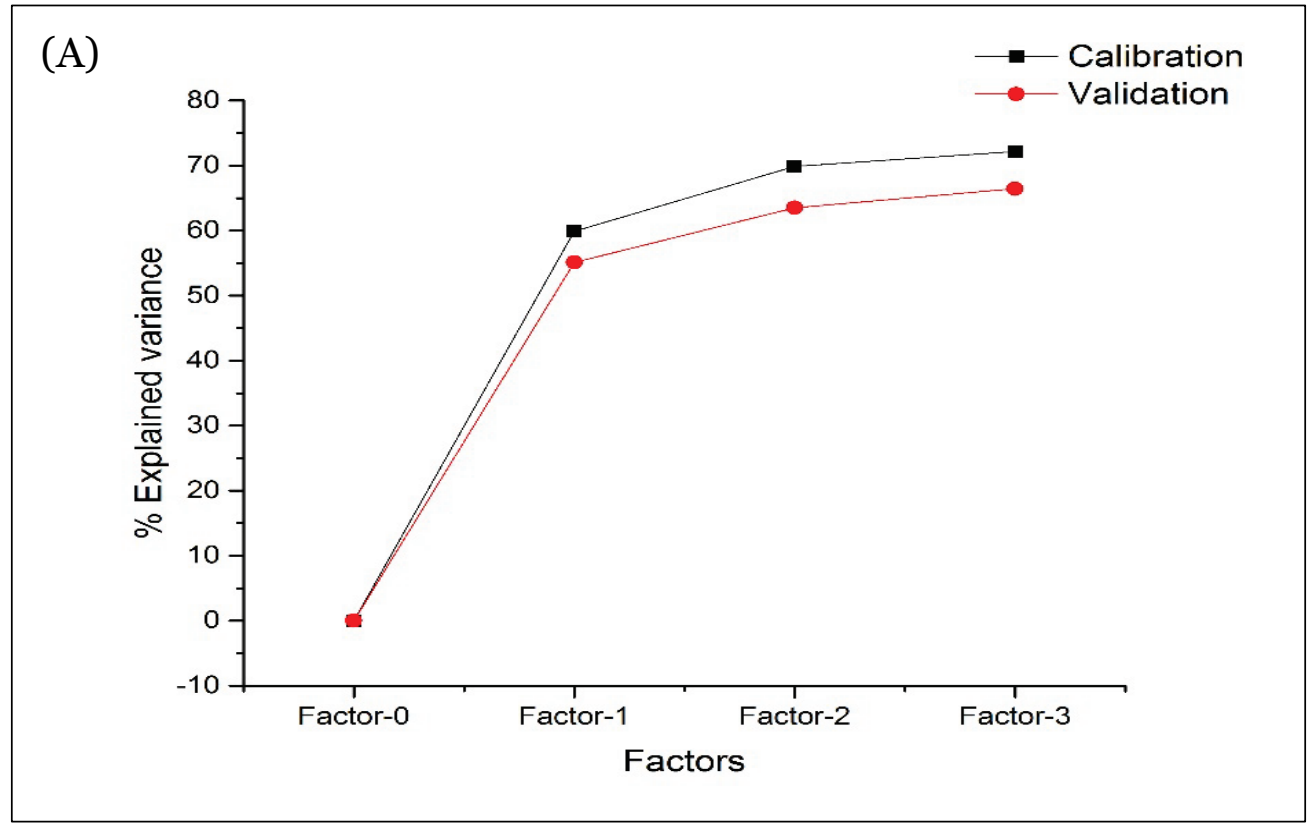

(B)

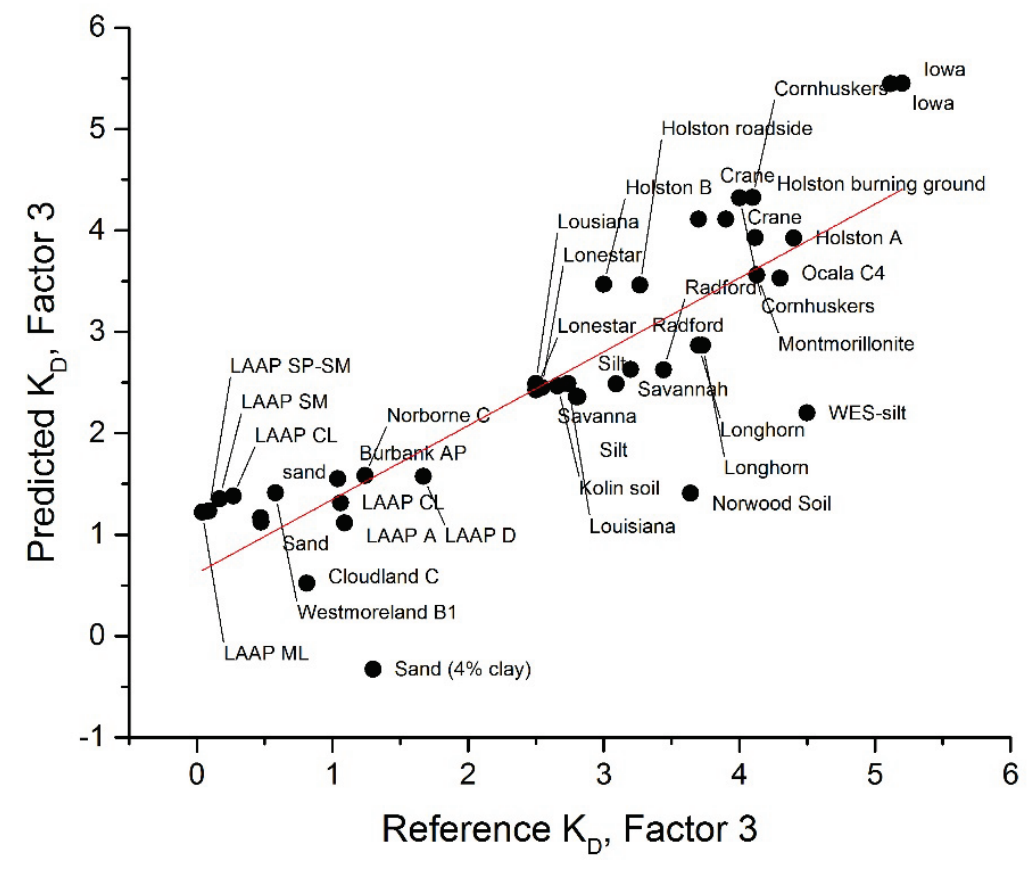


(C)

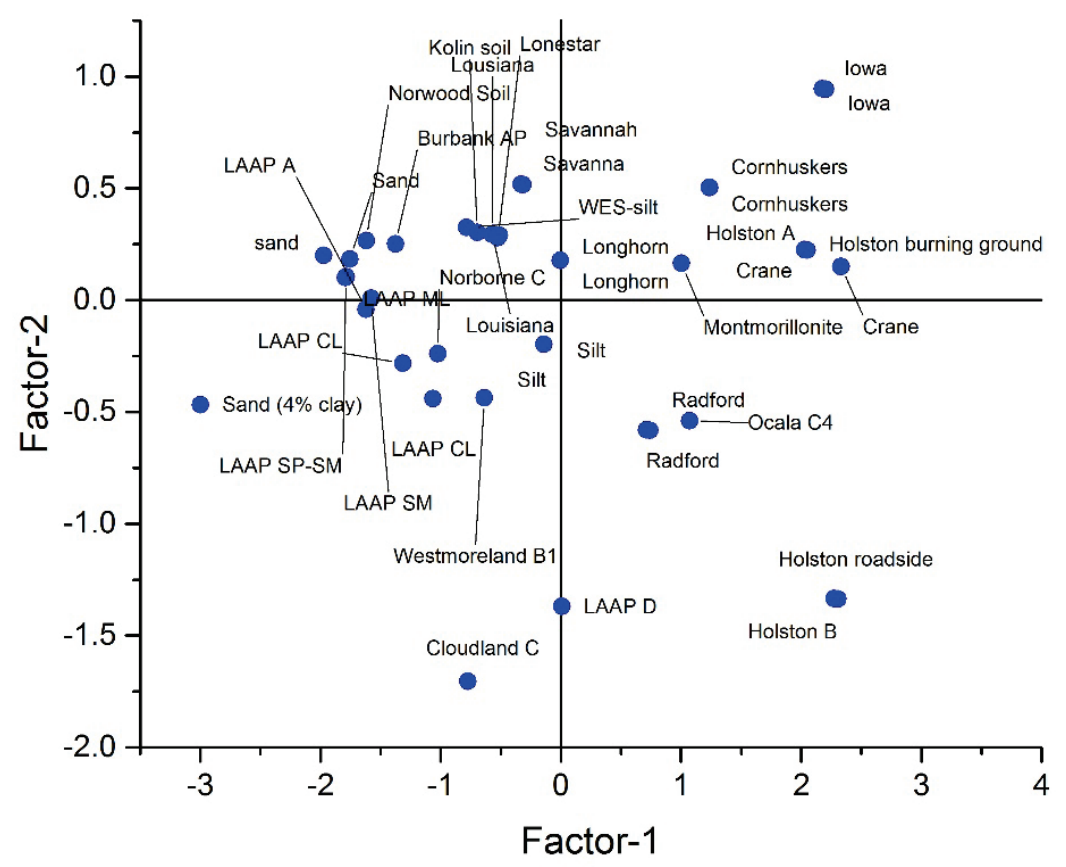

(D)

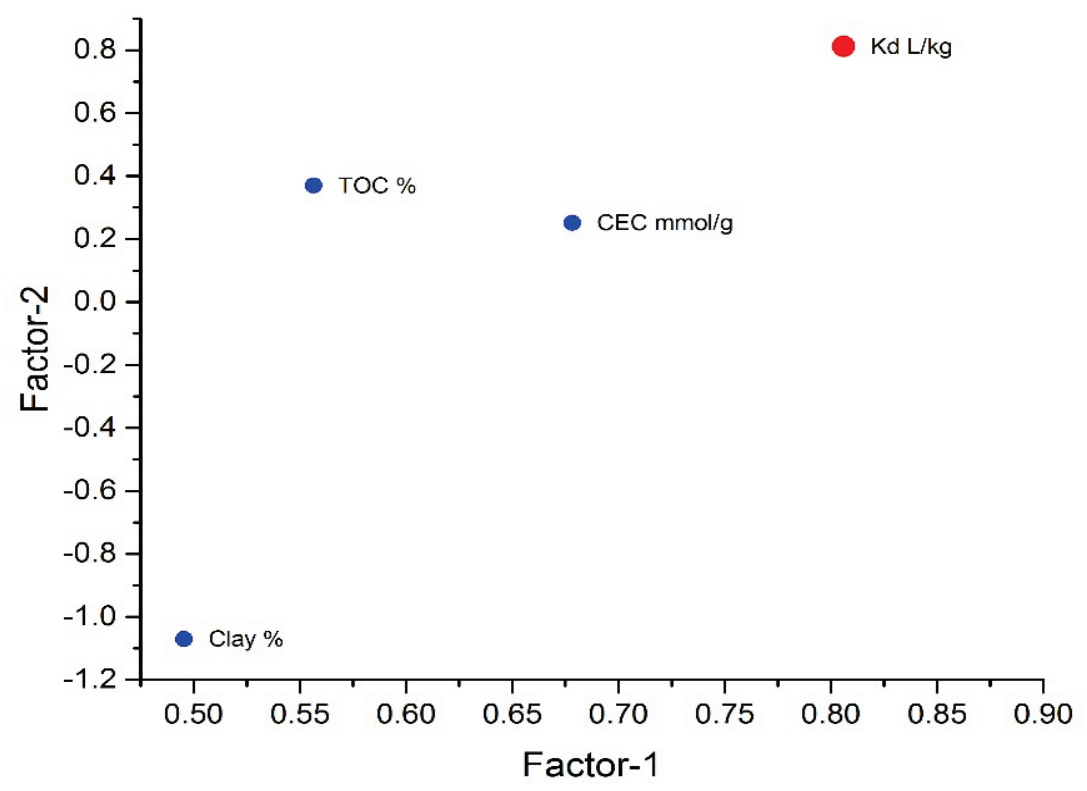

The coefficient of determination $\left(\mathrm{R}^{2}\right)$ was 0.721 . For the log-transformed RDX data, the authors used a simple two-factor model to predict its sorption (Figure 40) as in Equation 13 
With an $\mathrm{R}^{2}$ of 0.681 . Interestingly, in both models, the TNT and RDX $\mathrm{K}_{\mathrm{D}}$ values are directly correlated with CEC and negatively correlated with \%clay. As Chappell et al. (2011) suggests, this relationship emphasizes the influence of the soil/sediment organic matter's surface negative charge over the hydrophobic behavior. Thus, the CEC describes the functional nature of the soil charge to influence TNT and RDX sorption better the \%TOC. Note that for TNT sorption, a Martens stability test (Martens and Næs 1989) performed on the regression coefficients demonstrated that the statistical contribution of \%TOC to the prediction model is not significant; therefore, this variable was removed from the prediction equation.

Sorption coefficients are also presented by normalizing calculated $\mathrm{K}_{\mathrm{D}}$ values via the \%TOC. Values collected from the literature as well as calculated from the above information are shown in Figure 41.

\subsubsection{Photodegradation}

Reported data for the photolytic half-life of TNT and RDX are plotted in Figure 42. Statistical distribution analysis is given in Figure 43. Solute half-life $\left(\mathrm{t}_{1 / 2}\right)$ is calculated from the photolytic rate constant after Equation 8-8is performed. The photolytic half-life varies with the intensity of simulated sunlight exposure - solutes exposed to full "sunlight" illumination generally exhibited (but not always) lower $\mathrm{t}_{1 / 2}$ values than those exposed to less intense illumination. This data emphasizes the need for more uniformity when reporting these $t_{1 / 2}$ values.

\subsubsection{Biodegradation}

In the scientific literature, the $\mathrm{t}_{1 / 2 \text {-TNT }}$ of TNT generally ranges from $10-$ 10,000 hours, while the $t_{1 / 2}$ ranges from 10-1,000 hours, depending on experimental conditions (Figure 44 and Figure 45). This information does not discriminate between experiments conducted in the presence or absence of soils or sediments. Obviously, the variance in the $t_{1 / 2}$ values can be attributed to the microbial communities and their overall enzymatic activities within these experimental systems.

\subsubsection{Degradation in soil}

Figure 46 and Figure 47 summarizes the disappearance rates of TNT and RDX in soil suspensions. Kinetic rate constants for both munitions compounds generally varied by $4-5$ orders of magnitude. When 
comparing Figure 34 to Figure 40, it seems that MC solutes that exhibit high KD values for sorption show the highest degradation rates in suspension. Such a conclusion seems counter-intuitive given that sorption is expected to inhibit the degradation rate of the munitions by lowering the solute's chemical activity. Thus, the data suggests that enzymatic degradation is mediated by surface-colonized microbial communities, whose activity is largely influenced by the properties of the solid phase, such as its fertility status (Katseanes et al. 2015).

Basic statistics associated with the reported environmental fate parameters for TNT (Table 13) and RDX (Table 14) are given below.

Figure 40. Partial least squares (PLS) analysis (preliminary) of RDX soil sorption data compared to a small set of soil properties. (A) Percent explained variance using a 2Factor model; (B) plot showing correlation between the calculated and predicted $K_{D}$ values. (C) Score plot; (D) loading plot.

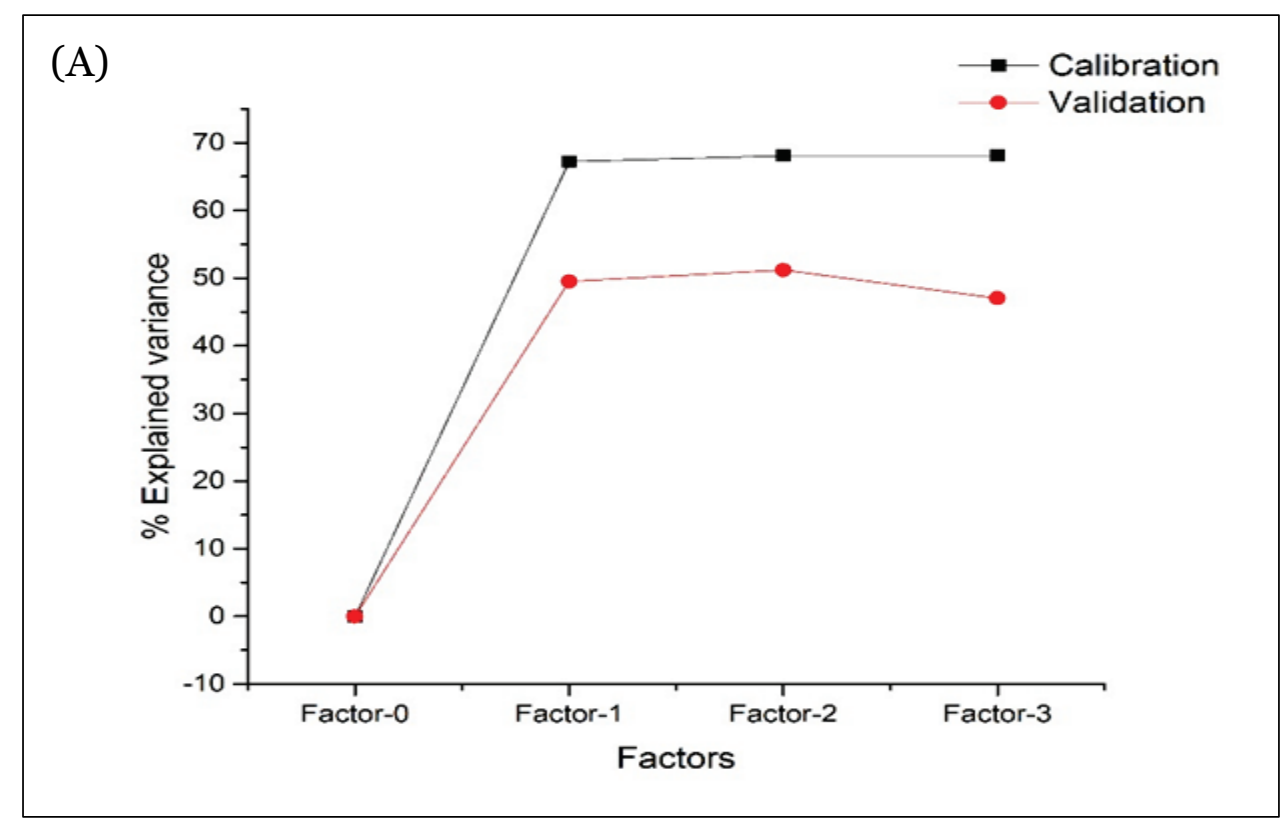


(B)

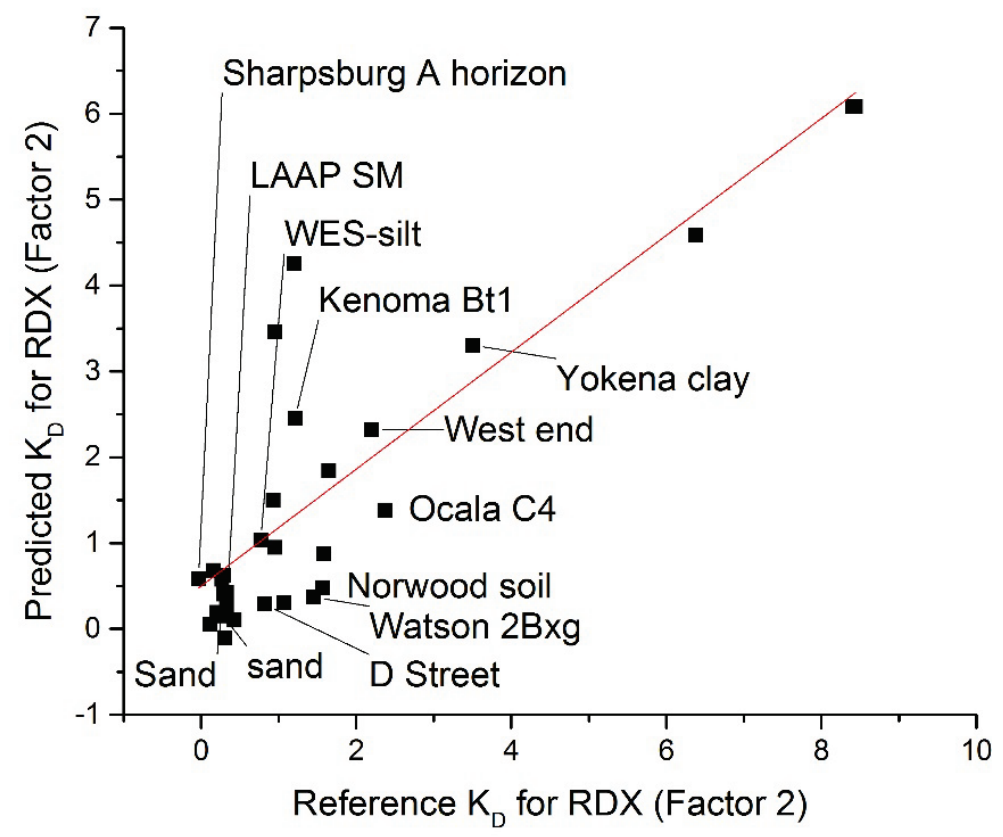

(C)

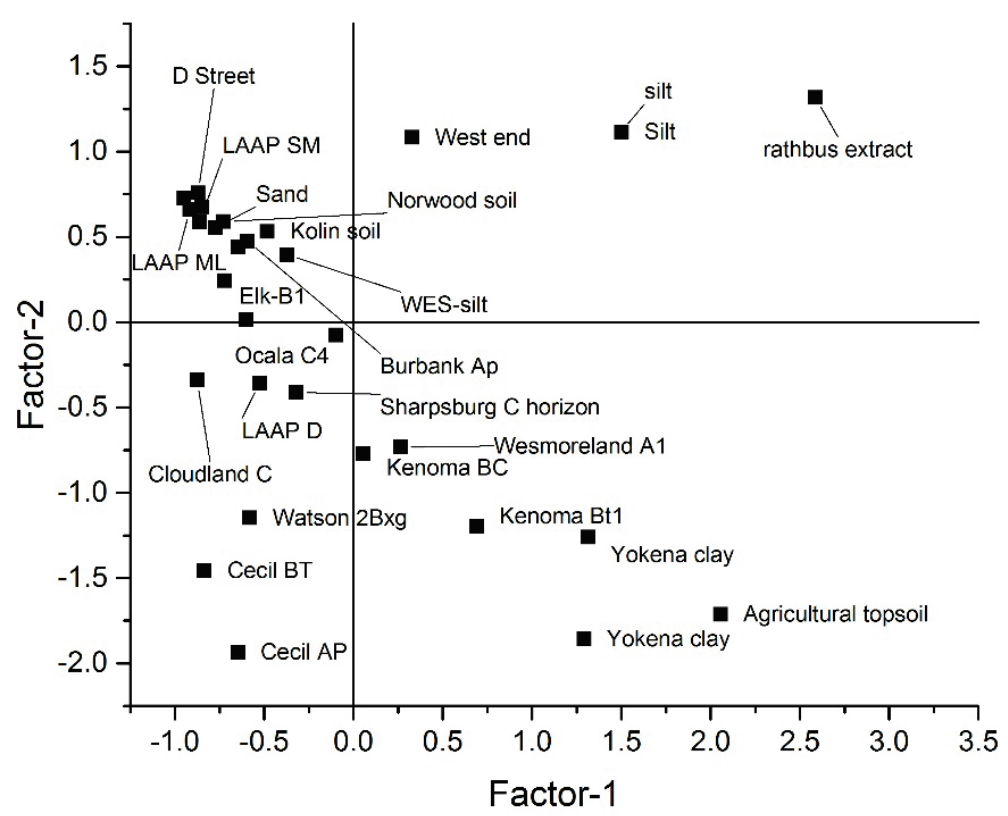


(D)

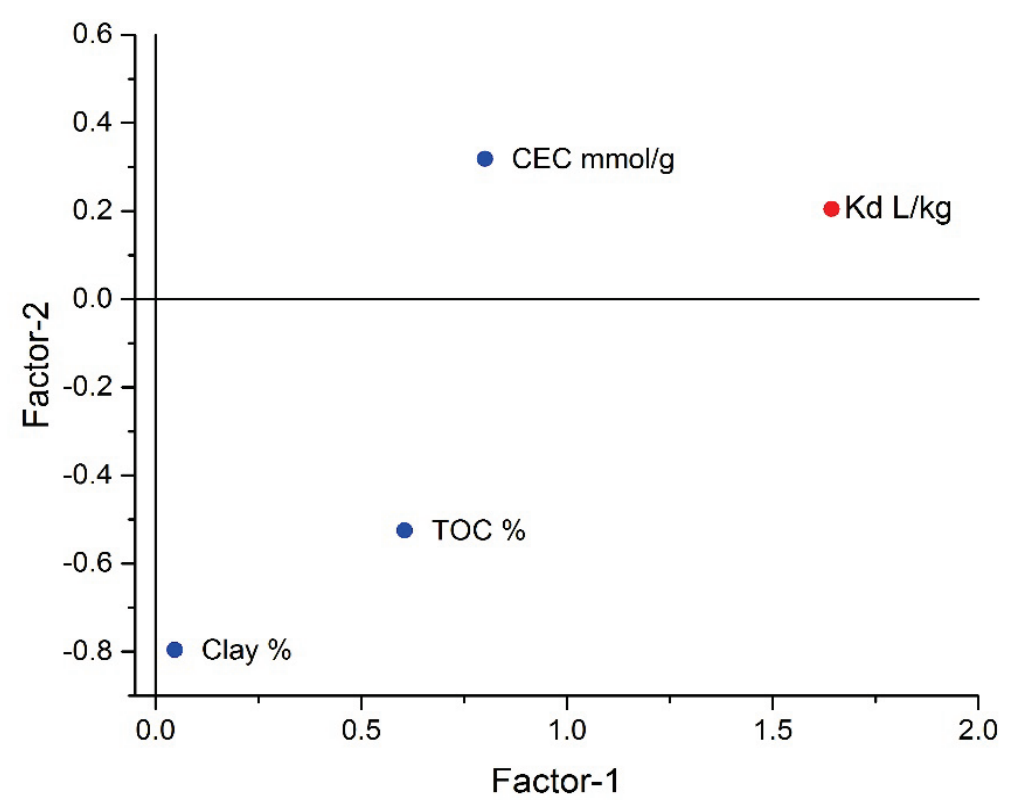


Figure 41. Box and whisker plot summarizing the reported Koc values as well as those calculated from $K_{D}$ values for TNT and RDX in the scientific literature. The middle line in the box represents the median of reported data; the dashed line represents the mean, and the borders on the box represent the first and third quartiles of the analytical data, respectively. The error bars represent the minimum and maximum values of the reported analytical data while the cross-hair on the error bars represents the values located outside the inner quartile range (i.e., outliers).

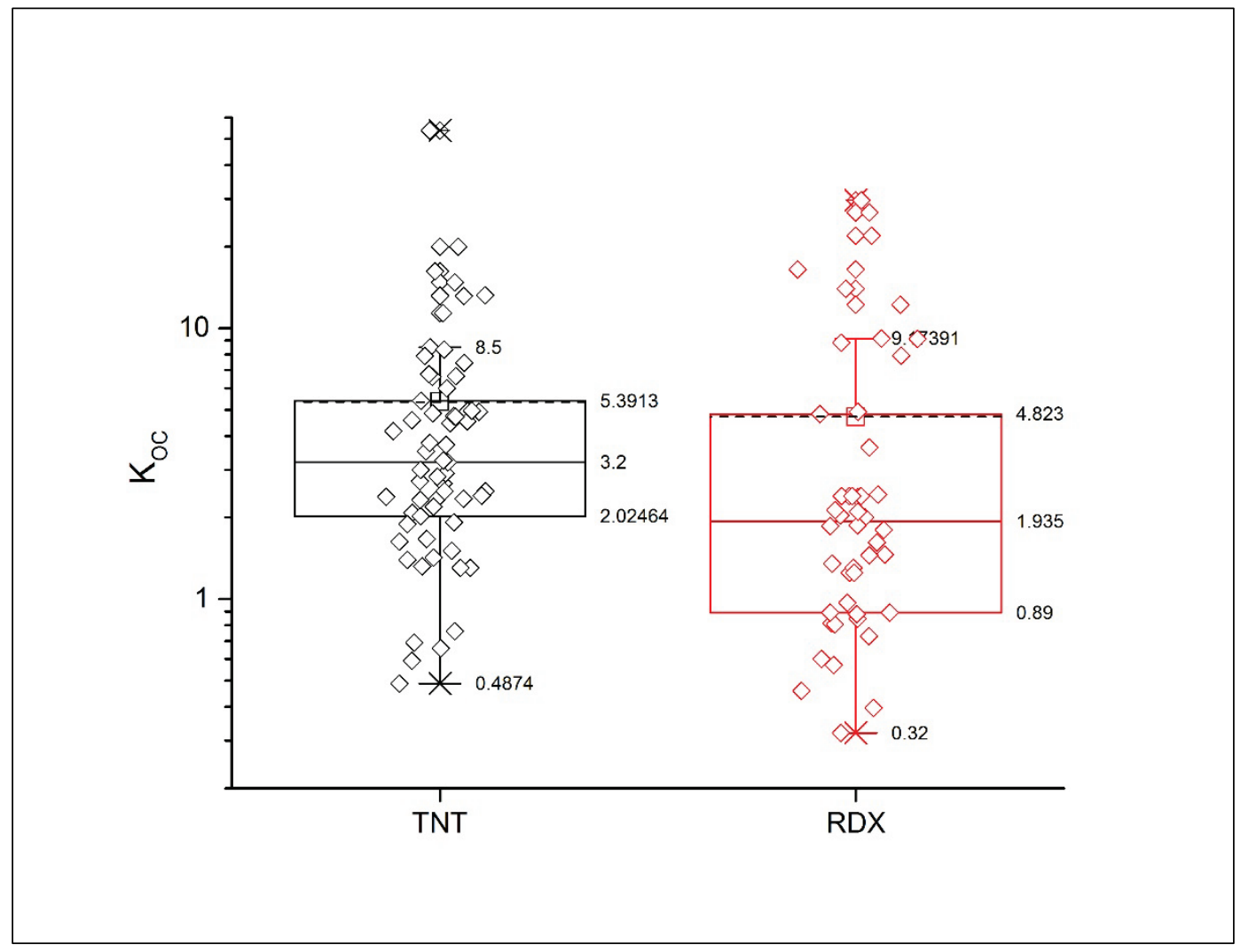


Figure 42. Data from the scientific literature showing the photodegradation half-life of (A) TNT and (B) RDX.

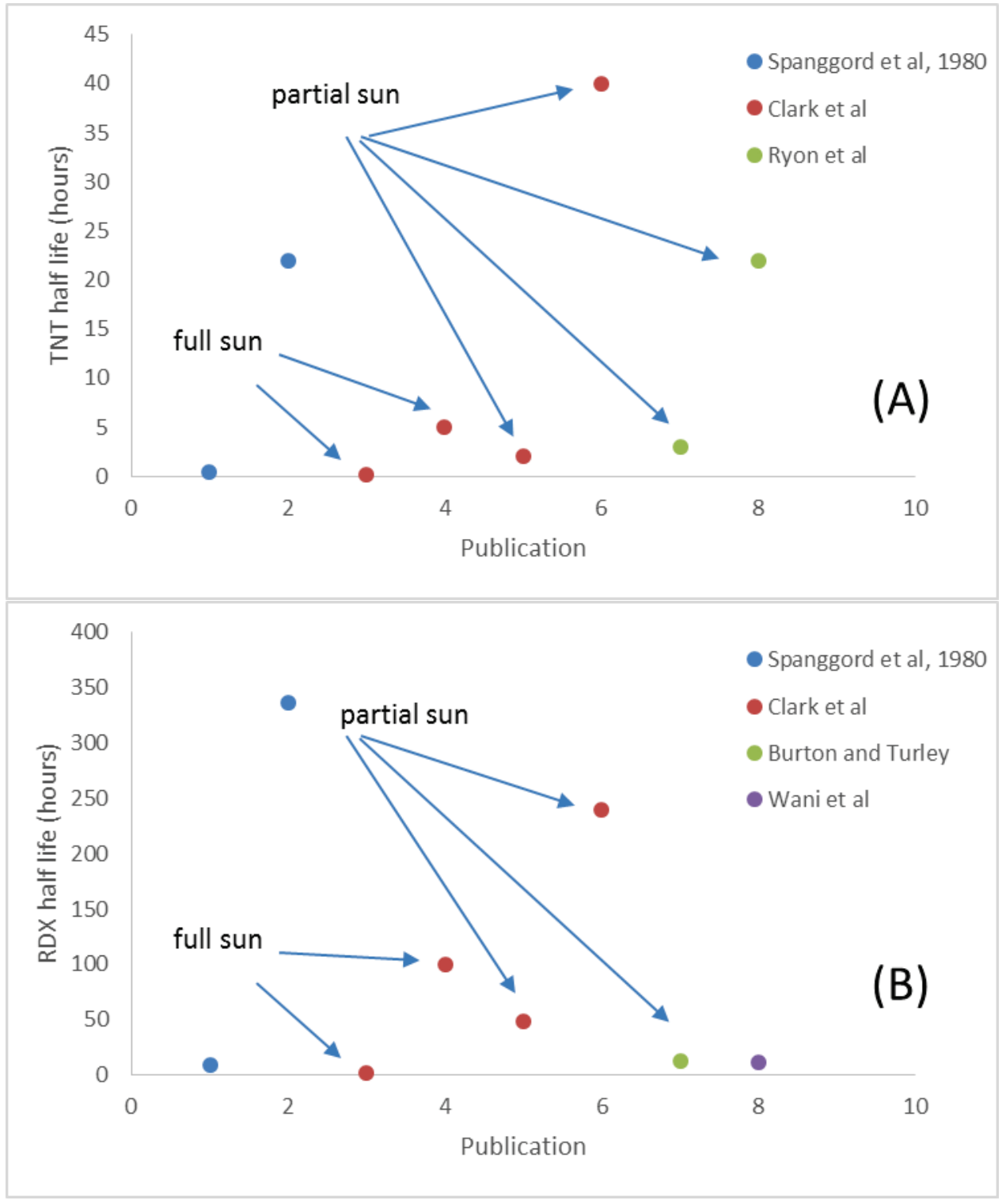


Figure 43. Box and whisker plot summarizing the reported photodegradation halflives $\left(t_{1 / 2}\right)$ for TNT and RDX in the scientific literature. The middle line in the box represents the median of reported data; the dashed line represents the mean, and the borders on the box represent the first and third quartiles of the analytical data, respectively. The error bars represent the minimum and maximum values of the reported analytical data while the cross-hair on the error bars represents the values located outside the inner quartile range (i.e., outliers).

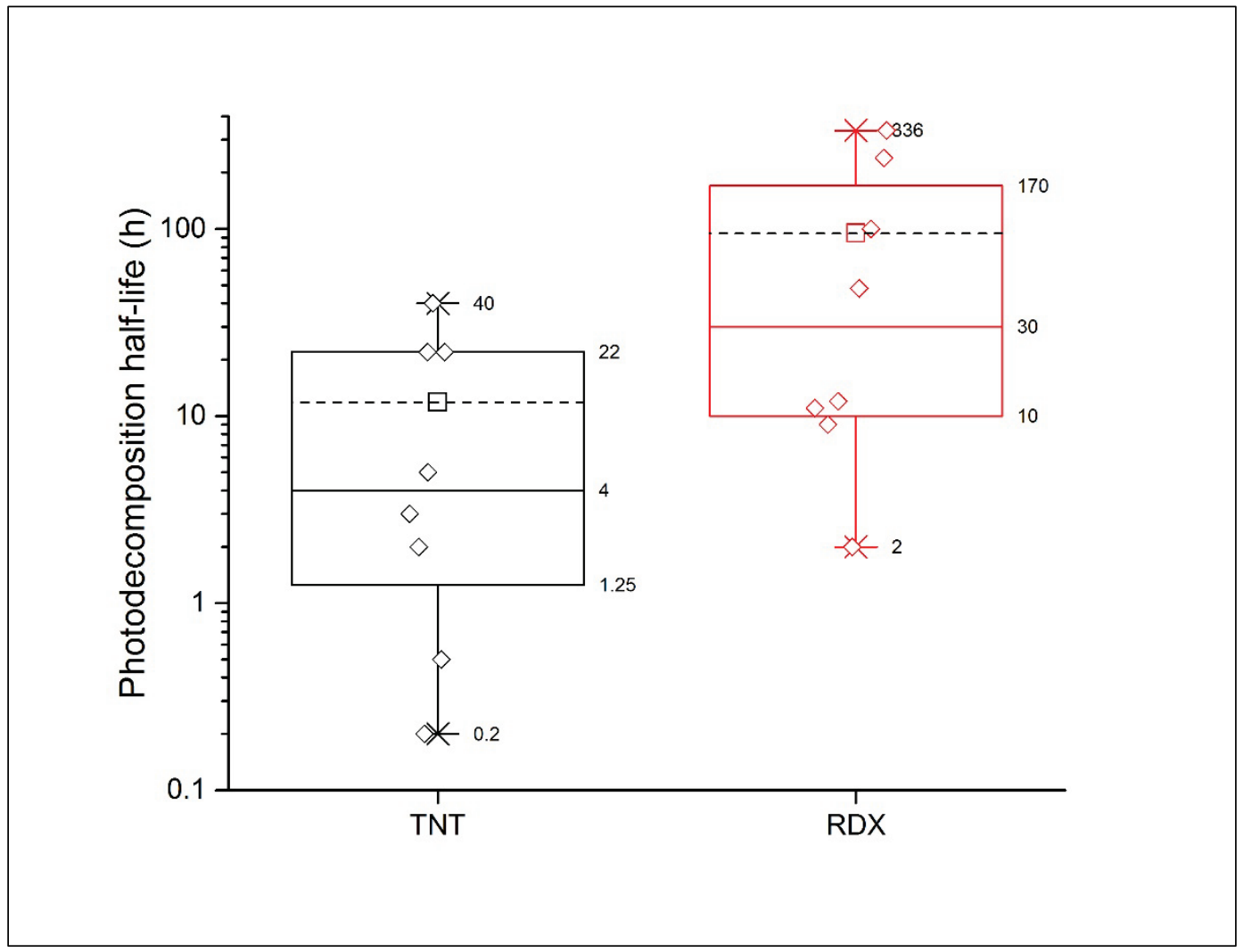


Figure 44. Data for the biodegradation half-life of (A) TNT and (B) RDX collected from the scientific literature. (C) Plot comparing the TNT biodegradation half-life

to experimental system temperature. For $A-B$, labels on the $x$-axis contain additional notes (when available) regarding the experimental test conditions.

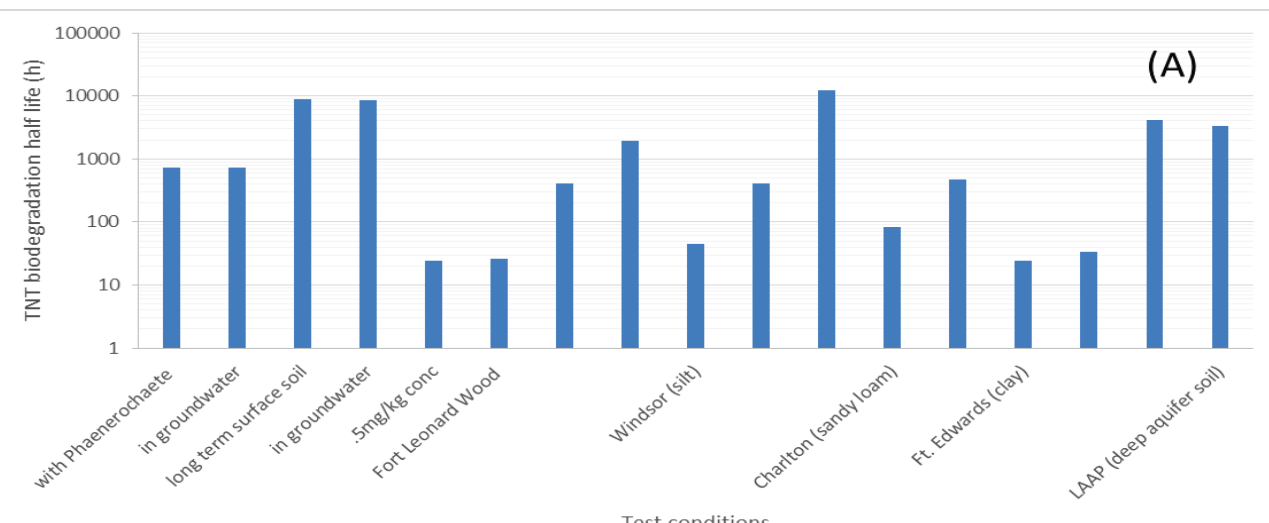

Test conditions
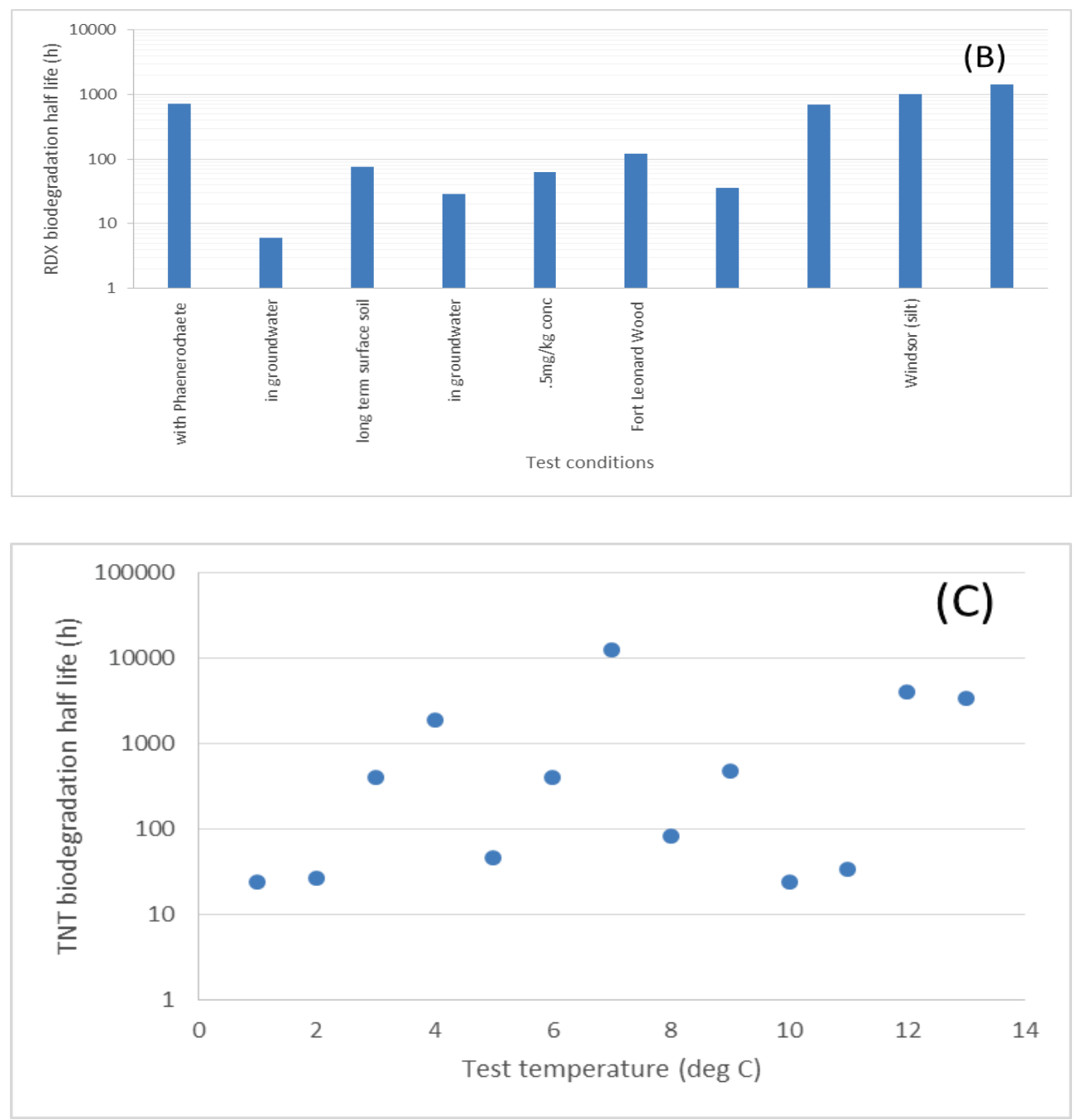
Figure 45. Box and whisker plot summarizing the reported biodegradation half-lives $\left(t_{1 / 2}\right)$ for TNT and RDX in the scientific literature. The middle line in the box represents the median of reported data; the dashed line represents the mean, and the borders on the box represent the first and third quartiles of the analytical data, respectively.

The error bars represent the minimum and maximum values of the reported analytical data while the cross-hair on the error bars represents the values located outside the inner quartile range (i.e., outliers).

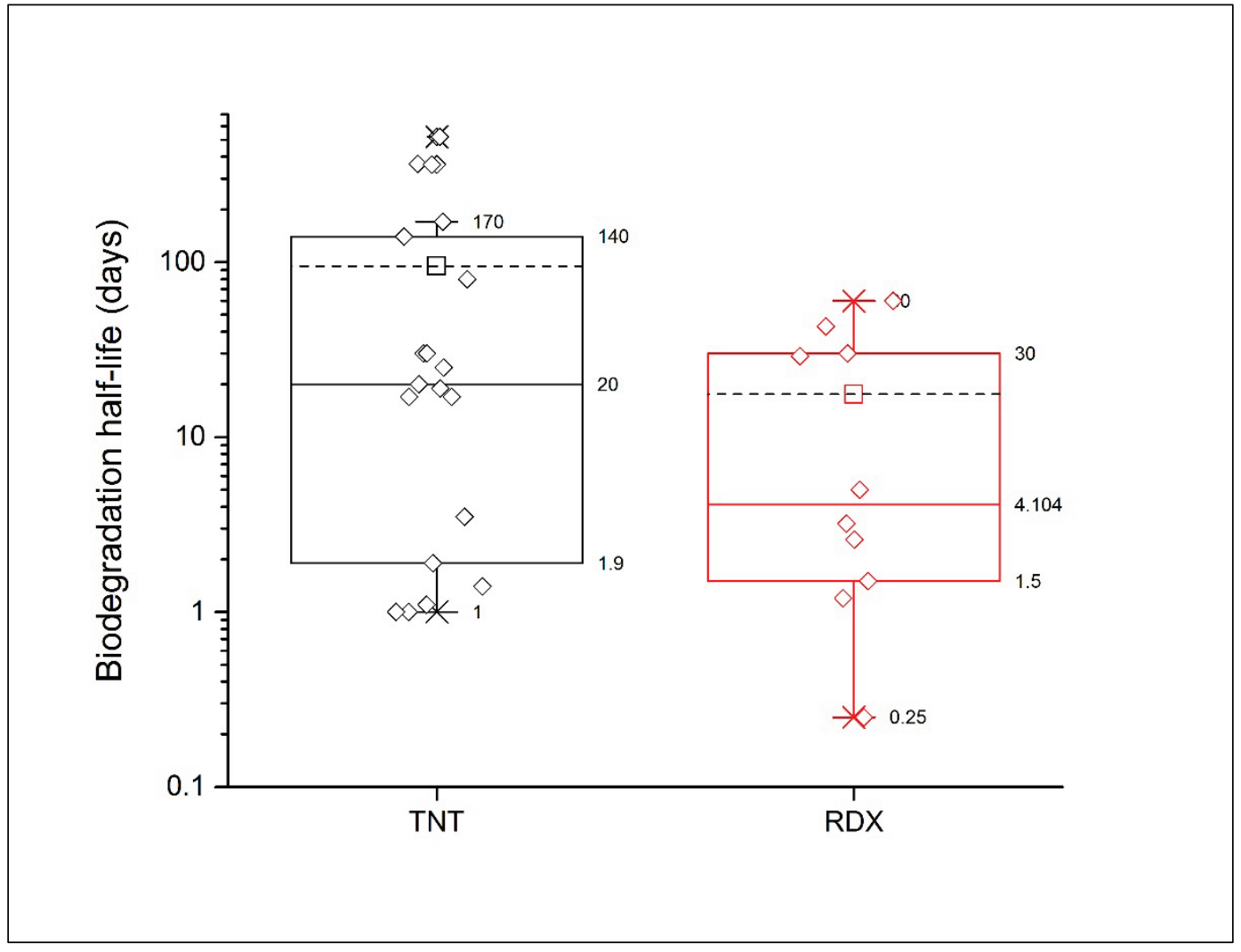


Figure 46. Box and whisker plot summarizing the reported biodegradation constants ( $k$ ) for TNT and RDX in the scientific literature. The middle line in the box represents the median of reported data; the dashed line represents the mean, and the borders on the box represent the first and third quartiles of the analytical data, respectively.

The error bars represent the minimum and maximum values of the reported analytical data while the cross-hair on the error bars represents the values located outside the inner quartile range (i.e., outliers).

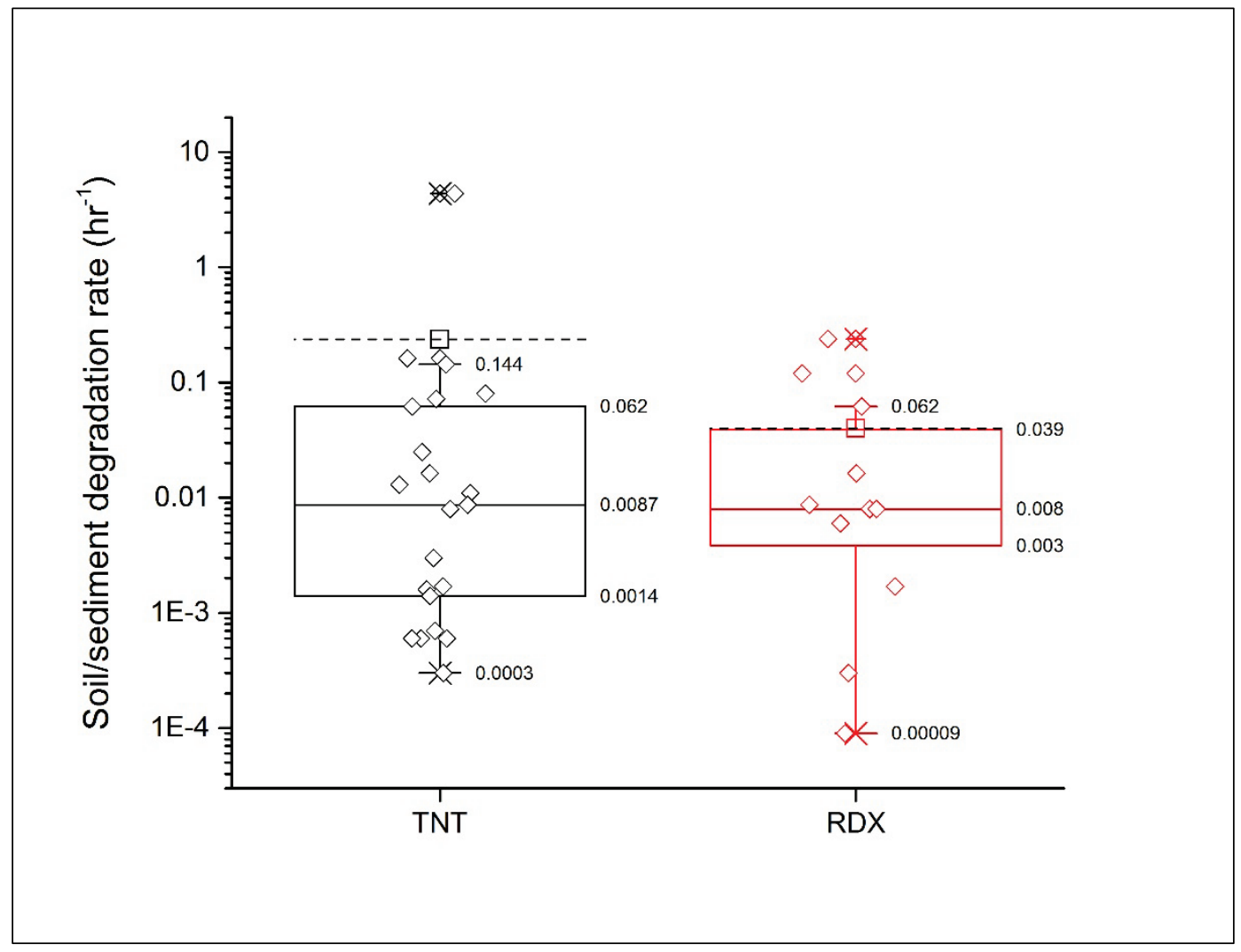


Figure 47. Data from the scientific literature showing the degradation rate of (A) TNT and (B) RDX in different soil types.
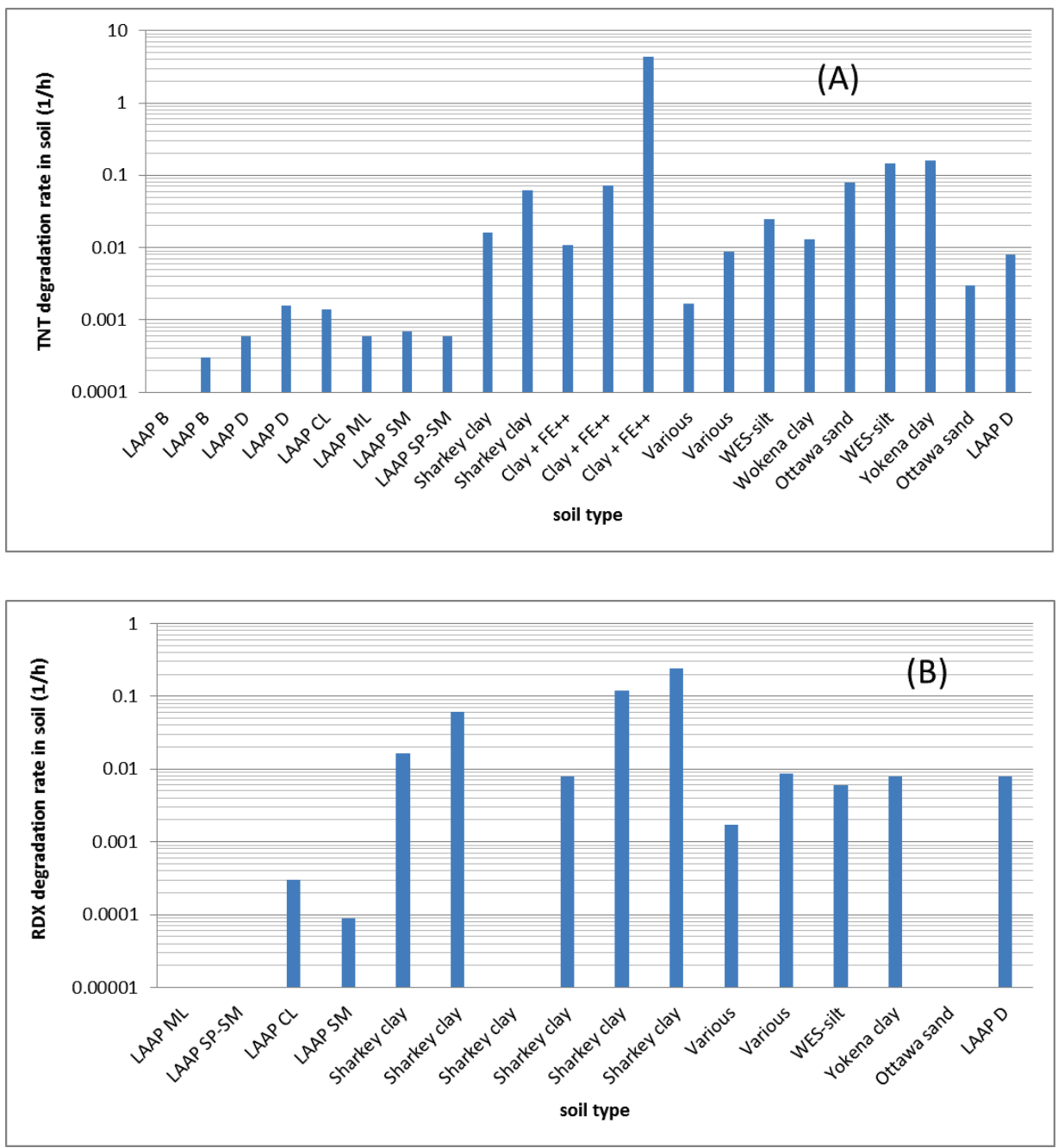
Table 13. Tests for normality and descriptive statistics and information regarding the environmental fate parameters for TNT reported in the scientific literature.

\begin{tabular}{|c|c|c|c|c|c|c|c|c|c|}
\hline Parameter & Skewness & Kurtosis & Mean & Stdev & Median & Min & Max & Units & $\begin{array}{l}\text { Data } \\
\text { Points }\end{array}$ \\
\hline Solubility & - & - & 302 & 618 & 100.5 & 50 & 2800 & $\mathrm{mg} / \mathrm{L}$ & 27 \\
\hline $\begin{array}{l}\text { Dissolution } \\
\text { rate }\end{array}$ & 0.04976 & -0.67373 & $5.2 \times 10^{-4}$ & $3.1 \times 10^{-4}$ & $6.6 \times 10^{-4}$ & $1.3 \times 10^{-4}$ & $1.2 \times 10^{-3}$ & $\mathrm{mg} \mathrm{cm} \mathrm{cm}^{-2} \mathrm{~s}^{-1}$ & 16 \\
\hline $\begin{array}{l}\text { Henry's } \\
\text { Constant }\end{array}$ & 1.49518 & 1.35794 & $1.077 \times 10^{-7}$ & 1.4 & $3.8 \times 10^{-3}$ & $4.5 \times 10^{-5}$ & $4.7 \times 10^{-2}$ & $\mathrm{~Pa} \mathrm{~m}^{3} / \mathrm{mol}$ & 15 \\
\hline Adsorption $\left(K_{D}\right)$ & 7.74492 & 61.20879 & 5.99 & 19.25 & 3.1 & 0.04 & 156 & $\mathrm{~L} / \mathrm{kg}$ & 64 \\
\hline $\begin{array}{l}\text { Biodegradation } \\
\text { half-life }\left(t_{1 / 2}\right)\end{array}$ & 1.87799 & 2.61870 & 94.89 & 152.904 & 480 & 24 & 12,480 & $\mathrm{~h}$ & 19 \\
\hline Photolysis & 1.19805 & 0.45285 & 11.84 & 14.27 & 4.00 & 0.2 & 40.00 & days & 8 \\
\hline $\begin{array}{l}\text { Soil/sediment } \\
\text { biodegradation } \\
\text { rate }(k)\end{array}$ & 4.67090 & 21.87060 & 0.226 & 0.924 & 0.0087 & 0.0003 & 4.36 & $h^{-1}$ & 22 \\
\hline Koc & 4.86449 & 29.51300 & 5.35 & 7.48 & 762 & 316 & 1585 & L/kg & 61 \\
\hline
\end{tabular}

Table 14. Tests for normality and descriptive statistics and information regarding the environmental fate parameters for RDX reported in the scientific literature.

\begin{tabular}{|c|c|c|c|c|c|c|c|c|c|}
\hline Parameter & Skewness & Kurtosis & Mean & Stdev & Median & Min & Max & Units & \begin{tabular}{|l|} 
Data \\
Points
\end{tabular} \\
\hline Solubility & 3.43370 & 11.70296 & 48.9 & 28.1 & 43.05 & 12.8 & 123 & $\mathrm{mg} / \mathrm{L}$ & 26 \\
\hline Dissolution & 2.34610 & 4.79071 & $5.2 \times 10^{-4}$ & $1 \times 10^{-3}$ & $9.7 \times 10^{-5}$ & $1.7 \times 10^{-5}$ & $3.6 \times 10^{-3}$ & $\mathrm{mg} \mathrm{cm} \mathrm{cm}^{-2} \mathrm{~s}^{-1}$ & 12 \\
\hline $\begin{array}{l}\text { Henry's } \\
\text { Constant }\end{array}$ & 1.15556 & 0.05926 & $1.18 \times 10^{-10}$ & $3.71 \times 10^{-10}$ & $1.18 \times 10^{-10}$ & $1.16 \times 10^{-11}$ & $8.72 \times 10^{-10}$ & $\mathrm{~Pa} \mathrm{~m} 3 / \mathrm{mol}$ & 5 \\
\hline Adsorption $\left(\mathrm{K}_{\mathrm{D}}\right)$ & 2.00922 & 3.04505 & 1.80 & 2.36 & 0.95 & 0.12 & 8.44 & L/kg & 36 \\
\hline $\begin{array}{l}\text { Biodegradation } \\
\text { half-life }\left(t_{1 / 2}\right)\end{array}$ & 1.04115 & -0.18086 & 17.57580 & 21.46500 & 160 & 6 & 14,400 & $h$ & 10 \\
\hline $\begin{array}{l}\text { Soil/sediment } \\
\text { biodegradation } \\
\text { rate }(k)\end{array}$ & 2.80262 & 8.04712 & 0.02994 & 0.06433 & 0.008 & $9 \times 10^{-5}$ & 0.24 & $h^{-1}$ & \\
\hline Photolysis & 1.36952 & 0.60518 & 94.75 & 126.11 & 30 & 2 & 336 & days & 8 \\
\hline Koc & 2.37293 & 5.28334 & 4.71 & 6.87 & 100 & 8 & 269 & L/kg & 46 \\
\hline
\end{tabular}

\subsection{Covariant structure in sediments: preliminary assessment as basis for developing improved MC persistence predictions}

This section briefly discusses investigations on the covariate structure of sediments. Covariance describes the "joint dependence" of variables with each other, forming the basis of multivariate structure. A covariant structure within a dataset provides the basis for developing multivariate models aimed at predicting particular processes based on this structure. 
Here, data from a multivariate analysis of the SedDB database found at http://www.earthchem.org/seddb, and hosted by Integrated Earth Data Applications (IEDA) and the National Science Foundation.

A complete set of characterization data was downloaded from the site, which contains thousands of samples. The data has been mainly obtained through X-ray fluorescence elemental analysis, combustion techniques for organic/inorganic carbon, total nitrogen, and sulfur. Because of the large number of missing characterization data (i.e., large data gaps in the matrix), covariate analysis was conducted using only seven reported elements, calcium ( $\mathrm{Ca})$, manganese $(\mathrm{Mn})$, iron $(\mathrm{Fe})$, magnesium $(\mathrm{Mg})$, titanium (Ti), aluminum (Al), and silicon (Si). The Pearson coefficient (r) was used to quantify pairwise covariances among the different variables within the sediment samples. In general, the greater the r values, the greater the covariant structure existing between the variable pair. Pearson coefficient values greater than 0.2 were considered significant. The most significant $r$ values were observed for the following pairs: Fe-Mn $(r=$ 0.448), Ca-Al ( $\mathrm{r}=-0.755), \mathrm{Al}-\mathrm{K} 2 \mathrm{O}(\mathrm{r}=0.453), \mathrm{Ca}-\mathrm{Na}(\mathrm{r}=-0.514)$, and Al$\mathrm{Na}(\mathrm{r}=0.468)$ (Table 15).

Based on the observed covariant structure from the selected variables, the dimension-reduction method and principal component analysis (PCA) were utilized to determine the overall latent structure in the sediment data. A five-PC model (non-optimized) described most of the datasets after substantial work was performed to remove leverage and residual outliers. Despite the limitations of the preliminary model, 93\% of the explained variance was contained in three PCs. Figure 48 shows the breakout of the samples in PC 1-2, where substantial grouping of samples is evident based on their sampling name. This clustering is important as it suggests the underlying structure is sufficient to statistically discriminate among all of the samples. Samples that are geochemically similar (based on seven characterization variables provided) break out similarly in reduced space.

Figure 49 shows the groupings in a two-dimensional space. $\mathrm{PC}-3$ is plotted on the y-axis, while in Figure 49A, PC-1 is plotted on the $\mathrm{x}$-axis. Figure 49B represents a 90-degree rotation of the "cube" to PC-2 along the $\mathrm{x}$-axis. The plots show some shifts in the clusterings, with some clusters becoming more clearly resolved in higher dimensional space. Finally, the data is shown in Figure 50 as a three-dimensional plot. 
Clearly, the sediments exhibit strong covariate structure. This is very promising for establishing the basis for predicting the persistence of MC based on sediment type, thus allowing for predictions that are more accurate than data that already exists. In particular, the latent structure in the data can be better reorganized by reclassifying the samples into categories including geological age, lithology, etc. For this approach to work, it would be important to conduct thorough characterizations of sediment samples, and then to correlate the multivariable covariant structure with the sediment sorption and/or degradation kinetics of MC.

Table 15. Pairwise Pearson correlation coefficients for the sediment data from the SedDB database. Values in bold indicate the correlation constants were statistically significant $(p=0.05)$. The diagonal (containing value $=1$ ) represent self-correlation.

\begin{tabular}{lrrrrrccccc}
\hline Variables & \multicolumn{1}{c}{$\mathrm{Ca}$} & \multicolumn{1}{c}{$\mathrm{Mn}$} & $\mathrm{P} 205$ & $\mathrm{Fe}$ & $\mathrm{Si}$ & $\mathrm{Ti}$ & $\mathrm{K} 20$ & $\mathrm{Mg}$ & $\mathrm{Na}$ & \multicolumn{1}{c}{$\mathrm{Al}$} \\
\hline $\mathrm{Ca}$ & 1 & -0.087 & -0.050 & -0.275 & -0.146 & -0.337 & -0.391 & -0.252 & -0.514 & -0.755 \\
$\mathrm{Mn}$ & -0.087 & 1 & 0.051 & 0.448 & -0.057 & 0.075 & -0.040 & 0.032 & 0.059 & -0.192 \\
$\mathrm{P} 205$ & -0.050 & 0.051 & 1 & -0.072 & -0.033 & 0.810 & -0.060 & -0.009 & 0.063 & -0.066 \\
$\mathrm{Fe}$ & -0.275 & 0.448 & -0.072 & 1 & -0.046 & 0.122 & 0.140 & 0.120 & 0.144 & 0.116 \\
$\mathrm{Si}$ & -0.146 & -0.057 & -0.033 & -0.046 & 1 & 0.003 & 0.000 & 0.579 & 0.336 & 0.096 \\
$\mathrm{Ti}$ & -0.337 & 0.075 & 0.810 & 0.122 & 0.003 & 1 & 0.066 & 0.113 & 0.191 & 0.311 \\
$\mathrm{~K} 20$ & -0.391 & -0.040 & -0.060 & 0.140 & 0.000 & 0.066 & 1 & 0.633 & 0.164 & 0.454 \\
$\mathrm{Mg}$ & -0.252 & 0.032 & -0.009 & 0.120 & 0.579 & 0.113 & 0.633 & 1 & 0.289 & 0.186 \\
$\mathrm{Na}$ & -0.514 & 0.059 & 0.063 & 0.144 & 0.336 & 0.191 & 0.164 & 0.289 & 1 & 0.468 \\
$\mathrm{Al}$ & -0.755 & -0.192 & -0.066 & 0.116 & 0.096 & 0.311 & 0.454 & 0.186 & 0.468 & 1 \\
\hline
\end{tabular}


Figure 48. Preliminary principal component analysis (PCA) of the sediment samples based on the selected geochemical characterization data. Samples were preliminarily grouped based on their sampling designations.

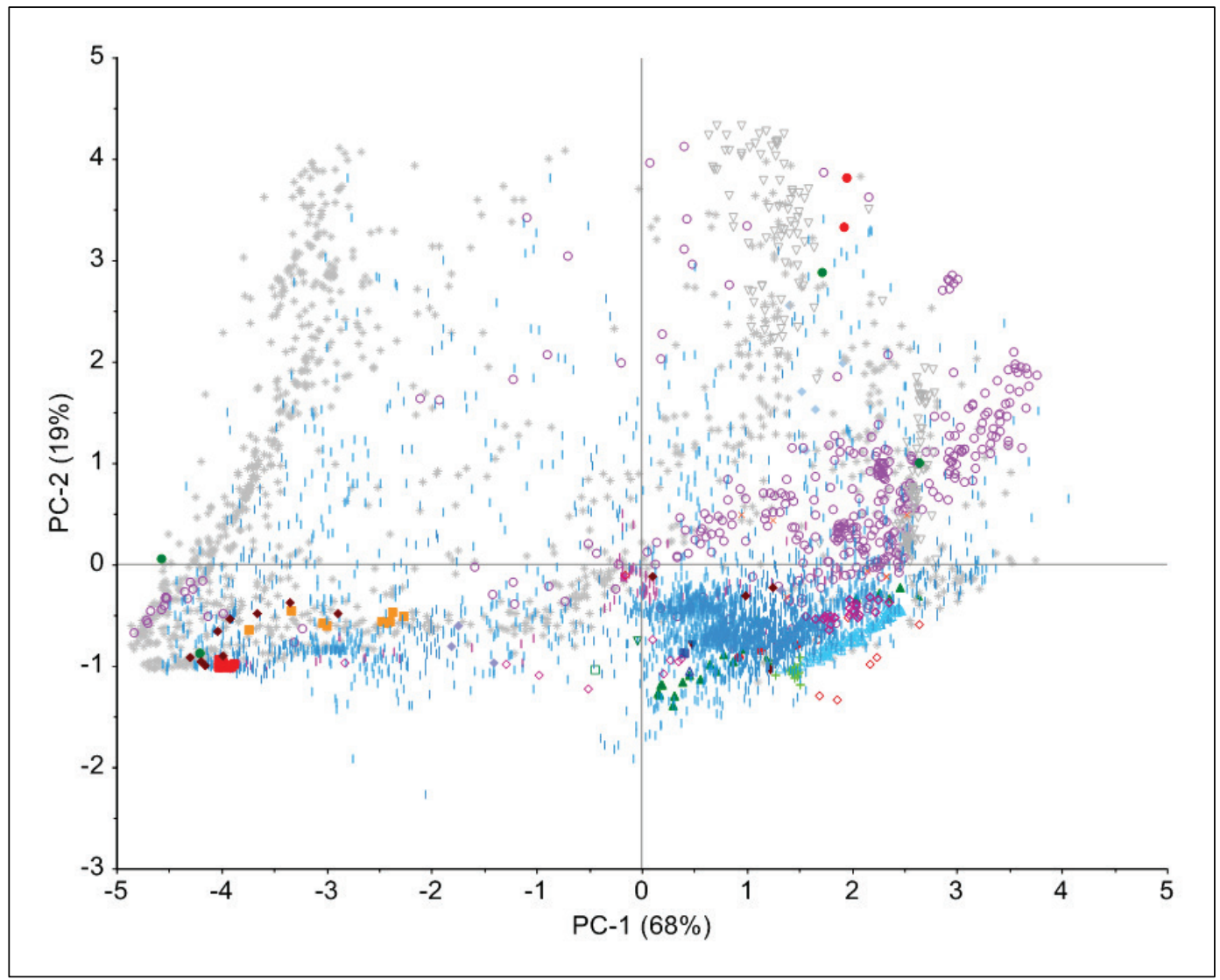

Figure 49. Two-dimensional representation of the PCs 1-3, where a 90 degree rotation of the $\mathrm{x}$-axis changes this axis from PC-1 to PC-2. The legend in Figure 8-19 explains the symbols used in this figure.
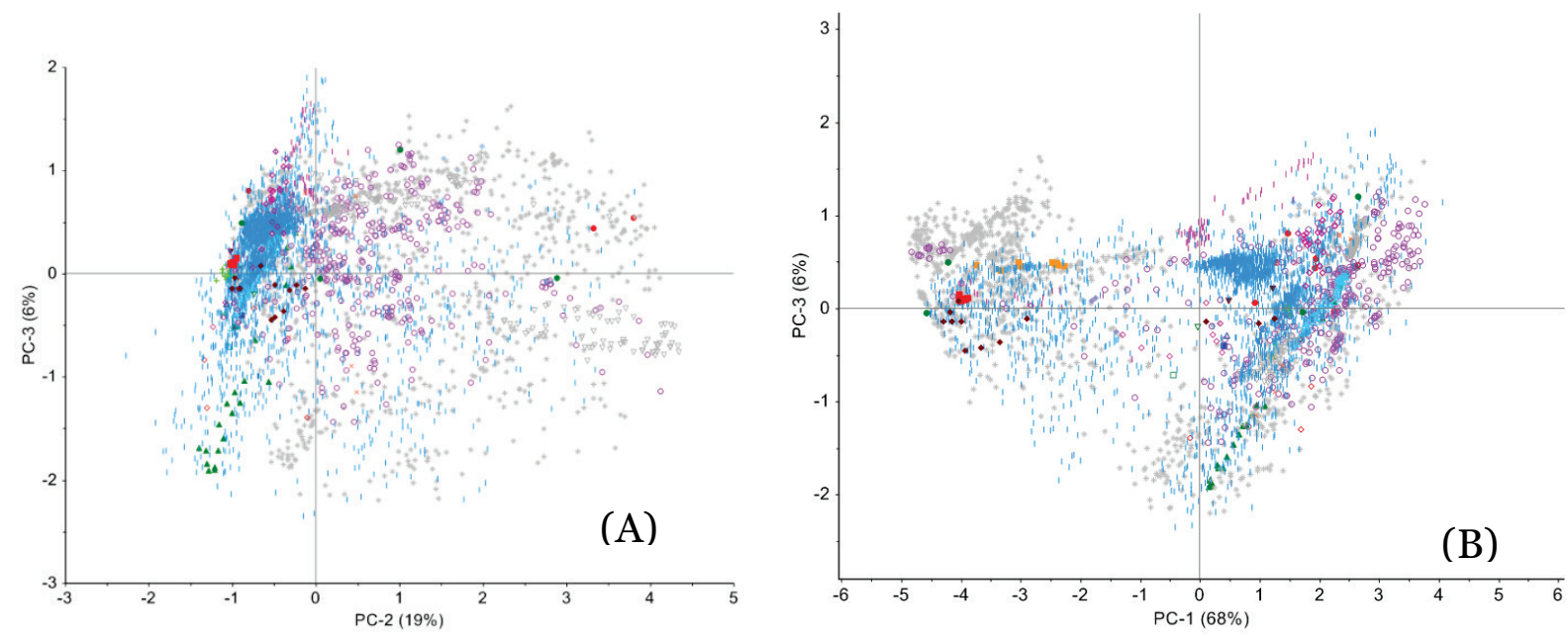
Figure 50. Three-dimensional representation of PC 1-3 from a multivariate decomposition of the SedDB characterization data. The legend in Figure 8-19 explains the symbols.
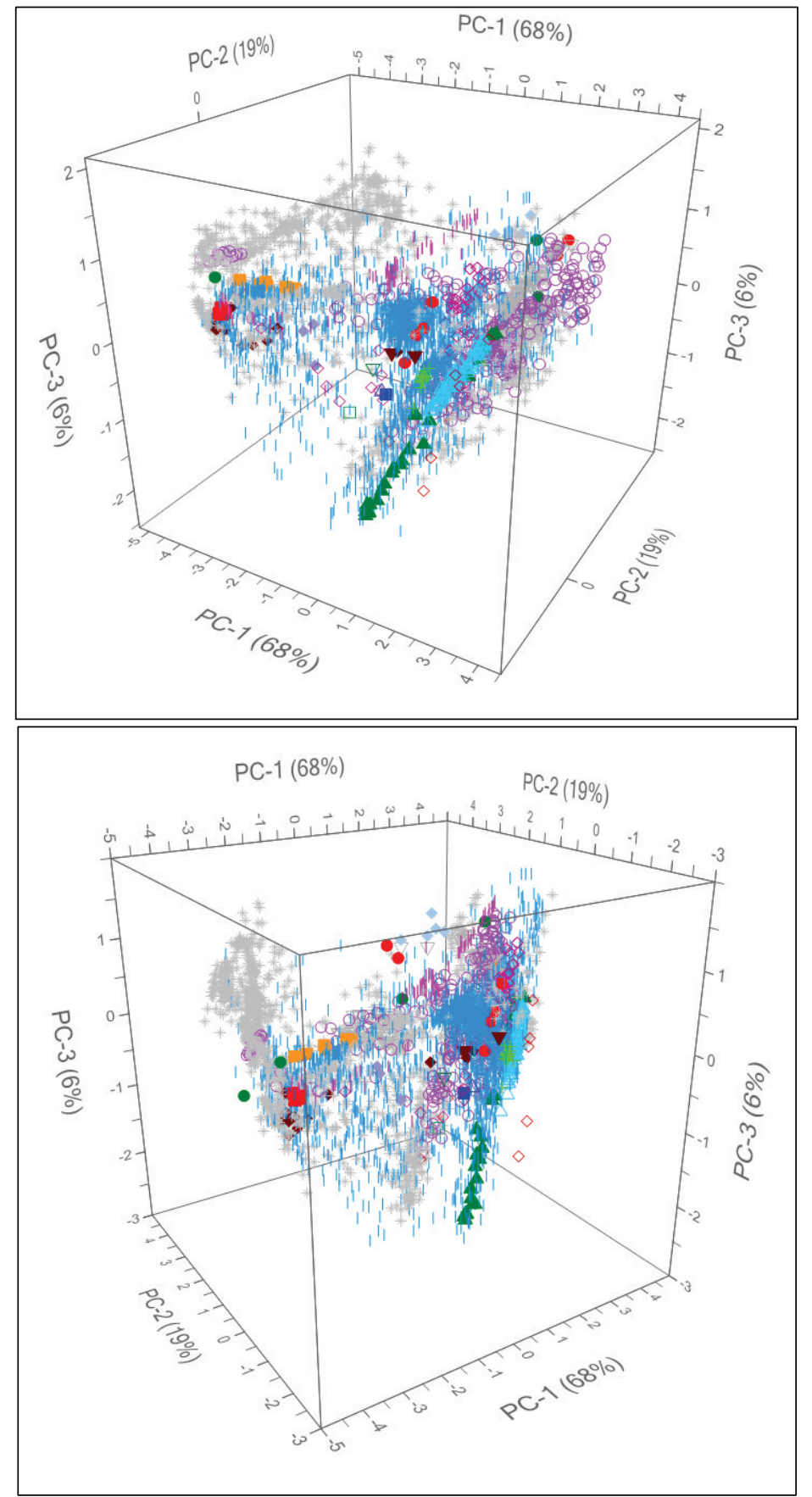

\subsection{TNT and RDX Environmental fate modeling}

Using the environmental fate parameters collected from the scientific literature, simulations of the fate of TNT and RDX in a water body were conducted using the Quantitative Water-Air-Sediment Interaction 
(QWASI) mathematical model (Figure 51). The QWASI model calculates the environmental fate of a chemical assuming that the water body is wellmixed, the calculations are based on the mass balance of chemical emissions, advective flows of water and suspended particles, and deposition from atmospheric inputs (Mackay et al. 1983a, Mackay et al. 1983b, Mackay et al. 2014). Based on these inputs, steady-state (Level III) mass balance equations are created for the water and sediment compartments with the rates of all processes expressed using $D$ values as previously described (Table 8-2), including terms for biodegradation rates, diffusion, and advective mass transport through the system. In particular, QWASI represents the different rate processes using the same units so that $\mathrm{D}$ values are directly comparable, allowing one to quickly identify the most important processes. Similar to the calculations described previously, QWASI calculates the fugacity (f), fugacity capacities (Z), and residence times of the contaminant for each compartment or phase. The QWASI model is represented conceptually in Figure 51. Note that QWASI's representation of a water body is simplified in that emissions inputs and releases from the controlled volume of the system represent hydrodynamics. Water bodies can be represented dynamically by creating separate models that represent increments along the system of interest and then connecting them in series (Mackay et al. 1983b).

Below, calculations using the QWASI v. 1.00 are presented. Likewise, the QWASI v. 1.00 is updated for use in Microsoft Excel in order to allow for more control of the environmental fate parameters and to make the calculations more transparent than with previous versions of the model (Mackay et al. 2014).

\subsubsection{Simulations of TNT and RDX environmental fate}

QWASI requires a large number of environmental fate parameters (as described in Table 9-Table 12) in order to describe a full-range of processes occurring in natural water bodies. Often, many of these parameters are unknown and potentially expensive to determine. Thus, many of the environmental fate parameters can be derived using a basic dataset of chemical properties. The calculations of this effort are largely based on the parameters collected from the scientific literature, with comparisons made using derived fate parameters. 


\subsubsection{Inputted TNT fate parameters}

Important chemical properties of TNT for calculating the derived environmental fate parameters are: molar mass $(\mathrm{MM})=227.13 \mathrm{~g} / \mathrm{mol}$; melting point $=81^{\circ} \mathrm{C}$ (Meyer et al. 2002); and vapor pressure $\left(\mathrm{P} @ 25^{\circ} \mathrm{C}\right.$ ) $=3.92 \times 10^{-3} \mathrm{~Pa}$ (Hikal et al. 2011). In Figure 35, the temperaturedependent solubility of TNT (as determined from the authors' review of the literature) was determined using Equation 14:

$$
\text { S-TNT }_{\text {T }}=50.484 \exp (0.0377 \mathrm{~T})
$$

so that $\mathrm{S}$-TNT $\left(25^{\circ} \mathrm{C}\right)=130 \mathrm{mg} \mathrm{L}^{-1}$. This value is equivalent to the value Pichtel (2012) reported, where S-TNT $\left(20^{\circ} \mathrm{C}\right)=130 \mathrm{mg} \mathrm{L}^{-1}$. From Equation 8 -14, S-TNT $\left(20^{\circ} \mathrm{C}\right)=107 \mathrm{mg} \mathrm{L}^{-1}$.

From the authors' review of the literature, $\mathrm{H}$ is calculated with the empirical function Equation 15 (Figure 31),

$$
\mathrm{H}_{\text {-TNT }}=8 \times 10^{-5} \exp (0.1024 \mathrm{~T})
$$

where, $\mathrm{T}$ is temperature in ${ }^{\circ} \mathrm{C}$. Thus, $\mathrm{H}$-TNT $\left(25^{\circ} \mathrm{C}\right)=1.03 \times 10^{-3} \mathrm{~Pa} \mathrm{~m}^{3} \mathrm{~mol}^{-}$ ${ }^{1}$, similar to the $\mathrm{H}$ derived with Equation 8-4 where $\mathrm{H}$-TNT $\left(25^{\circ} \mathrm{C}\right)=6.849 \mathrm{x}$ $10^{-3} \mathrm{~Pa} \mathrm{~m}^{3} \mathrm{~mol}^{-1}$. The calculated $\mathrm{KAW}=3 \times 10^{-6}$. Using a log Kow $=1.86$ (Pichtel 2012), the derived Koc values ranged from 25 to $29 \mathrm{~L} \mathrm{~kg}^{-1}$. This range of Koc values is an order of magnitude lower than the median value of $762 \mathrm{~L} \mathrm{~kg}^{-1}$ obtained from the scientific literature (Table 13).

The QWASI model also allows for the input of $t_{1 / 2}$ values for calculating the residence time of TNT within each compartment. $\mathrm{A}_{1 / 2}$ of 480 hours was selected for TNT in water, representing the median value for biodegradation from the literature review. For sediments, a $t_{1 / 2}$ of 83.4 hours was used, representing the median value for TNT residence in soil and sediment systems. Thus, the condition that TNT degradation in the sediment and suspended particles occurred more rapidly than when water was imposed-a view which is consistent with the general scientific literature with respect to organic compounds. Other sources view TNT residence times as indistinguishable between sediments and waters (Howard et al. 1991).

For these simulations, a hypothetical water body was created. The properties used in the calculations for the hypothetical water body are 
given in Table 16. The loading of UXO to the volume of the water body was approximated to $1000 \mathrm{~kg} \mathrm{year}^{-1}$. To best account for the diluting effect of the open water environment, the simulations were carried out so that the inflowing advective water (into the simulated water volume) was free of dissolved MC. Also, the authors assumed that no MC were deposited into the water via air emissions.

\subsubsection{Simulation results}

Partitioning coefficients $\left(\mathrm{L} \mathrm{kg}^{-1}\right)$ for TNT were calculated from the Koc-TNT and the organic carbon content of each (Table 17). Based on these calculations, the greatest partitioning of TNT was expected from the water to the suspended sediments in the water body. Compartment fugacity capacities (Z) for TNT were calculated for each compartment (and specific sub-compartments) based on the partitioning coefficients (Table 18). From the estimated rates of the different processes in the water body, more than 99\% of the removal of TNT is attributed to the short residence time in water due to biodegradation (Table 19). Thus, a loading of $1000 \mathrm{~kg} /$ year into the system results in a net $78.40 \mathrm{~kg}$ of TNT retained in the system (Figure 823). The estimated overall residence time was 28.62 days, with the estimated residence time in water being 28.68 days and in sediment, 5.01 days. The results are represented graphically in Figure 52.

Figure 51. Graphical representation of the different environmental processes captured in the QWASI model (Mackay et al. 1983a).

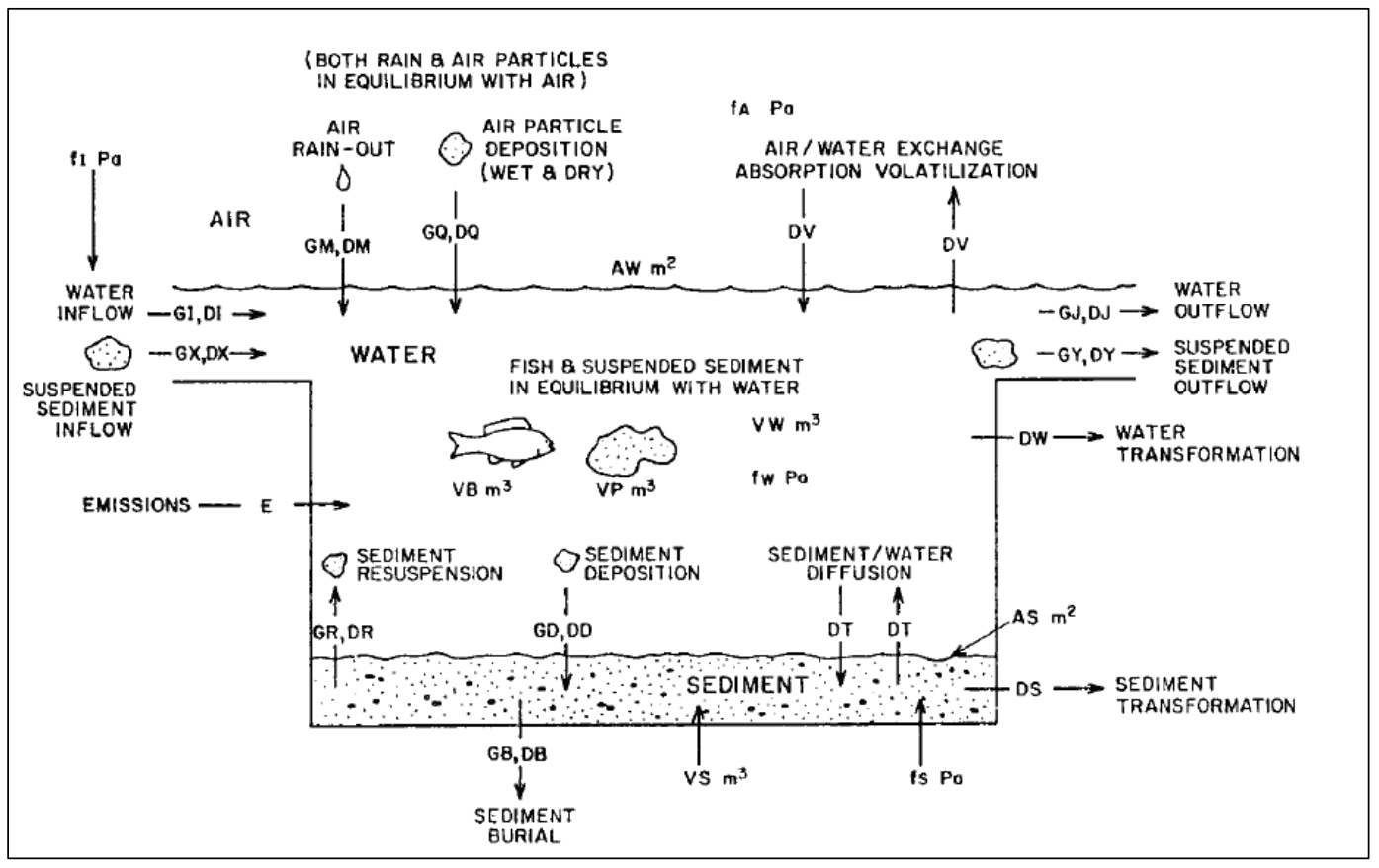


Table 16. Environmental properties of the hypothetical water-body.

\begin{tabular}{|c|c|c|}
\hline Category & Property & Value \\
\hline \multirow[t]{3}{*}{ Dimensions } & Water Surface Area $\left(\mathrm{m}^{2}\right)$ & $1.30 \mathrm{E}+10$ \\
\hline & Water Volume $\left(\mathrm{m}^{3}\right)$ & $6 \mathrm{E}+11$ \\
\hline & Sediment Active Layer Depth (m) & 0.005 \\
\hline \multirow[t]{4}{*}{ Concentration of solids } & Aerosols in Air $\left(\mu \mathrm{g} / \mathrm{m}^{3}\right)$ & 15 \\
\hline & in Water Column (mg/L) & 1.3 \\
\hline & in Inflow Water (mg/L) & 5 \\
\hline & in Sediment (vol/vol) & 0.15 \\
\hline \multirow[t]{3}{*}{ Density $\left(\mathrm{kg} \mathrm{m}^{-3}\right)$} & Aerosols & 1500 \\
\hline & Particles in Water & 2400 \\
\hline & Sediment Solids & 2400 \\
\hline \multirow{4}{*}{$\begin{array}{l}\text { Organic carbon (OC) content } \\
\text { (mas/mass) }\end{array}$} & Particles in Water & 0.14 \\
\hline & Particles in Water (inflow) & 0.14 \\
\hline & Sediment Solids & 0.03 \\
\hline & Resuspended Sediment & 0.025 \\
\hline \multirow[t]{8}{*}{ Rates } & Water Inflow $\left(\mathrm{m}^{3} / \mathrm{h}\right)$ & $7 \mathrm{E}+5$ \\
\hline & Water Outflow $\left(\mathrm{m}^{3} / \mathrm{h}\right)$ & $5 \mathrm{E}+6$ \\
\hline & Sedimentation (g/m².day) & 1.2 \\
\hline & Sediment Burial (g/m².day) & 0.4 \\
\hline & Sediment Resuspension (g/m².day) & 0.6 \\
\hline & Aerosol Deposition $(\mathrm{m} / \mathrm{h})$ & 7.2 \\
\hline & Scavenging Ratio (vol air/ vol rain) & $2 \mathrm{E}+5$ \\
\hline & Rain Rate (m/year) & 1.1 \\
\hline \multirow[t]{3}{*}{ Mass transfer coefficients $(\mathrm{m} / \mathrm{h})$} & Volatilization - Air Side & 1 \\
\hline & Volatilization - Water Side & 0.01 \\
\hline & Sediment-Water Diffusion & 0.0004 \\
\hline
\end{tabular}

Table 17. TNT partitioning among the different environmental compartments as calculated by the QWASI model.

\begin{tabular}{|l|c|c|}
\hline Compartment & Partitioning coefficient (unit less) & Partitioning coefficient (L kg-1) \\
\hline Air-water & $3 \times 10^{-6}$ & $\mathrm{n} / \mathrm{a}$ \\
\hline Suspended particle-water & 256 & 107 \\
\hline $\begin{array}{l}\text { Suspended particle-water } \\
\text { (inflow) }\end{array}$ & 256 & 107 \\
\hline Sediment-water & 54.86 & 22.9 \\
\hline Resuspended sediment-water & 45.72 & 19.1 \\
\hline
\end{tabular}


Table 18. Fugacity capacities (Z) describing the partitioning of TNT to different environmental compartments and selected sub-compartments as calculated by the QWASI model.

\begin{tabular}{|l|l|c|}
\hline Compartment & Sub-compartment & $Z\left(\mathrm{~mol} / \mathrm{m}^{3} \cdot \mathrm{Pa}\right)$ \\
\hline Air (bulk) & Gas phase & $4.03 \times 10^{-4}$ \\
\hline Water (bulk) & & 260.5 \\
\hline & Liquid phase & 260.4 \\
\hline & Suspended particles & $6.7 \times 10^{4}$ \\
\hline Inflow water (bulk) & & 260.6 \\
\hline & Liquid phase & 260.4 \\
\hline & Suspended particles & 0 \\
\hline Sediment (bulk) & & 2364.5 \\
\hline & Pore water & 260.4 \\
\hline & Solids & $1.43 \times 10^{4}$ \\
\hline
\end{tabular}

Table 19. Estimated TNT losses, calculated from the QWASI model.

\begin{tabular}{|l|c|}
\hline TNT removal process & Estimated rate $\left(\mathrm{kg} \mathrm{year}^{-1}\right)$ \\
\hline Volatilization & 0.134 \\
\hline Water outflow & 5.72 \\
\hline Suspended particle outflow & $7.93 \times 10^{-4}$ \\
\hline Transformation in water & 991.2 \\
\hline Transformation in sediment & 2.92 \\
\hline Burial (loss to deeper sediment layers) & $2.95 \times 10^{-3}$ \\
\hline
\end{tabular}


Figure 52. Output diagram representing the distribution and movement of TNT among the different compartments as calculated from the QWASI model.

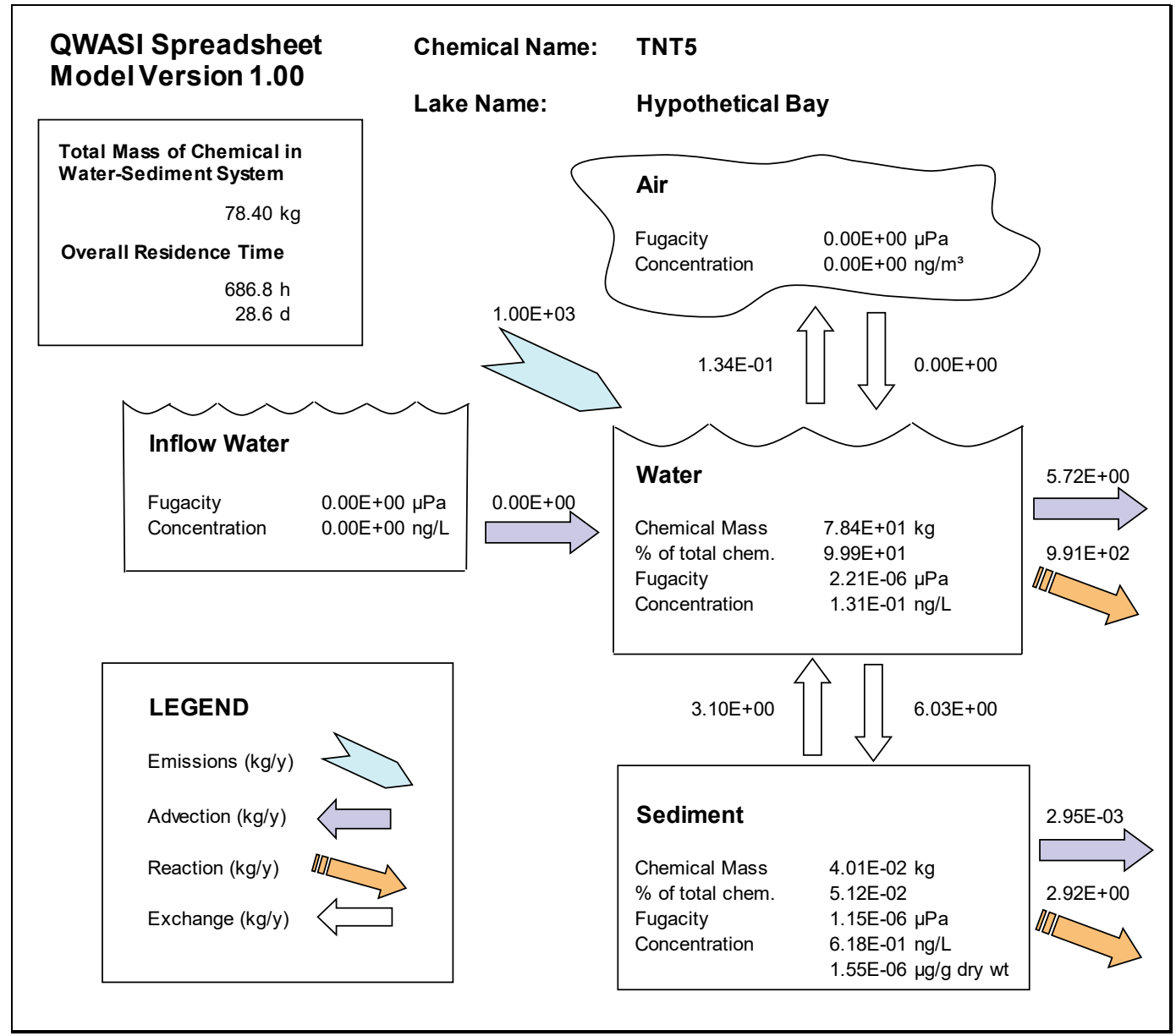

\subsubsection{Inputted RDX fate parameters}

Important chemical properties of RDX for calculating the derived environmental fate parameters were: molar mass $(\mathrm{MM})=\mathbf{2 2 2 . 1}$; melting point $=204{ }^{\circ} \mathrm{C}$ (Meyer et al. 2002); and vapor pressure $\left(\mathrm{P} @ 25{ }^{\circ} \mathrm{C}\right)=4.8 \mathrm{x}$ $10^{-6} \mathrm{~Pa}$ (Hikal et al. 2011) (Table 20). In Figure 35, the temperaturedependent solubility of RDX (as determined from the authors' review of the literature) was:

$$
S_{-R D X}=14.787 \exp (0.0448 \mathrm{~T})
$$

so that $\mathrm{S}-\mathrm{RDx}\left(25^{\circ} \mathrm{C}\right)=45 \cdot 32 \mathrm{mg} \mathrm{L}^{-1}$. From Equation $16, \mathrm{~S}-\mathrm{RDx}\left(2 \mathrm{O}^{\circ} \mathrm{C}\right)=$ $36.2 \mathrm{mg} \mathrm{L}^{-1}$. This value is lower than the value Pichtel (2012) reported, where S-RDX $\left(20^{\circ} \mathrm{C}\right)=42 \mathrm{mg} \mathrm{L}^{-1}$. 
From the literature review, $\mathrm{H}$ is calculated using the following empirical function (Figure 32) represented in Equation 17

$$
H_{-R D X}=1 \times 10^{-7} \exp (0.108 \mathrm{~T})
$$

where, $\mathrm{T}$ is temperature in ${ }^{\circ} \mathrm{C}$. Thus, $\mathrm{H}-\mathrm{RDX}\left(25^{\circ} \mathrm{C}\right)=1.49 \times 10^{-6} \mathrm{~Pa} \mathrm{~m}^{3} \mathrm{~mol}^{-}$ ${ }^{1}$, compared to the derived $\mathrm{H}$ (Equation 8-17) where $\mathrm{H}-\mathrm{RDX}\left(25^{\circ} \mathrm{C}\right)=2.53 \mathrm{x}$ $10^{-5} \mathrm{~Pa} \mathrm{~m}^{3} \mathrm{~mol}^{-1}$. The calculated $\mathrm{K}_{\mathrm{AW}}=1 \times 10^{-8}$.

Using a log Kow $=0.86$ (Pichtel 2012), the derived Koc values ranged from 2.5-3.0 $\mathrm{L} \mathrm{kg}^{-1}$ from Equation 6 and 7. This range of Koc values is an order of magnitude lower than the median value of $100 \mathrm{~L} \mathrm{~kg}^{-1}$ obtained from the scientific literature (Table 13). For RDX residence times, a $t_{1 / 2}$ of 99 hours was selected for RDX water, representing the median value for biodegradation from the authors' review. For sediments, a $t_{1 / 2}$ of 100 hours was used, which represent the median value for RDX residence in soil and sediment systems.

\subsubsection{Simulation results}

Calculated partitioning coefficients ( $\mathrm{L} \mathrm{kg}^{-1}$ ) among the different phases predicted that RDX would largely partition to the solid phases in the system. Thus, the calculated $Z$ values (Equation 2) reflected this partitioning, which impacted the low sediment to water ratio in the hypothetical water body. Like TNT, more than $99 \%$ of the RDX loss occurred in the water phase removal stage (Table 22).

Thus, a loading of RDX of $1000 \mathrm{~kg} /$ year to the system resulted in $16.29 \mathrm{~kg}$ remaining in the system. The estimated overall residence time was 5.94 days, with the estimated residence time being 5.94 days in water and 6.01 days in sediment. The results are represented graphically in Figure 53 .

\subsubsection{Model sensitivity}

Adjusting the $\mathrm{t}_{1 / 2}$ of TNT and RDX in water and sediment by $1-2$ orders of magnitude produced a negligible effect on the simulated overall residence time for the MC. Furthermore, lowering the temperature from 25 to $10^{\circ} \mathrm{C}$ (with corresponding adjustments in $\mathrm{P}, \mathrm{S}$, and $\mathrm{H}$ parameters) reduced the $\mathrm{Z}$ values among the different compartments. 
Table 20. RDX partitioning coefficients among the different environmental compartments as calculated by the QWASI model.

\begin{tabular}{|l|c|c|}
\hline Compartment & Partitioning coefficient (unit less) & Partitioning coefficient (L kg-1) \\
\hline Air-water & $1 \times 10^{-8}$ & $\mathrm{n} / \mathrm{a}$ \\
\hline Suspended particle-water & 33.6 & 14 \\
\hline $\begin{array}{l}\text { Suspended particle-water } \\
\text { (inflow) }\end{array}$ & 33.6 & 14 \\
\hline Sediment-water & 7.2 & 3.0 \\
\hline Resuspended sediment-water & 6.0 & 2.5 \\
\hline
\end{tabular}

Table 21. Fugacity capacities (Z) describing the partitioning of RDX to different environmental compartments and selected sub-compartments as calculated by the QWASI model.

\begin{tabular}{|l|l|c|}
\hline Compartment & Sub-compartment & $\mathbf{Z}\left(\mathrm{mol} / \mathrm{m}^{3} \cdot \mathrm{Pa}\right)$ \\
\hline Air (bulk) & Gas phase & $4.03 \times 10^{-4}$ \\
\hline Water (bulk) & & $6.76 \times 10^{5}$ \\
\hline & Liquid phase & $6.76 \times 10^{5}$ \\
\hline & Suspended particles & $2.27 \times 10^{7}$ \\
\hline Inflow water (bulk) & & $6.76 \times 10^{5}$ \\
\hline & Liquid phase & $6.76 \times 10^{5}$ \\
\hline & Suspended particles & 0 \\
\hline Sediment (bulk) & & $1.30 \times 10^{6}$ \\
\hline & Porewater & $6.76 \times 10^{5}$ \\
\hline & Solids & $4.86 \times 10^{6}$ \\
\hline
\end{tabular}

Table 22. Estimated RDX losses calculated from the QWASI model.

\begin{tabular}{|l|c|}
\hline RDX removal process & Estimated rate $\left(\mathrm{kg} \mathrm{year}^{-1}\right)$ \\
\hline Volatilization & $3.16 \times 10^{-5}$ \\
\hline Water outflow & 1.19 \\
\hline Suspended particle outflow & $2.16 \times 10^{-5}$ \\
\hline Transformation in water & 998.6 \\
\hline Transformation in sediment & 0.177 \\
\hline Burial (loss to deeper sediment layers) & $1.33 \times 10^{-4}$ \\
\hline
\end{tabular}


Figure 53. Output diagram representing the distribution and movement of RDX among the different compartments as calculated from the QWASI model.

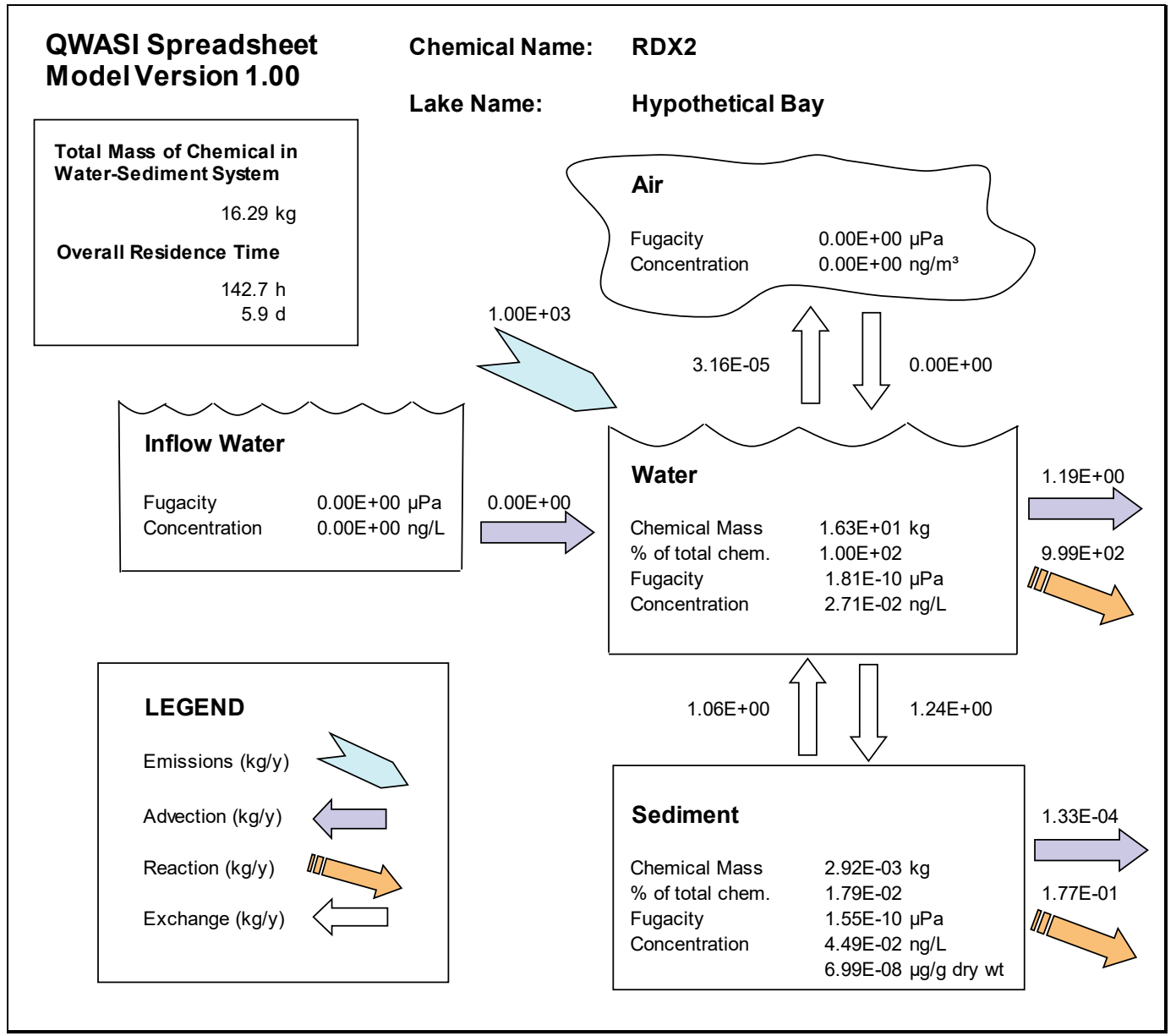




\section{Release of MC from Breached Shells in Aquatic Environments}

\subsection{Source characterization}

Source characterization is the term used to describe the type and amount of a contaminant that is introduced into the environment, generally, as part of an exposure pathway that requires the assessment of risk to human health and/or the environment. In the context of the shell model (Wang et al. 2011), it is defined as the estimation of the mass of MC (e.g., TNT, RDX, HMX and/or their breakdown products derived from their military compositions), in both quantity and form (i.e., chemical species) that are released from the breached shell into the water column and sediment.

The release of MC from an ensemble of munitions in unknown states of integrity (breach status) is what provides the source term in a risk characterization or risk assessment framework for an UWMM site. It is important to note that the shell model is not a computer code, but is rather an $\mathrm{MC}$ release function that forms the basis for evaluating total $\mathrm{MC}$ release at a UWMM site. It is a practical application of the analytical expression derived for a single shell that was developed and validated both numerically and empirically as described in Wang et al. (2013). The MC release function has also been further validated empirically as part of a recent flume effort conducted under ESTCP project ER-201433 using a dummy breached shell containing Comp B, an actual MC fill (Rosen et al. 2017). In that study, the predicted release function MC concentration was found to be within a factor of three when compared to the measured MC concentration. The release function is provided and discussed below, and its utility is explored using off-the-shelf software for purposes of demonstrating how one would go about estimating an aqueous $\mathrm{MC}$ source term for a UWMM site. For deterministic evaluations, the function is employed as a calculation on a computer (e.g., MS Excel or similar) or manually by assigning discreet values to the $\mathrm{MC}$ release function parameters as the authors did for this report; it is described in greater detail below. For probabilistic evaluations, the MC release function can be used with an off-the-shelf package (e.g., Crystal Ball or similar) to assign distributions instead of discreet values to appropriate parameters; again, the authors describe this in detail below. The use of the release function primarily has uncertainties associated with availability of input data or unknown empirical values or ranges (distributions) for the functional 
parameters, thus a probabilistic approach such as the one described and presented here is required.

To better understand the release of $\mathrm{MC}$ from munitions items, the shell model provides a way to quantify the fundamental processes that govern the MC release from any given shell or distribution of shells. These fundamental processes are described by physical and chemical properties that ultimately define the total magnitude and rate of $\mathrm{MC}$ released into the surrounding environment for scenarios of interest. Scenarios of interest include MC that are (1) lying on top of sediment, (2) entirely buried in sediment, or (3) exposed solid energetic material released directly to the underwater environment, such as that found in a low-order detonation. For scenarios 1 and 2, it was assumed that the release through a breach in a munition casing can be determined by the following five key parameters: (1) the start and growth of the breach or the hole (expressed as the radius of the hole); (2) the radius of the cavity formed due to loss of mass released from inside the shell ; (3) the chemical property (dissolution speed) from solid to aqueous phases of the MC inside the shell casing); (4) the outside ambient current to which the casing hole is exposed; and (5) mass of MC remaining inside. For scenario 3, low-order detonation contamination, dissolution speed, outside ambient current, and mass of $\mathrm{MC}$ remaining inside need to be considered as an extreme case where a breach is infinite in size. This effort applies the $\mathrm{MC}$ release rate function, a function of the five listed variables ( 1 to 5 above), as the process descriptor that dictates the release rate of $\mathrm{MC}$ from the munition casing.

\subsection{Release modeling for fate and transport purposes}

The shell model effort (Wang et al. 2011) defined and quantified the environmental process descriptors necessary to evaluate the $\mathrm{F}$ and $\mathrm{T}$ of dissolved MC in aquatic environments. When undissolved MCs (still contained within a shell) are introduced into the aquatic environment, there is no release until corrosion or other destructive processes eventually breach the shell. Compounds inside are then exposed to the ambient environment until totally depleted. Breach size (i.e., shell casing hole size) is assumed to be a function of time related to the corrosion process. While outside the scope of this effort, the results of a generalized/non-specific corrosion model could eventually be integrated into the release rate formulae, in which the hole size, $b$, would be a time-varying (growing) function derived from corrosive processes. Total MC mass remaining inside the shell $(\mathrm{Mc})$ is another time-varying parameter that can be found 
by calculating the difference between the initial mass and the total MC mass released from the shell, beginning with initial formation of the breached hole. Once released into the environment, the released MC sources undergo temporal and spatial processes that govern fate, (e.g. degradation and partitioning [Chapters 8 and 10]) and transport processes (e.g., diffusivity, advection and exchanges between the water column and the sediment bed through partitioning, settling and resuspension).

While not being used in this effort, two existing numerical models, the general water quality model, WASP (USEPA) and the fine-scaled $\mathrm{F}$ and $\mathrm{T}$ model, TRIM2D (USGS and SSC-PAC), can be used to simulate hydrodynamic $\mathrm{F}$ and $\mathrm{T}$ from the $\mathrm{MC}$ source release. Models resembling the Water Quality Analysis Simulation Program (WASP) and the two dimensional Tidal Residual Intertidal Mudflat (TRIM2D) are designed for modeling such processes in a site-specific manner. These models have been rigorously scrutinized, and their accuracies have been demonstrated nationally and internationally for decades. While the use of these models can minimize uncertainties associated with model performance, they require a site-specific understanding of the spatially and temporally dependent hydrodynamics for the water-body in which the munitions reside.

\subsection{Modeling release of MCs such as TNT, RDX and HMX}

The release rate function is used to provide release rates for a single shell under localized current velocity and shell integrity conditions. In the absence of adequate information about the quantity and magnitude of breached shells in DoD coastal and estuarine waters, the following assumptions are made:

1. The release rate function, which was developed and implemented into the shell model, can be used to predict the release rate for any single breached shell.

2. For multiple breached shells, the total release rates can be obtained by summing the release rates of each individual beached shell. This is valid (uncertainty is minimized) if sufficient information about the distribution and state of integrity for munitions is known or can be estimated for a given site.

The $\mathrm{MC}$ release rate relationship was previously obtained as follows: 


$$
F=\alpha U C(b) \pi b^{2}=\frac{2 \pi D C_{s}}{\frac{2 D}{\alpha U b^{2}}+\frac{D}{\mu R^{2}}+\frac{1}{b}-\frac{1}{R}}
$$

$\mathrm{F}$ is the mass release rate function, which, as depicted in Equation 18 is a closed-form solution with the five variables, including hydrodynamic diffusivity coefficient (D), ambient current (U), hole size (b), cavity radius (R) and dissolution speed of MC from solid to aqueous phase $(\mu)$. The model parameter $\alpha$, was defined as a geometry factor (Equation 9-1 in Wang et al. [2011]) and is typically set to 1.

A more complete model could eventually be developed to include integration of empirical MC release rates, shell corrosion rates, and MC rates of decomposition. Use of these empirical process descriptors, along with analytically/empirically verified release rate formulae, adequately describe and predict source release, and F and T of MC from a breached shell in water and sediment environments. This can ultimately be used to evaluate environmental risks where the breached shell resides. Here, multiple shell extrapolation is possible, given additional information relating the amount of $\mathrm{MC}$ with the number, type, and integrity of munitions in a prescribed area.

\subsection{Probabilistic modeling}

The five variables governing the mass release rate function $(F)$ for a single shell, as shown in Equation 18 can be described deterministically, probabilistically, or as a combination of both.

For example, the size(s) of the holes (with b as the radius) on a single shell will vary with time. The hole sizes may involve a range or distribution function, which represents variability associated with the variable, b. Ambient current, $U$, will also fluctuate due to the dynamic nature such as tidal force, wind speed, and freshwater effects of the marine environment in which shells may reside. Therefore, a range or distribution function is often used to represent a range of expected currents in the marine environment. Another source of probabilistic nature is the uncertainty or lack of data associated with certain variables, which requires the use of a probability function in order to make meaningful predictions. Predictions should also be interpreted in a probabilistic fashion using an output distribution. For example, hole sizes not only involve variability, they often are associated with uncertainty due to lack of sufficient data. 
When the mass release rate function, developed for a single shell, is implemented for multiple shells, the number of shells for each shell type also needs to be prescribed, either deterministically or probabilistically. When multiple variables are prescribed probabilistically, each with its own distribution function, predictions would require a large number of calculations so that the variables with a probability distribution can be adequately sampled. For example, in previous efforts during the shell model study, the Monte Carlo method was used to perform simulations with 10,000 calculations conducted for each scenario. However, simulation results from the 10,000 calculations did not show a noticeable difference among the results of 1,000 calculations.

\subsubsection{Underwater munitions site modeling approach and methodology}

For UWMM site-modeling purposes (multiple shells, multiple scenarios) envisioned for this effort, the parameters used by the release function were evaluated, and a flow chart was developed to more efficiently handle the various functional dependencies. This approach can accommodate the release process and individual contributions for any number of munitions. Likewise, it describes a process whereby the munitions distributed spatially over a specific site area can be evaluated. Such distributions can originate from either empirical or hypothetical (probabilistic) data. A preliminary evaluation of reasonably well-characterized distributions for two example sites with UWMM is presented in this report.

In preparation for implementing this process, a crude functional analysis was performed for $5 \% / 54$ caliber munitions containing TNT to demonstrate the functional dependencies of the release rate function $(F)$ as related to each of the terms in Equation 18. These data and corresponding values of $\mathrm{F}$ are tabulated below.

Note that when no cavity exists and MC fill is fully exposed, use of the cavity-dependent release function represented by Equation 18 is not valid, which gives negative release values for the extreme example at larger values of $b(0.1 \mathrm{~m})$ relative to munition size (inner diameter $=0.039 \mathrm{~m})$. This corresponds to a low-order detonation scenario as described previously, where there is still a valid dependence on MC dissolution rate, but there is no relationship to, or functional dependence on, (the nonexistent) cavity size. 
Example dependencies of $\mathrm{F}$ on Equation 18 variables are shown graphically below in Figure 55. For realistic ranges of values b, R, and $\mathrm{U}$ for the $5 " / 54$ caliber TNT-filled shell, see Table 23. The remaining variables (i.e., number and type of munitions) shown in the model process flow diagram (Figure 54) are site specific and will be discussed in the following section. 
Table 23. Discreet examples of functional values for shell model release defined by Equation 1.

\begin{tabular}{|c|c|c|c|c|c|c|c|}
\hline Diffusivity & Solubility & Ambient current & Hole radius & & Cavity radius & $\begin{array}{l}\text { Dissolution } \\
\text { Speed }\end{array}$ & $\begin{array}{l}\text { For one 5" shell } \\
\text { (TNT) }\end{array}$ \\
\hline D & $\mathrm{C}_{\mathrm{s}}$ & U & b & $\alpha$ & $R$ & $\mu$ & $F$ \\
\hline$\left(m^{2} / \mathrm{s}\right)$ & $(\mathrm{mg} / \mathrm{L})$ & $(\mathrm{m} / \mathrm{s})$ & $(\mathrm{m})$ & (unit less) & $(\mathrm{m})$ & $(\mathrm{m} / \mathrm{s})$ & (mg/s) \\
\hline $6.54 \mathrm{E}-08$ & 88.5 & 0.5 & $1.00 \mathrm{E}-06$ & 1 & 1.00E-09 & 0.00226 & $1.25671 \mathrm{E}-15$ \\
\hline $6.54 \mathrm{E}-08$ & 88.5 & 0.5 & $1.00 \mathrm{E}-06$ & 1 & 1.00E-06 & 0.00226 & 1.2454E-09 \\
\hline $6.54 \mathrm{E}-08$ & 88.5 & 0.5 & $1.00 \mathrm{E}-06$ & 1 & 0.039 & 0.00226 & 2.88254E-08 \\
\hline $6.54 \mathrm{E}-08$ & 88.5 & 0.5 & 1.00E-04 & 1 & 1.00E-09 & 0.00226 & $1.25671 \mathrm{E}-15$ \\
\hline $6.54 \mathrm{E}-08$ & 88.5 & 0.5 & $1.00 \mathrm{E}-04$ & 1 & $1.00 \mathrm{E}-04$ & 0.00226 & $1.2454 \mathrm{E}-05$ \\
\hline $6.54 \mathrm{E}-08$ & 88.5 & 0.5 & $1.00 \mathrm{E}-04$ & 1 & 0.039 & 0.00226 & $3.63634 \mathrm{E}-06$ \\
\hline $6.54 \mathrm{E}-08$ & 88.5 & 0.5 & $1.00 \mathrm{E}-02$ & 1 & 1.00E-09 & 0.00226 & $1.25671 \mathrm{E}-15$ \\
\hline $6.54 \mathrm{E}-08$ & 88.5 & 0.5 & $1.00 \mathrm{E}-02$ & 1 & 1.00E-02 & 0.00226 & 0.124540437 \\
\hline $6.54 \mathrm{E}-08$ & 88.5 & 0.5 & $1.00 \mathrm{E}-02$ & 1 & $0.039^{*}$ & 0.00226 & 0.000488909 \\
\hline $6.54 \mathrm{E}-08$ & 88.5 & 0.5 & $1.00 \mathrm{E}-01$ & 1 & 1.00E-09 & 0.00226 & $1.25671 \mathrm{E}-15$ \\
\hline $6.54 \mathrm{E}-08$ & 88.5 & 0.5 & $1.00 \mathrm{E}-01$ & 1 & $1.00 \mathrm{E}-01$ & 0.00226 & 12.45404374 \\
\hline $6.54 \mathrm{E}-08$ & 88.5 & 0.5 & $1.00 \mathrm{E}-01$ & 1 & $0.039^{*}$ & 0.00226 & -0.00232784 \\
\hline $6.54 \mathrm{E}-08$ & 88.5 & 0.05 & 1.00E-06 & 1 & 1.00E-09 & 0.00226 & $1.25671 \mathrm{E}-15$ \\
\hline $6.54 \mathrm{E}-08$ & 88.5 & 0.05 & $1.00 \mathrm{E}-06$ & 1 & $1.00 \mathrm{E}-06$ & 0.00226 & 1.15248E-09 \\
\hline $6.54 \mathrm{E}-08$ & 88.5 & 0.05 & 1.00E-06 & 1 & $0.039^{*}$ & 0.00226 & 1.00569E-08 \\
\hline $6.54 \mathrm{E}-08$ & 88.5 & 0.05 & $1.00 \mathrm{E}-04$ & 1 & 1.00E-09 & 0.00226 & $1.25671 \mathrm{E}-15$ \\
\hline $6.54 \mathrm{E}-08$ & 88.5 & 0.05 & 1.00E-04 & 1 & 1.00E-04 & 0.00226 & $1.15248 \mathrm{E}-05$ \\
\hline $6.54 \mathrm{E}-08$ & 88.5 & 0.05 & $1.00 \mathrm{E}-04$ & 1 & $0.039^{*}$ & 0.00226 & 3.5527E-06 \\
\hline $6.54 \mathrm{E}-08$ & 88.5 & 0.05 & $1.00 \mathrm{E}-02$ & 1 & $1.00 \mathrm{E}-09$ & 0.00226 & $1.25671 \mathrm{E}-15$ \\
\hline $6.54 \mathrm{E}-08$ & 88.5 & 0.05 & $1.00 \mathrm{E}-02$ & 1 & $1.00 \mathrm{E}-02$ & 0.00226 & 0.115247875 \\
\hline $6.54 \mathrm{E}-08$ & 88.5 & 0.05 & $1.00 \mathrm{E}-02$ & 1 & $0.039^{*}$ & 0.00226 & 0.000488755 \\
\hline
\end{tabular}




\begin{tabular}{|l|l|l|l|l|l|l|l|}
\hline Diffusivity & Solubility & Ambient current & Hole radius & & Cavity radius & $\begin{array}{l}\text { Dissolution } \\
\text { Speed }\end{array}$ & $\begin{array}{l}\text { For one 5" shell } \\
\text { (TNT) }\end{array}$ \\
\hline D & Cs & U & b & $\alpha$ & R & $\mu$ & F \\
\hline $6.54 \mathrm{E}-08$ & 88.5 & 0.05 & $1.00 \mathrm{E}-01$ & 1 & $1.00 \mathrm{E}-09$ & 0.00226 & $1.25671 \mathrm{E}-15$ \\
\hline $6.54 \mathrm{E}-08$ & 88.5 & 0.05 & $1.00 \mathrm{E}-01$ & 1 & $1.00 \mathrm{E}-01$ & 0.00226 & 11.52478751 \\
\hline $6.54 \mathrm{E}-08$ & 88.5 & 0.05 & $1.00 \mathrm{E}-01$ & 1 & $0.039^{*}$ & 0.00226 & -0.00232787 \\
\hline $6.54 \mathrm{E}-08$ & 88.5 & 0.005 & $1.00 \mathrm{E}-06$ & 1 & $1.00 \mathrm{E}-09$ & 0.00226 & $1.25671 \mathrm{E}-15$ \\
\hline $6.54 \mathrm{E}-08$ & 88.5 & 0.005 & $1.00 \mathrm{E}-06$ & 1 & $1.00 \mathrm{E}-06$ & 0.00226 & $6.60012 \mathrm{E}-10$ \\
\hline $6.54 \mathrm{E}-08$ & 88.5 & 0.005 & $1.00 \mathrm{E}-06$ & 1 & $0.039^{*}$ & 0.00226 & $1.33893 \mathrm{E}-09$ \\
\hline $6.54 \mathrm{E}-08$ & 88.5 & 0.005 & $1.00 \mathrm{E}-04$ & 1 & $1.00 \mathrm{E}-09$ & 0.00226 & $1.25671 \mathrm{E}-15$ \\
\hline $6.54 \mathrm{E}-08$ & 88.5 & 0.005 & $1.00 \mathrm{E}-04$ & 1 & $1.00 \mathrm{E}-04$ & 0.00226 & $6.60012 \mathrm{E}-06$ \\
\hline $6.54 \mathrm{E}-08$ & 88.5 & 0.005 & $1.00 \mathrm{E}-04$ & 1 & $0.039^{*}$ & 0.00226 & $2.88835 \mathrm{E}-06$ \\
\hline $6.54 \mathrm{E}-08$ & 88.5 & 0.005 & $1.00 \mathrm{E}-02$ & 1 & $1.00 \mathrm{E}-09$ & 0.00226 & $1.25671 \mathrm{E}-15$ \\
\hline $6.54 \mathrm{E}-08$ & 88.5 & 0.005 & $1.00 \mathrm{E}-02$ & 1 & $1.00 \mathrm{E}-02$ & 0.00226 & 0.066001199 \\
\hline $6.54 \mathrm{E}-08$ & 88.5 & 0.005 & $1.00 \mathrm{E}-02$ & 1 & $0.039^{*}$ & 0.00226 & 0.000487213 \\
\hline $6.54 \mathrm{E}-08$ & 88.5 & 0.005 & $1.00 \mathrm{E}-01$ & 1 & $1.00 \mathrm{E}-09$ & 0.00226 & $1.25671 \mathrm{E}-15$ \\
\hline $6.54 \mathrm{E}-08$ & 88.5 & 0.005 & $1.00 \mathrm{E}-01$ & 1 & $1.00 \mathrm{E}-01$ & 0.00226 & 6.600119905 \\
\hline $6.54 \mathrm{E}-08$ & 88.5 & 0.005 & $3.90 \mathrm{E}-02$ & 1 & $0.039^{*}$ & 0.00226 & 1.003878238 \\
\hline
\end{tabular}


Figure 54. Process flow for implementing the shell model release function at a site with discrete parameters or probabilistic parameter distributions.

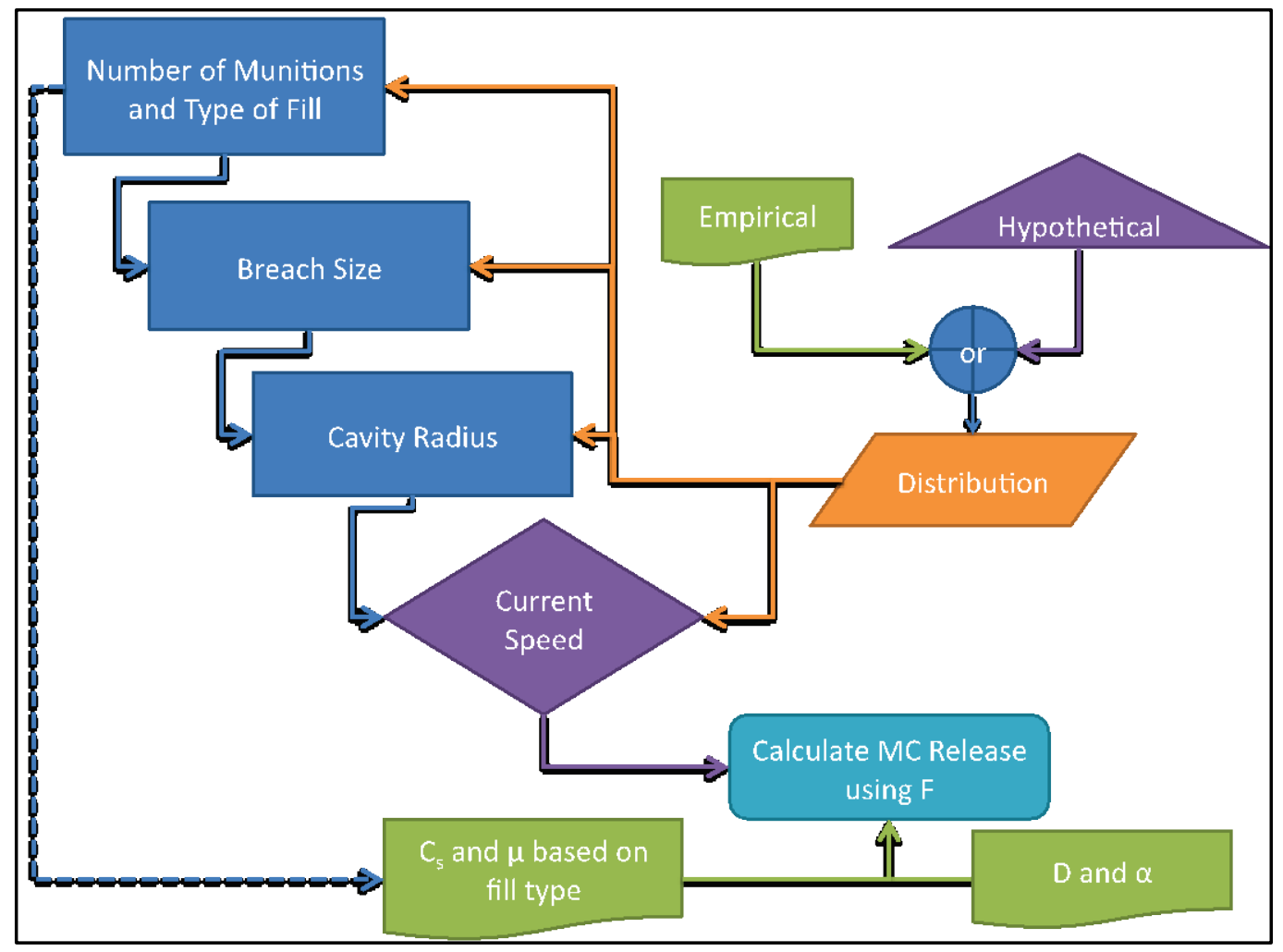

\subsection{Characterization of munitions distributions at UWMM sites}

Relatively few sites exist with sufficiently robust characterization of munitions distributions. Using the limited site-specific data available for two different types of sites, (1) Bahia Salinas del Sur Lagoon at the former Vieques Naval Training Range (fVNTR-BSS) and (2) Ordnance Reef (HIo6), quantities of total non-munitions, munitions debris, and individual munition types were compiled and evaluated to develop a suite of model release scenarios. The calculated percentages of munitions items illustrated in Figure 56 and Figure 57 allow for a comprehensive understanding of specific categories of munitions found at these types of sites and for the purpose of this project. These percentages will also be considered representative of such sites. 
Figure 55. Release rate function (F) dependencies on (a) Breach hole radius at $R=1 \mathrm{e}-2 \mathrm{~m}$ and $\mathrm{U}=0.5 \mathrm{~m} / \mathrm{s}$, (b) Internal cavity radius $(\mathrm{R})$ at $\mathrm{b}=1 \mathrm{e}-4 \mathrm{~m}$ and $U=0.5 \mathrm{~m} / \mathrm{s}$, and $(\mathrm{c})$ Current velocity $(U)$ at $b=1 \mathrm{e}-3 \mathrm{~m}$ and $R=2 \mathrm{e}-2 \mathrm{~m}$.

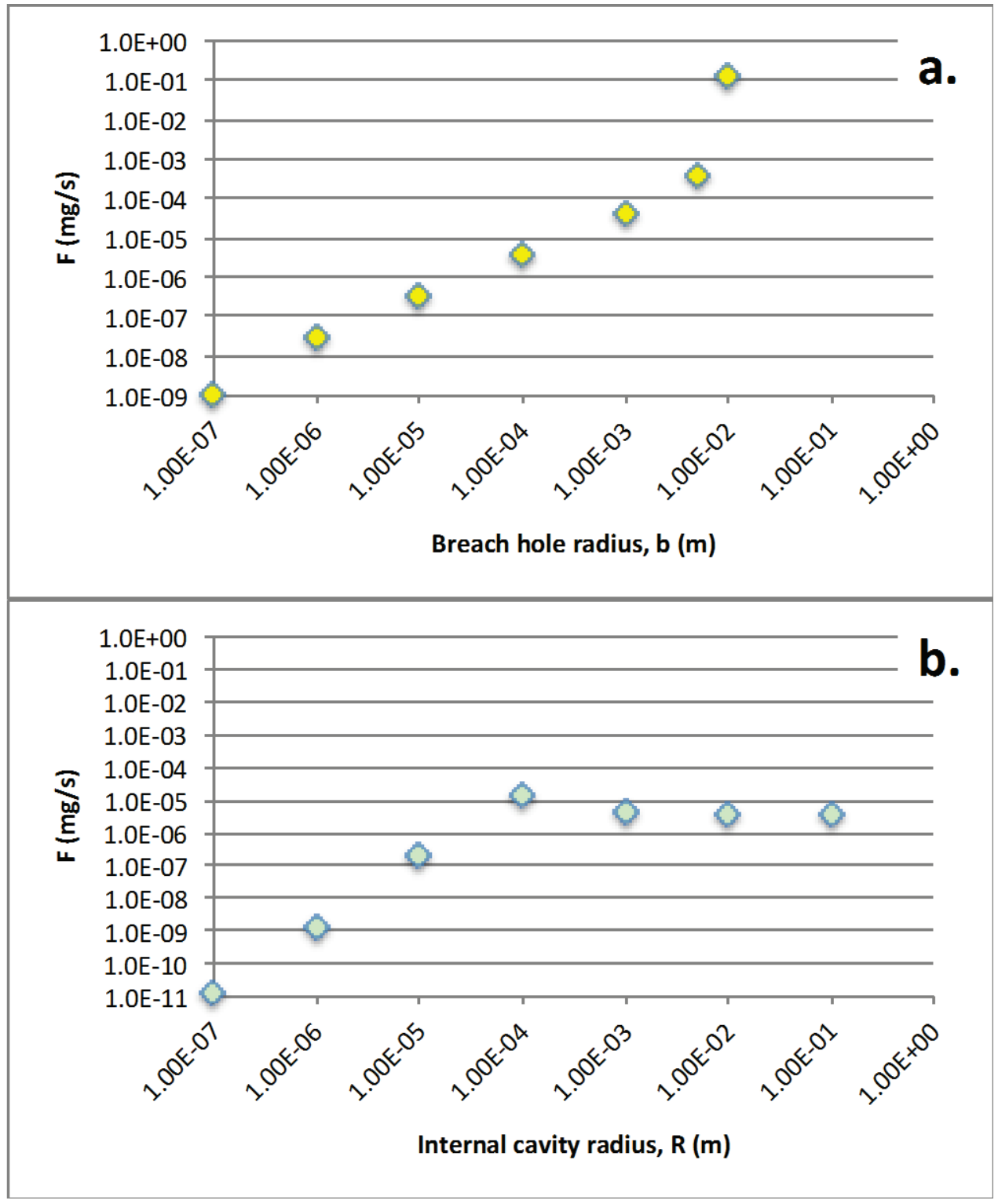




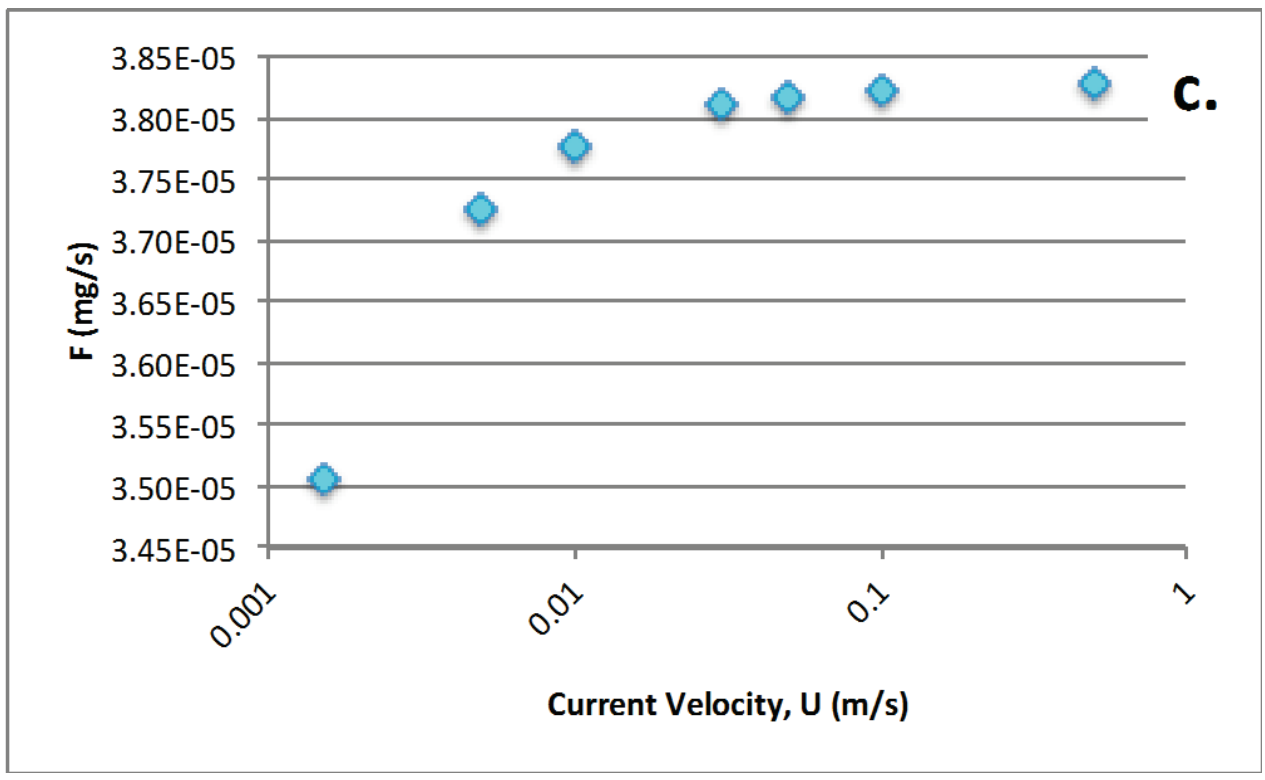

Figure 56. Distribution of munitions at Site 1, characterized as an underwater munitions site that was part of a former military training range.

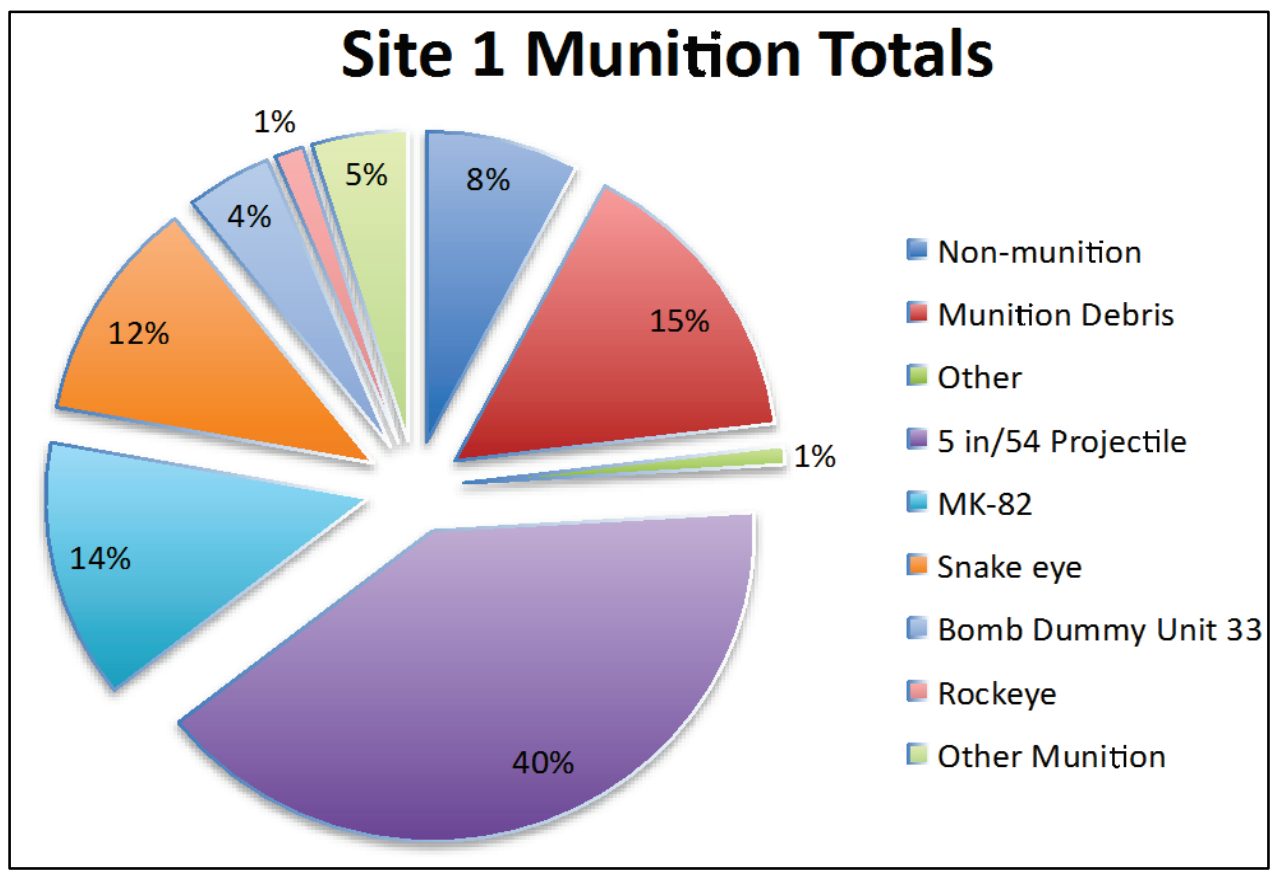


Figure 57. Distribution of munitions at Site 2, characterized as an underwater munitions site that was a former discarded military munitions area. (Based on Table 1 in Garcia et al. 2009) * Note: Totals do not include $20-\mathrm{mm}$ cartridges (49\% of total).

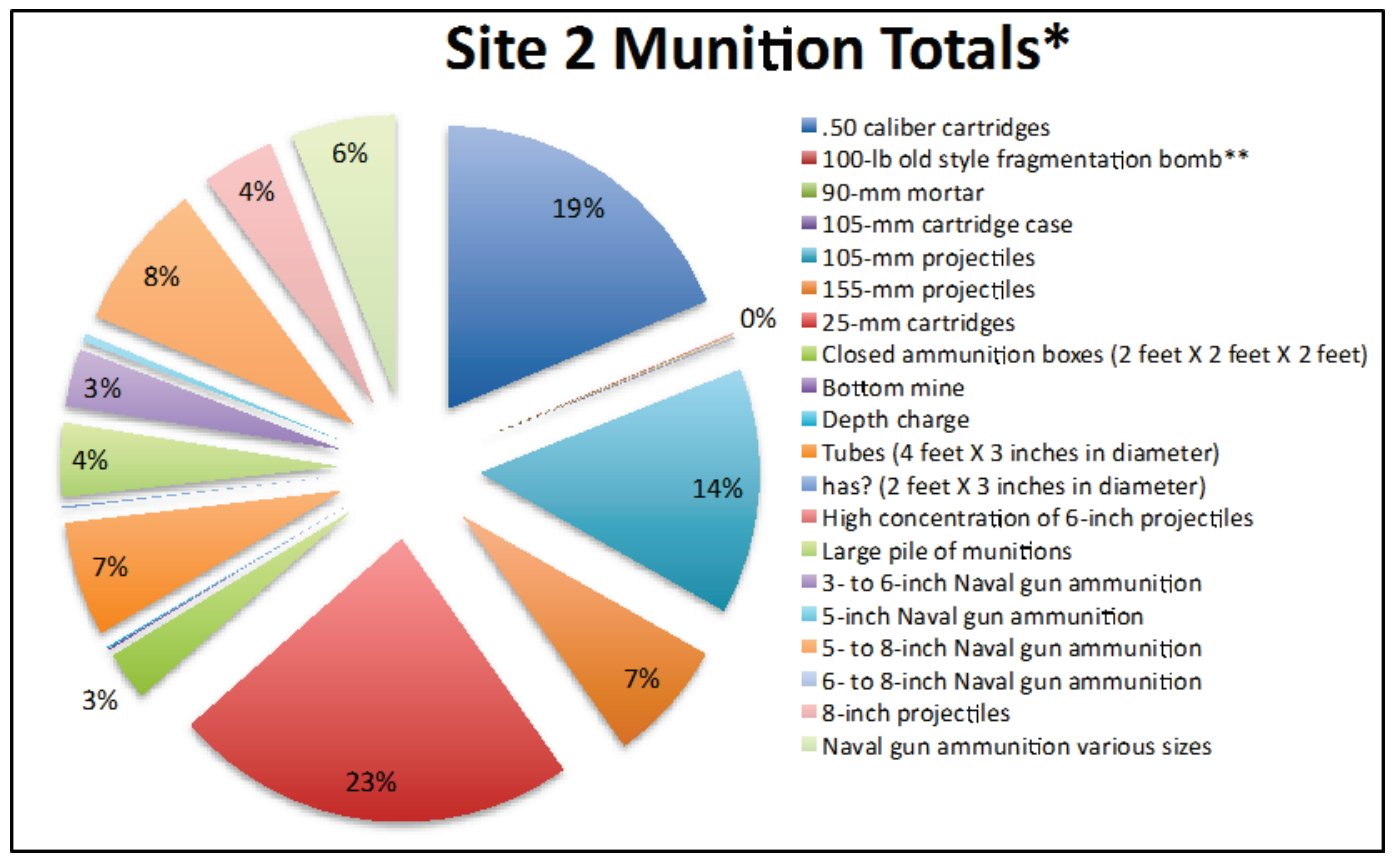

Note that these two sites exhibit very different numbers and types of munitions, but are considered representative of the extent or range of extremes expected for distributions present at real UWMM sites.

\subsection{Probabilistic MC release using munitions distributions at UWMM sites}

Two scenarios are addressed in this effort using empirical or semiempirical munition distributions to represent munitions that might be present at a site, and applying Equation 18 to each munition in that distribution. These distributions only reflect numbers and types of munitions. The breach state/integrity of the munitions items must also be addressed, either by calculation using corrosion-based temporal models or prescribing a distribution of breach states deterministically or probabilistically. While the former approach (dynamic/temporally variable release) is outside the scope of this effort, the latter (breach state distribution) approach will provide an estimate of release at any given point in time to use as a source term in environmental $\mathrm{F}$ and $\mathrm{T}$ processes.

Scenario A, described below, models munitions at a generic site using a hypothetical distribution for each of two types of munitions and treats the 
release of $\mathrm{MC}$ from these munitions probabilistically under the same site conditions. The purpose of this scenario is to illustrate how different munitions, with different fill types, behave under the same conditions as those treated by the MC release (shell) model.

Scenario B models munitions at a real UWMM site, which uses a semiempirical distribution for the types of munitions at the site and treats the release of $\mathrm{MC}$ from these munitions probabilistically under the same site conditions. The results of this model scenario are then used to derive a concentration at the site for an assessment of exposure and potential effects on aquatic organism endpoints of interest.

Scenario A. This scenario uses distribution functions for the parameters graphically represented in Figure 56 . Here, the authors are presuming that sufficient knowledge about the central tendency value in addition to minimum and maximum values exists so that a semi-empirical distribution can be employed. This allows the use of a beta-Program Evaluation Review Technique (PERT) distribution (see http://broadleaf.com.au/resource-material/beta-pert-origins/), a continuous probability distribution that is a form of triangular distribution based on central tendency, minimum, and maximum values. It is based on U.S. Navy methodology developed in the 1950 s to manage uncertainties in cost and schedule for the Polaris submarine missile program. However, for probability purposes or the Monte Carlo simulation, the sampling of a beta-PERT distribution is weighted, i.e., randomly sampled less towards the minimum and maximum values (low probability regions) and sampled more near the central tendency (highest probability region) values. This is unlike a normal or lognormal distribution, which is randomly sampled with equal weighting across the entire distribution. The remaining parameters in Equation 18 are treated deterministically using empirical values as indicated in Table 24 and Table 25. 
Figure 58. Graphical distribution functions for parameters treated probabilistically are

(a) ambient current velocity, (b) breach hole radius, (c) breach cavity radius, (d) number of breached munitions of a given type, and (e) mass remaining in each breached munition. Minimum, maximum, and central tendency (most likely) are tabulated in Tables 9-2 and 9-3.
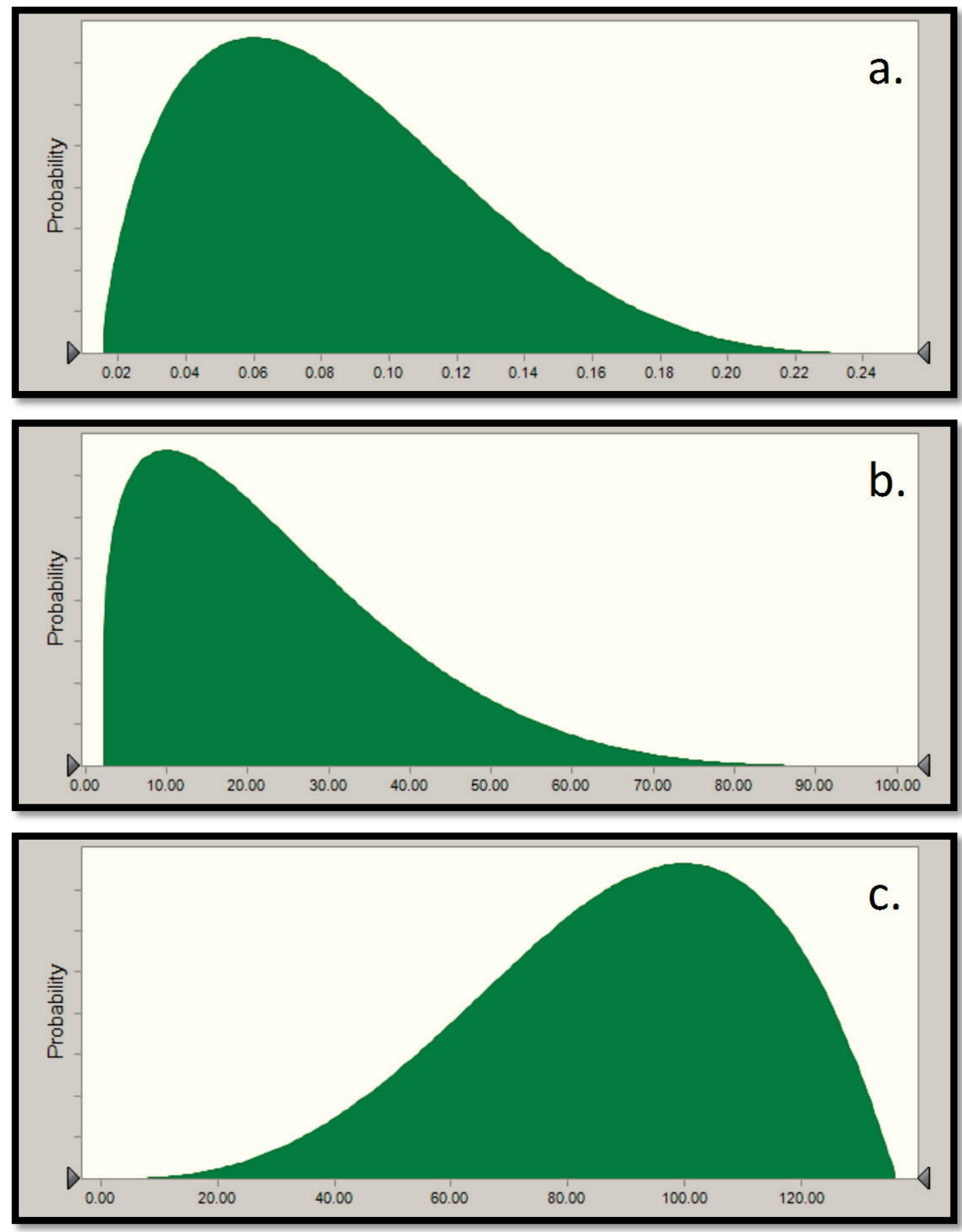


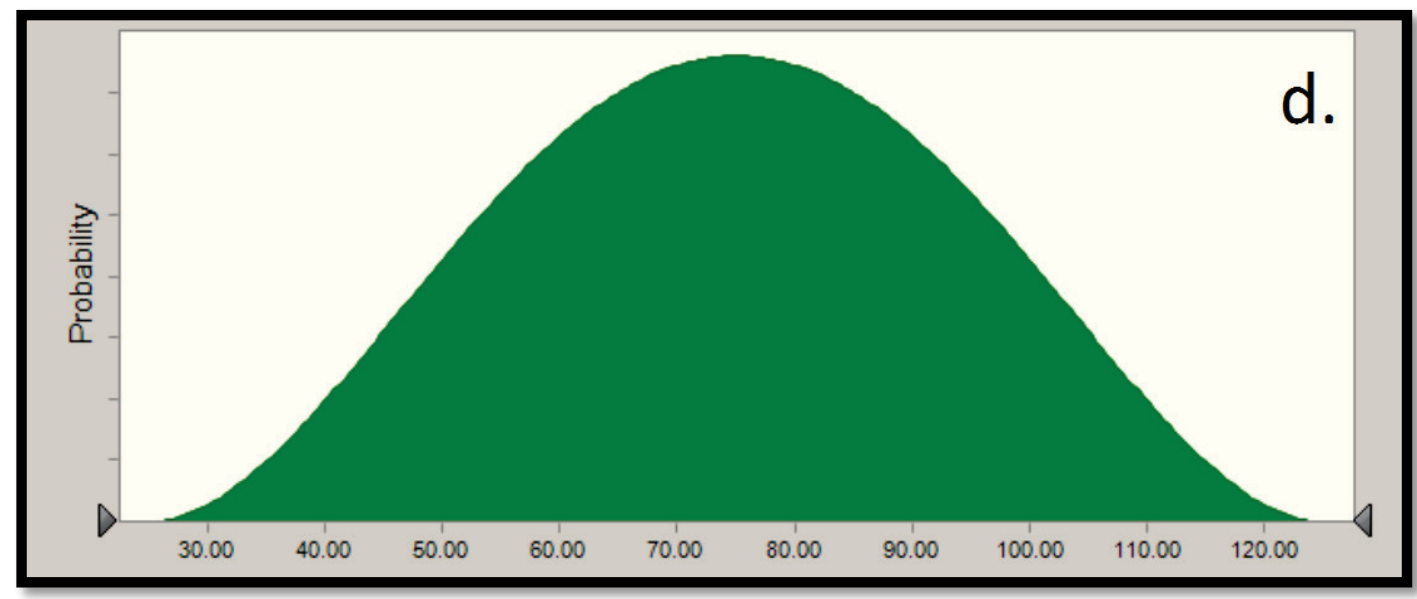

Table 24. Model parameters for TNT-filled munitions at a generic site. Distribution-based parameters are in gray and shown graphically in Figure 58.

TNT- generic site

Variable Name, Description

D Diffusivity, Molecular diffusivity from hydrodynamic mixing

Cs Concentration of Munition Contituent at Saturation (Sea Water)

A model parameter which is a function of the local geometry of the breach hole/crack and the thickness of the shell

Ambient Current

Radius of munition breach

Radius of cavity inside munition

Dissolution speed - Dissolution Flux divided by the munition saturation concentration @ boundry layer

MunNum \# of Munitions

MunMass Mass of Munition

\begin{tabular}{|l|r|r|r|r|}
\hline \multicolumn{4}{|c|}{ Distribution Parameters } & \\
\hline Units & Assumption or Static Value Min & Low Most Likely High Max \\
\hline $\mathrm{m}^{2} / \mathrm{s}$ & $6.54 \mathrm{E}-08$ & & & \\
\hline $\mathrm{mg} / \mathrm{L}$ & 88.5 & & & \\
\hline unitless & 1 & & & \\
\hline $\mathrm{m} / \mathrm{s}$ & & 0.015 & 0.06 & 0.25 \\
\hline $\mathrm{mm}$ & 2 & 10 & 100 \\
\hline $\mathrm{mm}$ & 0.0000226 & 0 & 100 & 136.5 \\
\hline $\mathrm{m} / \mathrm{s}$ & & & & \\
\hline & & 25 & 75 & 125 \\
\hline $\mathrm{kg}$ & & 0 & 3 & 56 \\
\hline
\end{tabular}

Table 25. Model parameters for Explosive D-filled munitions at a generic site. Distribution-based parameters in gray are the same as for TNT-filled munitions for purposes of comparison, as shown graphically in Figure 58.

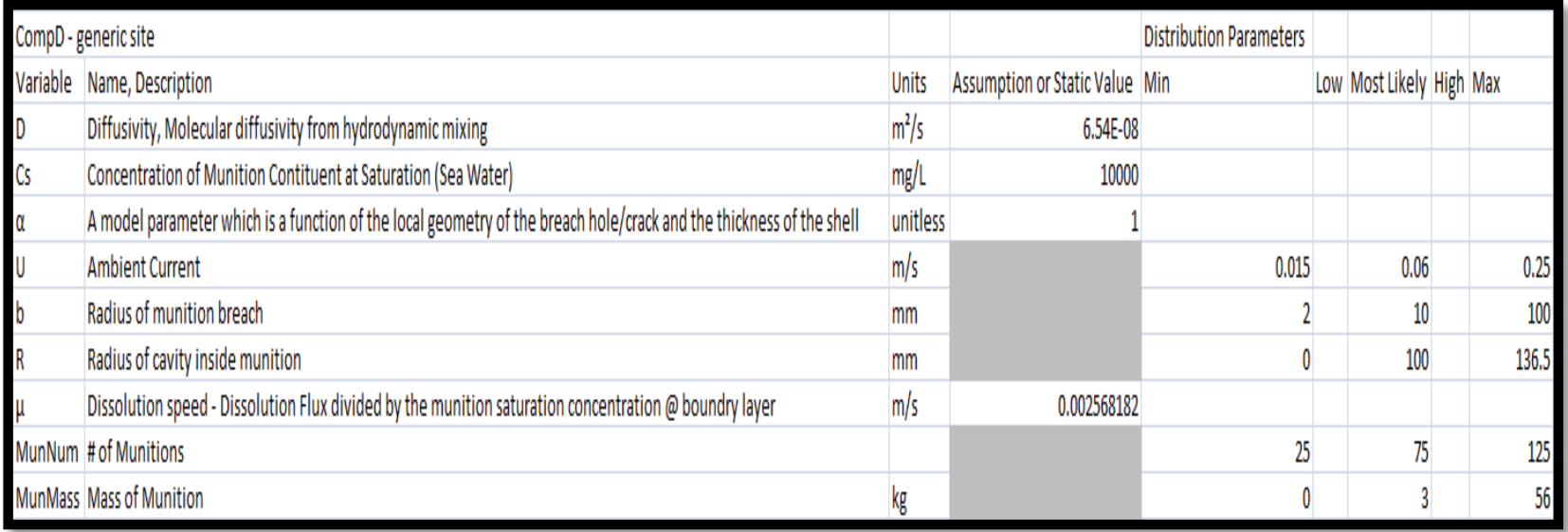


Using the above parameters, the release was modeled using the Monte Carlo method to provide a probabilistic estimate of the release function distribution $\mathrm{F}$ (single munition) and the total site release function distribution $\mathrm{F}$ ( $F$ applied to the distribution of munitions at the site). These results are presented below for each fill type, TNT and Explosive D. It is important to note that results from 1,000 trials were not significantly different compared to results from 10,000 trials, which are similar to observations reported during the original shell model effort (Wang et al. 2011).

Scenario A Results (TNT). Figure 59 and Figure 60 illustrate the behavior of TNT-filled munitions at a hypothetical site defined by the model parameters described in Figure 58 and Table 24. The results are shown graphically, both as a conventional distribution, and as a cumulative distribution function (CDF).

Figure 59. TNT release function distribution F (single munition).

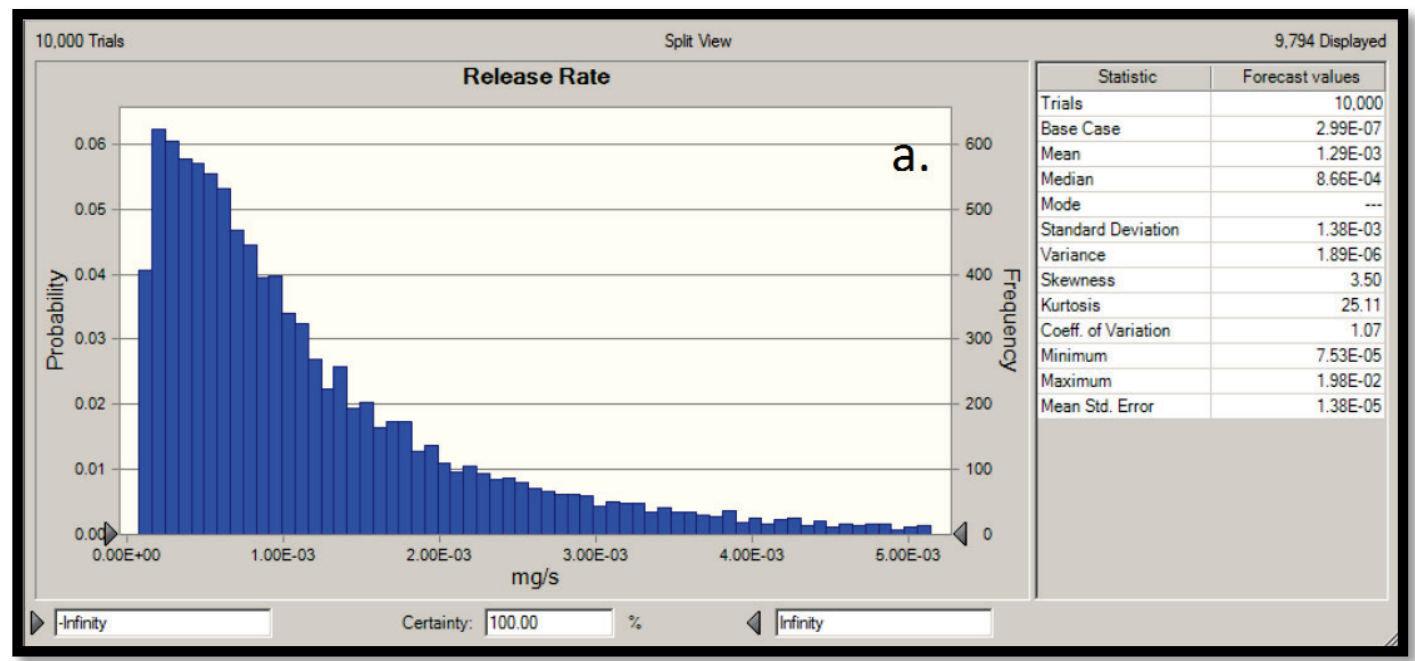




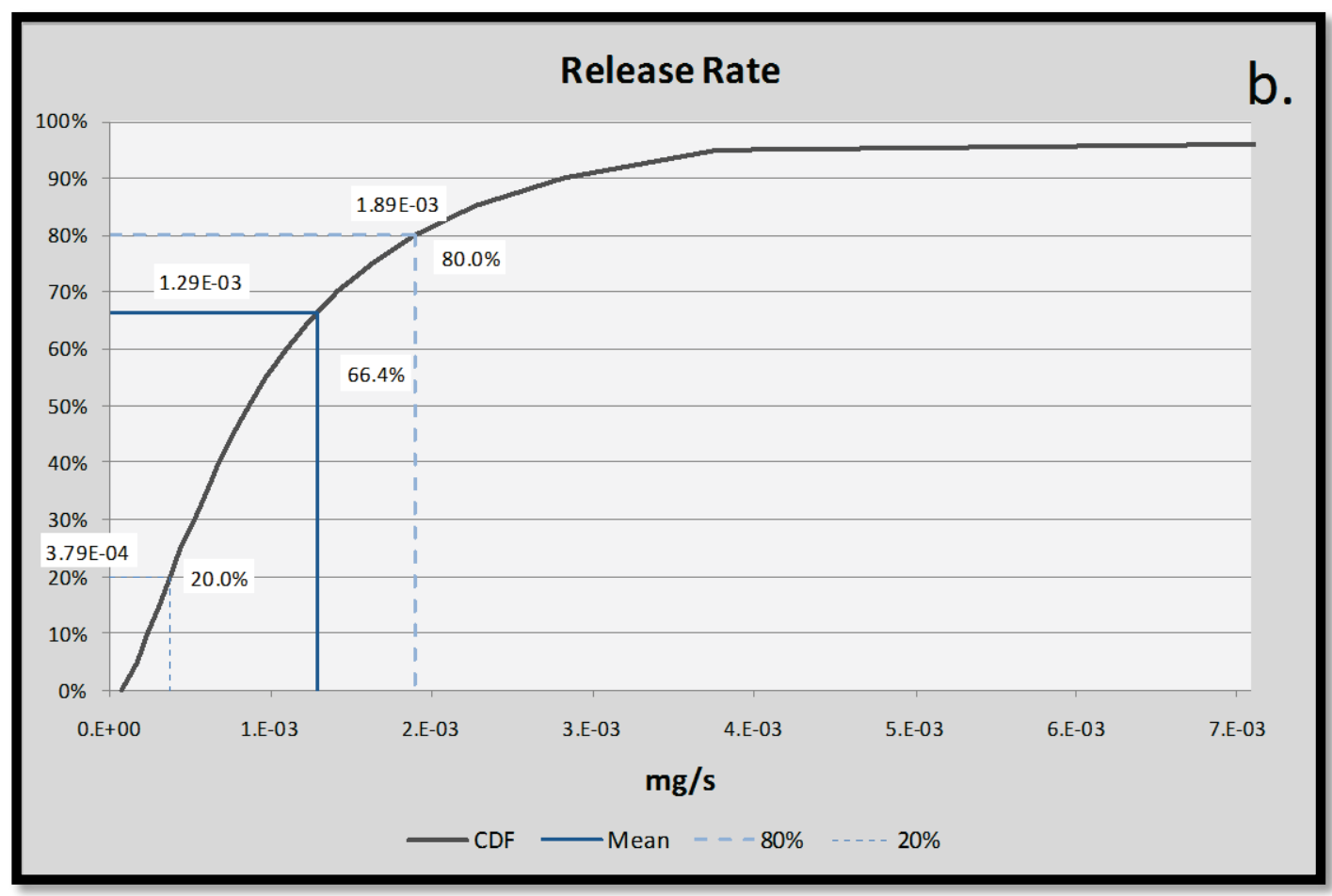

Figure 60.TNT total site release function distribution F' (F applied to the distribution of munitions at the site)

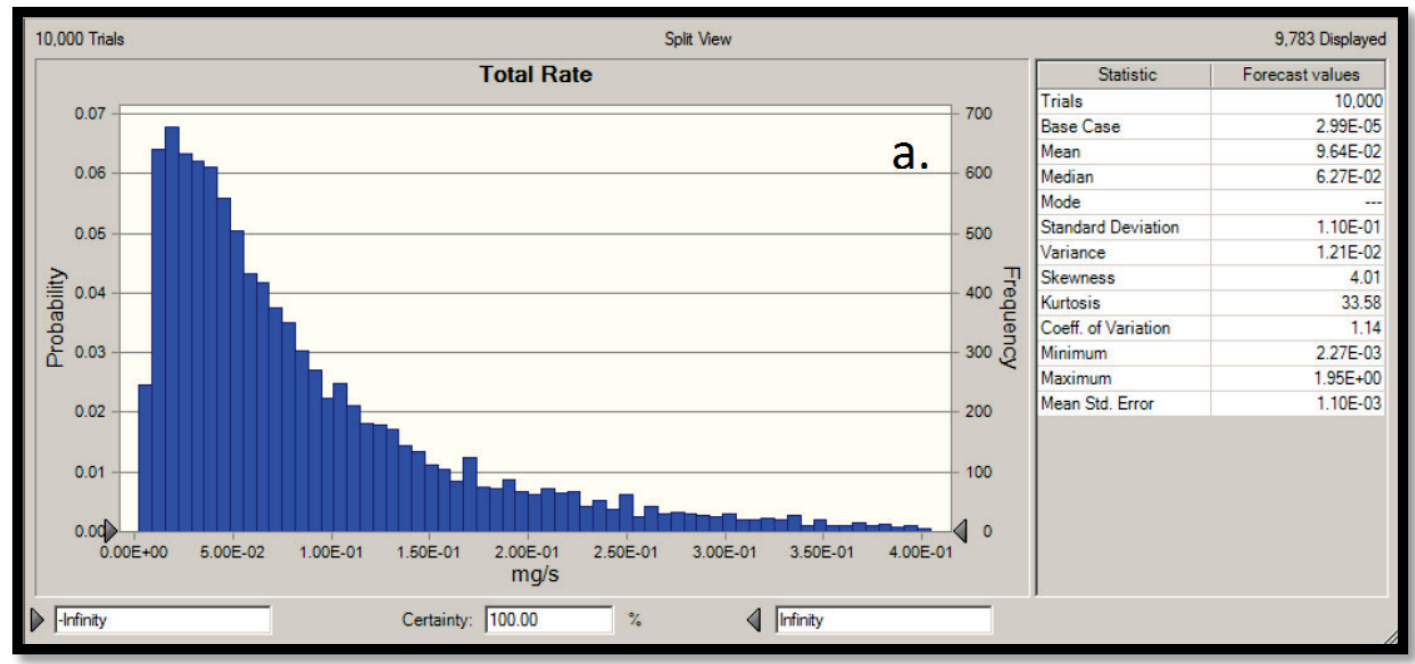




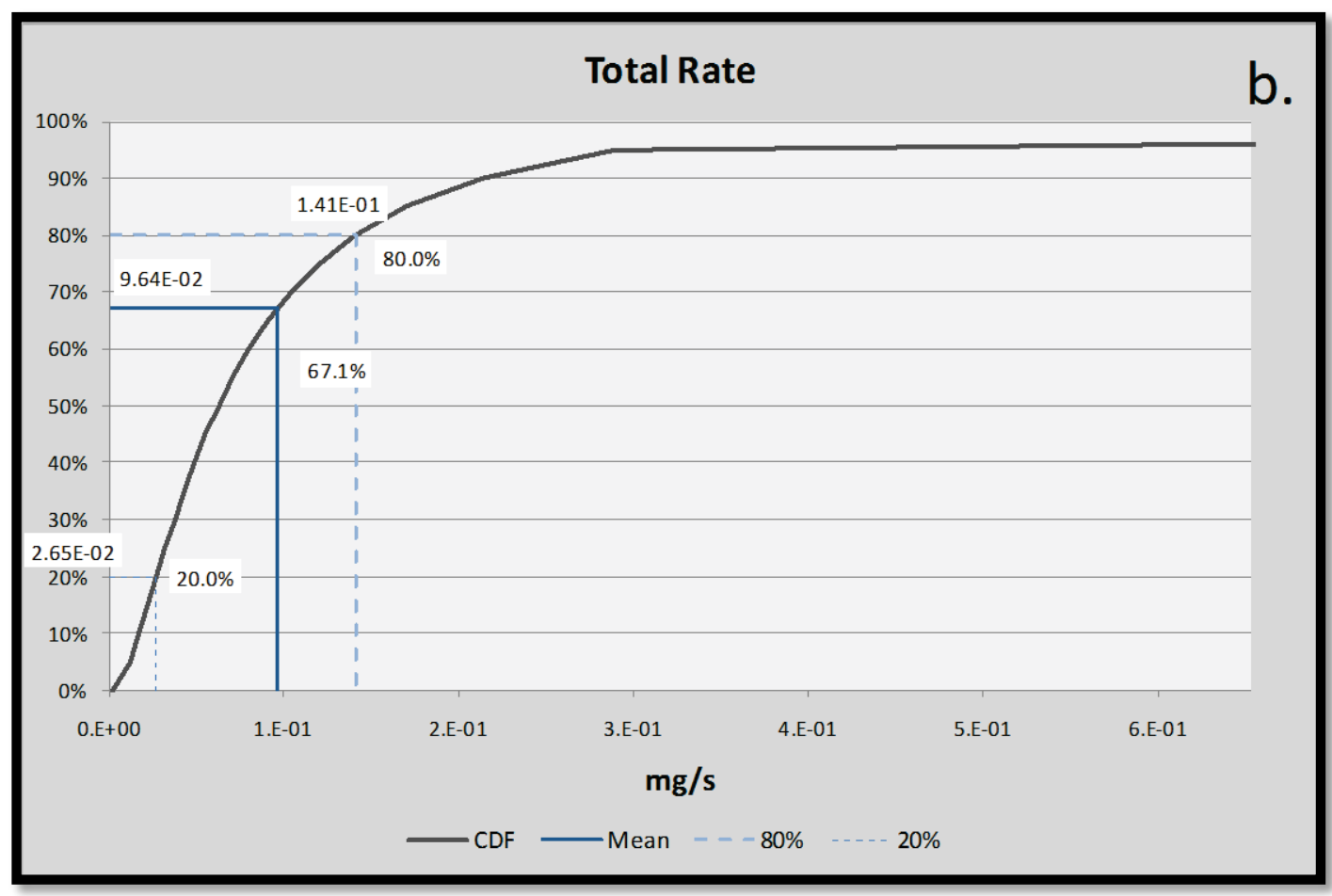

Scenario A Results (Explosive D). Figure 61 and Figure 62 illustrate the behavior of Explosive D-filled munitions at a hypothetical site defined by the model parameters described in Figure 58 and Table 25. The results are shown graphically, both as a conventional distribution, and as a CDF.

Figure 61. Explosive $D$ release function distribution $F$ (single munition).

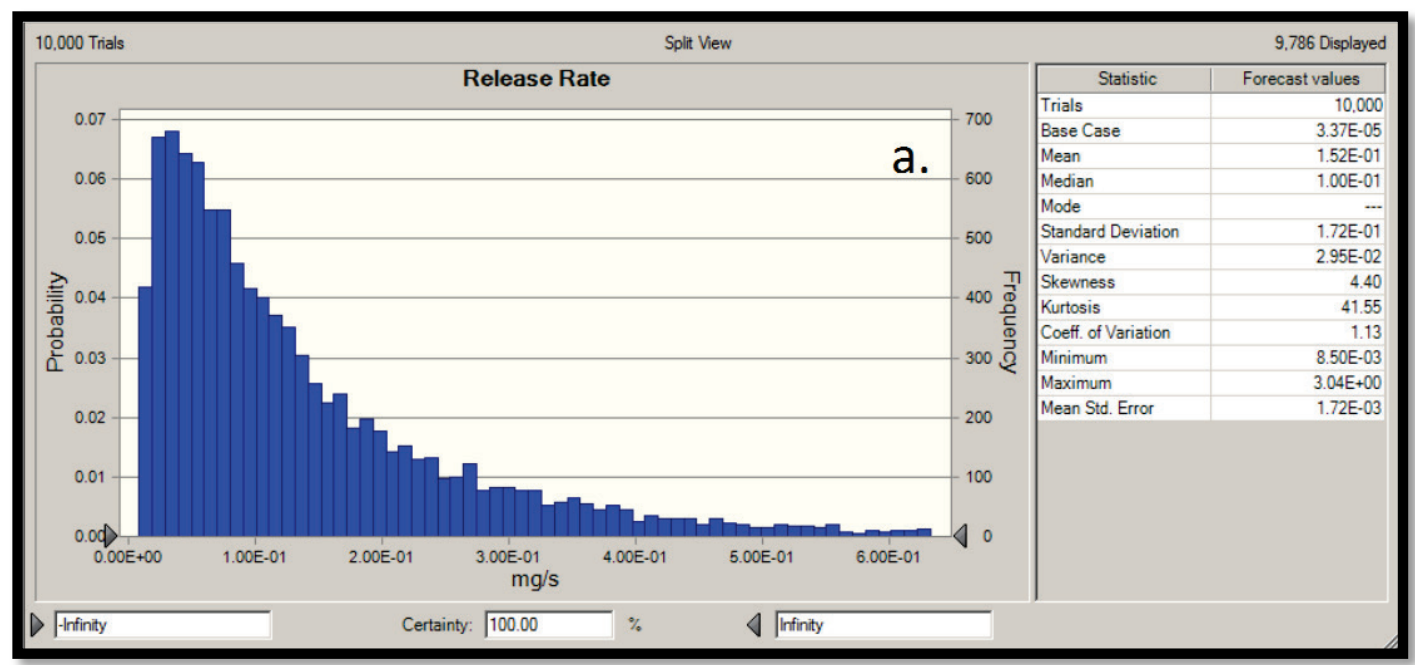




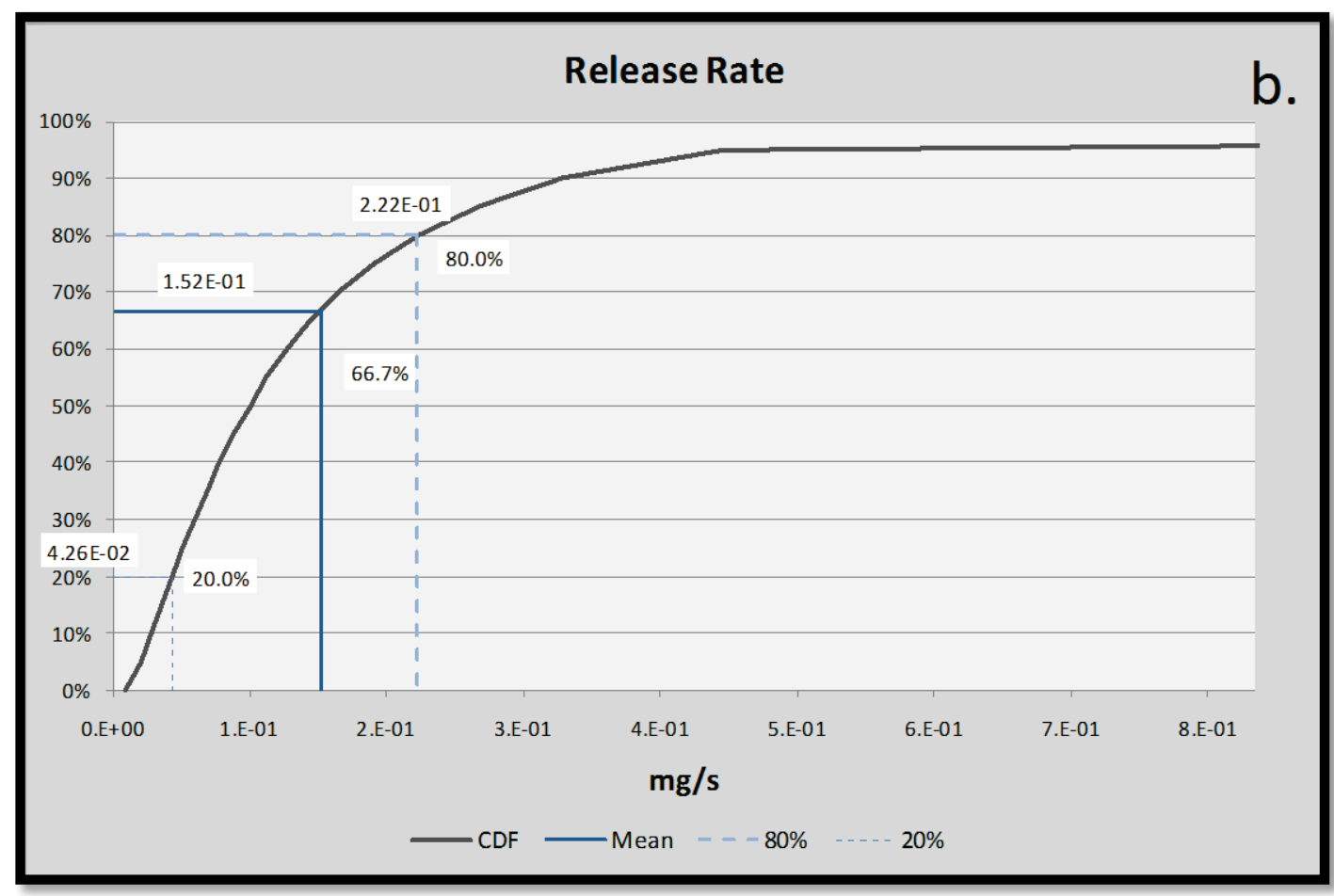

Figure 62. Explosive D total site release function distribution F' (F applied to the distribution of munitions at the site).

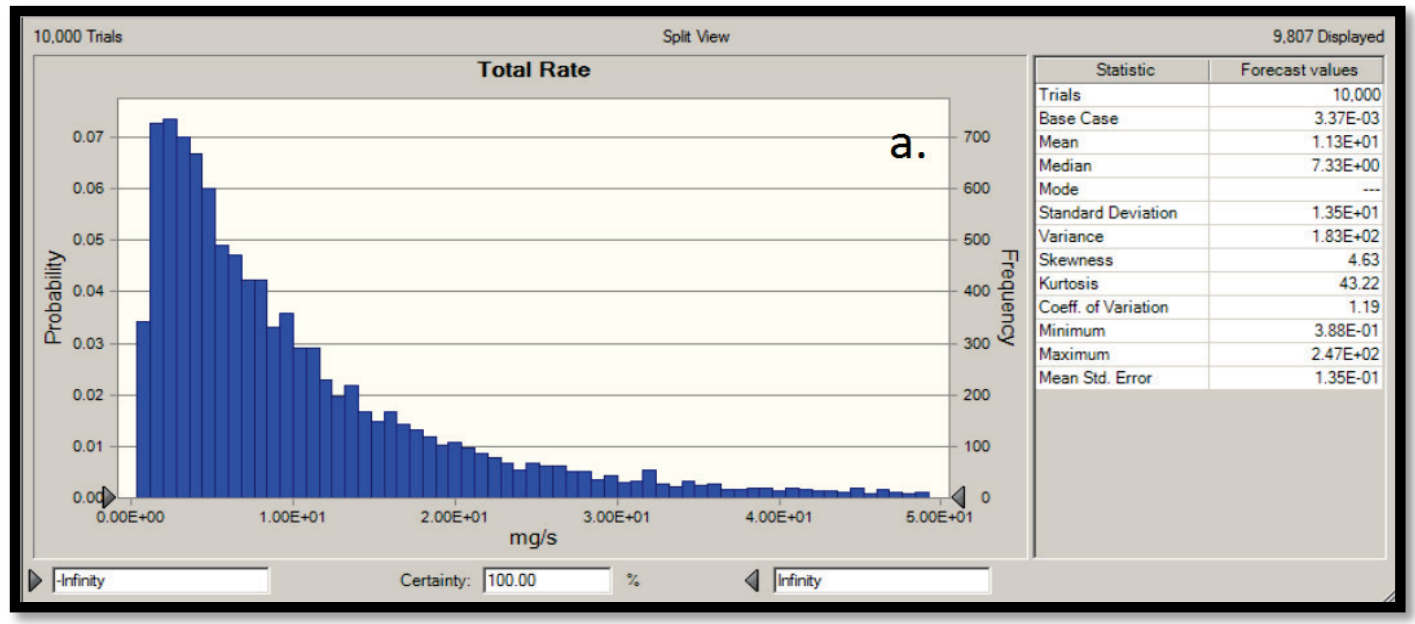




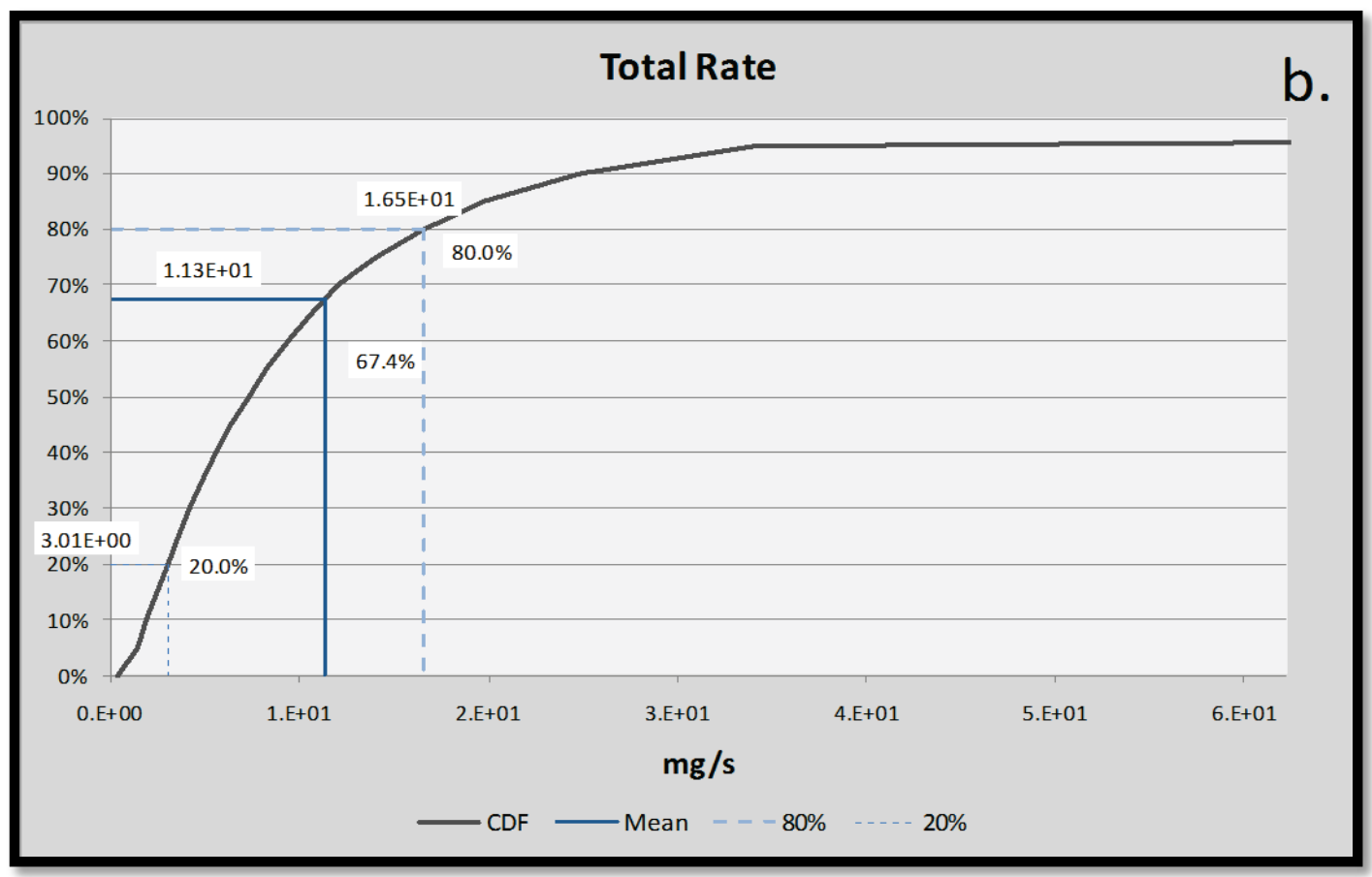

Scenario B. This scenario uses distribution functions for the parameters graphically represented in Figure 39. In this case, the authors have sufficient knowledge about the UWMM site, the fVNTR-BSS, and the munitions at the site through numerous site characterizations and diver verifications of site munition items. This allows the authors to employ semi-empirical beta-PERT distributions, similar to what was described above for the hypothetical generic site, for purposes of probabilistic (Monte Carlo) simulations. Again, similar to the above hypothetical site, remaining parameters in Equation 18 were treated deterministically using empirical values as indicated in Table 9-4. 
Figure 63. Graphical distribution functions for parameters treated probabilistically at fVNTR-BSS are (a) ambient current velocity, (b) breach hole radius, (c) breach cavity radius, (d) number of breached munitions of a given type, and (e) mass remaining in each breached munition. Minimum, maximum, and central tendency (most likely) are tabulated in Table 26.
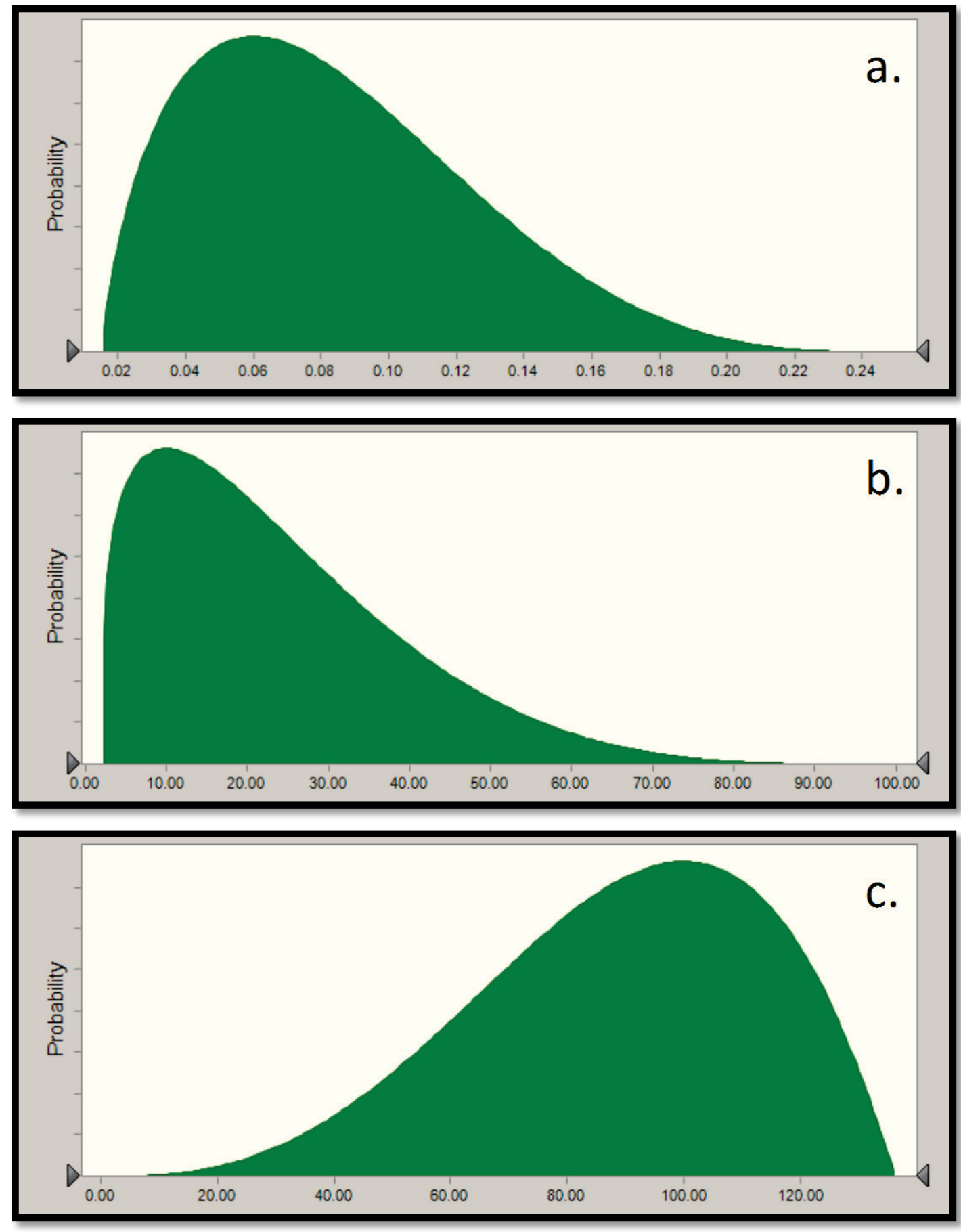

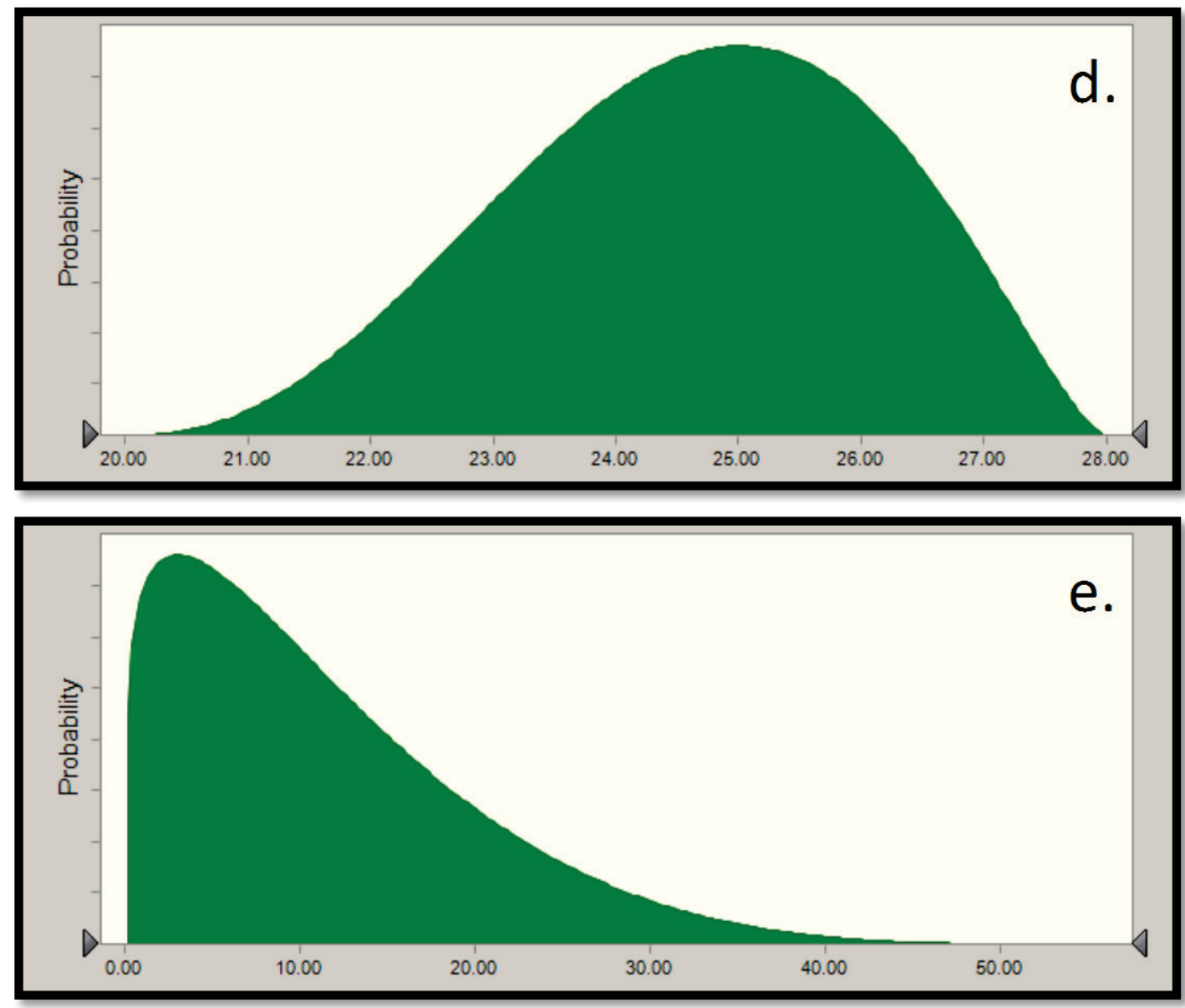

Table 26. Model parameters for Mk 82 TNT-filled munitions at fVNTR-BSS. Distribution-based parameters are in gray and shown graphically in Figure 63.

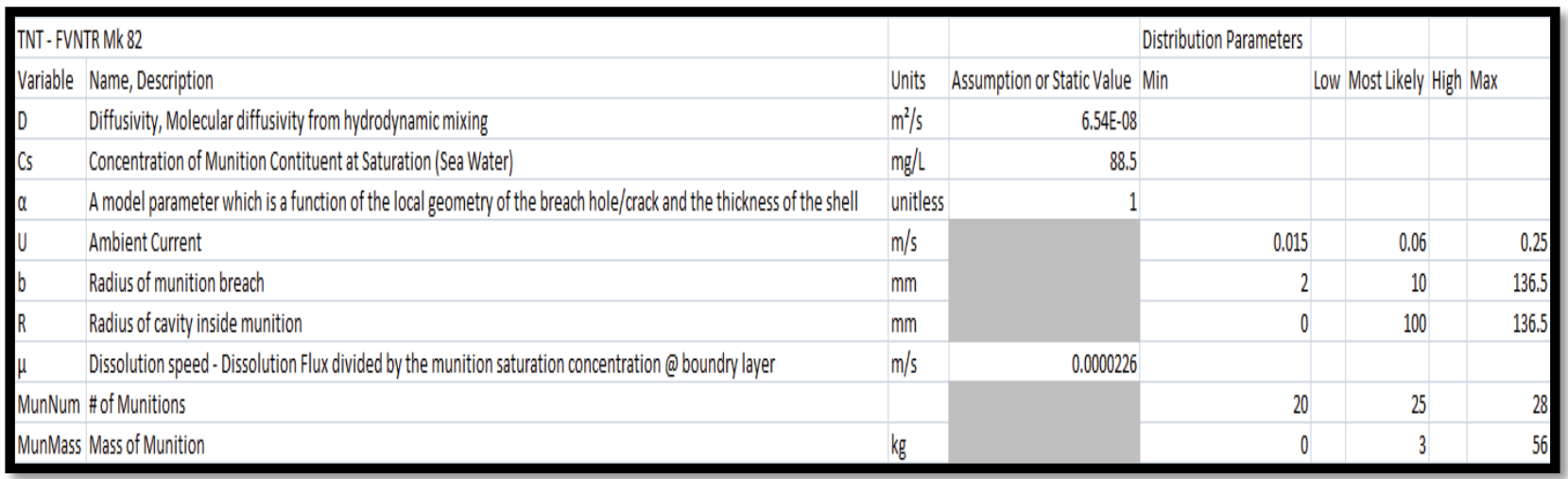

Scenario B Results. Using the above parameters, the release was modeled using the Monte Carlos method to provide a probabilistic estimate of the release function distribution $\mathrm{F}$ (single munition) and the total site release function distribution F' (F applied to the distribution of munitions at the site) for TNT-filled Mk 82 munitions at fVNTR-BSS. These results are 
presented in Figure 64 and Figure 65 below and illustrate the behavior of TNT release from breached Mk 82 munitions at fVNTR-BSS defined by the model parameters described in Figure 63 and Table 26. The results are shown graphically as both a conventional distribution and a CDF. As for the hypothetical site modeled above in Scenario A, results from 1,00o trials were not significantly different compared to results from 10,000 trials, an observation also reported during the original shell model effort (Wang et al. 2011).

Figure 64. TNT release function distribution $F$ (single munition).
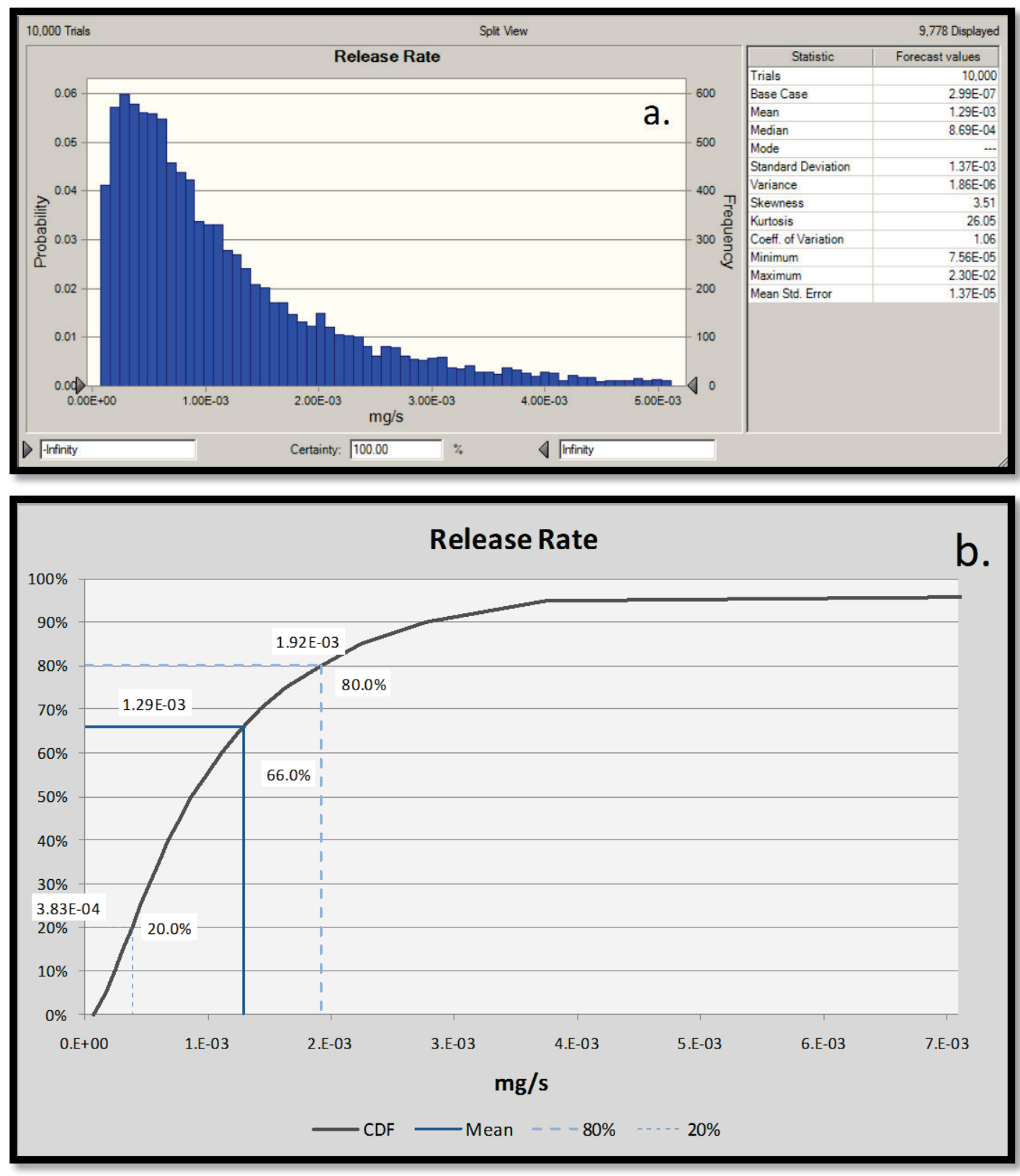
Figure 65. TNT total site release function distribution F' (F applied to the distribution of munitions at the site).
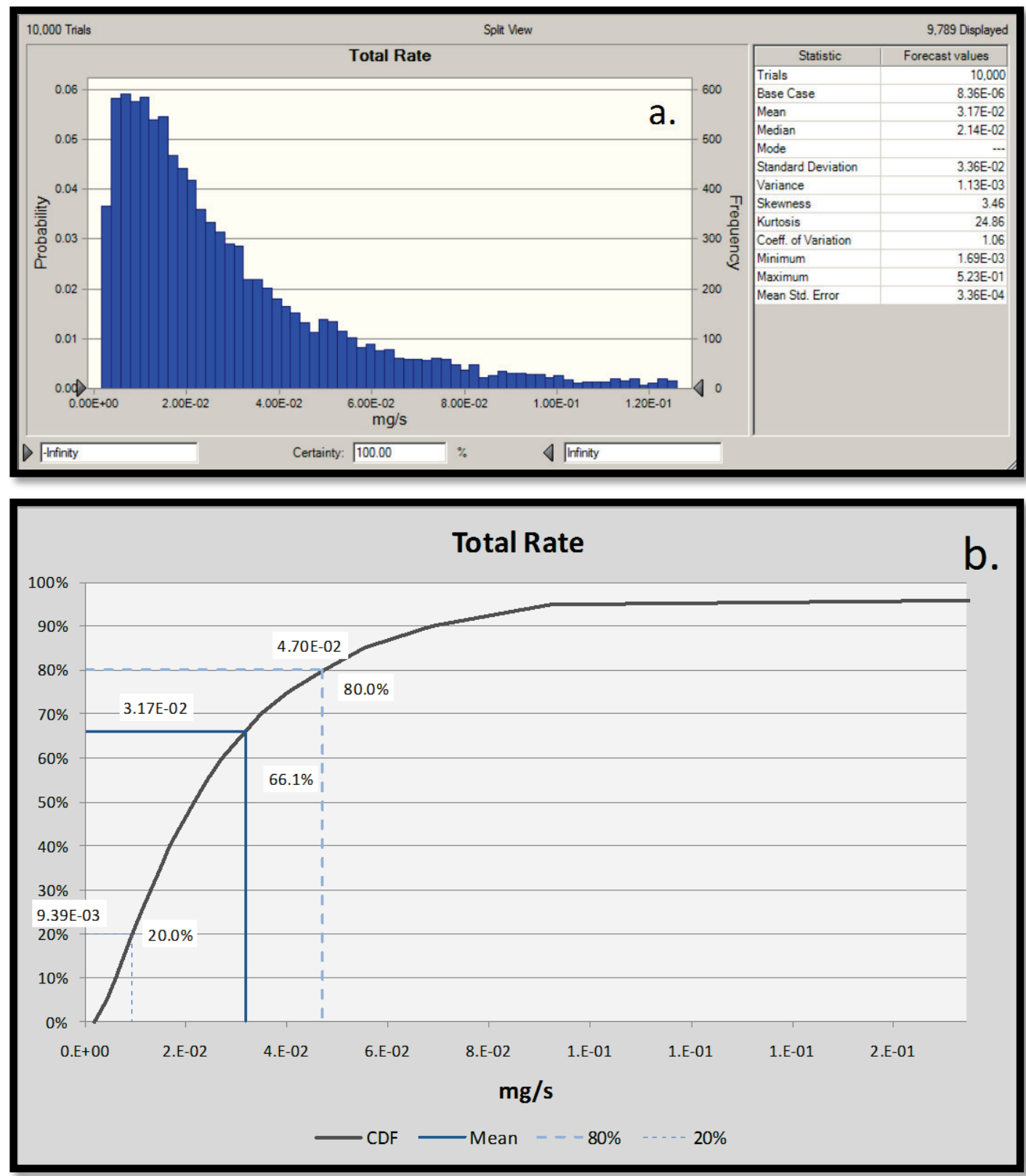

\subsection{Discussion of scenario $A$ and $B$ results.}

In the generic hypothetical scenario A, two types of munition fill were evaluated probabilistically, TNT and Explosive D. These explosive fill materials are comprised of MC with distinctly different physico-chemical properties. Solubility and dissolution rates were orders of magnitude lower for TNT compared with ammonium picrate, the MC in Explosive D-filled munitions. Consequently, the release rate function distribution and total 
site release function distribution were orders of magnitude different. Upon close inspection of scenario A, it was apparent that applying the probabilistic shell model to Explosive D, which has such a high solubility and dissolution rate, yields a distribution with mean release rate that is also very high, meaning even for munitions that are full, there is complete depletion of ammonium picrate in 7-8 years. More importantly, shells breached prior to that period are depleted, and only those shells initially breached in the past 8 years are actively releasing (future munitions are prospective and thus not modeled here.). Furthermore, current or recently breached munitions, versus those fired and breached 40+ years ago, are more likely corrosion-breached munitions, which occurs over a timeframe significantly longer than an 8-year period, ultimately resulting in very few shells actively releasing Explosive D. While the probabilistic approach would be useful for modeling release when fired and breached, it is not realistic to model Explosive D munitions fired many decades ago (typical legacy sites) using the probabilistic approach described here, particularly since the shell model does not replicate temporal dependencies. Such an approach (outside the scope of this and the prior shell model study), would be required to know when a breach occurs, i.e., to characterize the rate limiting step, corrosion. The behavior of Explosive D is in stark contrast to breached shells with TNT that have a significantly longer time to depletion ( $>10^{3}$ years), a timeframe during which the TNT fill can remain an active source due to extremely low release rates. This is the case for Scenario B.

Scenario B focused on using the probabilistic shell model for confirmed munitions that were fired into Bahia Salinas del Sur Lagoon at the former Vieques Naval Training Range. The average (mean) of the release rate distribution for TNT results in a total release rate (for all diver confirmed shells at/above the sediment) of $3.17 \mathrm{E}-2 \mathrm{mg} / \mathrm{s}$. Applying this to the site acreage (200 acres) and average water depth of 15 feet, compiled during the deployment of POCIS under ESTCP ER-201433, the authors received a daily water concentration increase of $0.740 \mathrm{ng} / \mathrm{L}$, assuming static conditions (no current-driven water exchange). If the authors conservatively assume a minimum of one full exchange per day, without taking into account any TNT degradation or decrease due to other mechanisms (also conservative), then this value provides an estimate of the maximum steady state concentration under conditions of minimal tidal flushing within the bay, which is suitable for exposure evaluation purposes. This conservative steady state concentration is lower than the DL reported for POCIS ( $\sim 7 \mathrm{ng} / \mathrm{L})$, which were recently deployed at the site 
to measure water column concentrations of TNT. POCIS TNT results at fVNTR-BSS were all at or below this DL. In short, the probabilistic shell model predicts values that are an order of magnitude lower than the POCIS DL, and at least three or more orders of magnitude lower than effects thresholds when compared to available marine toxicity data (Chapters 11 and 12). 


\section{Fate of TNT and RDX in Marine Environments Determined Using a Stable Isotopic Tracer}

Dr. Craig Tobias's research on the tracking, uptake, translocation, and transformation of $\mathrm{MC}$ in the marine environment using stable nitrogen isotopes completed under SERDP project ER-2122 is referenced throughout this section via published journal articles by graduate students (Ariyarathna and Ballentine) and a postdoctoral researcher (Smith). Publication of the final report for SERDP project ER-2122 is planned for 2017.

MC in UWMM will typically be released gradually into the aquatic environment (Wang et al., 2013). Once in surrounding water, they are expected to be removed (attenuated) from the aqueous compartment quickly, as most $\mathrm{MC}$ in aquatic environments are typically very chemically reactive. Removal of $\mathrm{MC}$ from the environment can be defined as total parent MC conversion to any possible transformation product.

Photolysis of $\mathrm{MC}$ in aqueous environments occurs readily producing breakdown products (Monteil-Rivera et al. 2009). TNT photolysis has been shown to produce transformation products including 4-A-2,6-DNT, 3,5-dinitroaniline, 2,4,6-trinitrophenol, 2,4,6-trinitrobenzyl alcohol, 2,4,6trinitrobenzoic acid, and 1,3,5-TNB (Monteil-Rivera et al. 2009). RDX photolysis appears to involve the homolysis of the $\mathrm{N}^{-\mathrm{NO}_{2}}$ bond that ultimately yields $\mathrm{HCHO}, \mathrm{HCOOH}, \mathrm{NH}_{3}, \mathrm{NO}_{2}{ }^{-}$, and $\mathrm{N}_{2} \mathrm{O}$ (Monteil-Rivera et al. 2009). Under photolysis, the aromatic ring of TNT normally remains intact, but ring cleavage products have been reported for RDX (Hawari et al. 2002).

Other abiotic processes, as well as biotic processes, interact with MC readily as MC are often released slowly via "leaking" from UWMM. Geochemical properties of the water and sediments must be considered in the removal of TNT and RDX from contaminated sites. Grain size, clay content and type, quantity of organic carbon in the sediments, and water salinity are the primary geochemical properties that control the equilibrium partition constants, such as the apparent sediment water distribution coefficient $\left(\mathrm{K}_{\mathrm{d}}\right.$ ), of MC, such as TNT and RDX (Ariyarathna et al. 2016). Smaller grain size, greater clay content, and greater total organic 
carbon (TOC) often leads to quicker reduction in concentration of the parent MC in the overlying water column (Harrison and Vane, 2010; Smith et al., 2013). The expected slow release rate (Wang et al. 2011) coupled with the rapid removal of MC in sediments near UWMM could facilitate the low concentrations measured in water surrounding UWMM (Chapter 5).

TNT and RDX vary in their physical structures and chemical properties, which effect how each MC reacts with the environment; however, both have several biotic pathways that can quickly breakdown the parent compound. Bacteria and fungi can transfer TNT under both aerobic and anaerobic conditions, but the presence of three nitro groups limits oxidative attack from aerobic organisms and the reductive mechanism predominates (Monteil-Rivera et al. 2009). TNT in sediment-water systems was rapidly reduced to aminonitrotoluenes in both aerobic and anaerobic conditions. Irreversible sorption of reduced transformation products to the sediment phase was nearly complete under aerobic conditions (Elovitz and Weber 1999). The reduction of TNT was strongly regioselective, with favored formation of 4-A-2,6-DNT and 2,4-DA-6-NT. When ${ }^{14} \mathrm{C}-\mathrm{TNT}$ was spiked into sediment, the parent compound rapidly disappeared, while increasing amounts of the activity, mostly corresponding to 2,4-DA-6-NT, became strongly associated with sediment particles and resisted organic solvent extraction under aerobic conditions as the reaction time progressed. The fraction of solvent-resistant transformation products of TNT, likely associated with the sediment through covalent binding, also increased with increasing sedimentcontaminants contact time in sandy and fine-grained marine sediments spiked with ${ }^{14 C-T N T ~(R o s e n ~ a n d ~ L o t u f o ~ 2005 ; ~ L o t u f o ~ e t ~ a l . ~ 2009 b) . ~}$

The cyclic nitramine RDX has different geochemical properties than that of nitroaromatic compounds. Likewise, it has lower water solubility and significantly less binding affinity with soil and sediment organic matter (Talmage et al. 1999; Brannon and Pennington 2002; Pennington et al. 2011). RDX may undergo alkaline hydrolysis with indications that the RDX molecule ring becomes cleaved to produce linear compounds (Balakrishnan et al. 2003).

Despite its differences from TNT, RDX has been shown to be taken up almost as quickly from water by sediment, and both TNT and RDX had uptake constants onto marine sediments nearly 100 times faster than 
freshwater sediments (Ariyarathna et al. 2016). Higher $\mathrm{pH}$ values in marine sediments that might allow for less site-specific $\mathrm{H}^{+}$competition along with high organic matter that has been shown to facilitate more sorption to sediments (Ariyarathna et al. 2016; Delle Site 2001) partially explain the faster uptake constants for marine sediments. . RDX does not seem to form a large fraction of derivatives compared to the concentration of parent MC, as TNT does in systems with sediments (Ballentine et al. 2016; Smith et al. 2013). With low concentrations of RDX primary derivatives in sediments, other transformation products form. In addition, using stable isotopes has helped in identifying potential pathways to those products.

The use of stable isotopes as a tracer is a novel approach to tracking the fate of $\mathrm{MC}$ and helps to understand the potential for toxicity in sediments. Using both ${ }^{14} \mathrm{C}$ and ${ }^{15 \mathrm{~N}}$ labeled $\mathrm{MC}$, a greater comprehension of the fate of $\mathrm{MC}$ contaminants can be fully achieved. ${ }^{14} \mathrm{C}$-labeled $\mathrm{MC}$ has been used to track the mineralization to ${ }^{14} \mathrm{CO}_{2}$ in laboratory incubations with various simulated environments (Best et al. 1999; Sheremata and Hawari 2000; Montgomery et al. 2011; Pennington et al. 2011). ${ }^{14 C}$ labeled MC studies have primarily focused on the mineralization of the carbon containing triazine ring. While these studies are important, they are often limited because many of the possible breakdown and mineralization products may not contain carbon. Some MC have a high nitrogen/carbon ratio such as RDX (2:1) that allows for greater detection sensitivity of MC breakdown products with studies that only use non-labeled or carbon labeled MC. High rates of organic matter deposition that could possibly increase the mineralization of MC into nitrogen containing compounds typically characterize coastal marine systems. The presence of sediments with high organic content has been shown to increase the removal of MCs in some environments (Ariyarathna et al. 2016; Smith et al. 2013); however, in more complex saltwater environments, MCs nor their breakdown products seem to be sequestered in large amounts in the sediments. Finally, marine systems are often characterized as N-limited environments that facilitate denitrification reactions. In these nitrogen limited environments, TNT nitro $\left(-\mathrm{NO}_{2}\right)$ groups are reduced. The experimental use of $15 \mathrm{~N}$ labeled $\mathrm{MC}$ can provide a degree of understanding of the fate of $\mathrm{MC}$ that the use of non-labeled or ${ }^{14 C} \mathrm{C}$-labeled MC cannot (Ariyarathna et al. 2016; MonteilRivera et al. 2009). 


\subsection{Tracing the fate of TNT using a stable isotopic tracer}

Mass balance calculations using ${ }^{15} \mathrm{~N}$ nitro-labeled MC has been completed in complex mesocosms (Smith et al. 2015b; Ballentine et al. 2016). The system consisted of two experimental aquaria connected to a common reservoir. Both aquaria shared the same recirculated seawater, so they were not considered replicates. The two experimental aquaria had $7 \mathrm{~cm}$ of sediment with Long Island Sound (LIS) seawater. Smith et al. (2015b) experimentally traced the fate of TNT during three distinct phases. The first phase consisted of a single TNT pulse followed by five days of monitoring with the purpose of simulating a pulsed delivery of TNT to an uncontaminated system and simplifying the estimation of first order decay coefficient. During the second phase, there were four days of continuous dosing to simulate in situ munitions "leaking" at a chronically contaminated site. The final phase terminated the dosing and monitored the loss of TNT while evaluating the fate of TNT after additions had ceased.

Smith et al. (2015b) spiked the system with an initial water column concentration of $0.90 \mathrm{mg} / \mathrm{L}$. TNT loss in the water column occurred quickly, within 24 hours of the initial spike, only $3 \%$ of the TNT remained. TNT was measured in the following pools from largest to smallest amounts: suspended particulate matter $>$ phototrophic tissue $>$ sediments $(0-2 \mathrm{~cm})>$ sediments $(2-4 \mathrm{~cm})>$ pore water $>$ heterotrophic tissue (Smith et al 2015b). ${ }_{15} \mathrm{~N}$ enrichment was observed in all dissolved inorganic nitrogen (DIN) pools with $\mathrm{NH}_{4}{ }^{+}$being the largest DIN endpoint and only accounted for as much as $7 \%$ of the TNT derived N added to the system for Smith et al. (2015b). However, the TNT in all of these pools only represented $27 \%$ of the total TNT introduced into the system, meaning that the majority of the ${ }^{15 \mathrm{~N}}$ was unaccounted for in the analytes measured (Smith et al 2015b). The missing ${ }_{15 \mathrm{~N}}$ correlated with the production of the TNT derivatives 2-A-DNT and 4A-DNT showing both a linear correlation $\left(\mathrm{R}^{2}=0.93\right)$ and a principal component analysis grouping. This indicated that the $15 \mathrm{~N}$ containing products were derived from the TNT derivatives 2-A-4,6-DNT and 4-A-2,6DNT (Smith et al. 2015b), although other TNT derivatives such as 2,4-DA6-NT, 2,6-DA-4-NT, 2,4-DNT, and 2,6-DNT have been measured in other studies (Nipper et al. 2004; Elovitz and Weber 1999). Smith et al. (2015b) suggest that deamination of the amine functional groups in 2-A-4,6-DNT and 4-A-2,6-DNT documented TNT transformation products in sediment very well and is the pathway that links the observed compounds to the unidentified MC products measured. The transformation chain from TNT to 
2-A-4,6-DNT or 4-A-2,6-DNT to other unidentified MC also accounted for a low fraction (2.6\%) of the mass of TNT added. Unidentified deaminated derivative could account for up to $26 \%$ of the missing ${ }^{15 \mathrm{~N}}$ in the complex mesocosms (Smith et al., 2015b). The remaining $75 \%$ of the missing ${ }^{15 \mathrm{~N}}$ could be attributed to biotransformation by bacteria that were too small to be captured, but have been documented in the biotransformation of MC (Montgomery et al. 2011) or sequestered in the sediments as carbon containing compounds (Pennington et al. 2011). The unknown ${ }^{15 N}$ TNT transformation products could also be attributed to similar compounds measured that undergo irreversible sorption to sediments particularly in aerobic conditions (Elovitz and Weber 1999; Pennington et al. 2011). The $15 \mathrm{~N}$ mass balance data in Table 27 originates from a semi-flow through intertidal marsh mesocosm experiment exposed to ${ }^{15 \mathrm{~N}}$ labeled TNT and RDX over a two-week period. The physical loss of $15 \mathrm{~N}$ in Table 27 was a combination of several different measurements including physical water outflow of parent $\mathrm{MC}$, derivatives, $\mathrm{N}_{2}, \mathrm{~N}_{2} \mathrm{O}, \mathrm{NH}_{4}{ }^{+}$, and $\mathrm{NO}_{3}{ }^{-}$, while the unaccounted of $15 \mathrm{~N}$ represents $15 \mathrm{~N}$ or $15 \mathrm{~N}$ containing compounds that were unknown, lost, or not measured. Ballentine's unpublished research also showed mass balanced ${ }^{15} \mathrm{~N}$ labeled TNT in an intertidal marsh mesocosm similar to the setup described previously and showed that a large percentage (35\%) of the total ${ }^{15 \mathrm{~N}}$ added to the system is unaccounted for (Table 27).

Table 27. ${ }^{15} \mathrm{~N}$ mass balance for MC addition into an intertidal marsh system.

\begin{tabular}{|c|c|c|}
\hline & TNT (\%) & RDX (\%) \\
\hline Physical Loss & 43 & 50 \\
\hline Aqueous parent $\mathrm{MC}$ & 1.6 & 3.2 \\
\hline Aqueous derivatives & 3.7 & 0.13 \\
\hline Aqueous $\mathrm{N}_{2}$ & 0 & 0.01 \\
\hline Aqueous $\mathrm{N}_{2}$ evasion & 0 & 1.1 \\
\hline Aqueous $\mathrm{N}_{2} \mathrm{O}$ & 0 & 0.44 \\
\hline Aqueous $\mathrm{N}_{2} \mathrm{O}$ evasion & 0 & 35 \\
\hline Aqueous $\mathrm{NH}_{4}^{+}$ & 0.14 & 0.001 \\
\hline Aqueous $\mathrm{NO}_{3}^{-}$ & 0.03 & 0.11 \\
\hline POM & 0.16 & 0.05 \\
\hline Parent MC porewater & 0.0003 & 0.01 \\
\hline Derivatives porewater & 0.001 & 0.05 \\
\hline Parent MC sediments & 0 & 0 \\
\hline Derivatives sediments & 0.55 & 0.08 \\
\hline $\mathrm{N}_{2}$ sediments & 0 & 0.004 \\
\hline $\mathrm{N}_{2} \mathrm{O}$ sediments & 0 & 0.01 \\
\hline $\mathrm{NH}_{4}{ }^{+}$sediments & 0.007 & 0.002 \\
\hline $\mathrm{NO}_{3}$ - sediments & 0 & 0 \\
\hline Sediments & 15 & 0.70 \\
\hline Biota & 0.73 & 0.17 \\
\hline Unaccounted & 35 & 9.5 \\
\hline
\end{tabular}


The low concentrations of TNT, 2-A-4,6-DNT, and 4-A-2,6-DNT in the sediments are to be expected as the TNT is rapidly transformed along with the partitioning of TNT and its breakdown products to the overlaying water where the DIN can be taken up or removed by off gassing. Smith et al. (2015b) reported that up to $95 \%$ of produced ${ }^{15} \mathrm{~N}_{2}$ was expelled from the system. The fate and mass balance of TNT in sediments is dependent on a combination of reductive transformation and sorption processes, and it is rapidly reduced to derivatives and other transformation products in both aerobic and anaerobic conditions (Elovitz and Weber 1999).

\subsection{RDX in Marine Systems}

In the sister experiment to the marine mesocosm investigation of the fate of ${ }^{15 \mathrm{~N}} \mathrm{TNT}$, Smith et al. (2015a) and Ariyarathna (unpublished work) investigated the fate of RDX in coastal marine environments using ${ }^{15} \mathrm{~N}$ labeled RDX spiked into a complex marine mesocosm. Both Smith et al. (2015a) and Ariyarathna's unpublished work used the same two experimental $70 \mathrm{~L}$ aquaria connected via a closed recirculating system of seawater to a common reservoir. Both experiments contained the same type and size (7-8 cm deep) sediments collected from subtidal waters of LIS. Smith et al. (2015a) added the ${ }^{15} \mathrm{~N}$-labeled RDX as a single addition, while Ariyarathna's unpublished work added an initial ${ }^{15 N}$-labeled RDX addition followed by metering in ${ }^{15} \mathrm{~N}$-labeled RDX using a peristaltic pump to target steady-state RDX. The ${ }^{15} \mathrm{~N}$ was detected in all pools measured and was found in the following pools in decreasing order: aqueous RDX $>\mathrm{N}_{2}>$ sediments $>$ biota tissue $>$ aqueous RDX derivatives $>\mathrm{NH}_{4}{ }^{+}$. Ariyarathna measured $15 \mathrm{~N}$ in an increasing range of $0 \%$ to $12 \%$ in the sediments of the total $15 \mathrm{~N}$ spiked into the marine mesocosms. Unlike TNT, ${ }_{15} \mathrm{~N}_{2}$ was

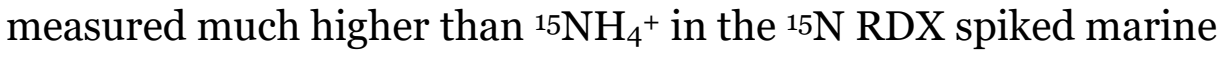
mesocosms with ${ }^{15} \mathrm{~N}_{2}$ accounting for as much as $33 \%$ and ${ }^{15 \mathrm{NH}_{4}{ }^{+}}$ accounting for only $1 \%$ of total added RDX. ${ }^{15 \mathrm{~N}_{2}}$ accounted for $21 \%$ of the spiked ${ }^{15} \mathrm{~N}$ labeled RDX in similar marine mesocosms without biota (Smith et al 2015a). A significant amount of measured ${ }^{15} \mathrm{~N}_{2}$ explains how studies using ${ }^{14} \mathrm{C}$ labeled RDX have indicated that RDX undergoes a transformation process that result in unidentified products that contain a higher solubility in water and partition more readily to the water column (Lotufo et al. 2001; Pennington et al. 2011). For ${ }^{14} \mathrm{C}$ labeled RDX, Pennington et al. (2011) reported that of all added ${ }^{14} \mathrm{C}$, large fractions of the recovered ${ }^{14} \mathrm{C}$ were found as $\mathrm{CO}_{2}(31 \%)$ and dissolved in the overlying water as both RDX and breakdown products (28\%). In that study, most of the radiolabel was measured in the sediments (36\%). In the similar 
intertidal marsh mesocosm, Ballentine reported that $9.5 \%$ of the total ${ }^{15 \mathrm{~N}}$ labeled RDX added to the system was unaccounted for along with the large percentage of $\mathrm{N}_{2} \mathrm{O}$ that was formed and lost via evasion (Table 27), which indicated that RDX transformation occurred in the mesocosm.

Transformation to ${ }^{15} \mathrm{~N}_{2}$ provides evidence for mechanisms accounting for the removal of RDX from sediment. A common reaction in anaerobic sediment layers is denitrification, which uses organic carbon to reduce nitrogen by the following pathway: $\mathrm{NO}_{3}{ }^{-} \rightarrow \mathrm{NO}_{2}{ }^{-} \rightarrow \mathrm{N}_{2} \mathrm{O} \rightarrow \mathrm{N}_{2}$ (Hawari et al. 2000a; Hattori 1983). The production of $\mathrm{N}_{2} \mathrm{O}$ through mineralization pathways in municipal sludge (Hawari et al. 2000a) and with fungus (Shermata and Hawari 2000), followed by denitrification to form $\mathrm{N}_{2}$, is a potential pathway of RDX removal from sediments (Smith et al., 2015a). This pathway along with denitrification of both $\mathrm{NO}_{3}{ }^{-}$and $\mathrm{NO}_{2}{ }^{-}$, which both can be generated during bacterial denitrification within bacterial cells, can account for the loss of RDX from sediments as well as the production of compounds that partition more readily to the water column and are transported away from the system. Smith et al. (2015a) has amended proposed mineralization pathways of RDX (Hawari et al. 200ob; Bhushan et al. 2002), which include denitrification that better illustrate a more complete mineralization of RDX in sediments.

The understanding of $\mathrm{MC}$ fate in aquatic systems depends on the geochemical properties of the environment where UWMM are located. The presence of sediments facilitates removal by fostering transformation and mineralization of $\mathrm{MC}$, and efficiently removes TNT and RDX from the aqueous compartment. The use of stable isotopes as tracers have allowed for a more complete understanding of not only the processes that drive the removal, transformation, and mineralization, but also the products of those processes that were previously unknown. 


\section{Overview of the Toxicity of Munitions Constituents to Aquatic Organisms}

This section provides an overview of the available data on the toxicity of MC to amphibians, fish, and aquatic invertebrates. The data were generated through laboratory exposures of test organisms to water spiked with energetic MC. A comprehensive, but not exhaustive, database of the available toxicity data is presented in Excel format (Appendix C: "Munitions Constituents Aquatic Toxicity Database"). Data derived from experiments investigating the effects of photo-activation on the toxicity of $\mathrm{MC}$ were not included in the database, but the effects of photo-activation are discussed in this chapter.

To support the assessment of risk associated with the presence of explosives in aquatic environments, contaminant-spiked water is often used in laboratory experiments to derive toxicity data for a variety of freshwater and marine species and endpoints. In order to bracket the toxic range and derive toxicity benchmarks, most studies involved the use of exposure concentrations significantly higher than those expected in the environment. Talmage et al. (1999) provided broad overviews of the effects of explosive compounds to aquatic organisms. Juhasz and Naidu (2007) and Nipper et al. (2009) compiled available aquatic toxicity data, which was expanded to include nitroaromatic and nitrophenolic compounds that are not considered MC or their transformation products. Lotufo et al. (2013) provided a recent summary review.

\subsection{Toxicity of MC to aquatic larval stages of amphibians}

For tadpoles of the African clawed frog (Xenopus laevis), the 4-day LC5O value for TNT (3.8 mg/L) was substantially lower than that for 2-A-2,4DNT (32.7 mg/L) or 4-A-2,6-DNT (22.7 mg/L) (Saka 2004) (Figure 66). Sublethal effects on malformation were observed at much lower concentrations, with EC5O values of 2.2, 3.3, and $16.9 \mathrm{mg} / \mathrm{L}$ for TNT, 2-A2,4-DNT, and 4-A-2,6-DNT, respectively (Saka 2004). Growth was also affected at sublethal concentrations of those MC. Tadpoles of the American bullfrog (Rana catesbeiana) were relatively tolerant to TNT, 2,4-DNT, and 2,6-DNT, with 4-day LC50 ranging from 40.3 to $92.4 \mathrm{mg} / \mathrm{L}$. However, mortality occurred at much lower concentrations when exposures were extended to 90 days, with the lowest-observable-effect concentration (LOEC) values ranging from 0.12 to $0.21 \mathrm{mg} / \mathrm{L}$ (Figure 66) 
(Paden et al. 2011). For tadpoles of the leopard frog (R. pipiens), the 4-day LC50 for TNT ( $4.4 \mathrm{mg} / \mathrm{L}$ ) was similar to that for the African clawed frog and similar to those observed by Paden et al., which extended the exposure, in this case, to $28 \mathrm{~d}$ and dramatically decreased the effects concentration ( $\mathrm{LOEC}=0.003 \mathrm{mg} / \mathrm{L}$ ) (Stanley et al. 2015). Tadpoles of the leopard frog were more tolerant to RDX than TNT during 10- and 28-day exposures (Stanley et al. 2015).

Figure 66. Lethal concentrations of $\mathrm{MC}$ to aquatic larval stages of amphibians.

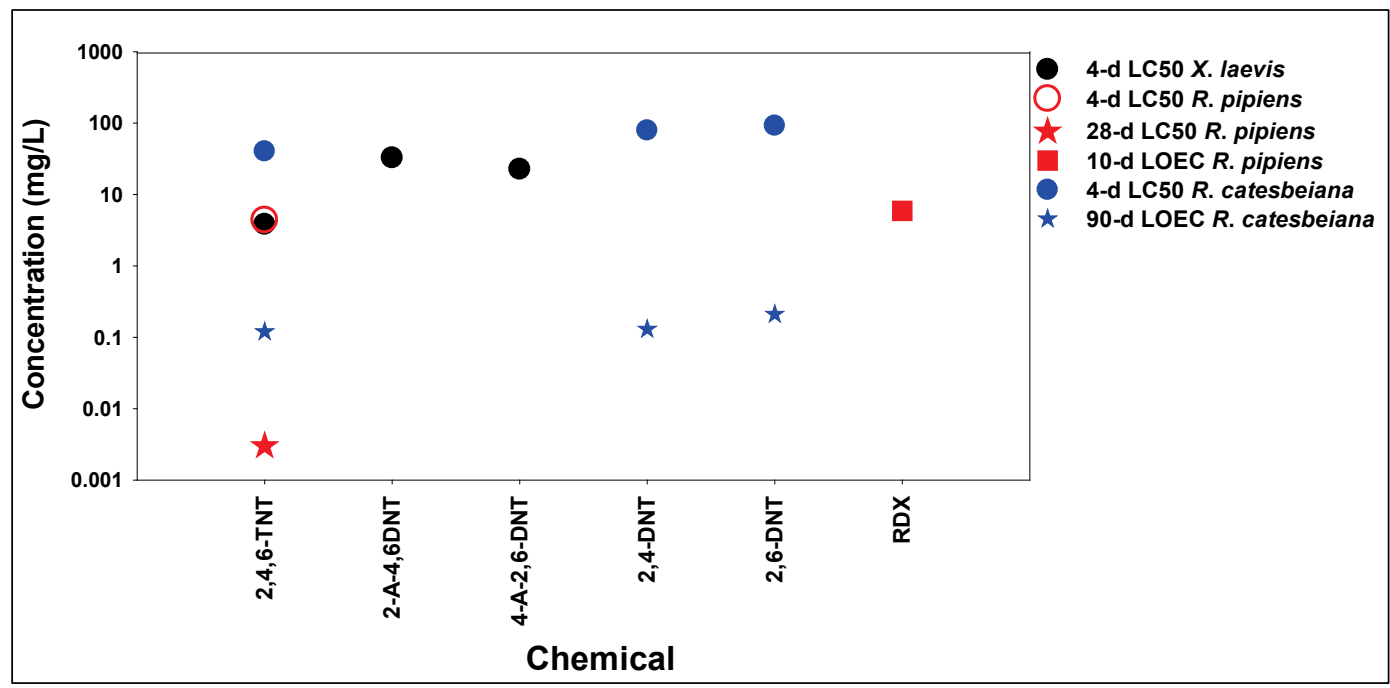

\subsection{Toxicity of MC to fish}

\subsubsection{Nitroaromatic MC}

Several studies reported the toxicity of nitroaromatic MC to a large number of freshwater fish, including fathead minnow, channel catfish, rainbow trout, bluegill, and zebrafish (see database for numerous references). In contrast, adverse biological effects of $\mathrm{MC}$ on marine and estuarine fish were reported mostly for red drum (Nipper et al. 2001) and for sheepshead minnow (Lotufo et al. 2010a, b, c).

Aquatic toxicity studies have reported that TNT caused decreased survival to a number of fish species, with $\mathrm{LC}_{50}$ values ranging from 0.8 to $7.6 \mathrm{mg} / \mathrm{L}$ (Figure 67). Bailey et al. (1985) and Burton et al. (1993) examined the long-term effects of the exposure of TNT on freshwater fish. During a 9 month TNT life cycle test with the fathead minnow, a significant reduction in total length of parental females after spawning was completed and observed at $0.014 \mathrm{mg} / \mathrm{L}$, while survival was not affected at concentrations up to $0.077 \mathrm{mg} / \mathrm{L}$ (Burton et al. 1993). While Bailey et al. (1985) found a 
significant reduction in the number of fathead minnows broods produced and the number of eggs hatched during spawning at concentrations down to $0.04 \mathrm{mg} / \mathrm{L}$, Burton et al. (1993) found no effect of TNT on these two reproductive parameters at concentrations up to $0.011 \mathrm{mg} / \mathrm{L}$. The lowest sublethal effects concentration reported for TNT was $0.014 \mathrm{mg} / \mathrm{L}$ for female fathead minnow growth (Burton et al. 1993). Reports on the chronic and sublethal effects of TNT on marine fish have not been found.

The lethal toxicity of TNT was compared to that of its aminated transformation products using sheepshead minnows (Lotufo et al. 2010b) and fathead minnows (Pearson et al. 1979). Nitro-reduction appears to decrease the toxicity of TNT to sheepshead minnows, as the 5 -day $\mathrm{LC}_{50}$ for the mono-aminated compound 2-A-4,6DNT $(8.6 \mathrm{mg} / \mathrm{L})$ was approximately four times higher than that for TNT $(1.7 \mathrm{mg} / \mathrm{L})$. Further amination appears to decrease toxicity even more dramatically, as the highest tested concentration for 2,4-DA-6-NT (50.3 mg/L) was 20 times higher than the $\mathrm{LC}_{50}$ for TNT, and yet that concentration failed to promote significant mortality. The 4-day $\mathrm{LC}_{50}$ for 2-A-4,6-DNT (14.8 mg/L) and 4-A-2,6-DNT $(6.9 \mathrm{mg} / \mathrm{L})$ were also higher than that of TNT $(2.4 \mathrm{mg} / \mathrm{L})$ for fathead minnows. Similarly, dinitrotoluenes were lethally toxic at higher concentrations than TNT (Figure 67), and when compared in the same study (e.g., Liu et al. 1983a, b; Pearson et al. 1979), the $\mathrm{LC}_{50}$ values for dinitrotoluenes were at least four times higher than for TNT. For the species of fish investigated, the toxicity of 2,4-DNT and 2,6-DNT was similar among species and between compounds. Different from the dinitrotoluenes and aminodinitrotoluenes, 1,3,5-TNB caused decreased survival of fish at lower concentrations than TNT for freshwater and marine fish (Pearson et al. 1979; van der Schalie 1983; Nipper et al. 2001; Lotufo et al. 2010b), with $\mathrm{LC}_{50}$ values ranging from 0.4 to $1.2 \mathrm{mg} / \mathrm{L}$ (Figure 67). 
Figure 67. Lethal concentrations, as $\mathrm{LC}_{50}$ values derived from exposure of varying durations, of MC to fish.

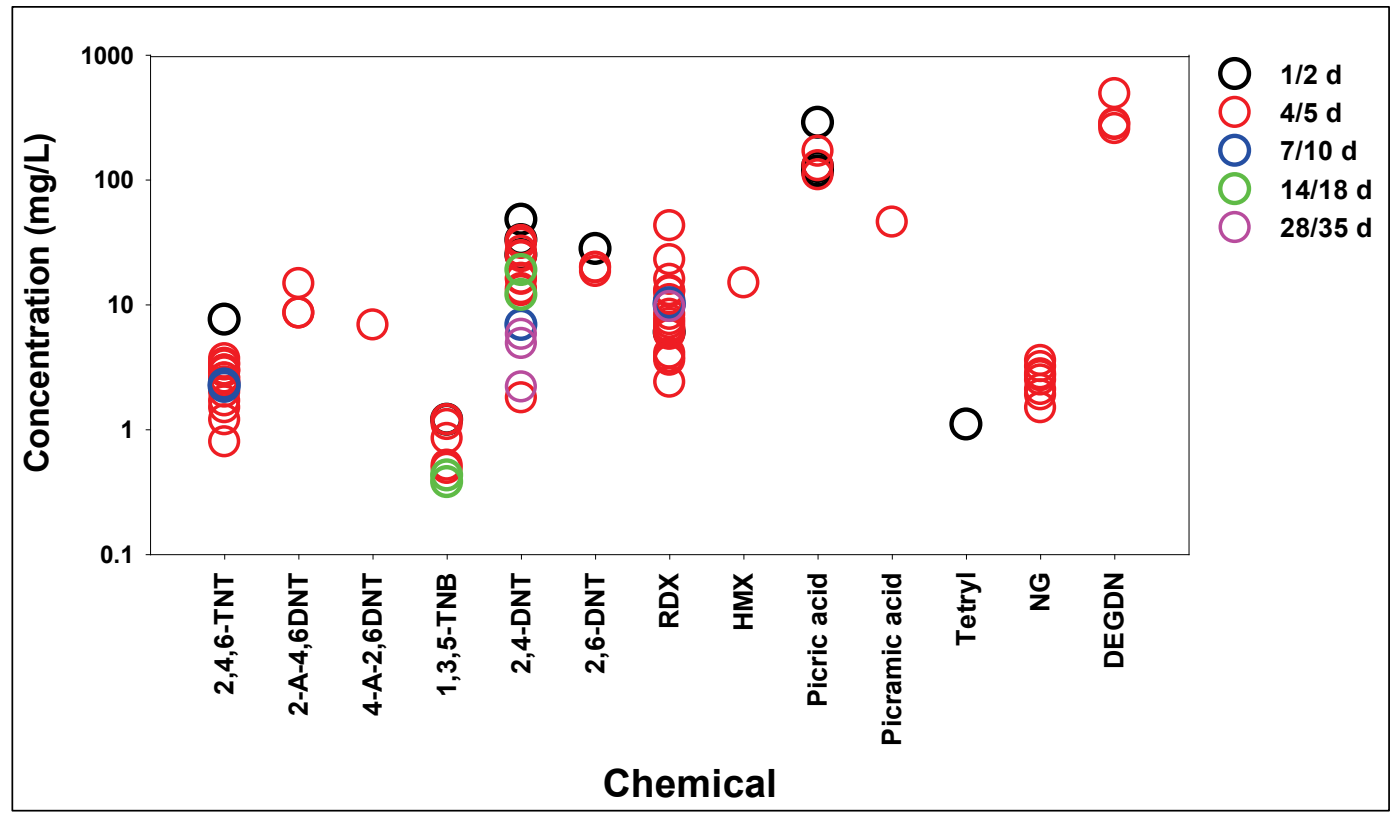

\subsubsection{RDX and HMX}

ENSR International (2005) provided a comprehensive summary review of the toxicity of RDX to aquatic organisms. Studies not included in that review include Lotufo et al. (2010a), Muhki et al. (2005), Muhki and Patino (2008), Gust et al. (2011b) and Warner et al. (2012). RDX caused decreased survival of some fish species at concentrations similar to those reported as acutely toxic for TNT, but other species were more tolerant. The range of toxicity for RDX to fish was substantially broader than that for TNT, with $\mathrm{LC}_{50}$ values ranging from 2.4 to $43 \mathrm{mg} / \mathrm{L}$ (Figure 67).

A saturated aqueous solution of RDX (68 mg/L, reported concentration) did not promote any effects on red drum during a 48-hour embryo hatching and larval survival (ELS) test (Nipper et al. 2001). RDX caused significant effects on the growth of fathead minnows at $2.4 \mathrm{mg} / \mathrm{L}$ during a 28-day early-life stage exposure (Burton et al. 1993; Burton et al. 1994) and at $5.8 \mathrm{mg} / \mathrm{L}$ during a 30-day ELS test (Bentley et al. 1977b). RDX at sublethal concentrations caused short-term negative effects on growth, but no negative effects on reproductive endpoints for zebrafish (Mukhi and Patino 2008). Maternal exposure to RDX did not affect egg fertilization and embryo hatching rates in zebrafish (Mukhi and Patino 2008). These observations indicated that RDX at water concentrations that do not cause significant parental mortality (up to $3.2 \mathrm{mg} / \mathrm{L}$ ) also do not have any 
deleterious effects on egg quality. Feeding behavior in zebrafish was affected during the first several weeks of exposure to RDX at $9.6 \mathrm{mg} / \mathrm{L}$, as fish were reported as relatively lethargic compared to fish in the control group. These differences in behavior eventually disappeared toward the end of the 12week exposure (Mukhi and Patino 2008). Incidence of vertebral deformity was observed at $1.8 \mathrm{mg} / \mathrm{L}$ for fathead minnows and at $13.8 \mathrm{mg} / \mathrm{L}$ for zebrafish after 96 hours of exposure, with approximately one-half of the concentrations exhibiting significant lethal effects, $3.5 \mathrm{mg} / \mathrm{L}$ for fathead minnows and $27.7 \mathrm{mg} / \mathrm{L}$ for zebrafish (Warner et al. 2012). Gust et al. (2011b) assessed the impacts of $0.83 \mathrm{mg} / \mathrm{L}$ of RDX on fathead minnows in one-year and multigenerational bioassays. RDX had no significant effect on survival and gonadosomatic index nor the condition factor assayed after up to 12 months. In addition, RDX had no significant effect on live-prey capture rates, egg production, or fertilization. Considering both marine and freshwater fish, the lowest sublethal effects concentration reported for RDX was $1.75 \mathrm{mg} / \mathrm{L}$ for vertebral deformity in fathead minnow (Burton et al. 1994).

Studies with freshwater fish (Bentley et al. 1977a) demonstrated that fathead minnows were susceptible to the effects of HMX at 7-day post hatch, but reported a 4-day $\mathrm{LC}_{50}$ value $(15 \mathrm{mg} / \mathrm{L}$ ) based on target concentrations that exceeded the solubility limit of $4.5 \mathrm{mg} / \mathrm{L}$ for that compound. Exposure to HMX at concentrations reported as its maximum achieved concentration in seawater failed to elicit mortality of exposed sheepshead minnows (Lotufo et al. 2010a). All other life stages for fathead minnows, other fish species, and invertebrates were unaffected by even the highest concentrations of HMX tested (Bentley et al. 1977a, 1984; Talmage et al. 1999; and Nipper et al. 2009). The highest no-effect concentrations reported in those studies were above the reported solubility limit of HMX.

\subsubsection{Nitrophenolic MC}

Fish were relatively tolerant to the lethal effects of picric acid, with $\mathrm{LC}_{50} \mathrm{O}$ values ranging from 110 to $287 \mathrm{mg} / \mathrm{L}$ (Figure 67). A single study with picramic acid reported an $\mathrm{LC}_{50}$ value $(46 \mathrm{mg} / \mathrm{L})$ lower than that for picric acid (110 mg/L) for rainbow trout (Goodfellow et al. 1983). The picric acid transformation products were more toxic than the parent compound; $\mathrm{LC}_{50}$ for picramic acid ( $46 \mathrm{mg} / \mathrm{L}$ ) was higher than that for picric acid (110 mg/L) (Goodfellow et al. 1983), and the $\mathrm{LC}_{50}$ for 2,4-DNP (0.6 mg/L) was substantially lower than that for picric acid (170 mg/L) to bluegills (Buccafusco et al. 1981). The observed tolerance to picric acid contrasts 
with the high sensitivity of red drum to tetryl $\left(\mathrm{LC}_{50}=1.1 \mathrm{mg} / \mathrm{L}\right)$ Nipper et al. (2001) reported in his study, which is the only study that addresses the toxicity of that compound to fish.

\subsubsection{Other MC}

The range of toxicity of NG to fish overlaps with that for TNT, with LC5O values ranging from 1.5 to $3.6 \mathrm{mg} / \mathrm{L}$ (Figure 67). During a 60-day ELS exposure to NG, growth of rainbow trout was reduced at $0.06 \mathrm{mg} / \mathrm{L}$, based on a reduction in dry weight (Burton et al. 1993). A 28-day ELS test with fathead minnow revealed that hatching success was reduced at a rate of $0.20 \mathrm{mg} / \mathrm{L}$ (Burton et al. 1993).

The toxicity of DEGDN was much less than that of TNT and NG, with $\mathrm{LC}_{50}$ values ranging from 258 to $491 \mathrm{mg} / \mathrm{L}$. Fish were tolerant to the lethal effects of NQ, with no significant toxicity occurring at exposure concentrations ranging from 1,050 to $3,320 \mathrm{mg} / \mathrm{L}$. NQ was not toxic to trout during an ELS test at the solubility limit of the compound in water and 7-day exposure to NQ concentrations up to $1,520 \mathrm{mg} / \mathrm{L}$ did not affect hatching success for rainbow (Burton et al. 1993). A 28-day post-hatch exposure to concentrations up to $1,520 \mathrm{mg} / \mathrm{L}$ did not affect fry survival, total length, wet weight, or dry weight; however, during an ELS test, fathead minnow total length was reduced at 2,030 $\mathrm{mg} / \mathrm{kg}$ (Burton et al. 1993).

\subsection{Toxicity of MC to invertebrates}

\subsubsection{Nitroaromatic MC}

The toxicity of nitroaromatic MC to freshwater invertebrates has been reported for a variety of freshwater species, including amphipods, midges, rotifers, cladocerans, and oligochaetes (summarized in Talmage et al. 1999; Nipper et al. 2009; Lotufo et al. 2013). Compared to studies with freshwater organisms, fewer studies addressed the effects of MC to marine invertebrates. Marine organisms used as test species included larval sea urchins, mysid shrimp (Nipper et al. 2001), larval and adult bivalves (Won et al. 1976; Goodfellow et al., 1983; Rosen and Lotufo 2007a), copepods (Won et al. 1976; Ek et al. 2006, 2007, 2008; Dave 2003; Dave et al. 2000), and a meiobenthic polychaete (Nipper et al. 2001). Mysid shrimp were the most sensitive species, while adult mussels were the most tolerant among the invertebrate species investigated. TNT caused decreased survival of all invertebrate species investigated, with $\mathrm{LC}_{50}$ values 
ranging from $0.26 \mathrm{mg} / \mathrm{L}$ in mysid shrimp (Nipper et al. 2001) to $43 \mathrm{mg} / \mathrm{L}$ in larval midge (Burton et al. 1993) (Figure 68).

Overall, aminodinitrotoluenes exhibited toxicity similar to that of TNT for cladocerans (e.g., Griest et al. 1998), amphipods (Sims and Steevens 2008), and midges (Lotufo et al. 2013), with the $\mathrm{LC}_{50}$ values ranging from 1.1 to $25.2 \mathrm{mg} / \mathrm{L}$ and 1.8 to $9.3 \mathrm{mg} / \mathrm{l}$ for $2-\mathrm{A}-4,6-\mathrm{DNT}$ and $4-\mathrm{A}-2,6-\mathrm{DNT}$, respectively (Figure 68). However, 2,4-DA-6-NT was more lethally toxic than TNT for an amphipod and a cladoceran (Sims and Steevens 2008; Griest et al. 1998), but substantially less toxic than TNT to midges (Lotufo et al. 2013) (Figure 68). The nitroaromatic compound 1,3.5-TNB exhibited lethal toxicity (Figure 68) that was similar to that of TNT for amphipods (Sims and Steevens 2008) and midges (Lotufo et al. 2013), but was more toxic than TNT to cladocerans (Griest et al. 1998; Pearson et al. 1979) and less toxic than TNT to mysid shrimp (Nipper et al. 2001).

The nitroaromatic compound 2,4-DNT and 2,6-DNT were lethally toxic at a higher range than TNT, with the $\mathrm{LC}_{50}$ values ranging from 4.4 to $47.5 \mathrm{mg} / \mathrm{L}$ and 5.0 to $21.8 \mathrm{mg} / \mathrm{L}$, respectively (Figure 68). Toxicity comparisons revealed that 2,4-DNT was less toxic than TNT to mysid shrimp (Nipper et al. 2001), cladocerans (Liu et al. 1983c), and copepods (Dave et al. 2000). 2,6-DNT was also less toxic than TNT to a mysid shrimp (Nipper et al. 2001) and to cladocerans (Liu et al. 1983c), but was more toxic to TNT to sea urchin embryos (Nipper et al. 2001). The isomer 2,6-DNT was more toxic than 2,4-DNT to cladocerans (Liu et al. 1983c), polychaetes, and sea urchin embryos (Nipper et al. 2001), but 2,4-DNT was more toxic than 2,6DNT to mysid shrimp (Nipper et al. 2001) and cladocerans (Deneer et al. 1989).

TNT promoted sublethal toxicity to a variety of invertebrates. For mussels, significant impairment of embryonic development occurred at concentrations $(\mathrm{EC}=0.8 \mathrm{mg} / \mathrm{L})$ substantially lower than those causing mortality of adult mussels $\left(\mathrm{LC}_{50}=19.5 \mathrm{mg} / \mathrm{L}\right.$ ) (Rosen and Lotufo 2007a). Decrease in offspring production at concentrations lower than those promoting mortality were reported for cladocerans and rotifers for TNT (Burton et al. 1993; Snell and Moffat 1992) and for 2,4-DA-6-NT (Griest et al. 1998) and to polychaetes for TNT, 1,3,5-TNB, 2,4-DNT, and 2,6-DNT (Nipper et al. 2001). Considering both marine and freshwater invertebrates, the lowest reported sublethal effects concentrations of TNT for invertebrates was $0.8 \mathrm{mg} / \mathrm{L}$ for TNT, in the embryonic development of mussels (Rosen and 
Lotufo 2007a), and for its transformation products and related products (1,3.5-TNB and dinitrotoluenes), $0.05 \mathrm{mg} / \mathrm{L}$ for 2,4-DA-6-NT in cladoceran reproduction (Griest et al. 1998).

Figure 68. Lethal concentrations, as $\mathrm{LC}_{50}$ values derived from exposure of varying durations, of MC to invertebrates.

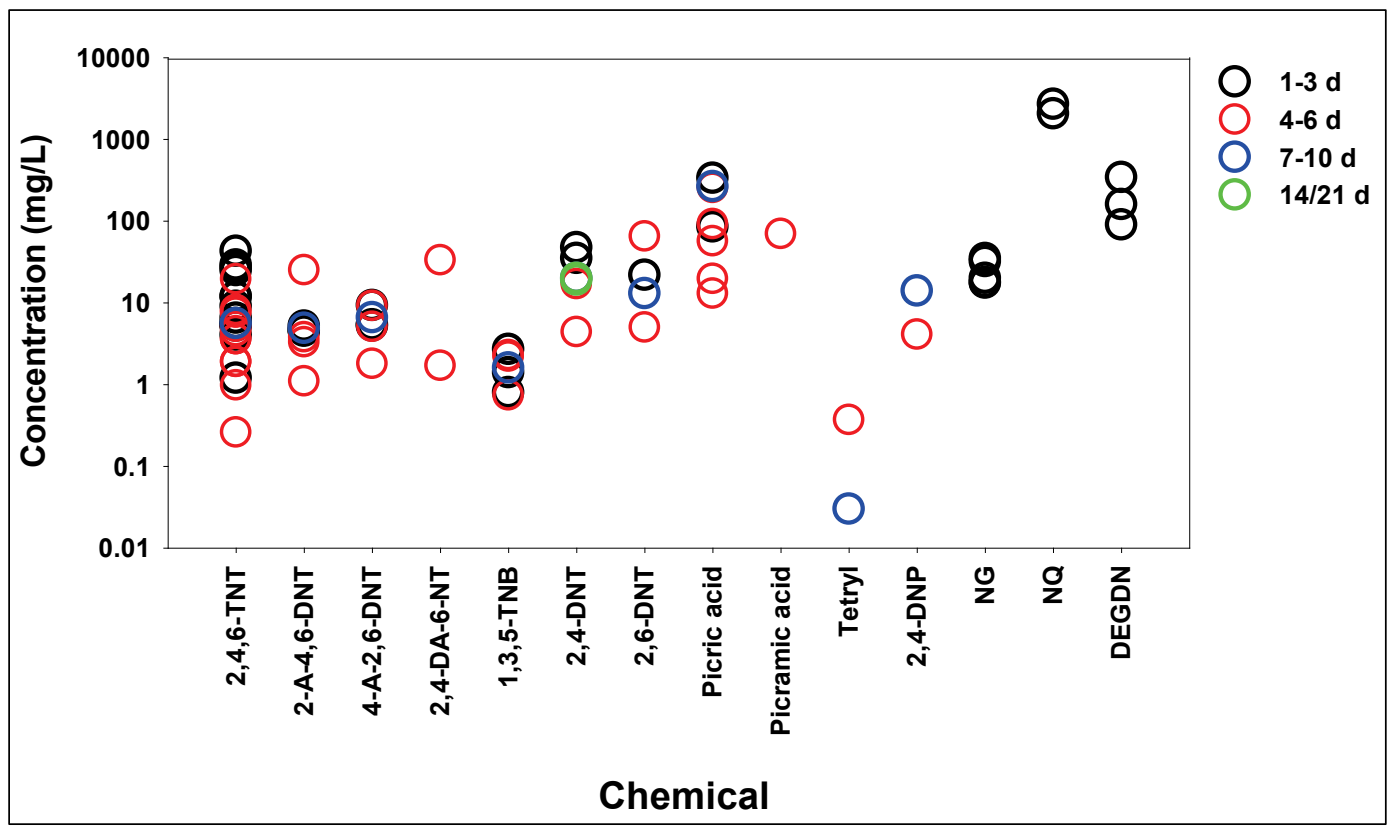

\subsubsection{RDX and HMX}

A variety of aquatic invertebrate species, both marine and freshwater, was tolerant to the lethal effects of RDX at the maximum concentration tested. Exposure to RDX at $28 \mathrm{mg} / \mathrm{L}$ or higher concentrations failed to elicit mortality in adult mussels, Dungeness crabs, mysid shrimp, polychaetes, cnidarians, midges, amphipods, cladocerans, and copepods (Peters et al. 1991; Burton et al. 1993; Dave et al. 2000; Nipper et al. 2001; ENSR International 2005; Rosen and Lotufo 2007a). Exposure to RDX at $7.2 \mathrm{mg} / \mathrm{L}$ failed to elicit mortality of the coral Acropora formosa (Gust et al. 2014).

Exposure to RDX at concentrations approaching the maximum solubility of that MC failed to impact the normal embryonic development of mussels and sea urchins (Rosen and Lotufo 2007a; Nipper et al. 2001). In addition, during 21 21-day exposures, RDX approaching the maximum solubility failed to cause significant decreased reproduction in Daphnia magna (ENSR International 2005). However, Bentley et al. (1977c) reported decreased reproduction of that species at $4.8 \mathrm{mg} / \mathrm{L}$. However, the 
sublethal effects reported by the latter study should be interpreted with caution because effects were only observed between 7 and 14 days, and mortality exceeded 20\%in some of the controls. RDX significantly reduced reproduction in Ceriodaphnia dubia at $6 \mathrm{mg} / \mathrm{L}$ (Peters et al. 1991; Burton et al. 1993). RDX also promoted decreased reproduction to polychaetes at sublehtal concentrations (Nipper et al. 2001). Considering both marine and freshwater invertebrates, the lowest reported sublethal effects concentrations of RDX for invertebrates was $4.8 \mathrm{mg} / \mathrm{L}$ in cladoceran reproduction (Bentley et al. 1977b).

Exposure to HMX at reported concentration levels that approached or exceeded its solubility limit failed to elicit toxicity to a variety of freshwater invertebrates (Bentley et al. 1977a) and mussels for both the survival and embryonic development endpoints (Rosen and Lotufo 2007a).

\subsubsection{Nitrophenolic MC}

When comparing the toxicity of $\mathrm{MC}$ using eight compounds of concern and marine toxicity tests with marine invertebrates, Nipper et al. (2001), reported that tetryl was the most toxic compound overall. It was also the most degradable compound, often being reduced to very low or belowdetection levels at the end of the test exposure. No other study of the toxicity of tetryl to invertebrates was found in available literature. Tetryl has not been manufactured in the United States for several decades and may no longer have any environmental relevance. In contrast to the high toxicity of tetryl, the nitrophenolic MC picric acid was lethally toxic at a much higher range, with the $\mathrm{LC}_{50}$ values ranging from 13 to $379 \mathrm{mg} / \mathrm{L}$ (Figure 68) for a variety of marine invertebrates (Goodfellow et al. 1983; Cajaraville et al. 1989; Dave et al. 2000; Nipper et al. 2001) and freshwater cladocerans (LeBlanc 1980). The transformation product 2,4-DNP $\left(\mathrm{LC}_{50}=4.1 \mathrm{mg} / \mathrm{L}\right)$ was substantially more toxic than the parent compound $\left(\mathrm{LC}_{50}=85 \mathrm{mg} / \mathrm{L}\right)$ to cladocerans (LeBlanc 1980). The same was observed for oysters $\left(\mathrm{LC}_{50}\right.$ values $=70 \mathrm{mg} / \mathrm{L}$ and $255 \mathrm{mg} / \mathrm{L}$ for 2,4-DNP and picric acid respectively) (Goodfellow et al. 1983).

Picric acid promoted decreased sea urchin embryonic development and copepod hatching success at relatively high concentrations (6o to $35^{2}$ $\mathrm{mg} / \mathrm{L}$ ), which were lower than their respective lethal concentrations (Nipper et al. 2001, 2005). Similarly, picramic acid and 2,4-DNP also promoted decreased copepod hatching success at concentrations lower than their respective lethal concentrations (Nipper et al. 2005). 


\subsubsection{Other MC}

Exposure of freshwater invertebrates to NG resulted in 48-hour $\mathrm{LC}_{50}$ values ranging from of 17 to $35 \mathrm{mg} / \mathrm{L}$ for (Burton et al. 1993) (Figure 68). Toxicity data for marine invertebrates exposed to NG was not found in the available literature.

The only marine receptor investigated for the toxicity of NQ was the copepod N. spinipes (Dave et al. 2000). No lethal effect to $N$. spinipes was reported even at the highest concentration tested $(683 \mathrm{mg} / \mathrm{L})$. Exposure of freshwater invertebrates to exceedingly high concentrations of NQ resulted in 48-h $\mathrm{LC}_{50}$ values for Hydra littoralis and Ceriodaphnia dubia of 2,061 and 2,698 mg/L, respectively (Burton et al. 1993) (Figure 68).

DEGDN toxicity to freshwater invertebrates was reported at $\mathrm{LC}_{50}$ values ranging from 90 to $491 \mathrm{mg} / \mathrm{L}$ (Fisher et al. 1989) (Figure 68). Toxicity data for marine invertebrates exposed to DEGDN was not found in the available literature.

In tests with the copepod $N$. snipes, the only marine receptor investigated for the toxicity of PETN, no effect was reported at the highest concentration tested (32 mg/L) (Dave et al. 2000). For the freshwater cladoceran Daphnia magna, immobilization was reported only for the highest test concentration (49 mg/L) (Dave et al. 2000).

Studies with NC indicated no toxicity at concentrations up to $1000 \mathrm{mg} / \mathrm{L}$ when tested with several species of freshwater invertebrates (Bentley et al. $1977 \mathrm{c}$ ). The concentrations, however, were derived from a target concentration of an active ingredient in static toxicity tests using "a slurry of poacher pit fines" collected at an army ammunition plant, with $\mathrm{NC}$ at $11.8 \%$ active ingredient. The overall lack of toxicity of $\mathrm{NC}$ is likely a result of its insolubility in water.

\subsubsection{Relative responsiveness of effects on reproduction}

Sublethal effects to invertebrates exposed to aqueous solutions of $\mathrm{MC}$ has been reported as embryonic development and byssal thread formation in mussels (Rosen and Lotufo 2007a), embryonic development in sea urchins (Davenport al. 1994; Nipper et al. 2001), egg hatching success in copepods (Nipper et al. 2005), growth and emergence success in midges (Bentley et al. 1977b), and reproductive success (as offspring production) in 
cladocerans (Peters et al. 1991; Burton et al. 1993; Van der Schelie 1983;

Griest et al. 1998; Bentley et al. 1978; Kuhn et al. 1989; Bentley et al. 1977b; ENSR International 2005), rotifers (Snell and Moffat 1992), copepods (Dave et al. 2000), midges (Burton et al. 1993), and polychaetes (Nipper et al. 2001). The use of organismal-level sublethal endpoints(e.g., offspring production) could be useful for the interpretation of potential long-term environmental effects of MC, as concentrations associated with sublethal endpoints were typically lower than those promoting mortality (Nipper et al. 2009).

Two studies were selected to illustrate the higher responsiveness of reproductive endpoints relative to lethality. Using a variety of MC, direct comparisons of the effects on mortality and reproduction were evaluated using the cladoceran Ceriodaphia dubia (Burton et al. 1983) and the polychaete Dinophilus gyrociliatus (Nipper et al. 2001). In both studies, the endpoints were evaluated during the same exposure to single MC. For the polychaete, 7-day $\mathrm{LC}_{50}$ and 7-day $\mathrm{EC}_{50}$ for offspring production are compared in Table 28 and Figure 69. The ratio of $\mathrm{EC}_{50}$ and $\mathrm{LC}_{50}$ values ranged from 0.16 to 0.58 , indicating the higher responsiveness of the sublethal endpoint. For the cladoceran, hypothesis-testing-based Noobservable-effect concentration (NOEC) and LOEC values for survival and offspring production are compared in Table 29. Offspring production was significantly decreased at sublethal concentrations for all MC examined.

Table 28. $\mathrm{LC}_{50}$ and $\mathrm{EC}_{50}$ values for survival and offspring production, respectively, of the polychaete Dinophilus gyrociliatus (from Nipper et al. 2001).

\begin{tabular}{|c|c|c|c|}
\hline & \multicolumn{2}{|c|}{ Endpoint } & \\
\hline MC & Survival & Offspring production & ${\text { EC } 50 / L_{50}}$ \\
\hline & 7-day LC50 $(\mathrm{mg} / \mathrm{L})$ & 7-day $\mathrm{EC}_{50}(\mathrm{mg} / \mathrm{L})$ & \\
\hline 2,4,6-TNT & 5.6 & 1.1 & 0.20 \\
\hline 1,3,5-TNB & 1.6 & 0.4 & 0.25 \\
\hline 2,4-DNT & 20 & 5.2 & 0.26 \\
\hline 2,6-DNT & 13 & 2.1 & 0.16 \\
\hline Picric acid & 265 & 155 & 0.58 \\
\hline Tetryl & 0.030 & 0.010 & 0.20 \\
\hline
\end{tabular}


Figure 69. $\mathrm{LC}_{50}$ and $\mathrm{EC}_{50}$ values for survival and offspring production, respectively, of the polychaete Dinophilus gyrociliatus (from Nipper et al.

2001).

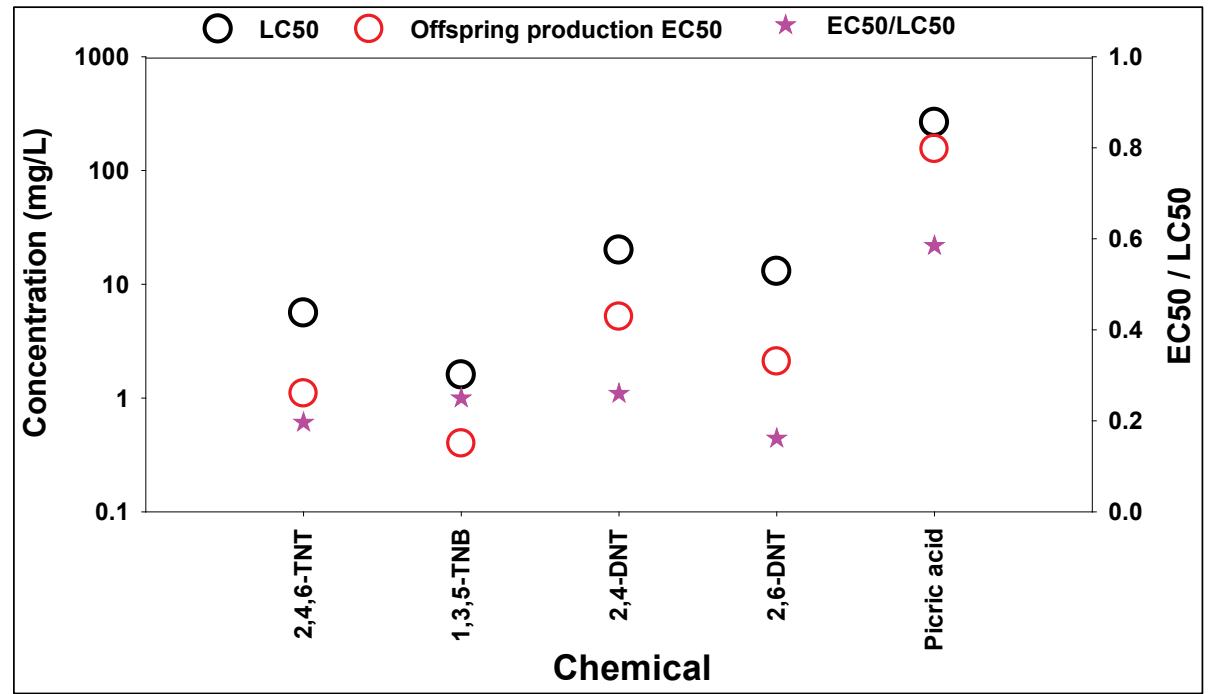

Table 29. Hypothesis-testing-based NOEC and LOEC values for survival and offspring production of the cladoceran Ceriodaphia dubia (from Burton et al. 1983).

\begin{tabular}{|c|c|c|c|}
\hline \multirow{2}{*}{ MC } & \multirow{2}{*}{ Endpoint } & \multicolumn{2}{|c|}{$\begin{array}{c}\text { Concentration } \\
(\mathrm{mg} / \mathrm{L})\end{array}$} \\
\cline { 3 - 4 } & & Survival & $\begin{array}{c}\text { Offspring } \\
\text { production }\end{array}$ \\
\hline NG & NOEC & 9.7 & 3.27 \\
\hline NG & LOEC & 16 & 5.5 \\
\hline NQ & NOEC & 1180 & 260 \\
\hline NQ & LOEC & 1400 & 440 \\
\hline RDX & NOEC & 16.4 & 3.6 \\
\hline RDX & LOEC & $>16.4$ & 6 \\
\hline TNT & NOEC & 2.7 & 1.6 \\
\hline TNT & LOEC & $>2.7$ & 2.7 \\
\hline
\end{tabular}

\subsection{Toxicity of MC to autotrophs}

\subsubsection{Nitroaromatic MC}

The toxicity of nitroaromatic MC to autotrophs has been reported for a variety of cyanobacteria, micro-and macroalgae and for an aquatic vascular plant (Nipper et al. 2009). TNT caused decreased population growth of cyanobacteria and microalgae, with $\mathrm{EC}_{50} \mathrm{O}$ and LOEC values ranging from $0.75 \mathrm{mg} / \mathrm{L}$ to $18 \mathrm{mg} / \mathrm{L}$ (Figure 70). Overall, aminodinitrotoluenes exhibited lower toxicity compared to TNT, as observed in an investigation comparing the toxicity of TNT $\left(\mathrm{EC}_{5} \mathrm{O}=0.75 \mathrm{mg} / \mathrm{L}\right)$ to that of its aminated breakdown products (EC50 from 2.5 to $49 \mathrm{mg} / \mathrm{L}$ ) for Pseudokirchneriella subcapitata 
(Sunahara et al. 1998). The nitroaromatic compound 2,4-DNT and 2,6-DNT were toxic at a similar range as TNT, with the $\mathrm{LC}_{50} \mathrm{O}$ values ranging from EC5O and LOEC values ranging from $0.9 \mathrm{mg} / \mathrm{L}$ to $16.5 \mathrm{mg} / \mathrm{L}$ (Figure 70). Toxicity comparison revealed that 2,4-DNT was less toxic than TNT to P. subcapitata (Dodard et al. 1999).

The effects of nitroaromatic $\mathrm{MC}$ to zoospore germination in green algae Ulva fasciata revealed that $1,3,5-\mathrm{TNB}\left(\mathrm{EC}_{50}=0.04 \mathrm{mg} / \mathrm{L}\right)$ was the most toxic compound tested, followed by TNT, 2,4-DNT, and 2,6-DNT (Nipper et al. 2001). The latter study also reported effects on germling growth for that species, which occurred at a similar range of concentrations. Toxicity of TNT to the common duckweed was reported as decreased frond production $\left(\mathrm{EC}_{50}=1.6 \mathrm{mg} / \mathrm{L}\right)$ (Burton et al. 1993).

Figure 70. Toxic concentrations of MC to autotrophs.

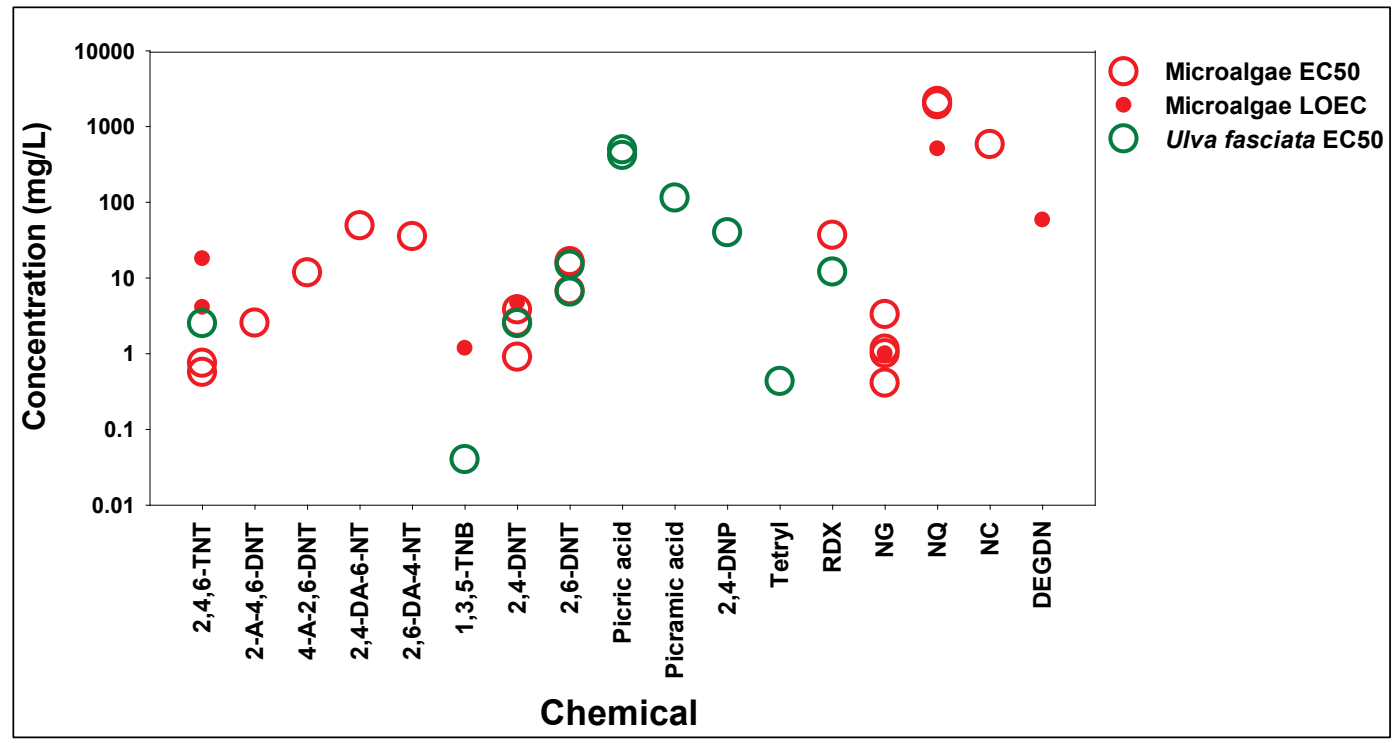

\subsubsection{RDX and HMX}

Cyanobacteria and algae were relatively tolerant to the effects of RDX, with $\mathrm{EC}_{50}$ and LOEC values ranging from 12.0 to $36.7 \mathrm{mg} / \mathrm{L}$ (Burton et al. 1994; Sunahara et al. 1998; Nipper et al. 2001) (Figure 70) and species tolerating exposure to $32 \mathrm{mg} / \mathrm{L}$ (Bentley et al. 1977b). Exposure to HMX at levels reported as concentrations that approached or exceeded its solubility limit failed to elicit toxicity to cyanobacteria and microalgae (Bentley et al. 1977a; Sunahara et al. 1998). 


\subsubsection{Nitrophenolic MC}

Cyanobacteria and microalgae were relatively tolerant to the effects of picric acid and 2,4-DNP (Bringmann and Kuhn 1978; Kuhn and Pattard 1990), with the lowest LOEC reported as $16 \mathrm{mg} / \mathrm{L}$ (Figure 70).

The effects of nitrophenolic MC to zoospore germination in green algae $\mathrm{U}$. fasciata revealed that tetryl was the most toxic compound tested $\left(\mathrm{EC}_{50}=\right.$ $0.46 \mathrm{mg} / \mathrm{L}$ ), followed by 2,4-DNP, picramic acid, and picric acid, which were toxic at much higher concentrations $\left(\mathrm{EC}_{50}\right.$ values ranged from 39.6 to $494 \mathrm{mg} / \mathrm{L}$ ) (Figure 70) (Nipper et al. 2005). The latter study also reported effects on germling growth for that species, which occurred at a similar range of concentrations.

\subsubsection{Other MC}

Exposure of freshwater microalgae to NG resulted in decreased population growth and reduction in chlorophyll $a$ at concentrations as low as 0.4 mg/L (Bentley et al. 1978; Burton et al. 1993) (Figure 70). Exposure to DEGDN caused decreased population growth of microalgae at $58 \mathrm{mg} / \mathrm{L}$, and NQ produced decreased population growth and reduction in chlorophyll $a$ at $508 \mathrm{mg} / \mathrm{L}$ or higher concentrations (van der Schalie et al. 1985) (Figure 70). Toxicity data for macroalgae (e.g., U.fasciata) and aquatic vascular plants exposed to NG, NQ, DEGDN, and NC was not found in available literature.

\subsection{Toxicity of photo-transformation products}

Nipper et al. (2009) provided a summary review of the toxicity of phototransformation products of MC and potential for photo-activation of the bioaccumulated compound. To the authors' knowledge, a new study has not been published since the Nipper et al. (2009) review addressed the topic. A brief summary of the effects of photo-irradiation on the toxicity of $\mathrm{MC}$ is provided below.

Rosenblatt et al. (1991) reported that photolysis of TNT reduced its toxicity to freshwater fish and cladocerans, but promoted no change in toxicity for amphipods and midges. Irradiation of test chambers containing $\mathrm{MC}$ with ultraviolet (UV) light for two hours at the end of a toxicity test resulted in significantly increased acute toxicity of 2,4-DNT to a cladoceran but not to estuarine copepods (Dave et al. 2000). Irradiation of TNT-spiked water 
with UV light promoted no change in toxicity to both species (Dave et al. 2000). Co-exposure with near-UV light only caused increased toxicity of 2A-4,6-DNT (10-fold) to a planarian, but not TNT and 4-A-2,6-DNT (Johnson et al. 1994). Co-exposure of sea urchin eggs or embryos to nearUV light increased the toxicity of TNT, 2,4-DNT, and 2,6-DNT relative to exposure to those MC in the dark (Davenport et al. 1994).

RDX caused decreases in the reproduction of a species of cladoceran at 6 $\mathrm{mg} / \mathrm{L}$ (Peters et al. 1991). Under the same exposure conditions, RDX spiked to water at $10 \mathrm{mg} / \mathrm{L}$ caused decreased survival and reproduction of cladocerans; however, the same solution exposed to sunlight for 28 days was non-toxic (Burton et al. 1995).

The mixture of chemicals produced by the photolysis of NQ caused a dramatic two orders of magnitude increase in toxicity to microalgae, cladocerana, and sheepshead minnows (van der Schalie et al. 1985; Burton et al. 1993).

Woodley and Downs (2014) exposed coral gastrodermal and calicoblast cells to TNT in both four-hour light and four-hour dark exposures. Woodley and Downs (2014) evaluated other MC that were not compared between light and dark exposures. Comparisons between light and dark exposures were compared using cell mortality $\mathrm{LC}_{50}$ values. Coral gastrodermal and calicoblast cells ( $P$. divaricata and $P$. damicornis) were roughly 20 times more sensitive to TNT when exposed in a four-hour light exposure compared to a four-hour dark exposure (Woodley and Downs 2014).

\subsection{Biochemical and histopathological effects}

When the common carp (Cyprinus carpio) was exposed to 2,4-DNT for 7 or 15 days, significant sublethal effects on the hepatosomatic index were reported (at $0.5 \mathrm{mg} / \mathrm{L}$ after 7 days) including, enzyme activity (at $0.1 \mathrm{mg} / \mathrm{L}$ after 7 days), energy reserves (at $1.0 \mathrm{mg} / \mathrm{L}$ after 4 days), and relative condition factor (at $0.1 \mathrm{mg} / \mathrm{L}$ after 15 days) (Xu and Jing 2012).

Sublethal biochemical effects can also occur due to exposure of organisms to explosive MC. Della Torre et al. (2008 a,b,c) conducted extensive investigations of biochemical-level effects on the European eel (Anguilla anguilla) using aqueous exposures. Their results seem to indicate an inhibitory effect of TNT on ethoxyresorufin- $O$-deethylase (EROD)dependent catalytic activities. Likewise, the results show a possible 
involvement of phase II enzymes as well as the reduction of nicotinamide adenine dinucleotide phosphate (NADPH) cytochrome $\mathrm{C}$ reductase in TNT metabolism in eels (Della Torre et al. 2008a). TNT effects on the eel's neurosteroidogenic pathways was also reported (Della Torre et al. 2008b), as well as an indication that TNT is a potential competitive inhibitor of cytochrome P450IA activities. A metabolic pathway for TNT involving $\mathrm{NADPH}, \mathrm{NADPH}$ cytochrome $\mathrm{C}$ reductase, and phase II enzymes was also suggested (Della Torre et al. 2008c).

Significant inhibition of EROD activity was also observed in juvenile rainbow trout (Onchorhynchus mykiss) dosed intraperitoneally with TNT at different concentrations (Ek et al. 2003). In a similar study, trout treated with TNT showed increased amounts of glutathione $S$-transferase and glutathione reductase activities, while showing a decreased percentage of oxidized glutathione compared to control fish (Ek et al. 2005), which indicates that TNT oxidizes macromolecules and activates antioxidant defense systems. The compounds TNT, 2-A-4,6-DNT, and 4-A-2,6-DNT were found in the hydrolyzed bile of the TNT-treated trout, indicating that this fish species can detoxify and excrete TNT. The presence of TNT and its transformation products in the bile may be suitable as a direct marker of TNT exposure in fish at contaminated sites (Ek et al. 2005).

Gust et al. (2014) demonstrated increased expression of cytochrome P450 in coral (Acropora formosa) that was exposed to RDX as a mechanism of detoxification. In addition, potential insult to coral health was evidenced by the significant increase of coral mucocyte densities at the maximum RDX exposure $(7.2 \mathrm{mg} / \mathrm{L})$. The zooxanthellae tissue densities were not affected.

Woodley and Downs (2014) investigated the toxicity of TNT, RDX, and 2,3DNT to two species of coral, Porites divaricate and P. damicormis using 24or 96-hour exposures of coral fragments to spiked seawater. Toxicity was evaluated using histopathological changes in tissues and on cell physiology as total porphyrin levels and other biomarkers. Porphyrins are macrocyclic compounds of the heme biosynthetic pathway and are ubiquitous in nature, forming the basic structure of hemoproteins that are found in most major metabolic pathways that include detoxification systems, respiration, and oxidative metabolism. TNT concentrations of $0.5 \mathrm{mg} / \mathrm{L}$ and higher promoted significant histopathological changes and reduction of porphyrin levels was reported at $2.5 \mathrm{mg} / \mathrm{L}$ (Table 30). Exposure to 2,3-DNT at 0.8 $\mathrm{mg} / \mathrm{L}$ promoted visible deterioration of tissue integrity, and $0.292 \mathrm{mg} / \mathrm{L}$ 
promoted decrease in porphyrin levels (Table 30). The highest concentration of RDX used in coral fragment exposures $(16 \mathrm{mg} / \mathrm{L})$ failed to promote histopathological changes or reduction on porphyrin levels (Table 30). In addition to experiments with coral fragments, Woodley and Downs (2014) also reported toxicity of TNT, 2,4-DNT, 2,6-DNT, RDX, HMX, and picric acid to calicoblast and gastrodermal cells of $P$. divaricate, $P$. damicormis, and P. lobata.

Table 30. MC toxic effects on marine corals fragments. Based on Woodley and Downs (2014).

\begin{tabular}{|c|c|c|c|c|c|}
\hline Species & MC & $\begin{array}{c}\text { Duration } \\
(\mathbf{d})\end{array}$ & $\begin{array}{c}\text { Toxic Effect } \\
(\mathbf{m g} / \text { L) }\end{array}$ & $\begin{array}{c}\text { Effect } \\
\text { measurement }\end{array}$ & Endpoint \\
\hline Porites divaricata & TNT & 4 & 0.1 & $\begin{array}{c}\text { Deterioration of } \\
\text { tissue integrity }\end{array}$ & NOEC \\
\hline Porites divaricata & TNT & 4 & 0.5 & $\begin{array}{c}\text { Deterioration of } \\
\text { tissue integrity }\end{array}$ & LOEC \\
\hline Porites divaricata & TNT & 4 & 0.5 & $\begin{array}{c}\text { Total porphyrin } \\
\text { levels }\end{array}$ & NOEC \\
\hline Porites divaricata & TNT & 4 & 2.5 & $\begin{array}{c}\text { Total porphyrin } \\
\text { levels }\end{array}$ & LOEC \\
\hline Porites divaricata & TNT & 1 & 0.5 & $\begin{array}{c}\text { Total porphyrin } \\
\text { levels }\end{array}$ & NOEC \\
\hline Porites divaricata & TNT & 1 & 2.5 & $\begin{array}{c}\text { Total porphyrin } \\
\text { levels }\end{array}$ & LOEC \\
\hline Porites divaricata & TNT & 1 & 5.4 & $\begin{array}{c}\text { Total porphyrin } \\
\text { levels }\end{array}$ & EC50 \\
\hline $\begin{array}{c}\text { Pocillopora } \\
\text { damicornis }\end{array}$ & $\begin{array}{c}2,3- \\
\text { DNT }\end{array}$ & 4 & 0.53 & $\begin{array}{c}\text { Visible } \\
\text { deterioration of } \\
\text { tissue integrity }\end{array}$ & NOEC \\
\hline $\begin{array}{c}\text { Pocillopora } \\
\text { damicornis }\end{array}$ & $\begin{array}{c}2,3- \\
\text { DNT }\end{array}$ & 4 & 0.80 & $\begin{array}{c}\text { Visible } \\
\text { deterioration of } \\
\text { tissue integrity }\end{array}$ & LOEC \\
\hline $\begin{array}{l}\text { Pocillopora } \\
\text { damicornis }\end{array}$ & $\begin{array}{l}2,3- \\
\text { DNT }\end{array}$ & 4 & 0.162 & $\begin{array}{c}\text { Total porphyrin } \\
\text { levels }\end{array}$ & NOEC \\
\hline $\begin{array}{l}\text { Pocillopora } \\
\text { damicornis }\end{array}$ & $\begin{array}{l}2,3- \\
\text { DNT }\end{array}$ & 4 & 0.292 & $\begin{array}{c}\text { Total porphyrin } \\
\text { levels }\end{array}$ & LOEC \\
\hline $\begin{array}{l}\text { Pocillopora } \\
\text { damicornis }\end{array}$ & RDX & 4 & 16.0 & $\begin{array}{c}\text { Visible } \\
\text { deterioration of } \\
\text { tissue integrity }\end{array}$ & $\begin{array}{c}\text { NOEC } \\
\text { (highest } \\
\text { tested) }\end{array}$ \\
\hline $\begin{array}{l}\text { Pocillopora } \\
\text { damicornis }\end{array}$ & RDX & 4 & 16.0 & $\begin{array}{c}\text { Total porphyrin } \\
\text { levels }\end{array}$ & $\begin{array}{c}\text { NOEC } \\
\text { thighest } \\
\text { tested) }\end{array}$ \\
\hline
\end{tabular}

Advances in molecular biology are extending the use of biomarkers to the level of the genes, which, when coupled with bioinformatics, are progressing toward the development of screening tools for ecotoxicologists. Environmental genomics (using gene expression profiles after exposure to toxicants, also called toxicogenomics) allow insight into modes of action that may be used to assess causal agents and potential toxicity (Garcia- 
Reyero et al. 2009). Recent research goals include development of robust methods for using gene expression analysis when identifying gene expression biomarkers of chemical exposure that can be further used to monitor specific chemical exposures in the environment (Garcia-Reyero et al. 2009, 2012).

Gust et al. (2011a) conducted a comprehensive investigation of the effects RDX exposure elicited on transcript expression in fathead minnow brain tissue. Significant mortality occurred at $10 \mathrm{mg} / \mathrm{L}$ after 10 days of exposure to spiked water. Conversely, microarray data indicated significant changes in transcript expression at RDX concentrations as low as $0.625 \mathrm{mg} / \mathrm{L}$. Individual gene functions affected by RDX exposures indicated changes in metabolic processes involved in: oxygen transport, neurological function, calcium binding/signaling, energy metabolism, cell growth/division, oxidative stress, and ubiquitination.

Decreased expressions of collagen-coding transcripts were associated with spinal deformity and were likely responsible for the susceptibility of zebrafish and fathead minnow to sublethal effects of RDX (Warner et al. 2012). The latter study also found that the number and magnitude of differentially expressed transcripts increased upon increasing RDX concentrations for both species. Differentially expressed genes were enriched in functions related to neurological disease, oxidative-stress, acute-phase response, vitamin/mineral metabolism, and skeletal/muscular disorders.

Using a custom complementary DNA (cDNA) microarray for Daphnia magna, Garcia-Reyero et al. (2009) identified distinct expression fingerprints in response to exposure at sublethal concentrations of MC. RDX exhibited a robust gene expression pattern, which affected diverse pathways involved in exoskeletal maintenance, such as protein catabolism, cell structure, and cellular transport. An induction of oxidative stress response genes was seen after exposure to 1,3,5-TNB, DNB, and TNT. Both 4-A-2,6DNT and 2,4-DNT affected genes (e.g., vitellogenin) directly involved in reproduction and development. TNT caused up-regulation of ferritin, which indicated possible interference with iron metabolism or oxidative stress. In a follow-up study, Garcia-Reyero et al. (2012) demonstrated that, to a limited extent, it is possible to predict gene expression changes in the $D$. magna, given the chemical mixture to which it has been exposed. 


\subsection{Toxicity of MC to aquatic invertebrates and fish in sediment exposures}

Toxicity of sediment-associated MC to marine and freshwater fish and invertebrates was investigated in laboratory studies using sediment amended with $\mathrm{MC}$ and whole-sediment or extracted porewater as test matrices.

Compared to investigations addressing the soil ecotoxicity of $\mathrm{MC}$ (Kuperman et al. 2009), relatively few studies addressed the toxicity of sediment-associated MC to marine invertebrates (Green et al. 1999; Dave et al. 2000; Lotufo et al. 2001; Nipper et al. 2002; Nipper et al. 2005; Rosen and Lotufo 2005), or freshwater invertebrates (Steevens et al. 2002; Conder et al. 2004; Lotufo and Farrar 2005). An evaluation MC toxicity to fish that were exposured to contaminated sediment was also investigated (Lotufo et al. 2010c).

Lotufo et al. (2009b) provided a summary review of the fate and toxicity of MC amended to sediments. In addition, Lotufo et al. (2013) expanded this effort four years later. To the authors' knowledge, a study addressing the toxicity of MC in sediment exposures has not been made available since the publication of Lotufo et al. (2013); therefore, the reader is referred to that review for a current and comprehensive data compilation for $\mathrm{MC}$ toxicity in whole-sediment and extracted porewater exposures. Table 31 summarizes the toxicity of MC to freshwater and marine invertebrates exposed to spike-sediments.

Table 31. Lethal toxicity data for MC determined for aquatic invertebrates using spiked sediment exposures.

\begin{tabular}{|c|c|c|c|c|c|c|c|}
\hline \multirow[t]{2}{*}{ MC } & \multirow[t]{2}{*}{ Species } & \multirow[t]{2}{*}{ Habitat } & TOC & Duration & NOEC & LOEC & \multirow[t]{2}{*}{ Reference } \\
\hline & & & (\%) & (d) & $\mathrm{mg} / \mathrm{kg}$ & $\mathrm{mg} / \mathrm{kg}$ & \\
\hline \multirow{6}{*}{ TNT } & $\begin{array}{l}\text { Leptocheirus } \\
\text { plumulosus }\end{array}$ & Marine & 2.7 & 28 & 116 & 228 & $\begin{array}{c}\text { Green et al. } \\
1999\end{array}$ \\
\hline & $\begin{array}{c}\text { Neanthes } \\
\text { arenaceodentata }\end{array}$ & Marine & 2.7 & 28 & 275 & 508 & $\begin{array}{l}\text { Green et al. } \\
1999\end{array}$ \\
\hline & Hyalella azteca & Freshwater & 0.65 & 10 & $\begin{array}{l}<0.1^{a} \\
(25)\end{array}$ & $\begin{array}{c}0.1 \\
(50)\end{array}$ & $\begin{array}{c}\text { Steevens et al. } \\
2002\end{array}$ \\
\hline & $\begin{array}{c}\text { Chironomus } \\
\text { dilutus }\end{array}$ & Freshwater & 0.65 & 10 & ND & $37(43)$ & $\begin{array}{l}\text { Lotufo and Farrar } \\
2005\end{array}$ \\
\hline & Tubifex & Freshwater & 0.96 & 28 & $\begin{array}{c}25 \\
(100)\end{array}$ & $\begin{array}{c}69 \\
(320)\end{array}$ & $\begin{array}{c}\text { Conder et al. } \\
2004 a\end{array}$ \\
\hline & $\begin{array}{c}\text { Eohaustorius } \\
\text { estuarius }\end{array}$ & Marine & 0.36 & 10 & $\begin{array}{c}20 \\
(100)\end{array}$ & $\begin{array}{c}38 \\
(200)\end{array}$ & $\begin{array}{l}\text { Rosen and Lotufo } \\
2005\end{array}$ \\
\hline
\end{tabular}




\begin{tabular}{|c|c|c|c|c|c|c|c|}
\hline 2-A-4,6-NT & $\begin{array}{l}\text { Chironomus } \\
\text { dilutus }\end{array}$ & Freshwater & 0.65 & 10 & $\begin{array}{c}23 \\
(51)\end{array}$ & $59(72)$ & $\begin{array}{l}\text { Lotufo and Farrar } \\
\qquad 2005\end{array}$ \\
\hline \multirow{5}{*}{ 2,4-DANT } & $\begin{array}{l}\text { Leptocheirus } \\
\text { plumulosus }\end{array}$ & Marine & 2.7 & 28 & $\begin{array}{c}<0.1^{a} \\
(57)\end{array}$ & $\begin{array}{c}3.0 \\
(113)\end{array}$ & $\begin{array}{l}\text { Lotufo et al. } \\
\quad 2001\end{array}$ \\
\hline & $\begin{array}{c}\text { Neanthes } \\
\text { arenaceodentata }\end{array}$ & Marine & 2.7 & 28 & $\begin{array}{l}187 \\
(444)\end{array}$ & $\begin{array}{c}574 \\
(1,185)\end{array}$ & $\begin{array}{l}\text { Lotufo et al. } \\
\quad 2001\end{array}$ \\
\hline & Hyalella azteca & Freshwater & 0.65 & 10 & $\begin{array}{c}<0.1^{a} \\
(25)^{a}\end{array}$ & $\begin{array}{c}0.3 \\
(50)\end{array}$ & $\begin{array}{c}\text { Steevens et al. } \\
2002\end{array}$ \\
\hline & $\begin{array}{l}\text { Chironomus } \\
\text { dilutus }\end{array}$ & Freshwater & 0.65 & 10 & $\begin{array}{l}110 \\
(400)\end{array}$ & ND & $\begin{array}{c}\text { Steevens et al. } \\
2002\end{array}$ \\
\hline & $\begin{array}{l}\text { Chironomus } \\
\text { dilutus }\end{array}$ & Freshwater & 0.65 & 10 & $\begin{array}{c}33 \\
(120)\end{array}$ & $\begin{array}{c}59 \\
(243) \\
\end{array}$ & $\begin{array}{l}\text { Lotufo and Farrar } \\
2005\end{array}$ \\
\hline \multirow{5}{*}{ 1,3,5-TNB } & $\begin{array}{l}\text { Leptocheirus } \\
\text { plumulosus }\end{array}$ & Marine & 2.7 & 28 & $\begin{array}{l}<0.1 \\
(119)\end{array}$ & $\begin{array}{l}<0.1 \\
(237)\end{array}$ & $\begin{array}{l}\text { Lotufo et al. } \\
2001\end{array}$ \\
\hline & $\begin{array}{c}\text { Neanthes } \\
\text { arenaceodentata }\end{array}$ & Marine & 2.7 & 28 & $\begin{array}{l}<0.1 \\
(468)\end{array}$ & ND & $\begin{array}{l}\text { Lotufo et al. } \\
\quad 2001\end{array}$ \\
\hline & Hyalella azteca & Freshwater & 0.65 & 10 & $\begin{array}{l}<0.1^{a} \\
(50)\end{array}$ & $1(100)$ & $\begin{array}{c}\text { Steevens et al. } \\
2002\end{array}$ \\
\hline & $\begin{array}{l}\text { Chironomus } \\
\text { dilutus }\end{array}$ & Freshwater & 0.65 & 10 & $\begin{array}{c}7.6 \\
(400)\end{array}$ & ND & $\begin{array}{c}\text { Steevens et al. } \\
2002\end{array}$ \\
\hline & $\begin{array}{l}\text { Chironomus } \\
\text { dilutus }\end{array}$ & Freshwater & 0.65 & 10 & $\begin{array}{c}59 \\
(140)\end{array}$ & $\begin{array}{l}131 \\
(289)\end{array}$ & $\begin{array}{l}\text { Lotufo and Farrar } \\
2005\end{array}$ \\
\hline \multirow{2}{*}{ 2,6-DNT } & Ampelisca abdita & Marine & 0.1 & 10 & 5 & ND & $\begin{array}{c}\text { Nipper et al. } \\
2004 \\
\end{array}$ \\
\hline & Ampelisca abdita & Marine & 1.1 & 10 & 0.5 & ND & $\begin{array}{l}\text { Nipper et al. } \\
2004\end{array}$ \\
\hline RDX & $\begin{array}{l}\text { Leptocheirus } \\
\text { plumulosus }\end{array}$ & Marine & 2.7 & 10 & 891 & ND & $\begin{array}{l}\text { Lotufo et al. } \\
2001\end{array}$ \\
\hline
\end{tabular}

TOC - total organic carbon, NOEC - No observed effect concentration, LOEC - lowest observed effect concentration, ND - not determined due to insufficient mortality , NOEC and LOEC reported as sum concentrations of parent and transformation products measured at experiment initiation (when available, target concentrations are shown in parenthesis), a Numerical value represents DL. 


\section{Aquatic Criteria and Screening Benchmarks}

\subsection{Aquatic acute and chronic ambient water quality criteria}

A variety of methods have been used to develop benchmark values that can be used to establish maximum levels of contaminant exposure, below which there should not be significant harm to aquatic biota. USEPA adopted some of the most widely accepted and detailed methods derive ambient water quality criteria (WQC) for the protection of aquatic life. The USEPA developed these methods for setting WQC and standards for compliance with the Clean Water Act. Acute and chronic aquatic WQC are screening benchmarks that can be considered ecotoxicological thresholds with acute and chronic WQC as the upper and lower screening benchmarks for chemical concentrations (Talmage et al. 1999). More information about WQC and chemical databases can be found on the following website: https://www.epa.gov/wqc/basic-information-water-quality-criteria. MC is not included among the chemicals for which the USEPA recommends National WQC for protecting aquatic life.

Both acute and chronic provisional WQC values were derived for a suite of $\mathrm{MC}$, as in Talmage et al. (1999). The provisional values for both acute and chronic WQC for TNT, 1,3,5-TNB, 1,3-DNB, 3,5-DNA, HMX, RDX, NG, and $\mathrm{NC}$ from previous studies are presented in Table 32. This report includes new acute and chronic values calculated from studies not included in previously derived provisional WQC. Revised values were generated because recent research shows that uninvestigated test organisms demonstrate great sensitivity to MC toxicity. In addition, provisional WQC were generated for 2,4-DNT for which provisional WQC values were not found in the available literature.

Talmage et al. (1999) provided tier I final acute values (FAV) guidance, which was used to calculate provisional acute WQC values for MC (Table 32). Talmage et al. (1999) and Table 2-1 of ENSR (2005) summarized eight different species guidelines for WQC to be considered tier I values. Talmage et al. (1999) also provided tier II FAV guidance for deriving Tier II WQC when requirements for deriving tier I WQC were not met. Tier II WQC uses secondary acute factors (SAFs) as adjustment values that can vary depending on the number of guidelines from tier I that were not met. The 
SAFs are summarized in Talmage et al. (1999). Provisional tier II WQC values are also presented in Table 32.

The provisional chronic WQC for TNT derived from this project was calculated using available toxicity data. In addition, a chronic WQC value for TNT was calculated using a revised acute-chronic ratio that included new studies. The new studies show that two tadpole species (R. pipiens and $R$. catesbeiana) have a much higher chronic sensitivity to TNT (Paden et al. 2011; Stanley et al. 2015).

For TNT, Talmage et al. (1999) reported a summary of results from different studies of freshwater species and calculated both acute and chronic provisional WQC values. Talmage et al. (1999) calculated a tier I acute aquatic WQC of $570 \mu \mathrm{g} / \mathrm{L}$ and a chronic WQC of $90 \mu \mathrm{g} / \mathrm{L}$. Nipper et al. (2009) compiled newer studies that were not available at the time of Talmage et al. (1999) and calculated a revised provisional WQC for both freshwater and marine environments. Nipper et al. (2009) reported that acute TNT WQC for freshwater $(1,130 \mu \mathrm{g} / \mathrm{L})$ and marine water $(85.4 \mu \mathrm{g} / \mathrm{L})$ were several orders of magnitudes different. Likewise, Nipper et al. (2009) calculated the chronic TNT provisional WQC for freshwater and marine water and found that they were not very different at 39.9 and $28.4 \mu \mathrm{g} / \mathrm{L}$, respectively. This report calculated new acute and chronic provisional WQC for freshwater, marine water, and a combined value using studies published after Nipper et al. (2009). The marine chronic WQC value was calculated using tier one equations presented in Talmage et al. (1999). The chronic value calculated was higher than the marine acute WQC calculated for this report. The values cited in Table 32 from this report fall within the range of values reported in both Talmage et al. (1999) and Nipper et al. (2009).

For 2-A-4,6-DNT, tier II acute and chronic freshwater provisional WQC were reported in Talmage et al. (1999). The WQC reported for both acute $(351 \mu \mathrm{g} / \mathrm{L})$ and chronic $(18.9 \mu \mathrm{g} / \mathrm{L})$ do not vary much from other reported MC (Table 32).

For 1,3,5-TNB, acute and chronic provisional WQC were calculated using Talmage et al. (1999). The WQC values were calculated using a tier II SAF of 6.5 with only 4 out of the 8 species necessary for a tier I WQC calculation. The acute WQC $(60 \mu \mathrm{g} / \mathrm{L})$ is the lowest acute WQC of all MC reported (Table 32). The chronic WQC (11 $\mu \mathrm{g} / \mathrm{L})$ is similar to those for other MC (Table 32). This study reported a tier I provisional acute 
$(189 \mu \mathrm{g} / \mathrm{L})$ and chronic $(25 \mu \mathrm{g} / \mathrm{L})$ WQC that were 2 times higher than Talmage et al. (1999) reported (Table 32).

For 1,3-DNB, acute and chronic aquatic tier II provisional WQC were calculated using Talmage et al. (1999). Similar to 1,3,5-TNB, 1,3-DNB acute WQC were calculated with only 4 out of the necessary 8 species for a tier I and therefor used a SAF of 6.5 (Talmage et al. 1999). The tier II acute $(215 \mu \mathrm{g} / \mathrm{L})$ and chronic $(17 \mu \mathrm{g} / \mathrm{L}) \mathrm{WQC}$ for 1,3 -DNB fell within most of the other MC values presented in Table 32. Combined provisional acute $(194 \mu \mathrm{g} / \mathrm{L})$ and chronic $(76 \mu \mathrm{g} / \mathrm{L})$ WQC were calculated in this report using studies published after Talmage et al. (1999). The acute WQC reported in this study is very similar to Talmage et al. (1999) although the chronic WQC was roughly 4 times higher than Talmage et al. (1999; Table 32).

Provisional WQC values for 2,4-DNT were not found in the available literature. Provisional acute and chronic tier I WQC were calculated for this report using both aquatic and marine data. The acute $(977 \mu \mathrm{g} / \mathrm{L})$ and chronic $(900 \mu \mathrm{g} / \mathrm{L}) \mathrm{WQC}$ fell closer to the higher WQC MC values when compared to the other reported MC WQC (Table 32).

RDX has five (i.e., three aquatic, one marine, and one combined aquatic and marine) different acute provisional WQC reported on Table 32. Bentley et al. (1977b) reported the lowest acute WQC of $351 \mu \mathrm{g} / \mathrm{L}$ when compared to Talmage et al. (1999), 1,390 $\mu \mathrm{g} / \mathrm{L}$, and ENSR (2005), $6,190 \mu \mathrm{g} / \mathrm{L}$. ENSR (2005) updated Talmage et al. (1999) summary of studies with additional species. ENSR (2005) lowest acute value $(859 \mu \mathrm{g} / \mathrm{L})$ is marine only acute WQC. All three chronic WQC for freshwater $(6,140 \mu \mathrm{g} / \mathrm{L})$, marine $(853 \mu \mathrm{g} / \mathrm{L})$, and combined $(2,700 \mu \mathrm{g} / \mathrm{L})$ were very similar to acute WQC for the same study. Talmage et al. (1999) chronic WQC was one order of magnitude less than the acute WQC. Bentley et al. (1977b) did not report an RDX chronic WQC.

HMX provisional WQC data was reported in both Talmage et al. (1999), tier II, and Bentley et al. (1977a), tier I. The acute WQC reported vary by an order of magnitude with Talmage et al. (1999) reporting a greater value $(3,750 \mu \mathrm{g} / \mathrm{L})$. Although chronic WQC could not be compared for HMX as Bentley et al. (1977a) did not report a chronic WQC, Talmage et al. (1999) chronic WQC $(329 \mu \mathrm{g} / \mathrm{L})$ was within the range of other reported MC WQC (Table 32). 
The only provisional acute and chronic WQC for NG were reported in Sullivan et al. (1979), who derived tier I acute (410 $\mathrm{mg} \mu \mathrm{g} / \mathrm{L}$ ) and chronic $(7 \mu \mathrm{g} / \mathrm{L}) \mathrm{WQC}$ values that are two times higher than the tier II acute (188 $\mu \mathrm{g} / \mathrm{L}) \mathrm{WQC}$ values derived for this project. The chronic WQC values are similar between Sullivan et al. (1979), $7 \mu \mathrm{g} / \mathrm{L}$, and this study $(6.8 \mu \mathrm{g} / \mathrm{L})$.

Bentley et al. (1977c) is the only author who has reported provisional acute WQC for NC. Bentley et al. (1977c) was an aquatic study and produced the highest acute WQC $(50,000 \mu \mathrm{g} / \mathrm{L})$ of all MC reported in this study (Table 32). Bentley et al. (1977c) did not report chronic WQC.

Table 32. Provisional Acute and Chronic Values Derived as Water Quality Criteria.

\begin{tabular}{|c|c|c|c|c|c|c|c|}
\hline \multirow{2}{*}{ MC } & \multicolumn{2}{|c|}{$\begin{array}{c}\text { Freshwater WQC } \\
(\mu \mathrm{g} / \mathrm{L})\end{array}$} & \multicolumn{2}{|c|}{$\begin{array}{c}\text { Marine WQC } \\
(\mu \mathrm{g} / \mathrm{L})\end{array}$} & \multicolumn{2}{|c|}{$\begin{array}{c}\text { Combined WQC } \\
(\mu \mathrm{g} / \mathrm{L})\end{array}$} & \multirow{2}{*}{ References } \\
\hline & Acute & Chronic & Acute & Chronic & Acute & Chronic & \\
\hline 2,4,6-TNT & 570 & 90 & -- & -- & -- & -- & Talmage et al. 1999 \\
\hline 2,4,6-TNT & 1,130 & 39.9 & 85.4 & 28.4 & -- & -- & Nipper et al. 2009 \\
\hline 2,4,6-TNT & 230 & 73 & 398 & $32.6^{a}$ & 140 & 61 & This study \\
\hline 2-A-4,6-DNT (II) & 351 & 18.9 & -- & -- & -- & -- & Talmage et al. 1999 \\
\hline 2-A-4,6-DNT (II) & -- & -- & -- & -- & 147 & 34 & This study \\
\hline 4-A-2,6-DNT (II) & 180 & 74 & - & - & -- & -- & This study \\
\hline 1,3,5-TNB (II) & 60 & 11 & -- & - & -- & -- & Talmage et al. 1999 \\
\hline 1,3,5-TNB & -- & -- & -- & -- & 189 & 25 & This study \\
\hline 1,3-DNB (II) & 215 & 17 & -- & - & & & Talmage et al. 1999 \\
\hline 1,3-DNB (II) & 194 & 76 & -- & -- & & & This study \\
\hline 2,4-DNT & -- & - & - & - & 977 & 900 & This study \\
\hline RDX (II) & 1,390 & 186 & -- & - & -- & -- & Talmage et al. 1999 \\
\hline RDX & 351 & NA & -- & -- & 351 & NA & Bentley et al. 1977b \\
\hline RDX & 6,190 & 6,140 & 859 & 853 & 2,720 & 2,700 & ENSR 2005 \\
\hline HMX (II) & 3,750 & 329 & -- & -- & -- & -- & Talmage et al. 1999 \\
\hline HMX & 749 & NA & -- & -- & -- & -- & Bentley et al. 1977a \\
\hline NG & 410 & 7 & -- & - & -- & -- & Sullivan et al. 1979 \\
\hline NG (II) & 188 & 6.8 & -- & - & -- & -- & This study \\
\hline NC & 50,000 & NA & - & - & -- & -- & Bentley et al. 1977c \\
\hline
\end{tabular}

\subsection{Biological Technical Assistant Group (BTAG) screening benchmark}

\subsubsection{Values}

The USEPA Region 3 Biological Technical Assistant Group (BTAG) screening benchmarks values are guidance for the evaluation of sampling data at Superfund sites (BTAG 2006). There are four different BTAG specific subjects that provide consistency in screening level ecological risk assessments through Region 3: (1) freshwater screening benchmarks, (2) 
marine screening benchmarks, (3) freshwater sediment screening benchmarks, and (4) marine sediment screening benchmarks. Benchmark values for all four specific subjects are available at the USEPA website (https://www.epa.gov/risk/biological-technical-assistance-group-btag-screening-values); values for MC are summarized in Table 33.

Table 33. Biological Technical Assistance Group screening benchmark values (BTAG 2006).

\begin{tabular}{|c|c|c|c|c|}
\hline \multirow{2}{*}{ MC } & \multicolumn{2}{|c|}{ Aqueous $(\mu \mathrm{g} / \mathrm{L})$} & \multicolumn{2}{c|}{ Sediment $(\mathrm{mg} / \mathrm{kg})$} \\
\cline { 2 - 5 } & Freshwater & Marine & Freshwater & Marine \\
\hline 2,4,6-TNT & 100 & 100 & 0.092 & NA \\
\hline 2-A-4,6-DNT & 1480 & NA & NA & NA \\
\hline $2,4-D N T$ & 44 & NA & 0.0416 & NA \\
\hline 2,6-DNT & 81 & NA & NA & NA \\
\hline RDX & 360 & NA & 0.013 & NA \\
\hline HMX & 150 & NA & NA & NA \\
\hline NG & 138 & NA & NA & NA \\
\hline
\end{tabular}

\subsubsection{Species sensitivity distributions using aqueous exposure data}

Species sensitivity distributions (SSD) were proposed in the late 1970s to describe the variations in sensitivity of species to environmental stressors (Suter, II 2002). The SSD is a statistical distribution constructed by fitting a cumulative distribution function to a series of species toxicity data against the rank-assigned centile (Wheeler et al. 2002). The cumulative distribution is then visualized where the hazardous concentration (HC) can be calculated, which provide the percentage of species expected to be affected. For example, an $\mathrm{HC}_{5}$ value in an SSD based on chronic toxicity data presents the probability of $5 \%$ of species being affected and has been commonly used to derive the water quality guidelines in ecological risk assessment (Li and You 2015). By plotting MC toxicity values on a statistical distribution such as an SSD, an uncertainty can be calculated for species sensitivities, and there is less confusion with borderline cases where the MC water concentrations fall close to the acute or chronic WQC where assumptions might need to be made (Forbes and Calow 2002). The creation of an SSD for MCs can provide a better estimate of the ecologically relevant effects and could be an improvement for risk assessment (Forbes and Calow 2002). The SSD for MCs could provide a better estimate than the use of only the acute and chronic WQC, as the WQC typically represents only the left most part of an SSD graph; subsequently, WQC are calculated from the most sensitive species. In addition, the SSD approach defines levels of protection in terms of likelihood of certain percentage of species being 
protected (Forbes and Calow 2002). To the authors' knowledge, SSD has not been developed for MC.

There is some debate in the literature on which measured endpoint is the most beneficial for determining the best estimate for the $\mathrm{HC}$ of most sensitive species, i.e., $5 \%$ of the species investigated $\left(\mathrm{HC}_{5}\right)$, which is used as a "safe" concentration for contaminants of concern (Iwasaki et al. 2015). The use of NOEC, the greatest concentration that does not cause a statistically significant adverse effect in a toxicity test, has been seen as potentially problematic. NOEC is problematic because NOEC values can vary depending on experimental design, statistical insignificance with impact of biology, and because the magnitude of effect is not explicitly defined (Isnard et al. 2001; Iwasaki et al. 2015; Moore and Caux 1997). NOEC and LOEC values are problematic as they are not direct observations, direct data, or measurements with an associated standard error or deviation (Landis and Chapman 2011). Effect concentration (EC) values have been proposed as an alternative in the use of ecotoxiological studies in place of NOEC and LOEC, specifically $\mathrm{EC}_{5}$ and $\mathrm{EC}_{10}$ (Van der Hoeven 1997). The major reason that NOEC and LOEC have not been replaced with a different metric for toxicological studies is that there have not been any statements from any regulatory or standardization authority, other than some basic guidance in the use of EC values (Warne and van Dam 2008). Despite those issues NOEC is still the most widely used parameter in the construction of SSD, and a majority of data available for MC is presented as NOEC and LOEC values. Iwasaki et al. (2015) determined that if the effect and no effect endpoints are properly selected, little difference will be seen in the calculated $\mathrm{HC}_{5}$.

For this report, the authors summarized the available toxicity data for MC (Chapter 11) and reported both, effect ( $\mathrm{LC}_{50}$ and $\mathrm{EC}_{50}$ values) and no effect (NOEC values), $\mathrm{HC}_{5}$ that were calculated from SSDs. Not all studies reported an effect $\left(\mathrm{LC}_{50}\right)$ and a no effect (NOEC) value. In some studies (i.e., HMX), NOEC was the highest concentration tested, so no effect data is the only data available. An SSD was generated for every possible effect and no effect MC. When a species in the effect SSD was not represented in the no effect SSD in an NOEC, but an LOEC was available, the LOEC was divided by two and used in place of an NOEC. There was not much instruction on how many species were required for an SSD to be created. In this study, a minimum of six different species were required before the construction of the SSD. Table 33 summarizes data collected for each MC 
that contained enough data for either the effect or no effect to create an $\mathrm{SSD}$. Then, the SSD was used to calculate the $\mathrm{HC}_{5}$ with the upper and lower confidence level values for $\mathrm{HC}_{5}$. SSD models were constructed for MC using the USEPA modeling spreadsheet, which is freely available on the USEPA website (https://www3.epa.gov/caddis/da ssoftware_ssdmacro.html). The SSD curves used to generate the $\mathrm{HC}_{5}$ reported in Table 34 are shown in Figure 71 - Figure 90.

Table 34. Hazardous concentrations of munitions constituents.

\begin{tabular}{|c|c|c|c|c|}
\hline $\mathrm{MC}$ & $\mathrm{HC}_{5}(\mu \mathrm{g} / \mathrm{L})$ & $\mathrm{LCL}(\mu \mathrm{g} / \mathrm{L})$ & UCL ( $\mu \mathrm{g} / \mathrm{L})$ & Endpoint used \\
\hline 2,4,6-TNT & 116 & 27 & 488 & Effects \\
\hline 2-A-4,6-DNT & 1,239 & 496 & 3,094 & Effects \\
\hline 4-A-2,6-DNT & 1,983 & 1,167 & 3,371 & Effects \\
\hline 1,3,5-TNB & 114 & 35 & 373 & Effects \\
\hline 1,3-DNB & 274 & 118 & 636 & Effects \\
\hline 2,4-DNT & 615 & 245 & 1,540 & Effects \\
\hline 2,6-DNT & 710 & 189 & 2,661 & Effects \\
\hline RDX & 2,074 & 1,511 & 2,846 & Effects \\
\hline $\mathrm{HMX}$ & NS & NS & NS & Effects \\
\hline Picric Acid & 24,460 & 15,342 & 38,996 & Effects \\
\hline Tetryl & NS & NS & NS & Effects \\
\hline$N G$ & 88 & 41 & 187 & Effects \\
\hline $\mathrm{NQ}$ & NS & NS & NS & Effects \\
\hline 2,4,6-TNT & 34 & 6 & 188 & No effects \\
\hline 2-A-4,6-DNT & NS & NS & NS & No effects \\
\hline 4-A-2,6-DNT & NS & NS & NS & No effects \\
\hline 1,3,5-TNB & 27 & 9 & 83 & No effects \\
\hline 1,3-DNB & 39 & 6 & 263 & No effects \\
\hline 2,4-DNT & 43 & 13 & 150 & No effects \\
\hline 2,6-DNT & 107 & 42 & 273 & No effects \\
\hline RDX & 4,560 & 2,681 & 7,755 & No effects \\
\hline $\mathrm{HMX}$ & 2,097 & 1,745 & 2,521 & No effects \\
\hline Picric Acid & 3,612 & 626 & 20,838 & No effects \\
\hline Tetryl & NS & NS & NS & No effects \\
\hline NG & 15 & 5 & 47 & No effects \\
\hline NQ & 7,827 & 43 & $1,409,117$ & No effects \\
\hline
\end{tabular}

HC5: Hazardous concentration for $5 \%$ of species

LCL: Lower confidence level

UCL: Upper confidence level

NS: Fewer than six species. No calculation 
Figure 71. Species sensitivity distribution for 2,4,6-TNT using effects data. The outer lines represent $95 \%$ confidence intervals.

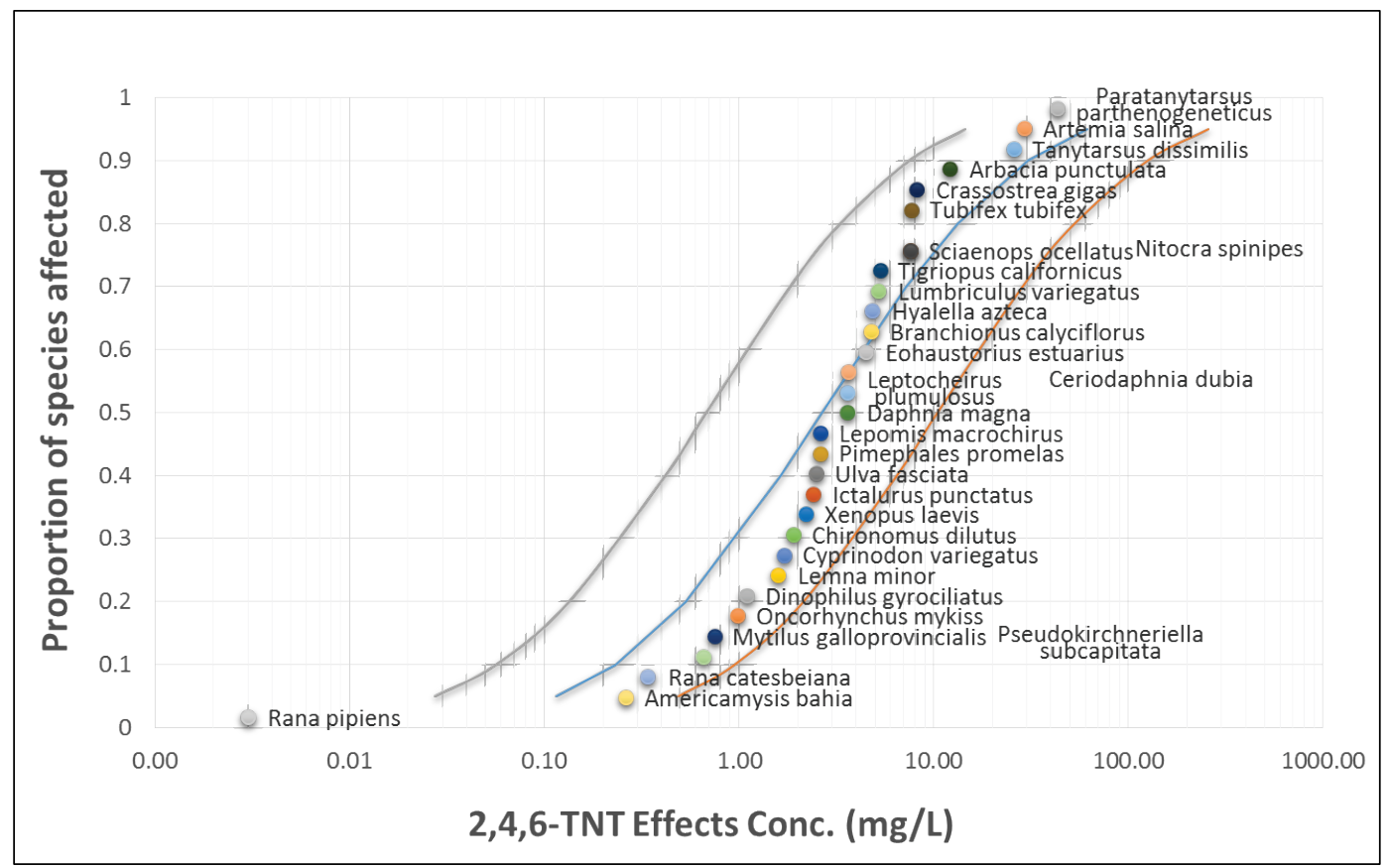

Figure 72. Species sensitivity distribution for 2-A-2,4-DNT using effects data. The outer lines represent 95\% confidence intervals.

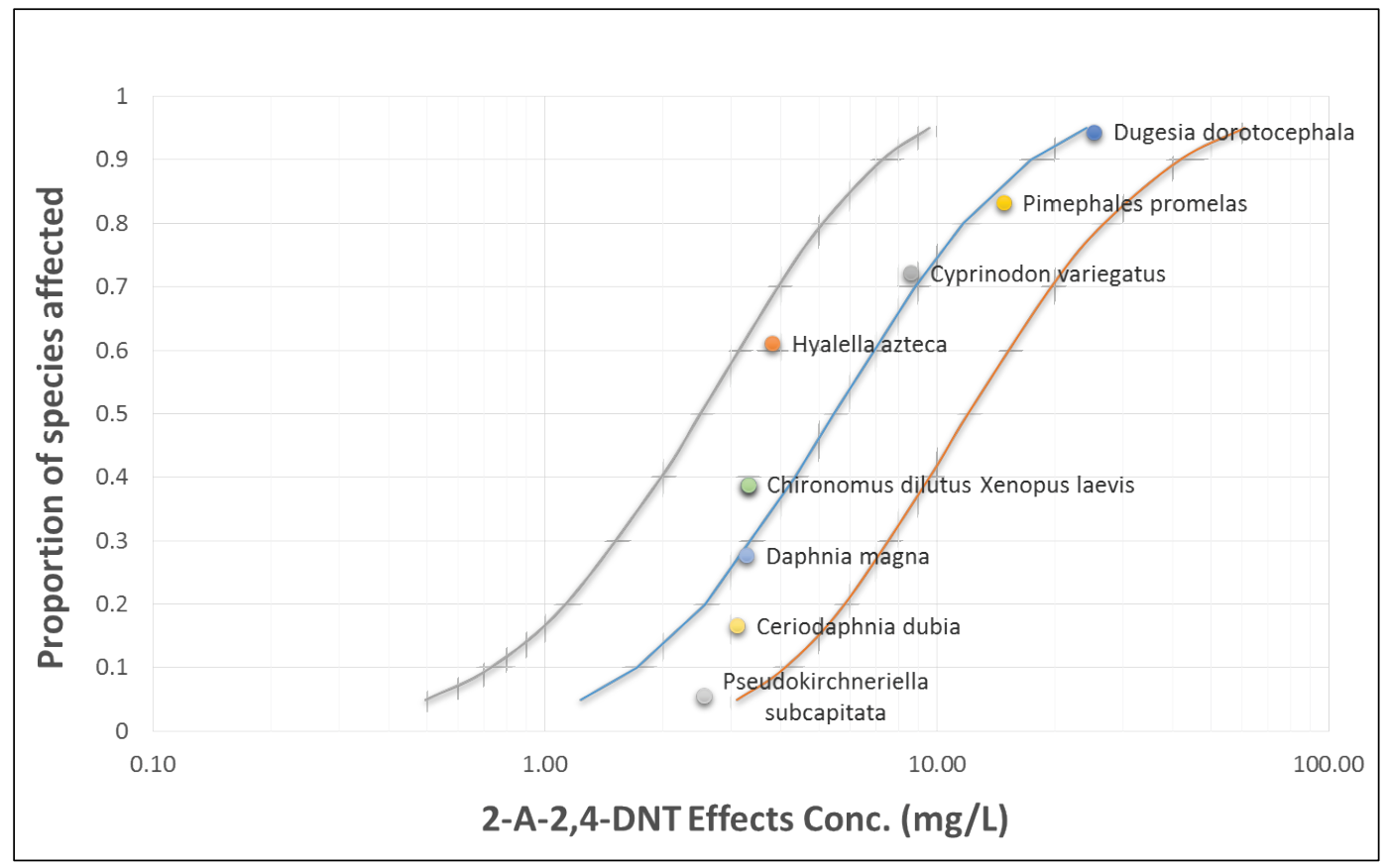


Figure 73. Species sensitivity distribution for 4-A-2,5-DNT using effects data. The outer lines represent $95 \%$ confidence intervals.

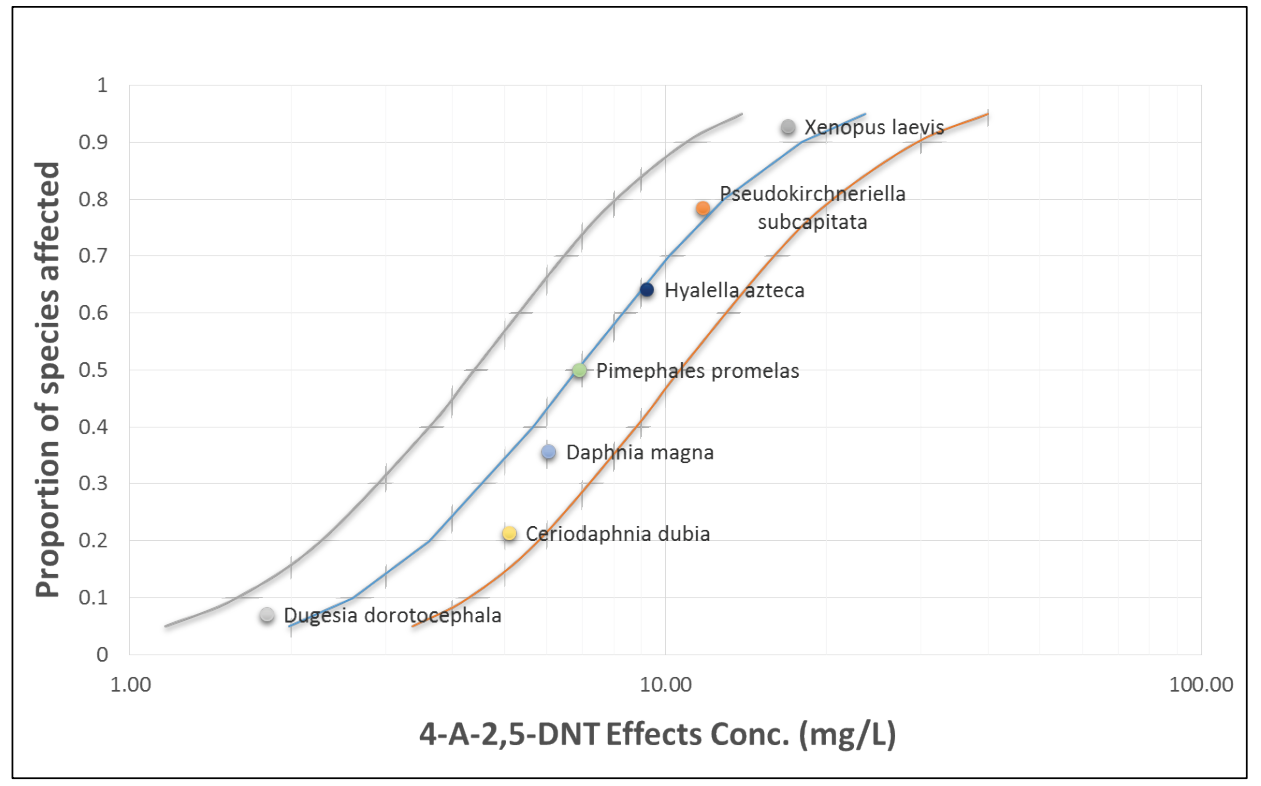

Figure 74. Species sensitivity distribution for 1,3,5 TNB using effects data. The outer lines represent $95 \%$ confidence intervals.

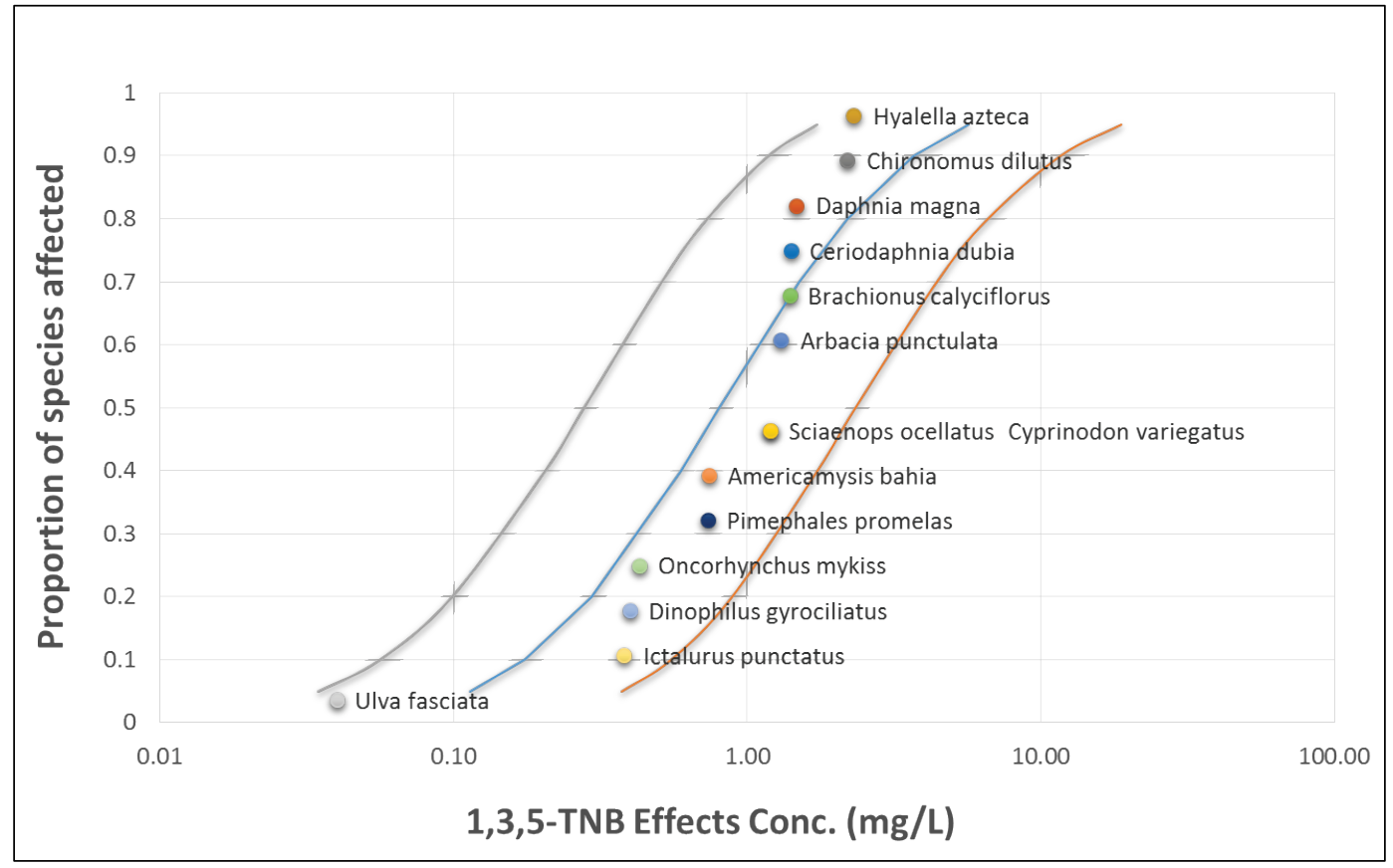


Figure 75. Species sensitivity distribution for 1,3 DNB using effects data. The outer lines represent $95 \%$ confidence intervals.

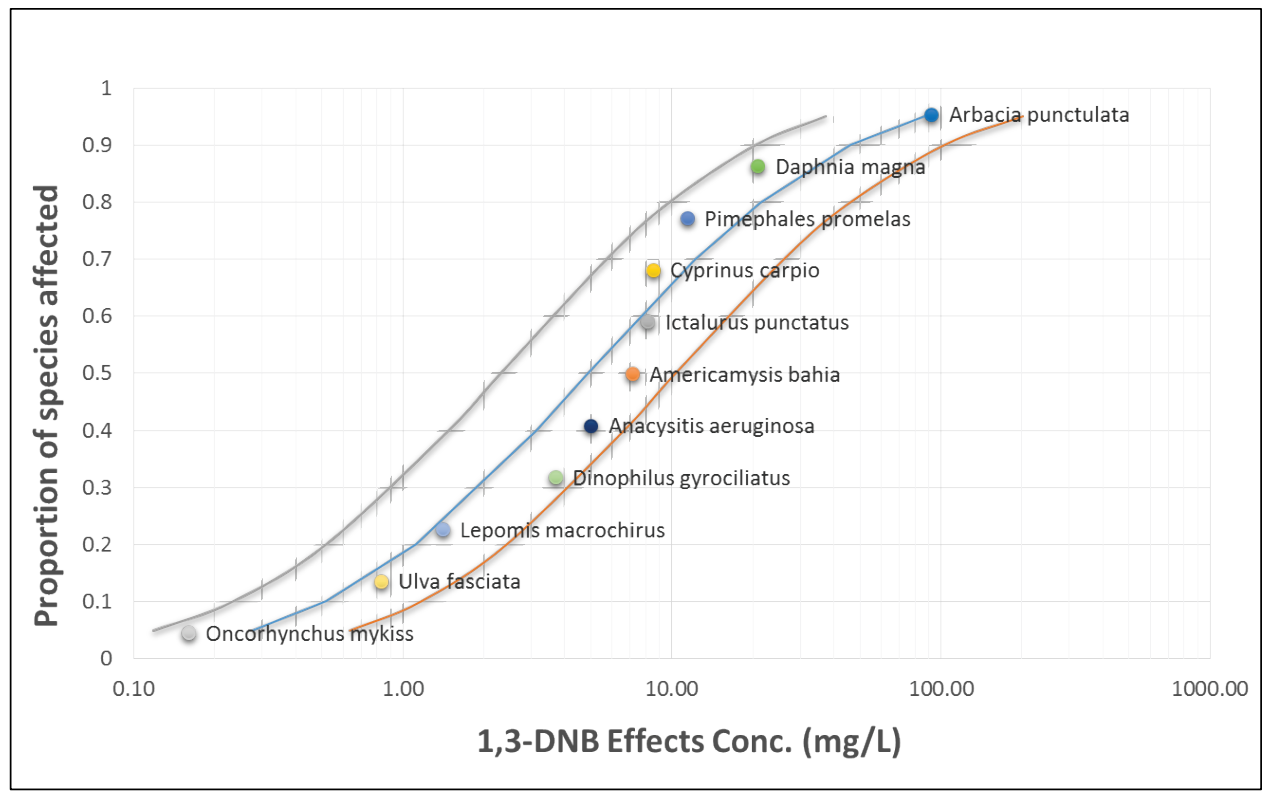

Figure 76. Species sensitivity distribution for 2,4 DNT using effects data. The outer lines represent $95 \%$ confidence intervals.

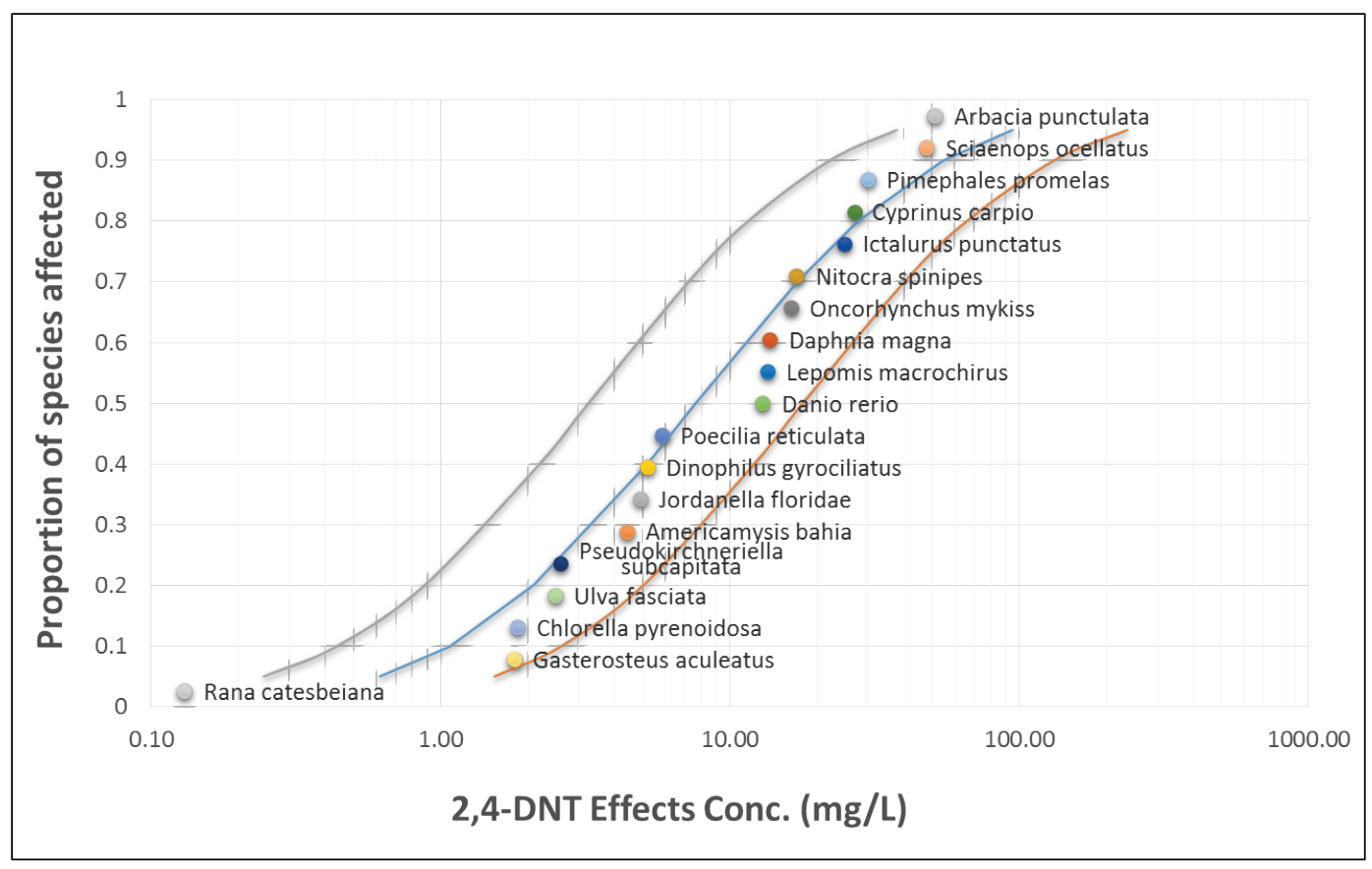


Figure 77. Species sensitivity distribution for 2,6 DNT using effects data. The outer lines represent $95 \%$ confidence intervals.

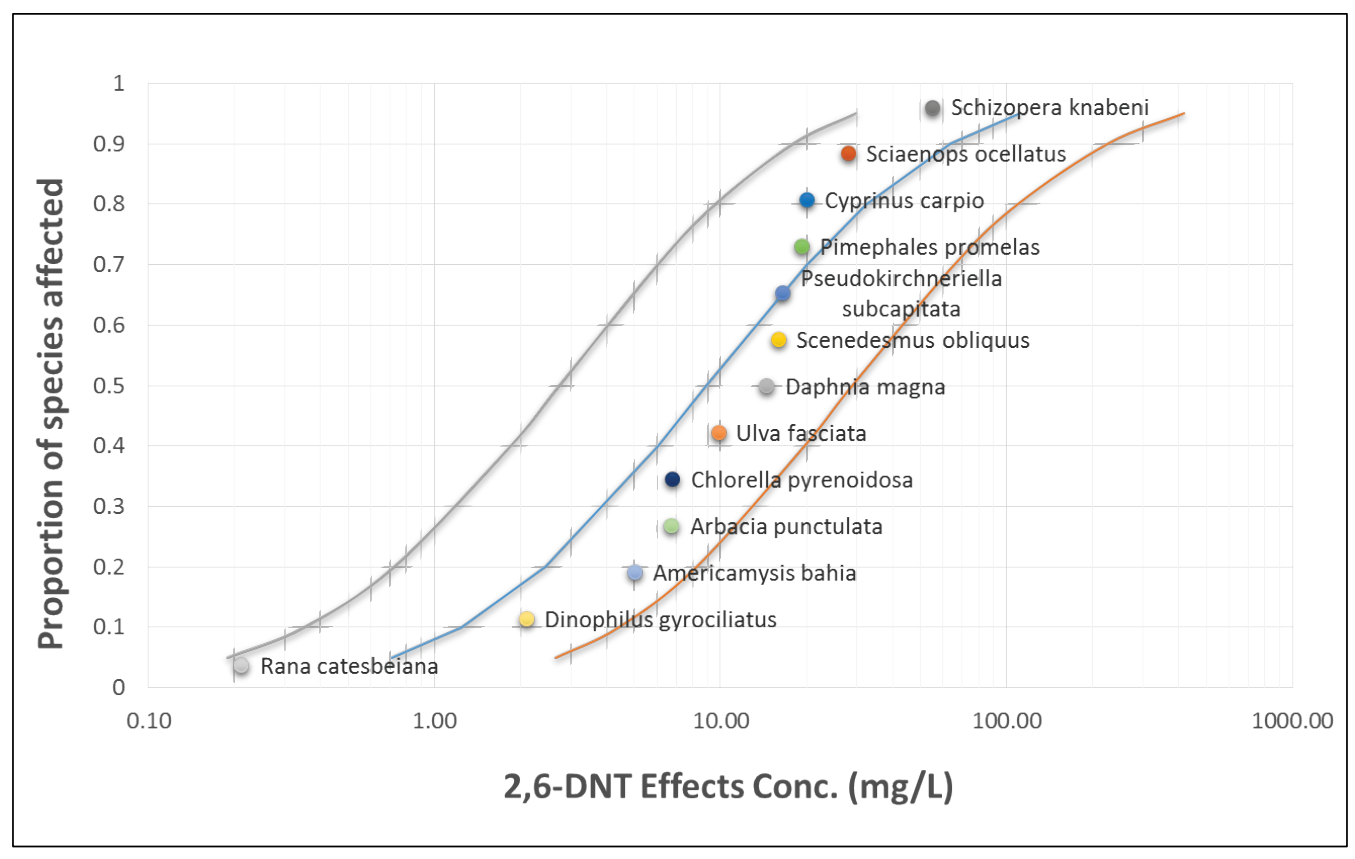

Figure 78. Species sensitivity distribution for RDX using effects data. The outer lines represent $95 \%$ confidence intervals.

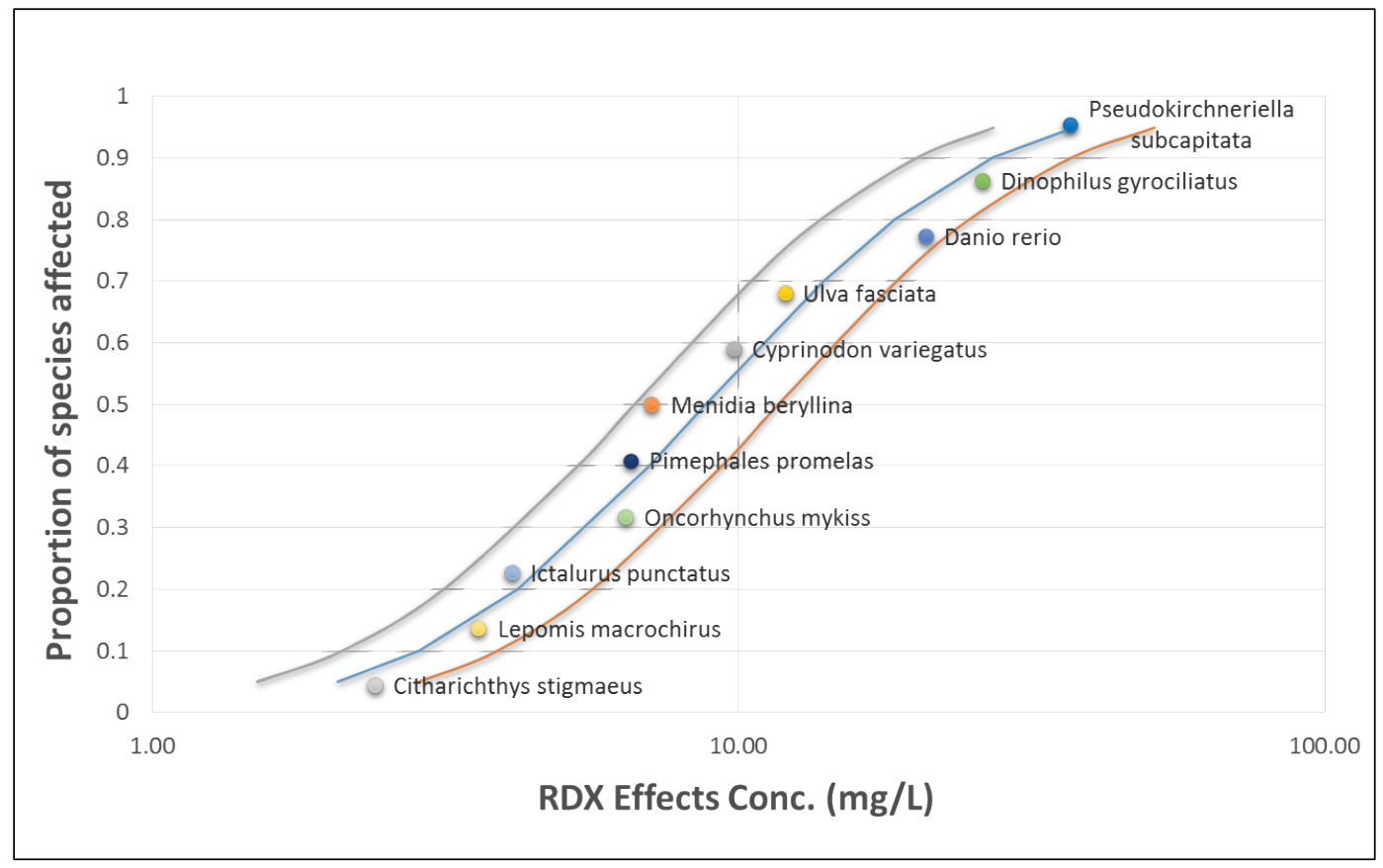


Figure 79. Species sensitivity distribution for Picric Acid using effects data. The outer lines represent $95 \%$ confidence intervals.

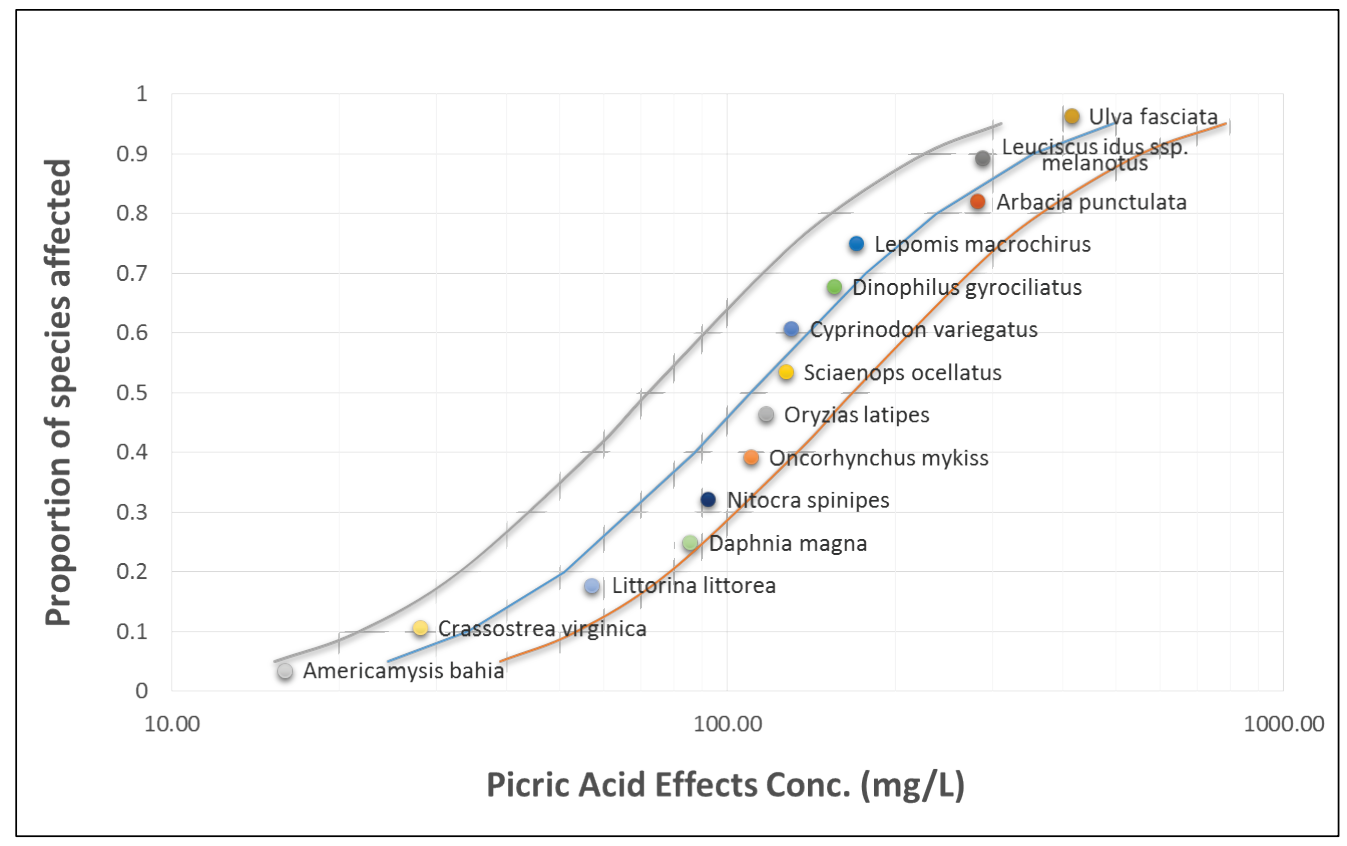

Figure 80. Species sensitivity distribution for NG using effects data. The outer lines represent $95 \%$ confidence intervals.

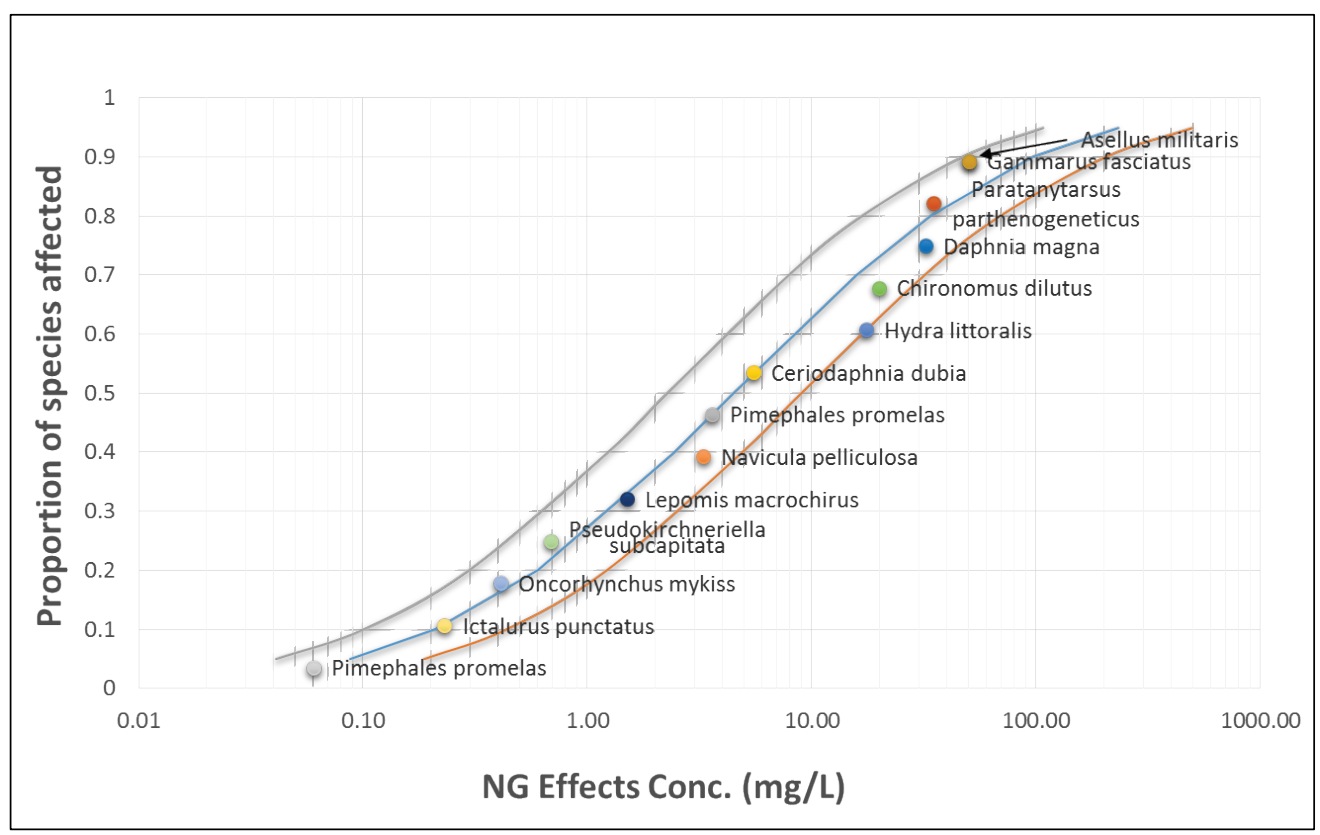


Figure 81. Species sensitivity distribution for 2,4,6-TNT using no-effects data. The outer lines represent $95 \%$ confidence intervals.

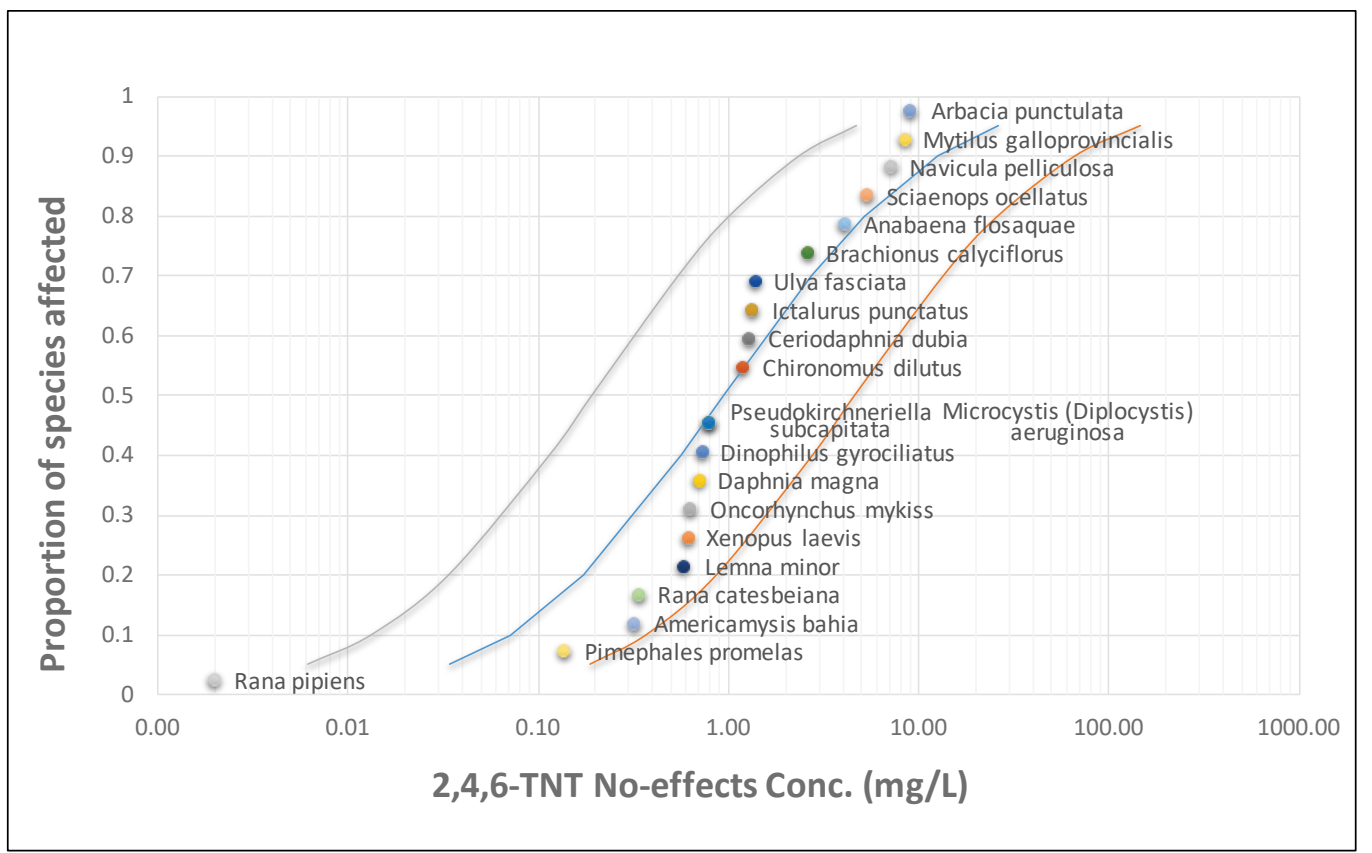

Figure 82. Species sensitivity distribution for 1,3,5-TNB using no-effects data. The outer lines represent $95 \%$ confidence intervals.

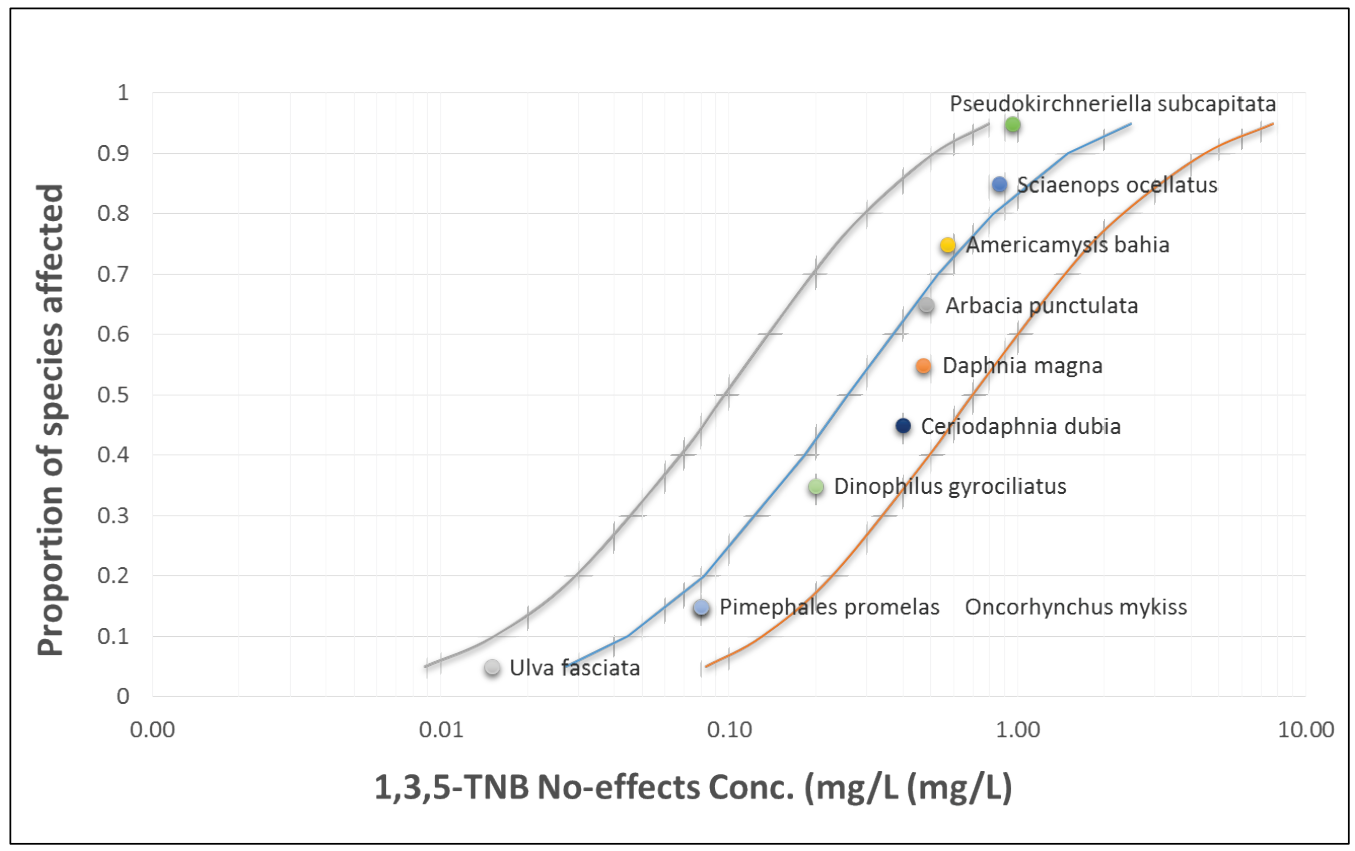


Figure 83. Species sensitivity distribution for 1,3-DNB using no-effects data. The outer lines represent $95 \%$ confidence intervals.

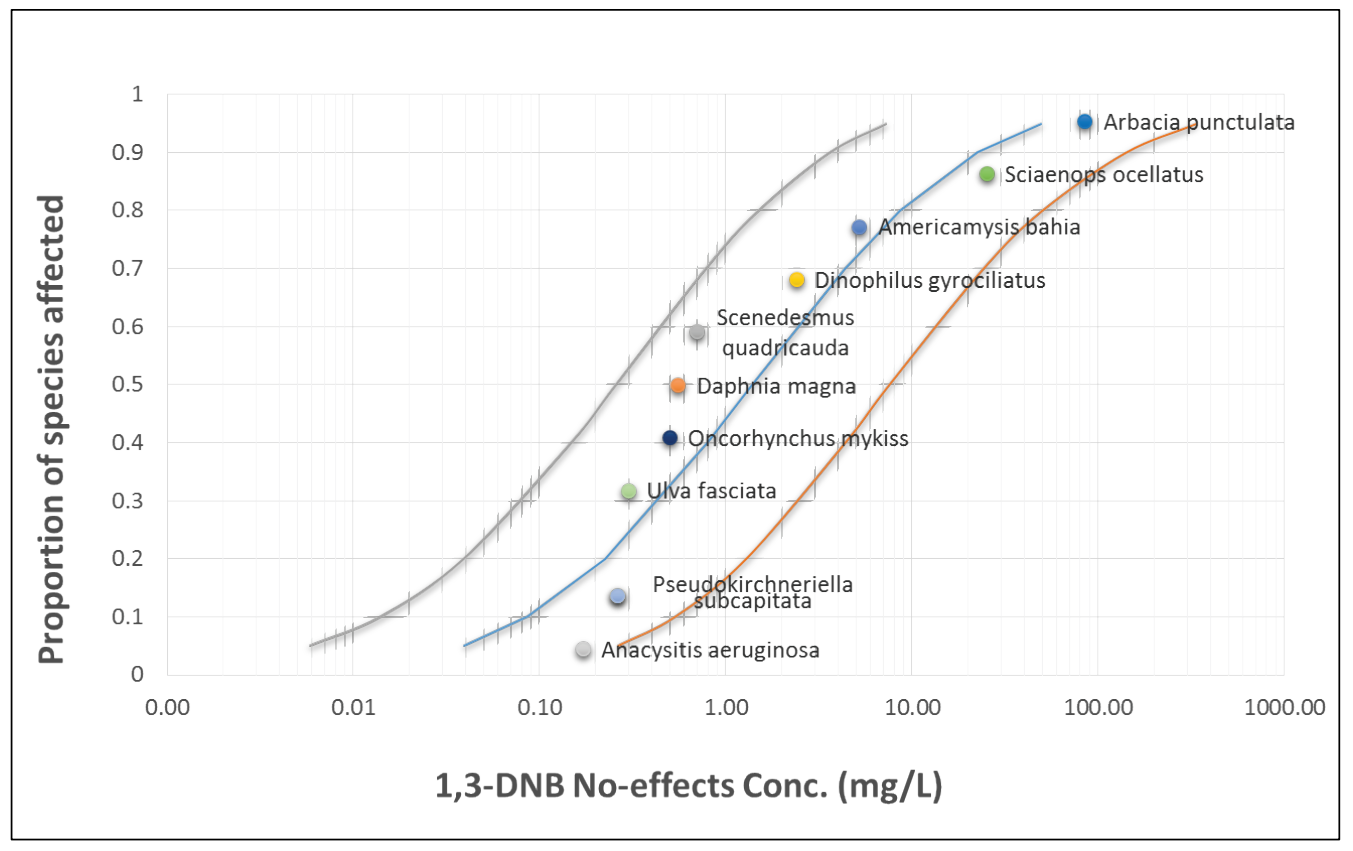

Figure 84. Species sensitivity distribution for 2,4-DNT using no-effects data. The outer lines represent $95 \%$ confidence intervals.

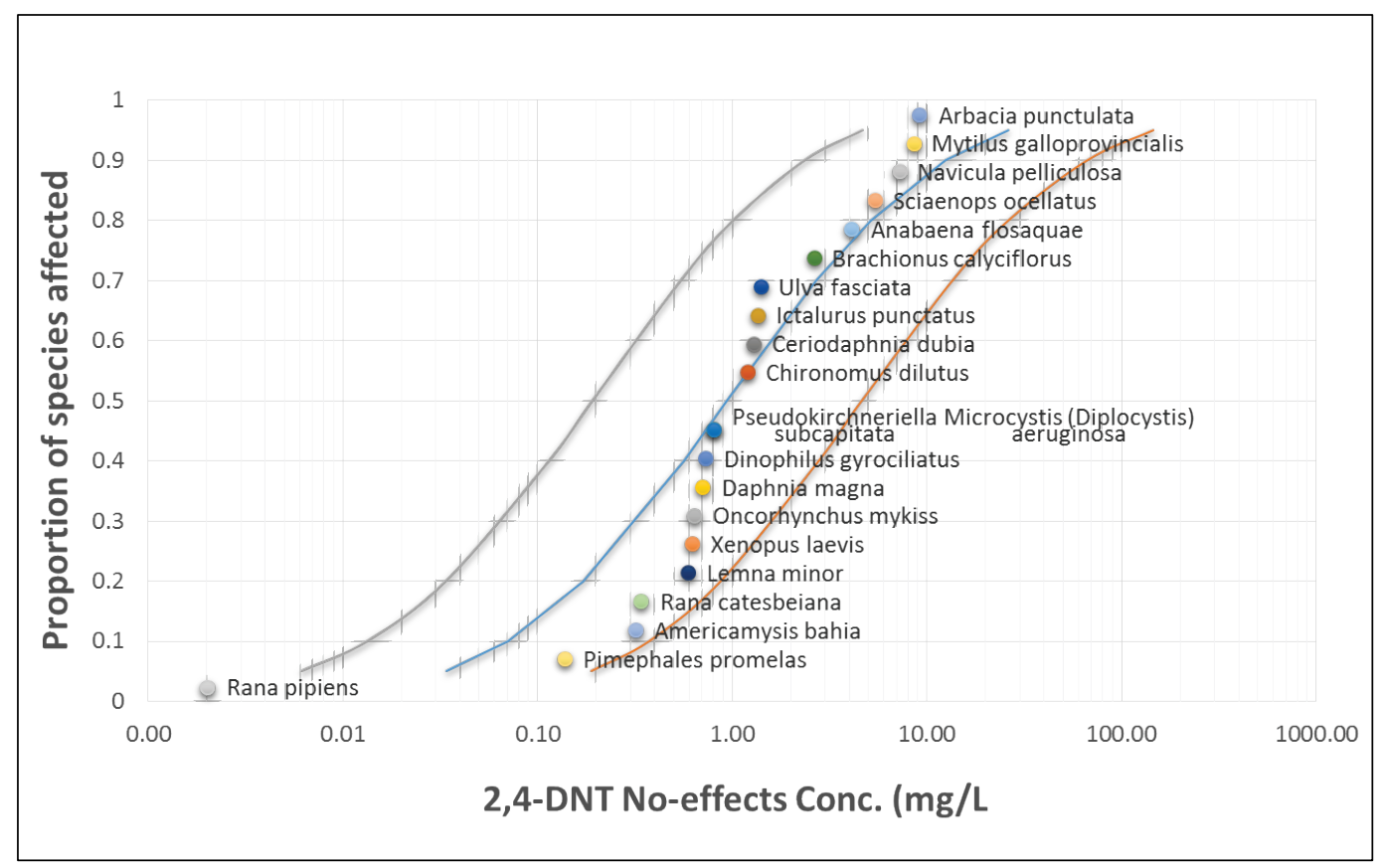


Figure 85. Species sensitivity distribution for 2,6-DNT using no-effects data. The outer lines represent $95 \%$ confidence intervals.

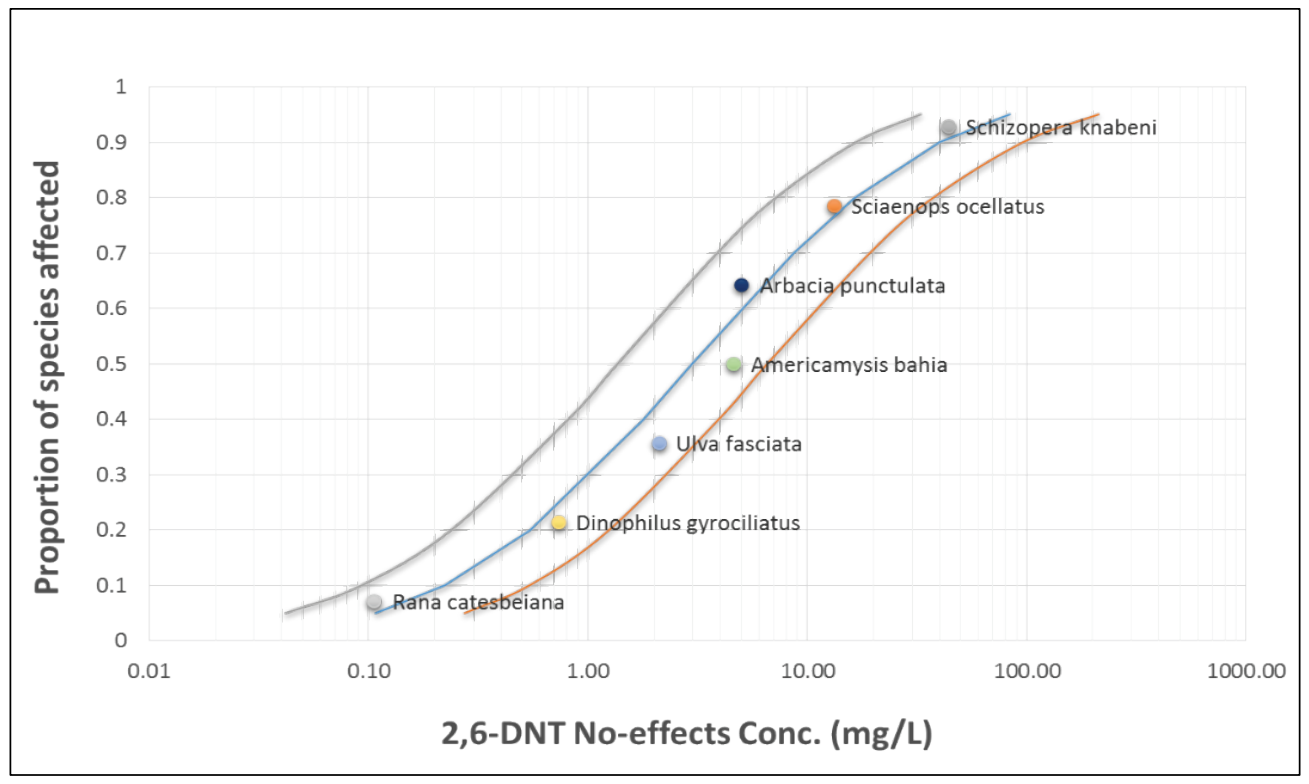

Figure 86. Species sensitivity distribution for RDX using no-effects data. The outer lines represent $95 \%$ confidence intervals.

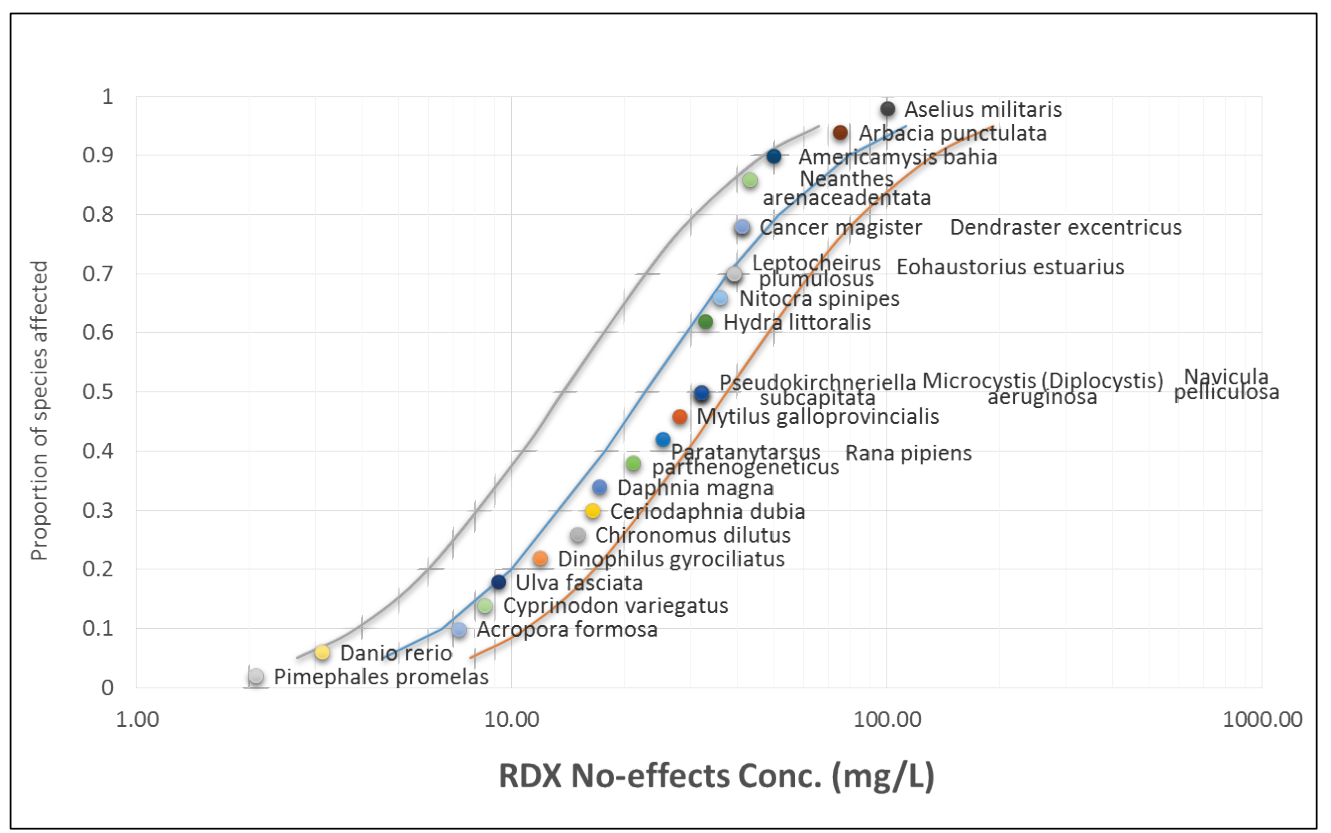


Figure 87. Species sensitivity distribution for HMX using no-effects data. The outer lines represent $95 \%$ confidence intervals.

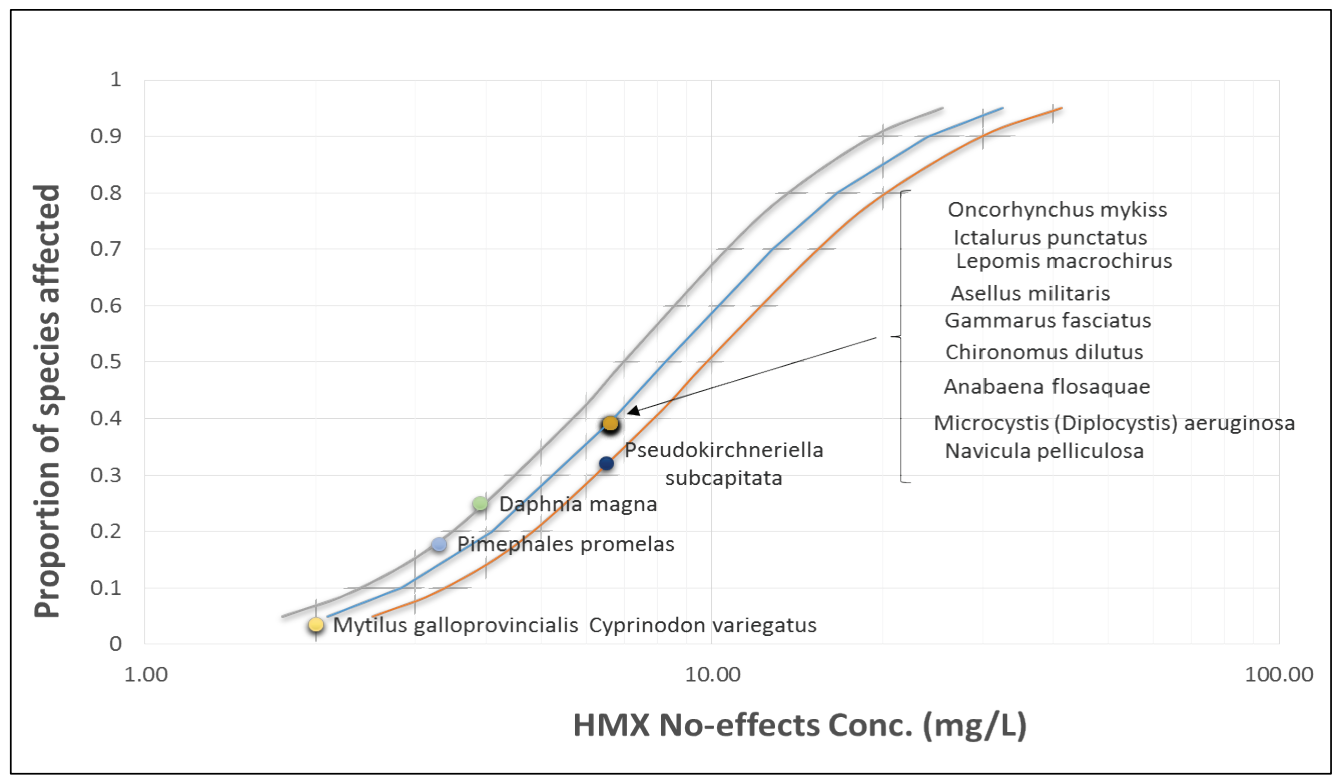

Figure 88. Species sensitivity distribution for Picric Acid using no-effects data. The outer lines represent $95 \%$ confidence intervals.

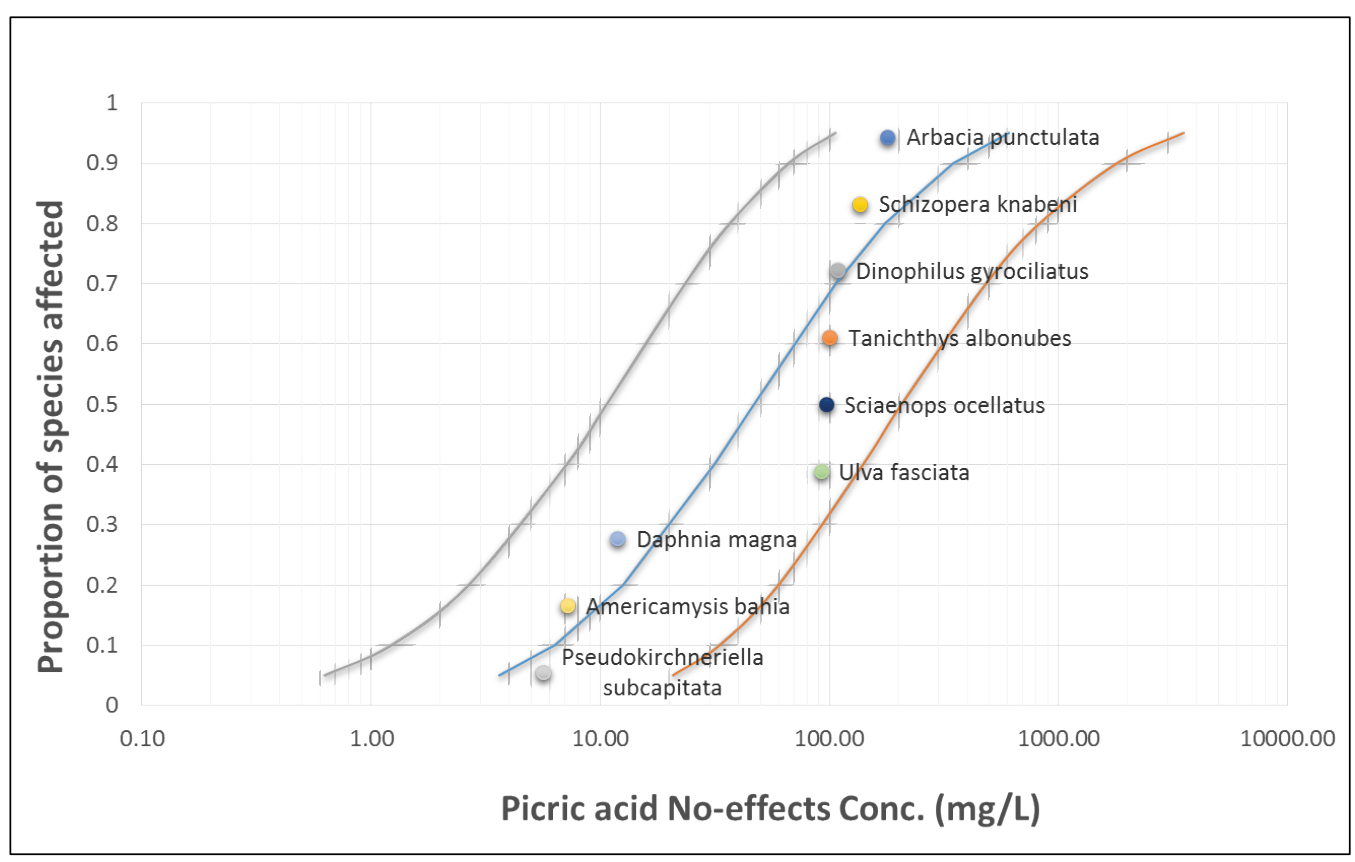


Figure 89. Species sensitivity distribution for NG using no-effects data. The outer lines represent $95 \%$ confidence intervals.

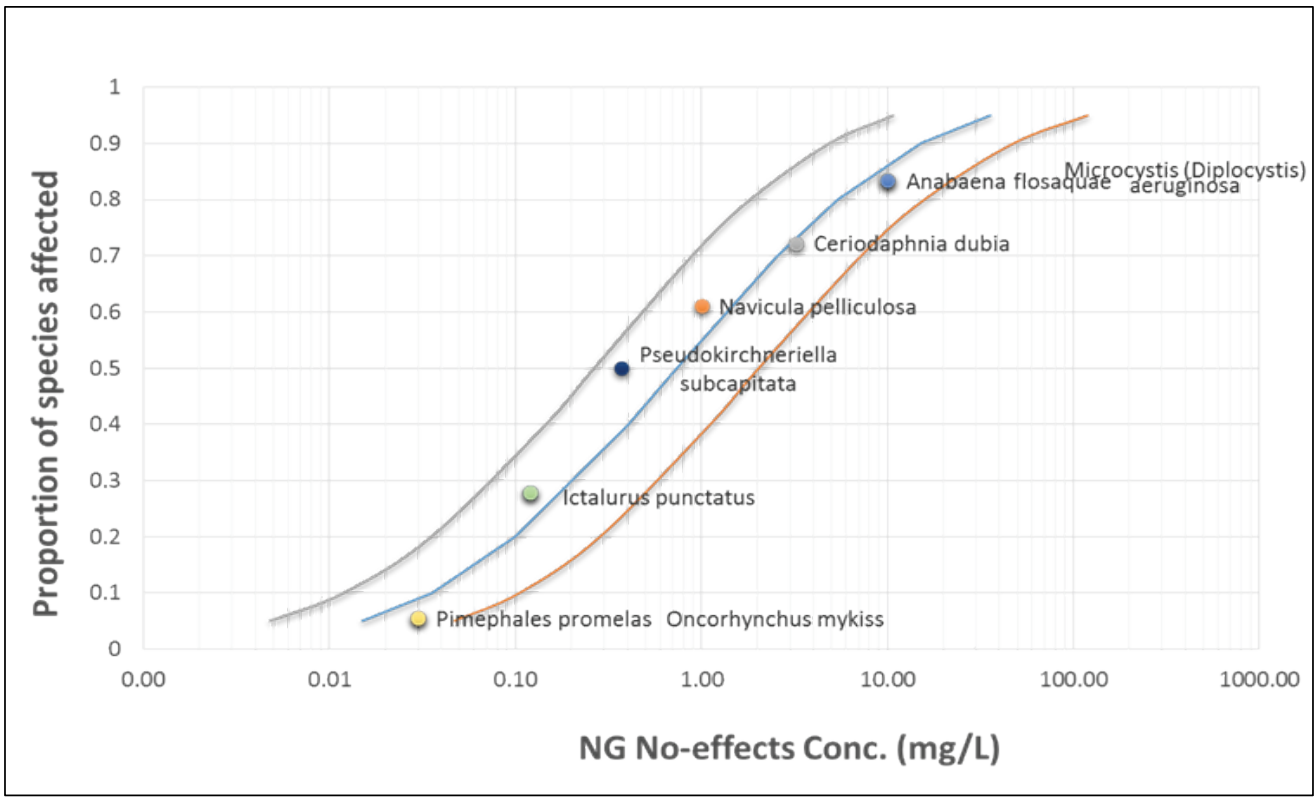

Figure 90. Species sensitivity distribution for NQ using no-effects data. The outer lines represent $95 \%$ confidence intervals.

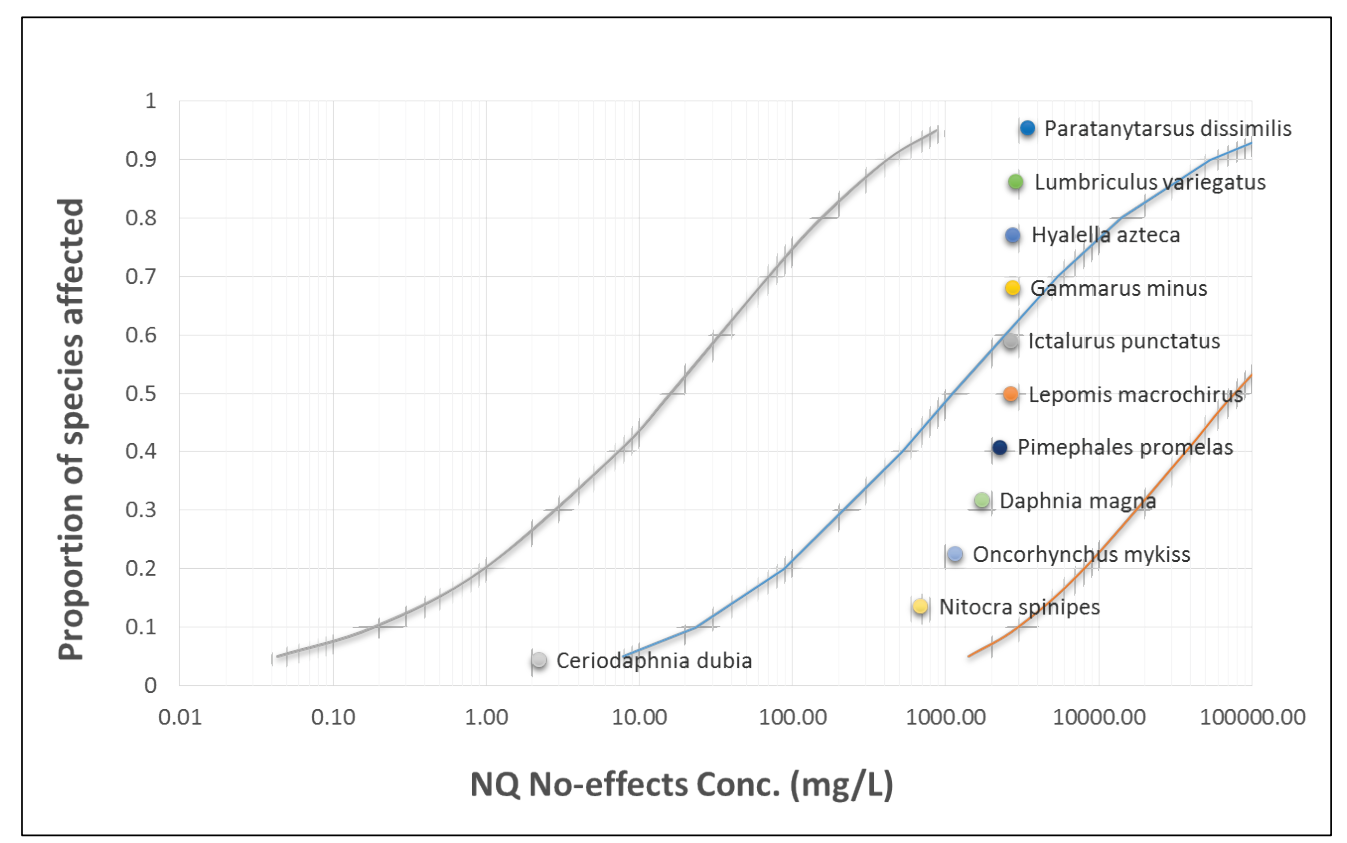

When comparing the effect and no effect $\mathrm{HC}_{5}$ values calculated from the SSDs, no effect values were, on average, one-sixth $(17 \% \pm 6.7$ standard deviation) the effect values, except for RDX. For RDX, the no effect $\mathrm{HC}_{5}$ was two times larger than the effect $\mathrm{RDX}$ that used $\mathrm{LC}_{50}$ and $\mathrm{EC}_{50}$ values for the SSD. The reason that the effect $\mathrm{HC}_{5}$ for $\mathrm{RDX}$ was lower than the no 
effect $\mathrm{HC}_{5}$ was due to the under representation of data points for the effect $\mathrm{HC}_{5}$. The effect $\mathrm{HC}_{5}$ had 2.4 times fewer data points as many of the species that were used for the no effect SSD did not have an acute effect value reported. Some of the NOEC values reported were close to or over the solubility of RDX in water (Bentley et al. 1977b; Dave et al. 2000; ENSR 2005; Nipper et al. 2001). With a NOEC reported at solubility, only $24 \%$ of the species used for the no effect SSD and $\mathrm{HC}_{5}$ were represented in the effect SSD and $\mathrm{HC}_{5}$.

\subsection{Preliminary sediment screening criteria for the protection of benthic invertebrates}

As an initial screening step in ecological risk assessment, detected concentrations of contaminants in sediment would typically be compared with risk-based sediment screening criteria to assess the potential for risk to benthic invertebrates. Sediment screening criteria for many MC are not available in sources typically used in regulatory-driven ecological risk assessments for contaminated sediment sites. Preliminary sediment quality benchmarks (SQBs) for protection of benthic invertebrates were developed for $\mathrm{MC}$ for use in a baseline ecological risk assessment at the JPHC Superfund Site, Bremerton, Washington, USA (see site summary in Chapter 5) (Pascoe et al. 2010).

Available sediment spiking experiments at the time were not used in the development of screening criteria for $\mathrm{MC}$ because of uncertainties associated with experimental design and interpretation of results. Instead, those SQBs were developed using freshwater, limited marine water-only toxicity values, and equilibrium partitioning to relate select aquatic toxicity values for MC that was expressed as concentrations in water to estimated concentrations in sediment (Burgess et al. 2013). Toxicity values were selected out of available chronic water screening benchmarks (e.g., final or secondary chronic values and/or NOECs from water toxicity tests. Using the equilibrium partitioning (EqP) procedure (Di Toro et al. 1991), the SQB values expressed on an organic carbon normalized basis were calculated using the selected water toxicity benchmark and the theoretical partitioning between water and sediment. Pascoe et al. (2010) presented SQBs for 25 MCs as organic carbon normalized values. Organic carbon partitioning coefficients were calculated using the lowest and highest $\log K_{\text {ow }}$ available in the literature and were used to calculate corresponding SQBlow and SQBhigh values. $\mathrm{SQB}$ low and $\mathrm{SQB}$ high values were also presented as dry weight values for various levels of organic carbon content of sediments. 
Pascoe et al. (2010) used the mechanistic approach, which is intended for use with compounds with $\log \mathrm{K}_{\mathrm{ow}}>2.0$ and sediment organic cargo content of $\geq 0.2 \%$ (Burgess et al. 2013). Partitioning behavior of MC with $\log \mathrm{K}_{\text {ow }}<2$ or not much higher than 2 (most MC [Table 2]) may deviate from this model according to Fuchsman (2003), who demonstrated that equilibrium partitioning may inaccurately predict the bioavailable concentration of organic compounds with $\log \mathrm{K}_{\mathrm{ow}}<3$. The equilibrium partitioning model assumption of negligible amounts of chemical in the dissolved phase may not hold truth for chemicals with low $\mathrm{K}_{\text {ow. }} \mathrm{A}$ substantial fraction of these chemicals may be in the dissolved phase, while the Pascoe et al. (2010) derived SQBs are unnecessarily low. Based on Fuchsman (2003), USEPA (2008) provided a modification to the equilibrium partitioning model for use with low $\mathrm{K}_{\text {ow }}$ organic compounds. Pascoe et al. (2010) provided a few examples of comparing his SQBs, which were derived by using Di Toro et al. (1991) with sample-specific revised SQBs which were derived by using Fuchsman (2003)'s modified model. For 2,4-DANT, the revised SQB ranged from 0.7 to $3.9 \mathrm{mg} / \mathrm{kgoc}$, which are higher than his SQB low of $0.09 \mathrm{mg} / \mathrm{kgoc}$. For 1,3-DNB, the revised SQB ranged from 1.1 to $3.9 \mathrm{mg} / \mathrm{kg}$ oc, compared with the $\mathrm{SQB}$ low of $0.5 \mathrm{mg} / \mathrm{kg}$ oc. For TNB, the revised SQB ranged from 0.5 to $2.4 \mathrm{mg} / \mathrm{kg}$ oc, compared with his SQB $\mathrm{B}_{\text {low }}$ of $0.16 \mathrm{mg} / \mathrm{kg}$ oc. Moreover, for HMX, the revised SQB ranged from 11.3 to $66.5 \mathrm{mg} / \mathrm{kg}$ oc, compared with his $\mathrm{SQB}$ low of $0.38 \mathrm{mg} / \mathrm{kgoc}$. Because of the demonstrated conservatism associated with the SQBs for MCs provided in Pascoe et al. (2010), revised SQBs were derived for this project using the modification to the equilibrium partitioning model used with low $\mathrm{K}_{\text {ow }}$ organic compounds (USEPA 2008). Although the toxicity values and the Koc values by Pascoe et al. (2010) selected for deriving SQBs should be revised to reflect new data, revised SQB values in Table 35 were calculated using the same toxicity and $K_{o c}$ values as used in Pascoe et al. (2010) because of the complexity associated with selecting new values for all MCs. Revised SQBs, SQBlow, and SQB ${ }_{\text {high }}$ presented in Table 35 as dry weight values were calculated using a fraction of solids at $70 \%$ and fraction of OC at $1 \%$. The use of lower OC fraction values would have resulted in lower SQB values, indicating that values in Table 35 may be overprotective for low OC sediment. The use of lower solids content would have also resulted in lower SQB values, indicating that values in Table 35 may be overprotective for sediments with high moisture content. Values in Table 35 were only slightly higher than those Pascoe et al. (2010) presented for MC with high Kow, such as 2,4- and 2,6DNT; however, values were substantially higher for $\mathrm{MC}$ with low Kow, such as RDX (8x higher) and HMX (38x higher). 
Table 35. Sediment quality benchmarks (SQB) for MC.

\begin{tabular}{|c|c|c|c|c|c|c|c|}
\hline & \multirow{2}{*}{$\begin{array}{l}\text { Selected toxicity } \\
\text { value (Pascoe et } \\
\text { al. 2010) } \\
\mu \mathrm{g} / \mathrm{L}\end{array}$} & \multicolumn{2}{|c|}{$\begin{array}{c}\text { Selected Koc (Pascoe et } \\
\text { al. 2010) }\end{array}$} & \multicolumn{2}{|c|}{$\begin{array}{c}\text { SQB at } 1 \% \text { OC (Pascoe } \\
\text { et al. 2010) }\end{array}$} & \multicolumn{2}{|c|}{$\begin{array}{c}\text { Revised SQB (1\% OC } \\
\text { and } 70 \% \text { solids) }\end{array}$} \\
\hline & & low & high & low & high & Iow & high \\
\hline & & & & \multicolumn{2}{|c|}{$\mathrm{mg} / \mathrm{kg}$} & \multicolumn{2}{|c|}{$\mathrm{mg} / \mathrm{kg}$} \\
\hline TNT & 28.4 & 37.4 & 451 & 0.011 & 0.128 & 0.023 & 0.140 \\
\hline 2-A-4.6-DNT & 19 & 65.9 & 81 & 0.013 & 0.015 & 0.021 & 0.024 \\
\hline 4-A-2.6-DNT & 30 & 116 & no data & 0.036 & - & 0.048 & - \\
\hline 2,4-DA-6-NT & 19 & 4.88 & no data & 0.0009 & - & 0.009 & - \\
\hline 2,6-DA-4-NT & 19 & 4.88 & no data & 0.0009 & - & 0.009 & - \\
\hline 2,4-DNT & 2400 & 88.4 & 300 & 2.1 & 7.2 & 3.2 & 8.2 \\
\hline 2,6-DNT & 1800 & 116 & 150 & 2.1 & 2.7 & 2.9 & 3.5 \\
\hline 2-NT & 3400 & 182 & no data & 6.2 & - & 7.6 & - \\
\hline 3-NT & 750 & 256 & no data & 1.9 & -- & 2.2 & - \\
\hline 4-NT & 320 & 214 & no data & 0.68 & - & 0.82 & - \\
\hline 1,3-DNB & 17 & 29.2 & 210 & 0.005 & 0.036 & 0.012 & 0.043 \\
\hline 1,3,5-TNB & 11 & 14.5 & 77 & 0.0016 & 0.0086 & 0.0063 & 0.0132 \\
\hline 3,5-DNA & 59 & 72.1 & no data & 0.0426 & & 0.0678 & - \\
\hline NB & 2700 & 65.9 & 131 & 1.8 & 3.5 & 2.9 & 4.7 \\
\hline Picric acid & 9200 & 37.4 & no data & 3.4 & - & 7.4 & - \\
\hline Picramic acid & 6980 & 8.21 & no data & 0.57 & - & 3.6 & - \\
\hline 2,4-DNP & 62 & 22.2 & 53 & 0.014 & 0.034 & 0.040 & - \\
\hline Tetryl & 15 & 41.9 & 406 & 0.006 & 0.061 & 0.013 & 0.089 \\
\hline HMX & 330 & 1.15 & 130 & 0.0038 & 0.43 & 0.1452 & 0.6 \\
\hline RDX & 186 & 6.26 & 42 & 0.012 & 0.078 & 0.091 & 0.2 \\
\hline NG & 3230 & 39.2 & 180 & 1.266 & 5.814 & 2.65 & 7.20 \\
\hline NQ & 260000 & 0.13 & 25 & 0.348 & 65 & 112 & 176 \\
\hline PETN & 850000 & 38.3 & 179 & 325 & 1522 & 690 & 1886 \\
\hline
\end{tabular}




\section{Screening-level Generic Risk Assessment of MC at UWMM sites}

The objective of this chapter is to evaluate whether $\mathrm{MC}$ has been released to the biologically accessible environment at UWMM sites at levels that could adversely affect fish and invertebrates inhabiting the impacted area. Evaluations were conducted using a screening-level risk assessment (SLRA) approach in accordance with guidelines set forth in the Tri-Service Ecological Risk Assessment Working Group (TSERAWG)-A Guide to Screening Level Ecological Risk Assessment (TSERAWG 2008). SLRAs are performed to identify contaminants that may pose unacceptable risks and those that can be conservatively ruled out as posing a concern. Exposure estimates were based on site-specific data (i.e., concentrations summarized in Chapters 5-7) while effects characterization were based on effects benchmarks discussed in Chapter 12. For the risk calculation, the hazard quotient (HQ) approach, which compares exposure values with toxicity benchmarks (i.e., a selected ecological screening level [ESL], is derived using Equation 19:

$$
\mathrm{HQ}=\text { Exposure value } / \mathrm{ESL}
$$

Where the exposure value is a concentration (e.g., $\mu \mathrm{g} \mathrm{MC} / \mathrm{L}$ water) and the ESL is a concentration representing the threshold of a safe exposure. Thus, for each MC and environmental medium, the HQ is expressed as the ratio of a potential exposure level to the applicable toxicity-based benchmark. Decision rules are applied to the results for interpretation of potential risks. For HQ values exceeding unity (1.0) the potential for adverse effects to the receptors of concern is concluded to be possible. In contrast, if the resulting HQ is equal to or less than unity, the potential for risks due to that chemical can be considered negligible, and therefore may be dropped from further consideration of risk for that exposure pathway. The logic is supported through the consistent application of conservative assumptions, biasing towards overestimating potential risks. Because of the high level of conservatism in an SLRA, the fact that a contaminant "fails the screening" (i.e., HQ >1) following an SLRA does not necessarily indicate a real risk. Conversely, an HQ $<1$ leading to contaminant being "screened out" of further concerns should convincingly indicate lack of risk (Hill et al. 2000). 
When HQ > 1, potential for adverse effects for the MC will be further evaluated using detection frequency information (TSERAWG 2008). The distribution of the chemicals present at a site or exposure area should be examined by identifying where the chemicals were and were not detected and their frequency of detection. If this evaluation indicates that the distribution of a chemical is low, i.e., it is detected in only one or a few locations, it may be reasonable to conclude that risk can be considered negligible for that exposure pathway. In addition, when HQ $>1$, uncertainties will be considered and additional lines of evidence will be used to further evaluate potential for risks.

\subsection{Evaluation of risk posed by MC in the water column}

Table 36 compares the maximum concentration of $\mathrm{MC}$ in the water column with screening benchmarks presented and discussed in Chapter 12. The only exceedances of screening benchmarks are for TNT, 1,3,5-TNB, 1,3-DNB, and 2,4 and 2,6-DNT Porter et al. (2011) reported for samples taken $10 \mathrm{~cm}$ away from a large bomb with a visible breach. Comparison of the measured concentrations to benchmarks indicate potential for toxicity to sessile sensitive marine species living in close proximity to the breach. Porter et al. 2011 (Figure 9) reports that the concentration of TNT drops substantially with distance, with a mean concentration of $13 \mu \mathrm{g} / \mathrm{L}$ reported for the sample taken $1 \mathrm{~m}$ from the breach. That concentration is lower than screening benchmarks. Assuming that the concentrations of 1,3,5-TNB, 1,3-DNB, and 2,4 and 2,6-DNT decrease in the same proportion from $10 \mathrm{~cm}$ to $1 \mathrm{~m}$, organisms living further than $1 \mathrm{~m}$ from the bomb are likely unaffected by the toxic effects of MC present in the water column. Using available information for MC contamination of the water column compartment of aquatic sites (Chapter 5), negligible risk is predicted for organisms living at UWMM sites that are expected to be impacted mainly by $\mathrm{MC}$ present in the water column compartment. Sessile organisms living directly on or in very close proximity (e.g., $0.1 \mathrm{~m}$ away) to a breached munition are exempt from this risk. 
Table 36. Maximum concentrations of MC in water samples collected at UWMM sites and ecological screening levels from Chapter 12. Values in bold indicate exceedance of one or more screening levels.

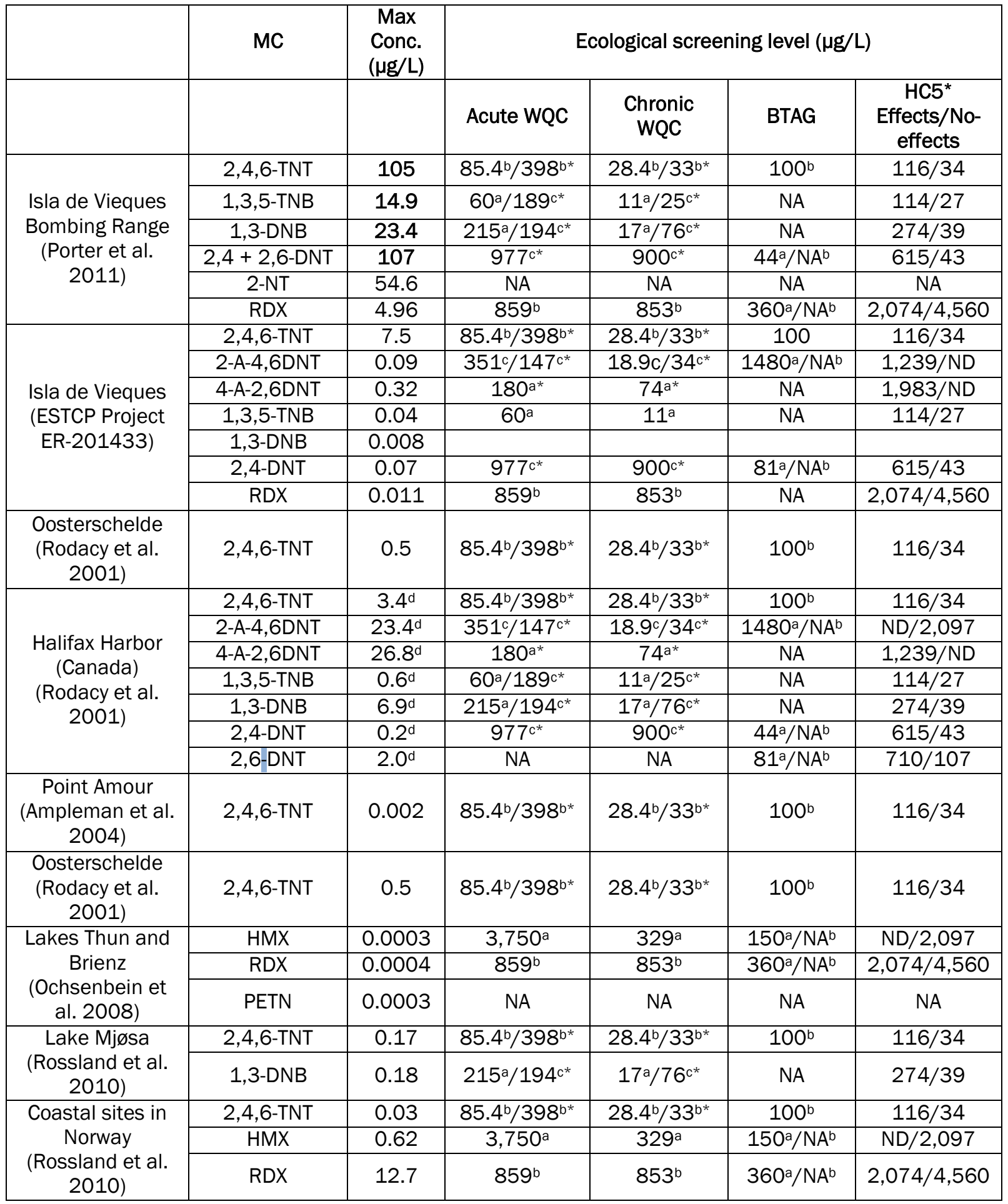

*Calculated in this report; a: Freshwater; b: Marine; c: Combined (freshwater and marine); d: Maximum concentrations are represented by their $95 \%$ UCL derived for detected values. 


\subsection{Evaluation of risk posed by MC in sediment}

Table 37 presents the maximum concentrations of $\mathrm{MC}$ in the sediment at UWMM sites, the HQ derived as the ratio of those maximum concentrations, and revised SQBs presented in Table 35 of Chapter 12. Exceedance of revised SQBs occurred for TNT, 4-A-2,6DNT, 1,3-DNB, 2,4DNT, RDX, and HMX in sediment are discussed below for each site where they occurred. No exceedances of revised SQBs occurred for the following sites investigated for sediment contamination by MC: JPHC (NAVFAC NW 2010a), Sea Disposal Site Hawaii (HI-06) "Ordnance Reef” during for the 2009 sampling events (UH 2014a), Sea Disposal Site Hawaii (HI-05) (Briggs et al. 2016), and Point Amour, Canada (Ampleman et al. 2004). Therefore, the potential for risks due to $\mathrm{MC}$ in the sediment can be considered negligible for those investigations.

\subsubsection{Sea disposal site Hawaii (HI-06) "Ordnance Reef”}

The HQ values calculated using the $95 \%$ UCL or maximum concentration were 1 or less (rounded to the nearest unit) for 2,6-DNT, 2-NT, 4-NT, and NG. Only 1 out of 56 samples had detectable concentrations $(0.14 \mathrm{mg} / \mathrm{kg})$ of RDX (DDM stratum). That concentration exceeded the SQBlow (0.091 mg/kg, Table 35) by a factor of 1.5, but was lower than the SQB $\mathrm{Bhigh}_{\text {. }}$ Considering the DL for RDX reported for that study, the 55 remaining samples had concentrations reported as less than the SQBlow. Therefore, potential for risks due to RDX in the sediment can be considered negligible when considering the distribution of that $\mathrm{MC}$ at the site.

The HQ for 2,4-DNT, detected in 31 out of 56 samples (55\%) in the DMM stratum, derived using the 95\% UCL sediment concentration $(6.91 \mathrm{mg} / \mathrm{kg})$, which exceeded the SQBlow by a factor of 2.2 (Table 35) and a factor of 0.8 when using the SQBhigh. Therefore, the potential for adverse effects of 2,4DNT to benthic organisms is possible. However, a closer examination of the data reveals that the maximum 2,4-DNT concentration, $110 \mathrm{mg} / \mathrm{kg}$ adjacent to a DMM, with the concentration decreased as the distance increased, which resulted in $6.7 \mathrm{mg} / \mathrm{kg}$ at $0.9 \mathrm{~m}$ and $2.3 \mathrm{mg} / \mathrm{kg}$ at $1.8 \mathrm{~m}$. The revised SQBlow $(3.2 \mathrm{mg} / \mathrm{kg})$ was exceeded in the sample with the highest concentration and two other samples, indicating that a limited distribution of potential risk to benthic invertebrates. In addition, much lower concentrations of 2,4 -DNT in sediment $(<0.05 \mathrm{mg} / \mathrm{kg})$ were reported for that site in a related previous study (UH 2014a), further suggesting limited distribution of 2,4-DNT above screening levels at the 
site. Studies evaluating the toxicity of 2,4-DNT to benthic invertebrates in exposures to spiked sediments were not found in the available literature; therefore, other lines of evidence were not available to further assess potential risk of this MC.

Table 37. Maximum concentrations (noted as $95 \%$ upper confidence limit, where indicated) of MC in sediment samples collected at UWMM sites, number of samples, detection frequency, and hazard quotients calculated using sediment benchmark values reported in Chapter 12. Values in bold indicate $\mathrm{HQ}>1$ (rounded to the unit).

\begin{tabular}{|c|c|c|c|c|c|c|c|}
\hline \multirow{2}{*}{ Site } & \multirow{2}{*}{ Study } & \multirow{2}{*}{ MC } & \multirow{2}{*}{$\begin{array}{c}\begin{array}{c}\text { Conc. } \\
(\mathrm{mg} / \mathrm{kg})\end{array} \\
95 \% \text { UCL }\end{array}$} & \multirow{2}{*}{$\begin{array}{c}\text { \# of } \\
\text { samples }\end{array}$} & \multirow{2}{*}{$\begin{array}{l}\text { Detection } \\
\text { freq. (\%) }\end{array}$} & \multicolumn{2}{|c|}{$\mathrm{HQ}$} \\
\hline & & & & & & low & high \\
\hline \multirow{6}{*}{$\mathrm{HI}-06$} & \multirow{6}{*}{$\begin{array}{c}\text { UH } \\
(2014 b)\end{array}$} & 2,4-DNT & $6.91^{a}$ & 56 & 55 & 2.2 & 0.8 \\
\hline & & 2,6-DNT & $1.6^{a}$ & 56 & 21 & 0.6 & 0.5 \\
\hline & & 2-NT & 1.1 & 56 & 4 & 1.3 & -- \\
\hline & & 4-TN & 0.49 & 56 & 2 & 0.2 & -- \\
\hline & & RDX & 0.14 & 56 & 2 & 1.5 & 0.9 \\
\hline & & $N G$ & 1.7 & 56 & 4 & 0.6 & 0.2 \\
\hline \multirow{4}{*}{$\begin{array}{l}\text { Seattle } \\
\text { Harbor }\end{array}$} & \multirow{4}{*}{$\begin{array}{l}\text { USACE } \\
(2013)\end{array}$} & 2,4-DNT & 0.97 & 12 & 25 & 0.3 & 0.1 \\
\hline & & 2,6-DNT & 0.12 & 12 & 8 & 0.04 & 0.03 \\
\hline & & RDX & 0.058 & 12 & 8 & 0.6 & 0.4 \\
\hline & & Tetryl & 0.23 & 12 & 8 & 15 & 3 \\
\hline $\begin{array}{c}\text { Isla de } \\
\text { Vieques }\end{array}$ & $\begin{array}{c}\text { Barton } \\
\text { and Porter } \\
(2004)\end{array}$ & TNT & $506^{b}$ & 4 & 50 & 22,200 & 3,608 \\
\hline \multirow{7}{*}{$\begin{array}{l}\text { Halifax } \\
\text { Harbor, } \\
\text { Canada }\end{array}$} & \multirow{7}{*}{$\begin{array}{l}\text { Rodacy et } \\
\text { al. (2001) }\end{array}$} & TNT & $0.0148^{a}$ & 23 & 100 & 0.7 & 0.1 \\
\hline & & 2-A-4,6-DNT & $0.0250^{a}$ & 23 & 30 & 1.2 & 1.1 \\
\hline & & 4-A-2,6-DNT & $0.1185^{a}$ & 23 & 39 & 2.5 & - \\
\hline & & 1,3,5-TNB & $0.0080^{a}$ & 23 & 96 & 1.3 & 0.6 \\
\hline & & 1,3-DNB & $0.0369^{a}$ & 23 & 22 & 3 & 0.9 \\
\hline & & 2,4-DNT & $0.0995^{a}$ & 23 & 48 & 0.0 & 0.0 \\
\hline & & 2,6-DNT & $0.2111^{a}$ & 23 & 35 & 0.1 & 0.1 \\
\hline \multirow{2}{*}{$\begin{array}{c}\begin{array}{c}\text { Solstrand } \\
\text { (pier), } \\
\text { Norway }\end{array} \\
\end{array}$} & \multirow{6}{*}{$\begin{array}{l}\text { Rossland } \\
\text { et al. } \\
\text { (2010) }\end{array}$} & TNT & 0.08 & 3 & 100 & 4 & 0.6 \\
\hline & & HMX & 0.06 & 3 & 33 & 0.4 & 0.1 \\
\hline \multirow{2}{*}{$\begin{array}{l}\text { Tælavåg, } \\
\text { Norwayb }\end{array}$} & & TNT & $0.05^{c}$ & 1 & 100 & 2.2 & 0.4 \\
\hline & & HMX & $0.24^{c}$ & 1 & 100 & 1.7 & 0.4 \\
\hline \multirow{2}{*}{$\begin{array}{l}\text { DS Selma, } \\
\text { Norway }\end{array}$} & & TNT & 0.31 & 2 & 100 & 14 & 2.2 \\
\hline & & HMX & 0.41 & 2 & 100 & 4 & 3 \\
\hline
\end{tabular}

*a: 95\% upper confidence limit; b: sample taken $0.1 \mathrm{~m}$ distance from bomb; c: sample taken before detonation. 


\subsubsection{Seattle Harbor piers 90 and 91 (USACE 2013)}

Four MC (2,4-DNT, 2,6-DNT, RDX and tetryl) were detected in up to 3 out of 12 samples. The nitroaromatic MC 2,4-DNT, 2,6-DNT, and RDX were detected at concentrations lower than the revised SQB for those MC; therefore, the potential for risks can be considered negligible. Tetryl was detected in 1 sample out of 12 at a concentration $(0.23 \mathrm{mg} / \mathrm{kg})$ that exceeded the revised SQB for this MC. Because the limit of detection for tetryl exceeded the revised SQBlow for that MC (Table 38), uncertainty remains regarding the risk tetryl poses to benthic invertebrates across all samples. The only study that addressed the toxicity of tetryl in sediment (Nipper et al. 2002) reported an NOEC of $0.5 \mathrm{mg} / \mathrm{kg}$ for sandy sediment and $0.1 \mathrm{mg} / \mathrm{kg}$ for fine-grained material (Table 31). Therefore, comparison to spiked sediment toxicity data indicated potential risk associated with tetryl present in one sample.

In addition to tetryl, the DL was higher than revised SQB values for TNT, 2-A-4,6-DNT, 4-A-2,6-DNT, 1,3-DNB, 1,3,5-TNB, 3,5-DNA, and HMX (Table 37). Therefore, even though those $\mathrm{MC}$ were not detected in any sample, uncertainty remains regarding the risk of those $\mathrm{MC}$ to benthic invertebrates.

In conclusion, using comparison of chemistry data reported in USACE (2013) to revised SQBs, potential for toxicity to benthic invertebrates from exposure to MC in sediment from the Seattle Harbor Piers 90 and 91 cannot be ruled out. Uncertainly associated with this screening-level evaluation exists in part because of analytical challenges associated with achieving limits of detection required for comparisons with SQB values, as noted by Pascoe et al. (2010), and by the provisional nature of the SQB values presented in Pascoe et al in Table 35 in this report. 
Table 38. Comparison of limit of detection for Seattle Harbor piers 90 and 91 study (USACE 2013) with revised sediment quality benchmark (SQB) values (Chapter 12).

\begin{tabular}{|c|c|c|c|}
\hline MC & $\begin{array}{c}\text { Limit of detection } \\
(\mathrm{mg} / \mathrm{kg})\end{array}$ & \multicolumn{2}{c|}{ Revised SQB (mg/kg) } \\
\hline & & low & high \\
\hline TNT & 0.06 & 0.023 & 0.140 \\
\hline 2-A-4.6-DNT & 0.16 & 0.021 & 0.024 \\
\hline 4-A-2.6-DNT & 0.16 & 0.048 & - \\
\hline 1,3-DNB & 0.16 & 0.012 & 0.043 \\
\hline 1,3,5-TNB & 0.06 & 0.006 & 0.013 \\
\hline 3,5-DNA & 0.16 & 0.068 & - \\
\hline Tetryl & 0.06 & 0.013 & 0.089 \\
\hline HMX & 0.16 & 0.15 & 0.60 \\
\hline
\end{tabular}

\subsubsection{Isla de Vieques bombing range}

Sediment (i.e., sand) sampled up to $0.1 \mathrm{~m}$ from a breached bomb had exceedingly high concentrations (5.39 to 19,333 mg/kg) of TNT, 1,3,5TNB, 1,3-DNB, TNT, 2,4-DNT, 2,6-DNT, 4- and 2-NT, and RDX. The concentrations exceed revised SQBs by many orders of magnitude. However, concentrations of TNT decreased exponentially when samples were taken at increasing distances from the bomb, which resulted in concentrations registering below the limit of detection at $1 \mathrm{~m}$ (Barton and Porter 2004). The concentrations of other MC from 0.01 to $2 \mathrm{~m}$ of the bomb were not reported. Because the LOD was not provided, uncertainty remains regarding the risk to benthic organisms living in proximity to a munitions at the bombing range site in Vieques.

\subsubsection{Halifax Harbor}

The HQ values calculated using the 95\% UCL for MC in sediment samples were 1 or less (rounded to the nearest unit) for TNT, 2-A-4,6-DNT, 1,3,4TNB, 2,4-DNT, and 2,6-DNT (Table 37). The HQ for 4-A-2,6-DNT, detected in $39 \%$ of the samples, was 2.5 using the revised SQBlow (Table 37). The HQ for $1,3-\mathrm{DNB}$, detected in $22 \%$ of the samples, was three using the revised SQBlow (Table 37). For 4-A-2,6-DNT, the selection of the chronic WQC derived in this study (Table 32) instead of the provisional value Pascoe et al. (2010) selected yields a revised SQBlow of $0.12 \mathrm{mg} / \mathrm{kg}$ at 1\% TOC, which is the same value as the 95\% UCL concentration and indicates negligible potential for risk to benthic invertebrates. Similarly, the selection of the chronic WQC derived in this study (Table 32) for 1,3-DNB instead of 
the provisional value Pascoe et al. (2010) selected yields a revised SQBlow of $0.055 \mathrm{mg} / \mathrm{kg}$ at $1 \%$ TOC, which is higher than the 95\% UCL concentration and indicates negligible potential for risk. In addition, the lowest NOEC for 1,3 -DNB reported for a marine invertebrate was $2,400 \mu \mathrm{g} / \mathrm{L}$ for the reproduction endpoint of the benthic marine polychaete Dinophilus gyrociliatus. This NOEC is orders of magnitude higher than the toxicity value Pascoe et al. (2010) selected or the revised chronic WQC from this study. When that polychaete NOEC value is used as the selected toxicity value, the resulting SQBlow is $1.7 \mathrm{mg} / \mathrm{kg}$ at $1 \%$ TOC, which is 25 times higher than the maximum concentration measured at that site. No spikedsediment toxicity data for 1,3-DNB or 4-A-4,6-DNT was identified. Therefore, the potential for adverse effects of MC present at Halifax Harbor UWMM sites as reported in Rodacy et al. (2001) can be considered negligible.

\subsubsection{Coastal fortifications in Norway}

The concentrations of TNT and HMX in most sediment samples taken in the proximity of UWMM at coastal fortifications in Norway (Rossland et al. 2010) exceeded revised SQBlow by factors ranging from 2 to 14 (TNT) and 2 to 4 (HMX) (Table 37). Based on spiked sediment studies that reported the lack of effects at the highest concentration tested (115 to $353 \mathrm{mg} / \mathrm{kg}$; Lotufo et al. 2001, Steevens et al. 2002) (Table 31), the maximum concentration of HMX reported across sites $(0.41 \mathrm{mg} / \mathrm{kg})$ was not expected to be associated with acute and sublethal effects to the benthos. Likewise, based on spiked sediment studies that reported NOEC values ranging from 20 to $275 \mathrm{mg} / \mathrm{kg}$ for marine invertebrates (Green et al. 1999; Lotufo et al. 2001; Rosen and Lotufo 2005) (Table 31), the maximum concentration of TNT reported across sites $(0.31 \mathrm{mg} / \mathrm{kg})$ was also not expected to be associated with acute and sublethal effects to the benthos. The concentrations for other MCs were reported as either "trace" or as below DL across sites. Because the LOD was not provided for most $\mathrm{MC}$ analyzed and scarcity of data derived from spiked-sediment toxicity tests (Table 31), uncertainty remains regarding the risk posed by additional MCs at that site.

\subsubsection{Conclusions regarding risk posed by MC in sediment}

Exceedances of MC concentrations in sediment relative to revised SQB values occurred in seven UWMM sites (Table 38 and Table 39). For sites where a relatively large number of samples were taken and for which the 
sampling effort aimed the characterization of the entire impacted area (HI-06, Seattle Harbor Piers 90 and 91, and Halifax Harbor), MC-specific exceedances of SQB values were limited to a small portion of the samples (12\% of the samples or less). Therefore, based on a conservative screeninglevel evaluation (Pascoe et al. 2010), the potential for risk to benthic invertebrates is limited to only a small portion of the site. However, risk from exposure to $\mathrm{MC}$ that may be present in sediment at Seattle Harbor Piers 90 and 91 (Table 38) cannot be ruled out because the LOD (USACE 2013) was lower than their respective revised SQBs.

Table 39. Number of samples, and hazard quotients for MC exceeding sediment quality benchmarks (SQB) at UWMM sites.

\begin{tabular}{|c|c|c|c|c|c|c|}
\hline \multirow{2}{*}{ Site } & \multirow{2}{*}{ Study } & \multirow{2}{*}{ MC } & \multirow{2}{*}{$\begin{array}{c}\text { \# of } \\
\text { samples }\end{array}$} & \multirow{2}{*}{$\begin{array}{c}\text { \# of } \\
\text { exceeding } \\
\text { SQB }\end{array}$} & \multicolumn{2}{|c|}{$\begin{array}{l}\text { HQ for highest } \\
\text { conc. }\end{array}$} \\
\hline & & & & & low & high \\
\hline \multicolumn{7}{|c|}{ Site-wide contamination characterization } \\
\hline \multirow{2}{*}{$\mathrm{HI}-06$} & \multirow{2}{*}{$\begin{array}{c}\text { UM } \\
(2014 b)\end{array}$} & 2,4-DNT & 56 & 3 & 2.2 & 0.8 \\
\hline & & RDX & 56 & 1 & 1.5 & 0.9 \\
\hline $\begin{array}{l}\text { Seattle } \\
\text { Harbor }\end{array}$ & $\begin{array}{l}\text { USACE } \\
(2013)\end{array}$ & Tetryl & 12 & 1 & 15 & 3 \\
\hline \multirow{2}{*}{$\begin{array}{l}\text { Halifax } \\
\text { Harbor, } \\
\text { Canada }\end{array}$} & \multirow{2}{*}{$\begin{array}{l}\text { Rodacy et } \\
\text { al. (2001) }\end{array}$} & 4-A-2,6DNT & 23 & 1 & 2.5 & -- \\
\hline & & 1,3-DNB & 23 & 5 & 3 & 0.9 \\
\hline \multicolumn{7}{|c|}{ Targeted contamination characterization } \\
\hline $\begin{array}{l}\text { Isla de } \\
\text { Vieques }\end{array}$ & $\begin{array}{c}\text { Barton } \\
\text { and Porter } \\
(2004)\end{array}$ & TNT & 4 & 4 & 22,200 & 3,608 \\
\hline $\begin{array}{c}\text { Solstrand } \\
\text { (pier), } \\
\text { Norway }\end{array}$ & \multirow{5}{*}{$\begin{array}{l}\text { Rossland } \\
\text { et al. } \\
\text { (2010) }\end{array}$} & TNT & 3 & 3 & 4 & 0.6 \\
\hline Tælavåg, & & TNT & 1 & 1 & 2.2 & 0.4 \\
\hline Norway & & $\mathrm{HMX}$ & 1 & 1 & 1.7 & 0.4 \\
\hline \multirow{2}{*}{$\begin{array}{l}\text { DS Selma, } \\
\text { Norway }\end{array}$} & & TNT & 2 & 2 & 14 & 2.2 \\
\hline & & HMX & 2 & 2 & 4 & 3 \\
\hline
\end{tabular}

The other sites listed in Table 38 were subjected to a limited assessment concerning contamination of MC in sediment surrounding one or several UWMM (concentrated in a small area). Potential for risk was identified at those targeted sampling areas, but lack of sampling beyond the targeted area prevented assessing risk to the benthic community inhabiting the study sites. Specific conclusions of those studies are as follows: 
- Potential for risk associated with sediment contamination with TNT exists in a shallow area under a demolished pier in coastal Norway (Rossland et al. 2010) where a large number of small munitions were found.

- Potential risk associated with sediment contamination with TNT and HMX exists in the benthic environment surrounding a naval mine from World War II found in coastal Norway (Rossland et al. 2010).

- Potential risk associated with sediment contamination with TNT and HMX exists in the benthic environment surrounding two UWMM located in the vicinity of the area where a World War II ship carrying munitions exploded and sank off coastal Norway (Rossland et al. 2010).

- Potential risk associated with sediment contamination with MC exists in the benthic environment immediately surrounding a 2,000 lb. GP air-dropped bomb located near the coast in the Island of Vieques, PR (Porter et al. (2011).

\subsection{Evaluation of risk using MC concentration in biota}

Studies of the lethal effects of MC have reported whole body tissue concentrations (or whole body burden) of test organisms sampled at termination of the exposure period used to generate toxicity data (Rosen and Lotufo 2007a; Lotufo et al. 2010a; Lotufo et al. 2013). Available critical residues associated with significant mortality of organisms exposed to $\mathrm{MC}$ are reported in Lotufo et al. (2013) as median lethal residues. In the case of exposures that did not result in significant mortality, they are reported as no-observed-effect residue, which are body residues in organisms surviving the highest exposure concentrations.

When the whole body residue can be linked to a specific biological effect, the body residue is termed the critical body residue (CBR) (McCarty and Mackay 1993). Tissue residue concentrations may be more directly relatable to toxic effects than water-based concentrations and provide an integrated assessment of the exposure an organism receives over time and space (Meador et al. 2006). However, given that body burdens can rapidly depurate, preventing tissue concentrations from persisting at levels that may cause detrimental biological effects, the elimination rates for $\mathrm{MC}$ has been reported as very rapid (Rosen and Lotufo 2007b; Lotufo et al. 2013, 2016). Fish and invertebrates inhabiting UWMM areas are expected to experience harmful effects only if under fairly constant exposure conditions. 
$\mathrm{MC}$ have a low propensity to bioaccumulate in fish and invertebrates via exposure to water and sediment (Lotufo et al. 2009a; Lotufo et al., 2013; Lotufo et al. 2016, Ballentine et al. 2015, and Ballentine et. al2016). The low bioaccumulation potential of MCs, joined with their propensity to rapidly disappear from exposed organisms following a decrease of MCs in the water compartment diminishes the relevance of using body residue in biota for assessing risks to fish and invertebrates inhabiting UWMM sites. The use of biota contamination data is further complicated by the paucity of tissue-based toxicity metrics used to gage the proper selection of toxicity reference values for assessing risk of MC. For the above reasons, an attempt to evaluate risk at UWMM sites using available biota data was not made. 


\section{Ecological risk assessment of MC at UWMM sites - summary and conclusions}

- The available sampling data collected from multiple sites indicate MC is present at detectable levels only within close proximity (e.g., $1 \mathrm{~m}$ ) of the area surrounding underwater munitions.

- Empirical and modeled data indicate that concentrations of $\mathrm{MC}$ in the water and sediment are typically in the low ppb parts-per-billion $(\mu \mathrm{g} / \mathrm{L}$ or $\mu \mathrm{g} / \mathrm{kg}$ ) range or lower.

- The available toxicology data indicate that most MC are toxic to most species in the ppm parts-per-million (mg/L or mg/kg) range. Few MCs are toxic to the most sensitive receptors in $\mu \mathrm{g} / \mathrm{L}$ range.

- Potential for toxicity is only predicted for sensitive organisms living in close proximity to underwater munitions that may be releasing $\mathrm{MC}$ into the environment.

- The weight of all available evidence indicates that risks to aquatic invertebrates and fish exposed to MC via the water column or the sediment at UWMM sites is negligible. 


\section{References}

Aberdeen Marine Laboratory. 1996. Surveys of the Beaufort's Dyke explosives disposal site, November 1995 - July 1996, Final Report. Fisheries Research Services Report No. 15/96. Aberdeen, Scotland: The Scottish Office Agriculture, Environment and Fisheries Department Marine Laboratory.

Agency for Toxic Substances and Disease Registry (ATSDR). 2003. Public Health Assessment, Fish and Shellfish Evaluation, Isla De Vieques Bombing Range Vieques, Puerto Rico. Atlanta, GA: U.S. Department of Health and Human Services, Public Health Service, Agency for Toxic Substances and Disease Registry.

Agency for Toxic Substances and Disease Registry (ATSDR). 2006. Health consultation: Land crab evaluation (National Oceanic and Atmospheric Administration Data). Isla de Vieques, Vieques, Puerto Rico. Atlanta, GA: U.S. Department of Health and Human Services, Agency for Toxic Substances and Disease Registry, Division of Health Assessment and Consultation.

Agency for Toxic Substances and Disease Registry (ATSDR). 2013. An evaluation of environmental, biological and health data from the Island of Vieques, Puerto Rico. Atlanta, Georgia: U.S. Department of Health and Human Services, Agency for Toxic Substances and Disease Registry, Division of Community Health Investigations.

Altenburger, R., T. Backhaus, W. Boedeker, M. Faust, M. Scholze, and L. H. Grimme. 2000. Predictability of the toxicity of multiple chemical mixtures to Vibrio fischeri: Mixtures composed of similarly acting chemicals. Environmental Toxicology and Chemistry 19(9): 2341-2347.

Ampleman, G., D. Faucher, S. Thiboutot, J. Hawari, and F. Monteil-Rivera. 2004. Evaluation of underwater contamination by explosives and metals at Point Amour Labrador and in the Halifax Harbour Area. Technical Report DRDC Valcartier TR 2004-125. Valcartier, Quebec, Canada: Defense Research and Development Canada.

Ariyarathna, T., P. Vlahos, C. Tobias, and R. Smith. 2016. Sorption kinetics of TNT and RDX in anaerobic freshwater and marine sediments: Batch studies. Environmental Toxicology and Chemistry 35(1): 47-55.

Atkins, P. W. 1998. Physical chemistry, Sixth Edition. New York, NY: Oxford University Press.

Bailey, H. C., R. J. Spanggord, H. S. Javitz, and D. H. W. Liu. 1985. Toxicity of TNT Wastewaters to Aquatic Organisms. Final Report. Vol. III. Chronic Toxicity of LAP Wastewater and 2,4,6-Trinitrotoluene. DTIC Accession No AD-A164 282. Menlo Park, CA: SRI International.

Balakrishnan, V. K., A. Halasz, and J. Hawari. 2003. The alkaline hydrolysis of the cyclic nitramine explosives RDX, HMX, and CL-20: New insights into degradation pathways obtained by the observation of novel intermediates. Environmental Science and Technology 37(9): 1838-1843. 
Ballentine, M. L., C. Tobias, P. Vlahos, R. Smith, and C. Cooper. 2015. Bioconcentration of TNT and RDX in coastal marine biota. Archives of Environmental Contamination and Toxicology 68(4): 718-728.

Ballentine, M. L., T. Ariyarathna, R. W. Smith, C. Cooper, P. Vlahos, S. Fallis, T. J. Groshens, C. Tobias. 2016. Uptake and fate of hexahydro-1, 3, 5-trinitro-1, 3, 5triazine (RDX) in coastal marine biota determined using a stable isotopic tracer,

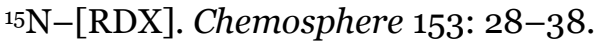

Barton, J. V., and J. W. Porter. 2004. Radiological, chemical, and environmental health assessment of the marine resources of the Isla de Vieques Bombing Range, Bahia Salina del Sur, Puerto Rico. Norfolk, VA: Underwater Ordnance Recovery, Inc.

Belden, J. B., G. R. Lotufo, J. M. Biedenbach, K. K. Sieve, and G. Rosen. 2015. Application of POCIS for exposure assessment of munitions constituents during constant and fluctuating exposure. Environmental Toxicology and Chemistry 34(5): 959-967.

Bentley, R. E., G. A. LeBlanc, T. A. Hollister, and B. H. Sleight, III. 1977a. Acute toxicity of 1,3,5,7-tetranitro-octahydro-1,3,5,7-tetrazocine (HMX) to aquatic organisms, Final Report. Prepared for the U.S. Army Medical Research and Development Command, Washington, D.C. DTIC Accession No. ADAo61 730. Wareham, MA: E $\mathrm{G}$ and $\mathrm{G}$, Bionomics.

Bentley, R. E., J. W. Dean, S. J. Ells, T. A. Hollister, G. A. LeBlanc, S. Sauter, and B. H. Sleight. 1977b. Laboratory evaluation of the toxicity of cyclotrimethylene trinitramine (RDX) to aquatic organisms, Final Report. Prepared for U.S. Army Medical Research and Development Command, Fort Detrick, MD. DTIC Accession No. ADA061730. Wareham, MA: E G and G Bionomics.

Bentley, R. E., T. A. Hollister, G. A. LeBlanc, and B. H. Sleight. 1977c. Laboratory evaluation of the toxicity of nitrocellulose to aquatic organisms, Final Report. Prepared for the U.S. Army Medical Research and Development Command, Washington D.C. ADA037749. Wareham, MA: E G and G, Bionomics.

Bentley, R. E., J. W. Dean, S. J. Ells, G. A. LeBlanc, S. Sauter, K. S. Buxton, and B. H. Sleight. 1978. Laboratory evaluation of the toxicity of nitroglycerine to aquatic organisms, Final Report. Prepared for the U.S. Army Medical Research and Development Command, Fort Detrick, MD. DTIC Accession No. ADAo61739. Wareham, MA: E G and G, Bionomics.

Bentley, R. E., S. R. Petrocelli, and D. C. Suprenant. 1984. Determination of the toxicity to aquatic organisms of HMX and related wastewater constituents: Part III, Toxicity of HMX, TAX and SEX to aquatic organisms, Final report. Prepared for the U.S. Army Medical Research and Development Command, Fort Detrick, MD. DTIC Accession No. AD-A172 385. Wareham, MD: Springborn Bionomics, Inc.

Best, E. P. H., S. L. Sprecher, S. L. Larson, H. L. Fredrickson, and B. F. Darlene. 1999. Environmental behavior of explosives in groundwater in groundwater from the Milan army ammunition plant in aquatic and wetland plant treatments. Removal, mass balances and fate in groundwater of TNT and RDX. Chemosphere 38(14): 3383-3396. 
Bhushan, B., A. Halasz, J. C. Spain, and J. Hawari. 2002. Diaphorase catalyzed biotransformation of RDX via N-denitration mechanism. Biochemical and Biophysical Research Communications 296(4): 779-784.

Biological Technical Assistance Group (BTAG). 2006. Screening benchmark values. United States Environmental Protection Agency Region 3. https://www.epa.gov/risk/biological-technical-assistance-group-btag-screening-values.

Blakley, N. 2005. Ostrich Bay sediment toxicity evaluation. Publication No. 05-03-023. Olympia, WA: Department of Ecology.

Brannon, J. M., and J. C. Pennington. 2002. Environmental fate and transport process descriptors for explosives. ERDC/EL TR-02-10. Vicksburg, MS: U.S. Army Engineer Research and Development Center.

Briggs, C., S. M. Shjegstad, J. A. K. Silva, and M. H. Edwards. 2016. Distribution of chemical warfare agent, energetics, and metals in sediments at a deep-water discarded military munitions site. Deep Sea Research Part II: Topical Studies in Oceanography 128: 63-69.

Bringmann, G., and R. Kuhn. 1978. Testing of substances for their toxicity threshold: Model organisms Microcystis (Diplocystis) aeruginosa and Scenedesmus quadricauda, Mitt. In Symposium, Experimental Use of Algal Cultures in Limnology, 26-28 October 1976, Sandefjord, Norway. Verhandlungen der Internationalen Vereinigung für Theoretische und Angewandte Limnologie 21: 275 .

Buccafusco, R. J., S. J. Ells, and G. A. LeBlanc. 1981. Acute toxicity of priority pollutants to bluegill (Lepomis macrochirus). Bulletin of Environmental Contamination and Toxicology 26(1): 446-452.

Burgess, R. M., W. J. Berry, D. R. Mount, and D. M. Di Toro. 2013. Mechanistic sediment quality guidelines based on contaminant bioavailability: Equilibrium partitioning sediment benchmarks. Environmental Toxicology and Chemistry 32(1): 102114 .

Burton, D. T., S. D. Turley, and G. T. Peters. 1993. Toxicity of nitroguanidine, nitroglycerin, hexahydro-1,3,5-trinitro-1,3,5-triazine (RDX), and 2,4,6trinitrotoluene (TNT) to selected freshwater aquatic organisms. WREC 93-B3. Laurel/Queenstown, MD: Johns Hopkins University Applied Physics Laboratory, The University of Maryland System, Agricultural Experiment Station, Wye Research and Education Center.

Burton, D. T., S. D. Turley, and G. T. Peters. 1994. The acute and chronic toxicity of hexahydro-1,3,5-trinitro-1,3,5-triazine (RDX) to the fathead minnow (Pimephales promelas). Chemosphere 29(3): 567-579.

Burton, D. T., and S. D. Turley. 1995. Reduction of hexahydro-1,3,5-trinitro-1,3,5-triazine (RDX) toxicity to the Cladoceran Ceriodaphnia dubia following photolysis in sunlight. Bulletin of Environmental Contamination and Toxicology 55: 89-95.

Cajaraville, M.P., A. Recio, V. Saez, and J.A. Marigomez. 1989. Acute toxicity of two hydroxylated hydrocarbons to the prosobranch gastropod Littorina littorea. Scientia Marina 53(2-3): 745-748. 
Carton, G., and A. Jagusiewicz. 2009. Historic disposal of munitions in U.S. and European coastal saters, how historic information can be used in characterizing and managing risk. Marine Technology Society Journal 43(4):16-32.

Carton, G., J. C. King, and R. J. Bowers. 2012. Munitions-related technology demonstrations at Ordnance Reef (HI-06), Hawaii. Marine Technology Society Journal 46(1): 63-82.

Chappell, M. A., C. L. Price, and L. F. Miller. 2011. Solid-phase considerations for the environmental fate of nitrobenzene and triazine munition constituents in soil. Applied Geochemistry 26(Supplement): S330-S333.

Clausen, J. L. 2011. Energetic residue observations for operational ranges. In Environmental chemistry of explosives and propellant compounds in soils and marine systems: Distributed source characterization and remedial technologies, ed. M. A. Chappell, C. L. Price, and R. D George. ACS Symposium Series 1069, 107-136. Washington, DC: American Chemical Society.

Clausen, J. L., N. Korte. 2011. Fate and transport of energetics from surface soils to groundwater. In Environmental chemistry of explosives and propellant compounds in soils and marine systems: Distributed source characterization and remedial technologies, ed. M. A. Chappell, C. L. Price, and R. D George. ACS Symposium Series 1069, 273-316. Washington, DC: American Chemical Society.

Conder, J. M., T. W La Point, J. A. Steevens, and G. R. Lotufo. 2004. Recommendations for the assessment of TNT toxicity in sediment. Environmental Toxicology and Chemistry 23(1): 141-149.

Connolly, J.P., C. J. Pederson. 1988. A thermodynamic-based evaulation of organic chemical accumulation in aquatic organisms. Environmental Science and Technology 22(1): 99-103.

Cox, E., E. H. De Carlo, and M. Overfield. 2007. Ordnance Reef, Wai'anae, HI: Remote sensing survey and sampling at discarded military munitions sea disposal site, Final Report. Marine Sanctuaries Conservation Series NMSP-07-01. Silver Spring, MD: U.S. Department of Commerce, National Oceanic and Atmospheric Administration, National Marine Sanctuary Program.

Crocker, F. H., K. J. Indest, and H. L. Fredrickson. 2006. Biodegradation of the cyclic nitramine explosives RDX, HMX, and CL-20. Applied Microbiology and Biotechnology 73(2): 274-290.

Darrach, M. R., A. Chutjian, and G. A. Plett. 1998. Trace explosives signatures from World War II unexploded undersea ordnance. Environmental Science and Technology 32(9): 1354-1358.

Dave, G. 2003. Field test of ammunition (TNT) dumping in the ocean. In Sediment Quality Assessment and Management: Insight and Progress, ed. M. Munawar, 213-220. East Lansing, MI: Michigan State University Press..

Dave, G., E. Nilsson, and A-S Wernersson. 2000. Sediment and water phase toxicity and UV-activation of six chemicals used in military explosives. Aquatic Ecosystem Health and Management 3(3): 291-299. 
Davenport, R., L. R. Johnson, D. J. Schaeffer, and H. Balbach. 1994. Phototoxicology. 1. Light-enhanced toxicity of TNT and some related compounds to Daphnia magna and Lytechinus variagatus embryos. Ecotoxicology and Environmental Safety 27(1): 14-22.

Davis, IV., A. D. 2009. Munitions Discarded at Sea. Marine Technology Society Journal 43(4): 11-13.

Della Torre, C., I. Corsi, A. Arukwe, L. Alcaro, E. Amato, and S. Focardi. 2008a. Effects of 2,4,6-trinitrotoluene (TNT) on phase I and phase II biotransformation enzymes in European eel Anguilla anguilla (Linnaeus, 1758). Marine Environmental Research 66(1): 9-11.

Della Torre, C., I. Corsi, S. Focardi, and A. Arukwe. 2008b. Effects of 2,4,6-trinitrotoluene (TNT) on neurosteroidogenesis in the European eel (Anguilla anguilla; Linnaeus 1758). Chemistry and Ecology 24(Supplement 1): 1-7.

Della Torre, C., I. Corsi, A. Arukwe, M. Valoti, and S. Focardi. 2008c. Interactions of 2,4,6-trinitrotoluene (TNT) with xenobiotic biotransformation system in European eel Anguilla anguilla (Linnaeus, 1758). Ecotoxicology and Environmental Safety 71(3): 798-805.

Delle Site, A. 2001. Factors affecting sorption of organic compounds in natural sorbent/water systems and sorption coefficients for selected pollutants. A review. Journal of Physical and Chemical Reference Data 30(1): 187-439.

Deneer, J. W., C. J. van Leeuwen, W. Seinen, J. L. Maas-Diepeveen, and J. L. M. Hermens. 1989. QSAR study of the toxicity of nitrobenzene derivatives towards Daphnia magna, Chlorella pyrenoidosa and Photobacterium phosphoreum. Aquatic Toxicology 15(1): 83-98.

Di Toro, D. M., C. S. Zarba, D. J. Hansen, W. J. Berry, R. C. Swartz, C. E. Cowan, S. P. Pavlou, H. E. Allen, N. A. Thomas, and P. R. Paquin. 1991. Technical basis for establishing sediment quality criteria for nonionic organic chemicals using equilibrium partitioning. Environmental Toxicology and Chemistry 10(12): 1541-1583.

Dodard, S.G., A. Y. Renoux, J. Hawari, G. Ampleman, S. Thiboutot, and G. I. Sunahara. 1999. Ecotoxicity characterization of dinitrotoluenes and some of their reduced metabolites. Chemosphere 38(9): 2071-2079.

Edwards, M. H., S. M. Shjegstad, R. Wilkens, J. C King, G. Carton, D. Bala, B. Bingham, M. C. Bissonnette, C. Briggs, N. S. Bruso, R. Camilli, M. Cremer, R. B. Davis, E. H. DeCarlo, C. DuVal, D. J. Fornari, I. Kaneakua-Pia, C. D. KelleyS. Koide, C. L. Mah, T. Kerby, G. J. Kurras, M. R. Rognstad, L. Sheild, J. Silva, B. Wellington, and M. Van Woerkom. 2016. The Hawaii Undersea Military Munitions Assessment. Deep Sea Research Part II: Topical Studies in Oceanography 128: 4-13.

Ek, H., G. Dave, E. Nilsson, J. Sturve, and G. Birgersson. 2006. Fate and effects of 2,4,6trinitrotoluene (TNT) from dumped ammunition in a field study with fish and invertebrates. Archives of Environmental Contamination and Toxicology 51(2): 244-252. 
Ek, H., G. Dave, G. Birgersson, and L. Förlin. 2003. Acute effects of 2,4,6-trinitrotoluene (TNT) on haematology parameters and hepatic EROD-activity in rainbow trout (Oncorhynchus mykiss). Aquatic Ecosystem Health and Management 6(4): 415421.

Ek, H., G. Dave, J. Sturve, B. C. Almroth, E. Stephensen, L. Förlin, and G. Birgersson. 2005. Tentative biomarkers for 2,4,6-Trinitrotoluene (TNT) in fish (Oncorhynchus mykiss). Aquatic Toxicology 72(3): 221-230.

Ek, H., E. Nilsson, G. Birgersson, and G. Dave. 2007. TNT leakage through sediment to water and toxicity to Nitocra spinipes. Ecotoxicology and Environmental Safety 67(3): 341-348.

Ek, H., E. Nilsson, and G. Dave. 2008. Effects of TNT leakage from dumped ammunition on fish and invertebrates in static brackish water systems. Ecotoxicology and Environmental Safety 69(1):104-111.

Elovitz, M. S., and E. J. Weber. 1999. Sediment mediated reduction of 2,4,6trinitrotoluene and fate of the resulting aromatic (poly)amines. Environmental Science and Technology 33(15): 2617-2625.

ENSR International. 2005. Derivation of toxicity reference values for the acute and chronic toxicity of hexahydro-1,3,5-trinitro- 1,3,5-triazine (RDX) to marine aquatic organisms - Final report. ENSR Project No. 09000-279-400/ U.S. Army Contract No. DACA67-00-D-2009. Prepared by Parametrix, Inc., Albany, OR; and ENSR International, Redmond, WA.

Fisher, D. J., D. T. Burton, and R. L. Paulson. 1989. Comparative acute toxicity of diethyleneglycol dinitrate to freshwater aquatic organisms. Environmental Toxicology and Chemistry 8(6): 545-550.

Forbes, V. E., and P. Calow. 2002. Species sensitivity distributions revisited: A critical appraisal. Human and Ecological Risk Assessment: An International Journal 8(3): 473-492.

Freidig, A. P., and J. L. M. Hermens. 2000. Narcosis and chemical reactivity QSARs for acute fish toxicity. Quantitative Structure-Activity Relationships 19(6): 547-553.

Fuchsman, P. C. 2003. Modification of the equilibrium partitioning approach for volatile organic compounds in sediment. Environmental Toxicology and Chemistry 22(7): 1532-1534.

Garcia, S. S., K. MacDonald, E. H. De Carlo, M. L. Overfield, T. Reyer, and J. Rolfe. 2009. Discarded military munitions case study: Ordnance reef (HI-06), Hawaii. Marine Technology Society Journal 43(4): 85-99.

Garcia-Reyero, N., B. L. Escalon, P. R. Loh, J. G. Laird, A. J. Kennedy, B. Berger, and E. J. Perkins. 2012. Assessment of chemical mixtures and groundwater effects on daphnia magna transcriptomics. Environmental Science and Technology 46(1): 42-50. 
Garcia-Reyero, N., H. C. Poynton, A. J. Kennedy, X. Guan, B. L. Escalon, B. Chang, J. Varshavsky, A. V. Loguinov, C. D. Vulpe, and E. J. Perkins. 2009. Biomarker discovery and transcriptomic responses in daphnia magna exposed to munitions constituents. Environmental Science and Technology 43(11): 4188-4193.

Goodfellow, Jr. W. L., D. T. Burton, W. C. Graves, L. W. Hall, Jr., and K. R. Cooper. 1983. Acute toxicity of picric acid and picramic acid to rainbow trout, Salmo gairdneri, and American oyster, Crassostrea virginica. Journal of the American Water Resources Association 19(4): 641-648.

Green, A., D. Moore, and D. Farrar. 1999. Chronic toxicity of 2,4,6-trinitrotoluene to a marine polychaete and an estuarine amphipod. Environmental Toxicology and Chemistry 18(8): 1783-1790.

Griest, W. H., A. A. Vass, A. J. Stewart, and C. H. Ho. 1998. Chemical and toxicological characterization of slurry reactor biotreatment of explosives-contaminated soils. Technical Report SFIM-AEC-ETCR-96186. Prepared for Aberdeen Proving Ground, MD: U.S. Army Environmental Center. Oak Ridge, TN: Oak Ridge National Laboratory.

Gust, K. A., M. S. Wilbanks, X. Guan, M. Pirooznia, T. Habib, L. Yoo, H. Wintz, C. D. Vulpe, and E. J. Perkins. 2011a. Investigations of transcript expression in fathead minnow (Pimephales promelas) brain tissue reveal toxicological impacts of RDX exposure. Aquatic Toxicology 101(1): 135-145

Gust, K. A., S. M. Brasfield, J. K. Stanley, M. S. Wilbanks, P. Chappell, E. J. Perkins, G. R. Lotufo and R. F. Lance. 2011b. Genomic investigation of year-long and multigenerational exposures of fathead minnow to the munitions compound RDX. Environmental Toxicology and Chemistry 30(8): 1852-1864.

Gust, K. A., F. Z. Najar, , T. Habib, G. R. Lotufo, A. M. Piggot, B. W. Fouke, J. G. Laird, M. S. Wilbanks, A. Rawat, K. J. Indest, B. A. Roe, and E. J. Perkins. 2014. Coralzooxanthellae meta-transcriptomics reveals integrated response to pollutant series. BMG Genomics 15(1): 591.

Harrison, I., and C. H. Vane. 2010. Attenuation of TNT in seawater microcosms. Water Science and Technology 61(10): 2531-2538.

Hattori, A. 1983. Denitrification and dissimilatory nitrate reduction. In Nitrogen in the marine environment, ed. E. J. Carpenter, and D. G. Capone, 191-232. New York, NY: Academic Press.

Hawari, J., A. Halasz, T. Sheremata, S. Beaudet, C. Groom, L. Paquet, C. Rhofir, G. Ampleman, and S. Thiboutot. 2000a. Characterization of metabolites during biodegradation of hexahydro-1, 3,5-trinitro-1,3,5-triazine (RDX) with municipal anaerobic sludge. Applied and Environmental Microbiology 66(6): 2652-2657.

Hawari, J., S. Beaudet, A. Halasz, S. Thiboutot, and G. Ampleman. 20oob. Microbial degradation of explosives: Biotransformation versus mineralization. Applied Microbiology and Biotechnology 54(5): 605-618. 
Hawari, J., A. Halasz, C. Groom, S. Deschamps, L. Paquet, C. Beaulieu, and A. Corriveau. 2002. Photodegradation of RDX in aqueous solution: A mechanistic probe for biodegradation with Rhodococcus sp. Environmental Science and Technology 36(23): 5117-5123.

Hikal, W. M., J. T. Paden, and B. L. Weeks. 2011. Thermo-optical determination of vapor pressures of TNT and RDX nanofilms. Talanta 87: 290-294.

Hill, R. A., P. M. Chapman, G. S. Mann, and G. S. Lawrence. (2000). Level of detail in ecological risk assessments. Marine Pollution Bulletin 40(6): 471-477.

Howard, P.H., R. S. Boethling, W. F. Jarvis, W. M. Meylan, and E. M. Michalenko. 1991. Handbook of environmental degradation rates. Boca Raton, FL: Lewis Publishers.

Isnard, P., P. Flammarion, G. Roman, M. Babut, P. Bastien, s. Bintein, L. Essermeant, J. F. Ferard, S. Gallotti-Schmitt, E. Saouter, M. Saroli, H. Thiebaud, R. Tomassone, and E. Vindimian. 2001. Statistical analysis of regulatory ecotoxicity tests. Chemosphere 45(4-5): 659-669.

Iwasaki, Y., K. Kotani, S. Kashiwada, and S. Masunaga. 2015. Does the choice of NOEC or EC10 affect the hazardous concentration for $5 \%$ of the species? Environmental Science and Technology 49(15): 9326-9330.

Jenkins, T. F., J. C. Pennington, T. A. Ranney, T. E. Berry, Jr., P. H. Miyares, M. E. Walsh, A. D. Hewitt, N. M. Perron, L. V. Parker, C. A. Hayes, and E. G. Wahlgren. 2001. Characterization of explosives contamination at military firing ranges. ERDC TR-01-5. Hanover, NH: U.S. Army Engineer Research and Development Center.

Johnson, L. R., R. Davenport, H. Balbach, and D. J. Schaeffer. 1994. Phototoxicology.: 3. Comparative toxicity of trinitrotoluene and aminodinitrotoluenes to Daphnia magna, Dugesia dorotocephala, and sheep erythrocytes. Ecotoxicology and Environmental Safety 27(1): 34-49.

Juhasz, A. L., and R. Naidu. 2007. Explosives: Fate, dynamics, and ecological impact in terrestrial and marine environments. In Reviews of Environmental Contamination and Toxicology. Volume 191, 163-215. New York, NY: Springer Publishing.

Kaplan, D. L., J. H. Cornell, and A. M. Kaplan. 1982. Decomposition of nitroguanidine. Environmental Science and Technology 16(8): 488-492.

Karickhoff, S. W. 1981. Semi-empirical estimation of sorption of hydrophobic pollutants on natural sediments and soils. Chemosphere 10(8): 833-846.

Katseanes, C.K., M. A. Chappell, and B. G. Hopkins. 2015. Multivariate soil fertility relationships for predicting the environmental persistence of 2,4,6Trinitrotoluene (TNT) among taxonomically distinct soils. Submitted for publication to the Journal of Environmental Management.

Koide, S., J. A. K. Silva, V. Dupra, and M. Edwards. 2016. Bioaccumulation of chemical warfare agents, energetic materials, and metals in deep-sea shrimp from discarded military munitions sites off Pearl Harbor. Deep Sea Research Part II: Topical Studies in Oceanography 128: 53-62 
Kuhn, R., and M. Pattard. 1990. Results of the harmful effects of water pollutants to green algae (Scenedesmus subspicatus) in the cell multiplication inhibition test. Water Research 24(1): 31-38.

Kuhn, R., M. Pattard, K. D. Pernak, and A. Winter. 1989. Results of the harmful effects of water pollutants to Daphnia magna in the 21 day reproduction test. Water Research 23(4): 501-510.

Kuperman, G. R., M. Simini, S. Siciliano, and P. Gong. 2009. Effects of energetic materials on soil organisms. In Ecology of explosives, ed. G. I. Sunahara, G. R. Lotufo, R. G. Kuperman, and J. Hawari, 36-72. Boca Raton, FL: CRC Press.

Landis, W. G., and P. M. Chapman. 2011. Well past time to stop using NOELs and LOELs. Integrated Environmental Assessment and Management 7(4): vi-viii.

Laugesen, J., and H. Bjørnstad. 2008. Dumped ammunition - An environmental problem for sediment management? In Proceedings, $5^{\text {th }}$ International SedNet Conference, 27-29 May, Oslo, Norway.

LeBlanc, G. A. 1980. Acute toxicity of priority pollutants to water flea (Daphnia magna). Bulletin of Environmental Contamination and Toxicology 24(1): 684-691.

Lewis, J., R. Martel, L. Trepanier, G. Ampleman, and S. Thiboutot. 2009. Quantifying the transport of energetic materials in unsaturated sediments from cracked unexploded ordnance. Journal of Environmental Quality 38(6): 2229-2236.

Li, H., and J. You. 2015. Application of species sensitivity distribution in aquatic probabilistic ecological risk assessment of cypermethrin: A case study in an urban stream in south china. Environmental Toxicology and Chemistry 34(3): 640648

Liss, P. S., and P. G. Slater. 1974. Flux of gases across the air-sea interface. Nature 247: 181-184.

Liu, D. H. W., H. C. Bailey, and J. G. Pearson. 1983a. Toxicity of a complex munitions wastewater to aquatic organism. In Proceedings, Aquatic toxicology and hazard assessment: Sixth symposium-ASTM STP 802, ed. W. E. Bishop, R. D. Cardwell, B. B. Heidolph, 135-150. Philadelphia, PA: American Society for Testing Materials.

Liu, D. H.W., R. J. Spanggord, H. C. Bailey, H. S. Javitz, and D. C. L. Jones. 1983b. Toxicity of TNT wastewaters to aquatic organisms, VoI. II. Acute toxicity of condensate wastewater and 2,4-Dinitrotoluene. DTIC Accession No. AD-A142 145. Menlo Park, CA: SRI International.

Liu, D. H., R. J. Spanggord, H. C. Bailey, H. S. Javitz, and D. C. L. Jones. 1983c. Toxicity of TNT wastewaters to aquatic organisms, Vol. I. Acute toxicity of LAP wastewater and 2,4,6-Trinitrotoluene. DTIC Accession No. AD-A142 144. Menlo Park, CA: SRI International.

Lotufo, G. R., J. D. Farrar, L. S. Inouye, T. S. Bridges, and D. B. Ringelberg. 2001. Toxicity of sediment-associated nitroaromatic and cyclonitramine compounds to benthic invertebrates. Environmental Toxicology and Chemistry 20(8): 1762-1771. 
Lotufo, G. R., and J. D. Farrar. 2005. Comparative and mixture sediment toxicity of trinitrotoluene and its major transformation products to a freshwater midge. Archives of Environmental Contamination and Toxicology 49(3): 333-342.

Lotufo, G. R., M. J. Lydy, G. L. Rorrer, O. Cruz-Uribe, and D. P. Cheney. 2009 a. Bioconcentration, bioaccumulation, and biotransformation of explosives and related compounds in aquatic organisms. In Ecotoxicology of explosives, ed. G. I. Sunahara, G. Lotufo, R. G. Kuperman, and J. Hawari, 136-155. Boca Raton, FL: CRC Press.

Lotufo, G. R., M. Nipper, R. S. Carr, and J. M. Conder. 2009b. Fate and toxicity of explosives in sediment. In Ecotoxicology of explosives, ed G. I. Sunahara, G. Lotufo, R. G. Kuperman, and J. Hawari, 117-134. Boca Raton, FL: CRC Press.

Lotufo, G. R., A. B. Gibson, and J. L. Yoo. 2010a. Toxicity and bioconcentration evaluation of RDX and HMX using sheepshead minnows in water exposures. Ecotoxicology and Environmental Safety 73(7): 1653-1657.

Lotufo, G. R., W. Blackburn, and A. B. Gibson. 2010b. Toxicity of trinitrotoluene to sheepshead minnows in water exposures. Ecotoxicology and Environmental Safety 73(5): 718-726.

Lotufo, G. R., W. Blackburn, S. J. Marlborough, and J. W. Fleeger. 2010c. Toxicity and bioaccumulation of TNT in marine fish in sediment exposures. Ecotoxicology and Environmental Safety 73(7): 1720-1727.

Lotufo, G. R., G. Rosen, W. Wild, and G. Carton. 2013. Summary review of the aquatic toxicology of munitions constituents. ERDC/EL TR-13-8. Vicksburg, MS: U.S. Army Engineer Research and Development Center.

Lotufo, G. R., J. B. Belden, J. C. Fisher, S-F. Chen, R. A. Mowery, C. K. Chambliss, and G. Rosen. 2016. Accumulation and depuration of trinitrotoluene and related extractable and nonextractable (bound) residues in marine fish and mussels. Environmental Pollution 210: 129-136.

MacDonald, J. A., M. J. Small, and M. G. Morgan. 2009. Quantifying the risks of unexploded ordnance at closed military bases. Environmental Science and Technology 43(2): 259-265.

Mackay, D. 1979. Finding fugacity feasible. Environmental Science and Technology 13(10): 1218-1223.

Mackay, D. 2001. Multimedia environmental models: The fugacity approach, 2nd ed. Boca Raton, FL: CRC Press.

Mackay, D., and P. J. Leinonen. 1975. Rate of evaporation of low-solubility contaminants from water bodies to atmosphere. Environmental Science and Technology 9(13): 1178-1180.

Mackay, D., and S. Paterson. 1981. Calculating fugacity. Environmental Science and Technology 15(9): 1006-1014. 
Mackay, D., M. Joy, and S. Paterson. 1983a. A quantitative water, air, sediment interaction (QWASI) fugacity model for describing the fate of chemicals in lakes. Chemosphere 12(7-8): 981-997.

Mackay, D., S. Paterson, and M. Joy. 1983b. A quantitative water, air, sediment interaction (QWASI) fugacity model for describing the fate of chemicals in rivers. Chemosphere 12(9-10): 1193-1208.

Mackay, D., L. Hughes, D. E. Powell, and J.Kim. 2014. An updated quantitative water air sediment interaction (QWASI) model for evaluating chemical fate and input parameter sensitivities in aquatic systems: Application to D5 (decamethylcyclopentasiloxane) and PCB-180 in two lakes. Chemosphere 111: $359-365$.

MacMillan, D.K., C. R. Majerus, R. D. Laubscher, and J. P. Shannon. 2008. A reproducible method for determination of nitrocellulose in soil. Talanta 74(4): 1026-1031.

Martens, H., and T. Næs. 1989. Multivariate calibration. New York, NY: John Wiley and Sons, Inc.

Mayo, M., Z. A. Collier, V. Hoang, and M. Chappell. 2014. Uncertainty in multi-media fate and transport models: A case study for TNT life cycle assessment. Science of the Total Environment 494-495: 104-112.

McCarty, L. S., and D. Mackay. 1993. Enhancing ecotoxicological modeling and assessment. Body residues and modes of toxic action. Environmental Science and Technology 27(9): 1718-1728.

McDonald, J. 2009. UXO detection and characterization in the marine environment. Travelogue and phenomenology report. Environmental Security Technology Demonstration Program Project MR-200324. Cary, NC: SAIC, Advanced Sensors and Analysis Division. https://www.serdpestcp.org/content/download/4457/66225/file/MM-0324\%20TR.pdf

Meador, J. 2006. Rationale and procedures for using the tissue-residue approach for toxicity assessment and determination of tissue, water and sediment quality guidelines for aquatic organisms. Human and Ecological Risk Assessment 12(6):1018-1073.

Meyer, R., J. Kohler, and A. Homburg. 2002. Explosives, $5^{\text {th }}$ Edition. Weinheim, Germany: Wiley-VCH, Verlag GmbH.

Monteil-Rivera, F., A. Halasz, C. Groom, J-S. Zhao, S. Thiboutot, G. Ampleman, and J. Hawari. 2009. Fate and transport of explosives in the environment: A chemist's view. In Ecotoxicology of explosives and unexploded ordnance, ed. G. Sunahara, G. Lotufo, R Kuperman, and J. Hawari, 5-33. Boca Raton, FL: CRC Press.

Montgomery, M. T., R. B. Coffin, T. J. Boyd, J. P. Smith, S. E. Walker, and C. L. Osburn. 2011. 2, 4, 6-trinitrotoluene mineralization and bacterial production rates of natural microbial assemblages from coastal sediments. Environmental Pollution 159(12): $3673-3680$. 
Moore, D. R. J., and P-Y. Caux. 1997. Estimating low toxic effects. Environmental Toxicology and Chemistry 16(4): 794-801.

Mukhi, S., and R. Patino. 2008. Effects of hexahydro-1,3,5-trinitro-1,3,5-triazine (RDX) in zebrafish: General and reproductive toxicity. Chemosphere 72(5): 726-732.

Mukhi, S., X. P. Pan, G. P. Cobb, and R. Patino. 2005. Toxicity of hexahydro-1,3,5trinitro-1,3,5-triazine to larval zebrafish (Danio rerio). Chemosphere 61(2): 178185 .

Naval Facilities Engineering Command Northwest (NAVFAC NW). 2010a. Baseline Ecological Risk Assessment Tier 2 Step 7, Risk Characterization: Supplemental Remedial Investigation at Operable Unit 2, Jackson Park Housing Complex/Naval Hospital Bremerton, Bremerton, Washington. Contract No. N62470-08-D-1001. King of Prussia, PA: Tetra Tech NUS, Inc.

Naval Facilities Engineering Command Northwest (NAVFAC NW). 2010b. Ecological Risk Assessment Tier 2 Step 6, Data Analysis Phase 1/Phase 2: Sediment Chemistry and Toxicity Data Report, Supplemental Remedial Investigation at Operable Unit 2: Jackson Park Housing Complex/Naval Hospital Bremerton, Bremerton Washington. Navy Contract No. N62470-08-D-1001. King of Prussia, PA: Tetra Tech NUS, Inc. .

Naval Facilities Engineering Command Northwest (NAVFAC NW). 2010c. Ecological Risk Assessment Tier 2 Step 6, Data Analysis Phase 2 Tissue Chemistry Data Report: Supplemental Remedial Investigation at Operable Unit 2, Jackson Park Housing Complex/Naval Hospital Bremerton. Contract No. N62470-08-D-1001. Silverdale, WA: Department of the Navy.

Naval Facilities Engineering Command Northwest (NAVFAC NW). 2011. Second FiveYear Review: Jackson Park Housing Complex/Naval Hospital Bremerton, Bremerton, Washington. EPA ID WA3170090044.

Nipper, M., R. S. Carr, J. M. Biedenbach, R. L. Hooten, K. Miller, and S. Saepoff. 2001. Development of marine toxicity data for ordnance compounds. Archives of Environmental Contamination and Toxicology 41(3): 308-318.

Nipper, M., R. S. Carr, J. M. Biedenbach, R. L. Hooten, and K. Miller. 2002. Toxicological and chemical assessment of ordnance compounds in marine sediments and porewaters. Marine Pollution Bulletin 44(8): 789-806.

Nipper, M., Y. Qian, R. S. Carr, and K. Miller. 2004. Degradation of picric acid and 2,6DNT in marine sediments and waters: The role of microbial activity and ultraviolet exposure. Chemosphere 56(6): 519-530

Nipper, M., R. S. Carr, J. M. Biedenbach, R. L. Hooten, and K. Miller. 2005. Fate and effects of picric acid and 2,6-DNT in marine environments: Toxicity of degradation products. Marine Pollution Bulletin 50(11): 1205-1217.

Nipper, M., R. S. Carr, and G. R. Lotufo. 2009. Aquatic toxicology of explosives. In Ecotoxicology of explosives, ed. G. I. Sunahara, G. Lotufo, R. G. Kuperman, and J. Hawari, 77-115. Boca Raton: CRC Press. 
Noblis, Inc. 2011. Physicochemical properties for explosives at the shallow water site Hawaii 6 (HI-06), O'ahu, Hawaii. Contract GS10F0189T. Prepared for the National Oceanic and Atmospheric Administration.

Ochsenbein, U., M. Zeh, and J. D. Berset. 2008. Comparing solid phase extraction and direct injection for the analysis of ultra-trace levels of relevant explosives in lake water and tributaries using liquid chromatography-electrospray tandem mass spectrometry. Chemosphere 72(6): 974-980.

O'Sullivan, D. W., J. R. Denzel, and D. J. Luning Prak. 2011. Photolysis of 2,4,6trinitrotoluene in seawater: Effect of salinity and nitrate concentration. In Environmental chemistry of explosives and propellant compounds in soils and marine systems: Distributed source characterization and remedial technologies, ed. M. A. Chappell, C. L. Price, and R. D. George, 157-169. ACS Symposium Series, 1069. Washington, D.C.: American Chemical Society.

Paden, N. E., E. E. Smith, J. D. Maul, and R. J. Kendall. 2011. Effects of chronic 2,4,6,trinitrotoluene, 2,4-dinitrotoluene, and 2,6-dinitrotoluene exposure on developing bullfrog (Rana catesbeiana) tadpoles. Ecotoxicology and Environmental Safety 74(4): 924-928.

Pait, A.S., A. L. Mason, D. R. Whitall, J. D. Christensen, and S. I. Hartwell. 2010. Assessment of chemical contaminants in sediments and corals in Vieques. In An ecological characterization of the marine resources of Vieques, Puerto Rico Part II: Field studies of habitats, nutrients, contaminants, fish, and benthic communities. NOAA Technical Memorandum NOS NCCOS 110. Silver Spring, MD: National Oceanic and Atmospheric Administration, National Centers for Coastal Ocean Science.

Pascoe, G. A., K. Kroeger, D. Leisle, and R. J. Feldpausch. 2010. Munition constituents: Preliminary sediment screening criteria for the protection of marine benthic invertebrates. Chemosphere 81(6): 807-816.

Pearson, J. G., J. P. Glennon, J. J. Barkley, and J. W. Highfill. 1979. An approach to the toxicological evaluation of a complex industrial wastewater. In Proceedings, Second Annual Symposium on Aquatic Toxicology(ASTM STP 667), 31 Oct-1 Nov 1977, Cleveland, Ohio, ed. L. L. Marking, and R. A. Kimerle, 284-301. . Philadelphia, PA: American Society for Testing and Materials.

Pennington, J. C., C. A. Hayes, S. Yost, T. A. Crutcher, T. E. Berry, J. U. Clarke, and M. J. Bishop. 2008. Explosive residues from blow-in-place detonations of artillery munitions. Soil and Sediment Contamination 17(2): 163-180.

Pennington, J. C., G. Lotufo, C. A. Hayes, B. Porter, and R. D. George. 2011. TNT, RDX, and HMX association with organic fractions of marine sediments and bioavailability implications. In Environmental chemistry of explosives and propellant compounds in soils and marine systems: Distributed source characterization and remedial technologies, ed. M. A. Chappell, C. L. Price, and R. D. George, 185-195. ACS Symposium Series. Washington, DC: American Chemical Society.

Peters, G. T., D. T. Burton, R. L Paulson, and S. D. Turley. 1991. The acute and chronic toxicity of hexahydro-1,3,5-trinitro-1,3,5-triazine (RDX) to three freshwater invertebrates. Environmental Toxicology and Chemistry 10(8): 1073-1081. 
Pichtel, J. 2012. Distribution and fate of military explosives and propellants in soil: A review. Applied and Environmental Soil Science. Article ID 617236. http://dx.doi.org/10.1155/2012/617236.

Podlipna, R., Z. Fialova, and T. Vanek. 2008. Toxic effect of nitroesters on plant tissue cultures. Plant Cell, Tissue and Organ Culture 94(3): 305-311.

Porter, J. W., J. V. Barton, and C. Torres. 2011. Ecological, radiological, and toxicological effects of naval bombardment on the coral reefs of Ilsa de Vieques, Puerto Rico. In Warfare ecology: A new synthesis for peace and security, ed. G. E. Machlis, T. Hanson, Z. Spiric, and J. E. McKendry, 65-122. NATO Science for Peace and Security Series C: Environmental Security. Dordrecht, The Netherlands: Springer.

Rocheleau, S., R. G. Kuperman, S. G. Dodard, M. Sarrazin, K. Savard, L. Paquet, J. Hawari, R. T. Checkai, S. Thiboutot, G. Ampleman, and G. I. Sunahara. 2011. Phytotoxicity and uptake of nitroglycerin in a natural sandy loam soil. Science of the Total Environment 40(24): 5284-5291.

Rodacy, P. J., S. D. Reber, P. K. Walker, and J. V. Andre. 2001. Chemical sensing of explosive targets in the Bedford Basin, Halifax Nova Scotia. Sandia report SAND2001-3569. Albuquerque, NM/Livermore, CA: Sandia National Laboratories.

Rosen, G, and G. R. Lotufo. 2005. Toxicity and fate of two munitions constituents in spiked sediment exposures with the marine amphipod Eohaustorius estuarius. Environmental Toxicology and Chemistry 24(11): 2887-2897.

Rosen, G, and G. R. Lotufo. 2007a. Toxicity of explosive compounds to the marine mussel, Mytilus galloprovincialis, in aqueous exposures. Ecotoxicology and Environmental Safety 68(2): 228-236.

Rosen, G, and G. R. Lotufo. 2007b. Bioaccumulation of explosive compounds in the marine mussel, Mytilus galloprovincialis. Ecotoxicology and Environmental Safety 68(2): 237-245.

Rosen, G., B. Wild, R. D. George, J. B. Belden, and G. R. Lotufo. 2016. Optimization and field demonstration of a passive sampling technology for monitoring conventional munitions constituents in aquatic environments. Marine Technology Society Journal 5o(6): 23-32.

Rosen, G., R. D. George, W. Wild, G. R. Lotufo, C. M. Woodley, D. L. Smith, J. Guerrero, M. Colvin, and J. B. Belden. 2017. Validation of passive sampling devices for monitoring of munitions constituents in underwater environments, Final Technical Report. Environmental Security Technology Demonstration Program Project \#ER-201433. San Diego, CA: Spawar Systems Center (SSC) Pacific.

Rosenblatt, D. H., E. P. Burrows, W. R. Mitchell, and D. L. Parmer. 1991. Organic explosives and related compounds. In The handbook of environmental chemistry, Vol 3., Part G: Anthropogenic Compounds, ed. O. Hutzinger, 195234. New York, NY: Springer-Verlag. 
Rossland, H. K., A. Johnsen, T. E. Karsrud, M. P. Parmer, A. Larsen, A. Myran, and S. V. Nordas. 2010. Forurensning fra ammunisjon i akvatisk miljø og på kystfort: innledene undersøkelser (English Translation: Pollution from ammunition in the aquatic environment and the coastal forts - initial investigations). FFI report 2010/o0239. Kjeller, Norway: Norwegian Defense Research Establishment.

Saka, M. 2004. Developmental toxicity of p,p '-dichlorodiphenyltrichloroethane, 2,4,6trinitrotoluene, their metabolites, and benzo[a]pyrene in Xenopus laevis embryos. Environmental Toxicology and Chemistry 23(4): 1065-1073.

Seth, R., D. Mackay, and J. Muncke. 1999. Estimating the organic carbon partition coefficient and its variability for hydrophobic chemicals. Environmental Science and Technology 33(14): 2390-2394.

Sheremata, T. W. and J. Hawari. 2000. Mineralization of RDX by the white rot fungus Phanerochaete chrysosporium to carbon dioxide and nitrous oxide. Environmental Science and Technology 34(16): 3384-3388.

Sims J. G., and J. A. Steevens. 2008. The role of metabolism in the toxicity of 2,4,6trinitrotoluene and its degradation products to the aquatic amphipod Hyalella azteca. Ecotoxicology and Environmental Safety 70(1): 38-46.

Singh, B, J. Kaur, and K. Singh. 2012. Microbial remediation of explosive waste. Critical Reviews in Microbiology 38(2): 152-167.

Singh, N., A. E. Berns, D. Hennecke, J. Hoerner, W. Koerdel, and A. Schaeffer. 2010. Effect of soil organic matter chemistry on sorption of trinitrotoluene and 2,4dinitrotoluene. Journal of Hazardous Materials 173(1-3): 343-348.

Sjöström, J., R. Karlsson, and U. Qvarfort. 2004. Environmental risk assessment of dumped ammunition in natural waters in Sweden - A summary. FOI-R--1307-SE. Umeå, Västerbotten, Sweden: Swedish Defence Research Agency.

Smith, R. W., P. Vlahos, C. Tobias, M. Ballentine, T. Ariyarathna, and C. Cooper. 2013. Removal rates of dissolved munitions compounds in seawater. Chemosphere 92(8): 898-904.

Smith, R. W., C. Tobias, P. Vlahos, C. Cooper, M. Ballentine, T. Ariyarathna, S. Fallis, and T. J. Groshens. 2015a. Mineralization of RDX-derived nitrogen to N-2 via denitrification in coastal marine sediments. Environmental Science and Technology 49(4): 2180-2187.

Smith, R. W., P. Vlahos, J. K. Bohlke, T. Ariyarathna, M. Ballentine, C. Cooper, S. Fallis, T. J. Groshens, and C. Tobias. 2015b. Tracing the cycling and fate of the explosive 2,4,6-trinitrotoluene in coastal marine systems with a stable isotopic tracer, N15-[TNT]. Environmental Science and Technology 49(20): 12223-12231.

Snell, T. W., and B. D. Moffat. 1992. A 2-d life cycle test with the totifer Brachionus calyciflorus. Environmental Toxicology and Chemistry 11(9): 1249-1257.

Spanggord, R. J., T.-W. Chou, T. Mill, R. T. Podoll, J. C. Harper, and D. S. Tse. 1985. Environmental fate of nitroguanidine, diethyleneglycol dinitrate, and hexachloroethane smoke- Final Report, Phase I. Contract No.DAMD17-84-C4252. DTIC Accession No. ADA185050. Menlo Park, CA: SRI International. 
Stanley, J. K., G. R. Lotufo, J. M. Biedenbach, P. Chappell, and K. A. Gust. 2015. Toxicity of the conventional energetics TNT and RDX relative to new insensitive munitions constituents DNAN and NTO in Rana pipiens tadpoles. Environmental Toxicology and Chemistry 34(4): 873-879.

Steevens, J. A., B. M. Duke, G. R. Lotufo, and T. S. Bridges. 2002. Toxicity of the explosives 2,4,6-trinitrotoluene, hexahydro-1,3,5-trinitro-1,3,5-triazine, and octahydro-1,3,5,7-tetranitro-1,3,5,7-tetrazocine in sediments to Chironomus tentans and Hyalella azteca: Low-dose hormesis and high-dose mortality. Environmental Toxicology and Chemistry 21(7): 1475-1482.

Strategic Environmental Research and Development Program, (SERDP) 2010. Munitions in the underwater environment: State of the science and knowledge gaps. Alexandria, VA: SERDP and Environmental Securities Technology Certification Program (ESTCP).

Sullivan, Jr., J. H., H. D. Putnam, M. A. Keirn, B. C. Pruitt, Jr., J. C. Nichols, and J. T. McClave. 1979. A summary and evaluation of aquatic environmental data in relation to establishing water quality criteria for munitions unique compoundsPart 2. Nitroglycerin, Final Report. DTIC Accession No. ADA082437. Contract No. DAMD 17-77-C-7027. Gainesville, FL: Water and Air Research, Inc.

Sunahara, G.I., S. Dodard, M. Sarrazin, L. Paquet, G. Ampleman, S. Thiboutot, J. Hawari, and A. Y. Renoux. 1998. Development of a soil extraction procedure for ecotoxicity characterization of energetic compounds. Ecotoxicology and Environmental Safety 39(3): 185-194.

Suter, II., G. W. 2002. North American history of species sensitivity distributions. In Species sensitivity distributions in ecotoxicology, ed. L. Posthuma, G. W. Suter, II., and T. P. Traas, 11-17. Boca Raton, FL: Lewis Publishers.

Talmage, S. S., D. M. Opresko, C. J. Maxwell, C. J. E. Welsh, F. M. Cretella, P. H. Reno, and F. B. Daniel. 1999. Nitroaromatic munition compounds: Environmental effects and screening values. In Reviews of Environmental Contamination and Toxicology, ed. G. W. Ware, Volume 161, 1-156. New York, NY: Springer-Verlag.

Thorne, P. G., and T. F. Jenkins. 1997. A field method for quantifying ammonium picrate and picric acid in soil. Field Analytical Chemistry and Technology 1(3): 165-170.

Tri-Service Ecological Risk Assessment Working Group (TSERAWG). 2008. Guide to screening level ecological risk assessment. Report No. TG-090801. Aberdeen Proving Ground, MD.

United States Army Center for Health Promotion and Preventive Medicine (USACHPPM). 2007. Health risk evaluation No. 39-EJ-06UY-07, ordnance reef discarded military munitions site, Wai'anae, O’ahu, Hawaii.

United States Army Corps of Engineers (USACE). 2013. Former Seattle naval supply depot piers 90 and 91- Port of Seattle, WA.: Formerly used defense site \#F10WA012501, remedial investigation/Final report. Contract No. W9128F-10D-0058, Delivery Order 04. Omaha, NE: U.S. Army Corps of Engineers, Omaha District. 
United States Army Public Health Command (USAPHC). 2012. Wildlife toxicity assessment for 2,4 and 2,6 Dinitrotoluene. Public Health Notice No. 0512-1.

United States Department of the Army, Headquarters. 1990. Military explosives. Army Technical Manual TM 9-1300-214 Rev. CHG-4. Washington, DC: U.S. Department of the Army, Headquarters.

United States Department of the Army, Headquarters. 1993. Ammunition, general. Army Technical Manual TM 9-1300-200 Rev. CHG-5. Washington, DC: U.S. Department of the Army, Headquarters.

United States Department of the Army. 1960. Encyclopedia of explosives and related items, Vol. 1. Dover, NJ : U.S. Army Research and Development Command TACOM, ARDEC, Warheads, Energetics and Combat Support Center, Picatinny Arsenal.

United States Department of the Navy. 1987. Use of explosives in underwater salvage. NAVSEA-SW061-AA-MMA-010. Washington, DC: Naval Sea Systems Command.

United States Department of the Navy. 1999. Chapter 3: Characteristics of explosives and ammunition. In NAVSEA OP5 Volume 1, Sixth Revision: Ammunition and explosives safety ashore. Washington, DC: Department of the Navy, Naval Sea Systems Command.

United States Environmental Protection Agency (USEPA). 1993. Handbook approaches for the remediation of federal facility sites contaminated with explosive of radioactive wastes. EPA/625/R-93/O13. Washington, DC: U.S. Environmental Protection Agency Office of Research and Development.

United States Environmental Protection Agency (USEPA). 2008. Procedures for the derivation of equilibrium partitioning sediment benchmarks (ESBs) for the protection of benthic organisms: Compendium of tier 2 values for nonionic organics. EPA-600-R-02-016. Washington, DC: U.S. Environmental Protection Agency Office of Research and Development.

United States Environmental Protection Agency (USEPA). 2012. Site characterization for munitions constituents. EPA federal facilities forum issue paper EPA/505/S11/o01. Washington, DC: U.S. Environmental Protection Agency.

University of Hawaii (UH). 2010. Hawai'i undersea military munitions mssessment (HUMMA), Final Investigation Report for Hawaii-05. Contract No. W74V8H-04005, Task Number 0496. Prepared for the National Defense Center for Energy and Environment.

University of Hawaii (UH). 2014a. Final environmental study: Ordnance Reef (HI-06), Wai'anae, O'ahu, Hawai'i. Contract No. Nooo24-08-D-6323. Prepared for the U.S. Army Corps of Engineers.

University of Hawaii (UH). 2014b. Ordnance Reef (HI-06) follow-pp investigation, final assessment report. NDCEE-CR-2013-170. Contract No. W91ZLK-10-D-o05, Task 0773. Johnstown, PA: National Defense Center for Entergy and Environment.

Van der Hoeven, N. 1997. How to measure no effect. Part 1: Towards a new measure of chronic toxicity? Environmetrics 8(3): 241-248. 
van der Schalie, W. H. 1983. The acute and chronic toxicity of 3,5-dinitroaniline, 1,3dinitrobenene, and 1,3,5-trinitrobenzene to freshwater aquatic organisms. TR 8305. Frederick, MD: U.S. Army Medical Bioengineering Research and Development Laboratory, Fort Detrick.

van der Schalie, W. H. 1985. The toxicity of nitroguanidine and photolyzed nitroguanidine to freshwater aquatic organisms. TR 8404. Fredrick, MD: U.S. Army Medical Bioengineering Research and Development Laboratory, Fort Detrick.

Van Ham, N., A. Creemers, and D. Meuken. 2007. Risks of sea dumped ammunition. In proceedings, "Security Impact of Munition and Propellant Disposal," 12-14 September, Bulgaria.

Wang, P. F., R. D. George, W. J. Wild, and Q. Liao. 2013. Defining munition constituent (MC) source terms in aquatic environments on DoD Ranges (ER-1453), Final Report. SSC Pacific Technical Report 1999. Report prepared for the Strategic Environmental Research and Development Program (SERDP). San Diego, CA: Spawar Systems Center (SSC) Pacific.

Wang, P. F., Q. Liao, R. George, and W. Wild. 2011. Release rate and transport of munitions constituents from breached shells in marine environment. Environmental chemistry of explosives and propellant compounds in soils and marine systems: Distributed source characterization and remedial technologies, ed. M. A. Chappell, C. L. Price, and R. D. George, ACS Symposium Series 1069: 317-340. Washington, DC: American Chemical Society.

Warne, M. S. J., and R. van Dam. 2008. NOEC and LOEC data should no longer be generated or used. Australasian Journal of Ecotoxicology 14(1): 1-5.

Warner, C. M., K. A. Gust, J. K. Stanley, T. Habib, M. S. Wilbanks, N. Garcia-Reyero, and E. J. Perkins. 2012. A systems toxicology approach to elucidate the mechanisms involved in RDX species-specific sensitivity. Environmental Science and Technology 46(14): 7790-7798.

Wheeler, J. R., E. P. M. Grist, K. M. Y. Leung, D. Morritt, and M. 2002. Species sensitivity distributions: Data and model choice. Marine Pollution Bulletin 45(1-12): 192202.

Woodley, C., and C. Downs 2014. Ecological risk assessment of munitions compounds on coral and coral reef health, Final Report. SERP Project ER-2125. Washington, D.C.: Department of Defense, Strategic Environmental Research and Development Program (SERDP).

Won, W. D., L. H. DiSalvo, and J. Ng. 1976. Toxicity and mutagenicity of 2,4,6trinitrotoluene and its microbial metabolites. Applied and Environmental Microbiology 31(4): 576-580.

Xu, J. B., and N. Jing. 2012. Effects of 2,4-dinitrotoluene exposure on enzyme activity, energy reserves and condition factors in common carp (Cyprinus carpio). Journal of Hazardous Materials 203-204: 299-307. 


\section{Appendix A: Munitions Constituents in Aquatic Systems Database}

Appendix A is a Microsoft ${ }^{\odot}$ Excel file containing 2 databases and 43 tables derived from the databases of several studies characterizing $\mathrm{MC}$ in the aquatic environment. Explanations for the databases and tables found at http://dx.doi.org/10.21079/11681/24830 are provided below.

Appendix Table A.1 is a database of munitions constituents. It is the data source for the Appendix A Tables A.3-A.17, which provide metadata for and data comparison between studies. It is also the data source for oddnumbered Appendix tables from A.19-A.39, and Appendix Tables A.40 and A.42, which provide data summaries for each study. The database contains fields for metadata, such as reference, reference data source, study name, study waterbodies, and location. It also contains data-related fields, including sampling site, phase, collection period, type, and source; biota information, munitions constituent, number of samples and detects, detection frequency, units, minimum and maximum LRLs for non-detects, and MDL.

Appendix Table A.2 is a database of detectable concentrations. It is the data source for Appendix Table A.18, which lists detectable concentrations for all studies according to their sample type. It is also the data source for even numbered Appendix tables from A.20-A.38 and Appendix Tables A.41 and A.43, which list detected concentrations for each study. It contains the same metadata fields as Appendix Table A.1, along with descriptive fields for each detectable concentration, including sampling site, phase, type, source, collection date, I.D., biota information, munitions constituent, result number, units, concentration, and qualifiers.

Appendix Table A.3 provides a summary of basic information for each study and includes fields for study waterbodies, country, canton/county/province/state, city, study name, and reference. Information for this database incorporates data from eight waterbodies and four countries, including Bahia Salina del Sur (Puerto Rico, USA), Canada Coastal Waterbodies (Newfoundland, Labrador, and Nova Scotia, Canada), Lakes Thun, Brienz, and tributaries (Bern, Switzerland), Ostrich Bay, Puget Sound (Washington, USA), and Sea Disposal Sites HI-05 and HI-06 (Hawaii, USA). Five of the eight waterbodies are located in the 
United States, with two of the U.S. waterbodies located in Hawaii and in Puerto Rico. Studies included in the database were Rosen et al. (2016, 2017), Ampleman et al. (2004), Rodacy et al. 2001, Ochsenbein et al. (2008), Rossland et al. (2010), NAVFAC NW (2010a, 2010b, 2011), Blakley (2005), USACE (2013), and the University of Hawaii (2010, 2014a, 2014b). Data for some study waterbodies were reported in multiple publications, including Canada coastal waterbodies (Ampleman et al. 2004; Rodacy et al. 2001), Ostrich Bay (NAVFAC NW 2010a, 2010b, 2011; Blakley 2005), and Sea Disposal Site HI-06 (University of Hawaii 2014a, 2014b). The studies for the Canada coastal waterbodies can be considered separate efforts, while the Ostrich Bay studies that the Navy conducted were a part of a comprehensive ecological risk assessment. For the Sea Disposal Site HI-06, the University of Hawaii (2014b) was a follow-up study for the 2009 sampling and characterization study (University of Hawaii 2014a).

Appendix Table A.4 provides a summary of sample collection periods for each study according to sample type. Sample types include water, sediment, and biota tissue. For almost half (six of thirteen) of the studies, samples were collected in 2009, and samples were collected prior to 2009 for only three studies. Rodacy et al. (2001) does not include sample collection dates, but obviously samples for this study were collected in 2001 or earlier.

Appendix Table A.5 displays the $\mathrm{MC}$ analyzed for and sample types collected in the waterbodies and analyzed for publication. Seven of the thirteen studies included the collection and analysis of water samples, nine included the collection and analysis of sediment samples, and six included the collection of biota for analysis of tissue samples. Munitions constituents commonly analyzed include 2-A-4,6-DNT, 4-A-2,6-DNT, and TNT. Most studies also included the analysis of 1,3,5-TNB, 1,3-DNB, 2,4and 2,6-DNT, 2- and 3-NT, HMX, nitrobenzene, RDX, and tetryl. Munitions constituents not commonly analyzed for include 2,4-DA-6-NT, 2,6-DA-4-NT, 2-and 4-nitrophenol, diethyl phthalate, di-n-butyl phthalate, diphenylamine, NC, NG, NQ, $N$-nitrosodiphenylamine, PETN, and perchlorate.

Appendix Table A.6 lists sampling site names for each study according to sample type and waterbodies. Each study has between one and five sites. 
Appendix Table A.7 provides tissue sample information, and includes fields for waterbodies, reference, biota, species, and tissue source. Biota collected were commonly fish, crustaceans, bivalves, and seaweed, and less commonly collected were sea cucumbers, snails, and octopus. At least two biota were collected for each study. Rossland et al. (2010) did not identify the species names or tissue sources of biota collected for analysis, and NAVFAC NW (2011) did not identify the crab species collected for analysis. Studies in the State of Washington (NAVFAC NW 2010b) and Hawaii (University of Hawaii 2010, 2012a, 2012b) included sampling and analysis of biota that was more likely to be consumed by humans.

Appendix Table A.8 provides a general data summary, and includes fields for sample type, waterbodies, reference, number of sites, number of samples with detectable concentrations, total number of samples, percent of samples with detectable concentrations, and number of data points for each study and sample type. Several studies, including Rodacy et al. (2001), Ochsenbein et al. (2008), and Rossland et al. (2010), reported a high percentage of water, sediment, and/or tissue samples with detectable concentrations. Sediment samples for NAVFAC NW (2010a), the University of Hawaii (2010, 2014b), and tissue samples for the University of Hawaii (2014a, 2014b) have greater than 1,000 data points, with sediment samples for NAVFAC NW (2010a) containing the largest number of data points $(3,022)$.

Appendix Table A.9 provides the number of data points according to sampling site and munitions constituent, as well as by sampling site, study and sample type, waterbody and sample type, and sample type. It also provides the number of samples collected by sampling site, study and sample type, waterbody and sample type, and sample type. In addition, it provides the number of data points for each combination of sample type and munitions constituent, as well as for all sample types and each munitions constituent. The table provides totals of samples and data points in more detail than Appendix Table A.6, and includes an array of groupings for which calculations were determined. This table was used to develop Appendix Table A.6. For all studies combined, a total of 379 sediment samples were analyzed to generate 7,199 data points, 290 tissue samples were analyzed to generate 5,537 data points, and 231 water samples were analyzed to generate 2,265 data points. The MC with the largest number of data points include 2-A-4,6-DNT (865 data points), 4-A2,6-DNT (892 data points), and TNT (895 data points). The MC with the 
highest number of data points by sample type includes 2-A-4,6-DNT (225 data points), 4-A-2,6-DNT (226 data points), and TNT (226 data points) for water samples. For sediment samples, the highest number of data points include 1,3,5-TNB (369 data points), 1,3-DNB (371 data points), 2,4- and 2,6-DNT (369 and 370 data points, respectively), 2-A-4,6-DNT (377 data points), 4-A-2,6-DNT (377 data points), and TNT (379 data points) for sediment samples. For tissue samples, the highest number of data points include 1,3,5-TNB (273 data points), 1,3-DNB (267 data points), 2,4- and 2,6-DNT (260 data points by compound), 2-A-4,6-DNT (263 data points), 2-, 3-, and 4-NT $(287,260$, and 287 data points, respectively), 4-A-2,6-DNT (290 data points), HMX (290 data points), nitrobenzene (287 data points), RDX (288 data points), and TNT (290 data points).

Appendix Table A.10 provides the number of samples, number of detectable concentrations, and detection frequency for each munitions constituent according to sample type, waterbodies, publication, and biota (for tissue samples). It also provides the number of data points, number of detectable concentrations, and detection frequency according to sample type, publication, and biota (for tissue samples). In addition, it provides the number of samples, number of detectable concentrations, and detection frequency for each combination of sample type and munitions constituent, as well as for each individual sample type and munitions constituent. Detection frequencies greater than $10 \%$ were reported for water samples for Rodacy et al. (2001) (27.8\%), Ochsenbein et al. (2008) (32.7\%), and Rossland et al. (2010) (25.7\%). Detection frequencies greater than $10 \%$ were reported for sediment samples for Rodacy et al. (2001) (52.2\%) and Rossland et al. (2010) (37.2\%). Detection frequencies greater than $10 \%$ were reported for biota (i.e., mussel, seaweed, and snail) samples for Rossland et al. (2010), although the number of samples from which detection frequencies were determined was small (4-5). For Rodacy et al. (2001), the high detection frequencies for water and sediment samples may be the result of sampling in close proximity $(0.3,1,2$, and 3 $\mathrm{m})$ to discarded military munitions. The high detection frequency in water samples for Ochsenbein et al. (2008) was due to the extremely low achieved DL. For Rossland et al. (2010), the high detection frequencies for water and sediment samples may be the result of sampling within close proximity to sites containing discarded military munitions following their on-site destruction by detonation. 
Review of the number of samples, number of detectable concentrations, and detection frequency for each combination of sample type and munitions constituent, as well as for each individual sample type and munitions constituent, reveals some, perhaps, useful findings for sample type and munitions constituent combinations using a large number of samples. When all of the data was combined, certain $\mathrm{MC}$ were relatively frequently detected in one or more sample types. For example, 2,4dinitrotoluene was detected in $14.4 \%$ of water samples ( $n=160$ ), $15.3 \%$ of sediment samples $(n=391)$, and $4.1 \%$ of tissue samples $(n=316)$. This munitions constituent in particular was detected for several references. In some cases, elevated detection frequencies may be highly influenced by one study (for example, Ochsenbein et al. (2008), which had high detection frequencies for HMX, PETN, and RDX due to extremely low DL.

Appendix Table A.11 provides MDL for each munitions constituent according to sample type, waterbodies, reference, and biota (for tissue samples only). Rosen et al. (2017), Ampleman et al. (2004), NAVFAC NW (2010a), USACE (2013) were the only studies which provided MDL. MDL was not provided for tissue samples.

Appendix Tables A.12-A.14 provide the minimum and maximum LRLs for samples with non-detectable concentrations for each munitions constituent according to sample type and study; biota was included for Appendix Table A.14 only. For the sake of comparison, values were colorcoded by order of magnitude according to the color-shading key below each table. Appendix Table A.12, which shows water samples, indicates that Ochsenbein et al. (2008) had the lowest reporting limits, which were several orders of magnitude lower than the other studies. Appendix Table A.13, which shows sediment samples, indicates that in many cases, NAVFAC NW (2010a) had the lowest reporting limits, while Blakley (2005) had the highest reporting limits. Appendix Table A.14, which shows tissue samples, indicates that in many cases, NAVFAC (2010b) had the lowest reporting limits, while UH (2014a, 2014b) had similar reporting limits.

Appendix Tables A.15-A.17 provides the ranges of detected concentrations for each munitions constituent according to sample type and study; biota was included for Appendix Table A.17 only. For the sake of comparison, values were color coded by order of magnitude according to the colorshading key below each table. Appendix Table A.15, which shows water 
samples, indicates that Ampleman et al. (2004) and Ochsenbein et al. (2008) had relatively low detected concentrations, and Rodacy et al. (2001) generally had the highest detected concentrations. Appendix Table A.16, which shows sediment samples, indicates that Rodacy et al. (2001) had a significant range of detected concentrations for each munitions constituent analyzed for the study, with a difference of 1-4 orders of magnitude between minimum and maximum detected concentrations. In addition, for NAVFAC NW (2010a), concentrations of MC were relatively low (generally less than $5 \mu \mathrm{g} / \mathrm{kg}$ ) with the exception of NC (1,600-31,000 $\mu \mathrm{g} / \mathrm{kg}), \mathrm{NG}(6,600 \mu \mathrm{g} / \mathrm{kg})$, and NQ $(140-650 \mu \mathrm{g} / \mathrm{kg})$. Detected concentrations of nitrobenzene and/or NG in tissue were common between biota and ranged from 290-950 for NAVFAC NW (2010b) (Appendix Table A.17). Tissue collected from all biota showed detected concentrations of HMX for Rossland et al. (2010). Several biota from Sea Disposal Site HI-06 (Ordnance Reef) showed detected concentrations of 1,3,5-TNB, and for UH (2014a), White and Red Goatfish samples showed detected concentrations of several MC, including 1,3,5-TNB, 2,4-DNT, 2and 4-NT, 3,5-DNA, HMX, RDX, and tetryl.

Appendix Table A.18 is a list of all detected concentrations for all studies, and includes fields for sample type, munitions constituent, reference, sampling site, phase, biota (for tissue samples), sample collection date and source, result number, concentration, units, and qualifiers.

Odd numbered Appendix tables from A.19-A.39 and Appendix Tables A.40 and A.42, which reference Appendix Table A.1 as their data source, are data summaries for each reference. Data summaries include fields for number of samples and detects, detection frequency, minimum and maximum concentration detected and reporting limit, and MDL for each sample type, biota (for tissue samples only), sample source, sampling phase, site, and munitions constituent. Organization of the data summaries permits within-reference comparison and evaluation of data.

Even numbered Appendix Tables from A.20-A.38 and Appendix Tables A.41 and A.43, which reference Appendix Table A.2 as their data source, are lists of detected concentrations for each reference. The lists organize the detected concentrations according to sample type, sample source, biota (for tissue samples), site, and munitions constituent. 


\section{Appendix B: Munitions Constituents General Environmental Properties Database}

Appendix B is a Microsoft ${ }^{\odot}$ Excel file found at http://dx.doi.org/10.21079/11681/24831 containing eight data tables for the following experimentally derived $\mathrm{F}$ and $\mathrm{T}$ parameters for TNT and RDX:

- Dissolution Rate

- Solubility

- Adsorption coefficient

- koc

- Soil transformation rate coefficients

- Biotransformation-biodegradation

- Photolysis

- Henry's law of constants 


\section{Appendix C: Munitions Constituents Aquatic Toxicity Database}

Appendix $\mathrm{C}$ is a Microsoft ${ }^{\odot}$ Excel file found at http://dx.doi.org/10.21079/11681/24832 containing a database, definitions of abbreviations, and a list of references. This database provides 696 toxicity data points extracted from 74 references. Although not intended to be exhaustive, it provides the bulk of the available data on the toxicity of MC to amphibians, fish, aquatic invertebrates, and aquatic autotrophs. The data were generated through laboratory exposures of test organisms to water spiked with energetic MC. Only data for organismal- or population level biological effects were included. Biochemical and histopathological effects were not included in the database, but were discussed in Chapter 11. Data derived from experiments investigating the effects of photoactivation on the toxicity of MC were also not included in the database, but the effects of photo-activation were discussed in Chapter 11.

Using a dropdown menu, data can be selected using different combinations of MC, taxonomic groups (e.g., amphibians, fish, invertebrates, cyanobacteria, green algae, and vascular plants), test organisms (e.g., carp, amphipod, species or green alga), species name, habitat (e.g., freshwater or marine), effects measurement (e.g., survival, growth or offspring production), endpoint (e.g., $\mathrm{LC}_{50}$ or $\mathrm{EC}_{50}$ ), concentration, chemical analysis (i.e., measure or unmeasured exposure concentrations), reference, and comment. 


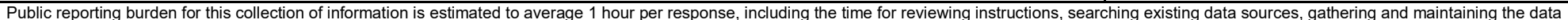

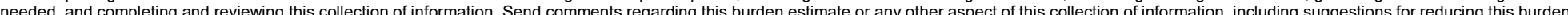

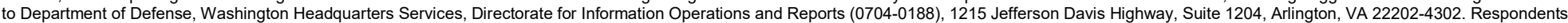

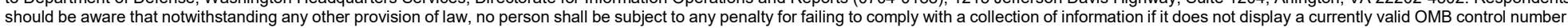
PLEASE DO NOT RETURN YOUR FORM TO THE ABOVE ADDRESS.
1. REPORT DATE (DD-MM-YYYY)
2. REPORT TYPE
Final report
3. DATES COVERED (From - To)
October 2017

4. TITLE AND SUBTITLE

Review and Synthesis of Evidence Regarding Environmental Risks Posed by Munitions Constituents (MC) in Aquatic Systems

5a. CONTRACT NUMBER

\section{5b. GRANT NUMBER}

5c. PROGRAM ELEMENT NUMBER

\section{AUTHOR(S)}

Guilherme R. Lotufo, Mark A. Chappell, Cynthia L. Price, Mark L. Ballentine, Ashley A. Fuentes, Robert D. George, Eric Glisch, and Geoffrey Carton

\section{5d. PROJECT NUMBER}

ER-2341

5e. TASK NUMBER

5f. WORK UNIT NUMBER

8. PERFORMING ORGANIZATION REPORT NUMBER

ERDC/EL TR-17-17

U.S. Army Engineer Research and Development Cente
3909 Halls Ferry Road, Vicksburg, MS 39180-6199

9. SPONSORING / MONITORING AGENCY NAME(S) AND ADDRESS(ES)

Headquarters, U.S. Army Corps of Engineers

Washington, DC 20314-1000
10. SPONSOR/MONITOR'S ACRONYM(S)

\section{DISTRIBUTION / AVAILABILITY STATEMENT}

SERDP ER-2341

Approved for public release; distribution unlimited.

\section{SUPPLEMENTARY NOTES}

\section{ABSTRACT}

Underwater military munitions (UWMM) may pose a risk to aquatic environments because they typically contain munitions constituents (MC) such as 2,4,6-trinitrotoluene (TNT) and hexahydro-1,3,5-trinitro-1,3,5-triazine (RDX). If UWMM become corroded or breaches, the fill material may leak or dissolve into the surrounding environment, which could potentially adversely affecting affect the exposed biota. In large part, because of the high cost and complexity associated with sampling MC at UWMM sites, detailed and reliable information about $\mathrm{MC}$ in water, sediment, and biota is available for only a few sites, and therefore temporal and spatial uncertainties persist. Examination of available data indicates that concentrations of $\mathrm{MC}$ in water and sediment were largely below detection or were relatively low (e.g., parts per billion), with higher concentrations being highly localized and typically near a point source. These findings were in accordance with predictive modeling and with fate studies. Available toxicity data derived for a variety of freshwater and marine species were compiled and used to derive interim water quality criteria and protective values derived from species sensitivity distributions. Toxicity varied widely across a diversity of $\mathrm{MC}$ and species. For most aquatic sites, MC contamination in sediment and in the water-column presents low risk to the resident biota.

\begin{tabular}{ll}
\hline 15. SUBJECT TERMS & Aquatic habitats \\
Military weapons & Water--Pollution \\
Unexploded ordnance--Environmental aspects & Pollution--Risk assessment
\end{tabular}

16. SECURITY CLASSIFICATION OF:

a. REPORT

UNCLASSIFIED

\begin{tabular}{|l|l|}
\hline b. ABSTRACT & c. THIS PAGE \\
UNCLASSIFIED & UNCLASSIFIED
\end{tabular}

17. LIMITATION
OF ABSTRACT

18. NUMBER
OF PAGES
252

19a. NAME OF RESPONSIBLE PERSON 19b. TELEPHONE NUMBER (include area code) 